\title{
Serge Moscovici
}

\section{Essai sur}

l'histoire humaine de la nature

\author{
Flammarion, éditeur, Paris 1968
}

Un document produit en version numérique par Jean-Marc Simonet, bénévole, professeur retraité de l'enseignement de l'Université de Paris XI-Orsay

Courriel: jmsimonet@wanadoo.fr

Dans le cadre de la collection: "Les classiques des sciences sociales"

Site web: http://classiques.uqac.ca/

Une collection développée en collaboration avec la Bibliothèque

Paul-Émile-Boulet de l'Université du Québec à Chicoutimi

Site web: http://bibliotheque.uqac.ca/ 


\section{Politique d'utilisation de la bibliothèque des Classiques}

Toute reproduction et rediffusion de nos fichiers est interdite, même avec la mention de leur provenance, sans l'autorisation formelle, écrite, du fondateur des Classiques des sciences sociales, Jean-Marie Tremblay, sociologue.

Les fichiers des Classiques des sciences sociales ne peuvent sans autorisation formelle:

- être hébergés (en fichier ou page web, en totalité ou en partie) sur un serveur autre que celui des Classiques.

- servir de base de travail à un autre fichier modifié ensuite par tout autre moyen (couleur, police, mise en page, extraits, support, etc...),

Les fichiers (.html, .doc, .pdf., .rtf, .jpg, .gif) disponibles sur le site Les Classiques des sciences sociales sont la propriété des Classiques des sciences sociales, un organisme à but non lucratif composé exclusivement de bénévoles.

Ils sont disponibles pour une utilisation intellectuelle et personnelle et, en aucun cas, commerciale. Toute utilisation à des fins commerciales des fichiers sur ce site est strictement interdite et toute rediffusion est également strictement interdite.

\section{L'accès à notre travail est libre et gratuit à tous les utilisa- teurs. C'est notre mission.}

Jean-Marie Tremblay, sociologue

Fondateur et Président-directeur général, LES CLASSIQUES DES SCIENCES SOCIALES. 
Cette édition électronique a été réalisée par Jean-Marc Simonet, ancien professeur des Universités, bénévole.

Courriel: jmsimonet@wanadoo.fr

À partir du livre de

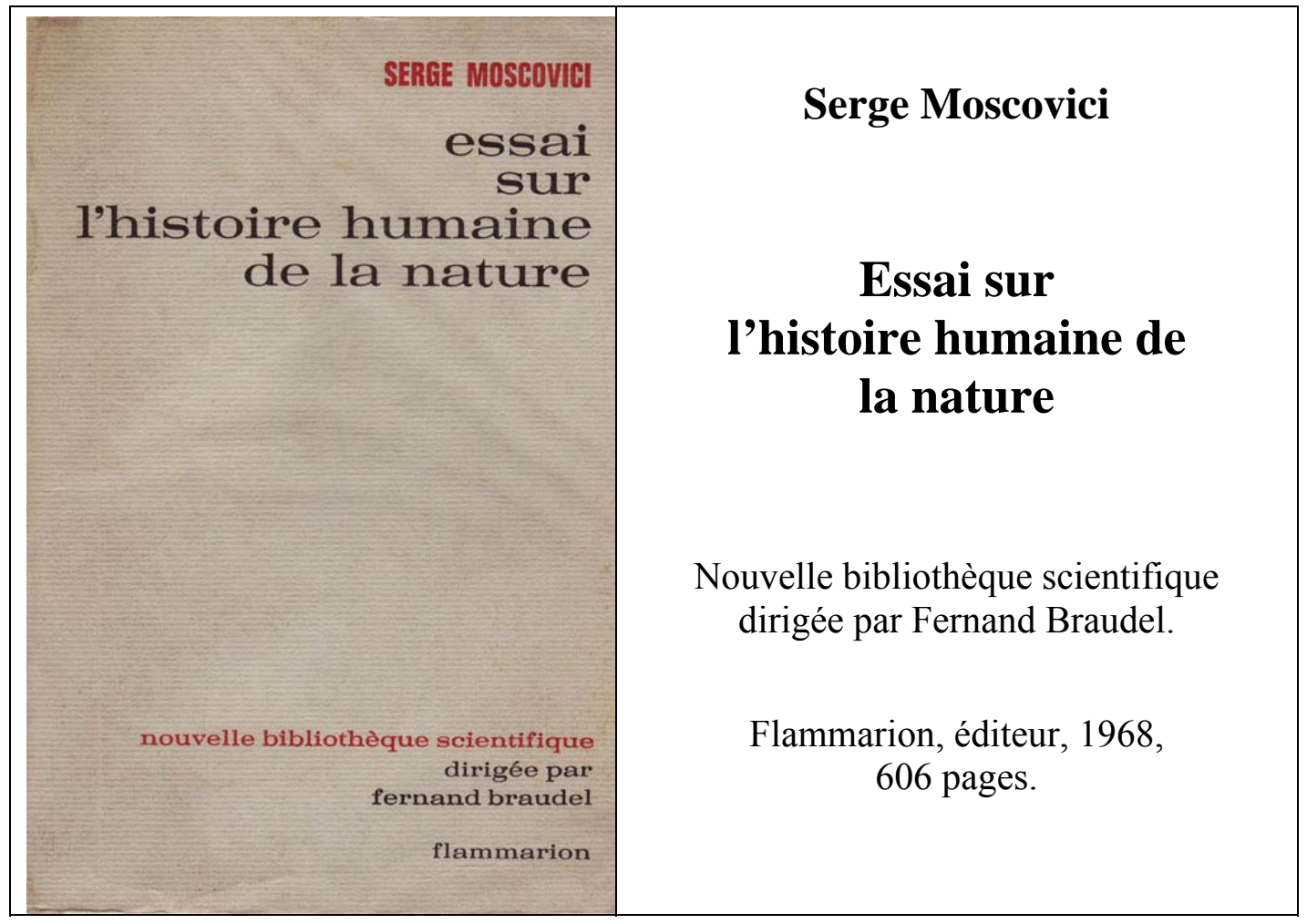

Polices de caractères utilisées :

Pour le texte: Times New Roman, 14 et 12 points.

Pour les notes de bas de page : Times New Roman, 10 points.

Édition électronique réalisée avec le traitement de textes Microsoft Word 2004 pour Macintosh.

Mise en page sur papier format : LETTRE (US letter), 8.5'’ x 11'’)

Édition numérique réalisée le 13 novembre 2007 à Chicoutimi, Ville de Saguenay, province de Québec, Canada. 


\section{Table des matières}

\section{$\underline{\text { La question naturelle }}$}

\section{Première partie \\ Les processus naturels et la succession des états de nature}

\section{Chapitre $\mathrm{I}^{\mathrm{er}}$. La nature, art de l'homme}

$\underline{\text { I. De la matière organisée }}$

II. L'art et la technique ne constituent pas une contre-nature

III. La nature humaine : difficultés d'une idée

IV. L'histoire humaine de la nature

\section{Chapitre II. La création du travail}

I. Produire des objets, créer du travail

II. Deux processus naturels l'invention et la reproduction

III. L'activité inventive

1. Inventer le savoir-faire ;

2. Découverte et substitution.

IV. Les dimensions reproductibles du travail

1. La reproduction naturelle;

2. Le système de reproduction.

$\underline{\mathrm{V} \text {. Processus naturels et processus sociaux }}$

1. Le fondement naturel ;

2. Richesses, ressources et appropriation ;

3. Travail aliéné et travail inaliénable.

\section{Chapitre III. La succession des états de nature (I)}

$\underline{\text { I. De l'état de nature }}$

II. Le travail artistique et la substance

1. L'identité de l'homme et de l'habileté ; 
2. La nature organique.

III. L'univers des formes et des mouvements

1. Le règne de l'instrument et de la force ;

2. La mécanisation du monde.

Chapitre IV. La succession des états de nature (II)

I. La nature cybernétique

1. La matière finale ;

2. Le domaine de la régulation;

3. La prédominance de l'invention ;

4. Une nature historique.

$\underline{\text { II. Le contenu des états naturels et la fonction des disciplines naturelles }}$

Chapitre V. La division naturelle

$\underline{\text { I. Quelques questions préliminaires }}$

II. Catégories naturelles, espèces biologiques et classes sociales

$\underline{\text { III. La séparation des catégories naturelles : conditions et conséquences }}$

IV. Le caractère nécessaire de la division naturelle

$\underline{V}$. Les formulations indirectes du processus de division naturelle

\section{Chapitre VI. La transformation des ressources}

$\underline{\text { I. Distribution des richesses et éclatement du savoir-faire }}$

1. L'accumulation de surplus sociaux ;

2. La division ou la subdivision du travail.

II. La substitution des ressources matérielles ou inventives

1. L'état d'équilibre ;

2. La formation des ressources complémentaires ;

3. La lutte pour la nature ;

4. Conclusion. 


\title{
Deuxième partie L'évolution des catégories et des disciplines naturelles
}

\author{
Première Section \\ La nature mécanique et la structure des catégories naturelles
}

Chapitre $\mathrm{I}^{\mathrm{er}}$. La formation des catégories naturelles et l'unité de l'histoire de leurs disciplines

$\underline{\text { I. Les deux fonctions d'une catégorie naturelle }}$

1. Des filiations évidentes ;

2. La fonction productive et la fonction auto-créatrice.

II. Deux conséquences de la division naturelle

1. Arguments contre une histoire universelle et séparée des sciences des arts, des philosophies et des techniques ;

2. Groupements de disciplines et états de nature.

\section{Chapitre II. L'originalité de l'ingénieur}

I. Les nouvelles ressources complémentaires

1. La renaissance de l'artisanat;

2. La convergence des arts et les agents inanimés.

II. Une catégorie naturelle indépendante : l'ingénieur

1. Le maître d'engins, artisan supérieur ;

2. Les grands affrontements.

\section{Chapitre III. Les origines de la technique}

I. La méthode de l'ingénieur

II. La création des facultés mécaniques

1. Un nouveau mode de reproduction naturelle;

2. Les impératifs de l'invention.

III. De l'art mécanique à la technique

\section{Chapitre IV. La révolution philosophique}

I. La hiérarchie des disciplines naturelles

II. La mécanique au centre de la philosophie

1. Le problème historique ; 
2. La crise de la hiérarchie des disciplines dans la philosophie naturelle;

3. La place de la mécanique.

\section{Chapitre V. De l'univers de la machine à la machine de l'univers :}

I. Le philosophe mécanicien

$\underline{\text { I. Le philosophe constructeur d'instruments mécaniques et doctrinaire de }}$

l'art d'inventer

1. Le but du philosophe mécanicien ;

2. La méthode philosophique et l'art d'inventer.

II. Habileté mécanicienne et connaissance philosophique

1. L'expérience en tant que méthode analytique;

2. La mesure et l'unité du savoir.

Chapitre VI. De l'univers de la machine à la machine de l'univers :

II. La nature mécanique

$\underline{\text { I. Le monde en question }}$

1. La forme et la matière;

2. L'unité des espèces de mouvement ;

3. Le point de vue organique.

II. La naturalisation des artifices

1. Jouer et faire;

2. La réalité ultime.

Deuxième Section

Science, travail inventif et progression naturelle

\section{Chapitre VII. L'univers froid et l'univers chaud}

$\underline{\text { I. Les philosophies, les sciences et le nouveau rapport des disciplines natu- }}$ $\underline{\text { relles }}$

II. Médecine, arts chimiques et arts mécaniques

1. Le monde terrestre et le monde souterrain ;

2. Le sommeil de l'alchimie.

III. L'opposition à la mécanique

1. L'ébauche d'une nouvelle catégorie naturelle;

2. L'instrument chimique, l'univers froid et l'univers chaud. 
Chapitre VIII. L'annonce de la révolution scientifique

I. Les deux visages de l'art expérimental

II. Un nouvel ordre de philosophes : la prophétie de J. B. Priestley

III. Le regroupement des disciplines naturelles

Chapitre IX. La science et ses effets

I. Systèmes stables et théories périssables

II. L'assimilation des modèles mécaniques

III. La primauté de l'effet

Chapitre X. La transformation opérée par les sciences dans l'histoire humaine de la nature

I. Le dépérissement des techniques

1. Les nouvelles ressources complémentaires;

2. Les sciences appliquées ;

3. La mutation du travail humain.

II. La progression naturelle

1. Les sciences institutionnalisées et leur reproduction;

2. Le travail inventif ;

3. La matérialisation des savoir-faire;

4. Progrès scientifique et technique ou progression naturelle ;

5. Des phénomènes encore inexplorés.

\section{Troisième partie Société et histoire humaine de la nature}

\section{Introduction à la troisième partie}

Chapitre $\mathbf{I}^{\mathrm{er}}$. La main et le cerveau : les manifestations sociales de la division naturelle

I. L'illusion organique

1. Un modèle abstrait ;

2. L'exemple grec.

II. La querelle des arts et l'artisan supérieur

1. Les arts libéraux et les arts mécaniques ; 


\section{Conclusion.}

Chapitre II. Le gouvernement de la société et la conquête de la nature

I. Le corps naturel et le corps politique

II. Le gouvernement de la société

1. Le savoir naturel, le savoir social et la science du pouvoir ;

2. Les qualités de l'homme humain ;

3. Les deux visages de l'humanisme;

4. L'éducation de l'élite politique.

III. La nature externe

1. Une pédagogie souterraine ;

2. Une figure de rhétorique la conquête de la nature.

\section{Chapitre III. L'exploitation des choses}

I. Le gouvernement de la nature

1. Progrès plein et progrès vide ;

2. L'expression actuelle d'un thème révolutionnaire.

$\underline{\text { II. La société, forme de la nature }}$

\section{$\underline{\text { Conclusion }}$}

I. Pour une nouvelle science : la technologie politique

1. Le chaînon manquant ;

2. Le programme de la technologie politique.

II. Deux cultures ou une seule 


\section{La question naturelle}

Il y a la peste en ce moment, que faire quand la peste est là ?

HOMÈRE.

Chaque siècle est parcouru par une interrogation essentielle qui mobilise ses forces vives. Du dix-huitième siècle, on peut dire qu'il a été mû tout entier par la question politique. Les révolutions qui le modèlent, les doctrines qui proclament et justifient ces révolutions, sont inspirées par la quête du meilleur gouvernement, et la recherche des lois qui s'accordent avec la dignité du citoyen et l'orgueil des nations nouvellement nées.

Le $\mathrm{XIX}^{\mathrm{e}}$ siècle donne la primauté à la question sociale. La société civile déclare son autonomie face à l'État. Claude de Saint-Simon imagine qu'une catastrophe extermine soudain l'élite des ministres, des parlementaires, des généraux : les richesses n'en seraient pas diminuées, les conditions de vie habituelles ne subiraient pas de changement. En revanche, il soutient dans cette parabole que la disparition de l'élite des industriels, des banquiers, des ingénieurs et des savants aboutirait à paralyser la société, à compromettre la production des biens et à instaurer la pénurie. L'éclosion de l'économie dans la pensée et dans les faits, la démonstration du caractère historique des sociétés, donc de leur avènement et de leur déclin, sont les conséquences de cette autonomie présumée de l'ordre social. Les classes sociales trouvent dans ces théories l'écho systématisé de leurs croyances et un 
guide d'action. La lutte entre prolétaires et capitalistes, le lien que l'on entrevoit entre la dépossession fiévreuse du travail et l'accumulation triomphante du capital inspirent les entreprises pratiques et intellectuelles du siècle. Quelles sont les racines de l'inégalité sociale, de quelle façon peut-on la combattre ? Quelle est la société la plus juste? Voilà les demandes auxquelles on est pressé de fournir une réponse.

Si nous nous tournons vers l'époque contemporaine, nous nous apercevons qu'au premier plan de ses préoccupations figure la nécessité de situer l'humanité parmi les forces de l'univers matériel, d'augmenter sa capacité de s'adapter aux bouleversements dont cet univers est constamment le lieu, et de combler les écarts qui en résultent. A cette nécessité s'associe le mouvement qui tend à faire du progrès scientifique le critère des rapports entre les sociétés existantes et des relations à l'intérieur de chacune d'elles. Les deux tendances convergent pour soulever dans notre siècle la question naturelle. Son originalité, la teneur de ses intérêts s'y expriment complètement.

Sans conteste, la carrière ouverte par les changements survenus dans les sciences - touchant leur contenu, leur fonction, leur rythme s'inscrit parmi les événements les plus révolutionnaires de l'histoire humaine. La conception du temps, de l'espace, l'armature des lois physiques, les informations sur la structure de la matière organique et inorganique, les moyens d'observer et d'expérimenter sont constamment mis à jour. Rien qui ressemble à un arrêt, à une ossification en systèmes achevés, rien qui entrave sérieusement l'avancée audacieuse sur les voies multiples qui s'ouvrent. Ce renouvellement n'affecte pas seulement la substance des sciences. La place qu'elles occupent parmi les facteurs décisifs dans l'organisation de nos relations sociales et de nos contenus mentaux n'a pas d'équivalent dans le passé. Les connaissances jadis réputées désintéressées alimentent nos productions de façon active. Les machines ne se contentent plus de l'aide de l'ingénieur: elles recourent au savoir du philologue, du logicien, du philosophe. Ceux qui contemplaient les formes tranquilles du ciel des idées et s'adonnaient aux jeux innocents de l'esprit ont saisi les leviers de commande des occupations terrestres, comme si les images incluses dans des milliers de rêves s'avéraient soudain plus adéquates au réel que les pensées les plus pondérées et les plus topiques. 
Il est avéré désormais que la main-mise de la physique quantique ou de la cosmologie relativiste sur notre histoire ne le cédera en rien à la profondeur de la marque laissée par la Révolution française. La situation générale actuelle est définie avec autant de vigueur par l'invention de la cybernétique que par le passage de la Russie ou de la Chine d'une structure sociale ancienne à une structure sociale nouvelle. La place prise par les mathématiques parmi les opérations et les habitudes prévalentes sera peut-être, un jour, mise en parallèle avec la diffusion de l'écriture, sinon avec celle du langage humain lui-même.

L'ampleur des puissances matérielles auxquelles nous sommes confrontés et l'étendue des efforts déployés à cette fin traduisent bien la nouvelle dimension de notre milieu :

« Nous sommes à présent au cœur d'une révolution scientifique sans précédent, qui promet d'amener des changements profonds dans les conditions de la vie humaine. Les forces et les processus que l'homme parvient maintenant à maîtriser commencent à égaler en grandeur et en intensité la nature elle-même, et la totalité de notre milieu ambiant est à présent soumise à l'influence humaine $\gg{ }^{1}$.

En effet, consciemment, méthodiquement, nous sommes à même d'intervenir dans l'équilibre biologique de la plupart des espèces végétales ou animales, de les préserver ou de les détruire, d'aménager le climat, de modifier le cycle des transformations énergétiques. Notre action géomorphique ne connaît plus de limites ${ }^{2}$.

Simultanément le genre humain est sur le point de subir une mutation profonde. Après avoir réussi à être le seul animal à habiter toute la planète, l'homme se prépare à devenir une espèce capable de subsister à l'échelle du système planétaire, de faire coïncider sa géographie et son astronomie. L'emploi des fusées, outre la découverte d'un moyen inédit de locomotion et de communication, laisse entrevoir la possibilité pour les groupes humains de s'établir dans des milieux

\footnotetext{
Science, 1957, 125, p. 143.

2 J. LEBRUN: Équilibres naturels et recherche scientifique, Impact, 1964, 14, nº I, pp. 21-40.
} 
physiques qualitativement différents. Pendant de nombreux siècles, le champ des voyages extra-terrestres, si follement cultivé par ses pionniers, a intrigué ou amusé les esprits réservés. A présent nous y revenons, munis des leçons de la dernière décennie, désireux de mesurer l'étendue d'une conversion aussi exceptionnelle. Ce qui était utopie, plénitude innocente de la fantaisie, se range, sans équivoque, dans le cadre de notre ordre naturel en expansion. Tout ce qui a été conçu, éprouvé à l'échelle de notre planète, devra subir une révision. Les préliminaires sont là, ils ont valeur indicative. Resserrement de nos liens avec les puissances matérielles, extension des conditions d'existence possibles au-delà de la surface de la terre, bouleversement corrélatif de notre intelligence et de nos instruments, telles sont les composantes de notre réalité visible, immédiate. Des moyens importants sont réunis pour déchiffrer et orienter son cours; des millions d'individus se consacrent à cette tâche. Il est certain que l'avenir qui se prépare ainsi dépend de nous. Paradoxalement, il nous semble inconnu et, à certains égards, incompréhensible.

Au demeurant, ce serait faire un songe creux que de sous-estimer le rôle des circonstances sociales et politiques qui accompagnent cette évolution et lui fournissent l'arsenal de ses mobiles. Tout d'abord, l'affrontement de deux systèmes sociaux, le système capitaliste et le système socialiste. Dans cet affrontement, un rôle essentiel revient à la capacité d'inventer, d'assimiler les ressources matérielles par la science et la technique ${ }^{3}$. Une société est censée perdre sa raison d'être lorsque son cœur matériel, les connaissances qu'elle détient, les productions grâce auxquelles elle entretient ses institutions civiles et préserve son genre de vie, sont supplantés par des connaissances et des productions qu'elle n'est pas en mesure de se procurer. Le rayonnement et la permanence du pouvoir politique en dépendent.

Pénétrer les mystères de l'univers, c'est aussi assurer, sans mystère, la puissance et la victoire de sa propre nation. La violence comportant actuellement des risques incalculables, on substitue, au combat

3 « C'est une re-création de la nature et de l'homme, en tant qu'il est fragment de la nature, que signale l'inspiration observable dans les mouvements puissants de ces sociétés (soviétique et américaine). F. PERROUX » : Les mesures des progrès économiques et l'idée d'économie progressive, Cahiers de l'I.S.E.A., 1956, 47, p. 38. 
direct par lequel on soumet l'adversaire en lui enlevant le fruit de ses travaux ou en renversant le régime qu'il s'est donné, des efforts qui visent à anéantir les fondements objectifs de son existence. Bref, au lieu de s'approprier sans détours les biens de l'autre, on essaie de maîtriser sa nature. Le procédé nous rappelle singulièrement l'habitude des cultivateurs qui, lorsqu'ils ne peuvent extirper directement une espèce animale ou végétale, modifient la flore ou la faune, privant ainsi l'espèce jugée nuisible de moyens de défense et de reproduction. La course aux armements, l'accroissement de la productivité du travail, ou encore la lutte pour la primauté dans l'espace, revêtent le même sens.

Peut-être la paix entre les peuples n'est-elle souvent, quand les circonstances particulières le commandent, qu'un combat mené par le truchement de la nature. Aujourd'hui cette paix est une guerre ouverte où la bataille décisive se livre sur le terrain des lois et des forces du monde extérieur que l'on voudrait annexer. La dignité, l'adéquation et l'efficacité des systèmes sociaux, fait symptomatique, ne sont pas estimées en termes intrinsèques de justice et d'égalité. Elles se rapportent à la capacité d'exercer une influence sur les phénomènes naturels et sur le développement subséquent des sciences et des techniques :

«L'utilisation des conquêtes des sciences naturelles, écrit-on ${ }^{4}$, devient un des plus importants problèmes sociaux de l'époque moderne. Dans la compétition des systèmes sociaux, le régime qui vaincra sera celui qui utilisera le mieux, de la façon la plus efficace dans l'intérêt des hommes, les conquêtes de la connaissance scientifique et assurera en fin de compte la plus haute productivité du travail ».

L'importance prise par le progrès scientifique dans la conscience collective ne reflète pas seulement l'antagonisme des formes sociales. Ce progrès figure également parmi les remèdes souverains idoines à résoudre nos difficultés politiques et économiques, une fois la cause de celles-ci diagnostiquée. A ce titre, on lui demande soit de remplir le rôle de complément à une répartition des richesses qui laisse subsister des inégalités sociales, soit de se substituer au conflit qui oppose les

$4 \quad$ P. Fedosseiev, in La nouvelle revue internationale, 1964, 10, p. 95. 
classes d'une société. Ce problème mérite de nous retenir plus longuement.

Assurément, les dons innés, la place de l'individu dans la division du travail, l'appropriation des moyens et des biens de production sont les critères principaux qui déterminent la hiérarchie, la jouissance et le pouvoir des membres d'une société

« La première cause de la subordination, écrivait Ferguson ${ }^{5}$, vient de la différence des talents et des dispositions naturelles ; la seconde, de l'inégalité dans le partage de la propriété; et la troisième résulte des habitudes qui se contractent dans la pratique des différents arts ».

Cette troisième inégalité acquiert d'autant plus d'importance que la première, l'inégalité biologique, est aléatoire ou subordonnée, et que la seconde, due à l'existence des classes sociales, est destinée à s'atténuer ou à disparaître. Les sociétés socialistes ont vu s'éliminer, dans une large mesure, les différences provenant de la disparité des fortunes privées. L'équité que ces sociétés ont voulu introduire demeure cependant hors d'atteinte ${ }^{6}$ aussi longtemps que les techniques productives maintiennent, entre autres, une division du travail en occupations manuelles et tâches intellectuelles. La séparation des travailleurs en " mains » et "cerveaux », en exécutants et dirigeants, préserve une distance qui tend à se perpétuer, les enfants de chaque catégorie suivant la carrière de leurs parents et récoltant les avantages ou les désavantages de leur position ${ }^{7}$. Pour éliminer les conséquences de cette situation, un autre mode de répartition des richesses serait inopérant. Il faudrait transformer le travail lui-même, en agissant sur la somme et la structure des savoirs créés jusqu'à ce jour. En définitive, la solution résiderait dans l'invention de nouvelles habiletés,

5 A. Fergusson : Essai sur l'histoire de la société civile, Paris, 1783, t. II, p. 138.

6 «La base économique de la disparition totale de l'État, c'est le communisme arrivé à un si haut degré de développement que tout antagonisme disparaît entre le travail intellectuel et le travail manuel, et que, par conséquent, disparaît l'une des principales sources de l'inégalité sociale contemporaine, source que la seule socialisation des moyens de production, la seule expropriation des capitalistes ne peut en aucune façon tarir d'emblée ». V.I. LENINE : L'État et la Révolution, Moscou, 1946, p. 120.

7 F.L. MANEVICH : Abolition of the differences between mental and physical labor in the period of full-scale construction of communism, Soviet Sociology, 1962-3, I, p. 13. 
d'un autre appareil productif, d'échanges différents avec la matière. De là la conviction que « le progrès technique est le moteur principal $\mathrm{du}$ rapprochement du travail manuel et intellectuel ${ }^{\mathbf{8}}$. Supprimant une division millénaire, le progrès se présente comme le signe d'une nouvelle finalité dans les sociétés qui se proposent d'instituer des rapports collectifs fondés sur l'association harmonieuse des groupes humains. A savoir, de proscrire la troisième inégalité, celle des talents et des connaissances.

Par contre, dans les sociétés capitalistes, le progrès scientifique et technique synthétise de plus en plus l'ensemble des mesures destinées à se substituer à une réorganisation radicale des structures sociales. Les indices conventionnels de comparaison entre individus et collectivités sont devenus ceux de la productivité, de la croissance, du développement, c'est-à-dire qu'ils portent sur les quantités d'énergie disponibles, le nombre d'industries, la surface habitable, l'éventail des machines à usage public et privé. Par voie de conséquence, la différence entre les modalités de répartition des richesses, donc la composition des classes sociales, n'est plus considérée comme essentielle et se trouve reléguée au second rang. Une société n'est pas d'abord socialiste ou capitaliste, mais industrielle, scientifique ou technique.

En accord avec cette doctrine, la maîtrise des processus naturels est la meilleure voie qu'une classe ou une nation puisse suivre pour accroître le bien-être de tous et de chacun. A la distribution équitable des richesses, on voit opposer l'augmentation du volume des biens en général, sans que cela implique nécessairement, pour une catégorie sociale, la diminution de sa dépendance par rapport à une autre :

«Une fois que l'on en vient à considérer la croissance économique comme un terme qui peut se substituer à la distribution, sa supériorité potentielle dans la création du bien-être apparaît rapidement. Même ceux qui sont au niveau le plus bas de l'échelle des revenus ont plus à gagner, à brève échéance, d'un progrès rapide que d'une redistribution ${ }^{9}$.

$8 \quad$ Les principes du marxisme-léninisme, Moscou, 1961, p. 831.

9 H.C. Wallich : The Cost of Freedom, New York, 1960, p. 114. 
L'individu est invité à mesurer les avantages offerts par le nombre d'esclaves mécaniques qui lui sont attribués, et par la masse de commodités dont il dispose. Un parallèle avec la quantité de besoins qu'il aurait pu satisfaire s'il avait vécu au siècle dernier, et avec ceux qu'il satisferait certainement s'il vivait au siècle prochain, le rassure au sujet de son aisance actuelle et future. Le bilan de cette comptabilité est obligatoirement positif. On constate, en effet, que la gamme de nos serviteurs muets est aujourd'hui plus étendue que la cour des domestiques vivants dont disposait un prince chrétien d'il y a dix siècles, ou dont dispose un potentat mineur de nos jours. L'inégalité présente est de ce fait rendue tolérable, la comparaison avec les empereurs de l'industrie, de la banque ou de l'État étant éminemment nuisible au véritable progrès ${ }^{10}$. Celui-ci, nous invite-t-on à conclure, compense les menaces d'insécurité, de privation de liberté qu'une partie de l'humanité fait peser sur l'autre. Laissons donc à la propagation des sciences et des techniques le soin d'obvier aux imperfections inévitables qui viennent au jour dans le déroulement des processus socioéconomiques. Telle est l'opinion sur laquelle se fait le consensus : à la maîtrise de la société, il faut préférer la maîtrise de la nature. Peut-on voir dans cette visée la source d'un élan propre à réconcilier l'homme avec son destin ? Le progrès scientifique ${ }^{11}$, la croissance économique peuvent-ils remplacer la recherche avouée d'une justice sociale que le $\mathrm{XIX}^{\mathrm{e}}$ siècle - sur les idées duquel nous continuons à vivre - a proclamée indispensable?

Ainsi la question naturelle porte sur notre réalité tout entière. Mettre en évidence le poids de l'univers matériel qui nous sollicite, c'est s'arrêter à une de ses manifestations particulières. L'enjeu que cet univers représente inverse l'ordre des préoccupations coutumières et provoque un déplacement du point d'application de l'initiative et de l'effort humain. C'est d'autant plus évident que la signification de ce qu'il s'agit désormais de poursuivre et de découvrir n'est pas inscrite

«On peut en conclure sans erreur possible que le progrès s'installera plus rapidement si on tolère un certain degré d'inégalité ». H.C. WALLICH: op. cit. p. 120.

11 «L'apparition de la science en tant qu'agent important de la sphère sociale est un pas décisif et irréversible dans l'histoire générale de l'humanité. Avec les changements économiques et politiques auxquels elle est inévitablement liée, c'est un événement du même ordre d'importance que le fut l'apparition de la race humaine elle-même ou de sa première civilisation. J.B. BERNAL : Science in History, Londres, 1954, p. 879. 
dans un « livre de la nature », difficile à parcourir mais achevé, qu'il nous suffirait de déchiffrer. En fait, il nous faut remplacer un cadre qui nous semblait donné par un cadre que nous façonnons nousmêmes. La détermination que nous fixions dans le cosmos et qui ne paraissait pas être de notre ressort part aujourd'hui de nous :

«Maintenant que le milieu naturel donné ne peut plus opposer d'obstacle insurmontable à la technique moderne, et qu'aucune appréhension n'empêche plus l'homme de soumettre à ses fins tout ce qui existe, il faut un plan général d'action propre qui doit remplacer le plan mondial ou naturel donné, tel qu'il est contenu, par exemple, dans toute pensée religieuse $\gg{ }^{12}$.

Le constat et ses conséquences sont éminemment pratiques, puisqu'ils nous incitent à concevoir une méthode correspondant à un tel plan, à créer les qualités d'intelligence et d'action sans lesquelles une coordination rationnelle de nos échanges avec les puissances matérielles s'avère impossible. A travers le zèle ininterrompu qui s'applique à résoudre les difficultés d'une science ou d'une technique spécifique, nous l'apprenons de la sorte, loin qu'un univers déjà constitué se dévoile, c'est un ordre qui s'instaure. Cependant cette possibilité naissante d'influer sur les liens et l'équilibre des forces matérielles a une répercussion plus vaste. Mise à la disposition des corps politiques, elle définit le contexte de leurs décisions et la condition de leur supériorité. Étayée par les courants qui, dans ces sociétés, visent à remplacer «l'exploitation de l'homme » par «l'exploitation des choses », elle justifie leur démarche. Que cela ait lieu dans les circonstances que je viens de décrire n'a rien qui doive surprendre. C'est la présence de deux cités rivales, Sparte et Athènes, et la guerre intestine, qui a contraint les Grecs à examiner l'essence de la cité et à rechercher les principes qui la rendent parfaite. De façon plus impérieuse encore, toutes les conditions sont réunies aujourd'hui pour situer le gouvernement de la nature au cœur des relations entre les hommes et des rapports de ceux-ci avec le monde extérieur, pour en fixer le sens et en faire une nécessité. 
Pour saisir pleinement cette conjoncture, force nous est de réintroduire la nature, l'exigence radicale de la gouverner, dans une pensée et une vision de l'évolution de l'humanité caractérisées par un effort tenace pour les en exclure et les couper de la société. Dans notre passé récent, Jean-Jacques Rousseau, paradoxalement, avait donné le signal de cette mise à l'écart. Avant lui, on pouvait encore considérer l'ordre social comme une phase ou un degré de perfection de l'ordre naturel, une des fins auxquelles celui-ci s'efforçait d'atteindre. Sans réticence aucune, Adam Smith s'accordait la liberté d'envisager une époque « où la nature avait formé le genre humain pour la société ». De cette continuité, l'auteur du Contrat social — et c'est là son génie a disposé avec rigueur et raison, en indiquant la coupure que l'inégalité des richesses introduit entre deux périodes de la société humaine, plaçant justement l'origine de cette inégalité dans les rapports politiques et non pas dans la constitution de l'univers ou de l'espèce. La confusion, si tenace, de la progression des sciences et des arts avec l'avancement moral et intellectuel, avec la disparition de la misère des peuples, n'a jamais été depuis plus clairement démasquée. Ce faisant, Rousseau avait rendu impossible toute tentative de retour naïf vers une harmonie perdue à jamais. Après lui, la nature cessa d'être le lieu privilégié d'où venaient les solutions aux problèmes qui assaillent les hommes; elle n'expliquait pas non plus comment ils avaient été amenés à se les poser. Elle ne justifiait plus le présent, ses injustices, ses tourments, elle n'inspirait pas davantage les actions futures. Toute la nécessité, aussi bien pratique que théorique, se concentra dans la société, et toute la contingence se réfugia dans la nature; l'une apparaissait entièrement réservée au règne du sujet, l'autre exclusivement concédée à la domination de l'objet. La première reposait sur la seconde comme sur un vide, indispensable pour subsister, inutile pour devenir.

Pareille césure permit à la société humaine de se ressaisir, de voir qu'elle possédait à la fois vérité et puissance, qu'elle était œuvre de l'homme autant que les catégories humaines étaient son œuvre. Rejetant la prédétermination de leurs actes par des processus cosmiques, récusant une causalité qui en tirait sa substance, les individus et les groupes sociaux retrouvèrent, du même coup, leur responsabilité et leur initiative. Ils se découvrirent au sein de la vie sociale acteurs et 
sujets, auteurs de rapports qui les rendaient mutuellement solidaires. Le capitaliste qui combattait son passé, la féodalité, et le prolétaire qui élevait les barricades de son avenir, le socialisme, avaient appris qu'une organisation collective fait suite à une autre, qu'elle naît d'un état passé et non pas d'un ordre naturel contemporain. A l'articulation nature-société se substitua l'articulation société-société - le « devenir société de la société », dit George Lukàcs - le mouvement continu, la longue marche au cours de laquelle chaque forme sociale s'installe sur les débris d'une autre. Les révolutionnaires qui ébranlèrent sans relâche les assises des États n'avaient plus à craindre de desceller les piliers de l'univers ${ }^{13}$ : ils ne faisaient qu'abattre ce qui paraissait voué à la destruction. La pensée humaine se sentit dotée d'une énergie inconnue qui la portait au delà des limites dans lesquelles on l'avait enfermée ${ }^{14}$. L'autonomie de la société, l'existence de lois et d'un dynamisme qui lui sont propres, furent les axiomes qui reçurent un prolongement philosophique et scientifique. L'histoire prit la place de la nature, et c'était elle qui démontrait clairement la genèse des formations sociales, à partir du moment où on lui attribuait un sens, et où les classes sociales prenaient l'engagement de le reconnaître et de modeler son visage par la richesse, le travail et la lutte. Ses décrets semblaient être inexorables. Si la naissance et la mort des ordres humains perdaient leur caractère de cataclysme universel - le social étant engendré par le social et non plus par le non-social - leur succession s'avéra soumise à la logique des faits et à l'exigence stricte des principes. La liberté de la société était obéissance à sa nécessité historique, une classe d'hommes se voyant investie de tous les privilèges que confèrent le rang de maître et la qualité de sujet historique, pourvu que ce fût à son heure.

A la faveur de ce renversement, l'histoire en vint à représenter l'antinature. On peut désormais renoncer à cette négation: elle est

« Or je demande pourquoi une institution arbitraire des hommes et qu'ils auraient pu ne pas établir ne peut-être changée sans ruiner l'ordre même de la nature ». G. de MALBY : Doutes proposés aux philosophes économistes, La Haye, 1768, pp. 6-7.

14 «Il n'est pas probable que des penseurs européens de tout premier ordre auraient accordé autant d'attention à ce qu'on appelle à présent le problème social, n'eût été que le bouleversement politique (la Révolution française) avait été accompagné et suivi par une révolution dans les idées bien plus grande encore ». J.T. MERZ : A history of European thought in the nineteenth century, Londres, 1923, t. IV, p. 422. 
contraire aux phénomènes observés. Il faut également la pousser à son terme pour dégager la vision qui l'inspire de la sentimentalité et de la routine où elle s'enlise. J'essaierai de m'expliquer à ce propos.

Dans une description cohérente de la genèse de la société, on pose au commencement une humanité dominée par des besoins primaires. Pour apaiser la tyrannie de ces besoins, elle agit sur le monde extérieur. Ce faisant elle le modifie et le transforme parallèlement. Au cours de ce processus, les individus et les groupes nouent des liens économiques, politiques, intellectuels, destinés à leur assurer l'appropriation des biens, la continuité des productions et la perdurabilité des institutions. Les sociétés qui en résultent se distinguent les unes des autres autant par la congruence de chacune à une configuration particulière des pouvoirs matériels que par la manière dont les classes sociales s'allient et se combattent. L'accord est unanime sur le rôle déterminant des innovations techniques et des forces productives - expressions de ces pouvoirs — dans la succession des formations sociales.

A partir de ces prémisses, rien ne permet plus de rejeter le substrat naturel dans la région des êtres passifs et neutres, ni de nier l'ingérence de notre espèce dans son cours ordinaire. Les variations de l'état social dues à la différenciation des contenus et des structures de l'ordre naturel mettent en évidence une évolution de ce dernier aussi perceptible que celle du premier. Bien plus, l'historicité des entreprises collectives, pour autant qu'elle s'articule avec un renouvellement du monde matériel, des échanges avec lui, apporte et suggère la preuve expérimentale d'une histoire des ordres naturels. Comment l'homme élèverait-il son édifice social à partir du monde environnant sans remplir à son tour de fonction constitutive dans le déroulement des formes et la composition des éléments de celui-ci ? Du fait que son travail s'y enracine et lui impose sa marque, on ne peut minimiser son influence sur les modifications de la nature, ni refuser de voir en celle-ci un lieu où l'humanité à la fois intervient et s'épanouit. Et si nous sommes dans la dépendance, «à la fin », selon le mot de Goethe, «nous dépendons pourtant des créatures que nous faisons ». Face à une entité close et abandonnée à son instinct de répétition, simple réceptacle de forces et de matériaux, il ne saurait y avoir de devenir. 
L'histoire de la société ne pourrait que retomber dans la contingence et la finitude. Par un retournement normal, la non-historicité de la nature, la rupture entre elle et l'humanité et sa conquête en tant que super-objet, apparaissent comme autant d'illusions et d'impossibilités. Ce que nous connaissons effectivement,

« c'est toujours une nature cultivée mais qui, à cause de sa permanence et de sa stabilité plus ou moins grande, nous semble familière, et ainsi nous laisse croire que nous avons affaire à la nature seule. C'est seulement en rétrospective historique que nous découvrons combien cette nature est culturelle ${ }^{15}$.

Si on néglige cette évidence, l'on s'enferme dans des rêveries de puissance. Le rappel de notre supériorité, de l'exception que nous représentons au regard des autres espèces animales - par l'intelligence, l'indice de cérébralité, l'outil ou le langage - semble nous y inviter. Certes, sous le double patronage de la certitude et de l'indifférence, on accepte le postulat d'une humanité attachée au règne naturel, à l'instar des pierres, de l'eau ou des végétaux. De manière passive, on l'y situe par les aspects qui sont les moins spécifiques, les moins humains, allais-je dire. Toutefois, dès l'instant où nous affirmons notre particularité humaine, nous nous projetons enivrés hors du monde naturel, rendu ainsi à l'extériorité. Nous y voyons un grand réservoir de substances ayant leurs régularités et leurs impulsions qu'il convient de soumettre, d'exploiter, afin de les connaître et d'accroître leur utilité. Masse hétérogène et opaque, sans communication immédiate avec nos désirs, sans langage commun avec notre esprit, la nature ainsi conçue est le cercle dont nous tentons constamment de nous évader et dont nous sommes constamment expulsés :

«Il ne faut jamais perdre de vue, nous avertit Jean-Paul Sartre ${ }^{16}$, que l'extériorité - c'est-à-dire la quantité, et en d'autres termes la Nature — est à la fois la menace du dedans et la menace du dehors ».

La défense acharnée et l'agression tenace se complètent à ce propos. L'humanité se sent grandie lorsqu'elle remporte une victoire dans

A.G. van MELSEN : Science and Technology, Pittsburgh, 1961, p. 291.

16 J.-P. SARTRE : Critique de la raison dialectique, Paris, 1960, p. 158. 
cette lutte sans merci. Si la société se dégage de la nature, elle se reforme surtout contre elle. Habité par la violence, soustrait à l'oppression objective et dure, l'homme sorti de l'anonymat des êtres animaux affirme sa suprématie, sa singularité, son indépendance. De là découle sa vocation à dominer l'univers, à en extraire, par le truchement de ses sciences et de ses techniques, les pouvoirs et les connaissances dont il ne dispose pas encore à sa guise. La lutte impitoyable des espèces animales et le rapport du maître à son esclave inspirent ce paradigme familier. Il a pour contrepartie l'activité concrète des sociétés et des individus.

Partout, on se préoccupe simplement d'accroître l'équipement qui permet d'emmagasiner des inventions, des sources d'énergie, des cerveaux instruits par l'université et des mains façonnées par l'industrie. La quantité de ces cerveaux et de ces mains dont on dispose est censée témoigner d'une emprise proportionnelle sur le monde extérieur. Dans cet inventaire, les sciences et les techniques figurent les véhicules flexibles et commodes, aussi bien qu'importants et révérés, d'une foule d'intérêts et de nécessités auxquels les collectivités accordent leur véritable attention. Chacun se soucie d'augmenter ces savoirs en tant que moyens. Pour plus de sûreté, on y associe la communauté des savants susceptibles de prévoir les tendances propres à la théorie et à l'expérience de leur discipline. Dans le conseil des États, les fonctionnaires humanistes, " payés par le fort pour prêcher le faible », et qui, aux dires de Rousseau, «ne savent parler au faible que de ses devoirs et au fort que de ses droits ", se voient préférer les administrateurs éduqués à l'école de la science. Ceux-ci ont pour mission de déceler les imperfections de la nature et de proposer les procédés par lesquels nous pourrons y maintenir notre empire. Leur présence est gage de raison, exprimant nos droits sur l'univers et les devoirs de celui-ci envers nos manques et nos ambitions. La progression de chaque groupe social par rapport aux autres, l'ascendant dont il jouit, se juge au nombre de savants ou d'ignorants, à la vitesse des fusées qu'il construit ou à la hauteur de leur orbite, à la distance en annéesconnaissance qui le sépare de la lune. De l'accroissement de la puissance de toutes sortes d'engins et de l'accumulation des publications, 
on conclut à une maîtrise équivalente sur la sphère naturelle ${ }^{17}$. La comparaison est ici raison. Comme l'avare, à la vue de l'or thésaurisé, crie au triomphe de sa vertu, l'humanité, devant la réunion de tant de science, acclame la toute-puissance de son esprit. Si des régions immenses lui échappent, elle sait que rien ne lui résiste. Son confort trouve sa source dans la croyance au caractère spontanément positif et inéluctable du progrès, dans l'assurance que les inventions de l'intelligence ne peuvent être nuisibles. On tient pour acquis, à la fois que la connaissance est pouvoir, que l'essor des sciences ou des arts aiguise la conscience qu'une société peut avoir de ses actes, et que ces actes s'inspirent d'idéaux élevés.

Il est inutile d'insister sur la fragilité de cette croyance. Les savants tout les premiers en sont troublés ${ }^{18}$, tant la finalité de leurs travaux leur apparaît fréquemment déviée par des ingérences étrangères. Les déceptions naissent des espoirs qu'on a nourris au mépris des leçons du réel. Régulièrement, on nous rappelle que l'éclosion de nos sciences «nous permet d'envisager un monde dans lequel les hommes pourraient être heureux ${ }^{19}$, en oubliant qu'il n'y a là rien qui s'inscrive automatiquement dans la texture de nos liaisons avec les forces extérieures. Élaborer notre milieu ambiant, ce n'est pas essentiellement faire le décompte de son contenu en phénomènes chimiques, lois physiques ou chevaux-vapeur; c'est d'abord, c'est surtout comprendre les antécédents et les conséquences de ces phénomènes et de ces lois, c'est donner un sens au mouvement qui les fait apparaître pour nous et avec nous. Nous sommes depuis longtemps en possession de telles lois, de tels phénomènes, sans être parvenus à leur im-

«Les hommes des sociétés sur-développées ont l'impression que la conquête manifeste de la nature, la victoire sur la pénurie est virtuellement achevée. Or il semble dans ces sociétés que la science — principal instrument de cette conquête — soit sans attache et sans but, et qu'il faille lui redonner une valeur ». C.W. MiLls : The sociological imagination, New York, 1961, p. 15 .

18 «Le fait que la science soit davantage estimée pour ces applications (politiques) que pour ses buts fondamentaux - étude libre de la nature - conduit à des pressions qui ont commencé à menacer l'intégrité de la science elle-même ». Science and human Welfare, Science, 1960, 132, p. 68.

19 Linus PAUling, in B. RUSSEL : L'homme survivra-t-il ? Paris, 1963, p. 10. 
primer une direction qui soit le fruit d'une décision délibérée ${ }^{20}$. Ce constat illustre suffisamment la précarité d'une méthode et d'une conception qui ne prennent en considération que l'accroissement des sciences en volume et en étendue. L'appel à la soumission du monde extérieur, répercuté dans des métaphores creuses, s'éteint dans le vide d'un discours dont les lieux communs masquent mal l'absence de visées précises.

Dès lors, quelle perspective adopter, quelle voie suivre? Un trait indélébile a été tiré lorsqu'on a cessé de considérer l'homme comme produit de l'élan cosmique, de la vitalité animale ou végétale. L'affirmation maintes fois réitérée de ses privilèges, l'accent mis sur sa situation exceptionnelle ${ }^{21}$, ne sont que l'écho de cette rupture. Mais on n'en a pas envisagé les conséquences dans toute leur rigueur : l'homme est non pas "possesseur» ou "révélateur», mais créateur et sujet de son état de nature. C'est assez dire que son dessein n'est pas de s'approprier un univers qui lui serait étranger, auquel lui-même resterait extérieur : il consiste au contraire à accomplir sa fonction de facteur interne et régulateur de la réalité naturelle ${ }^{22}$.

Faut-il s'en étonner? Nous tenons depuis trop longtemps pour assuré que les connaissances et les expériences fournies par les disciplines techniques ou scientifiques sont de pures données, fruits d'un agencement extérieur, qu'un travail incessant amène à la surface. L'avancement de ces disciplines est conçu comme une avancée vers quelque fondement dont nous nous rapprochons de plus en plus par-

«L'occident méconnaît l'origine, la nature créatrice et le sens de sa propre civilisation scientifique et technique ». in R. Aron, G. Kennan, R. Oppenheimer : Colloques de Rheinfelden, Paris, 1960, p. 43.

21 «Lorsque l'homme s'est séparé de la nature et l'a transformée en un être soumis à sa domination et sa maîtrise par des manipulations symboliques - à ce moment-là l'homme a été amené à ancrer son propre être central dans quelque chose situé au delà de ce monde. Celui qui s'était placé aussi audacieusement au-dessus du monde ne pouvait plus se considérer simplement comme un «numéro » ou une «partie» de ce monde». M. SCHELER : Man's place in Nature, New York, 1961, p. 90.

«A chaque pas nouveau nous sommes ainsi amenés à penser que nous ne dominons nullement la nature, à l'instar du conquérant d'un peuple étranger, comme si nous étions placés en dehors de la nature - mais qu'au contraire nous lui appartenons tout entiers, par la chair, le sang, le cerveau, et en faisons partie ». F. ENGELS : Dialectique de la Nature, Paris, 1950, p. 387. 
faitement, les diverses réalités que nous en saisissons n'étant que les étapes indispensables pour atteindre la réalité complète. C'est bien ce que l'on entend par aspirer à soumettre et conquérir l'univers. Toutefois, nous sommes plus près de la vérité et nous disposons d'une certaine liberté d'initiative si nous acceptons de voir dans ces connaissances et ces expériences les démarches par lesquelles l'humanité édifie son propre état naturel. Par leur truchement, elle diversifie ses facultés et améliore ses qualités physiques ou intellectuelles, s'attache les forces matérielles de manière inédite, et leur imprime une figure conforme à leurs principes et aux combinaisons dans lesquelles elles s'insèrent à un moment de l'évolution générale.

L'observation empirique le prouve, quand elle se porte sur la modification incessante de l'équipement psycho-physiologique de l'espèce ; constamment on voit se renouveler les forces qui contribuent à marquer le contenu du monde objectif et la vision que nous en prenons. Les lois de notre intelligence, celles de nos savoirs, peuvent être datées par les formes de mouvement ou les sources matérielles auxquelles elles se rapportent, puisque les unes et les autres participent de notre nature dès l'instant où elles pénètrent dans l'orbite de notre capacité d'action. Nul partage rigoureux ne saurait avoir lieu entre la nature de l'homme et la natura rerum, la nature des choses, et rien ne pourrait les fixer à un stade déterminé et définitif.

Héraclite enseignait que «ceux qui descendent dans les mêmes fleuves se baignent dans le courant d'une eau toujours nouvelle ». La vérité est plus dramatique. L'eau des Grecs est celle du potier, de l'humide, des quatre éléments qui se combinent entre eux, comme dans la physique qualitative des Ioniens. Au XVII siècle, l'eau est celle des moulins et des pompes, de l'ingénieur, de la pesanteur et de la mécanique quantitative d'un Galilée. Pour nous, l'eau peut revêtir l'apparence de l'" eau lourde », si nous considérons les énergies déclenchées au niveau du noyau. Chaque fois, cette « eau » a exigé des hommes le recours à une connaissance différente, à un autre mode d'action, à une nouvelle image du monde, sous peine de se confondre avec le néant primordial. On y reconnaît le propre de l'homme qui n'est pas tant de fabriquer des outils ou d'être raisonnable que de se 
créer lui-même, de se combiner avec les autres êtres, bref, d'engendrer son état naturel.

Si la nature est simultanément une donnée et une œuvre, les découvertes, l'augmentation du savoir-faire ne sont pas des jalons sur le chemin d'un fondement dernier, mais les indices de son renouvellement, provoqué par notre intervention. C'est seulement en tant qu'agents d'une transformation dont les ordres successifs constituent la réalité objective que nous pouvons prétendre prévoir et instituer celle-ci. On reprochera peut-être à cette vue d'être anthropocentrique. On oublie trop facilement que tous nos modèles de la nature le sont, sous une forme ou une autre, et que celle-ci est peuplée d'êtres humanoïdes ou qui le deviennent. L'ordonnateur du cosmos grec est bien un démiurge, un artisan: Platon et Aristote en témoignent. Dans l'univers de Newton, les corps se meuvent à la façon d'un boulet de canon ou d'une horloge. Dieu y accomplit sa mission comme le ferait un mécanicien ou un fabricant d'instruments mathématiques. La conception que nous avons actuellement de l'agencement des forces matérielles ne saurait se passer d'une description de l'observateur. Comme ces différents modèles ne se réfèrent pas à un "anthropos » constant ni ne traduisent une morphologie identique, force est d'y reconnaître les manifestations d'une évolution, une histoire. On accuse ces moments en stipulant, dans un langage négatif, que chacun d'eux recule un peu plus les frontières de notre milieu matériel. Renonçant à ce langage, on peut soutenir que ce sont nos propres frontières, nos limites qui s'élargissent, chaque fois que la nature, décidément humaine, atteint une nouvelle phase, exprime une nouvelle constitution.

Cela n'a rien d'arbitraire ou de subjectif : en parcourant ces étapes, nous suivons sans cesse les lois de la matière et celles de notre condition. Il serait aussi faux de croire que les effets se cantonnent dans la sphère des idées, en affirmant que seules nos conceptions ont changé, se sont rapprochées par retouches successives du portrait ressemblant de la véritable et ultime structure de l'univers. Une telle opinion suppose un être omniscient et omnipotent, ou, au contraire, limite les gains de nos œuvres effectives à ceux de la pensée dissociée de ses résultats. Ce résidu d'une croyance religieuse laisse dans l'ombre le fait que chaque passage d'un état naturel à un autre a été provoqué par 
un labeur immense qui, en retour, a opéré un bouleversement de notre esprit et de nos instruments, organiques ou non, a réuni différemment l'humanité à la matière.

Qu'est-ce à dire, sinon que cette perspective - à savoir, l'homme créateur et sujet de la nature - nous impose de reconnaitre l'existence d'une histoire humaine de la nature, histoire non pas dérivée ou complémentaire de celle de la société, mais autonome et représentant l'approfondissement original de celle-ci. L'apparition de cette histoire comme clé de voûte de nos préoccupations et lieu de nos actions est notre véritable question naturelle.

Jusqu'ici on a surtout été enclin à envisager notre histoire du point de vue des intérêts des États et des classes sociales. "Je parle des classes, elles seules doivent occuper l'histoire ». Les circonstances se prêtaient à cette vue tranchée d'Alexis de Tocqueville, qui avait sous les yeux, comme ses contemporains, l'exemple des sociétés mûes par le capital dans l'hémisphère occidental. Que les peuples sortent de leur isolement et de leur dépendance, que des circuits visibles relient toutes les parties de notre planète, que les systèmes sociaux les plus divers s'opposent, alors l'expérience de centaines de nations converge vers le même laboratoire de l'histoire universelle. Du coup, les rapports variés que les hommes entretiennent avec les pouvoirs objectifs s'étalent sur un tableau complet ${ }^{23}$, illustrant dans l'espace ce qui s'est formé dans le temps.

La distance qui sépare deux fragments de l'humanité n'apparaît pas seulement comme distance entre des enveloppes sociales : elle se juge aussi aux écarts qui séparent les complexions naturelles où s'inscrit chacun. Nous savons à présent qu'édifier et diriger une société appelle également une réforme et une réorganisation de ses soubassements matériels. Jadis les structures d'une société se manifestaient au terme

«A ce moment-là il nous faudra trouver un moyen de développer une agriculture vraiment productive dans les énormes territoires d'Afrique, d'Amérique du Sud et de vastes parties de l'Asie qui sont si peu exploités à présent. Et cette tâche forcera, je crois, l'humanité à se rendre compte de ce que la société humaine vit sa vie en tant que partie d'un système de processus naturels équilibrés de manière complexe et délicate ». C.H. WADDINGTON in N. CALDER : The world in 1984, Londres, 1964, t. 2, p. 13. 
d'un cheminement lent et inconscient, après que les forces de l'homme et du milieu naturel s'étaient amalgamées sans propos délibéré. Maintenant les modèles de société auxquels on aspire sont devenus plus transparents les uns aux autres. Les trajets qui conduisent à l'invention de ressources adaptées à ces modèles, aux savoirs indispensables, ont perdu de leur obscurité et acquis l'indépendance. L'existence d'une logique interne de leur établissement, des règles spécifiques auxquelles obéit leur apparition — la science, à cet égard, est exemplaire - devient visible. Là se reflètent pour nous le devoir et la responsabilité d'accepter lucidement la prise en charge de la nature, son passé et son avenir ${ }^{24}$, de même qu'au siècle dernier les hommes ont accepté le même devoir et la même responsabilité sur le plan de la société. Dès lors, le gouvernement de l'ordre naturel ne peut plus être envisagé comme une violence exercée sur les éléments pour obéir aux injonctions irrépressibles de la puissance ou du besoin individuel ou collectif. La portée, la rationalité qui lui sont propres, les fins vers lesquelles il tend ne sauraient être énoncées avec retenue et sans poncifs, si elles ne sont pas situées dans le cadre de l'histoire humaine de la nature.

L'objet de la présente étude est justement cette histoire ; la question naturelle en est le motif. Dans sa première partie, je me propose de montrer en quoi l'homme est créateur et sujet de sa nature, quels sont les principes et les processus de cette création. Les propositions théoriques fondamentales qui découlent de la conception que j'ai avancée et dont je viens de donner une esquisse trouveront alors leur confirmation.

A partir de là, j'analyserai l'histoire humaine de la nature en fournissant des preuves en faveur de la théorie explicative soutenue. Celle-ci n'étant toutefois que le travail de la réalité sur elle-même, de sa composante conceptuelle sur les autres composantes, ne peut prétendre à une intelligibilité transparente à jamais, sans perdre sa raison d'être. Stricto sensu, la compréhension des événements et de

«C'est précisément dans le fait d'élaborer un monde objectif que l'homme commence à faire réellement ses preuves d'être générique. Cette production est sa vie générique active. Grâce à cette production, la nature apparaît comme son œuvre et sa réalité. » K. MARX : Manuscrits de 1844, Paris, 1962, p. 64. 
l'histoire, si elle atteint la vérité, est un moment de ces événements et de cette histoire. On remarquera en son lieu que les déductions théoriques auxquelles je procède, dans cette deuxième partie de l'ouvrage, correspondent à une phase dans l'évolution des pouvoirs humains visant à instaurer leur ordre naturel.

Dans toute la troisième partie, je m'efforcerai d'établir la teneur des relations de la société à la nature en tant que relations entre deux histoires qui supposent, de concert, la participation humaine. Notre espèce, et c'est là un de ses traits caractéristiques, travaille en permanence dans ces deux systèmes de référence, suit constamment leur cours, répond à la double charge, à la double exigence qu'ils imposent : «L'homme est un animal cosmique, prenons-en notre parti » ${ }^{25}$.

Enfin, je décrirai les contours d'un champ de recherches - celui de la technologie politique — destiné à traiter méthodiquement toutes ces matières actuellement dispersées, sinon négligées.

Je ne puis espérer indiquer ici toutes les ramifications de cette entreprise à laquelle j'ai l'intention de consacrer plusieurs essais - on trouvera ici le premier. Celui-ci aura atteint son but s'il ordonne en un ensemble cohérent des phénomènes qui sont généralement observés sans que l'on cherche à établir entre eux des liens nécessaires, et s'il brise la résistance de la langue et des représentations qui la soustendent, relatives à la nature et à l'homme considéré comme son sujet. 


\section{PREMIÈRE PARTIE}

\section{LES PROCESSUS NATURELS ET LA SUCCESSION DES ÉTATS DE NATURE}




\title{
Chapitre premier.
}

\author{
La nature, art de l'homme
}

\section{De la matière organisée}

\section{$\underline{\text { Retour à la Table des Matières }}$}

Le parti-pris d'insérer l'homme dans la définition de la nature se heurte à des obstacles intellectuels très puissants. Il faut rétablir d'emblée la précision du langage et dissiper les confusions qu'il perpétue.

Le vocable de nature s'applique tantôt au monde extérieur, aux forces qui s'y exercent, tantôt au substrat physiologique et psychique de notre espèce. Que recouvre alors le concept de matière qui s'emploie à peu près de la même façon, dans le sens de milieu naturel sans l'homme, avant l'homme, au delà de l'homme ? Ou bien «nature » et «matière » sont synonymes, et nous pouvons nous dispenser de l'un d'eux; ou bien leur acception diffère, et pour mettre un terme à l'ambiguïté et à la laxité ${ }^{26}$, il importe de restaurer leur signification véritable.

Le terme de matière dénote des processus, des forces - chimiques, gravifiques, nucléaires, etc. — et des structures organiques ou inorgaples européens... Les auteurs qui s'en sont servis n'ont généralement pas pris conscience de son ambiguïté et de tout temps ont eu tendance à glisser, inconsciemment, d'un de ses sens à un autre ». A.O. LOVEJOY : Primitivism and related ideas in antiquity, Baltimore, 1935, p. 12. 
niques, régis par des lois propres. L'énoncé de celles-ci met en évidence des régularités spécifiques : le principe d'inertie suppose le déplacement des corps en ligne droite, les énergies nucléaires ne sont sensibles qu'à des distances définies du noyau, etc. De plus, les conditions de validité de ces propositions théoriques permettent d'isoler convenablement les systèmes individuels, qualitativement déterminés. Ainsi les principes qui gouvernent les mouvements mécaniques des pendules reçoivent leur pleine application si on néglige l'humidité, la température, et d'autres facteurs chimiques. La possibilité de saisir un phénomène sous l'angle quantitatif facilite son intégration à une famille plus vaste, caractérisée par une dimension plus générale, que ce soit celle de l'espace, du temps ou de l'énergie. Pratiquement, la matière est à la fois la désignation d'une classe de phénomènes, et la marque de chacun envisagé à part.

La nature se rapporte à la matière d'un point de vue particulier. Elle désigne l'organisation des puissances matérielles, la totalité de leurs rapports concrétisés en une configuration :

« J'appellerai donc éléments, écrivait Denis Diderot ${ }^{27}$, les différentes matières hétérogènes, nécessaires pour la production générale des phénomènes de la nature, et nature le résultat général actuel ou les résultats généraux successifs de la combinaison des éléments ».

Par nécessité, la chaîne des arrangements qui aboutissent à un tel ordre naturel peut varier dans le temps et dans l'espace. L'apparition d'une substance ou d'un être matériel inconnus auparavant modifie l'architecture du monde objectif, entraîne un remaniement de sa disposition. Dans toute la biosphère, et notamment dans les voies par lesquelles s'y forment les matières, des influences réciproques s'expriment entre systèmes organiques et systèmes inorganiques. L'éclosion de la vie sur la planète a eu des conséquences faciles à reconnaître. L'ampleur des échanges, grâce à la photosynthèse, a réussi non seulement à créer la couche dense d'oxygène, mais aussi à la conserver. Les hydrocarbures, par exemple, qui, avant l'existence des 
micro-organismes, se constituaient par des processus a-biogéniques, se constituent depuis lors par biogénèse.

Les composantes de la réalité naturelle varient d'une planète ou d'une étoile à une autre, d'une période à une autre. Imaginer un agencement unique et universel de ces composantes, c'est faire abstraction des différences qui s'opèrent dans les divers points de l'espace et au cours de l'histoire. Par ailleurs, pour parvenir à concevoir un tel agencement, on serait obligé de retenir uniquement les forces et les structures communes à la plupart des combinaisons qui coexistent aujourd'hui.

A la suite de cette réduction, le tableau de l'univers ne contiendrait plus que des puissances inorganiques, et les lois de celles-ci traduiraient seules son fonctionnement. Si l'on veut pouvoir identifier les configurations variées qui résultent des interactions entre éléments, il faut ajouter à ces dénominateurs communs la pluralité des pouvoirs propres à un moment ou à un lieu précis, qu'ils soient biologiques ou sociaux.

La nature définit donc une constellation de matières organisées en séries simultanées ou successives. Ce sont là ses ordres ou ses états. Nous sommes en droit de considérer un nombre fini de substances ou de mouvements, qui représentent une unité effective et provisoire, concomitante d'autres ensembles analogues. Le temps intervient pour signaler une évolution qui provoque «les résultats successifs de la combinaison des éléments ». La pluralité des ordres naturels et leur devenir se correspondent.

Les indications que j'ai fournies contribuent à écarter la synonymie mentionnée au début de ce chapitre : la matière se réfère aux catégories d'éléments ou de mécanismes obéissant à des lois particulières, et la nature à la combinaison de ces éléments ou de ces mécanismes lorsqu'ils entretiennent des rapports directs, nécessaires et déterminés. Spontanément, on recourt à de tels énoncés: la convention a l'avantage de fixer leur contenu avec précision et d'en détailler les conséquences. 
Serge Moscovici - Essai sur l'histoire humaine de la nature (1968) 35

Retour à la Table des Matières 


\section{L'art et la technique ne constituent pas une contre-nature}

$\underline{\text { Retour à la Table des Matières }}$

Tout porte à inclure l'homme parmi les pouvoirs matériels qui contribuent à déterminer, à un moment donné, l'organisation de la nature.

De prime abord, l'existence des êtres vivants, fussent-ils très simples, est un événement remarquable. Sur un million d'étoiles, il peut n'y en avoir qu'une seule ayant auprès d'elle une planète où des organismes soient capables de subsister. Parmi ceux-ci, l'humanité jouit non seulement du privilège d'avoir occupé la plupart des régions de la terre, mais aussi d'être, jusqu'à ce jour, une espèce rare. Pour bien saisir la portée de ce dernier fait, il suffirait de se rappeler les conditions particulières qui ont dû être réunies pour que la vie puisse se maintenir et se développer pour aboutir, par sélection et mutation, à des structures biologiques de plus en plus complexes, de mieux en mieux adaptées à un milieu différencié. Ces conditions ne se rencontrent dans aucune autre partie de notre système solaire : rien, non plus, ne permet de supposer qu'elles soient déjà rassemblées dans un autre système. La nature, telle que nous la connaissons, a pour trait distinctif l'homme : elle est bien sa nature.

Toutefois, cette solidarité ne doit pas être vue uniquement comme une donnée ${ }^{28}$. Elle est, par excellence, un produit. L'humanité appartient à l'univers objectif; elle y intervient en découvrant les moyens d'en infléchir les circuits matériels et en acquérant les qualités d'intelligence et les habiletés organiques correspondantes.

« Parce que l'être de l'homme est fait d'une étoffe si étrange qu'il est en partie apparenté à la nature et en partie non, à la fois naturel et hors de la nature, en quelque sorte centaure ontologique dont une moitié plonge dans la nature et l'autre moitié la transcende ». J. ORTEGA Y GASSET : History as a system. New York, 1961, p. III. 
«Ainsi l'homme n'entre pas en rapport avec la nature simplement par le fait qu'il en est lui-même partie, écrit Gramsci ${ }^{29}$, mais activement par le travail et la technique $»$.

$\mathrm{Au}$ cours de cette transformation progressive de ses qualités et de son environnement, l'humanité remet en cause son identité avec les espèces animales ou les puissances inanimées. Cette confrontation ne débouche cependant pas sur un monde sis au-delà ou au-dessus de la nature $^{30}$ : elle entraîne une réordination de l'état naturel lui-même. L'homme s'inscrit dans le milieu cosmique comme un de ses agents, et le milieu cosmique est un immense champ ouvert à ses entreprises. Pourtant, cette qualité d'agent lui est ordinairement refusée. Du moment qu'il a atteint le stade de l'homo sapiens, on lui dénie les fonctions reconnues à la totalité des êtres vivants. En même temps, on estime que la place qu'a prise, parmi ses préoccupations, le perfectionnement des organes sociaux, l'a séparé définitivement de la communauté des autres forces matérielles.

Certes, les changements biologiques et sociaux ont renouvelé les rapports entre notre espèce et les diverses puissances organiques et inorganiques. La substitution à un lien antérieur d'un lien qualitativement différent n'autorise cependant pas à raisonner comme s'il n'existait pas. De tels sauts se produisent dans les processus évolutifs de tous les êtres, marquant la naissance d'activités et de métabolismes nouveaux. Considérons le phénomène d'apparition de la vie. Des organismes capables de subsister sans oxygène ont préparé la voie à des organismes qui ont institué des échanges inédits avec les corps chimiques, en consommant et en produisant de l'oxygène libre en quantité suffisante. Le passage de la première forme de relation à la seconde a été un pas très important dans la constitution du milieu matériel planétaire. Pouvons-nous parler uniquement de la première comme d'une forme matérielle, en refusant ce caractère à la seconde ?

A. GRAMSCI : Euvres choisies, Paris, 1959, p. 52.

«Il est parfaitement raisonnable de parler de la 'double nature' de l'homme; tout en continuant à appartenir à la nature, il a créé une 'contre-nature' ou 'surnature' ». E. FISCHER : The necessity of Art, Harmondsworth, 1963, p. 32. 
Il en va de même pour l'homme. Ses interactions avec la matière se sont profondément modifiées depuis plus d'un million d'années, et non pas seulement depuis l'individuation de l'homo sapiens ${ }^{31}$. Grâce à quel critère infaillible pouvons-nous décider que seules ses interactions antérieures autorisent à le placer dans la nature, à le regarder sous l'angle naturel, et que nous devons changer de perspective, compte tenu des interactions qui nous sont actuellement familières? Suivant ce dernier point de vue, il est légitime de parler de la biosphère, ce milieu engendré par les bactéries, les plantes et les animaux dans leur travail sur l'écorce terrestre. Mais cette désignation n'est plus légitime lorsqu'on y envisage l'action de l'homme qui, somme toute, s'intègre, en le continuant, dans un cycle universel.

Le prolongement du labeur humain ne serait pas un ordre naturel mais un monde d'artifices. L'expérience quotidienne semble l'enseigner. Le bois auquel s'ajoute l'habileté du menuisier devient objet œuvré, l'eau à laquelle s'applique le savoir de l'ingénieur se change en énergie réglée. Les arts et les techniques, partout où ils se manifestent, altèrent le cours primesautier des processus matériels, rompant avec la simplicité de leurs dispositions originales. De la sorte s'édifie pour les hommes une seconde nature, qui s'impose au reste de l'univers comme une anti-nature. Mais ni ces expériences, ni ces descriptions, et moins encore les présupposés dont elles procèdent n'ont la rigueur qu'on leur attribue.

L'illusion la plus tenace est celle d'une seconde nature surajoutée au substrat intact d'une première nature. On imagine en l'occurrence une constitution organique, mûe par des impulsions autonomes et plastiques, à laquelle on superpose le moule de réflexes stéréotypés, de lois rationnelles abstraites, de mouvements d'outils ou de machines, soumis aux exigences des forces mécaniques. La contrainte ressentie au cours de cette adjonction nous fait percevoir ce conditionnement de notre corps, de nos sens, par une organisation qui ne lui est pas ajustée d'emblée. Cependant, à mieux y regarder, on constate que ce qui est supposé primitif, originel, purement biologique, demeure à jamais inaccessible. Les analyses poussées et les comparaisons appro- 
fondies avec les enfants et les préhominiens nous permettent d'identifier uniquement des adaptations du milieu devenu intérieur au milieu encore extérieur, et ces adaptations elles-mêmes prolongent toujours des élaborations déjà secondaires. Les habitudes auxquelles nous initient les outils ne sont que des modifications d'habitudes antérieures acquises à d'autres fins. Aussi loin que nous puissions remonter dans la chaîne des filiations, nous ne reconnaissons que des secondes natures se succédant les unes aux autres, sans aboutir à aucune formation pure, primitive. Le volume accru de la boîte crânienne, la station debout ne précèdent pas l'éclosion des artifices: ils l'accompagnent ou lui font suite. La main et le cerveau sont des « appareils » qui ont été inventés - et continuent à l'être - au même titre que la lunette astronomique, la machine à calculer ou les matières chimiques, qui n'existaient pas avant d'avoir été conçues par nous.

Toute démonstration concernant un état biologique initial est affectée d'un doute, d'autant plus prononcé que l'on ne saurait fixer avec netteté, dans l'évolution humaine, une phase où la transformation du substrat organique soit indépendante de la transformation générale de l'espèce ou s'interrompe ${ }^{32}$. L'homme sans art, sans technique mentale ou gestuelle, nous est inconnu. S'il est vrai qu'une substance biologique préexiste partout, elle n'est pas directement domestiquée en tant que telle. Nous agissons sur un de ses aspects, qui est nécessairement un produit, et dont la matière, telle qu'elle s'est formée spontanément, demeure pour nous du domaine de la fiction. Le contraste que l'on signale entre une première et une seconde nature n'est pas, à bien y réfléchir, si dirimant que l'on puisse accepter à son sujet une hétérogénéité radicale, une division perpétuelle de nos organes vitaux.

D'autant moins sommes-nous en droit de voir, dans la technique ou l'art, une structure éminemment anti-naturelle, édifiée pour contrecarrer ce qui est spécifique de notre espèce, approprié à l'état que l'on juge normal pour elle. Plus l'homme, estime-t-on, accroît sa compétence et son pouvoir de fabrication, plus il concrétise ses intentions dans des ouvrages importants, et plus la nature reflue, échappe à son contact et disparaît. Suivant cette opinion, il se retrouve seul, dans un 
monde froid et silencieux, engagé dans un dialogue pathétique avec les astres lointains, à la recherche de congénères sur des planètes brûlantes ou glacées, éloigné des harmonies physiques dans lesquelles il baignait. Ce thème de l'incompatibilité d'une existence naturelle et d'une existence artificielle, de ce que l'homme reçoit ou possède et de ce qu'il produit ou ordonne, est diffus dans la société. Dès que notre activité se manifeste, un processus se déclenche qui annonce l'artifice, le cortège des anti-natures. Sénèque déjà était déchiré par la nostalgie des lieux que l'art n'avait pas violés, des rivières qu'aucun canal n'avait asservies.

Ces pensées ont leur poésie, plus inspirée que celle qui chante les hauts fourneaux, l'art industriel ou la fusée spatiale. Sa qualité persuasive peut toucher le sentiment et raviver la mémoire du passé. Elle n'ajoute rien à la valeur du raisonnement sous-jacent, qui institue entre l'art et la nature un rapport d'exclusion si sévère que la progression de l'un implique la régression de l'autre ${ }^{33}$. Cette exclusion ou cet antagonisme dénote en fait deux situations connexes et parallèles : un art ou une technique s'oppose à un autre art ou à une autre technique ; conjointement, un ordre naturel s'oppose à un autre ordre naturel. Dans ces conditions, l'affrontement suppose une dissymétrie des termes que l'on met en relation. Lorsqu'on clame, à grands cris, que la technique moderne nous prive de notre nature, on commet une faute de jugement. Le seul spectacle que l'on veuille contempler est celui des fusées, des appareils géants, des machines productives, des villes qui refoulent les arbres et les animaux, détruisant la mesure d'une existence conçue par et pour un individu. On oublie, ce faisant, de voir que ces fusées et ces machines incarnent d'autres forces matérielles, dont l'éclosion et l'existence sont normales. Le milieu naturel n'est pas vaincu, diminué par des techniques, mais modifié par un autre milieu naturel auquel il s'intègre. Les artifices contemporains représentent une composition d'éléments, de pouvoirs, de lois, manifestent une architecture de l'univers. Leur extension conduit, on le sait, à abandonner non seulement les techniques établies, mais aussi les élé-

«L'homme façonné par le milieu technique..., perd tout contact avec la nature, sollicité par tous les gadgets, y compris le gadget dernier-né, le gadget suprême : la-machine-à-sepromener-dans-le-cosmos ». G. FRIEDMANN : La civilisation technicienne, Arguments, 1962, 6, p. 52. 
ments, les règles qui définissaient un ordre du monde parfaitement naturel. Un art ne fait pas reculer la nature : mais un état de celle-ci est bouleversé par l'apparition d'un autre état. Cela ne signifie pas la transformation $\mathrm{du}$ monde naturel en monde technique, mais l'évolution du monde naturel lui-même.

C'est probablement pour échapper à cette conséquence logique que l'on introduit une dichotomie dans les arts eux-mêmes, certains étant jugés plus proprement naturels, ou que l'on réserve la qualification d'arts naturels à l'agriculture, à la chasse ou à la médecine.

«Dans ce milieu (naturel) écrit Georges Friedmann ${ }^{34}$, les outils sont des prolongements directs du corps, adaptés au corps. Par ailleurs les outils, dans ce milieu naturel, sont le prolongement direct de l'habileté professionnelle... enfin ces outils sont associés à l'expérience et à la connaissance du matériau sur lequel travaille l'artisan ».

N'en vient-on pas ainsi à ruiner tout ce qu'on a échafaudé avec tant d'ardeur? Si l'outil est adapté au «milieu naturel», au corps, à la main de l'artisan, s'il prolonge l'habileté professionnelle, la machine n'est-elle pas aussi adaptée au «milieu naturel» du cerveau de l'ingénieur, ne prolonge-t-elle pas directement sa technique ? Descartes soutenait que :

«Lorsqu'une montre marque les heures par le moyen des roues dont elle est faite, cela ne lui est pas moins naturel qu'à un arbre de produire des fruits ».

Mais il y a une déduction qu'il ne faut pas négliger. A savoir que toute pratique humaine, du fait qu'elle est humaine, n'est pas génératrice d'artifice ou d'anti-nature; elle s'inscrit commodément dans le mouvement de l'univers matériel lui-même. Autrement dit, par la même action, l'homme institue son art et sa nature ${ }^{35}$.

«La nature qui agit sur l'homme, la nature qui intervient dans l'existence des sociétés humaines pour les conditionner, ce n'est pas la nature vierge, indépendante de tout contact humain, c'est une nature déjà profondément agie, profondément modifiée par l'homme ». L. FEBVRE : La terre et l'évolution humaine, Paris, 1949, p. 5. 
La technique, cela n'est guère discutable, est une manière d'établir des rapports universels et de s'y attacher. Les animaux, dans l'élevage, le jeu ou la chasse, nous mettent en communication avec les cycles biologiques. Les horloges nous enseignent les lois de la pesanteur et le langage des mathématiques. L'électricité ou la gravité, avant d'être reconnues comme forces matérielles, n'ont été que des effets techniques. Partout artifice et nature se correspondent et s'engendrent réciproquement ${ }^{36}$. Le fait que l'homme y soit impliqué ne suffit pas à les distinguer. Parmi ses pratiques, il serait bien malaisé de discerner ce qui tient au processus naturel lui-même et ce qui est de l'art, lequel n'est pas seulement un moyen mais aussi un «mode de dévoilement $»^{37}$.

L'artifice est net et apparent lorsque les propriétés d'un élément sont reproduites dans et par un autre élément. La pensée est bien une pensée artificielle lorsqu'elle jaillit d'une machine électromagnétique au lieu de naître dans la matière grise. Le tableau du peintre, le monument du sculpteur sont des transpositions analogues, puisque l'artiste recrée sur la toile ou dans la pierre ce qui était dans la vie. Néanmoins, à travers ces modifications, «l'art constitue un cas particulier de la nature ${ }^{38}$ et non pas sa négation.

Des tentatives identiques pour améliorer les propriétés d'une espèce ou d'une structure matérielle n'aboutissent pas forcément à des effets artificiels. Si la taille des enfants s'élève, si la population se maintient ou s'accroît, si les mécanismes intellectuels s'affinent et se diversifient, ces phénomènes s'accordent avec la définition du naturel. Peut-on dire d'une taille, d'une loi de l'esprit, d'un volume de population qu'ils sont plus naturels que les autres ? L'apparition du doryphore de la pomme de terre ou du rat musqué en Europe, l'introduction du lapin ou du figuier de Barbarie en Australie, à la suite des migrations humaines, ne sont-ils pas des événements habi-

«L'homme constructeur est un facteur géologique ». J. PACOTTE : La pensée technique, Paris, 1931, p. 5. 
tuels au règne de la nature et propres à celui-ci ? Les particules libérées dans le laboratoire, les combinaisons de molécules qui engendrent des synthèses sans équivalent « naturel », ne méritent pas, à strictement parler, le nom d'artifices. Les démarches par lesquelles nous les suscitons ne diffèrent pas, en principe, de celles de toutes les espèces animales lorsqu'elles élaborent les éléments de leur milieu. Les organismes vivants ont reconstitué les strates superficielles de la terre, les dépôts minéraux et une atmosphère d'origine " secondaire », composée surtout d'oxygène et d'azote. Des phénomènes inorganiques - par exemple 1' " analyse » de l'eau et le dégagement de l'anhydride carbonique - qui ont lieu uniquement à des températures élevées peuvent être réalisés, sur une grande échelle, par des microorganismes qui ont « appris » à le faire à la température ordinaire.

Toutes ces créations humaines sont des créations d'un «nouveau naturel, le naturel de l'œuvre ${ }^{39}$. Accessible de cette seule façon, l'état naturel est présent à travers l'artifice qui le fonde. L'homme, par sa diligence, engendre sûrement la technique, car il fait exister le monde sur un mode différent; mais il engendre aussi la nature, puisqu'il acquiert une existence en face des facteurs matériels, puisque ceux-ci s'ajoutent à lui comme il s'ajoute à eux.

Sans doute n'avons-nous pas l'habitude de nous penser en tant qu'agents de notre ordre naturel. Pourtant il est notre art, comme nous sommes le sien.

Je n'ajouterai pas d'autres arguments, ils iraient tous dans le même sens. A savoir qu'il n'y a rien de factice et d'arbitraire à vouloir compter l'homme social et biologique parmi les forces matérielles qui, se combinant entre elles, établissent une organisation commune.

«Par la production pratique d'un monde objectif, l'élaboration de la nature non-organique, l'homme fait ses preuves en tant qu'être générique », observe Karl Marx ${ }^{40}$.

P. KLEE : Théorie de l'art moderne, Paris, 1964, p. 46. 
Non seulement l'homme élabore sa nature non-organique, mais il ne peut la concevoir autrement ni sur le plan pratique, ni du point de vue de l'intelligibilité. La nature, c'est l'homme avec la matière, et ce ne peut rien être d'autre ${ }^{41}$.

Retour à la Table des Matières

41 Faute d'un concept de nature qui fasse de l'homme un de ses termes, on lui crée une nature particulière, une nature technique : "Mais l'automatisme vise à leur conférer (aux systèmes industriels) une autonomie qui les rapproche des systèmes naturels. Ils dépendent d'une nature technique, cela n'est pas douteux. Mais n'est-ce pas encore une nature? Et ouvrée par l'agriculture n'est-elle pas de longue date une nature ouvrée, seconde? L'homme lui-même comme créateur n'est-il pas devenu une nature autonome vis-à-vis de la grande nature ? ». P. NAVILLE : Vers l'automatisme social ? Paris, 1963, p. 40. 


\section{La nature humaine : difficultés d'une idée}

$\underline{\text { Retour à la Table des Matières }}$

Certes, les éléments et les processus matériels sont susceptibles d'entrer dans de nombreuses combinaisons, en édifiant tout autant d'ordres naturels. Leurs termes seuls peuvent être inclus dans la coalition réelle qui nous comprend, l'unique ordre qui nous soit accessible, et a fortiori, celui que nous sommes en mesure de connaître le mieux. Cette proposition prolonge un constat que le mouvement des sciences a amplement vérifié : à savoir que les lois physiques et biologiques, leur enchaînement, leurs applications, sont entérinés et vérifiés relativement à l'expérience accumulée ${ }^{42}$, au degré d'élaboration de notre intelligence ou de nos informations, et à l'importance des puissances matérielles avec lesquelles des liens durables sont noués. Les principes de Newton ont signifié clairement la présence de la gravité dans la composition manifeste de notre réalité. Tous les événements qui ont conduit à leur promulgation scandent le « passage d'un type de nature à un autre $»{ }^{43}$. Dès l'instant, cependant, où de nouveaux phénomènes matériels - chimiques, électriques — ont commencé de pénétrer dans notre milieu concret, le sens de la gravité et les principes newtoniens eux-mêmes ont subi une refonte totale. Cette métamorphose fut accomplie par la mécanique relativiste et l'électro-dynamique. Les vérités qui sont découvertes successivement ne fournissent pourtant pas une vision plus exacte de quelque chose qui subsisterait indépendamment de notre mode d'agir ou de notre perception ${ }^{44}$. Elles marquent

« Après tout, nous ne connaissons la nature que par l'intermédiaire de l'expérience humaine ». C.F. von WEIZSAECHER : The History of Nature, Chicago, 1959, p. II.

P. Rossi : Les arts mécaniques et la science nouvelle, Arch. Europ. de Sociol. 1963, 4, p. 222.

«Ainsi nous ne pouvons nourrir l'illusion que les lois que nous découvrons soient véritablement des « lois de la nature ». Ce ne sont que des lois de la nature en ses rapports avec notre sensation et notre intelligence. Et sans doute il demeure vrai que nous ne pouvons connaître que des rapports. Mais il faut préciser, restreindre cette proposition, en sous-entendant que les seuls rapports que nous puissions réellement connaître sont ceux où nous-mêmes formons l'un des termes. S'il existe des choses du monde extérieur, il est clair qu'il doit exister des rapports entre elles ; mais ces rapports, nous ne pouvons les connaître, tout comme les choses ellesmêmes, que par rapport à nous "). E. MEYERSON : De l'explication dans les sciences, Paris, 1925, p. 17. 
l'évolution de nos liens avec les propriétés de la matière, et ce sont ces liens qu'elles déterminent :

« S'il est permis de parler de l'image de la nature selon les sciences exactes de notre temps, note Heisenberg ${ }^{45}$, il faut entendre par là plutôt que l'image de la nature, l'image de nos rapports avec la nature ».

La notation serait encore plus exacte si l'on substituait, dans le dernier membre de phrase, le vocable de «matière » à celui de «nature $»$.

Ce que la science nous offre, en effet, c'est un tableau de la nature, c'est-à-dire une relation ordonnée de l'homme et de la matière. Cette perspective n'a rien de subjectif. Elle exprime les modalités par lesquelles notre espèce institue le monde objectif. Les sciences, les arts ou les techniques ne se bornent pas à refléter un domaine concret extérieur. Leur fonction est d'allier les pouvoirs humains et non-humains, de transformer les uns en conditions d'existence des autres. De même que le champ magnétique modifie les effets propres à la gravitation, ou que le volume des précipitations atmosphériques infléchit le cycle végétal ou animal, de même, par le savoir-faire théorique ou pratique, l'humanité impose aux forces animées ou inanimées un développement qui s'articule avec le sien propre. Parce que ces forces entrent en contact avec elle à des étapes distinctes, on voit surgir des qualités inconnues auparavant, des facteurs non-humains et de nouvelles facultés humaines. Il ne s'agit pas là d'un pur dévoilement, de la pénétration progressive, dans un circuit pré-établi, d'êtres qui subsistaient tels quels avant cette intervention. Provoquer leur apparition, c'est aussi, immédiatement, leur conférer une structure, les investir d'attributs dans un contexte qui est déjà nôtre. Hors de ce rapport, rendus à l'extériorité, ils sont comme inexistants.

«En tant que force naturelle abstraite, l'électricité existait même avant de devenir force productive, mais elle n'opérait pas dans l'histoire, et elle était sujet d'hypothèse dans l'histoire naturelle, et avant, elle était le " néant» his- 
torique parce que personne ne s'en occupait et que, pour mieux dire, tous l'ignoraient » ${ }^{46}$.

C'est de ce néant que nous faisons sortir les forces matérielles, en les intégrant au cercle des forces ou des substances qui appartiennent déjà à notre nature. L'observation qui vaut pour l'électricité vaut encore davantage pour les métaux qui auparavant n'existaient ni librement, ni individuellement, l'aluminium, le magnésium, le calcium, etc. C'est pourquoi tous les éléments peuvent être qualifiés d'inventés :

«Si d'abord on eût fixé la signification, on eût reconnu que les hommes étaient, si j'ose dire, les créateurs de la matière, écrit Helvétius ${ }^{47}$, que la matière n'est pas un être, qu'il n'y avait dans la nature que des individus auxquels on donne le nom de corps, et qu'on ne pouvait entendre par ce mot de matière que les propriétés communes à tous les corps ».

Ainsi l'état naturel n'est pas tant l'aboutissement d'un acte intellectuel de révélation ou de mise en rapport d'êtres inconnus ou séparés, que le résultat d'un acte créateur de ces êtres. Une des erreurs les plus répandues est de ne retenir à ce sujet que l'accroissement quantitatif des connaissances ou des substances, en négligeant les renversements de structures et de relations qu'il sous-tend. Pourtant l'antiquité la plus reculée et le $\mathrm{XX}^{\mathrm{e}}$ siècle diffèrent moins par le volume de matières ou d'énergies recensées que par les liens qu'ils entretiennent avec celles-ci. En général, la suite des inventions s'accompagne du passage d'une modalité d'association des forces matérielles - y compris l'homme - à une autre modalité, et de la transformation des propriétés sensorielles et intellectuelles requises des individus jointe à la modification de la gamme de leurs besoins organiques. Ce qui est remis en cause, à cette occasion, et ce qui surgit, est leur nature, au sens fort. A une certaine organisation des pouvoirs humains et non-humains se substitue une organisation différente, un monde objectif défini fait place à un autre monde. Leur succession chronologique nous met en position de comparer l'ensemble de ces ordres naturels, à la constitution desquels nous avons contribué, et qui sont nôtres. 
La possibilité de cette évolution historique se heurte à la croyance en l'existence d'un état de nature qui soit propre à l'homme. Il est rassurant de penser qu'en un point, à un certain moment, notre vie intime, le rythme de nos perceptions et de nos réflexions, rencontrent la mesure de l'univers. L'agitation de l'histoire suspendue ou rendue seulement passagère, la quête achevée, la vérité triomphante, telles sont quelques-unes des vertus de cet ordre dont on aurait le droit d'affirmer qu'il est « naturel» à l'homme puisqu'il répond, sans aucune discordance, à sa complexion intime. Aussi jouit-il du privilège de la norme, et nous permet-il de juger de la valeur de nos actions et d'estimer notre proximité ou notre éloignement de l'idéal. Les difficultés commencent lorsqu'on est sommé de désigner cette nature et d'en cerner le caractère normatif. Les deux doctrines prévalentes à ce sujet divergent fortement. La première ${ }^{48}$ projette cet ordre aux débuts brillants de l'espèce. Alors l'humanité en pleine sympathie avec son milieu accédait, sans effort excessif, aux choses auxquelles son appétit l'inclinait. Les créatures végétales et animales, l'eau, le vent, étaient à son niveau, elle les comprenait par communication spontanée, intuitive, grâce à un code pré-établi entre son âme et le monde. Tout ce qui écarte l'homme de cet état premier le rattache au domaine des artifices qui conviennent si peu au substrat organique de l'espèce, qu'ils surchargent et gauchissent ${ }^{49}$. Par l'invention, de tous côtés, de structures inanimées, de nourritures chimiques, d'œuvres conçues grâce à des manipulations auxquelles font défaut le souffle de la vie et la finesse du sentiment, c'est une réalité déshumanisée qui s'installe. Notre nature subit nécessairement une altération profonde. C'est justement à ce propos que surgit l'incertitude. L'état naturel authentique est toujours un « ailleurs » : la simple cueillette et l'agriculture, les plantes et les animaux, symbolisaient pour les anciens la félicité originelle. Les arts et la cité jalonnaient la rupture avec la nature (Divina natura dedit agros, ars humana aedificavit urbes). Pour notre époque, cet ordre

«Selon les théories reçues sur l'hérédité, l'humanité civilisée devrait être apte, de par ses dons natifs, à vivre dans des conditions de sauvagerie peu évoluée, auxquelles s'oppose la civilisation machiniste. Ni dans les conditions physiques qu'elle impose, ni dans les modes habituels d'observation et de raisonnement qu'elle requiert, l'époque machiniste n'est donc adaptée à l'équipement inné courant de la race ». T. VEBLEN : The instinct of workmanship, New York, 1937, p. 320. 
naturel préférentiel est celui où les hommes exerçaient des métiers artisanaux, et même celui du début de l'ère industrielle. Georges Friedmann y perçoit ce

«milieu naturel, ce milieu des civilisations ou communautés prémachinistes dans lequel l'homme réagit aux stimulations venues pour la plupart d'éléments naturels, la terre, l'eau, les saisons, ou œuvres d'êtres vivants, animaux ou hommes $\gg{ }^{50}$.

Cette inconséquence même fait pressentir la coexistence de plusieurs états tous également naturels, dont un seul est investi d'une prérogative et par là qualifié d'humain. Cependant, tout en sachant que cet état est révolu, on ne réussit pas à le définir avec précision. L'appel du « retour à la nature » est puissant. Mais à quelle nature ?

La seconde croyance, celle du progressisme naturel, décrit les débuts d'une humanité encore plongée dans le monde animal, à l'existence précaire, livrée à l'ignorance, aux hasards de la maladie, des saisons et de la pénurie ${ }^{51}$. L'essentiel est de sortir de l'engourdissement originel. La robustesse et l'intelligence de notre espèce augmentant, les sciences parviennent à pallier les infirmités de notre constitution. Pourvu que l'on ne songe à ce passé que pour s'en détourner, on parviendra, dans l'avenir, à maîtriser l'univers qui aura enfin trouvé un antagoniste à sa taille ${ }^{52}$. Aussi cette doctrine, forte de maint exemple, soutient-elle que la perfection de nos instruments et de notre savoir nous achemine vers l'état de nature transparent et achevé. Alors seulement nous quitterons le règne animal. Jusque-là, toutes nos connaissances, nos actions, nos images du monde ne sont que des esquisses passagères, imparfaites, d'une étape dernière qui aura la vertu du vrai, couronnant toutes nos recherches et nos découvertes.

«L'orientation (des sciences), soutenait Max Planck ${ }^{53}$, consiste dans le raffinement de notre connaissance du monde par réduction de ses éléments à

\footnotetext{
G. FRIEDMANN : op. cit. p. 401.

«L'homme, à l'origine, ne paraissait pas avoir des perspectives très prometteuses dans la lutte générale pour l'existence » B. RUSSEL : L'homme survivra-t-il ? Paris, 1963, p. 16. 
une réalité plus haute et moins naïve. Le but en est l'élaboration d'une idée de l'univers dont les éléments auraient un caractère définitif. Nous n'aurons et ne pourrons jamais avoir la preuve que nous avons atteint ce but, mais pour lui donner un nom, nous désignerons par monde réel, au sens absolu, métaphysique, cette réalité ultime ».

Cette façon de concevoir notre curiosité pour les phénomènes et la course aux connaissances et aux moyens de les obtenir qui l'accompagne n'a en elle-même rien de convaincant. Peut-on espérer que, grâce au parachèvement des disciplines scientifiques et techniques, la quantité des choses connues augmentera tandis que la quantité des choses inconnues diminuera? Nous n'avons aucun motif d'estimer que leur somme est fixe, ni de supposer quelque proportionnalité entre leurs fluctuations. Qu'est-ce qui nous garantit, du reste, la possibilité d'un ordre naturel ayant épuisé toute l'épaisseur de la matérialité ? Celle-ci se métamorphose : de nouvelles substances naissent dans le mouvement universel, et des constellations multiples surgissent ou s'abîment dans le cosmos. A aucun moment, rien ne saurait indiquer que la quête millénaire a pris fin. La nature dite ultime, impossible à identifier, ne s'inscrit assurément pas à son terme. Faut-il donc renoncer à la découvrir?

Si nous nous en tenons aux faits, nous avons le loisir de penser que la « conquête » et le « perfectionnement» de notre état naturel, résultant d'une réorganisation de ce qui a déjà été assimilé, intégré, représentent une expression nouvelle de notre rapport aux forces matérielles qui éclôt et remplace leur expression antérieure. L'évolution s'il y en a une, et on doit le démontrer - est ce qui part d'une structure donnée du réel pour la transformer, la remplacer, et non pas ce qui se dirige, inspiré par un programme pré-établi, vers une structure qui serait la seule en accord avec l'humanité ${ }^{54}$. Notre lien, à un moment donné, avec les éléments, est en même temps notre état de nature, qui correspond à l'intelligence, aux besoins et au potentiel de production de cette époque. A partir des conditions qui lui sont propres peuvent se développer d'autres éléments, d'autres règles de découverte, d'autres facultés intellectuelles et d'autres dextérités ma- 
nuelles, et, somme toute, un autre milieu qui représente en même temps un autre état tout aussi naturel que celui dont il est issu. Le problème essentiel est soulevé non par le passage de l'outil de pierre à l'outil de fer, du vêtement tissé à la main au vêtement tissé à la machine, mais par la transformation du rapport entre l'homme et le milieu matériel, l'apparition de chacun des états naturels correspondants. Le clivage entre des mondes ayant des caractères distincts, voilà le résultat d'importance véritablement historique.

La possibilité de cette évolution historique se maintient, dans la conscience de la majorité, à l'état diffus. Ceux qui demandent le « retour à la nature » ne réclament-ils pas en fait la suspension de certaines relations avec des forces matérielles, le rétablissement de liaisons qui existaient antérieurement? Ils nous conseillent de nous associer aux êtres animés et de nous détacher des êtres inanimés, des corps chimiques ou électriques. Lorsque, avide de progrès, un philosophe comme Francis Bacon aspire à un ordre naturel nouveau, qu'exige-t-il sinon que l'on adjoigne aux végétaux et aux animaux les forces mécaniques?

« Je classerais volontiers, écrit-il, l'histoire des arts comme une partie de l'histoire naturelle. On a affirmé l'opinion invétérée que l'art est une chose différente de la nature et que les choses artificielles diffèrent des choses naturelles. Il en est résulté l'inconvénient que nombre de ceux qui ont écrit sur les choses naturelles croient avoir atteint leur but en composant une histoire des animaux, des végétaux, des minéraux, et en omettant les expériences des arts mécaniques ».

Éliminer une partie de la nature en la qualifiant d'artifice ${ }^{55}$ ou convertir cet artifice en une partie de la nature et s'attribuer la capacité d'opérer cette conversion, revient implicitement à reconnaître un

Le passage d'un état de nature à un autre état et leur coexistence soulèvent, étant donné les conceptions actuellement répandues, une contradiction logique : contradiction entre l'unité postulée et la pluralité réelle des natures. On la résout habituellement par la transformation d'un des termes en « artifice », l'autre étant déclaré norme du naturel. Ainsi, lors de la séparation de l'agriculteur et de l'artisan, le monde du premier fut jugé naturel et celui du second rejeté comme artificiel. A une époque plus récente, c'est l'ingénieur, comparé à l'artisan, qui est le représentant de l'artifice, du non-naturel. Le phénomène historique est dès lors nié, et le mouvement qui lui est propre remplacé par des coupures successives entre les êtres naturels et les êtres artificiels. 
mouvement de composition et de décomposition des rapports de l'homme et de la matière. Subrepticement ce mouvement décrit le passage d'un état naturel à un autre état qui restaure ou bouleverse le premier.

Dans l'abstrait, il peut y avoir réversibilité. Cela permet de garder la mémoire du passé et de le croire efficace, ou de tisser un avenir de fiction et de le proposer pour certain. Toutefois, si l'on renonce, ainsi que la réalité nous y convie, à ce caractère réversible, on se trouve, non pas devant une marche qui peut emprunter une direction arbitraire, mais devant une histoire ${ }^{56}$. Elle signifie le fil conducteur de toutes les figures particulières que l'homme a suscitées dans l'univers.

$\underline{\text { Retour à la Table des Matières }}$

56

Ces conclusions vont toutes à l'encontre d'une conviction solidement enracinée, à savoir que la nature n'a pas d'histoire, car l'homme n'y est pas impliqué. La version complémentaire de cette proposition consiste à refuser à l'homme toute association avec la nature, puisque, par définition, l'histoire - quelle histoire ? peut-on se demander - est le propre de l'homme. ( «L'homme... n'a pas de nature : ce qu'il a est une histoire ». J. ORTEGA Y. GASSET : op. cit. p. 257.) Poser la nature et l'histoire en tant que termes d'une alternative réduit toute question à la platitude vide des couples matière-esprit, corps-âme, externe-interne, etc. La richesse des relations réelles est sacrifiée au balancement d'un discours qui résiste à la mort des idées par la vie présumée des mots. 


\section{L'histoire humaine de la nature}

\section{Retour à la Table des Matières}

La conception d'une histoire humaine de la nature ne fait pas scandale. Ni son pôle matériel ni son pôle humain n'étant statiques, leur résultante ne saurait l'être. L'examen des faits le prouve. Avant de devenir un facteur décisif de sa nature, l'homme a passé notoirement par les phases d'une évolution commune à toutes les espèces. La substance biologique a été soumise à des adaptations, a subi des mutations positives favorables à la survie. La station debout, la modification morphologique du crâne, la différenciation des membres, la mobilité autonome des doigts, ponctuent les étapes de son individuation. Les essais ont été nombreux jusqu'à ce que se forme l'homo sapiens, dont on soutient qu'il s'est dissocié du stock animal commun et a affronté la plupart des espèces comme force indépendante. Sa constitution sociale a acquis la faculté d'établir des règles et de se soustraire aux déterminations biologiques auxquelles sont soumises les autres sociétés animales ${ }^{57}$. Cela ne veut pas dire qu'elle ne remplisse plus les fonctions organiques générales propres à toutes les constitutions du même genre. Nous l'observons par analogie. L'humanité n'est cependant pas passée du règne de la nature au règne de la société, mais d'un règne de la nature où la présence humaine n'avait pas d'avantages visibles au regard de nombreuses espèces, à un règne où elle en a, d'un état de société qu'elle partageait avec tous les animaux à un état où la division du travail, la hiérarchie des groupements et des échanges collectifs s'exercent par l'intermédiaire des institutions, des langages articulés et des symboles. C'est donc en tant qu'elle parachève un développement et possède une histoire ayant un moteur propre que l'humanité est devenue le terme d'un nouveau type d'interaction avec les éléments. Ceux-ci ne sont pas des êtres non-historiques : ils se rattachent, au contraire, à une lignée historique dont nous sommes séparés et que nous reprenons à notre compte. Les corps matériels dérivent les uns

«L'organisation sociale est la catégorie générale dont l'organisation sociale humaine n'est qu'une manifestation particulière ». L. WHITE : The Evolution of Culture, New York, 1959, p. 58. 
des autres à partir de quelques structures simples, que ce soit celle de l'hydrogène ou du carbone. L'univers, on le sait depuis le siècle dernier, s'est agrégé dans le temps. L'agencement cosmique change et se recrée sans discontinuer. La cosmologie enseigne ce qu'il a été il y a des milliards d'années et conjecture qu'il ne restera pas tel qu'il est actuellement. Les étoiles et les planètes se sont dispersées dans l'espace galactique. La vie est apparue sur deux ou trois planètes du système solaire, les plantes, les animaux et les hommes ont surgi sur terre, à des époques précises et distinctes. Au rebours, il y a un temps sans hommes, sans animaux, sans plantes, sans matières solides et sans certains systèmes solaires. La radio-astronomie nous restitue ces périodes écoulées, en détectant les messages de galaxies telles qu'elles existèrent il y a quelques millions ou quelques milliards d'années.

A cette échelle, l'histoire humaine de la nature est brève. Au début, l'homme s'est combiné avec les manifestations les plus hautes de la vie. Ensuite, il a exploré ses propres pouvoirs organiques et les qualités des substances. Tour à tour, les forces inanimées immédiates l'eau, le vent - les propriétés chimiques, électriques, nucléaires s'y sont adjointes et se sont remplacées mutuellement. Transportons-nous un instant par la pensée dans un univers fini et statique où il n'y aurait que des espèces végétales et animales. On pourrait les domestiquer et les multiplier indéfiniment, on ne les développerait pas au delà d'un certain stade ; a fortiori, on n'arriverait pas à modifier consciemment leur code génétique. Ou bien acceptons la suggestion - elle n'est pas neuve - que toutes les forces matérielles sont mécaniques. Devant nous s'étalerait un arrangement de corps mûs par des chocs, freinés par des résistances, entraînés par des poulies, des leviers, des bielles. Nous aurions beau comprendre ces mécanismes dans le détail et en accroître l'emploi, nous ne soupçonnerions pas la réalité d'une transmutation des éléments; nous n'arriverions pas dans la lune. Les conclusions de cette spéculation, à peine abstraite, sont évidentes : l'homme ne fait pas qu'emmagasiner les ressources données dans leur simultanéité, il reproduit leur histoire. "L'animal ne reproduit que lui-même, tandis que l'homme reproduit la nature », notait Karl Marx. Non content de la reproduire, il la poursuit également lorsqu'en partant des structures subsistant à l'état virtuel il en suscite de nouvelles. Jusqu'à un certain point, l'activité de l'homme revient à parcourir - 
peut-être en sens inverse - et à recommencer une partie de l'histoire accomplie de la matière ${ }^{58}$. Elle la récapitule, l'assimile et l'élargit.

S'il y a une histoire naturelle de l'homme - j'entends de l'homme biologique et social — c'est parce que la matière a connu elle-même une évolution, et s'il y a une histoire humaine de la nature, c'est parce que l'homme, en se transformant, est devenu apte à reconstituer et à prolonger cette évolution. Pour cette raison, la nature humaine est une histoire et elle a une histoire. Elle est conversion progressive de deux mouvements qui ont conduit nécessairement à une synthèse indépendante, inédite. Elle réside dans ce processus où l'homme s'approprie et récupère, en qualité d'agent, l'histoire de la matière dont il fait son histoire, tout en continuant de faire de son histoire propre, sur un autre mode, l'histoire de la matière ${ }^{59}$. Point n'est besoin de lui découvrir une origine ou une fin permanente: le processus seul importe. L'action dans le monde réel ne requiert guère le moule d'une théodicée qui l'orienterait vers une destination prescrite et invariante. Ni les sciences, ni les techniques, qui sont les parties de cette action, ne se dirigent vers un milieu où sont gravés à l'avance les traits de la loi absolue et de l'efficacité. Depuis longtemps, on a renoncé à aborder avec de tels postulats l'étude de la vie et de la société. L'idée d'une lignée des espèces traduisant un plan instauré par un être suprême a été abolie. La sélection naturelle, mécanisme général, montre comment les organismes, des plus simples aux plus complexes, sont le résultat d'un phénomène d'élimination et d'adaptation des individus et de transmission des caractères indispensables à la vie. Les simiens ne sont pas censés être apparus afin de préparer la voie à l'homme, ni l'australopithèque pour permettre la naissance de l'homo sapiens. Dans les doctrines sociales et économiques, on voit les mêmes principes à l'œuvre. Le passage d'une société à une autre n'a pas lieu exclusivement en fonction de quelque impératif externe de justice ou de bonheur, ni par le simple écoulement du temps qui veut que chaque collectivité ait son printemps et son hiver. Ce sont les mouvements internes à une société qui expliquent et déterminent l'éclosion d'une nature, et parce que la nature elle-même est historique ». C.F. von WEIZSAECKER : op. cit. p. 7. 
société nouvelle. L'évolution sociale n'a pas sa raison d'être dans l'apothéose d'un socialisme qu'elle préparerait : celui-ci n'est qu'une de ses manifestations, et le capitalisme n'en est pas le précurseur obligatoire.

Ces attitudes sont les seules compatibles avec l'esprit scientifique. Elles dictent les conclusions de l'analyse à laquelle je viens de procéder.

- La nature ne contient pas seulement l'homme en tant qu'il est uni aux forces matérielles, qu'il est une partie de ces forces; elle le contient en tant qu'être spécifique, au même titre que chacune de ces forces.

- L'humanité parcourt des états naturels variés, une pluralité de configurations des pouvoirs humains et non-humains; aucun n'est le refuge ou le sommet prédestiné de son développement.

— L'unité de ces états est historique - et non pas substantielle et représente notre histoire de la nature.

Les problèmes auxquels il faut chercher une solution sont alors : comment l'homme se donne-t-il son état naturel ? Quels sont les mécanismes par lesquels il s'achemine vers ce résultat? A quels principes obéit l'histoire humaine de la nature? 


\section{Chapitre II.}

\section{La création du travail}

\section{Produire des objets, créer du travail}

\section{$\underline{\text { Retour à la Table des Matières }}$}

La distance que l'homme a parcourue depuis des millénaires est jalonnée par l'éclosion et la disparition d'ordres naturels. L'acte essentiel par lequel ces ordres s'établissent et évoluent est la création du travail. Telle est l'idée centrale de ma recherche, celle dont tout le reste découle.

Pour l'énoncer avec plus d'exactitude, il convient de distinguer dans la production humaine, suivant ses fins, deux grandes classes d'effets : les objets et le travail. Par objets, il faut entendre les biens matériels, les services indispensables à la conservation de la vie biologique et sociale, et l'aboutissement des opérations effectuées sur une substance donnée en vue de l'utilité ou de la jouissance. Le travail dénote ici toute habileté ou connaissance qui modifie l'organisme humain et lui permet d'agir directement ou indirectement sur les forces physiques, de les reproduire ou de les développer. Ce peut être une habileté immédiate ou quasi-inconsciente comme celle du chasseur, ou une connaissance rationnelle et formelle comme celle du scientifique. La notion de travail recouvre non seulement les pratiques contraignantes, mais aussi celles qui s'apparentent au jeu, renfermant en elles-mêmes leurs règles et leurs buts. Pour éviter toute confusion, je qualifierai de productions les activités qui se cristallisent en biens 
ou en objets, réservant le terme de créations aux opérations qui donnent naissance aux facultés et aux dextérités humaines.

La séparation entre production et création, proposée déjà par l'économiste John $\operatorname{Rae}^{60}$, marque bien l'originalité du processus où le travail, qui est obligatoirement conséquence d'un autre travail, est également son propre parachèvement. Certes, dans la production aussi, la répétition des gestes et des recettes, la combinaison des substances, améliorent les talents mis en œuvre. Obtenir une habileté ou un savoir-faire n'en demeure pas moins une action particulière dirigée vers une fin spécifique.

Une fois élaborées, les structures nouvelles font appel à des facultés inédites de notre intelligence et suscitent des propriétés nouvelles de nos ressources physiques. Solidairement, dans cette interaction, les forces matérielles se transforment en parties de l'organisme humain, tandis que cet organisme se convertit en ces forces. L'individu se rend capable de fonctionner comme cheval, chute d'eau ou machine, et enseigne aux pouvoirs mécaniques, chimiques, ou électriques à sentir, penser ou marcher. L'échange réalisé dans ces circonstances est important, il a le travail pour but et l'état de nature pour effet. Mais voir dans cet échange le sens de l'hypothèse que j'ai proposée serait inexact. Son acception est en réalité la suivante : l'humanité se donne un fondement naturel lorsqu'elle se propose pour objet principal de son activité le transfert de ses propriétés à la matière et vice-versa. Elle édifie ce fondement non par le fait de travailler, mais par le fait de créer du travail. Plus explicitement encore : l'homme s'affirme sujet de la nature en utilisant ses forces et ses talents à engendrer d'autres talents, des habiletés, des savoirs, et non pas en les appliquant simplement à produire. avant a été employé dans un autre sens ». J. RAE : Statement of some new principles on the subject of political economy, Londres, 1894, p. 15. 
Dans le circuit familier de la production, l'invention et la recherche du travail sont rangées parmi les données ${ }^{61}$ et jouent un rôle subalterne par rapport aux biens qu'il s'agit d'obtenir. Elles sont déclarées improductives, comme si leur poursuite était entachée de quelque manque ou de quelque infériorité. Pour toute société, cependant, la présence et l'acquisition des savoirs sont des conditions préalables de fonctionnement. Les groupes industriels ou les gouvernements récompensent, quand un autre choix ne leur est pas laissé, ceux qui inventent des sciences ou des arts nouveaux. On attire les spécialistes, non pour accroître la population ou la somme de connaissances, mais afin de disposer d'un travail qu'on puisse faire exécuter dans son pays, en le fixant au cerveau et aux muscles de ses propres ressortissants.

La qualité essentielle du travail est de se répéter indéfiniment sans pour autant se consumer dans ce transfert. Par là il diffère radicalement des autres services ou biens de consommation et se rapproche des qualités régénératrices de la matière :

«L'idée nouvelle a des caractères notables; elle ne s'use pas; elle n'est pas perdue pour celui qui la cède; elle ne se présente pas comme un service et comme un bien semblable aux autres $»{ }^{62}$.

Appréhendé sous cet angle, le travail donne vie aux substances ${ }^{63}$, ajoute aux individus des qualités intellectuelles et physiques qu'ils n'avaient pas auparavant, infléchit leur relation au milieu et ce milieu lui-même. L'objet n'est plus dès lors qu'un dérivé quelconque du savoir qui n'en exprime cependant pas l'essence. L'ingénieur, mettant en œuvre les mêmes facultés et les mêmes connaissances, construit indifféremment une machine à tisser ou une machine à faire des machines. L'habileté est la base à partir de laquelle sont produits les objets les plus divers : non seulement elle peut satisfaire les besoins es-

«La seule chose qui puisse être dite emmagasinée d'avance est l'habileté du travailleur Si l'habileté du boulanger, du boucher, de l'éleveur, du tailleur, du tisserand, n'était pas créée et emmagasinée au préalable, les biens de consommation que produit chacun d'eux ne pourraient pas êtres obtenus ». T. HodGSKIN : Labour defended against the claims of capital, Londres, 1825, p. 46.

F. PerrouX : La conquête spatiale et la souveraineté nationale, Diogène, 1962, 39, p. 5.

63 A. Touraine : Travail et organisation, Archives européennes de sociologie, 1962, 3, pp. 3 et seq. 
sentiels, mais elle est également capable de susciter des besoins nouveaux. Engendrer du travail, c'est faire surgir, indirectement, à la fois un bien et une nécessité, en déterminant les mécanismes biopsychologiques correspondants.

Le parallélisme de l'objet et du travail, le premier étant produit, le second créé, doit être maintenu fermement. La réalité de cette bipartition ne s'est dégagée que récemment. L'apparition d'une industrie consacrée à la découverte, la spécialisation du domaine de l'invention scientifique, ont isolé ce qui était auparavant confondu. Du coup s'est trouvée mise en lumière l'autonomie de chaque secteur d'activité. L'étude de l'histoire humaine de la nature se confond avec celle de la création du travail. Cette dernière, ayant acquis une importance manifeste, éclaire vivement la réalité dans laquelle nous baignons, non seulement les traits d'un avenir qui nous est encore inconnu, mais aussi les contours d'un passé que nous pensions connaître. 


\section{Deux processus naturels : l'invention et la reproduction}

$\underline{\text { Retour à la Table des Matières }}$

Concrètement, la création du travail qui, en nous associant aux autres éléments, confère l'existence à notre être naturel, s'effectue par le truchement de deux processus aux fonctions spécifiques : l'invention et la reproduction. Pour les distinguer de l'invention sociale, ou innovation, et de la reproduction sexuelle ou sociale, il faudrait préciser: invention naturelle et reproduction naturelle. Mais cette dénomination sera motivée en son lieu.

L'invention désigne les méthodes par lesquelles l'homme ajoute des habiletés, des connaissances, des réflexes à ceux qui existaient déjà, forçant les phénomènes du monde matériel à interférer entre eux et avec son organisme. Systématiquement ou par tâtonnements chaque segment de la totalité est mis à l'épreuve, reporté dans un autre cadre, utilisé à la résolution de problèmes nouveaux. L'eau appliquée au moulin qui était actionné à la main ouvre la voie à la découverte de la gravité. Que depuis des temps immémoriaux une parcelle du travail humain soit directement ou indirectement consacrée à l'invention, ce fait indique bien que nous avons conscience d'un effort spécifique indispensable pour échafauder notre monde réel. Nulle part, en effet, l'invention d'un savoir n'institue une contre-nature artificielle ou une surnature : notre nature elle-même en est l'aboutissement. Kenneth Boulding le souligne :

«Il est absurde de supposer que nous puissions penser la nature comme un système séparé de la connaissance, car c'est la connaissance qui, dans une mesure croissante, détermine le cours de la nature $\gg{ }^{64}$. 
Le second processus, la reproduction ${ }^{65}$, assure pour un groupe humain la liaison entre ses capacités et les principes matériels correspondants, entraînant la permanence de son ordre naturel et son expansion dans l'espace. Tout d'abord les actes productifs y contribuent. Leur répétition consolide les relations avec les autres espèces, avec le milieu et l'organisation existante. La culture des plantes favorise la vie de certaines variétés animales aussi bien que la fixation de l'humus, le tracé des rivières, ou la distribution des eaux. Ensuite, reproduisant d'une génération à l'autre savoirs et techniques, chaque individu connaît une seconde naissance qui rattache son être biologique et social au milieu physique prédominant. Sans transfert des gestes, des postures et des lois de la pensée, sans perpétuation des procédés de repérage sensoriel, les ressources diminuent ou disparaissent, l'humanité se transforme de fond en comble. L'interruption partielle $\mathrm{du}$ processus de reproduction est le moyen souverain de provoquer le « retour à la nature », qui est retour à une autre nature. La continuité des groupes humains, de leur production, de leurs institutions, a pour condition la continuité des cycles biotiques, chimiques, physiques, et celle des talents qui possèdent la clé de leur déroulement. Un vieux proverbe chinois l'énonce clairement : "Donne à un homme un poisson, il mangera un jour. Apprends-lui à pêcher, il mangera le reste de ses jours ». Ce qui est transmis à cette occasion, c'est une certaine relation durable entre l'homme et la matière, l'aptitude à poursuivre le commerce avec les pouvoirs universels, et l'universalité de la faculté idoine chez l'homme. La structure même de la nature est reprise, conservée, rendue limpide à ses participants.

Parce que l'invention et la reproduction agissent sur les mécanismes humains et non-humains, parce qu'elles font surgir les propriétés des uns et des autres, dans un univers commun, elles sont, comme ces mécanismes mêmes auxquels elles s'appliquent, des processus naturels, spécifiques et exclusifs à la fois. C'est par leur entremise transmission du travail est appropriée : «L'éducation et l'apprentissage donnés à autant de membres de la génération montante qu'il est nécessaire pour compenser les pertes en forces de travail dûes à la mort et à la retraite peuvent recevoir le nom de reproduction de la connaissance $» \ldots$.. bien sûr connaissance ne renvoie ici qu'à la portion qui contribue aux habiletés et aux capacités de travail ». F. MACHLUP : Production and distribution of knowledge in the United States, Princeton, 1962, p. 124. 
qu'interfèrent la force de la matière et la constitution de l'homme, et que se différencient les éléments de la première et les caractères du second. Ce sont les seuls processus où le travail — le savoir, l'habileté - apparaisse non pas comme un moyen, un instrument, mais en qualité de fin et d'objet, sa propre fin et son propre objet. Par là ils se distinguent de la production ${ }^{66}$, de la consommation qui, ne connaissant que l'utilisation des attributs du travail sont, jusqu'à un certain point, des dérivés, des transmutations de l'activité inventive et reproductive. Leurs répercussions se font sentir à tous les niveaux, et chaque phénomène réel, si minime soit-il, les enregistre. sciences que nous nommons - peut-être hâtivement - sciences économiques... La production (dans l'économie) est essentiellement une transformation d'objets matériels qui sont rendus utiles ou plus utiles ». F. PERrouX : La création collective dans l'économie de notre temps, Revue philosophique, 1963, p. 455. 


\section{L'activité inventive}

$\underline{\text { Retour à la Table des Matières }}$

\section{Inventer le savoir-faire.}

L'importance de l'invention, sa priorité, ne sont jamais passées inaperçues. Par qui et comment les arts et les sciences ont-ils été fondés ? Les religions, les mythes et les philosophies de tous les peuples ont conçu une réponse à cette question. Les louanges prodiguées aux inventeurs - n'ont-ils pas été proclamés d'essence divine ? — n'ont eu d'égales que les fortunes amassées par leurs successeurs.

Il ne fait pourtant point de doute que l'invention est une opération assez ordinaire, qui accompagne tout exercice du travail humain. $\mathrm{La}$ preuve en est fournie par le nombre de brevets demandés et celui des perfectionnements apportés chaque jour aux activités productives. L'ouvrier qui améliore un geste ou une opération, le peintre dont la palette s'enrichit d'une seule couleur, l'ingénieur qui propose une version modifiée d'une machine et l'étudiant qui fait une expérience en vue d'obtenir un diplôme sont aussi des inventeurs.

On est toutefois resté en-deçà de la vérité en s'efforçant de cantonner toutes ces créations admirables ou seulement méritoires dans un cadre restreint. On n'a pas assez remarqué et analysé le fait que l'homme, en inventant, donne un corps et un esprit à sa nature et bouleverse les conditions d'existence des êtres animés et inanimés. Toute innovation appelle une réorganisation de notre milieu, une refonte de notre capacité et de notre vision, en les imbriquant dans une composition réelle unique. On a pris l'habitude de présenter l'invention comme ce qui produit un instrument, un procédé ou une combinaison nouvelle d'éléments externes. Ainsi, Galilée a inventé le télescope et Brunelleschi la perspective linéaire, Watt la machine à vapeur et Newton le calcul infinitésimal, etc. 
C'est là un point de vue étroit. Tous ces grands esprits ont inventé d'abord un savoir-faire, une connaissance à reproduire, un rapport avec la matière destiné à être préservé, et aussi un type d'homme. Pour ne prendre que le cas de Watt, celui-ci n'est point tant l'inventeur de la machine à vapeur que l'inventeur de la manière de faire des machines à vapeur, l'initiateur d'une suite d'hommes capables d'appliquer cette manière. Que tous les exemplaires de ces machines soient détruits, comme furent détruits tous les modèles construits par les grands mécaniciens d'Alexandrie, les descriptions restantes de ce savoir-faire suffiraient à assurer une nouvelle production, la reprise d'une même activité humaine.

Les législateurs ont devancé sur ce point la philosophie la plus répandue. Si l'inventeur est tenu, pour en obtenir l'exclusivité, de donner une description détaillée de sa découverte, c'est afin d'enseigner aux autres hommes l'art ou la science qu'il leur apporte. Il acquiert, en échange, la propriété de son invention pour une durée limitée - le temps nécessaire précisément pour qu'elle se généralise :

«Sur ce point, il est clairement établi, déclarait le juge anglais Buller ${ }^{67}$, qu'un homme pour recevoir le droit au bénéfice d'un brevet de monopole, doit dévoiler son secret et spécifier son invention de telle sorte que d'autres puissent en apprendre à faire la chose pour laquelle le brevet est accordé ; car la fin et la signification de la description est d'enseigner au public, après le laps de temps pour lequel le brevet est accordé, ce qu'est l'art ».

En ce sens, tout effort de recherche et d'invention est une production de connaissances ${ }^{68}$, de capacités de travail et de ressources humaines et non-humaines disponibles, donc bien davantage qu'une pure production d'instruments, de théories ou de procédés.

Les hommes créent la substance de leur travail en inventant. Ceci signifie d'une part qu'une loi ou une propriété de la matière se change en loi et propriété de l'homme ; c'est ce que nous nommons habileté,

R. GORDON : A practical treatise on the law of patents for inventions, Londres, 1840, p. 106. 
art, connaissance, science. D'autre part, les qualités du travail, celles de nos organes, en s'ajoutant à la matière, lui ouvrent des domaines d'existence nouveaux et lui impriment des formes inédites. Nous savons, à coup sûr, que chacun de nos talents traduit un attribut de la matière auquel il s'accorde. Cultiver des fruits, c'est respecter, consciemment, le rythme de croissance des arbres et celui des saisons. Le paysan est ainsi astronome, biologiste et physicien ; il édifie ou possède une théorie efficace de la culture qu'il pratique. Longtemps les savants n'ont pas fait autre chose qu'adapter ces théories à un langage systématisé. L'opinion d'autrui leur servait de laboratoire. Inversement, toute force matérielle qui pénètre dans le circuit de nos pratiques a revêtu au début la figure d'un travail. La machine à calculer reprend le calcul mental, le premier outil à tisser a été le doigt, et les hommes ont tiré des fardeaux avant d'atteler les animaux à cette tâche.

Tout travail actuel est, en quelque sorte, matière en puissance, et tout travail en puissance est quelque part actuellement matière. Le processus d'invention englobe aussi la transformation continuelle de l'invention, cercle vicieux, si l'on veut, qui assure notre vie comme la perche tenue par le funambule l'empêche de tomber. Dans ce courant, les liaisons entre les deux pôles - travail et matière - changent, de même que changent les rapports entre les hommes. La fraction qui possède à un moment donné la capacité de travail essentielle est convertie en force matérielle, tandis qu'une autre fraction prend sa place dans le réseau des échanges avec les pouvoirs matériels, munie d'un autre savoir-faire, incarné dans d'autres cerveaux et d'autres mains. Ainsi l'ascension des ingénieurs a dégradé les artisans en simples organes de la force mécanique et de la transmission de son mouvement. Les découvertes ne nous installent pas dans des états naturels nouveaux sans affecter les liens inter-humains à l'égard de la reproduction des habiletés indispensables. C'est là une des constantes de l'histoire de notre nature.

L'invention elle-même a un caractère historique. Pendant la majeure partie de l'existence déjà écoulée de notre espèce, elle n'a été qu'un processus sporadique, sans finalité autonome fortement accentuée. Aussi pouvait-on l'attribuer purement et simplement au hasard : 
«Les découvertes, soutenaient les auteurs de l'Encyclopédie, suivant ce que nous venons de dire, sont donc le fruit du hasard ou du génie : elles sont souvent le fruit du hasard dans les choses de pratique, comme dans les arts et les métiers ; c'est sans doute pour cette raison que les inventeurs des choses les plus utiles dans les arts nous sont inconnus, parce que le plus souvent elles se sont offertes à des gens qui ne les cherchaient pas ».

A partir du XIX ${ }^{\mathrm{e}}$ siècle, cependant, le mouvement de découverte est devenu continu, constant, intense. A une époque plus récente encore, il est passé du stade individuel au stade social. Son évolution témoigne d'un remaniement des voies par lesquelles la société édifie l'état de nature sur lequel elle se fonde, et décrit aussi les contraintes qui sont les conditions nécessaires d'un tel remaniement.

Retour à la Table des Matières

\section{Découverte et substitution.}

On a fait de nombreuses tentatives pour distinguer la découverte de l'invention suivant la «noblesse » de leur objet. La première embrasserait les sciences, les théories, les lois des phénomènes; la seconde serait plus limitée et plus proche de la pratique. A l'article DÉCOUVERTE de l'Encyclopédie, on peut lire que « les découvertes moins considérables s'appellent seulement inventions ».

La controverse est alimentée par le désir de classer séparément d'une part les résultats des sciences et des théories, et d'autre part ceux des arts et des pratiques. Elle semble procéder de l'hypothèse d'une méthode destinée à déceler des choses qui existent déjà, contrastant avec la création d'objets sans existence préalable. Cette dichotomie terminologique recouvre une transposition des opinions courantes qui distinguent entre le caractère spontané des objets naturels et le caractère artificiel de ceux qui sont dûs à l'intervention humaine - cette dernière jouant dans un cas le rôle de révélateur, dans l'autre celui de créateur. Toutefois une théorie ou science contient des 
hypothèses qui sont autant d'inventions ${ }^{69}$ dûes à notre esprit, et une technique s'appuie sur des éléments recueillis, découverts dans le milieu ambiant. Ainsi que l'observe l'auteur de l'article INVENTION de l'Encyclopédie Britannique, "l'atome est une invention ». Cette proposition peut s'appliquer à n'importe quelle connaissance, à toute cosmologie ancienne ou moderne, et l'auteur conclut son enquête en affirmant qu' « on ne peut établir de distinction précise entre l'invention et la découverte ». Je me range à cet avis; il rétablit l'unité d'un processus que seule la méconnaissance de ses implications ou la référence à la variété de ses effets permet de diviser, bien inutilement.

Plus évidente, dans le développement de l'invention, est l'articulation de deux phases, de deux connotations, dont la première, la découverte, la rattache davantage à la matière, alors que la seconde, la substitution, la relie aux opérations habiles, aux connaissances déjà constituées. Cependant, découverte et substitution, pour autant qu'elles animent ou fixent le cadre de l'acte inventif, ne subsistent pas l'une sans l'autre et ne se différencient que dans la totalité qui les comprend toutes deux. Découvrir revient, en définitive, à ajouter au fonds matériel pré-existant des contenus physiques ou intellectuels jusqu'alors inconnus; c'est provoquer une combinaison nouvelle sans y être conduit par un exemple et sans obéir à un modèle. Un lien absolument neuf en résulte sans qu'aucun autre lien soit rendu caduc. Au contraire, il s'ajoute, en les renforçant, à ceux qui existent déjà, de sorte qu'on ne peut ni les concevoir séparément, ni oublier qu'ils naissent les uns des autres. Les théories chimiques ou physiques, les nouveaux continents, les instruments d'expérience et de production sont tous des chaînons assurant la présence régulière des puissances matérielles de notre vie, et la conformité de notre vie à l'intensité de cette présence. Toutefois l'invention peut tendre et a fréquemment tendu à remplacer une chose existante par une chose nouvelle, ce qui lui impose une direction. en fait. " The rate and direction of inventive activity, ed. cit. p. 20.

«Les savants faisaient des découvertes, les ingénieurs des inventions. Ceci n’est pas valable, même de façon approximative. Le continent américain fut découvert, non par des savants mais par des explorateurs navigateurs et aventuriers. Le calcul infinitésimal a été inventé, mais pas par un ingénieur ». F. MACHLUP : op. cit. p. 163. 
Dans la substitution, la nécessité d'inventer est infléchie par ce qui est connu, établi, et le but est atteint lorsqu'une structure nouvelle prend la place de l'ancienne. La tentative de capter l'énergie du soleil est motivée par le désir d'éliminer d'autres sources d'énergie moins abondantes ou plus coûteuses. Les chimistes se proposent souvent de reproduire un composé organique au laboratoire. Il n'est pas possible de trouver dans chaque cas un substitut analogique. La transmission des messages par ondes hertziennes s'inscrit dans la lignée de transmission des messages par pigeons voyageurs, mais il s'agit là d'une filiation purement hypothétique, non d'une filiation réelle. Par contre, le tissu synthétique a été conçu pour rendre les mêmes services que le tissu de laine ou de coton ; l'opération machinale est d'abord une opération manuelle ou cérébrale multipliée. Les substitutions surgissent parfois de manière fragmentaire, dans un contexte déjà existant. L'automobile a d'abord été un cabriolet à moteur, la machine à vapeur une pompe modifiée. Partant de ce segment nouveau, l'ensemble se transforme jusqu'à ce que tous ses éléments aient été intégrés. La machine à vapeur qui, au début, était la seule partie du système machinal à être construite en fer a obligé les ingénieurs à renoncer au bois et à tout bâtir en fonte et en acier. Une découverte est source de substitutions en chaîne.

Découvrir et substituer sont les moments essentiels d'une conversion réciproque de la force matérielle et de l'action humaine. Ils sont l'un pour l'autre, l'un par l'autre. Leur opposition n'éclate que dans le processus concret. La découverte désigne surtout l'assimilation des savoirs et leur expansion, tandis que la substitution se réfère à l'usure, à la consommation des facultés, et à la possibilité de les rajeunir. Leur ampleur dépend du nombre d'individus qui s'y consacrent, de la quantité de connaissances qu'ils possèdent et qu'ils manient. Avec les forces objectives correspondantes, ces connaissances forment les ressources matérielles ou inventives ${ }^{70}$, qu'il s'agit d'augmenter, de réduire ou de bouleverser. 
L'efficacité inventive ne saurait guère se comparer à l'efficacité des productions ordinaires, à la fois parce que nous manquons, jusqu'à ce jour, d'indices valables, et parce que tenter quelque chose de neuf suppose des essais innombrables, des redécouvertes inutiles; finalement, seule une très petite parcelle de ces essais est appelée à se généraliser. Toutefois, ce qui a requis tant d'ébauches, la vision merveilleuse d'une nouveauté surprenante, finit toujours par s'intégrer au sens commun. La reproduction perpétue ce qui a été saisi dans un élan fugitif et en garantit la valeur, rendant une partie de l'humanité apte à conserver et à élargir cette expérience unique. De même que les premiers traits de l'homo sapiens, une fois apparus, ont été fixés par la multiplication de cette espèce jusqu'à entraîner la disparition complète des autres hominiens, de même l'apparition des cultivateurs ou des mécaniciens s'est répétée jusqu'à rendre une grande partie de l'humanité cultivatrice ou mécanicienne. Le processus d'invention qui pénètre ainsi nos gestes, nos pensées, nos routines, réorganise la physionomie humaine et nous oblige à renaître pour la nature avec des qualités dont l'aspect extraordinaire nous frappe à un instant donné. 


\section{Les dimensions reproductibles du travail}

Retour à la Table des Matières

\section{La reproduction naturelle.}

Le processus de renouvellement des rapports naturels revêt la forme générale d'une imprégnation et d'une communication de savoir-faire, de talents, dans le temps et dans l'espace. D'une génération à l'autre, le ciel, l'ordonnance des champs, le cours des eaux, les musées, les laboratoires, les usines, les langages, les instruments ou les livres contribuent au croisement et au remplacement des individus. L'imitation des gestes, des recettes, des modes de pensée, l'implantation des habitudes, motrices et réflexives, d'un individu à l'autre, marquent visiblement la biographie de l'initiateur et de l'initié, chacun prenant le relais d'une lignée. Dans certains régimes, comme celui des castes, l'enfant ne naît pas seulement de sexe masculin ou féminin, riche ou pauvre, il naît aussi d'emblée artisan ou agriculteur. Le transfert d'un pays à un autre, d'un groupe à un autre, de connaissances et d'aptitudes par le truchement d'écrits, d'outils, d'échantillons ou d'immigrants, est le canal par lequel se propagent les capacités de travail. Pour la collectivité qui accueille cette capacité, elle équivaut à une invention provoquant le jaillissement d'un milieu différent, la multiplication d'individus dont le comportement et la pensée se chargent de qualités inédites dans un monde renouvelé.

Toujours le point de départ est constitué par l'association de pouvoirs humains et de pouvoirs non-humains. Le but souhaité est la reproduction d'une faculté, la perpétuation des échanges dans la nature. Ajoutée à un millier ou à un million d'individus, cette faculté n'est ni augmentée ni diminuée (« Je peux consommer une journée d'ouvrier mais non le talent de l'ouvrier $\gg)^{71}$. 
Pour cette renaissance des individus qui suit leur naissance biologique et sociale, la seule dépense est celle de l'énergie. Le symbole rejoint la réalité dans cette coutume qui voulait que l'apprenti de l'artisan devînt son fils adoptif, le fils consacré à l'action naturelle de l'art, après avoir été le fils d'un père qui l'avait consacré à la vie.

Pourtant le processus de reproduction que tout cela exprime ne reste pas inchangé au cours de l'évolution historique. S'il remplit la triple fonction d'entretenir, de préserver et de diffuser le travail, le lien aux pouvoirs physiques, il y parvient différemment à chaque époque. Son existence quasi inconsciente au sein des rites a pris fin lorsque l'initiation aux gestes et aux opérations sur la matière s'est associée explicitement au travail spécialisé, à l'habileté définie comme réalité indépendante. Le caractère de processus spécifique lui a été conféré par les disciplines artistiques, avec leurs règles précises de communication des procédés et des méthodes nécessaires pour modifier les substances dont sont tirées des œuvres sublimes ou ordinaires. Depuis, cette tendance s'est constamment accentuée, et le travail n'a pas cessé de se détacher parmi les fonctions de la collectivité, requérant, afin de se perpétuer, des efforts d'investissement et des savoirs appropriés.

\section{$\underline{\text { Retour à la Table des Matières }}$}

\section{Le système de reproduction.}

La reproduction prépare l'organisme à ses rapports naturels et productifs, concourt à l'organisation du travail, et se manifeste dans la répartition des habiletés et des connaissances.

De toute évidence, c'est dans la formation de nos facultés que son action apparaît le plus clairement. Une analyse plus circonstanciée permet d'observer le substrat donné, la force de travail, qui représente la matière relativement informe et précaire, hommes, femmes et enfants. Cette forme est modelée, assortie d'une habileté ou d'un talent, code de prescription qui lui donne la latitude de fonctionner dans un cadre déterminé. Le code ou le talent peuvent être très simples — res- 
ter assis, écouter un bruit - ou très complexes - écrire un livre, construire un appareil, résoudre une équation. Dans cette contexture, le savoir ou le talent incarne les principes matériels rattachés à un ordre qui les rend perméables à l'homme, à ses intentions. Le milieu physique opaque s'éclaire, se structure, et, une fois inventorié, classé selon des schémas ou des repères, peut s'intérioriser, se fondre avec nos sens, nos réflexes, pour les étoffer.

Cependant, afin que la synthèse réussisse, habileté et force de travail requièrent la présence d'un troisième facteur qui est la puissance matérielle, pour autant qu'elle a pris, à des degrés variés, un aspect humain : outil, machine, instrument, etc. Le talent et la dextérité sont obligatoirement relatifs aux organes qui renforcent l'énergie de l'individu, qui adjoignent à l'homme de l'intelligence ou des appareils sensoriels pénétration des calculs, sens de la mesure ou du rythme, etc. - donc relatifs aux organes de reproduction qui assurent leur conservation et leur exercice. En effet, envisagé sous l'angle du processus destiné à reproduire les liaisons naturelles, un outil ou une machine est moins une prothèse, un instrument, qu'un genre de bras, de nerf, d'œil, et même une pluralité de bras, de nerfs, ou d'yeux ${ }^{72}$. Ce qui permet d'instruire l'œil ou le bras humain, c'est justement le fonctionnement simultané de tous ces organes non-humains qui répètent, par analogie plus ou moins lointaine, les organes de l'homme. L'invention tire profit de l'aspect contraire, c'est-à-dire de l'aptitude des systèmes anatomiques et physiologiques humains à s'assimiler aux systèmes similaires non-humains. La communauté à laquelle la reproduction biologique confère un nombre donné d'appareils sensoriels disposant d'une gamme finie de qualités, reçoit, dans la reproduction naturelle, un nombre différent d'appareils dont la gamme s'est étendue et embrasse des qualités nouvelles. Relativement à un secteur spécialisé de la production, ces organes de reproduction ne sont que des instruments, des appareils de guerre ou de laboratoire. Ils contribuent cependant à parachever l'organisme en complétant ses attributs. Former en vue d'une science ou d'un art revient ainsi à convertir les dispositions biologiques, grâce à l'habileté jointe à un organe de reuniverselle ». A. LEROI-GOURHAN : Milieu et techniques, Paris, 1945, p. 471. 
production (ensemble ils forment les moyens de reproduction) et à les rendre, au sens précis du terme, naturelles, donc actives. Elles peuvent ensuite être intégrées aux diverses branches de la division sociale du travail, qu'il s'agisse de l'industrie, de l'art, de la philosophie, de la science, etc. Réciproquement, l'étendue de ces branches et leur diversité dépendent du travail déjà formé, constitué.

Organiser le travail, en fonction des qualités et des quantités de ce travail dont on dispose, entre les différentes parties d'une production matérielle et intellectuelle, conduit à mettre cette production en rapport avec les forces de travail et les besoins d'une société, suivant leur abondance ou leur rareté. Le développement et la diversification des métiers, des postes de travail dans un atelier, une usine, au laboratoire ou à l'école, appellent cette mise en relation et cette préparation. En conséquence, les deux termes - la force de travail et les moyens de production - prennent une pluralité de formes techniques, c'est-àdire qu'ils sont définis par le contexte des diverses productions et de la demande sociale. Du point de vue naturel, à un certain moment, les individus ont des facultés et des connaissances identiques. Cependant ils peuvent les posséder en tant qu'ingénieurs civils ou militaires, occupés à la fabrication d'engins ou à la construction de bâtiments, donc former autant de versions techniques d'un lien unique aux puissances matérielles. Il en va de même pour les organes de reproduction. Le télescope a été conçu par des artisans pour voir mieux, plus loin, pour viser sur les champs de bataille, et aussi pour amuser princes et courtisans. Galilée en a fait un instrument astronomique. Quelle que soit leur forme technique, l'organe de reproduction ou l'habileté exercent des effets analogues sur le monde physique et sur nous, ils constituent l'essence de multiples variantes qui les concrétisent. Bien entendu, chaque individu ne s'assimile qu'une fraction des facultés indispensables au maintien de notre ordre naturel. Aucune fraction ne peut subsister sans les autres; seule leur réunion garantit l'emploi de chacune et la bonne marche de l'ensemble. Journellement, tout talent reproduit un autre talent et s'y reproduit. L'architecte conçoit les proportions, le tracé des édifices, eu égard aux matériaux qui lui sont fournis. Qu'un de ces matériaux, maîtrisé par l'ingénieur, vienne à manquer - ou à être remplacé par un autre, produit au laboratoire - et le savoir qui le met en œuvre demeure imparfait, une facette des talents de 
l'architecte reste sans exercice et se perd. A chaque instant, des facultés collaborent, se détruisent et se renouvellent mutuellement.

La répartition du travail est un moment synthétique : elle suppose aussi bien la distribution des individus entre les formes techniques existantes (travaux, professions) que l'attribution des connaissances et des savoir-faire requis que les individus s'adjoignent. Former les hommes signifie déjà les répartir, les préparer à être ceci plutôt que cela, agriculteurs et non chasseurs, chimistes et non pas mathématiciens. Mais c'est seulement dans le cadre de l'organisation des productions matérielles et intellectuelles qu'ils sont vraiment ceci ou cela, que l'habileté virtuelle devient effective, techniquement définie. A la faveur de ce passage d'un état potentiel à un état actualisé, la somme des capacités incluses dans le travail général qu'il s'agit de répartir cesse d'être l'indice d'une pure collection de sujets ou d'objets. Elle s'affirme comme un champ différencié et hiérarchisé qui règle la place des individus, en se partageant entre eux et les autres forces matérielles. Le travail devient ainsi une manière de distinguer les hommes : ceux-ci se séparent suivant qu'ils ont acquis une qualification, autrement dit, des pouvoirs et des facultés spécifiques. Quoiqu'une marge de variation subsiste dans chaque cas, les directions essentielles sont tracées. Le paysan, l'artisan, l'ingénieur ou le scientifique ont chacun un secteur respectif délimité. Les catégories ainsi fixées à leur savoir-faire sont extérieures les unes aux autres, bien que profondément interdépendantes, de même que les soleils sont simultanément des individus astronomiques et les éléments d'un système galactique. Le respect obligatoire des proportions qualitatives - le nombre des chimistes étant, par exemple, en rapport avec celui des physiciens, ou le nombre des tisserands avec celui des fileurs — n'est en dernière analyse qu'une façon de traduire le fait que chaque entité est qualifiée par un rapport, nommément désigné, avec les forces matérielles.

L'écart de qualification est aussi un écart de valeur, le signe d'une hiérarchie. Une partie de l'humanité est équipée uniquement du strict nécessaire lui permettant de dépenser sa force de travail, et sa qualification lui fournit tout juste le cadre dans lequel elle peut s'ajouter aux autres matières premières, c'est-à-dire qu'elle produit essentiellement des biens ou des objets. Une autre partie de l'humanité, grâce à ses 
facultés, a pour but de son activité la création du travail, partiellement comme l'ingénieur, ou en totalité comme le scientifique.

La place des hommes, lorsqu'ils forment, organisent et répartissent le travail, dépend de la qualification de celui-ci, de la manière dont il les différencie et les réunit. En d'autres termes, reproduire le travail n'est pas uniquement garantir la continuité des ressources humaines ou non-humaines, mais aussi maintenir un ensemble de liaisons qui le domine et constitue un système de reproduction. A l'intérieur de ce système, le potentiel biologique des individus s'allie aux forces matérielles qui s'expriment en habiletés ou en organes non-humains, traduisant et fécondant des organes humains. Les positions ainsi acquises sont relatives. L'artisan en rapport avec l'agriculteur ou en rapport avec l'ingénieur se meut dans deux réalités radicalement hétérogènes. L'outil, les qualités sensorielles de la force humaine, les produits organiques, sont les principes spécifiques de la première. Dans la seconde, le calcul, la force mécanique, la machine décident du contenu du milieu naturel. Les systèmes qui englobent le même individu dans les deux cas sont sans commune mesure. Les liaisons réciproques qui s'ensuivent définissent la participation de ces diverses catégories à l'établissement de leur état de nature. Que ces liaisons entre êtres humains soient naturelles, on a beaucoup de peine à l'admettre. Dans notre civilisation, on a l'habitude d'accorder de l'attention uniquement aux corrélats sociaux de toute différence ou de tout rapport. Ainsi est entretenue une confusion dangereuse. La différence qui sépare les classes est sociale uniquement dans la mesure où elle est le signe d'un antagonisme ou d'une inégalité dans l'appropriation des richesses sociales. Le capitaliste accule l'artisan à l'état de prolétaire en s'appropriant ses outils et en l'empêchant, par le mécanisme du marché, d'en acquérir de nouveaux. Lorsque l'ingénieur réduit l'artisan à n'être plus qu'une partie de la machine en rendant caducs ses dons traditionnels, le cheminement n'est pas le même. Les rapports de l'artisan et du paysan ou de l'ingénieur, pour être simultanément sociaux, n'en sont pas moins déterminés par l'insertion dans le monde matériel, et, en conséquence, par le travail pour lequel ils sont préparés. 
Serge Moscovici — Essai sur l'histoire humaine de la nature (1968) 77

Retour à la Table des Matières 


\section{Processus naturels et processus sociaux}

$\underline{\text { Retour à la Table des Matières }}$

\section{Le fondement naturel.}

Tout ce que je viens d'avancer n'a de cohérence que si le domaine naturel et le domaine social ne se recouvrent pas, bien que l'homme soit le protagoniste de l'un et de l'autre. A partir de là, je rattache au premier la création du travail, au second la production des objets, et j'examine la reproduction et l'invention en tant que processus naturels. Il s'agit à présent de justifier de telles prémisses sur le plan de la théorie.

Le trait qui différencie nature et société, l'écart du groupe humain à lui-même, comme sujet naturel d'une part et sujet social de l'autre, sont inscrits dans le travail créé. L'économie nous propose le terrain le meilleur, ou du moins le plus défini, pour mesurer cet écart, analyser cette différence. Mais auparavant il convient de comparer le concept de nature auquel je me suis arrêté et celui qu'a adopté la science sociale et économique.

Celle-ci, partant de la production, y reconnaît généralement trois facteurs : le travail, le capital et la nature, qui désignent respectivement l'effort dépensé pour produire, la direction et l'appropriation des moyens de production, et enfin les ressources. Ces notions personnifient évidemment la présence simultanée dans un système unique de la classe des travailleurs dont l'énergie assure le fonctionnement de l'appareil productif, de la classe des capitalistes qui, en décidant de l'investissement et du profit, façonne les caractères de l'industrie, et, en troisième lieu, des fondements matériels sans lesquels le tableau ne serait pas complet et la propriété n'aurait pas de corps.

La notion de nature n'a pas été employée sans ambiguïté pour décrire le fonctionnement de la société, et son contenu a évolué. Les tout premiers philosophes ou économistes, suivant la coutume ou l'état de 
fait, ont identifié le troisième facteur de la production, la nature, à la terre. Le choix de celle-ci se comprend, car les éléments utiles à la vie sont emmagasinés dans le sol, et la richesse, lorsque l'agriculture est l'occupation principale, est proportionnelle à l'aire occupée.

L'essor de l'industrie, la diffusion des techniques mécaniques, l'importance prise par les forces inanimées, ont contribué à modifier le contenu concret de la notion de terre.

«Qu'est-ce que la terre? Évidemment, nous n'entendons pas seulement par ce mot le sol terrestre, le champ qui produit la moisson, ce qui porte la forêt ou qui recèle les métaux; nous entendons aussi le vent qui fait tourner les ailes du moulin, la chute qui met en mouvement l'outillage de la fabrique, l'électricité qui transmet nos pensées, toutes les forces, en un mot, de la nature propres à servir les desseins de la vie ${ }^{73}$.

La terre, surface sur laquelle subsistent végétaux et animaux, soussol renfermant les minéraux, voit son empire restreint. Elle se classe parmi les autres pouvoirs de la nature dont elle n'est plus qu'une variété particulière :

«Les économistes, écrit Senior ${ }^{74}$, ont depuis longtemps divisé les instruments de la production en trois grandes branches, le travail, la terre et le capital. J'ai préféré l'expression "agents naturels» au mot de terre, afin de ne point distinguer tout un genre par une de ses espèces et de ne point commettre l'erreur commune à plusieurs qui se souviennent rarement des autres espèces ou les oublient tout à fait ».

Affirmer la diversité et la communauté des agents naturels, c'est envisager deux implications qu'on ne peut pas dissocier. D'une part on admet l'expansion possible des facteurs matériels. D'autre part on reconnaît au travail manuel et intellectuel le droit d'appartenir à cette famille d'agents. Par contre-coup, le vocable «terre » ou tout autre qui se rapporte à un contenu substantiel invariant, particulier, devient

E. LEVASSEUR : Du rôle de l'intelligence dans la production, Paris, 1867, p. 34.

74

N.W. SENOIR : Principes fondamentaux de l'économie politique, Paris, 1836, p. 309. 
arbitraire, voire métaphorique ${ }^{75}$. Ce n'est plus qu'une autre manière de parler de la nature. Mais il ne s'agit pas là d'une pure convention : le concept lui-même est en cause.

Privativement, la nature signifie un instrument de production, préalable objectif qui n'est ni capital ni travail pouvant faire l'objet d'une appropriation. Positivement, elle englobe la totalité des forces et des capacités participant de cet instrument, notamment le travail en tant qu'habileté et savoir-faire. C'est le cours normal des déductions qui y conduit. On sait que l'expansion des pouvoirs matériels, leur accroissement, ne sont pas automatiques ; l'homme doit y ajouter la connaissance des régularités du monde physique, un travail particulier qui a pour but de les engendrer et de les perfectionner. L'intelligence se confond ici avec la matière, l'une et l'autre représentant le soubassement naturel. Métamorphose qui apparaît clairement dans cette formule destinée à préciser la place du troisième terme - à côté du capital et du travail :

«Ce qu'on nomme intelligence se distingue proprement des deux autres en ce qu'il tend à fournir sa coopération à titre gratuit, sans que la valeur intrinsèque de ses services se trouve amoindrie ${ }^{76}$.

Aux expressions telles que agents naturels ou terre se sont donc substitués, dans l'équation de la production, les vocables d'intelligence ou de savoir, leurs équivalents. John Stuart Mill l'atteste lorsqu'il écrit ${ }^{77}$ :

«Parmi les conditions (de la richesse) les unes sont physiques : elles découlent des propriétés de la matière, ou plutôt de nos connaissances possédées en certain lieu, certain temps, sur ces propriétés ».

75 « Donc les airs, les eaux et la terre, et même les lois physiques qui déterminent leurs combinaisons, peuvent être considérés comme les instruments premiers de la formation de la richesse. Pour éviter des périphrases inutiles, cependant, les agents naturels qui constituent les instruments premiers de la production sont généralement compris sous le nom de terre ». R. TORRENS : On the production of wealth, Londres, 1821, p. 67.

E. LEVASSEUR : op. cit. p. 45.

77 J.S. Mill : Principes d'économie politique, Paris, 1861, p. 23. 
Le changement de point de vue est net. Au début, la nature est assimilée à une structure matérielle unique, la terre. Ensuite on y découvre la présence d'espèces naturelles, d'agents; le travail en tant que talent, dextérité, est rangé parmi ces espèces. Enfin la connaissance, l'intelligence - aujourd'hui le progrès des sciences et des techniques - cessant d'être un moyen, est associée aux forces primordiales et se substitue à elles en regard du travail et du capital, facteurs de richesse sociale. De façon plus générale, la nature, le dernier des facteurs productifs, se détache en tant qu'ensemble de propriétés des êtres humains et non-humains, comme leur réunion active et solidaire. Cela n'a rien d'étonnant puisque c'est grâce à la création de facultés, à la division des travaux, que les puissances matérielles se multiplient avant de pénétrer dans la production. En confrontant ces observations à la critique des opinions les plus répandues, je suis arrivé à une vue analogue de l'ordre naturel. La convergence que je viens de mettre en avant entre la théorie sociale et économique et la théorie esquissée ici est un préalable. Il faut à présent franchir le seuil qui sépare l'état de nature de l'état de société, et expliciter cette démarche.

Retour à la Table des Matières

\section{Richesses, ressources et appropriation.}

Dénombrant les facteurs productifs, l'économiste, on vient de le voir, en retient trois : le travail, le capital et la nature. La notion et la réalité de nature n'interviennent pas, dans cette formule, pour ellesmêmes. Elles subviennent au besoin théorique et pratique de poser le travail, agent générateur de richesses, et le capital, somme de richesses, en tant qu'instruments sociaux de production. Quel est le critère qui sépare le troisième facteur productif des deux autres et assoit une convention ? Substances et phénomènes sont situés dans le cycle naturel tant qu'on les juge disponibles de manière illimitée et, par conséquent, gratuite :

«Ainsi la haute région de l'air, du ciel, et les corps célestes, comme aussi le vaste océan, n'étant pas susceptibles de propriété, on ne saurait légitime- 
ment les mettre à prix, quoiqu'il en revienne une grande utilité à la vie humaine $\gg{ }^{78}$.

Ce point de vue commande l'adhésion. Les hommes ne peuvent ni accumuler des biens, ni se différencier socialement par le moyen de la lumière, de l'eau, du mouvement de la terre ou du métabolisme des plantes. Ces processus ne sauraient faire l'objet de transactions qui leur fixent une valeur : ils n'appellent pas notre effort pour être. Leur place dans le champ, distinct, de la société, suppose une certaine dépense, un investissement constant de nos forces. « La richesse est la matière sous une forme particulière », déclarait en style lapidaire Torrens. Ce qui la rend particulière est le fait qu'il s'y ajoute du travail humain. Ce travail représente, en l'occurrence, une certaine quantité de temps ou de force que son possesseur cède sur le marché à un acheteur pourvu d'un capital divisé en salaires et moyens de production qui sont eux-mêmes du travail accumulé :

«Concrètement, le capital se compose de toutes les formes de matière vendables sur le marché qui englobent du travail ${ }^{79}$.

Dans ce contexte, celui de l'acquisition et de la distribution des fruits du labeur général, les éléments de l'ordre naturel sont des parties de l'ordre social, obéissant à ses normes et à sa structure. Transposés en travail ou en capital, ils synthétisent la consommation ou l'échange, la circulation de la force de travail conformément aux dispositions de l'État ou d'une classe particulière. La production combine les moyens techniques et l'énergie des individus, et fournit une somme de biens susceptibles d'être répartis entre les membres de la société suivant leur rang. Le travail joue le rôle de facteur productif et se dévoile en tant que signe et mesure des rapports économiques et sociaux. La nature se situe hors de ce mouvement qui institue les symboles et les instruments de la collectivité, les lois de la propriété et du pouvoir. Son individualité en découle. Parce qu'ils ne peuvent faire l'objet d'une appropriation, on soutient que ses dons sont gratuits. D'après ce qu'on vient de voir, elle est aussi l'état des choses qui nous

S. de Puffendorf : Le droit de la nature et des gens, Bâle, 1771, t. II, p. 42. 
sont fournies sans travail, puisque ce travail métamorphose les ressources en richesses, rendant son contenu aliénable et appropriable. Le critère recherché semble être, de la sorte, défini. En fait, sa fonction demeure purement négative: il nous dit ce que l'ordre naturel n'est pas et permet uniquement de donner un sens à son contraire supposé : l'ordre social. Je tenterai de montrer maintenant sa face positive et ce qu'elle implique ${ }^{80}$.

Retour à la Table des Matières

\section{Travail aliéné et travail inaliénable.}

\section{L'état de nature, appréhendé dans sa spontanéité foncière qui} n'aurait pas demandé une dépense d'efforts et de savoir serait, nous

Les forces productives ont un contenu analogue à celui de la nature dans les doctrines économiques. Elles sont des combinaisons des éléments matériels et de l'homme armé de ses facultés. Cependant, au lieu d'apparaître comme substances passives et éléments contingents de la richesse, elles représentent le milieu physique humain qui a, par ses fonctions actives, un impact décisif sur la réalité sociale et historique. Les rapports de production désignent, par contraste, dans la terminologie marxiste, le mode d'appropriation du travail et l'ensemble de la superstructure idéologique. Ils sont considérés comme irréductibles aux forces productives. « Dialectique des concepts de force productive (moyens de production) et rapports de production, dialectique dont les limites sont à déterminer et qui ne supprime pas leur différence réelle ». (K. MARX : Contribution à la critique de l'économie politique, ed. Paris, 1957, p. 173). La « différence réelle » réside en grande partie dans le fait que les premières ne sont pas déterminées principalement par les lois sociales de la propriété, tandis que les secondes incarnent ces lois. Je dirai que cette différence met mieux en évidence le double rôle joué simultanément par l'homme, à la fois sujet social et sujet naturel, d'une part agent de la production, de l'échange et de la distribution des richesses, d'autre part créateur du travail, de ses ressources, donc force productive. Si le parallélisme entre société et nature, rapports de production et forces productives — l'ordre naturel envisagé du point de vue social — est fondé, il s'ensuit que :

- l'histoire humaine de la société est une figure et une transposition de l'histoire humaine de la nature ;

- la dialectique des rapports de production et des forces productives n'est autre que la dialectique de ces deux mouvements historiques

- sans une connaissance approfondie de l'histoire humaine de la nature, il n'y a pas de connaissance approfondie de l'évolution des forces productives ("Malheureusement, l'étude des forces productives n'a pas été suffisamment développée »... A. ZVORIKINE : Technology and the laws of its development, Technology and Culture, 1962, 3, p. 451). Leur emploi explicatif semble avoir dispensé les théoriciens de les expliquer à leur tour. A l'instar du progrès scientifique et technique, elles sont une version du deus ex machina, qui prétend jeter une lumière sur la réalité, tout en restant enveloppé dans la plus impénétrable des obscurités. Une lacune persiste à leur sujet. Concevoir un processus historique de notre nature, qui détermine ouvertement le processus historique de notre société, eût impliqué une rupture avec cet «impérialisme sociologique », auquel la conscience moderne est si profondément attachée. 
l'avons constaté, un pur néant. A y regarder de plus près, il s'agit d'un état auquel fait défaut le labeur « susceptible de propriété », et non pas le labeur tout court. Au contraire, afin que ses composantes physiques soient prêtes à recevoir le supplément qui les transforme en ressources, il est indispensable qu'elles aient été d'abord découvertes, mises sous forme de lois, qu'elles soient devenues intelligentes et intelligibles. La dimension naturelle du travail y est nécessairement concernée, la dimension sociale en est écartée. Pour que cette bipartition du travail soit perceptible et possible, il a fallu qu'il se modifie. Tant qu'il restait impliqué dans le processus productif sous la forme complexe d'un emploi du corps ou de la main façonnés par l'exercice d'un savoir, il passait conjointement pour naturel et social, c'est-à-dire pour une matière première semblable aux autres et une manière de s'approprier les biens économiques. Dans cette composition subtile, on discernait difficilement ce qui appartenait à l'individu, sa force de travail, son temps, actuel ou accumulé, et ce qui ressortissait à la nature commune, à la société prise collectivement: l'habileté dont il avait l'usufruit. La société capitaliste a mis fin, de façon dramatique, à cette ambiguïté, l'a rendue transparente. Ayant découvert et statué que la vraie richesse n'était ni l'or ni la terre, mais la sueur, la fatigue, le dénuement des hommes, des femmes et des enfants, les adeptes révolutionnaires de l'industrie se sont consacrés à leur exploitation consciencieuse :

«C'est un résultat bien remarquable de l'histoire philosophique de 1'humanité, notait Storch ${ }^{81}$ que le progrès de la société en population, en industrie et en lumière est toujours acquis aux dépens de la santé, de la dextérité et de l'intelligence de la grande masse du peuple ».

En effet, avec une persévérance toute philosophique, le labeur de la majorité des hommes a été réduit de plus en plus à une série de gestes insignifiants. Toute dextérité, tout lien créateur avec le produit, ont été éliminés, aboutissant à une complète indifférence envers la tâche effectuée. L'évolution millénaire qui conduit à une différenciation des bras et des jambes, de la tête et des mains, a été renversée ${ }^{82}$, méta- 
morphosant l'individu en organe d'une suite de machines et de mouvements. Le travail, ainsi laminé, quantifié, peut recevoir un équivalent en argent. A juste titre, Karl Marx l'a qualifié d'abstrait. Lui faisant face, la connaissance, l'habileté se dressent comme attributs d'un autre travail. Concrétisé dans la machine ou le livre, il conserve ses vertus inventives, intelligentes, et son rapport à la matière. Socialement, il n'est que le multiple quantitatif du travail commun, abstrait, comme si cent hommes rabaissés à l'état animal valaient un savant. Dans l'optique du directeur d'entreprise et de son porte-parole économique, il revient du reste au même d'avoir à employer une grande intelligence ou de comprimer l'intelligence de cent adultes, si la rentabilité est identique. Le dédoublement avéré de l'activité productive est conforme à la réalité : d'un côté la possibilité d'appropriation économique, de l'autre l'intervention dans les processus matériels. La version «sociale » et la version « naturelle » du travail en général se détachent symboliquement et s'opposent concrètement ${ }^{83}$. La théorie enregistre cette séparation quand elle mentionne avec J. B. Say ${ }^{84}$ «le travail ou les services productifs des capitaux» et «le travail ou les services productifs de la nature ».

Nous approchons ainsi d'une dichotomie tranchée. Amalgamés à une substance dans laquelle ils s'incarnent, en lui conférant une valeur et une utilité, l'énergie ou le temps d'un individu ou de mille accroissent par voie de conséquence l'avoir d'un employeur ou d'une collectivité particulière. L'habileté, scientifique ou technique, tout en servant de catalyseur à cette transaction, n'y est pas incluse. Personne ne la paye, au sens économique, et personne ne se l'approprie de façon durable. Cette qualité rend, par surcroît, les pouvoirs humains semblables aux pouvoirs non-humains d'un état naturel ${ }^{85}$. Les réflexes, les

tré de faire avec leurs mains tous les gestes nécessaires, s'aider de la tête comme d'un troisième bras ».

«Si... le capital mobile n'est qu'un travail coexistant, et le capital fixe un travail habile, il doit être clair que... toutes les vastes améliorations apportées à la condition de la race humaine que l'on a en général attribuées au capital, sont causées en fait par le travail et par la connaissance et l'habileté qui informe et dirige le travail ». T. HODGSKIN : op. cit. p. 108.

84 J.B. SAY : op. cit. 85.

85 «La seule différence par rapport aux autres éléments de production est que le produit scientifique, matérialisé dans les moyens de production ou incarné dans la production en tant qu'élément de la reproduction de la puissance de travail, c'est-à-dire quand il a sa réalité dans l'esprit des travailleurs eux-mêmes, peut-être considéré dans la production matérielle comme 
postures, les dextérités, les informations qui entrent dans notre activité quotidienne, se conservent depuis des millénaires et se renouvellent à chaque génération, sont instamment présents dans nos productions. Comme l'eau, l'air ou la lumière, ils sont distribués partout. La station debout, la loi d'Archimède, l'alphabet, le jugement qui discrimine une couleur d'une autre, ainsi que des milliers de micro-opérations qui s'ajoutent à notre organisme, font partie du fonds inépuisable de notre nature. Du reste, comment pourrait-on dire qu'il y a de l'eau, de l'air, du minerai ou de la terre, si les sensations et les perceptions correspondantes n'avaient pas été d'abord différenciées et ensuite transmises d'homme à homme depuis des temps immémoriaux? Anciennes ou nouvelles, les connaissances ont le même caractère ; les utiliser ne les fait pas diminuer et chacun peut les posséder si les moyens lui en sont fournis. Le travail qui, en nous intégrant au monde matériel, nous attache à celui-ci par la modification de nos capacités en liaison avec les puissances physiques, ne peut être ni échangé, ni consommé dans le sens courant ${ }^{86}$.

Comme tout agent matériel, à l'intérieur de certaines limites, il est à la fois indispensable et commun à l'espèce en son entier. Par Isocrate nous savons que « les talents corporels, ceux de la défense et de la course, périssent naturellement avec le corps, tandis que les sciences sont faites pour rester toujours utiles à ceux qui s'en servent $»$. Étant «service productif de la nature», ce travail qui permet à des milliers d'hommes d'agir dans un milieu tout en bouleversant ce milieu est et a toujours été envisagé hors de la sphère économique :

«Considéré du point de vue national et universel, le travail du savant, du penseur, est aussi bien une partie du travail de la production que celui de l'invention d'un art pratique. Un grand nombre de ces inventions a pour base unique les découvertes scientifiques; toute extension de la connaissance des phénomènes naturels a pour résultat plus ou moins immédiat un accroissement de la production. Cependant, comme ces résultats matériels, bien qu'ils soient dûs au travail du savant, en sont rarement le mobile direct, et que sa rémunéra-

un don de la nature ». S. StRUMILINE : in Role of Science in modern society, World Marxist Review, 1963, 6, p. 40. 
tion ne saurait peser sur l'accroissement de la production dont, en fin de compte, il est la cause, il n'est guère utile à l'explication des phénomènes d'économie politique, à l'élucidation de ses principes, de les prendre en considération $\gg{ }^{87}$.

Les théories et les expériences scientifiques, au même titre que les procédés codifiés par un artiste ou un ouvrier, rentrent dans le fonds universel de l'humanité. Des parties de ce fonds peuvent être accaparées de manière exclusive pour une courte durée, mais ce ne sera jamais qu'une adjudication précaire, contraire à l'essence de ce travail. En raison de ses qualités de durée et d'inaliénabilité, celui-ci prend place parmi les ressources dans lesquelles s'exprime l'unité de l'homme œuvrant et de la matière créée :

«Un système de ressources, écrit Firey ${ }^{88}$, est une structure homme-espritterre qui impose une sorte de contrainte ou de nécessité à ses agents humains ».

Les raisons pour lesquelles on peut dire que la reproduction et l'invention sont des processus naturels apparaissent maintenant clairement. D'une part, par leur truchement, l'humanité se donne son assise physique et sa force en liaison avec celle-ci dans un ensemble qui les comprend toutes deux. La matière en conjonction avec laquelle le travail est créé n'est pas une table rase, un chaos indifférent et indifférencié. Au contraire, elle est déjà ordonnée et doublement ordonnée. D'abord par ses lois intrinsèques, résultant de l'interaction des forces matérielles elles-mêmes. Ainsi les lois auxquelles obéissent les êtres vivants prolongent les lois physico-chimiques dont elles constituent une version entièrement originale. Ensuite, les règles de l'action humaine imposent aux pouvoirs matériels une configuration qui les prépare à d'autres actions ou les rend capables d'effectuer celles-ci. Les mouvements et les forces mécaniques se trouvaient inclus dans les méthodes de tissage ou celles de construction des horloges, les lois newtoniennes de la gravitation offraient un modèle intellectuel aux lois de l'électricité. Les rayons X préfiguraient les propriétés de la radioactivité. La découverte d'habiletés, de propriétés naturelles, dépend

87

88

J.S. MiLl : op. cit. p. 46. 
de cette double prédétermination des structures objectives, et c'est sur elles qu'il est indispensable d'avoir prise. Cela signifie qu'en agissant sur la matière, l'homme agit simultanément sur lui-même ; que toute réorganisation des rapports avec les puissances du milieu matériel est une réorganisation de ses rapports avec lui-même. L'agriculteur ou le pasteur qui domestique plantes ou animaux oblige le chasseur à disparaître ou à se réfugier sur d'autres terres. De multiples inventions sont nécessaires pour aboutir à cette domestication. Parallèlement, pour sustenter les nouvelles espèces, pour préserver les nouvelles conditions d'humidité, de fertilité ou d'étendue du sol, une transmission rigoureuse des pratiques et des rites est obligatoire. C'est de cette manière que l'humanité se développe et se transforme, que des fragments de l'univers prennent du relief.

D'autre part, les processus créateurs de talents, de sciences ou de techniques sont pourvoyeurs de "dons gratuits de la nature ». Leur spécificité découle de ce trait qui les rapproche de la plupart des mécanismes généraux, chimiques, biologiques, etc., producteurs de phénomènes et d'êtres organiques ou inorganiques. A cette différence près qu'ils incluent l'homme.

Du point de vue social, on a tendance à estomper l'originalité de la reproduction et de l'invention. Nous savons que les résultats économiques, industriels, sont identiques, que le savoir-faire soit engendré dans le cadre d'une nation ou qu'il soit acquis dans un pays étranger. La pratique des brevets d'invention est fort instructive à cet égard. Jusqu'au XIX ${ }^{\mathrm{e}}$ siècle, aussi bien en France qu'en Angleterre, un brevet était attribué à une personne non pas pour avoir fait quelque découverte, mais afin qu'elle enseignât son art aux citoyens du pays. Sans aucun respect pour le droit de propriété, si chéri par ailleurs, un homme au XVIII ${ }^{\mathrm{e}}$ siècle avait le titre et les prérogatives de l'inventeur pourvu qu'il importât une invention faite à l'étranger, c'est-à-dire qu'il la reproduisît. Ces pratiques subsistent de nos jours, où il suffit d'une modification minime et souvent superflue pour obtenir des avantages analogues à ceux de l'individu ou de l'entreprise qui a fait le premier la recherche ou la découverte. Pour la société, la reproduction est donc souvent une invention relative - une nouvelle possibilité d'accroître les ressources s'ajoutant à celles qui existent déjà — et 
l'invention une reproduction absolue, puisque l'inventeur est récompensé uniquement dans la mesure où il communique au public ce qu'il est seul à connaître. L'individualité des deux processus n'est, sous cet angle, ni essentielle, ni tranchée. De toute manière, ils n'infléchissent directement à aucun degré la situation ou les rapports qui prédominent dans une société. Les découvertes les plus importantes, du simple moulin à eau aux corps chimiques les plus complexes, peuvent en tant que telles se multiplier, attirer des foules de curieux ou dormir dans les ouvrages savants, en attendant que la collectivité les remarque, que la propriété les réclame. C'est uniquement à partir du moment où elles s'intègrent aux cycles de la production, de l'échange et de la consommation, qui les absorbe et les transfigure ${ }^{89}$, que l'invention et la reproduction ont un impact sur l'anatomie et la physiologie d'une société ${ }^{90}$. De même que les mécanismes physico-chimiques n'interviennent dans et à travers les mécanismes de la vie que profondément modifiés et dans des circonstances spéciales, de même les talents créés n'acquièrent une portée socio-économique qu'à partir d'un certain degré de réceptivité et de perfectionnement :

«Lorsque nous attribuons une valeur économique à l'invention, c'est sa valeur après (et non avant) le plein développement qui est en cause. » ${ }^{91}$

Sur tous les autres points de leur cours, les inventions restent uniquement des dons de la nature, "dons inépuisables, dons gratuits », semblables en cela aux astres, aux animaux ou aux minéraux. S'ils ajoutent quelque chose à l'espèce, en eux-mêmes ils ne perturbent pas l'équilibre des richesses distribuées entre les classes d'une société. La gamme des ressources qui symbolise cette richesse n'est que le témoin

Le grand économiste S. Schumpeter tenait à distinguer clairement entre l'invention et l'innovation économique : «De plus, les innovations que les hommes entreprenants ont pour fonction de promouvoir n'ont pas forcément besoin d'être des inventions. Il n'est donc pas conseillé et il pourrait être tout à fait erroné de souligner l'élément inventif autant que le font de nombreux auteurs ». (Theory of economic development, Oxford, 1961, p. 88).

« Des éléments naturels qui interviennent dans la production sans rien coûter, quel que soit le rôle qu'ils jouent, n'entrent pas dans la production en tant que composantes du capital, mais en tant que force naturelle gratuite du capital, c'est-à-dire comme productivité naturelle et gratuite du travail qui, cependant, dans le système capitaliste de production, se présente, comme toute force productive, sous l'aspect de force productive du capital ». K. MARX : Le capital, t. 7, p. 130.

91 The rate and direction of inventive activity, ed. cit. p. 48. 
muet sans lequel rien n'aurait été entrepris, mais qui ne confère pas un sens à l'entreprise par laquelle les possessions augmentent ou diminuent. Parce qu'on a reconnu ce fait depuis longtemps, on a également reconnu l'hétérogénéité de la faculté «inventive» comparée à la faculté « accumulative ${ }^{92}$ ». Nous l'avons déjà remarqué : ni les efforts investis dans l'invention, ni les résultats qui la consacrent ne sont essentiellement disponibles à l'achat ou à la vente. Ils ont des conséquences si disproportionnées à leur coût et suivent un chemin tellement imprévisible que le calcul de leur rentabilité est des plus malaisés. Ceci parce que, comme on le sait de longue date, le devenir marchandise des découvertes est incertain, voire impossible :

«On verra que, dans ce travail, le résultat ne peut jamais être certain ou prévu avec précision ; que le temps, les efforts, le concours des individus nécessaires pour y arriver, ne sauraient être calculés ; que le travail est susceptible de se produire sous plusieurs formes et à divers degrés, avant d'arriver à un état où il puisse être immédiatement utilisé ; que, même parvenu à ce terme, il ne peut sortir de l'atelier scientifique qu'après avoir subi une préparation, que ses auteurs ne peuvent lui donner; et pour toutes ces raisons, enfin, il ne saurait être susceptible, à aucun des termes de son élaboration, de devenir une marchandise et payé comme tel ${ }^{93}$.

La transmission des facultés obéit à des contraintes identiques. Les peines prises pour développer une personne sont innombrables. $\mathrm{Ce}$ que l'individu, sa vie durant, enregistre dans ses muscles, ses yeux, ses cellules nerveuses, a pour lui un prix inestimable, sans qu'il se l'approprie vraiment un seul instant.

« Puisqu'elle (l'éducation) devient partie intégrante d'une personne, elle ne peut ni s'acheter ni se vendre ni être traitée comme une propriété dans le cadre de nos institutions $»{ }^{94}$.

« De même que les individus semblent en général s'enrichir en saisissant des portions toujours croissantes de la richesse existant déjà, de même les nations s'enrichissent en produisant une richesse qui n'existait pas auparavant. Les deux processus différent en ceci que l'un est une acquisition, l'autre une création ». J. RAE : op. cit. p. 12. La doctrine saint-simonienne, Paris, 1830, t. II, p. 367. 
Ni l'invention, ni la reproduction, on a pu s'en convaincre, ne donnent naissance à une appropriation séparée ou semblable à celle que la production et l'échange autorisent et protègent quotidiennement. Pour affirmer le caractère naturel de ces processus, point n'est besoin de soutenir que l'homme n'y est pas présent, actif, en tant qu'être social. $\mathrm{Au}$ contraire, une coopération étroite est indispensable aux techniciens, aux artistes, aux scientifiques, pour faire surgir les qualités du monde physique, et obliger les collectivités à s'intéresser à leurs savoirs et à les consolider. Les investissements sont toujours consentis par la société ou par ses membres individuellement, au cours de l'exercice de l'intelligence et des énergies biologiques, de façon normale, tout comme ils respirent ou parlent. La dimension sociale de l'humanité est inhérente à son pouvoir matériel.

Indiquer, comme je l'ai fait, une frontière entre l'état naturel et l'état social ne revient pas à en dénombrer séparément les contenus. La masse de la société n'est pas celle de l'homme opposée à la masse des puissances extérieures. Les deux états comprennent les mêmes facteurs humains et non-humains; seules les relations dans lesquelles ils entrent, les fins qu'ils servent, les rattachent au premier ou au second ${ }^{95}$. Nous pouvons souligner ce qui définit et isole société et nature; nous devons renoncer à les traiter comme des zones hypostasiées du réel, ou à les mettre en concurrence comme des êtres substantiels clos. Partant, l'homme est à la fois leur commun dénominateur et le sujet, aux attributs distincts, de l'une et de l'autre. Nous l'avons constaté : sa particularité sociale éclate à propos de l'aliénation du travail et de la distribution de richesses, sa particularité naturelle à propos de la création des ressources inépuisables et inappropriables et de la répartition des habiletés. Par la propriété il fait un premier monde, par le talent il fait un second monde. Telle est la règle qu'il suit, telle est la règle qui sépare les mouvements respectifs ${ }^{96}$. Décrire

«La société et la nature, si on les considère comme deux systèmes différents d'éléments, résultent de deux méthodes de penser différentes et sont seulement en tant que telles deux objets différents ». H. KELSEN : Society and Nature, Chicago, 1943, p. VII.

96

« Le travail, dit Karl Marx (Manuscrits... ed. cit. p. 12) n’apparaît en économie politique que sous la forme d'activité en vue de gain ». Faut-il s'en étonner? Les sciences de l'économie et de la société tournent leur attention vers l'univers matériel considéré sous l'angle de la richesse. Le cœur et l'aboutissement des rapports sociaux sont enfouis. L'étude du travail dans un cadre différent, celui de la nature, est à peine entamée. Dans cette perspective, l'opposition 
en termes vagues leur complémentarité ou leur opposition, une superposition qui se donne les allures d'une hiérarchie, serait revenir à des énoncés purement empiriques. N'étant plus ni repère consacré à mesurer des réalités d'un autre genre - sociétés, artifices - ni dénomination commode à l'usage des sciences, des arts et des techniques, l'état naturel voit ses processus, son autonomie déterminés par des démarches théoriques. Cela favorise son étude directe et écarte les obstacles qui s'opposent à une enquête approfondie sur les parties et les liens dont il se compose ${ }^{97}$.

Retour à la Table des Matières

du travail aliénable et inaliénable est essentielle. Ce serait cependant une erreur d'identifier le premier aux activités qui peuvent faire l'objet d'une appropriation et le second aux activités qui ne sauraient faire l'objet d'une telle appropriation. Il serait tout aussi erroné de croire que le premier s'intègre à la propriété privée et que le second demeure propriété collective. En effet, si un travail engendre des « dons gratuits de la nature », s'il est foncièrement social, il reste néanmoins peu susceptible de faire l'objet d'une appropriation. Ses créations appartiennent à l'espèce humaine dans son ensemble, se perpétuent à travers toutes les formations économico-sociales, et aucune société, à quelque moment que ce soit, n'a de raison ni d'intérêt à le compter parmi ses richesses, si ce n'est à titre transitoire.

97 Dans ce chapitre j'ai parlé de la société capitaliste ; les arguments peuvent être généralisés et le seront plus tard. 


\section{Chapitre III.}

\section{La succession des états de nature (I)}

\section{De l'état de nature}

\section{Retour à la Table des Matières}

L'idée de processus naturel et la forme sous laquelle je la propose invitent à abandonner l'image de la nature comme réceptacle inerte de planètes, de végétaux, d'animaux, ou comme assemblage ordonné de puissances et d'éléments. Il faut lui substituer une représentation qui mette en évidence les rapports des forces humaines et des forces nonhumaines. Ceux-ci se dégagent à travers l'action de reproduire et celle d'inventer. Mais le point de départ n'est pas le même dans les deux cas. Lorsqu'on désire reproduire un travail ou un objet, on part d'une masse initiale de muscles et de nerfs à laquelle on adjoint des moyens de reproduction. Le résultat en est tout l'éventail des talents propres à maintenir le contact avec le milieu, à produire ce qui est indispensable à la vie physique et intellectuelle. Dans l'invention, par contre, ces moyens de reproduction font office de matériaux bruts auxquels s'appliquent une habileté, une connaissance distinctes. L'ingénieur ou le scientifique, armés de leurs méthodes, se penchent sur l'information, la dextérité détenues par l'agriculteur ou l'artisan, par un autre ingénieur ou un autre scientifique. Le savoir de chacun reçoit une signification nouvelle ${ }^{98}$. Il ne traduit pas seulement l'efficacité d'une technique, d'une structure organique, ou encore la conformation d'un être humain. Il symbolise avant tout une puissance matérielle. 
L'attitude à l'égard d'un individu de notre espèce se confond avec l'attitude envers une entité objective quelconque. Le transport des fardeaux ne retient pas l'attention du mécanicien parce qu'il déforme le corps ou rétrécit l'intelligence, mais parce qu'il concrétise un déplacement du centre de gravité, une dépense d'énergie. De la sorte, on peut le rapprocher de la classe des déplacements ou des dépenses d'énergie, en général, et comparer les effets obtenus. Les mouvements que fait l'homme pour s'élever sur un plan incliné, les gestes effectués pour opérer par l'intermédiaire d'un outil, sont observés comme par transparence : les vitesses et les forces mécaniques s'y profilent exclusivement, en relief. Réunir et superposer une habileté à des moyens de reproduction, déchiffrer ceux-ci à la lumière de celle-là et lui fournir une contre-partie physique, c'est proprement inventer. Telle est la raison pour laquelle on fait dépendre l'invention de l'« état des arts industriels ». On y aperçoit la condition d'une découverte par le moyen d'une action sur ce qui est susceptible d'être reproduit.

Ces quelques exemples suffisent à montrer que les savoirs, les connaissances - ainsi que les substances et les énergies qui les accompagnent - constituent ce qu'il convient de nommer des ressources matérielles ou inventives. Ce sont, bien entendu, les ressources d'un groupe humain, déterminées par ses talents, lesquels, en s'exerçant, tendent à les développer ou à les changer en ressources nouvelles - et, parallèlement, en travail nouveau. Reproduit, ce travail facilite la consommation des énergies biologiques, leur intégration dans un circuit matériel inédit. Par la même occasion, des facultés sont éliminées, rendues désuètes. Au cours de l'invention, l'état de nature apparaît sous l'angle des ressources matérielles - et inventives - c'est-à-dire comme une relation entre les régularités du monde physique et celles qui relèvent proprement des facultés de l'homme.

Le processus reproductif éclaire différemment cet état. Là, un premier facteur du travail, sa force organique, fait fonction d'objet, tandis qu'un deuxième facteur, la connaissance, la dextérité, est le sujet qui lui impose une direction déterminée. Préparer, conserver, élargir leur réunion, compte tenu des exigences collectives et de l'environnement, est une tâche permanente. Ainsi se consolide et s'élargit le rapport de l'espèce à son pôle matériel. Cependant, à l'arrière-plan du processus 
reproductif, intervient entre les hommes une différenciation en fonction des talents et des ressources. On a observé que les capacités d'une fraction de l'humanité servaient de moyens à une autre fraction. J'ai déjà mentionné l'exemple de l'artisan qui, en reprenant dans son atelier des productions qui avaient occupé l'agriculteur - tissage, tressage, etc. - établissait avec ce dernier une relation distincte de celle qui l'associe à l'ingénieur, lequel transfère à une machine les dextérités accumulées par l'art. Le monde objectif sous-jacent est, d'une part, celui du corps humain avec ses sens, ses muscles, sa fine coordination de gestes manuels appliqués à la résistance de la terre, à la posture d'un animal ; c'est, d'autre part, l'articulation avec les phénomènes mécaniques, gravité ou percussion, qui prédomine. La conversion de ces contenus matériels, de ces échanges, suscite une formation et une répartition des habiletés adaptées à chaque partenaire. En l'occurrence, l'ordre naturel est la trame dans laquelle ils sont placés, le système d'interactions déterminées par les facultés respectives, bref, un ordre inter-humain.

La correspondance des ressources inventives ou matérielles et du système de reproduction définit, pour l'homme, son état naturel. Les formes techniques prises par l'activité productive et les organismes pédagogiques particuliers complètent ce modèle d'une association des pouvoirs humains et non-humains.

Ce n'est là pour l'instant qu'une affirmation, qu'il s'agit d'étayer par une description, encore intuitive. Seulement, il faut bien voir ce que cette description présuppose : la société, la nature nous sont inaccessibles. Nous vivons, nous approchons, nous comprenons des sociétés, des natures. En regardant l'enchaînement réel des événements, des phénomènes, n'est-on pas en droit de reconnaître qu'il existe différentes natures et que ce que nous appelons la nature désigne leur devenir et leur totalité ? J'exposerai ici les caractères principaux des états de nature qu'on peut appeler organique, mécanique et cybernétique. 


\section{Le travail artistique et la substance}

$\underline{\text { Retour à la Table des Matières }}$

\section{L'identité de l'homme et de l'habileté.}

Pour décrire le premier de ces états, la nature organique, il faut partir du travail, car il en est à la fois l'élément le plus synthétique et le plus actif. Il apparaît d'emblée avec des exigences multiples, irréductibles. C'est un mouvement organisé ayant un sens autonome et au développement duquel l'individu doit se consacrer consciemment, méthodiquement. Sens et développement transcendent l'individu; ils visent des buts stables et indépendants de la conduite arbitraire de celui qui les incarne. Toutefois ils ne sont pas, ils ne peuvent pas être suffisamment objectivés dans des théories transparentes, conservés fidèlement dans des livres ou des théorèmes : par quelque biais, le savoir s'échappe. Les hommes sont encore sa meilleure mémoire, leurs gestes son meilleur langage. Sa présence ne s'identifie pas à leur comportement: elle le conditionne. Le travail est cependant dans l'homme : une fois attribué à Pierre ou Paul, Pierre ou Paul en font leur être et s'y expriment, comme si, depuis toujours, ce travail avait été leur travail, comme s'il avait commencé avec eux. La sculpture, la poterie, le tissage ne sont pas saisis en dehors du sculpteur, du potier ou du tisserand. Le travail se situe ainsi au centre des moyens d'action de l'homme, et la réalité objective est potentiellement en lui. Pour l'artisan, travailler se définit par ce qu'il sait faire autant que par ce qu'il fait effectivement. Donc tout ce qui est extérieur - objet, outil est, à vrai dire, extériorisation de ce qui est déjà acquis intérieurement et antérieurement, en tant qu'habileté, dans le corps, la main, le cerveau du travailleur. Le subjectif et l'objectif coïncident, comme le travail et le travailleur. Ce qui est produit ne peut être pensé qu'en fonction directe de la dextérité, de la compétence d'une classe d'hommes, de sa réalisation humaine. «La perfection de l'œuvre est toujours en raison de la perfection des ouvriers » enseigne Aristote. La main est le symbole suprême de leur spécialisation. La droite est nerveuse, active, virile, la gauche paisible, tonique, marquante. L'une soutient le mouvement de l'autre et s'y adapte. La finesse des accords, la souplesse 
des doigts, le relief des muscles, les craquelures de la peau ou son grain expriment l'outil adjoint, l'œuvre accomplie. Le corps en est déformé, plaqué à sa tâche, incliné, tordu. Tout part de la main et y retourne.

«La main, écrit Aristote dans ses Questions mécaniques, n'est pas un instrument unique : elle est plusieurs instruments à la fois. Elle est, pourrait-on dire, un instrument qui remplace tous les instruments ».

L'apparition des arts signifie donc l'organisation minutieuse des activités annexes qui fixent, déterminent et renforcent la capacité biologique. A cette dernière, c'est-à-dire à l'homme pris en tant qu'être physique, s'ajoute une faculté spécifique, nettement individualisée, qui dirige ses postures et ses gestes et commande ses productions: l'habileté. L'amélioration quantitative et qualitative des pratiques habiles repose sur l'exercice, sur une élaboration lente de leurs parties, correspondant à une plus grande finesse du geste, une plus grande acuité du regard. Les traditions les perpétuent. Chaque région, chaque ville les cultive, de manière à ce que l'univers sache que les tissus de Millet, les poteries de Corinthe sont les plus beaux et les plus parfaits, car les tisseurs de Millet, les potiers de Corinthe savent le mieux travailler la laine ou l'argile. Ce qui distingue un artisanat d'un autre, c'est bien le degré de connaissance, et non pas son industrie proprement physique, ainsi qu'il en allait presque toujours pour l'agriculture :

« La terre, écrivait Xénophane, permet de bien discerner ceux qui ne valent rien. Les paresseux, en effet, ne peuvent pas, comme dans les autres arts, prétexter qu'ils ne connaissent rien ».

La connaissance imprimée dans la main et le corps, l'habileté, s'exprime par et dans les objets. Elle les contient en quelque sorte leur forme immatérielle y est inscrite. Le modèle n'est ni dans l'outil, ni dans l'énergie utile; il est vivant dans l'opération du corps, des bras, des sens, cristallisé dans l'ensemble des ouvrages déjà accomplis. L'objet œuvré est la réalisation, au sens strict, du savoir-faire, donc son équivalent; l'habileté est ce qui s'ajoute à la matière en vue de cette fin. 
Pour l'art, les ressources matérielles sont des données, des matériaux — des matières premières (bois, pierre, laine, argile) auxquelles s'applique la dextérité des hommes qui leur imposent, en leur donnant une forme ou en modifiant leur forme, le statut d'objet : taille de la pierre, coupe du bois, modelage de l'argile.

« Dans les produits de nos arts, constate Giordano Bruno ${ }^{99}$, quand du bois est faite la statue, nous ne disons pas qu'au bois s'ajoute un être nouveau, car il reste bois ni plus ni moins qu'auparavant ; ce qui reçoit l'être, ce qui devient actuel, c'est le nouvel objet produit, c'est le composé, c'est la statue ».

Jusqu'à un certain point, ces matériaux sont accessoires eu égard au talent, au contenu du travail, et en dernière analyse ils n'ont de réalité qu'en tant qu'ils fournissent à l'objet un support, une consistance. L'artisan entre en contact avec eux en s'attachant à leurs propriétés au regard des sens et des outils. Dureté, friabilité, mollesse, couleur, tolérance au chaud ou au froid, à l'humide ou au sec, sont quelques-uns des critères selon lesquels on les juge. L'artisan peut les soupeser, les choisir en vue de ses fins, les soumettre à quelque préparation; il ne les modifie pas radicalement. Son univers est celui où l'on façonne les matériaux, où tout converge dans l'objet et y reçoit une forme. Cependant « on peut considérer que la matière impose sa propre forme à la forme $»{ }^{100}$. Le travail suit les indications, les dessins de la matière elle-même, triomphe de ses accidents et en prend avantage. Les instruments sont des intermédiaires indispensables mais non pour autant indépendants de la dextérité et de la force de celui qui les manie ${ }^{101}$. D'aucune manière ils ne constituent un but en euxmêmes ; ils prolongent l'habileté de l'individu, ils en font partie. Aristote l'a clairement aperçu: "Pour cela nous appelons la partie de l'habileté qui remédie à cette difficulté un procédé (instrument) ».

101

G. BRuno : Della causa, principio ed uno, ed. Gottinga, 1888, IV, p. 244.

H. FOCILLON : La vie des formes, Paris, 1964, p. 51.

«Les diverses technés constituaient dans la pensée de Protagoras de véritables fonctions caractéristiques de l'espèce humaine comme les moyens d'attaque, de fuite ou de défense sont les fonctions caractéristiques des espèces animales. Elles sont, bien que capables de culture, notre nature même ». A. ESPINAS : Les origines de la technologie, Paris,1897, p. 200. 
Les outils de l'art se rangent parmi les accessoires du travail et non pas dans le règne des ressources matérielles non-humaines. Ces ressources sont des données extérieures, relativement indépendantes: leur rôle purement passif est de recevoir une configuration qui les anime et les rend usuelles. Thomas d'Aquin élève au rang de théorie cet aspect des possibilités d'œuvrer de son temps : "Le véritable sujet de l'existence est le composé de matière et de forme », réunion de la matière première et de la capacité de transformer celle-ci en objet. Le monde des objets, qui n'existent évidemment pas sans l'intervention visible du savoir-faire humain, est aussi celui de la matière seconde. Par cette mutation, l'ouvrier rend le réel ostensible; la relation que nous voyons se dessiner informe en même temps chacun de ses termes :

- Le travail se définit comme travail artistique entièrement centré sur l'habileté, sur la modulation des dispositions biologiques à se mouvoir, à adopter une posture, à combiner des gestes et à spécialiser les organes en vue de réaliser certains modèles des choses indispensables à la vie et à la jouissance ;

- La matière lui fait face en tant que substance ou matière première, c'est-à-dire comme un élément dont seules les qualités immédiates sont pertinentes pour le travail.

La réunion du travail artistique et de la matière envisagée en tant que substance façonne les contours de la nature organique.

\section{Retour à la Table des Matières}

\section{La nature organique.}

Les prémisses de cet état naturel apparaissent à la fin de l'époque néolithique. L'art et la philosophie des Grecs reflètent son épanouissement. A la Renaissance, ses bases objectives sont renversées, et un nouvel état commence à se substituer à l'ancien. 
Les ressources matérielles (inventives) de la nature organique sont déterminées par la reproduction et l'invention du travail artistique. A ce propos, il convient de signaler le caractère systématique de la reproduction, qui est découverte en tant que processus autonome. Avant l'apparition des arts, le transfert des habiletés n'était pas un acte distinct du transfert des multiples connaissances et des réflexes que réclame la vie en société ${ }^{102}$. Après cette apparition, l'habileté devient l'objet d'une attention particulière, un champ d'investissement d'énergies intellectuelles et physiques. Reproduire un savoir constitue une activité dont la place distincte est reconnue. La perception des gestes, le dialogue, l'aphorisme, les recettes, la critique des accidents, le cumul des expériences sensorielles sont les voies d'accès aux secrets de l'art. Secrets de l'inexprimable et de l'inexprimé, interdits d'expression, apanage de ceux qui sont initiés. La reproduction est distincte de la production ; c'est seulement au terme de cette préparation que l'on travaille, à proprement parler. Les facultés sont censées mûrir, inconsciemment, au contact de la matière, en s'appropriant intimement les détails de la technique.

L'enrichissement du talent est, en un sens, accidentel. Une importante fraction de ce qui est gagné par l'exercice répété du métier se perd : le génie de l'individu se concentre sur l'objet plus que sur les autres aspects de son travail. Les effets cumulatifs sont lents à se faire sentir. Dans le travail artistique, quelle que soit l'excellence de l'œuvre, la reproduction a le pas sur l'invention, celle-ci ne modifiant celle-là que de manière insensible. En quelque sorte, l'acte inventif intervient surtout à l'origine, à la naissance d'un art ou d'une manière de faire. Il possède un caractère cyclique et se manifeste à l'occasion de la réorganisation, par division, des habiletés. Instinctivement, si l'on peut dire, l'ensemble se réordonne dans chaque art, provoquant les réajustements nécessaires. L'invention est obligatoirement subordonnée à la stabilité, à la structure de l'ensemble, qu'elle élargit plus qu'elle ne la bouleverse.

V.G. Childe remarque avec raison que la reproduction du travail, avant l'époque qui nous préoccupe, ne constitue pas un processus vraiment autonome : « En fait, chaque enfant apprend, même si c'est seulement par l'imitation et le jeu, les techniques simples essentielles pour faire du feu, chasser, jardiner, construire ou fabriquer à la main, de même qu'il apprend à parler, à marcher, à nager ou à se laver ». Science in the preliterate societies and the ancient oriental civilisations, Centaurus, 1953, 3, p. 16. 
L'organe de reproduction primordial est l'outil. Celui-ci a cessé d'être l'artefact qui s'associe aux ruses de la chasse ou s'inscrit parmi les accessoires de la culture du sol. Son indépendance, sa spécificité sont absolues. Mais il joue essentiellement le rôle d'instrument pour «l'instrument des instruments », la main ${ }^{103}$. L'éclosion du travail artistique développe la potentialité de l'outil, le marque et lui confère toute son importance. La découverte première de l'espèce atteint, en l'occurrence, son apothéose. Avec l'outil, l'homme ne se hausse pas seulement au rang de force spécifique : il prend conscience de ce rang. Ce qui est conçu comme instrument ${ }^{104}$, dans sa partie inanimée, nonorganique, est ce qui prolonge, renforce, intègre les organes de l'homme à une unité et les fait apparaître sous une forme extérieure, objective, comme les résultats de sa volonté et de son action. Les outils l'aident à agir sur le réel là où il ne pourrait intervenir (pince pour saisir le fer chauffé au rouge), lui permettent de mieux coordonner ses gestes (le tour du potier met à contribution, de concert, la main et le pied), amplifient l'effort musculaire et en accroissent l'efficacité (poulie, levier). Néanmoins, quelles que soient les différences, ces auxiliaires sont adaptés au corps humain : modelé consciemment, soigneusement, celui-ci est une œuvre, l'œuvre principale des arts. Sans conteste, le corps reçoit une grande attention, d'une part parce qu'il donne vie à l'outil, en lui prêtant sa force, d'autre part parce qu'il lui sert d'archétype et est à l'origine de sa structure comme de sa fonction. Cette conception s'affirme nettement dans l'écrit hippocratique Du régime :

«Ils (les hommes) ne savent pas que dans la nature humaine se trouve le modèle des arts qu'ils exercent $»$.

Les outils sont ainsi des parties dépendantes, des formes passives dont le contenu vivant réside dans l'appareil neuro-musculaire activé

103 Pappus, dans ses Collections mathématiques appelle l'art instrumental organiké.

104 «Quant aux anciens, du moins à l'époque que nous considérons, ils ne faisaient pas de distinction entre les deux concepts de corps animé et de machine. On se servit pendant tout le $\mathrm{VI}^{\mathrm{e}}$ siècle du mot organon pour désigner les pièces d'un mécanisme ou d'une machine ". A. ESPINAS : L'organisation de la machine vivante, Revue de Métaphysique et de morale, 1903, p. 707. 
et dans l'habileté qui est leur cœur, leur raison d'être. L'ouvrier-artiste représente la sensibilité, la pensée, le microcosme du champ instrumental, tout comme il incarne la pensée, et la sensibilité des œuvres auxquelles il sert de moteur premier, qui ne sont que par lui, et qu'il contient comme un macrocosme. Si quelque technique lui fait défaut, si ses matériaux sont défaillants, ce ne sont point les instruments ou les opérations qui seront examinés, perfectionnés, mais directement les facultés de l'homme. A propos de la progression des techniques au Moyen-Age, Bernard Gille note :

«C'est encore moins l'outil et la technique qu'on cherche à perfectionner que le tour de main ou le mélange savamment dosé pour la teinture. Le progrès est encore inhérent à l'homme et non pas à ses auxiliaires inanimés que sont l'outil et la machine. Même au $\mathrm{XV}^{\mathrm{e}}$ siècle, on cherche davantage à former des bons pilotes que de bons constructeurs de navires ${ }^{\mathbf{1 0 5}}$.

L'homme est donc au centre de tout, à la fois comme le premier sujet et le plus parfait, mais aussi paradoxalement comme le plus admirable des objets. Les organes de reproduction de son travail restent des expressions de ses organes biologiques. Sa force de travail - muscles, nerfs, mouvements - apparait matérialisée dans ses outils, tandis que son habileté demeure en lui à titre d'idée, de puissance, de structure. Le contact prolongé avec les matériaux enrichit sa sensitivité, son horizon est élargi par la gamme des aides inanimés qu'il se donne pour manipuler les choses; accroissant le domaine d'action du corps, ces moyens de reproduction sont organiques.

La description que je viens d'en donner fait voir que ces moyens - savoir-faire et organes de reproduction - s'intègrent aux ressources matérielles de manière particulière. La matière est dans le travail en tant que matrice, substance de l'art préfiguré en elle. Les éléments physiques et l'homme se rencontrent en un rapport qui fait de ce dernier l'acteur privilégié, la figure centrale dont l'univers objectif est le répondant exact puisqu'elle y est contenue comme unité et partie : d'Histoire mondiale, 1956, III, p. 95. 
« La conception grecque de la nature en tant qu'organisme intelligent était basée sur une analogie : analogie entre le monde de la nature et l'être humain individuel $\gg{ }^{106}$.

S'il est moule ou paradigme, l'être humain est aussi dépositaire de tout mouvement, de toute causalité, de l'activité constructive sans laquelle on ne saurait concevoir un ordre des éléments matériels; il fournit le principe d'organisation et la forme. Le monde réel est un monde d'intentions, de causes finales. Aristote observe dans le projet de l'artiste la source des causes, des fins ordonnatrices de toute opération concrète.

Cet univers, cette nature sont stables : l'auto-création de l'homme sous l'espèce du travail artistique l'est également, tout comme les ressources inventives dont le relatif équilibre n'ajoute pas constamment des forces nouvelles à celles qui existent déjà. Toutefois l'état de cette nature n'est pas l'inertie, puisque toute matière contient quelque vie, quelque souffle ou quelque potentialité, ne serait-ce que ceux que lui donne l'art ${ }^{107}$; ainsi la nature parcourt des cycles et subit une évolution qui n'est pas sans analogie avec l'évolution propre à sa puissance matérielle principale, l'homme. En effet, le développement de la nature, des êtres qu'elle contient, n'est pas désordonné, soumis à l'intervention constante de forces inconnues: il tend vers un ordre qu'elle vise parce qu'elle le contient déjà. Les relations qu'on y observe sont souvent qualitatives, intentionnelles, puisque l'observateur humain approche les phénomènes matériels de façon directe et, pour ainsi dire, clinique. Non qu'il ne cherche à connaître des quantités ; toutefois il ne les atteint pas, puisqu'il lui faudrait aborder le monde à travers des médiateurs détachés de lui-même, alors que ses instruments ne sont que ses copies, ses prolongements. Ce faisant, il cesserait d'être ce qu'il est, une force de ce monde semblable aux autres.

Dans cet ordre naturel organique, rien ne demeure hors du contact avec l'homme, et tout, d'une certaine façon, en relève. Il n'y a donc

\footnotetext{
106 R.G. Collingwood : The Idea of Nature, Oxford, 1945, p. 8.

107 «La physique (d'Aristote) aurait pour forme fondamentale l'idée d'une nature apparentée à l'âme et à la divinité, d'une nature qui est à la lettre d'un démiurge et un bon démiurge » L. BRUNSCHWICG : L'expérience humaine et la causalité physique, Paris, 1949, p. 143.
} 
aucune discontinuité radicale entre celui-ci et les substances auxquelles il confie une forme, en leur imprimant le sceau de son savoir. Si l'artisan se retirait, outils et matières premières, dépouillés de son art, retomberaient dans l'indifférenciation. A l'instar de ceux-ci, dépourvu de son agent humain, l'univers rejoindrait le chaos. Pour le garantir contre ce risque, pour le mouvoir, le soutenir et l'expliquer, une intelligence et un élément artistes — feu, eau ou air — sont indéfectiblement présents.

$\underline{\text { Retour à la Table des Matières }}$ 


\section{L'univers des forces et des mouvements}

$\underline{\text { Retour à la Table des Matières }}$

\section{Le règne de l'instrument et de la force.}

L'unité de la nature organique a été ébranlée par la métamorphose de la matière et du travail. L'évolution de nouvelles ressources a été conditionnée par un élément décisif, le fait que la matière puisse acquérir le caractère de travail humain et réciproquement. Si la dextérité des hommes peut devenir dextérité de n'importe quel pouvoir mécanique, la solidarité intime qui relie le substrat biologique de l'espèce à sa matrice habile s'estompe. Chaque terme acquiert une autonomie relative qui facilite sa modification, son remplacement. On suppose donc qu'une pratique productive peut se substituer à une autre, pourvu qu'elle entraîne des résultats au moins équivalents. Tout d'abord du point de vue des effets moteurs : les hommes, les animaux, les chutes d'eau ou l'expansion de la vapeur d'eau deviennent à cet égard interchangeables ; les distinctions qui existaient auparavant entre eux disparaissent. Ensuite la combinaison d'une habileté et d'une force de travail a toujours cours, mais elle est guidée par des attributs quantitatifs, des critères mesurables. Pour établir ces équivalences et fixer ces critères, il faut rendre le travail à la fois mesurable et indépendant des perturbations provenant de la diversité des dons individuels, de leur mutabilité purement psychique ou physiologique. On le sépare ainsi de toute incidence particulière pour le regarder dans sa généralité comme dépense de temps, d'énergie, etc. En résumé, le travail se définit comme un objet, ayant des propriétés quantitatives clairement déterminées, et dont la réalisation est pour ainsi dire extérieure au sujet qui l'accomplit.

On connaît les conséquences de cet état de choses. Saisi objectivement, le travail est traité en tant qu'instrument et moyen, et non plus en tant que partie, soit de l'activité de l'homme qui le possède dans 
son corps ou son cerveau, soit de la configuration du produit auquel il aboutit $^{108}$.

La seule hétérogénéité que l'on apprécie entre les travaux et qui décide de leur opportunité, donc de leur valeur, est celle qui provient de leur efficacité :

«Qu'un homme porte un fardeau, écrit Cournot ${ }^{109}$, sans bouger de place, ou en cheminant le long d'une route de niveau: il ne travaillera pas, dans le sens de la définition technique qui vient d'être donnée ; tandis qu'il travaillerait si la route devenait montante ou s'il s'attelait à un brancard pour trainer le même fardeau le long d'une route de niveau ».

Dans ce contexte, le travail peut être manipulé en fonction de règles géométriques et de lois mécaniques. On peut l'accroître, l'accélérer, le diviser, lui imposer n'importe quelle contrainte. Rien dans le monde des puissances matérielles ne lui est étranger. Bien plus, tout ce que l'homme essaie d'accomplir intellectuellement, manuellement, se traduit en travail. Celui-ci peut être transformé, étendu, transféré, changé en attribut de n'importe quel individu - quel que soit son âge ou son sexe — et de n'importe quel élément physique.

«Le concept de travail n'a été manifestement reporté sur les machines qu'en comparant leurs dispositifs mécaniques à ceux des hommes et des animaux qu'elles étaient destinées à remplacer » ${ }^{110}$.

Le fait de qualifier le travail d'instrumental ressort des conditions dans lesquelles il se développe et de son but essentiel. Celui-ci est, d'une part, de s'attacher à un instrument machinal, dont les effets peuvent s'exercer de manière relativement indépendante.

D'autre part, cet instrument est la visée de l'effort créateur du mécanicien, de l'ingénieur. Il a également pour mission de structurer, d'organiser le savoir-faire. Bien plus, une habileté est dépourvue de 
valeur si elle n'est pas conçue autour de quelque instrument mécanique, mathématique - horloge, pompe, lunette - qu'elle concourt à parachever. Loin d'être pris en considération, l'objet en tant que tel table, chaise, tissu, etc. — reste secondaire. Le moyen de parvenir à sa construction, la conjugaison des énergies, des vitesses et des résistances qui y sont à l'œuvre, reçoivent une attention exclusive.

Face au travail instrumental, la matière apparait tout d'abord en tant que force. Sa structure est celle d'un ensemble de corps homogènes, doué de mouvement et source de mouvement :

«Cette nature en général écrit Boyle à propos de la nature mécanique ${ }^{111}$, est le résultat de la matière universelle ou la substance corporelle de l'univers, considérée telle qu'elle est disposée dans la structure et la constitution présente du monde, par laquelle tous les corps qui la composent sont rendus capables d'agir les uns sur les autres et aptes à souffrir les uns par les autres, selon les lois fixées du mouvement ».

C'est dans l'arrangement des corps en vue d'une certaine action ou de la transmission du mouvement que l'on décèle la présence des principes matériels. La production de certains effets (choc, accélération, pression) mène à l'établissement de lois précises de l'activité objective. La connaissance de ces lois donne la possibilité de transformer le mouvement - de changer par exemple le mouvement rectiligne en mouvement circulaire, la rotation en impulsion, etc. Les corps euxmêmes se définissent moins par leurs qualités que par la force qu'ils manifestent ${ }^{112}$. Élastiques ou rigides, à l'état liquide ou solide, ils n'interviennent que par ces propriétés et se distinguent uniquement par des indices dynamiques. Directement ou non, le principe du travail mécanique commande la manière dont sont formulées les lois auxquelles obéissent les éléments physiques. La matière apparaît ainsi en tant que source d'énergie, et on cherche à la transformer sous cet angle. Son caractère de substance, de matière première, s'évanouit.

\footnotetext{
111 R. BOYLE : An inquiry into the received notion of nature, Londres, 1738, p. 372.

112 «Dans les sciences physiques, la matière apparaît invariablement comme une puissance, ou une force, ou un agent, ou comme subissant l'action d'une puissance, d'une force ou d'un agent ». P.E. DovE : The theory of human progression, Londres, 1850, p. 513.
} 
Comme force, elle apparaît douée de quelques propriétés remarquables :

- Elle semble pouvoir exercer indéfiniment, dans certaines conditions idéales, une action déterminée. Si le mouvement d'une horloge était bien agencé, si aucun frottement ou échauffement ne se manifestait, une force fournie initialement pourrait l'entretenir en état de marche permanente. Ce qui est nécessaire, ce n'est pas un premier moteur mais une première chiquenaude.

- Son économie est impérieuse et soumise à des règles rigoureuses. Ainsi une machine, celle du monde comme celle de l'homme, ne peut se mouvoir sans consommer de l'énergie, sans qu'il y ait des variations d'accélération, des écarts de température, etc. Tous ces phénomènes peuvent être représentés par des paramètres spécifiques, mais ils se manifestent pour toute matière du moment qu'elle apparaît comme force et comme source énergétique.

Il en découle deux conséquences dont nous reconnaîtrons l'importance par la suite. La première est liée à l'effacement de la distinction qualitative entre les structures matérielles : celles-ci sont désormais saisies avant tout dans le cadre d'une production du mouvement où la différence est marquée par une variation dimensionnelle. La seconde a trait à la possibilité de perfectionnement continuel d'un modèle, d'un agencement donné, sans que lui-même soit modifié. Les forces matérielles se dessinent, pour leur part, comme des éléments interchangeables dans la perspective énergétique et leur ordre une fois donné peut se révéler progressivement sans être perturbé de façon fondamentale.

\section{$\underline{\text { Retour à la Table des Matières }}$}

2. La mécanisation du monde. ${ }^{113}$ 
Le travail instrumental et la matière en tant que force sont les nouveaux termes du rapport naturel. Le premier est apte à prendre des formes multiples, la seconde est elle-même source de travail, capacité de faire un travail défini. Au regard de la nature organique, la révolution est profonde. Depuis le XVI ${ }^{\mathrm{e}}$ siècle jusqu'à nos jours nous n'avons cessé d'en ressentir les effets.

Dans les arts, la matière comptait dans la mesure où elle pouvait devenir objet, et le travail se détachait du reste des activités humaines par ses potentialités productives accordées à la dextérité, à la force musculaire et au goût de l'individu. Il était propre à l'homme. Dans la nature mécanique, le travail devient l'attribut de n'importe quelle force matérielle, animée ou inanimée, et chacune de ces forces est reconnue en grande partie sous l'angle du travail.

Dans la nature organique, c'est aux organes physiologiques, la main surtout, et à l'énergie biologique que se rattachaient les organes de reproduction, qui se trouvaient renforcés, multipliés, affinés de la sorte. Dans le travail instrumental, force de travail et habileté se séparent nettement. L'énergie neuro-musculaire de l'individu est envisagée en tant que dépense de puissance motrice qui peut être complétée puis supplantée par d'autres puissances. Le mouvement passe de l'organique à l'inorganique, et celui-ci vient occuper la première place.

Les organes de reproduction non seulement accroissent mais modifient la sensibilité. Le télescope ou le microscope améliorent la vision, ils l'assurent aussi dans des conditions nouvelles. La perception se double d'estimations et de calculs ${ }^{114}$ : l'œil voit géométriquement. Le fonctionnement des mécanismes, de l'horloge au tour universel, crée des sens nouveaux, par exemple celui de la mesure, du jugement quantitatif, inhérents aux gestes et à la posture. La sensibilité se dégage de l'expérience immédiate et cesse d'être flair, coup d'œil, toucher. La construction des appareils suivant les lois propres au mouvement et à la force contribue à aiguiser certaines facultés biologiques mais en laisse dépérir d'autres. Par conséquent, les organes de repro- 
duction engagent les possibilités des sens et de la réflexion sur une voie nouvelle. Ce sont désormais les qualités premières - mouvement, volume, étendue - qui sont saisies, au détriment des qualités secondes - couleur, forme, etc.

Une autre évolution est également décisive. Non seulement l'énergie biologique - comme c'était déjà le cas pour les ressources organiques mais avec des caractères qualitativement différents - peut apparaître en tant que matière, mais il en va désormais de même de l'habileté. Pourvu que l'on réalise la configuration cinématique nécessaire, un mécanisme peut soutenir la comparaison avec les doigts du tisserand le plus habile, avec le savoir longuement mûri du forgeron. Le travail et la matière sont, partout, totalement unis dans une relation d'équivalence quantitative et qualitative, à tel point que tout ce qui est « humain » peut désormais apparaitre comme ensemble non-humain.

Ainsi l'homme cesse d'être la matière première du travail, le modèle de l'art et le principe matériel dominant. Les rapports qu'il entretient avec la matière deviennent des rapports entre forces matérielles mécaniques, saisies sous l'angle du travail, réductibles les unes aux autres et ne représentant que des étapes d'un dévoilement général. Au terme de ce dévoilement, tout doit être volume, étendue, mouvement, force. Le mouvement de l'être vivant est un schéma du déplacement de son centre de gravité, le squelette un système de poids et de leviers.

Le monde façonné de la sorte aspire à l'identité, le divers tend à se réduire à l'unique, par multiplication de celui-ci en autant d'exemplaires que l'on désire. Les organes humains tout les premiers prolifèrent en tant qu'éléments des forces matérielles qui les copient, les remplacent, les modifient et les intègrent pour les changer en composantes passives d'une chaîne de corps solides. Le mouvement de va-et-vient, le télescope, les automates reproduisent l'œil, le pied, la main qui figurent, à titre de parties quelconques, dans les organes machinaux de reproduction. Le renversement est saisissant : l'organe de reproduction est à présent le dépositaire de l'habileté et de la force de travail dont il permet l'exercice, tandis que la sensibilité humaine ne joue plus dans ces organes que le rôle d'un facteur quelconque. 
Les conditions dans lesquelles s'élaborent les nouvelles habiletés changent elles aussi. Ces dernières ne dépendent plus d'un exercice direct, d'une lente adaptation du savoir-faire à l'objet, ni même de la division des travaux - bien que toutes ces circonstances demeurent - mais de l'ensemble des organes de reproduction (machines, instruments) et de ce qu'ils reproduisent. Ainsi une habileté nouvelle amplifie une dextérité existante en la fixant à un automatisme ou à une opération matérielle. Le savoir-faire du meunier devient celui du mécanicien à partir du moment où le moulin est actionné par un moteur inanimé et un mécanisme de transmission. L'organe de reproduction mécanique assimile la force de travail et l'habileté. Il est l'aboutissement d'une mutation qui transforme la dextérité et absorbe le travail de l'artisan ${ }^{115}$. La faculté de celui-ci devient mécanique dans un double sens : elle se cristallise dans des mécanismes nonhumains, et toutes ses opérations sont conçues en fonction de forces mécaniques. Grâce à cette médiation, ces forces sont injectées dans le mode d'œuvrer humain, ce dernier étant saisi à son tour comme celui de la matière. Avant de devenir élément de machine, dans l'industrie ou dans l'univers, l'homme est lui-même regardé comme un mécanisme :

« De même que le macrocosme est un automaton, de même le microcosme (l'homme) est une sorte de machine qui se déplace seule, qui accomplit ses différents mouvements au moyen de certains ressorts et de certaines roues $\gg{ }^{116}$.

La reproduction de cette habileté mécanique est nécessairement marquée par un phénomène dont les conséquences ont été considérables : les opérations de l'énergie mécanique relaient celles de la main. Désormais la reproduction du travail dépend de la possibilité de le remplacer par le travail d'un mécanisme. Elle est donc déterminée par les oscillations des rapports entre les deux systèmes : celui des organismes humains pris collectivement et celui des mécanismes. La répartition de l'activité productive entre ces deux systèmes obéit à des

E. BuRET : De la misère des classes laborieuses, Paris, 1840, p. 152.

116 T. Powell : Human industry, or a history of most manual arts, Londres, 1661, p. 25. 
impératifs mesurables. L'idéal qui domine ces relations est celui de l'assimilation radicale de toute intervention humaine à l'ordre et à l'exécution des effets du mécanisme. La situation d'équilibre privilégiée est celle où tout le travail humain aura été reproduit sous l'espèce de la matière, l'un des systèmes prenant la relève de l'autre comme un instrument en relaie un autre.

La reproduction se dédouble et devient mouvante. Dans un certain contexte, elle garde un caractère relativement organique, mais son contenu et son centre de gravité changent. Le mécanicien, l'ingénieur, pendant très longtemps encore, se forment dans l'atelier ${ }^{117}$ au cours de la production, en ajoutant à ce savoir une information recueillie dans les écoles et dans les livres. Leur attention se porte beaucoup plus sur l'instrument et la machine que sur les autres éléments du processus d'action sur la matière. L'acquisition des facultés ne se cantonne plus dans la répétition mais devient plus active.

Le second aspect de la reproduction est la transmission du savoirfaire humain aux puissances mécaniques, et il est en liaison étroite avec le processus d'invention. Celui-ci est permanent et diffus. Partout où le travail est reproduit, transformé en agent matériel, il est indispensable d'établir de nouveaux rapports avec la manière d'inventer. Cette manifestation de la création du travail est dominée par l'habileté existante, par la reproduction ; son sens est déterminé d'avance. Très souvent, inventer, c'est substituer. Pour cette raison, l'invention est relativement discontinue, l'impulsion dynamique lui est extérieure, préfigurée par ce qui existe ${ }^{\mathbf{1 1 8}}$.

Le processus d'invention est donc conçu comme un processus fini, qui atteint dans son cours une limite pré-établie, une fois que sa fonction est assurée et l'idéal vers lequel il tend réalisé. Il en est ainsi quels que soient les éléments ou les dimensions auxquels il

117 F.H. NEWELl, C.E. BRAYER : Engineering as a career, New York, 1916.

118 "C'est ainsi qu'au XVIII ${ }^{\mathrm{e}}$ et au début du XIX ${ }^{\mathrm{e}}$ siècles se développe une technique fondée sur l'exploitation d'événements mécaniques. La machine ne fait souvent ici qu'imiter la main de l'homme. C'est pourquoi on a d'abord considéré cette forme de la technique comme le développement de l'ancien artisanat ». W. HEISENBERG : op.cit. p. 21. 
s'applique. Cependant, dans ce cadre, quelle liberté et quels moyens ! Le mécanicien ajuste des énergies incommensurables à celles de l'individu, combine des mouvements plus riches en possibilités que ceux du corps, incite son intelligence à affronter une substance qu'il doit constamment organiser et transformer. Si le monde où il opère ne livre pas au regard des lumières et des couleurs, ce monde est cependant tout entier structuré par des relations géométriques. Son génie inventif est là pour les dévoiler comme rapports inconscients de son intellect et règles d'action de ses mains, qui combinent ou guident les forces matérielles. Le résultat de l'inventivité est manifeste. Chaque tisseur, chaque graveur, chaque potier, revenant sur terre, pourrait se reconnaître dans son incarnation machinale associée à toutes les générations de tisseurs, de graveurs ou de potiers. Il renaîtrait à un autre monde, à une autre nature, qui, telle que les savants l'ont définie, peut être désignée du nom de mécanique.

Elle suit des lois clairement énoncées, ayant des paramètres quantitatifs et mesurables. Ces lois sont objectives, indépendantes de l'intervention de l'homme ${ }^{119}$, cette dernière étant réductible à l'action de n'importe quelle autre force matérielle. Comparée à la nature organique, cette nouvelle nature ${ }^{\mathbf{1 2 0}}$ ne connaît pas l'homme en tant que puissance unitaire, interne, agissant en vue d'une fin, qui se reflète dans l'ensemble de l'univers. L'homme opère en révélant les lois de son action dans celles des forces matérielles, en faisant abstraction de sa démarche propre, en s'identifiant à la force matérielle ${ }^{121}$ et en se plaçant hors de l'organisation intime de celle-ci. C'est bien ainsi qu'apparaît le travail humain. La partie de ce travail qui doit obligatoirement être transférée au mécanisme, et l'ordonnateur du mécanisme,

« Au XVIII ${ }^{\mathrm{e}}$ siècle, la nature semblait se dérouler selon des lois dans l'espace et le temps; en décrivant ce déroulement, on peut faire abstraction de l'homme et de son intervention, sinon de façon pratique, du moins en principe ». W. HEISENBERG : op. cit. p. 15.

« La nature n'est plus un organisme mais une machine : c'est-à-dire que ses changements et ses processus sont conduits et dirigés non par des causes finales mais seulement par des causes efficientes ». R.G. COLLINGWOOD : op. cit. p. 103 notre but présent, que je ne regarde pas un corps humain comme une montre ou un moulin à main, c'est-à-dire comme une machine composée uniquement de parties solides ou du moins consistantes, mais comme un engin hydraulique ou plutôt hydro-pneumatique, qui ne se compose pas seulement de parties solides et stables, mais de fluides qui se trouvent, eux, en mouvement organique ». R. BOYLE : op. cit. p. 409. 
sont nettement séparés. Si l'individu reste le modèle, c'est dans la mesure où le mouvement des corps, l'impulsion du choc et la variation de la gravité le reflètent. Les puissances matérielles humaines et nonhumaines s'assimilent les unes aux autres pour former une machine homogène et uniforme. Homogène d'abord : toute différence qualitative, toute hiérarchie de structure est bannie, car elle peut et doit être réduite à une différence de volume, de poids, d'étendue. Plus qu'une réalité, c'est un impératif catégorique. En vertu de l'uniformité des lois qui sont censées s'appliquer à tous les phénomènes de l'univers, chaque élément peut être envisagé séparément et révèle, sous un certain angle, la totalité. Celle-ci n'est en définitive, que la somme, par simple addition, d'éléments identiques dont chacun conserve les qualités de l'ensemble. Les parties de l'univers ne se distinguent que par la dimension, l'homme et la matière ne diffèrent que par le nombre de ressorts, d'engrenages, de leviers, et par les conséquences de leur agencement. Les transformations que l'on recherche ne sont en somme que des réarrangements qui entraînent une dépense mesurable d'énergie, dont il s'agit de réduire le coût au minimum, sous peine de perdre la force que l'on entend renouveler. L'ensemble est conservatif ${ }^{122}$, constant, les perturbations des facteurs doivent obligatoirement se compenser, la stabilité est générale. L'équilibre entre les forces matérielles est supposé réalisable partout. L'échange qui s'effectue entre l'homme et la machine est soumis à la même règle.

Les dimensions sont susceptibles de s'accroître indéfiniment; toutefois, si cette infinité admet des éléments de plus en plus nombreux, ou qui possèdent des masses ou des vitesses variées, la loi qui l'exprime et les relations qui l'appuient semblent invariantes dans le grand comme dans le petit. Le travail de la nature ${ }^{123}$, quel qu'il soit, se résout en force et en mouvement. Son universalité est conçue d'après la simplicité des effets qu'on en attend, déplacer, mouvoir plus vite, tracer une courbe, etc.

« Je ne vois pas non plus de raison suffisante à accorder que la nature elle-même (quoi qu'elle soit) produit aucun mouvement de novo, mais seulement qu'elle transfère et règle celui qui a été communiqué à la matière au commencement du monde ». R. BOYLE : op. cit. p. 417.

${ }^{123}$ «On peut dire que le concept de nature peut être saisi par le mot unique de travail». K. FROHME : op. cit. p. 10. 
Concurremment, la nature elle-même est limitée, finie ; ses limites se trouvent à notre portée. L'invention est censée tendre vers un point où la clarté de la machine universelle, une fois atteinte, la fera retomber dans la reproduction, la répétition et la mise en ordre formelle des mêmes données. Cette conviction d'immutabilité et de clôture des possibilités de ressources matérielles est corroborée par la modalité d'existence de la matière, saisie en tant que force et mouvement. La maîtrise du mécanisme ne peut que déboucher sur un état de perfectibilité de celui-ci; la force se déplace d'un corps à l'autre sans pour cela nous révéler des structures nouvelles ${ }^{124}$. Au delà de certaines limites, après avoir réalisé les principes naturels, ordonné le travail et épuisé ses formes, l'homme en se créant lui-même retrouvera la sphère immobile de Parménide.

$\mathrm{Si}$, dans la nature organique, l'homme se produit en reproduisant surtout ce qui a déjà été créé, dans la nature mécanique la totalité est censée être assimilée, rendue transparente, au terme d'une activité inventive continue et déterminée. Pour l'une, l'homme ne connaît du réel que ce qui est supposé possible ; pour l'autre, il n'aperçoit de possible que ce qui est déjà réel. Ni l'un ni l'autre de ces états naturels ne reconnaît à l'homme simultanément, pleinement, sa fonction génératrice de possibilités et sa capacité de créer la réalité naturelle. Seul le troisième état, la nature cybernétique, lui ouvre de tels horizons.

«Mais ce qui caractérise particulièrement cette période, c'est l'élaboration d'une vue d'ensemble originale dont l'idée de l'immutabilité absolue de la nature constitue le noyau. Quelle que soit la manière dont la nature a pu se constituer, son existence étant donnée, elle devait demeurer telle qu'elle était tant qu'elle existait. » F. ENGELs : Dialectique de la nature, ed. cit. p. 117. 


\section{Chapitre IV. \\ La succession des états de nature (II)}

\section{La nature cybernétique}

\section{$\underline{\text { Retour à la Table des Matières }}$}

\section{La matière finale.}

La nature que je propose de nommer cybernétique pourrait également être qualifiée de synthétique, s'il n'y avait là quelque scandale pour nos habitudes mentales.

Loin d'être donné une fois pour toutes, capté une fois pour toutes dans les rets de ses déterminismes et formé d'êtres que l'on isole par des contraintes successives, l'univers de la matière se découvre par sa fluidité, sa créativité incessante à laquelle nous sommes aptes à participer. Pour la première fois, sur une grande échelle, l'homme a entrepris de reproduire, de développer, d'engendrer des matériaux. Ce n'est pas sous leur forme première mais sous leur forme finale qu'ils s'incarnent dans des objets, qu'ils se présentent aux sens. La science chimique crée des matières nouvelles par voie de synthèse. On a généralement tendance à les nommer artificielles, sous prétexte qu'elles n'auraient pas d'équivalent dans la nature. Il s'agit en réalité de matières propres à notre nature, dues à notre combinaison avec le monde matériel, et qui sont absentes d'autres combinaisons ou d'autres organisations de matières, résultant, elles, d'ordres naturels différents. C'est donc bien là une étape de l'histoire de notre nature que cette 
production de matières qui lui sont propres, matières originales dont ni le nombre ni l'évolution ne sont actuellement prévisibles.

« Aujourd'hui nous avons commencé à 'créer' en quelque sorte, c'est-àdire à déclencher nous-mêmes des processus naturels, qui ne se seraient pas produits sans nous... » ${ }^{\mathbf{1 2 5}}$.

La prolifération de nouvelles substances, la saisie des modalités par lesquelles les qualités d'une matière peuvent être modifiées dans le sens désiré, transférées d'une substance à une autre, illustre cette aisance nouvelle dans les rapports de l'humanité à la matérialité. Les matières plastiques empruntent leurs propriétés les unes aux autres, elles épousent celles du métal, du verre ou du tissu, elles sont formées de manière à obéir à des exigences de température ou de solidité établies à l'avance. Le cycle de la synthèse ne se réfère plus au contraste de l'organique et de l'inorganique, au passage du premier au second; il a trait à l'ensemble des rapports internes de la matière, au mode humain qui les fait communiquer. En effet, si jusqu'à présent l'homme savait les façonner, - le bois devenant statue — ou les transformer - la vapeur se changeant en source de travail mécanique - désormais il sait les développer, c'est-à-dire transmettre à une matière les propriétés d'une autre, l'ordonner à nouveau et ouvrir la voie à des enchaînements inédits. La « chimisation » des procédés techniques exprime le caractère structural de notre intervention ${ }^{126}$. Aux méthodes d' " enlèvement » des matières, à la percussion, etc., se substituent des méthodes qui rendent les matériaux traités analogues aux fluides en recourant à la décomposition chimique, à la pulvérisation ou à l'action thermique. Dans cette chaîne, la texture solide de l'objet n'est que l'état correspondant aux habitudes actuelles d'utilisation.

Ce qui frappe d'emblée, c'est la révolution du champ matériel. De quelle matière s'agit-il ? Ce n'est ni la substance de l'univers organique, ni la force de l'univers mécanique - bien que ce soit aussi cela. Elle se manifeste sous la forme de systèmes matériels, c'est-à-dire de

\footnotetext{
125 H. ARENDT : La condition humaine, Paris, 1961, p. 166.

126 «Si l'on tient compte dans la mesure voulue de la vanité de l'époque, il est néanmoins permis à notre génération de parler de 'révolution chimique'. » J. BRADY : Organization, automation and society, Los Angeles, 1961, p. 202.
} 
structures, d'ordres définissables par leurs propriétés physiques, chimiques ou biologiques. "Si le XIX siècle a vu le triomphe de l'énergie, le $\mathrm{XX}^{\mathrm{e}}$ voit celui des structures », observe Pierre Auger ${ }^{127}$. En effet, c'est bien au niveau de ces structures qu'ont lieu la plupart des actions, et que l'on apprend à changer le donné. Les qualités perceptibles, la balance énergétique sont dirigées en modifiant les liaisons, les interactions à l'intérieur d'un système et celles des systèmes, entre eux. A partir de l'analyse des organisations de la matière, on engendre des corps nouveaux, des combinaisons dotées de tous les attributs désirables. On crée des cristaux purs, ou ayant un taux d'impureté calculé, on dose les facteurs moléculaires suivant les effets que l'on veut obtenir. Les propriétés d'un système matériel sont atteintes à travers celles d'un autre. Ainsi, par exemple, la résistance du métal est réalisée à l'aide de la restructuration moléculaire convenable d'une fibre plastique.

Nulle part la matière n'apparaît douée d'une morphologie stable et homogène. L'atome dans lequel la mécanique voyait un fragment minuscule d'une masse infinie, à l'image d'un morceau infime de bois qui représenterait tout un arbre, s'est révélé être le siège d'une diversité extraordinaire ${ }^{\mathbf{1 2 8}}$. Chaque champ matériel et chaque corps sont le lieu d'une configuration mouvante de particules élémentaires. Tout déplacement d'une de ces particules, soit par bombardement atomique, soit par évolution spontanée, a pour effet de faire apparaître une autre configuration avec ses propriétés spécifiques et son mode d'émission d'énergie. Les transmutations dont résultent les substances physiques et chimiques et auxquelles participent une trentaine de particules ${ }^{129}$, représentent essentiellement cette reconstitution des systèmes matériels et laissent voir la manière dont ils se convertissent. C'est à ce niveau que se situe le travail, celui de permutation des éléments et de remodelage des structures, qu'il s'agisse $(a)$ de rendre élastiques les limites (de température, de pression, etc.) entre lesquelles il est possible de produire les phénomènes, ou $(b)$ de provoquer l'apparition de phénomènes entièrement inédits.

P. Auger : Les tendances actuelles de la recherche scientifique, Paris, 1961, p. 22.

8

129

C.N. YANG : Elementary particles, Princeton, 1962. 


\section{Le domaine de la régulation.}

Face à cette nouvelle matière, quel est alors le travail de l'homme ? On peut le qualifier, eu égard à ses principes, de régulateur. Drainer des informations afin de contrôler un circuit d'appareils ou de processus physico-chimiques asservis, assurer leur bonne marche, fixer des normes de fonctionnement et corriger les écarts par rapport à ces normes, tels sont ses aspects principaux.

Sa signification se dégage si l'on tient compte de deux familles d'hypothèses. Les premières portent sur l'élimination de l'agent humain dans le processus directement productif, les secondes sur la différence de fonctions qui sépare le travail de la matière.

Le cri le plus inspiré de tous les prophètes de la machine a été «Pas d'hommes!» Ils préféraient la coopération des mécanismes dociles. L'automatisation des procédés de transmission du mouvement et de transformation des matières premières comble cet élan du cœur, pour libérer la matière de l'homme et éliminer l'ouvrier de l'entreprise. Dans la nature organique, l'homme, par son ouvrage, se révèle comme l'agent direct qui, armé d'outils, donne à une substance la forme désirée. Dans la nature mécanique, l'agent principal est le mécanisme de transmission qui sert d'intermédiaire entre la machineoutil et la puissance motrice, imprimant au mouvement la direction, l'intensité et la complexité voulues. L'homme lui prête ses organes sensoriels; il est en même temps directement présent dans le mécanisme, comme une de ses parties, ou se tient à côté de lui pour le réparer et s'assurer de ses effets.

La transmission mécanique présente toujours une grande difficulté et consomme des quantités importantes d'énergie. A partir d'une puissance centrale - la machine à vapeur - par des poulies, des courroies, des engrenages et des leviers, le mouvement arrive à l'outil mécanique diminué et parfois déréglé. La découverte de l'électricité a 
permis de remplacer le moteur central par un moteur propre à chaque machine. Au début, rien ne laissait présager qu'elle serait autre chose qu'un type d'énergie susceptible de s'intégrer au mécanisme et de le perfectionner. Bientôt le besoin de modifier le mode de transmission de l'électricité se fit sentir, et, grâce à la découverte d'éléments électroniques, il se trouva bouleversé. Actuellement, l'économie de puissance, l'élimination du frottement et des autres causes de déperdition du mouvement, jouent un rôle bien moindre. La machine n'est plus modifiée à l'atelier par un mécanicien ingénieux : elle est directement conçue au laboratoire par un chercheur. Le trajet qui va d'une loi de la nature à son application immédiate se trouve considérablement raccourci.

Un deuxième facteur intervient qui a trait, lui, à la communication des produits du travail, à l'organisation de celui-ci. Tandis que la fabrication de chaque unité devenait plus rapide, le temps exigé par les manipulations et le transport des pièces restait tout aussi considérable, par suite de la discontinuité qui existait entre les différentes unités productives. L'économie de ce temps de transport et des manipulations s'imposait.

Nous voyons ainsi converger vers une unité plus vaste deux lignées de communications : celle de l'énergie et du mouvement, et celle du résultat du travail. La machine de transmission, par l'intégration du moteur et de la machine-outil, et l'organisation des opérations productives imposent l'une et l'autre la nécessité d'un processus continu qui joigne les différents moments de la production.

L'automation - aidée par la science cybernétique ${ }^{130}$ — a synthétisé ces tendances dans une solution révolutionnaire ${ }^{131}$. Les orientations qu'elle a suivies peuvent se résumer ainsi : (a) unification de tous les éléments productifs depuis l'énergie motrice jusqu'au traitement de l'objet; $(b)$ création de procédés de guidage, d'autorégulation du fonctionnement d'une machine rendue sensible à ses propres actions ; $(c)$ intégration complète des étapes de la production.

N. WIENER : Cybernetics, New York, 1949.

131 J. DieBold : Automation, New York, 1952. 
Dans un tel système, les différences entre les parties (machine-outil, machine de transmission, etc.) deviennent tout à fait secondaires, l'unité de l'ensemble important seule.

Les phénomènes qui se déroulent dans les ensembles automatiques sont traités méthodiquement, et leur succession est fixée à l'avance par un programme. Si l'automatisation pousse la mécanisation jusqu'à ses dernières conséquences en se dispensant des bras de l'ouvrier ${ }^{132}$, elle s'en écarte aussi sur plus d'un point. L'autonomie de fonctionnement n'est pas celle de l'horloge qui, une fois mise en mouvement, suit un tracé prédéterminé ne dépendant que des accidents extrêmes (frottement, échauffement, etc.) qui en diminuent l'énergie, ni celle de l'automate travaillant sur un plan donné à l'avance. Les constructions cybernétiques dépendent de l'échange d'information avec le monde extérieur, et leur action est réglée par les " éléments sensoriels » qui renseignent sur le comportement à adopter et déterminent celui-ci, au fur et à mesure de l'exécution, par action en retour. Un des plus courants de ces «éléments sensoriels " est la cellule photoélectrique, « œil » dont la vision se modifie électriquement lorsqu'un rayon lumineux l'atteint. Les dépenses énergétiques de tous ces organes de contrôle et de guidage, destinés à élaborer et à transmettre l'information fournie par les divers phénomènes et processus, sont minimes. Je ne m'étends pas plus longuement sur les détails qui abondent dans les traités spécialisés. Ces mêmes traités font voir les effets les plus notables de la technique cybernétique: (a) élimination de l'homme dans le processus productif immédiat; (b) combinaison de phénomènes divers (électriques, mécaniques, hydropneumatiques, etc.) en un ensemble coordonné ; (c) contrôle et communication des messages prenant le pas sur l'aspect énergétique de l'agencement du système machinal ${ }^{133}$. Les usines ou les laboratoires deviennent des

132 V. BroldA: Automatisme, régulation automatique, servomécanismes, Paris, 1956; F. Pollock: L'automation, Paris, 1957; C. Vincent, W. Grossin: L'enjeu de l'automatisation, Paris, 1958.

133 «Dans la troisième phase (celle de la régulation et de l'intégration) les machines sont des procédés automatiques, auto-régulateurs, qui assurent donc aussi la fonction d'opération et de contrôle du cerveau humain. Dans cette phase, les signaux rétro-actifs acquièrent une signification décisive. La machine opératrice, ou le groupe de machines, et le procédé régulateur, doivent être considérés ensemble, comme un système dynamique unique, et l'on ne peut plus considérer la machine comme étant purement mécanique ». A. DOROGOV : The development of machines in history, Actes du XX Congrès Inter. d'Hist. des Sc. 1959, p. 202. 
unités intégrées qui peuvent être traitées comme des systèmes matériels physico-chimiques dans leur totalité, non seulement parce qu'on ne doit plus tenir compte des organes, de la sensibilité, de l'habileté manuelle de l'homme, mais aussi parce que leur intervention dans d'autres systèmes matériels est plus directe que celle de l'homme.

En fait, celui-ci n'a plus en face de lui une machine, c'est-à-dire une organisation de mouvements destinée à transformer et à assembler des corps solides. Les systèmes automatiques sont des combinaisons d'appareils susceptibles d'agir sur des phénomènes chimiques ou mécaniques, d'en assurer la continuité dans des conditions sur lesquelles les sens et les nerfs humains n'ont plus de prise. Les variations de température, de pression — et de bien d'autres dimensions — dans les opérations de la pétro-chimie sont telles que l'organisme ne pourrait ni les supporter ni les discriminer. Seule la sensibilité des instruments permet l'intervention requise sur les phénomènes matériels au niveau de leur structure. Pierre Naville écrit avec raison que

(les automatismes) «s'incorporent de plus en plus au processus de transformation interne de la matière... et rapprochent la matière traitée et son traitement dans un opération 'unitaire' $\gg{ }^{134}$.

A la limite, il ne s'agit plus de machines au sens habituel du terme, et les machines, en général, sont susceptibles d'être remplacées par des ensembles organisés où les phénomènes physiques sont combinés de manière tout à fait directe ${ }^{135}$. Des recherches sont en cours qui visent à produire l'énergie électrique par des transformateurs magnétiques et des processus liés à la dynamique des gaz.

Nous nous rapprochons du moment où l'objet conscient du travail sera la loi et la composition des puissances matérielles, et où l'outil, la machine, ne seront plus les médiateurs de la puissance humaine mais signifieront l'intervention d'une autre puissance matérielle. Au reste,

\footnotetext{
134 P. NAVILLE : L'automation et le travail humain, Paris, 1961, p. 43.

135 «La science travaille à présent à la création d'un nombreux outillage de travail qui signifiera le passage à la production sans mécanisme ». A. ZVORIKINE: Technology and the laws of its development, Technology and Culture, 1962, 3, p. 455.
} 
le monde des artifices, on le reconnaît généralement, a acquis une autonomie de fonctionnement qui l'éloigne peut-être de nous, car il n'est plus le prolongement de nos organes, mais le rapproche des systèmes matériels dont les principes et l'évolution se passent de toute ingérence de l'homme ${ }^{136}$.

Pourtant celle-ci demeure indispensable. A quel niveau? Pour quelle raison?

Tout d'abord, pour assurer la régulation du système automatique. Comme on le sait, la marche d'un tel système est dictée par des normes théoriques de rendement, de température, de vitesse ou de volume. Ces normes doivent être fixées, leur réalisation programmée, imposée à chacun des éléments et calculée sur l'ensemble. Au cours de l'application, les appareils ouvrent sans faire appel à la présence humaine effective. Des signaux enregistrés sur un tableau permettent de constater la conformité ou l'écart relativement aux normes et au plan fixé. Contrôler, surveiller et interpréter ces signaux, cette régularité, est travail humain. Les messages sont transmis à un autre système ou à un autre homme. Mais cela ne suffit pas. Ces unités sont complexes et sensibles, elles "se fatiguent», oscillent, manifestent des comportements "névrotiques" lors des changements de conditions. Leur entretien est une tâche qui accompagne en permanence l'activité productive. L'opérateur humain est ici gardien de la loi matérielle qui, sans lui, ne saurait s'appliquer indéfiniment. Son travail ne consiste pas, comme ce pouvait être le cas dans le passé, à effectuer des réparations en cas d'accident : il s'agit véritablement de maintenir le système en état de marche, d'assurer la continuité et l'indépendance du cycle matériel auto-régulateur. L'homme est donc appelé à pallier la «dégradation» de l'énergie, à lutter contre le chaos. De multiples connaissances - mécaniques, électroniques, physiques, chimiques sont nécessaires, en plus des habiletés manuelles. La spécialisation, idéal du passé, fait place à la combinaison des connaissances et des nomie qui les rapproche des systèmes naturels ». P. NAVILLE : op. cit. p. 8. 
dextérités, à la coopération immédiate d'hommes ayant des qualifications différentes. Fait exprimé clairement par Alain Touraine ${ }^{137}$ :

«Le véritable principe d'organisation (d'un atelier automatique) n'est plus la ligne de commandement, mais l'installation technique qui requiert la coopération d'hommes de niveaux hiérarchiques et de compétences techniques très variables. »

Le travail régulateur appartient donc à une espèce nouvelle. Façonner des objets n'est pas sa mission. L'efficacité d'une machine ne donne pas la mesure de son rendement. Les producteurs non-humains remplissent ces rôles. Les producteurs humains se réservent un domaine particulier, celui où il faut interpréter des messages, surveiller et contrôler les phénomènes physico-chimiques, organiser leurs liaisons et surtout soutenir ces phénomènes une fois qu'ils sont organisés en systèmes.

Régulateur, le travail l'est encore à un autre point de vue. Dans la nature mécanique, pour ne mentionner qu'elle, l'habileté et la force de travail se matérialisent en mouvement et en force. Lorsque l'habileté de l'homme devient celle de la matière, elle acquiert des qualités nouvelles - celles du mécanisme - et une portée plus grande. Les machines reproduisent, dans un sens, les muscles de l'homme, ses gestes. La force mécanique remplace la force humaine, la prolonge, «apprend » d'elle. Les circonstances changent lorsque les forces matérielles « apprennent» les unes des autres, se substituent les unes aux autres et se reproduisent mutuellement. La chute d'eau remplace le muscle; la turbine hydroélectrique, le générateur nucléaire se substituent l'un à l'autre ou à la machine à vapeur. Les mécanismes de transmission avec leurs leviers et leurs engrenages reflètent l'habileté humaine. La transmission électrique a trait à $l^{\prime}$ ' "habileté » d'une machine mécanique. Avec quelque exagération, mais non sans motif, on peut soutenir qu'une force matérielle nouvelle, une fois organisée, englobe la dextérité générale du travail, qu'il soit humain ou nonhumain. Les organes de reproduction prolongent et développent en- 
core nos propres organes; ils sont cependant à un degré équivalent des reproducteurs des organes propres à toute puissance matérielle.

Il s'en dégage la conclusion suivante : tout travail humain peut désormais apparaître sous forme matérielle, et tout élément matériel est susceptible de fournir un travail productif relativement différencié.

Comment s'élaborent les nouvelles habiletés, comment les forces matérielles sont-elles mises en rapport avec le cerveau et le corps humain ? Ce n'est plus par l'exercice de la capacité productive sur une substance déterminée, ni par le transfert d'une dextérité existante au moyen d'un instrument. Les connaissances et les facultés humaines naissent de la transformation des diverses « habiletés » matérielles, du transfert de ces habiletés d'une force matérielle à une autre - de l'électricité à la force nucléaire, etc. — et de leur enrichissement. Le travail humain s'enrichit en partant du travail productif de l'homme et, pour ainsi dire, du travail productif de la matière ${ }^{138}$. Les systèmes matériels eux-mêmes deviennent sources d'innovation, capables de multiplier et de diversifier les opérations praticables. Les calculatrices ne font pas qu'exécuter des programmes pré-établis, elles contribuent à formuler des solutions nouvelles, savoir limité mais qui, ajouté à celui qui existe déjà, peut cesser d'être négligeable. Nous voyons à l'œuvre un principe fécond : les moyens de reproduction - connaissances ou organes - expriment le fait que le travail s'exerce moins sur des matériaux auxquels il doit assurer une existence d'objets instrumentaux ou non - que sur un autre travail, qu'il soit humain ou non-humain. Envisagé sous l'angle productif, il cesse d'être spécifique de l'homme. Toute matière particulière peut, à des degrés divers, rendre des services analogues. Les systèmes cybernétiques n'ont plus recours à la combinaison intime de l'homme et de la machine des êtres vivants, ils possèdent la tendance à organiser, à s'opposer à la dégradation de l'énergie ; des êtres matériels, ils ont la soumission aux principes de l'entropie, donc la dispersion de l'ordre instauré. Ils évoluent en fonction de leur constitution propre, de lois qui définissent un domaine particulier, sans obéir aux contraintes du muscle, de l'œil ou du cerveau du travailleur. Sur le plan productif, le travail de l'homme 
s'avère imparfait et peut être repris par un pouvoir non-humain qui le remplace et l'affine. Le seul travail, le seul talent qui lui demeure propre, c'est l'invention. Là, il remplit aussi son rôle de régulateur puisqu'il anime et accompagne l'échange qui a lieu entre les agents matériels libérés, rendus indépendants, mais également parce qu'il doit commander son propre développement, veiller à l'équilibre de ses composantes et, finalement, s'appréhender lui-même en tant que système d'information ou ensemble de dextérités. A l'intérieur du cycle des découvertes, de la recherche des habiletés, le travail, qui avait toujours paru dirigé par un élément externe, objet ou matériau, se révèle comme son objet, son but, son matériau privilégié.

Retour à la Table des Matières

\section{La prédominance de l'invention.}

L'expansion des savoir-faire, leur organisation technique et scientifique, ont abouti à poser les fondements d'une action méthodique dans le champ des forces matérielles, visant à modifier profondément leur texture et à utiliser leur énergie. L'homme intervient dans l'« histoire » de la matière, ou bien lui fournit une histoire. Le caractère d'évidence croissante de l'évolution naturelle est intimement lié aux modalités de la création du travail. Celle-ci s'avère évolutive, convertible dans la vie de chaque individu; de plus, elle revêt une expression autonome et méthodique. Autonome, car, pour la première fois, créer du travail devient un processus spécifique dont l'extension, la modification, la constitution, ne sont plus complémentaires d'autres processus (notamment la production ou l'éducation). L'invention n'est plus un aspect des occupations de l'ingénieur, et ses résultats théoriques ne servent pas, avant tout, à confirmer une vision du monde. L'autonomie découle assurément de cette particularité de la création d'habileté, du fait qu'elle se conforme à des principes clairement établis des sciences ou des techniques. Réciproquement, une pareille indépendance conduit à une clarification plus rigoureuse des limites, des cheminements, bref à l'éclosion des traits systématiques de l'ensemble du processus. Pour atteindre une fin née à l'intérieur de la science ou qui lui a été proposée de l'extérieur, les démarches suivent certaines règles, dictées par l'expérience ou la théorie, qui permettent 
d'examiner chaque alternative et d'explorer la valeur de ses termes. La méthode ne prétend pas ici donner des recettes d'invention, et Kant avait sûrement raison de dire que le génie ne peut

« indiquer scientifiquement comment il réalise son œuvre; il ne sait pas lui-même d'où lui viennent les idées, et il ne dépend pas de lui d'en concevoir à volonté ».

De telles recettes, quoi qu'en pensent certains philosophes ou psychologues, n'aident nullement l'individu. Cependant, au niveau de la communauté, le balisage des voies à suivre, l'émulation réciproque, l'intensité des échanges, l'élimination des essais condamnés à l'avance, jouent un rôle décisif pour stimuler les découvertes et les préparer.

Dans cette incessante auto-création des facultés humaines, dans la création du travail, l'invention domine. Elle en est le centre et ne connaît de contraintes qu'internes. La reproduction dépend de plus en plus de l'état des inventions, des perspectives qu'elles dessinent. Les dextérités que l'on ajoute à l'organisme biologique pour le transformer n'ont plus de sens définitif. Au cours de la vie de l'individu, elles changent, s'accroissent, dépérissent. Si, dans les états antérieurs, le talent appris, les facultés assimilées gardaient une valeur certaine pendant toute la durée de l'existence, si la reproduction pouvait être détachée de l'emploi proprement dit de la force de travail modifiée, de la production, désormais la reproduction du travail commence à représenter une exigence permanente. Jusqu'à un certain point, de même qu'un travailleur doit conserver sa force de travail en se nourrissant, en se reposant, de même il doit entretenir son habileté en en éliminant les parties que les découvertes ont rendues caduques et en y ajoutant de nouvelles connaissances. Celles-ci ne proviennent pas de l'exercice immédiat des capacités mais, souvent, indirectement, du domaine de l'invention scientifique et technique.

Sur quoi débouche cette mouvance, cette diversité des savoirfaire ? Dans le laps de temps d'une vie individuelle, le mouvement de navette qui va des facultés qui se renouvellent aux pouvoirs matériels qui se convertissent les uns dans les autres, détache le travail du pôle 
humain ou non-humain avec lequel il se confondait. En d'autres termes, il ne s'identifie plus à l'organisme humain ni au patron proposé par le mécanisme ou les propriétés d'une force matérielle particulière. Collée, incrustée, pour ainsi dire, au corps de l'artisan, l'activité productive s'affirmait totalement subjective. Projetée et cristallisée dans le mouvement et l'énergie, cette activité s'était muée en objet, en négation réifiante de la dextérité humaine. Déterminé à faire apparaître son essence objective, le travail se découvre concrètement rapport du pôle humain au pôle non-humain, adaptation variable et réciproque dans une tâche productive dont la structure n'a plus rien de figé.

Le travail régulateur et inventif d'une part, la matière en tant que structure d'autre part, expriment la physionomie de la nature cybernétique. Elle s'exprime en premier lieu dans un fait remarquable : la séparation entre le domaine des artifices et celui des êtres purement matériels, dits "naturels », est abolie. En effet, les systèmes cybernétiques ne sont pas des "prothèses » qui prolongent l'organisme. L'autonomie de leurs processus rappelle celle des forces matérielles. L'univers des objets s'intègre lui-même plus étroitement à celui de la matière et lui correspond. Ainsi l'automatisation ne signifie pas que les choses conçues jusqu'à ce jour seront fabriquées à l'aide d'outils différents ${ }^{139}$. Au contraire, ce sont les objets qui devront être conçus eu égard à la structure matérielle désormais maîtrisée et automatisée.

Donc, d'une part, les artifices proclament leur indépendance vis-àvis de la domination humaine et se rapprochent de la classe générale des éléments matériels. D'autre part, l'action directe de l'homme sur la matière dont il développe, bouleverse ou crée les propriétés, est devenue courante. Même si la situation n'est renversée qu'en apparence, elle n'en est pas moins porteuse de sens. La distance qu'on plaçait habituellement entre « artifice » et « nature » devient de plus en plus difficile à maintenir. Le lien entre ces deux champs de notre réalité cesse d'être rigide, et la présence ou l'absence de l'homme, longtemps tenue pour un critère infaillible, s'avère inopérante. A un niveau plus pro-

«Par exemple, si les industries du bâtiment devaient être automatisées, cela ne signifie pas qu'on inventerait des machines pour faire les nombreuses tâches qui sont à présent dévolues à l'homme, mais plutôt que l'on projetterait la structure des bâtiments de telle sorte qu'ils puissent être construits par des machines ». M. PHILIPSON : Automation, New York, 1962, p. 79. 
fond, l'indépendance relative des artifices dévoile la continuité des processus naturels et des processus dits «non-naturels », et symbolise l'interpénétration de l'histoire de notre nature et de l'histoire universelle de la matière. Jusqu'ici, on a toujours confondu la première avec l'évolution des techniques, ce qui la séparait de la seconde et même les opposait radicalement. On voit qu'il n'en est rien. Par symétrie, la capacité humaine d'engendrer des matières nouvelles, d'étendre leurs propriétés, de bouleverser les structures existantes, nous conduit à regarder l'histoire humaine de la nature, avec ses processus spécifiques, non seulement comme reprise de celle de la matière, mais aussi comme sa continuation, qui la fait progresser au delà des formes atteintes jusqu'à ce jour. C'est parce que nous pouvons aborder notre histoire objective dans cette perspective, à la lumière de ce mode d'agir, que l'état de nature qui lui correspond s'avère être lui-même historique.

\section{Retour à la Table des Matières}

\section{Une nature historique.}

Dans la nature cybernétique, le temps n'est plus une catégorie générale externe, il est devenu une dimension interne. Certes, l'atmosphère engendrée par l'irruption des conceptions évolutionnistes et historiques dans le champ biologique et social a joué son rôle ${ }^{140}$. Il faut cependant remarquer que ces conceptions sont liées à des possibilités d'action : modifier les espèces dans un cas, faire consciemment l'histoire sociale de l'homme dans l'autre. Il en est de même pour la nature.

Le processus inventif arrive à un tournant de son histoire, et sa dimension méthodique n'est plus la même. Les contacts avec la matière ne se parent plus d'une aura dramatique, il ne s'agit plus de fouiller au cœur de substances opaques pour en extraire les forces ultimes. Ce qui était perçu négativement comme exploitation des ressources jusqu'à leur épuisement reparaît positivement comme la croissance de potentialités qui s'épaulent mutuellement. Le hasard et le tâtonnement

W. de Sitter : Kosmos, Cambridge, 1932. 
font place à une véritable stratégie de la découverte. L'homme est le sujet, qui se veut tel, d'un nombre sans cesse diversifié d'échanges avec l'univers matériel, échanges qui ne sont pas près de se figer ou de se clore. Bousculés par cette effervescence, les rapports naturels ont perdu la stabilité commandée par un modèle rigide, une hiérarchie stricte des éléments du réel. Constamment des phénomènes nouveaux, des forces nouvelles pénètrent dans leur champ.

Le tableau évolutif de la nature est ainsi concrétisé et vivifié. Nous ne l'identifions plus à une puissance matérielle unique, comme c'était le cas pour la nature mécanique. Au contraire, la pluralité des forces matérielles, le réseau de leurs liens, l'influence qu'elles exercent les unes sur les autres, expriment l'ordre naturel. De la force nucléaire ou de la force gravifique, nous savons qu'elles sont actives dans certains états physiques d'une étoile ou d'une planète, et passives, stabilisées dans d'autres états. Entre elles nous recherchons une certaine hiérarchie, toute relative, qui dépend de la variable choisie : le dégagement d'énergie, la distance par rapport au noyau, la vitesse, etc. Si l'on passe d'un domaine à l'autre, les lois changent et peuvent se transformer les unes dans les autres. Ainsi, pour des vitesses relativement petites, nous restons dans le cadre coutumier de la mécanique newtonienne, l'espace tri-dimensionnel et rectiligne. Lorsqu'on envisage des vitesses très grandes de déplacement d'un corps, d'autres lois régissent les phénomènes ${ }^{141}$. Le déterminisme lui-même n'est pas uniforme, c'est-à-dire qu'il n'est pas le même aux divers niveaux. Rigoureux, classique, il est à l'échelle des machines, des planètes; à l'échelle des atomes, la probabilité conduit nos raisonnements et dirige notre conduite pratique. Structuré en niveaux variant suivant l'échelle à laquelle on l'aborde, tel est l'ordre naturel cybernétique.

Cependant, tout en étant agencement de phénomènes et de corps coprésents, cet ordre est saisi comme le résultat d'une révolution continue, d'une mobilité à l'échelle cosmique. Chaque fait est simultanément un événement, chaque rapport synchronique est soutenu par son correspondant diachronique. A coup sûr, ce qui distingue le charbon du pétrole relève, nous le savons, à la fois de leurs qualités res- 
pectives et de la durée géologique de leur génération. L'univers engendre du temps, s'engendre dans le temps et y baigne. L'idée d'une géométrie liée au cycle chronologique ${ }^{142}$, d'une courbure de l'espace variable suivant l'instant où elle est mesurée, est l'expression la plus poussée de cette temporalisation des phénomènes matériels. Nous ne savons pas encore si cette notion est définitive; qu'elle ait pu être formulée avec sérieux sans qu'on lui oppose une réfutation sans appel est un signe de sa vraisemblance. De plus, les étoiles que nous croyions éternelles, soleils posés sur les orbes célestes imaginaires, nous parlent de l'évolution de la matière ${ }^{143}$, tout comme les diverses espèces biologiques nous apprennent l'évolution des êtres animés. La spécificité de leur couleur ou de leur luminosité nous renseigne sur leur âge, indiqué par une température de surface et une émission d'énergie spécifique ${ }^{144}$. La physique atomique a prouvé la transformation des noyaux les uns dans les autres : elle a aussi ouvert la voie à une étude comparative des réorganisations de la structure matérielle $\mathrm{du}$ soleil et d'autres astres. Les processus par lesquels les atomes d'hydrogène se muent en atomes d'hélium, la vitesse des réactions propres à chaque étoile nous livrent des informations sur leur jeunesse ou leur vieillissement ; les étapes parcourues nous permettent d'écrire l'histoire du fragment accessible de l'univers. Histoire hypothétique, certes, mais quelle histoire ne l'est pas?

Ce qui nous est donné dans l'espace traduit conjointement un lien dans le temps. En regardant Sirius ou la nébuleuse d'Andromède, nous voyons à travers huit ou dix millions d'années-lumière ${ }^{145}$. Ce qui distingue le soleil, la terre et les planètes est, autant qu'une différence de position, une différence de développement, de situation parmi les corps célestes. De même, chaque corps chimique d'aujourd'hui représente, en face d'un autre corps, une étape ; le plomb l'avenir du radium et ce dernier le passé du premier.

\footnotetext{
142 A. FRIEDMAN : Über die Krümmung des Raumes, Zeitschr. f. Physik, 1922, p. 377.

143 O. STRUVE : Stellar evolution, Princeton, 1940.

H. BONDI : Cosmology, Cambridge, 1952.

144 F.G. WATson : Between the planets, Cambridge (Mass.), 1956.

145 J. SINGH : Great Ideas and Theories of Cosmology, New York, 1961.
} 
La réalité naturelle nous apparaît ainsi marquée par une diversité sur le plan quantitatif, un mouvement sur le plan temporel. Ce qui est biologique, vivant, n'est pas exclu de la chaîne ni proclamé hétérogène. Dans la pratique, les systèmes automatisés représentent la matière douée d'intelligence et tendent à s'assimiler les phénomènes de la vie. Une discipline particulière, la bionique, s'y emploie. Ce n'est là cependant qu'une première phase. De manière régulière, l'importance croissante des processus biologiques, leur interaction avec les processus physicochimiques, nous orientent vers une saisie de la matière qui est, à la longue, révolutionnaire. La réunion des pouvoirs matériels organiques et inorganiques s'opère dans une perspective nettement génétique, chacun apparaissant comme l'aboutissement de la transformation de l'autre. Pour dérouler la chaîne de ces transformations, il faut prendre en considération les événements qui ont lieu sur d'autres planètes, dans d'autres galaxies, parallèlement à ceux dont la terre est la scène. Nous ne nous étonnerons guère si nous voyons un jour se manifester, quelque part dans l'espace, une matière que nous avons prévue et produite - si elle n'y existe déjà. Le cas du technitium est relativement ancien. Cet élément n'est pas observable sur terre, puisqu'il ne possède pas d'isotope stable. En bombardant du molybdène par des noyaux de deutérium, on a pu le fabriquer au laboratoire. En cherchant à dater les étoiles, grâce à un de ses isotopes, on a constaté la présence de technitium dans des étoiles âgées de plusieurs centaines de millions ou de quelques milliards d'années. Les échanges entre les diverses composantes du système planétaire nous deviendront plus perceptibles avec les voyages interplanétaires, qui confirmeront cette participation de l'être humain au monde qu'il remodèle continuellement.

La nature cybernétique commence à peine à se dessiner. En pousser plus loin la description n'est pas nécessaire au but que je me suis proposé. D'ores et déjà, en effet, il est clair que les fondements d'un nouvel ordre naturel s'édifient, et qu'ils sont originaux. Leurs prémisses remontent au début de ce siècle, et leurs conséquences ne se feront pas toutes sentir avant sa fin. L'intervalle de temps est relativement court. Des pratiques et des relations nouvelles sont à l'ouvre, mêlées à un tourbillon de visions qui rappelle l'époque des philosophes présocratiques. Les incertitudes qui les traversent sont la rançon de leur 
inachèvement. En revanche, il est hors de doute que le genre humain est entré dans une ère nouvelle de son histoire naturelle.

$\underline{\text { Retour à la Table des Matières }}$ 


\section{Le contenu des états naturels et la fonction des disciplines naturelles}

\section{$\underline{\text { Retour à la Table des Matières }}$}

La tradition, reprise et embellie dans le vieux poème d'Hésiode, Les travaux et les jours, nous enseigne que les hommes ont connu un âge d'or, un âge d'argent, un âge de bronze, un âge des héros et un âge de fer. Les premiers hommes demeuraient sur une terre spontanément prodigue de ses fruits, sans guerre ni violence. Les derniers qu'Hésiode ait dépeints, ceux de l'âge du fer, étaient cruels et travaillaient durement. A chaque âge, une humanité disparaît et à chaque nouvel âge une autre surgit. Les caractères de ces humanités successives ne sont pas identiques. L'humanité de l'âge d'argent a une jeunesse très longue et une vie adulte très brève, celle de l'âge du bronze jouit d'une supériorité physique et mentale considérable.

L'idée que je développe ici n'a pas ses racines dans le mythe, quoiqu'elle en dise la sobre vérité. Les hommes changent avec la nature, ils naissent et meurent avec leur état naturel. Les facultés et les actions qu'ils déploient dans chacun de ces états reproduisent et expriment totalement une intelligence, un comportement, des besoins qui lui sont consubstantiels. Les pouvoirs matériels, qu'ils soient ou non modifiés par la technique, font écho aux contraintes de cet état et sont institués de manière à le soutenir et à le fortifier. A l'intérieur de ces frontières, propriétés physiques des éléments et appareils sensoriels, modes d'exploration du milieu ambiant et critères de déchiffrage des informations reçues du monde, s'articulent directement les uns avec les autres. L'homme que ses réflexes moteurs, sa tournure d'esprit, ses activités productives insèrent dans la nature organique perçoit et recherche la tonalité des couleurs, les aspérités révélées au toucher, la finalité qui relie une substance à l'outil qui s'y adapte, la hiérarchie des qualités qu'elle est susceptible de manifester. Celui qui appartient à l'ordre mécanique ne percevrait en quelque sorte que des figures, des volumes, des longueurs et des masses, le jeu des percussions et des résistances, les quantités d'énergie nécessaires pour engendrer un effet souhaité. Tandis que le premier appréciera un mor- 
ceau de bois suivant l'essence de l'arbre dont il provient, la disposition des nœuds et des veines, le degré d'humidité ou de sécheresse, le second n'y verra que sa capacité de supporter un poids, la proportion qui existe entre sa longueur et sa section. Cette relativité des rapports avec le réel, peu importante en elle-même, prend une signification différente, projetée à l'échelle historique. En effet, l'involution d'un état de nature implique aussi celle d'une classe d'hommes, puisque les ressources et les dextérités qui constituent l'être véritable d'une telle classe se désagrègent, s'amenuisent ou s'anéantissent ensemble. De concert, l'homme et la matière qui composent cet état disparaissent sous une certaine forme pour renaître, entièrement transfigurés, sous une autre forme.

Depuis longtemps, archéologues et anthropologues classent les époques suivant les matériaux utilisés. Ils nous enseignent ainsi qu'à l'âge de pierre succède celui du bronze, et que l'âge du bronze est suivi par l'âge du fer; aujourd'hui nous nous trouverions dans l'âge de la matière plastique ${ }^{146}$. Dans un sens voisin, on énumère les cycles des substitutions : la gravité succède au muscle, l'électricité à la gravitation, l'énergie atomique à l'énergie électrique, etc. ${ }^{147}$ Parallèlement, on dessine la progression graduée de l'intelligence humaine et de son soubassement biologique. On en voit un indice direct dans l'augmentation de volume du cerveau, la multiplication des connexions entre ses parties, l'aptitude de l'espèce à survivre. La composante externe, matérielle, et la composante interne, bio-sociale, de l'être humain, reflètent ainsi séparément un mouvement linéaire qui, par addition d'âges ou de stades, serait également une histoire. Cette conception - qui a certes son utilité sur le plan opératoire n'atteint pas la hauteur de l'intuition mythique, laquelle ne pouvait

« Nous voyons un âge de pierre, suivi par un âge du métal, à l'intérieur duquel se trouvent un âge du cuivre, un âge du bronze, et un âge du fer, dans lequel l'humanité se trouve toujours actuellement. Mais on peut déjà apercevoir les contours d'un âge des polymères ", et il se peut que les archéologues futurs parlent un jour de deux grandes ères : l'ère des matières naturelles - celles qu'a créées la nature - et l'ère des matières synthétiques - celles qu'a créées l'homme " . N.Y. KONRAD : Notes on the meaning of history, The Soviet Review, nov. 1962, p. 24.

147 «S'il y a une histoire générale de l'humanité, c'est bien celle de l'évolution technique. Elle seule nous fournit, au delà du foisonnement des religions, de l'art, des structures sociales, quelques repères macroscopiques objectifs ». L. de HEUSCH : Réflexions ethnologiques sur la technique, Les Temps Modernes, 1963, 19, p. 1022. 
détacher, et elle avait raison, l'ordre des choses de celui des hommes. Si pourtant elle réunit tant de suffrages, c'est que l'idée d'une nature permanente, progressivement maîtrisée grâce aux moyens élaborés par l'homme, est profondément ancrée dans les esprits. Même lorsque l'observation ou la simple logique imposent de reconnaître la succession de natures différentes, on décrit celle-ci comme une succession de concepts :

\begin{abstract}
«Dans l'histoire de la science en Europe, observe un historien des sciences ${ }^{148}$, on peut distinguer trois concepts principaux de la nature : la nature en tant qu'elle est faite de choses dont l'essence est un principe actif d'opération (formes substantielles, causes secondaires); la nature en tant que mécanique, où seules les causes proches sont objet de science; et la nature en tant que processus, ce qui soulève une fois de plus la question des causes finales. Le premier de ceux-ci a gouverné l'esprit des hommes du début de la science grecque jusqu'au XVII ${ }^{e}$ siècle; le second depuis Galilée et Newton jusqu'à la fin du XIX ${ }^{\mathrm{e}}$ siècle ; depuis lors il partage cette suprématie avec le troisième ».
\end{abstract}

Autant dire : la nature organique, la nature mécanique, la nature cybernétique. Mais on ne le dit pas, puisque ce serait donner une existence concrète aux abstractions. Autant l'idéalisme est superbe et sans crainte lorsqu'il se tient coi dans la sphère de l'esprit, autant il est honteux et timoré lorsqu'il s'agit d'aller jusqu'au bout de ses postulats, où il rencontrerait son contraire. Ces concepts, si prudemment isolés, ne sont-ils pas les filtres par lesquels s'instaure tout échange avec les puissances du monde matériel, les échafaudages dont on se sert pour agir au moment où l'on veut comprendre ? Et ne viennent-ils pas à nous, non seulement en tant que simulacres ou images mais aussi en tant qu'ils participent à ce qui est imaginé, s'articulant avec la réalité dont ils émanent et sur laquelle nous apposons notre marque ?

Il faut donc faire un pas en avant. La possibilité de diluer ou de déguiser l'histoire des états naturels en histoire de leurs concepts naît de l'incertitude où l'on se trouve quant au contenu de ces états. Pour pénétrer le sens de ce contenu, il faut se rappeler que les ressources, pour être inventées ou reproduites, se cristallisent à l'intérieur d'un nals of Science, 1948, 6, p. 56. 
cadre strict de savoirs soumis à des contraintes et à des règles données. De ce cadre dépendent les propriétés d'une entité naturelle, avec les instruments et les normes qui permettent de les saisir. Il représente nécessairement une discipline qui relie les appareils sensoriels aux compartiments de l'intelligence, sélectionne les informations recueillies à propos du monde réel, et unifie ipso facto les composantes humaines et non-humaines des êtres objectifs. Les disciplines - arts, sciences, philosophies, techniques — sont donc de vastes synthèses qui unissent le travail à la matière, relient nos facultés aux éléments physiques sur lesquels elles s'exercent. Elles constituent à la fois l'inventaire des talents créés par l'espèce et un mode particulier d'appréhender les attributs des forces matérielles, aussi bien que les processus d'invention et de reproduction. C'est par l'intermédiaire de leur art, de leur science, de tout savoir auquel ils ont accès, que les hommes adressent à l'univers le discours de Faust : "Voici le temps de prouver par des actions que la dignité de l'homme ne le cède en rien à la grandeur des dieux $\gg$.

Certes, on pourrait assimiler les disciplines à l'équipement quasiphysiologique de l'espèce, à l'une de ses grandes fonctions, la raison ou bien l'imagination. Leur diversité prolongerait alors la spécialisation du corps et de l'esprit : la science, la pensée scientifique ; la technique, la pensée technique ; l'art, la coordination des appareils sensoriels, et ainsi de suite. De véritables entités organiques, conçues pour la circonstance - l'homo sapiens et l'homo faber — seraient censées leur correspondre et éclairer leur évolution :

«C'est au pythagorisme surtout, écrit Léon Brunschvicg ${ }^{149}$, que l'hellénisme a dû la création de la méthodologie mathématique, c'est-à-dire à l'apparition de l'homo sapiens, entendu non au sens ordinaire de l'anthropologie par opposition à l'animal, mais dans la pleine acception qui l'oppose à l'homo faber des sociétés orientales ».

Tel est le schéma reconnu : la lente élaboration des connaissances mathématiques jusqu'à leur agrégation en une discipline autonome œuvre des Grecs - est rendue plus dramatique par le contraste entre 
la raison spéculative de ceux-ci et l'intuition pratique des Orientaux. Le cheminement décrit n'est pas conçu comme une substitution de problèmes nouveaux aux problèmes anciens - il est inclus tout entier dans le déploiement altier de l'intelligence. Le jaillissement et le devenir des disciplines illustrent la progression des facultés psychiques différenciées, poussent à la perfection leurs principes intrinsèques. $\mathrm{Si}$, comme le croyait Émile Meyerson, ce principe est celui de la recherche de l'identité dans le flux des événements et des observations, alors les sciences, les philosophies, les mythes suivent fidèlement cet idéal. Le choix du paradigme assigné à l'esprit humain dépend du point de vue adopté. Le postulat qui légitime son emploi ne varie guère: l'histoire d'une discipline est l'histoire de la réalisation des canons, estimés permanents, de la raison ou de l'intuition. La distance, grande ou petite, qui l'en sépare, mesure le degré de perfection du savoir et traduit les pulsations essentielles de sa transformation.

Assurément, un groupement de disciplines se laisse aussi saisir comme l'enregistrement des régularités et des propriétés de la matière ou de notre texture biologique. Il serait alors le commentaire de l'homme sur les conditions d'existence des phénomènes qui se déroulent en dehors de lui. La chimie a trait aux phénomènes chimiques, l'électricité aux phénomènes électriques, etc. La multiplication et l'avancement des sciences ne font, d'un côté, que retracer la succession des énergies, des substances domestiquées par l'humanité. D'un autre côté, la diminution du nombre d'erreurs et l'augmentation concomitante du nombre de vérités indiquent la direction de leur ascension, fournissent le gradimètre de leur objectivité et celui de la finesse de nos instruments. On affirme que ces sciences ou ces techniques sont sciences ou techniques de la matière, de la nature. Décalques fidèles d'une configuration extérieure, on les change en langages privés de sujets, en représentations qui ne sont ni du monde, sans nous, ni dans le monde, avec nous.

Qu'on en fasse les projections d'une structure mentale ou les reflets d'une réalité protéiforme, les disciplines semblent être destinées à codifier séparément les signaux provenant de nous-mêmes ou ceux qui émanent des êtres physiques formant notre entourage. La vérité qu'elles établissent demeure à chaque instant une simple approxima- 
tion d'une vérité plus accomplie, ensevelie dans la raison ou dans les choses. L'homme ordonnateur de ces vérités incarnerait tantôt une machine algorithmique traitant les informations qui lui sont proposées suivant un programme inhérent à son esprit, tantôt une machine analogique ayant à simuler de manière artificielle des dispositions et des dynamismes naturels dont il aurait changé les dimensions.

Partant de prémisses opposées, ces conceptions manquent l'une et l'autre de saisir l'essentiel, à savoir la marque indélébile que la création de nos talents imprime aux sciences, aux techniques, aux philosophies. Le poids généralement excessif conféré aux résultats de l'invention et de la reproduction au détriment de ces processus euxmêmes a eu pour effet d'instaurer une séparation entre les principes, changeant au cours de l'histoire, qui commandent la formation de nos facultés et de nos ressources, et la structure interne des disciplines. Faute d'être déduites de ces processus naturels, leur organisation et leur évolution sont imputées parfois à l'univers ambiant, parfois au milieu autonome des catégories de l'entendement. Se refusant à mesurer la portée réelle des disciplines, on aboutit à mutiler de sa nature l'histoire de l'humanité, et à déposséder la nature de son histoire humaine.

Manifestement, les mobiles immédiats comme la visée ultérieure des arts ou des sciences obéissent aux impératifs d'une pédagogie effective : ceux que dictent la découverte et la diffusion des dextérités, du colligement des idées et des techniques par lesquelles les hommes participent à la vie authentique du monde. Que l'on considère le véritable cheminement de l'invention et du transfert des connaissances jusqu'à ce qu'elles se canalisent en disciplines: leur trajectoire est jalonnée par une mortalité effrayante, des déchets et des ratés innombrables. Combien de « secrets », combien de tours de main, combien de théories ne se sont pas perdus, et combien de fois ne les a-t-on pas redécouverts! Combien de tentatives engagées dans des voies sans issue, pour aboutir à une seule invention mémorable ! Le tableau des familles de pseudo-sciences ou de pseudo-techniques - alchimie, astrologie, arithmétiques mystiques, etc. - que nous avons tendance à négliger ou à tenir pour négligeables, fait partie du bilan impressionnant de nos recherches, de notre histoire réelle. La virulence de tant 
d'efforts stériles à côté de quelques efforts féconds, la présence de tant de discours délirants à côté des rares discours soutenus par le génie, témoignent de l'impulsion irrépressible, du besoin constant des hommes d'entrer en relation avec les autres hommes et avec les parties inexplorées de l'univers matériel. Nous avons récemment pris l'habitude de percevoir les disciplines sous leur aspect livresque, de les enfermer dans des écoles. Durant des millénaires, pourtant, elles n'avaient subsisté que sous forme de gestes, de réflexes mentaux, de liens d'individu à individu, de postures et d'exemplaires concrétisés en œuvres, en plantes ou en animaux. Elles ordonnaient l'atmosphère dans laquelle baignaient les hommes et où ils évoluaient. Les recettes, les manuels, les rites furent les signes de l'originalité d'un ensemble naturel, tout comme la régularité apportée aux outils, la présence des matières premières étaient les indices de sa possibilité. La suite des découvertes, leur reprise incessante, génération après génération, colore la vie des disciplines, entrelace l'univers humain et l'univers nonhumain dans une même célébration. La distance parcourue a modulé les fonctions initiales, elle ne les a pas abolies.

Sciences, arts, techniques et philosophies visent donc à notre union avec la matière. Avant de s'associer à un groupement de disciplines, une faculté de l'homme ou une propriété des éléments demeure un «néant historique ». Toute discipline doit être envisagée à ce titre, pour autant qu'elle contribue à constituer un état de nature, et non pas seulement pour autant qu'elle le dévoile ou s'y dévoile. C'est ce qui permet à un savant d'écrire :

« Dans son essence, le «système de la Nature », dans un sens élargi, correspond à ce que j'appelle le corpus scientiarum » ${ }^{150}$.

Ces remarques renouent avec une conception répandue à l'aube de l'époque moderne : celle de la coïncidence des arts, des philosophies, avec le contenu de l'histoire de la nature. Très clairement, Francis Bacon propose d'intégrer à l'étude de la réalité historique naturelle toutes nos activités dès l'instant où elles fondent le réel. Par ce moyen, and Sci. 1944, 35, p. 491. 
estime-t-il, l'humanité augmente sa puissance - connaître, c'est pouvoir - et dilate son être. Le développement des sciences et des arts n'est pas développement d'une science à part, il est celui de la nature elle-même. Sur cette voie, il a été suivi par les Encyclopédistes, qui rattachent au domaine de l'histoire naturelle les lois de la matière (du ciel, de la terre, des forces, etc.) ses écarts (prodiges, monstres) et ses usages (arts, métiers, manufactures).

Si cette conception appelle un renouvellement, il doit porter sur la signification qu'elle a conférée à l'histoire. A ses commencements, l'histoire prend la forme d'une chronologie des événements coutumiers ou étranges, d'une accumulation d'actes individuels, animée par la volonté de reconstituer le passé. Deux siècles ont changé tout cela. Ce que nous attendons désormais de l'histoire, c'est moins la justification des espérances du présent que la découverte, dans ce présent même, des ferments de l'avenir. Nous n'y suivons pas une trajectoire finie dont notre époque serait le couronnement; nous nous y déplaçons en fonction du chemin que nous aspirons à parcourir. L'intérêt suprême de l'histoire n'est pas d'instaurer un ordre parmi des épisodes irrémédiablement révolus, mais de donner à imaginer la rationalité d'un avenir qui nous concerne au premier chef. C'est pourquoi l'aspect narratif et encyclopédique des ébauches primitives d'une histoire humaine de la nature est devenu manifestement accessoire.

La manière d'appréhender les disciplines a été elle aussi remise en question. Depuis Charles Darwin, on sait que les espèces évoluent sans discontinuer. Les connaissances, les techniques créées comptent parmi les agents décisifs de cette évolution: elles remodèlent l'organisme et sa complexion intellectuelle. Chaque science, chaque art donne une nouvelle épaisseur aux aptitudes et aux choses, les imprégnant profondément. Parallèlement, sur le plan social et productif, les diverses disciplines s'avèrent renfermer les germes de la richesse et exprimer les dimensions des rapports collectifs. Aussi ne passentelles plus pour être de magnifiques collections de faits, de lois ou de curiosités, destinées à instruire les jeunes gens, à occuper les loisirs des âmes vertueuses ou à favoriser le commerce. Le soubassement productif de la société les absorbe. La carte que l'on dresse de « l'histoire de la nature » ne reproduit plus uniquement les contours 
du milieu extérieur : elle évoque une aventure humaine. Les travaux artistiques, scientifiques, techniques sont les symptômes incontestables du déroulement de cette histoire. Karl Marx qui dénonce l'ignorance dans laquelle on les tient ${ }^{151}$ — observe le fait :

«L'industrie est le rapport historique réel de la nature, et, par suite, des sciences naturelles de l'homme; si elle est donc comprise comme révélation exotérique des forces de l'être humain, l'être humain de la nature ou l'être naturel de l'homme est également compris, les sciences naturelles perdent donc leur tendance matérielle abstraite ou leur tendance idéaliste et deviennent base de la science humaine comme elles sont actuellement déjà devenues quoique sous une forme aliénée - la base de la vie humaine réelle ; et c'est de prime abord un mensonge que de dire qu'il y a une base pour les sciences et une autre pour la vie. La nature qui naît dans l'histoire humaine - dans l'acte générateur de la société humaine - est la nature réelle de l'homme, donc la nature telle qu'elle devient — bien que sous une forme aliénée — par l'industrie, la vraie nature anthropologique $»{ }^{152}$.

Partout où nous nous rencontrons à l'œuvre, nous nous reconnaissons dans nos disciplines naturelles. Une rose n'est pas seulement une plante qui éclôt c'est aussi une manière de la faire éclore, un savoir. Il y a deux siècles, la même rose nous renvoyait à d'autres gestes, à d'autres sols, à d'autres nuances de lumière et de parfum. Un réflexe physique ou mental n'est pas seulement un réflexe le procédé qui permet de le susciter lui est associé, le nom de l'inventeur est attaché à lui. Les montagnes et les cratères de la lune portent chacun un nom, une date. Il en est de même des phénomènes physiques, chimiques, biologiques.

Le constat comporte une conclusion importante : l'enquête sur l'histoire humaine de la nature est en même temps une enquête sur l'histoire des arts, des sciences, des techniques, et des philosophies, qui en sont le contenu. Nous ne pouvons espérer comprendre l'histoire de notre nature si nous ne prenons pas appui sur les faits qui nous permettent de cerner et d'éprouver sa vérité, faits inclus dans ces dis-

151 «Les historiens eux-mêmes se réfèrent aux sciences de la nature en passant, comme à un moment du développement des lumières, d'utilité, qu'illustrent quelques grandes découvertes ». K. MARX : Manuscrits.. : ed. cit. p. 95.

152 K. MARX : Euvres philosophiques, Paris, 1934, t. VI, p. 35. 
ciplines. Inversement, faute de se référer à son contenu naturel, l'histoire des arts, des sciences, etc., se prive de sa signification universelle. Il s'agit plus précisément de savoir pourquoi les groupements de disciplines évoluent et se transforment conjointement avec les ordres naturels, pourquoi un groupement particulier — art ou technique - correspond à un ordre naturel particulier — organique ou mécanique - et, enfin, pourquoi le mouvement que nous voyons s'y exprimer est nécessaire ${ }^{153}$.

L'analyse que je propose accentue l'originalité du développement des disciplines naturelles, originalité liée aux processus et à la succession des états de nature. Elle nous place devant les deux termes d'une alternative nettement tranchée :

- ou bien les sciences, les arts, les philosophies, embrassant le champ de notre existence naturelle, peuvent être ramenés, sans détours considérables, au domaine économique et social, jugé essentiel, et dans ce cas la conception que j'ai avancée de la nature humaine, de son histoire, perd sa raison d'être ;

- ou bien la formation de ces groupements de disciplines relève fondamentalement, mais non pas exclusivement - les lois de la pensée et celles de la société y étant toujours impliquées - de l'histoire de la nature ; dans ce cas, chercher à la comprendre et à en saisir les assises objectives demeure un projet légitime.

Il existe un grand nombre de tentatives destinées à démontrer la détermination socioéconomique des arts, des sciences, etc. Le marxisme les a inspirées pour la plupart. (Voir notamment B. HESSEN : The social and economic roots of Newton's Principia, Sydney, 1946 ; G. THOMSON : Studies in ancient Greek society, Londres, 1955 ; J.D. BERNAL : Science in History, ed. cit.; F. BORKENAU : Der Übergang vom feudalen zum bürgerlichen Weltbild, Paris, 1934). Les travaux remarquables de R. K. MERTON (Science, technology and society in seventeenth century England, Osiris, 1938, IV, pp. 367-632, et Science and economy of seventeenth century England, in B. BARBER et W. HIRSCH : The sociology of Science, New York, 1962, pp. 67-88) ont pour base la sociologie de Max Weber. Jusqu'à ce jour, rien de convaincant ni de décisif n'a paru pour justifier le rattachement pur et simple des disciplines naturelles à l'histoire sociale. (A. R. HALL : Merton revisited, History of Science, 1963, 2, pp. 1-16). Devant cet échec, on s'est replié sur des positions moyennes. La thèse initiale est la même les conditions économiques et sociales modèlent le devenir des arts, des sciences, des techniques, des philosophies. Il s'y ajoute un correctif : chaque discipline, chaque science en particulier, a un mouvement propre autonome. Son histoire est donc commandée par deux déterminismes : le premier, qui provient de la société, est externe ; le second, qui correspond à une structure intrinsèque, est interne. (S. LILLEY : Social aspects of the History of Science, Arch. Int. d'Hist. des Sc. 1949, 28, pp. 376-443 ; E. KolmaN : Ueber die Gesetze der historischen Entwicklung der Naturwissenschaft, in G. HARIG (ed.) Sowjetische Beiträge zur Geschichte der Naturwissenschaft, Berlin, 1960, pp. 18-26).

Toutefois une grave dissymétrie subsiste. Lorsqu'on définit le premier déterminisme, on se réfère à quelque chose de précis : l'économie, la guerre, la politique et leurs lois supposées connues. La détermination « interne », elle, n'éveille aucune résonance concrète, et n'a guère fait l'objet de recherches ou d'études. C'est un simple aphorisme qui permet d'attribuer à une causalité interne ce qui n'a pas été éclairci par une causalité externe. En dernier lieu, cela permet à la fois de celer le manque d'approfondissement théorique, et de préserver la prééminence de la société. Des difficultés auxquelles on se heurte pour y aboutir, je tire argument, à côté de ceux que j'ai déjà apportés, en faveur du second terme de l'alternative posée au début de cette note. Celui-ci ne doit pas couvrir entièrement le réel, ni le réel lui correspondre exactement d'emblée, pour pouvoir constituer une hypothèse féconde. 


\section{Le tableau que j'ai esquissé dans les pages qui précèdent, en le soumettant au jugement du lecteur, est préparatoire. Je le compléterai à présent par l'étude du processus sous-jacent à la succession des états de nature.}

Retour à la Table des Matières

En attendant, la conjonction de l'évolution des disciplines et de celle de la société, la possibilité de pousser jusqu'à un certain point la vraisemblance d'un rapport de détermination, ne manquent pas de fondement. Elles tiennent à ce que sciences, techniques, philosophies, arts, sont dotés d'une forme sociale, qui est ainsi démontrée. Dans la communication avec l'univers ambiant, la conversion des propriétés de la matière en propriétés de notre organisme, et viceversa, nous sommes actifs et présents en tant qu'individus et groupes sociaux. Il ne s'ensuit pas que l'essence des groupes de disciplines soit sociale : elle peut fort bien être du domaine de l'histoire humaine de la nature. La contribution d'un facteur à un mouvement général n'implique pas que les propriétés du mouvement puissent être ramenées aux propriétés de ce facteur, en l'occurrence la société. ("On a prétendu expliquer l'art par la société, tandis que c'est l'art qui explique en partie les véritables ressorts de la société ». P. FRANCASTEL : Peinture et société, Lyon, 1951, p. 78). Le puissant retentissement des phénomènes physicochimiques sur l'organisation biologique n'enlève aucunement à celle-ci sa spécificité ni ne nous contraint à la cataloguer comme physique ou chimique. La fusion de la manifestation et de son fonds ravale la vérité au rang de morne tautologie, maintenue sans fin et sans profit. La théorie du déterminisme sociologique en a fait l'expérience (Voir S. MoscovicI : L'histoire des sciences et la science des historiens, Arch. Europ. de Sociol. 1966, 7, pp. 116-126). Sa fonction positive a été d'arracher les sciences, les techniques, etc. à la fantaisie métaphysique pour laquelle elles étaient de simples matières premières. Amarrer à la réalité l'intelligence ivre d'elle-même est une initiative féconde, sauf si c'est à une réalité sans intelligence. Ainsi s'est trouvé posé le problème d'une explication de l'histoire des disciplines ; toutefois la réponse n'était pas là où on la cherchait. 


\section{Chapitre V.}

\section{La division naturelle}

\section{Quelques questions préliminaires}

\section{$\underline{\text { Retour à la Table des Matières }}$}

Découvrir le ressort de la succession des états naturels, c'est, de façon concrète, répondre à deux questions : Quel est le sujet déterminé d'un état de nature? Quel est le principe qui commande le passage d'un état de nature à un autre ?

Tout au long de l'histoire humaine, les groupes humains se différencient en fonction de leurs habiletés, de leurs savoir-faire respectifs, et en fonction de la manière dont ils créent, c'est-à-dire s'adjoignent, des talents en incorporant à leur être profond les attributs des facteurs matériels. Corrélativement, le visage du milieu physique se diversifie. En présentant la nature organique, j'ai souligné l'adéquation du travail artistique à la matière appréhendée comme substance. Par ailleurs, en rappelant l'importance du travail instrumental dans la nature mécanique, j'ai mis l'accent sur le caractère de force qu'y prennent les ressources matérielles. Toutefois, au cœur de ces entités - travail organique, substance, force, travail instrumental - nous percevons la présence d'agents incarnés et rendus manifestes, qui sont les artisans pour l'une de ces natures, les ingénieurs pour l'autre. Chacune de ces collectivités représente une forme et une partie des pouvoirs inanimés, chacune possède, associées au cerveau et au corps de ses membres, les régularités et les lois de ces pouvoirs. Envisagés sous cet angle, les groupements humains constituent des catégories naturelles. En inven- 
tant et en reproduisant leurs ressources, les hommes l'ont fait, jusqu'à ce jour, dans le cadre de l'une ou de l'autre de ces catégories à laquelle ils appartenaient, et c'est aussi l'écart subsistant entre elles qui les a marqués toutes les fois qu'ils se sont retrouvés les uns en face des autres. Une liste plus exhaustive inclurait, outre l'artisan et l'ingénieur, le chasseur, l'agriculteur — et sans doute le pasteur - et enfin le scientifique.

L'existence des catégories naturelles est un fait. On peut en concevoir la teneur et l'importance si l'on étudie l'histoire humaine de la nature et, en particulier, le mouvement qui la commande. Saisir ce mouvement, c'est d'abord saisir le problème de la formation de ces catégories ; c'est ensuite concevoir le rôle qu'elles ont joué aux différents moments de l'histoire dans la reproduction et l'invention de nos habiletés. Marc Bloch en a eu l'intuition. A propos des bouleversements techniques, il observe en effet :

«La première question à résoudre serait celle que voici : dans une société donnée, quels sont les groupes porteurs d'invention? ${ }^{154}$.

Ces groupes — quel historien ne le sait ? — ont varié :

«Certaines sociétés ont connu, avant tout, l'invention des artisans » ${ }^{155}$.

En réfléchissant à la situation qui a régné pendant la seconde moitié du XVII ${ }^{\mathrm{e}}$ siècle, Marc Bloch se demande

«pourquoi les artisans n'inventent plus et pourquoi les savants n'inventent pas encore ${ }^{156}$.

Des légions de chercheurs ont tenté de déceler les raisons pour lesquelles une institution ou une classe sociale sont prédominantes ou actives à une époque, et pourquoi elles cessent de l'être à une autre.

154 Journal de Psychologie, 1948, 41, p. 112.

156

id. p. 113. 
Personne n'a, toutefois, fait écho à ces questions ni ébauché de réponse indiquant quels étaient ces «porteurs d'invention » ${ }^{157}$. L'interrogation portant sur la genèse et le caractère historique de leur action est cependant capitale. Lorsque Marc Bloch nous interpelle «pourquoi les artisans n'inventent plus », il nous somme - et il aurait pu le faire à propos des agriculteurs, des ingénieurs, etc. — de rechercher le processus régissant l'existence et les rapports mutuels des catégories naturelles.

En anticipant, on peut noter, pour l'instant, les traits de ce processus tel qu'il se présente dans la séparation des groupes d'individus eu égard à leurs facultés et aux ressources inventives ou matérielles auxquelles ils font appel : séparation de l'agriculteur et de l'artisan, de l'artisan et de l'ingénieur, de l'ingénieur et du scientifique, etc. Quant aux effets, on peut dire que le démiurge-artisan préside à l'organisation du cosmos antique ; l'ingénieur-mécanicien est le constructeur avisé de l'univers mécanique; le scientifique instaure aujourd'hui partout le règne de la nature cybernétique. Les grandes révolutions de notre histoire de la nature, en parachevant ces ruptures, obligent à procéder à la révision consécutive des liens interhumains, en centrant notamment les relations au monde matériel sur un nouveau groupe dominant de "porteurs d'invention». La substitution qui s'accomplit ainsi fait de lui, pour des siècles ou des millénaires, un détenteur des "mystères" relatifs à l'activité des hommes et à l'opération des substances. Pour l'essentiel, un seul principe est à l'œuvre, au cours de ces changements successifs c'est le principe de la division naturelle. Je justifierai plus loin sa dénomination et son originalité parmi les phénomènes analogues. J'ai voulu d'abord tenter de le mettre en relief et de montrer qu'il intéressait simultanément le pôle humain et le pôle matériel de la nature.

157 R.C. EPSTEIN : Industrial invention : heroic or systematic, Quart. J. of Econ. 1926, 40, pp. 255-6. W. KAEPFFERT : Invention and society, Chicago, 1930. 


\section{Catégories naturelles, espèces biologiques et classes sociales}

\section{$\underline{\text { Retour à la Table des Matières }}$}

La notion de catégorie naturelle n'a rien d'insolite. Elle associe, dans un raccourci, l'idée de l'homme en général à celle d'un savoirfaire particulier. L'artisan, par exemple, est une fraction de notre espèce identifiée au travail artistique. Deux remarques complémentaires justifient le choix de ce terme. La première est que les collectivités humaines, en réformant le savoir et le commerce avec l'univers matériel, engendrent des écarts entre elles et font naître des relations appropriées avec les parties de cet univers matériel. La seconde précise la raison de ces écarts, qu'elle attribue aux facultés naturelles, c'est-àdire aux aptitudes des groupes d'individus à susciter et à conserver l'organisation biologique et mentale qui s'accorde avec un état des pouvoirs non-humains. Le mode de reproduire et d'inventer est une dimension essentielle de leur particularité et un critère de hiérarchie entre eux :

« La classification certaine des humanités (je souligne) existe, c'est celle de leurs techniques, de leurs machines, de leurs industries, de leurs inventions »,

note excellemment Marcel Mauss ${ }^{158}$. Ces « humanités » dont nous avons encore à expliquer comment elles se forment, annoncent les catégories naturelles auxquelles je me réfère. Au concept de catégorie, on aurait pu préférer celui de classe ou d'espèce. Les physiocrates ont parlé, dans un sens voisin, de la classe des agriculteurs ou de la classe des artisans. Cependant, le vocable classe a aujourd'hui une connotation purement sociale. Il concerne exclusivement le partage de la propriété et du pouvoir, la distribution des biens dans une société. Au vocable d'espèce s'attachent, par contre, des résonances entièrement bio- 
logiques. Or la notion de catégorie naturelle ne disparaît pas derrière ses composantes sociale ou organique, ni ne se confond avec elles.

On accède au cœur de cette notion en considérant qu'aucune abstraction ne saurait scinder notre fonds biologique d'avec les forces matérielles. Le premier ne s'identifie pas à l'espèce humaine, les dernières ne sont pas de purs accessoires ajoutés à des éléments organiques : l'existence de l'un et des autres est soudée. L'art nous le fait voir lorsqu'il imagine les centaures ou les automates. L'évolution nous l'enseigne s'il en était besoin. Le genre homo ne se démarque pas suffisamment des autres primates par des indices anatomiques. Seul l'outillage qui accompagne les fossiles remplit cette fonction de trait distinctif et d'événement mémorable. Est-il l'effet ou bien la cause de notre séparation d'avec les autres espèces animales supérieures ? La découverte à Olduvai Gorge, dans le Tanganyika, par L.S.B. Leakey et sa femme, d'un site riche en vestiges d'une très grande ancienneté $^{159}$, a montré que le singe anthropoïde connaissait déjà l'usage et, probablement, la fabrication des outils. Voilà qui prouve de façon éclatante que la marche vers le perfectionnement du cerveau a eu en quelque sorte pour condition le développement des dextérités de la main. En termes clairs, J. Napier a dressé le bilan de cette découverte $^{160}$ :

« De plus il faut aussi considérer si le passage de l'emploi des outils à la fabrication des outils et le progrès subséquent de la technique de fabrication des outils peuvent s'expliquer uniquement en fonction de l'expansion du cerveau et de l'affinement des mécanismes neuro-musculaires périphériques, ou si un facteur périphérique, la modification de la main, a joué un rôle également important dans l'évolution de l'espèce humaine ».

De l'oréopithèque, le premier hominien, jusqu'à l'espèce actuelle, en passant par le pithécanthrope et le paléanthropien, des transformations biologiques significatives précèdent ou suivent chaque amélioration des instruments ou de leur emploi. Depuis environ deux millions d'années d'histoire humaine - ne devrait-on pas abandonner l'idée

L.S.B. LEAKEY : Olduvai Gorge 1951-1961, Londres, 1965.

160 J. NAPIER : The evolution of the hand, Scientific American, 1962, 207, p. 557. 
de préhistoire ? c'est là une donnée permanente. L'évidence milite en faveur de cette alternance du pouvoir fabricateur de l'homme et du changement de sa constitution biologique. Ne nous contentons toutefois pas de parler de main, de cerveau, d'outils. Les derniers mentionnés, par eux-mêmes, ne définissent guère l'homme. Ils ne se rencontrent jamais seuls. Leur signification se dégage à l'intérieur d'une chaîne d'opérations dont ils font partie et par rapport à un effet en vue duquel ils ont été conçus. Bref, ce sont les manifestations d'une structure et les organes d'une fonction : artefacts pour les chasseurs, machines pour les ingénieurs, etc. Le développement de chacun ressort d'un ensemble d'actions qui façonnent le milieu naturel et social de l'homme, et c'est parallèlement que se différencient « humanités » et milieux.

« Il nous faut supposer, écrit W. Etkin ${ }^{161}$, que l'écologie de l'homme avait changé de façon fondamentale pour expliquer le caractère unique de son évolution intellectuelle. Ceci n'est pas pour nier que l'emploi des outils a contribué effectivement à l'évolution de l'équipement intellectuel humain ».

On affirme que cet équipement est notre seconde nature, s'ajoutant à la structure organique de l'espèce. Dorénavant, grâce à tant de recherches précises, nous en avons la preuve ; cette structure est ellemême un résultat, auquel l' « équipement intellectuel » - et matériel - a puissamment contribué. On le concède pour les époques révolues, en admettant que « le premier chapitre de l'histoire humaine est encore entretissé d'histoire naturelle ${ }^{162}$. Je ne souscris pas à cette opinion. Puisqu'on ne peut pas délimiter avec certitude «le premier chapitre de l'histoire humaine », sans se référer à des instruments, comment le distinguer des suivants ? Pourquoi ceux-ci ne seraient-ils plus « entretissés d'histoire naturelle»?

Les catégories naturelles, telles que je les ai décrites, sont donc naturelles de par les rapports qu'elles entretiennent avec la matière, de par le caractère original de l'activité, créatrice de "dons gratuits »,

161 W. ETKIN : Social behavior and the evolution of man's mental faculties, in M. F. Ashley Montagu (ed.), Culture and the Evolution of Man, New-York, 1962, p. 146.

162 V.G. CHILDE : What happened in history, Londres, 1942, p. 27. 
qu'elles représentent. A cet effet, elles supposent des aménagements biologiques de l'espèce; cependant elles ne sont pas biologiques de façon intrinsèque, primitive. Les chasseurs n'ont probablement pas tous été de l'espèce homo sapiens. Pour les agriculteurs et les artisans, cette appartenance est un fait ; il n'a rien de décisif.

Dès l'instant où l'on passe de l'évolution humaine dans la nature à l'histoire humaine de la nature, les aspects liés à l'espèce, aux races, à la variation biologique animale n'ont plus d'autonomie véritable. La question de Charles Darwin: "Le genre humain se compose-t-il d'une ou de plusieurs espèces? » reçoit une réponse différente sur le plan de l'histoire et sur celui de l'évolution. Au plan de l'histoire, on ne saurait exclure l'homo habilis, l'homme de Neanderthal, pour se fixer à l'homo sapiens. Leur spécificité, si c'est le critère biologique qui est choisi, est incontestable. Leur communauté en regard de l'outil, de la chasse, de la cueillette, ne l'est pas moins, jusqu'à un certain point. La division marquante, effective, quant aux causes de leur diffusion et de celle de leurs ressources, est la division en catégories naturelles. Cela est vrai quelle que soit, sur l'échelle globale du temps, l'espèce à laquelle elle s'applique. La gradation des catégories inclut la différence de structure des organismes, sans pourtant en dépendre.

Néanmoins, si je récuse le particularisme biologique en tant que raison de la différenciation naturelle, au sens entendu plus haut, je ne me rallie pas à cette vision placide qui, depuis son triomphe au XVIII ${ }^{\mathrm{e}}$ siècle, proroge l'existence indolente de principes inactifs, élevant le préjugé et la croyance au rang de raisonnement théorique. A savoir que l'homme est toujours et partout le même, et que les seuls changements qui l'affectent, ceux des instruments, des contenus intellectuels, des connaissances, lui sont pour ainsi dire extérieurs. Selon cette opinion, la progression de toutes ces techniques, de toutes ces sciences, l'assimilation de toutes ces forces matérielles, glisseraient sur notre capital organique originel sans y laisser de traces. L'homo sapiens, la dernière en date des espèces hominiennes, ne s'est-il pas définitivement stabilisé depuis trente mille ans ? L'ère des réorganisations anatomiques et physiologiques des hominiens est close : seule la superstructure des moyens artificiels, de l'acquis, reste susceptible de changer. En réalité, cette stabilité ne dure que depuis trente mille ans, 
période qui représente environ le sixième de notre évolution, et nous ne sommes pas près de nous éteindre en tant qu'espèce. Rien ne nous permet de soutenir que ces bouleversements techniques, intellectuels, nous soient purement extérieurs. Les études anthropologiques démontrent le contraire : ils ont trait à notre fonds biotique, ils déterminent notre être et nos possibilités d'action. Si nous ne connaissons bien que l'histoire des cinq ou six derniers millénaires, nous devons néanmoins nous penser comme existant depuis deux mille millénaires. Ce décalage des échelles du temps nous indique dans quelle perspective se situe l'avenir eu égard au passé dans lequel on se reconnaît. L'histoire pensée historiquement et le passé le plus reculé nous fournissent un enseignement clair. L'homme n'est pas demeuré le même ; entité organique et matérielle, il n'a pas gardé la même nature humaine, qu'elle soit seconde ou première, depuis le moment où il a commencé à faire, à organiser ses propres états de nature. Ce faire a eu pour résultat l'apparition de nouvelles catégories de «porteurs d'invention », dont l'individualité ne requiert pas celle des espèces, des races ou des ethnies, ni ne se ramène à une simple possession adventice d'instruments matériels ou intellectuels. Pour cette dernière raison, les limites de son impact ne sauraient être imposées à l'avance et par décret.

Le problème se pose maintenant de savoir quelle relation existe entre les catégories naturelles et les classes sociales. Il est amené notamment par les faits suivants: (a) les membres des catégories les moins importantes sont exploités du point de vue économique et relégués au bas de la hiérarchie sociale ; $(b)$ la répartition des habiletés est également un processus social. Autrement dit, la division en catégories naturelles a-t-elle un sens propre, ou bien n'est-elle qu'une manière déguisée d'exprimer la séparation de la société en classes?

Certes, il faut refuser cette dernière façon de voir. La distance d'une classe sociale à une autre est réglée par la loi d'appropriation des richesses ; au contraire les indices distinctifs des catégories naturelles sont le degré de qualification et le genre de travail créé. Du point de vue économique et social, l'écart qui sépare l'ingénieur du travailleur agricole est uniquement d'ordre quantitatif ; ils sont ensemble les représentants du travail salarié. Ce n'est pas l'absence de 
connaissances ni le rôle dans la production qui fait le prolétaire ou l'esclave. Seule est en cause leur place dans l'organisation sociale. Là, intégrées à la production et à l'échange, envisagées du point de vue de leurs produits, ces catégories apparaissent comme des instruments sociaux et sont décrites uniquement comme des professions. Inversement, la place d'une collectivité dans la hiérarchie n'a aucun rapport avec son insertion dans l'état naturel et technique. Un riche propriétaire ou un industriel très actif - est-il nécessaire de le mentionner? - ne dépasse pas forcément, par ses facultés, le niveau de l'artisan prolétaire, que la machine a privé de ses talents les plus précieux pour l'obliger à se tenir debout douze heures d'affilée.

S. Clegg, un des pionniers de l'architecture des machines, en a fait la remarque :

«Il faut se rappeler que la majorité de ceux pour qui les machines sont construites ne peuvent concevoir le mérite de leur activité ou de leur performance comparative; ne voulant pas renoncer à juger, ils jugent sur les apparences, comme ils le feraient pour un tableau ou une statue, dont le seul but est de charmer le regard, de stimuler les impressions agréables de l'esprit, par la représentation de la nature dans ses effets les plus sublimes. C'est seulement sur ceux qui, par leur éducation, sont qualifiés pour juger du mérite intrinsèque, que l'on peut dire que la nature ou l'art produisent des impressions correctes $\gg{ }^{163}$.

Voilà tracée rigoureusement la frontière, dont on a tendance à sous-estimer l'importance, qui sépare l'individu propriétaire du moyen ou de la force de travail, de l'individu capable d'inventer ou de manier ces moyens et ces forces. Les classes sociales sont marquées par les échanges entre les hommes relativement aux richesses, les catégories naturelles par leur reproduction relativement aux ressources, et par le genre de travail créé.

Pour cette raison, un même groupe social peut se répartir entre deux ou plusieurs catégories naturelles ; certaines différences peuvent exister entre ses membres, mais elles ne sont pas essentielles au plan 
de la société. Les esclaves de l'antiquité étaient aussi bien le «bétail humain ${ }^{164}$ dont les souffrances, l'abaissement dépassent l'imagination, que le matériel organique dont on faisait volontiers des potiers, des médecins ou des philosophes. Si, de ce fait, le destin de tous les esclaves n'était pas identique, le sceau de l'esclavage n'en était pas moins apposé sur chacun.

Qu'il s'agisse d'esclaves, de serfs ou de prolétaires, les écarts naturels ont surtout trait à leur insertion directe ou indirecte dans la création des dextérités ou des connaissances. Réciproquement, ces écarts se prolongent et se conservent malgré la diversité des systèmes sociaux qui les embrassent. Ce qui caractérise le capitaliste, le propriétaire d'esclaves, le prolétaire, est leur position à l'intérieur d'une société particulière. Lorsque la société disparaît, un individu cesse d'être prolétaire ou esclave, il reste toujours ingénieur ou artisan ${ }^{165}$. Les exemples sont grossis et ces vérités tombent sous le sens. On les oublie facilement en amalgamant les inégalités subsistant entre les classes sociales aux disparités dues à la division en catégories naturelles.

Comparées aux classes sociales, les catégories naturelles ne sont pas — telle est l'opinion implicite ${ }^{166}$ — des groupements fondamentaux ${ }^{167}$. Tant que le critère économique et politique est considéré comme le plus décisif et, en définitive, l'unique critère, cette hiérarchie peut paraître justifiée ; mais si on envisage l'histoire de notre nature, on est bien obligé d'affirmer et de maintenir la primauté de ces

164 «Ce bétail humain comportait des hommes fort instruits, docteurs, hommes de science, artistes, clercs et artisans, à côté de prostituées et de manœuvres ». V.G. CHILDE : De la préhistoire à l'histoire, Paris, 1964, p. 307.

165 La continuité et la persistance des forces productives à travers plusieurs ordres socioéconomiques décrivent nécessairement les catégories naturelles. On peut dire de celles-ci ce qu'on dit de leurs organes de reproduction, les formes techniques : «Bien que le développement de la technique soit soumis aux lois économiques de toute formation sociale, il ne se termine pas, comme d'autres facteurs économiques, lorsque cessent les lois de formation. Lorsque, dans le processus de la révolution, les anciens rapports de production se brisent, la technique demeure, et, soumise aux lois économiques de la nouvelle formation, continue à se développer avec une vitesse accrue ». A. ZVORIKINE : The history of technology as a science and as a branch of learning : a Soviet view, Technology and Culture, 1961, p. 2. Mise à part l'idée inexpliquée de vitesse, ce texte décrit assez fidèlement les faits.

166 R. ARON : La lutte des classes, Paris, 1964.

167 Les principes du Marxisme-Léninisme, ed. cit. p. 184. 
catégories. Dans son contexte, ce sont les classes sociales qui apparaissent comme dérivées ou secondaires.

Je sais qu'il est choquant de parler de l'homme, aujourd'hui, en termes naturels, de classer les hommes en catégories qualifiées de naturelles. Les connotations biologiques sont immédiatement visées. On l'a vu, elles sont secondaires. De plus, «naturel » signifie pour la plupart d'entre nous inné, perpétuel, inchangé, non-social. A la lumière des arguments exposés, on conçoit qu'il s'agit au contraire d'un caractère mouvant qui se constitue au cours du processus d'auto-création de ces « humanités » auxquelles faisait allusion Marcel Mauss, et dans le cadre de leurs relations. 


\section{La séparation des catégories naturelles : conditions et conséquences}

\section{$\underline{\text { Retour à la Table des Matières }}$}

Les catégories naturelles se forment et s'individualisent par division. L'observation confirme l'importance du phénomène et nous l'impose pour point de départ de l'analyse théorique. D'emblée nous devons nous assurer de sa spécificité. La division sociale, réunissant sous une même rubrique les travaux les plus dissemblables — de l'administration politique ou militaire des hommes au gouvernement technique et intellectuel du monde physique - affirme avant tout comme une nécessité objective la ségrégation relative des tâches dévolues aux membres du corps social. Elle ne se réfère pas de manière plus particulière à la distribution des talents productifs, ni à celle des connaissances. La division du travail, de son côté, englobe les méthodes employées pour développer les savoir-faire d'une collectivité, d'un cycle de production. Il ne faut pas faire figurer parmi ses effets l'apparition de ce cycle ou ces savoir-faire, préliminaires obligatoires de la spécialisation recherchée des individus. La division naturelle, par contre, a pour champ d'action la création du travail ; elle affecte les liens qui unissent les groupes humains pour autant qu'ils reproduisent et inventent leurs facultés. Ce qui sépare l'agriculteur de l'artisan ou du scientifique doit être appréhendé sous cet angle. La première des trois divisions mentionnées répond à la demande suscitée par l'organisation des États et celle des échanges, et par le contrôle des divers secteurs de la société. La seconde est née de l'exigence impérieuse d'économiser la main-d'œuvre dans les ateliers, les manufactures ou les industries. La division naturelle, elle, n'a jamais été aussi marquée qu'à notre époque. Les processus de création des savoirs se dissocient d'avec la production des objets. La place prise par l'invention continuelle de nouveaux genres de travail, l'attention croissante portée à cette multiplication des genres de travail plutôt qu'à leur efficacité, témoignent de l'importance de ces processus. Le besoin clairement formulé de connaître et de régir la génération des disponibilités en forces matérielles et en habiletés suppose la recherche d'une règle générale. Les vocables conventionnels et imprécis tels 
que croissance, développement ou progrès, n'en expriment pour l'instant aucune. Chaque division reflétant une facette du travail distribution dans la société, productivité technique, transformation en un autre travail - vient requérir en son temps la dignité de concept. La division qui parcourt et domine l'histoire humaine de la nature accède au sien à travers l'analyse $(a)$ de la différenciation des catégories naturelles et (b) du classement des ressources matérielles et de l'organisation des systèmes de reproduction des talents qui les prolongent.

Les catégories naturelles se distinguent en tant qu'ensembles d'individus, exerçant dans des sphères objectives des capacités appropriées ensembles presque identiques du point de vue biologique et social, mais distincts sous l'angle de leur symbiose avec les puissances du milieu physique. La découverte du scientifique est l'aboutissement d'un effort délibéré, systématique, et se situe au niveau même de l'organisation de la matière. La découverte de l'ingénieur conserve les traces d'un tâtonnement laborieux, parfois inconscient de ses fins dans l'aire des machines et des sources d'énergie. Les rapports entre les hommes retracent, en général, des rapports concomitants entre des entités non-humaines. L'agriculteur se compare au pasteur, comme le règne végétal au règne animal; l'ingénieur se situe en face de l'artisan, représentant la matière inanimée mécanique en face de la matière animée organique. La position d'un homme vis-à-vis d'un autre homme décrit et reflète la position d'une première puissance de la matière en regard d'une seconde puissance. L'ordre inscrit de la sorte à l'intérieur de l'humanité correspond à l'ordre, qui varie au cours de l'histoire, embrassant les parties du monde matériel.

La primauté d'une manifestation de la matière et celle d'une partie de l'humanité sont simultanées. Certes, nous sommes avertis que des facultés et des forces s'élaborent successivement, s'ajoutant à celles qui ont été engendrées il y a des centaines de milliers d'années. La totalité de ce mouvement aurait cependant pour nous l'opacité de la caverne platonicienne si, régulièrement, un pouvoir matériel, un secteur de l'univers ne devenaient prédominants, différenciateurs ; ainsi leur vocation de ressource est complétée par une fonction de critère à partir duquel s'ordonnent tous les processus objectifs. Tour à tour le 
règne végétal et l'agriculteur, la puissance sensorielle, musculaire et l'artisan, la force mécanique et l'ingénieur, l'énergie électro-chimique et le scientifique ont rehaussé les sommets de la nature et imaginé ses fondements derniers. L'enchaînement de ces réalités proclamées « ultimes » est visible. Il concrétise simultanément la succession et la hiérarchie introduites parmi les secteurs de l'ordre cosmique. Lorsqu'un de ceux-ci se détache en relief; il annonce la formation d'une catégorie naturelle et mesure son degré d'existence pratique à un moment défini. L'affinité qui les unit, très étroite, ne saurait être ramenée à une pure analogie. Au contraire, elle accuse la communauté des conjonctures : celles qui réorganisent le milieu physique auquel nous faisons face et celles qui distribuent les savoirs entre lesquels nous nous divisons.

Par ailleurs, et pour compléter ce qui vient d'être dit, la répartition des savoirs appelle une définition corrélative des mêmes éléments du milieu matériel. Pour l'agriculteur, la terre est matrice nourricière des plantes et des animaux, lieu de vie et de croissance. La succession des saisons, l'union féconde du mâle et de la femelle, le croisement et la perpétuation des espèces, l'irrigation et la protection des sols imprègnent sa vision du réel et règlent son existence concrète. Une solution de continuité apparaît avec les arts et l'artisan. Du sein de la terre qui, comme toute substance, peut être cuite, brûlée, broyée, ne sortent plus seulement fleurs ou céréales mais aussi pierres à bâtir et pierres précieuses, métaux, colorants, etc. Les animaux existent pour leur laine, leur peau, leur corne, les arbres pour leur bois. La complémentarité des catégories naturelles, la solidarité qui les unit dans un système de reproduction assurant à chacune l'emploi de ses talents et les matériaux auxquels ils s'appliquent, découlent de l'articulation de leurs ressources. L'évolution de leurs rapports n'en exprime pas moins une vive opposition. Chaque catégorie, soucieuse d'indépendance, déterminée par les processus naturels qui lui sont propres et dans lesquels elle est engagée, porte atteinte à la plénitude et à la pérennité de l'autre. L'antagonisme de deux fractions de l'humanité prend le masque de l'antagonisme de chacune de ces fractions à son fonds matériel. Celui-ci est toujours représentatif d'un ensemble de connaissances, dépositaire de l'énergie, de la vitalité d'une collectivité qui garde l'accès à un aspect de l'univers. Le pasteur détient pour l'agriculteur 
les clés du monde animal, et il ne pénètre ni n'acquiert le contenu de ce monde sans affronter son gardien. A ce titre, une catégorie naturelle peut être assimilée aux ressources d'une autre catégorie. Cette dernière incarne à ses yeux l'opacité du pôle matériel, qu'il importe pour elle de dissiper afin de s'affirmer le pôle humain d'un état naturel.

L'exemple désormais classique, qui résume une expérience millénaire - le meurtre du pasteur Abel par l'agriculteur Caïn en offre la contrepartie mythique - est la métamorphose de l'artisan, de son métier, en forces et mécanismes dus à l'inventivité de l'ingénieur. Placés côte à côte, le premier maître de son outil et des règles de l'art, le second armé d'instruments mathématiques et de savoirs mécaniques, que sont-ils d'autre que deux types de créateurs, dégageant chacun de façon originale une physionomie de la matière ? En même temps, le corps et la dextérité du tisseur, du potier, du forgeron, du sculpteur, ainsi que leurs outils, présentent aux yeux de l'ingénieur la réalisation, aux dimensions près, des lois des forces gravifiques ou inertiales, une variante, douée de vie, de ces forces. Merveilleuse orchestration de leviers, de poulies, d'engrenages, l'habileté artisanale articulée avec un organisme est déjà le programme prometteur d'une machine humaine combinée à une machine non-humaine, soumises toutes deux à des règles identiques. La vision, la pratique de l'ingénieur traitent l'artisan comme une fraction ou comme un équivalent de son champ matériel d'action, la force mécanique. L'hétérogénéité instaurée est à tel point radicale qu'elle réduit à l'insignifiance les traces de l'appartenance de deux catégories naturelles à une même espèce biologique : l'espèce humaine.

Il s'ensuit que, lorsqu'une partie des hommes vient à s'affirmer en s'adjoignant les propriétés de la matière comme habileté et connaissances, une autre partie de l'humanité s'engouffre dans la matière; ce qu'elle s'est donné pour intelligence devient inintelligence, ce qu'elle s'est arrogé pour particularité humaine devient sa généralité nonhumaine. A l'humanité qui peut se percevoir comme générique, car 
elle synthétise les traits d'un état de nature, s'oppose l'humanité nonhumaine ${ }^{168}$, représentant une force matérielle quelconque de cet état.

L'écart entre les classes d'hommes est l'écart qui sépare, à une époque historique, l'homme de la matière. Il faut y voir, pour revenir à l'exemple choisi, l'aboutissement d'une évolution où les rapports des hommes avaient d'abord été rapports de deux arrangements distincts de forces matérielles spécifiques, quand l'ingénieur ou le philosophe mécanicien, ce curieux et ce virtuose, découvrait dans les gestes et les mains de l'artisan et dans ses outils une dextérité et une énergie, une modification des potentialités biologiques et intellectuelles, qui faisaient de lui l'indice d'une puissance matérielle différente des autres. L'étape ultérieure a consisté à le transformer en matière, matière mécanique, d'une catégorie nouvelle. L'homme recherche et fixe, dans la matière, non seulement l'autre de l'homme mais aussi l'essence d'un autre homme.

Le processus a toujours été abordé de biais. On a voulu y voir la substitution universelle des opérations non-humaines aux opérations humaines la relève libératrice des esclaves humains par des esclaves mécaniques. Je ne dispute pas l'évidence de cette substitution, seulement je la crois secondaire. Au contraire, le fait fondamental me paraît être le suivant: ce n'est pas la matière qui vient à la place de l'homme, mais une matière qui vient à la place d'une autre matière, un homme à la place d'un autre homme. L'ingénieur remplace l'artisan, la variété des substances et de leurs qualités est subordonnée à la force mécanique. De cette façon naissent des liens nouveaux - et des genres nouveaux de liens - entre les hommes, entre ceux-ci et le monde physique. Mais la condition requise pour l'apparition de quelque chose de neuf est la métamorphose de l'homme en matière, avec la métamorphose simultanée de la matière en homme. Telle est du moins la règle qui a prévalu jusqu'à ce jour. La formation d'une catégorie naturelle nouvelle et la conversion d'une autre catégorie naturelle en sa ressource matérielle et inventive résultent de cette condition et traduisent le devenir humain de la matière et le devenir matériel de l'homme. 
Ce devenir s'opère à travers une séparation des collectivités qui place les unes au pôle humain et les autres au pôle matériel d'un état de nature particulier. De la sorte, comme le remarquait Marc Bloch, certains groupes cessent d'être capables d'inventer. Toutes leurs capacités physiques et intellectuelles se consument dans la production des objets, tandis que leurs talents sont comptés parmi les moyens de reproduction du groupe qui peut se prétendre, quant à lui, «porteur d'invention ", créateur de savoirs. Non pas de manière exclusive, certes, mais de manière suffisamment importante pour marquer un écart qui instaure parmi les hommes l'inégalité des situations et une différence analogue à celle qui existe entre une catégorie spécifique et sa principale force matérielle. Assurément, la division naturelle modifie les rapports de notre espèce aux diverses espèces animées ou inanimées. Sa qualité de processus historique transparaît surtout dans le fait qu'elle affecte la relation de l'homme à l'homme, en la doublant d'un rapport de la matière à la matière. 


\section{Le caractère nécessaire de la division naturelle}

$\underline{\text { Retour à la Table des Matières }}$

Pourquoi la transformation des échanges entre l'homme et l'univers matériel se produit-elle par division ? Pourquoi une catégorie naturelle, au lieu de se modifier directement en s'annexant les habiletés qu'elle crée et les forces matérielles qui l'accompagnent, se convertit-elle en donnant naissance à une autre catégorie naturelle qui se détache d'elle?

Je rapporte, en premier lieu, la nécessité de cette division à la structure du travail productif général, à la place qu'il occupe dans l'emploi de nos disponibilités physiques et intellectuelles. L'humanité s'intègre à ce travail productif comme partie de la matière non-humaine, soit par sa force musculaire brute, soit par son sensorium apte à servir et à compléter une puissance motrice quelconque, celle de l'eau ou des animaux, celle du vent ou de la vapeur. Le potentiel biologique des organes, des muscles humains a été pendant le laps de temps écoulé la source principale du travail productif et continue à l'être.

Notre corps a également été - et est toujours - le dépositaire de la plupart des informations recueillies et des habiletés engendrées pour rendre le travail productif. Ces habiletés, il ne faut pas l'oublier, sont aussi des théories des phénomènes matériels, des livres dont le texte, au lieu d'être imprimé sur du papier et enfermé dans une bibliothèque, est inscrit dans le cerveau, les postures, les rites des individus. Si on se tourne vers le passé, on observe que les savoirs qui donnaient vie à un ensemble artistique ou technique étaient gravés avant tout dans l'espèce, et ont péri avec les individus et les corporations auxquels ils étaient destinés. De même que l'incendie de la bibliothèque d'Alexandrie a détruit à jamais une part importante des œuvres et des témoignages grecs, de même la mort, la conversion lente ou l'anéantissement de générations de producteurs et de créateurs nous ont privés de ces théories, de leurs conceptions et de leurs démarches concernant la matière ; nous n'en retrouvons que les coquilles vides, 
sous forme d'instruments, de langages, d'œuvres, auxquels notre imagination incontinente parvient à insuffler quelque âme - mais au prix de quel anachronisme!

Cette interdépendance étroite des éléments organiques et nonorganiques entraîne une fixation réciproque des dextérités et des propriétés objectives, une stricte adéquation des unes aux autres. D'une manière générale, une fraction importante des disponibilités biologiques et intellectuelles doit être consacrée à des tâches purement motrices. La productivité, pour autant que l'homme est une composante de tout travail productif, dépend largement de la subdivision et de la spécialisation. Cette spécialisation, outre l'économie qu'elle représente, est aussi fusion intime de l'individu avec son activité : elle réduit ses degrés de liberté, accentue l'étroitesse de son champ, limite son horizon. La répétition, au cours de plusieurs générations, de démarches et d'opérations identiques, l'obéissance aux injonctions à observer, le respect du classement déjà établi des habiletés et des attributs à l'égard du milieu, engendrent des cadres rigides. La routine étendue au fonctionnement du corps et de l'esprit, à leur coordination productive, préserve de la contingence inhérente à tout commencement, fortifie les résistances nées dans un secteur du savoir-faire par les résistances à l'ouvre dans un autre, de façon à maintenir la stabilité de l'ensemble. La rigidité, le compartimentage rigoureux engendrés par la subdivision du travail pour accroître la productivité, font de la séparation des " porteurs d'invention » une démarche pratique inéluctable. Les règles sociales, les incompatibilités biologiques ${ }^{169}$ font le reste.

Toutefois les exigences de la création des dextérités et des connaissances exercent une pression plus forte, amenant une rupture qui constitue la division naturelle. La structure des facultés, leur fixation subjective aux organes humains, font obstacle à ce qu'un même homme ou un même groupe d'hommes assimilent et pratiquent des genres de travail doués de qualités antagonistes. Quel que soit le temps dont dispose l'agriculteur néolithique pour travailler les métaux, le cadre gé-

« Un emprunt technique est facilité lorsqu'il ne nécessite pas une nouvelle attitude corporelle, tandis qu'une modification dans l'outillage ou le mode d'emploi de celui-ci se heurte à des habitudes difficiles à modifier ». A.C. HAudricourT, M.J. BRunHeS-DElAmARE : L'homme et la charrue, Paris, 1957, p. 33. 
néral dans lequel il exerce son habileté ne lui permet guère de la parfaire au delà d'un certain seuil. En effet, la matière première dont il dispose se trouve dans une aire limitée, l'impossibilité de se déplacer lui interdit des échanges féconds, l'apprentissage agraire n'encourage pas la sélection et la conception de méthodes particulières, tellement il s'étend à tous les aspects de la vie sociale et naturelle et reste nonspécifique en tant qu'apprentissage. La femme potier ou tisseur est dans une situation analogue. La culture de la terre développe un esprit de dépendance vis-à-vis du cycle des saisons, des phénomènes spontanés propres à la vie, des rythmes qu'il s'agit avant tout de respecter. $\mathrm{Au}$ contraire, l'artisan aborde la matière comme un objet, auquel il peut donner consciemment des formes variées. Que l'on songe aussi à la diversité des relations que le chasseur et le pasteur entretiennent avec le règne animal. L'un épie, attire, recherche, piège l'animal pour le tuer; l'autre s'efforce de le maintenir en vie, se préoccupe de sa croissance, de ses liens avec les autres animaux et avec les hommes. Ou encore, comparons l'ingénieur et l'artisan. Le premier développe ses talents, résout les problèmes auxquels il doit faire face grâce à l'emploi des instruments de mesure et à l'invention des mécanismes ; le second, pour arriver à ses fins, améliore son agilité manuelle, coordonne ses gestes, combine les informations reçues par ses sens, s'intéresse exclusivement aux qualités perceptibles des matières premières, etc. Donc, pour parachever et conserver ses capacités particulières, chacun de ces groupes doit les reproduire séparément et affirmer son indépendance. Le trait organique, subjectif, de tout savoir fait que ceux qui possèdent ce savoir sont amenés à se disjoindre du circuit des connaissances et des habiletés qui contrarierait la logique interne de leur épanouissement.

A la suite de cette disjonction, les ouvrages animés qui constituaient les répertoires des habiletés et des ressources se prêtent à une retranscription sous forme d'autres ouvrages animés. Pour y parvenir, c'est-à-dire pour transformer une première dextérité, une loi de l'univers matériel enregistrée dans des individus biologiques, on doit l'appréhender comme objet d'une seconde dextérité. Le savant moderne peut prendre connaissance des propriétés physiques ou chimiques de la matière par une étude systématique de la littérature spécialisée. L'artisan n'accède aux recettes du tissage, au secret du choix 
des argiles qu'auprès de la cultivatrice qui tisse et fait de la poterie. L'architecte-ingénieur de la Renaissance commence à pouvoir recourir au livre, mais c'est l'observation attentive des opérations du charpentier ou du forgeron qui lui ouvre les voies de la force et du mouvement mécaniques. L'invention n'a souvent été que cela, à savoir la reproduction d'un travail dans un contexte différent, hors des associations habituelles avec la matière. Là aussi, une séparation est indispensable : si l'on n'envisage pas de l'extérieur cet arrangement organique, il est vain de prétendre le bouleverser. C'est de cette manière qu'on peut tenter de combiner ces forces matérielles dans un monde nouveau.

La division naturelle trouve sa raison d'être dans ce phénomène sur lequel j'ai déjà attiré l'attention : l'institution du rapport de l'homme à la matière passe directement par un autre homme. L'antagonisme qui en résulte est indicatif et fécond, car, à un moment, les deux variantes d'un même savoir se font face concrètement : l'agriculteur-fabricateur domestique et l'artisan, le maître-maçon et l'architecte-ingénieur. Ceux qui y ont vu une simple subdivision de la totalité, un fractionnement des capacités existantes propre à alléger les efforts de chaque couche productive, ont négligé ce phénomène essentiel qu'est la recombinaison d'une famille de facultés, les unes sous leur forme originale et les autres sous un aspect transformé. C'est qu'ils se sont attachés au stade final, sans tenir compte de la genèse réelle.

Chaque catégorie naturelle est en quelque sorte la transposition plus ou moins élargie d'une catégorie d'origine, elle est cette catégorie transposée. L'artisan est la version transfigurée d'un secteur de l'activité agricole, l'ingénieur est la forme neuve d'une fraction du travail artisanal, tout comme l'agriculteur néolithique, la femme, pour être plus précis, était une variante révolutionnaire du chasseur et cueilleur primitif. Ces changements représentent des essais d'adaptation de l'espèce au milieu matériel renouvelé ; compte tenu des modalités de création du travail, qui est biologique dans une grande mesure, ils appellent une coupure, une scission. La reproduction et l'invention des savoirs et des dextérités imposent une distanciation, une hétérogénéité des groupes humains, afin que leurs potentialités puissent se développer et les ressources dont ils disposent s'actualiser. Cependant, et ceci 
décrit l'allure d'ensemble du processus historique, la quantité de travail destinée à inventer, à reproduire, demeure relativement faible. La plupart des hommes consacrent leurs efforts et leurs capacités à produire des objets, à manier des outils, à façonner directement la matière première ou à la transporter. De plus, l'activité inventive est fréquemment subordonnée aux pratiques courantes, noyée parmi elles. Seule une série d'événements exceptionnels, une intervention extrinsèque l'arrache aux routines familières pour la placer dans un cycle distinct et lui conférer une individualité certaine ${ }^{170}$.

En résumé, la faiblesse de la quantité de travail proprement inventif d'une part, l'imbrication étroite du processus inventif et du processus productif d'autre part, ont pour conséquence une élaboration lente et dispersée des ressources et des savoirs. La communication des découvertes dépend étroitement du déplacement des populations ne sontelles pas scellées aux nerfs et aux muscles des individus?

«Il y a un peu plus de deux siècles seulement que les connaissances techniques se transmettent autrement que par le geste et la parole $»{ }^{171}$.

L'estimation de M. Daumas est optimiste. Pour ma part, je ferais remonter à environ un siècle seulement le moment où l'homme n'a plus été introduit par un autre homme dans le commerce avec la matière et ses propriétés, à l'aide d'une initiation quasi biologique.

Les rencontres et les contacts entre les hommes accélèrent ce processus. Ils permettent également de combiner et de compléter les inventions qui ont été classées parmi les occupations indéfiniment répétées des individus. L'augmentation de volume de la collectivité, la mobilité de ses membres sont des facteurs importants : ils accroissent la probabilité et la vitesse de convergence de fragments de connaissance disparates. Messages en chair et en os, séparés de leur contexte, métiers et talents circulent, s'associent ou se dissocient, jusqu'à reconstituer un nouveau discours, s'unir dans un nouveau code. Dans Techniques, Paris, 1962, t. I, p. 55. 
ces conditions, il est hors de question que la chaîne des talents et des matériaux à découvrir ou à remplacer soit anticipée, que le changement éventuel soit prévu ou qu'il porte systématiquement sur la totalité des productions ou des savoir-faire. Au contraire, tout semble résulter d'une succession de hasards: l'apparition de phénomènes matériels inconnus, le regroupement des capacités nouvelles, l'invention d'un procédé, etc. Un remaniement conscient, global, de l'ensemble du système de reproduction, des échanges avec la matière, est chose très difficile. Parallèlement, l'accommodation d'une catégorie naturelle aux forces objectives naissantes ne saurait avoir lieu que de manière lente, incomplète, fragmentaire, somme toute discontinue dans l'espace et dans le temps. Un renouvellement effectué dans un secteur de connaissances, de techniques ou de règles opératoires ne se diffuse que très tardivement dans les autres secteurs, figés depuis des siècles, voire depuis des millénaires, et qui se sclérosent de plus en plus. Les initiatives qui provoquent ce renouvellement ne sont pas les plus énergiques, ni les plus conscientes de leurs buts, ni les mieux intégrées dans une action d'ensemble. Si cent hommes s'attellent simultanément à une tâche, leur travail aura un rendement bien supérieur à celui de cent hommes dont l'effort s'étale sur plusieurs siècles : ce dernier cas est la règle qui a prévalu au cours de l'histoire. Dès lors l'impact des inventions n'est pas suffisamment ramassé, puissant, pour renverser les relations instaurées à l'intérieur d'une catégorie définie et leur en substituer d'autres, sans passer par la séparation et l'opposition qui transforment une figure de l'humanité en une autre figure d'elle-même.

Toutefois les conditions dans lesquelles nos facultés sont reproduites et inventées subissent actuellement un remaniement profond. La substitution des forces non humaines à l'énergie humaine et leur fonctionnement qui ne dépend plus de nos organes sensoriels bouleversent la structure du travail productif. L'extension des procédés non biologiques (livres, systèmes documentaires, machines à mémoire, moyens audio-visuels, etc.) pour l'enregistrement des informations venues du monde extérieur accélère et facilite l'assemblage et le traitement des capacités et des connaissances les plus diverses. Avant que ces développements atteignent toute leur ampleur, le principe de la division naturelle répond, dans les limites de la formulation donnée, aux exi- 
gences qui ont prévalu dans le déploiement des dimensions et des facultés de notre espèce, au cours de son insertion parmi les autres espèces et forces.

$\underline{\text { Retour à la Table des Matières }}$ 


\section{Les formulations indirectes du processus de division naturelle}

\section{$\underline{\text { Retour à la Table des Matières }}$}

Le sens de la division naturelle se précise maintenant, sur le plan réel et sur le plan théorique.

Sur le plan réel, elle découpe un champ d'action dont les problèmes sont nettement définis ils ont trait à la métamorphose des genres de travail et de connaissance, et cernent la nécessité d'expliquer et de diriger l'évolution de nos facultés et du milieu ambiant dont elles participent.

Sur le plan théorique, pour autant que l'existence et le développement des catégories naturelles se rattachent au phénomène de division, celui-ci paraît affecter conjointement la transformation des facultés humaines et des puissances matérielles, dans leurs domaines respectifs, et la qualité de leurs rapports. J'ai signalé en son lieu l'enchaînement, la correspondance qui existent entre l'ordre des parties de la matière et celui des parties de l'humanité. Ensemble elles accèdent à la vie historique de notre nature. Il en découle que cette vie n'est pas, comme on veut le croire, un destin anonyme et désordonné, une longue marche dépourvue de lois et de fins, mais la mesure exacte de nos actes et de nos rapports.

La perspective véritablement naturelle du processus de division se traduit de la façon suivante : elle exerce une influence simultanée sur tous les facteurs qui composent la nature humaine, et a fortiori elle intervient au niveau des liaisons qui représentent ces facteurs, dans le passage d'un de ses états à un autre. J'ai quelque peu grossi ses traits. Je l'ai fait pour montrer à quel point la division naturelle était un processus original et général. Néanmoins, durant la plus grande partie de notre histoire, cette division a revêtu le caractère d'une séparation des sexes et, à un moindre degré, des générations. L'affectation des individus à des tâches définies semblait prolonger une tendance commune 
à la plupart des espèces animales, la nôtre incluse. Cette apparence est à la source de ce qu'on a appelé " la division dite 'naturelle' du travail », qui « se base sur l'âge et le sexe $»{ }^{172}$. Pour autant qu'elle recouvre une période où l'on ne dispose pas d'un surplus de travail et de richesse, où la densité de la population est faible, on ne peut guère la décrire comme une division sociale ${ }^{173}$ ou issue de la différence de position sociale des hommes et des femmes ${ }^{174}$. Ce serait extrapoler indûment que de rapporter la division proprement dite du travail à une production dont on ne se propose pas consciemment d'accroître la productivité, soit dans le sens d'une augmentation de l'efficacité des techniques, soit dans celui de la perfection systématique de l'habileté ou du produit. Nous y contemplons le modèle - en ces temps très rudes et mythiques à nos yeux — d'une humanité pour laquelle la reproduction sexuelle et sociale était associée immédiatement à la reproduction naturelle, et pour laquelle les relations entre les hommes et les femmes avaient une correspondance explicite dans les ressources respectives de chaque groupe. Les différenciations sociales et techniques ne se détachent pas de leur matrice naturelle pour devenir les médiatrices complexes, autonomes, que nous connaissons, pas plus que n'apparaît l'écran qui recouvre leur origine. L'état naissant où nous les rencontrons laisse apercevoir, par contraste, le tracé de la division essentielle dont elles procèdent.

Doit-on considérer que le sexe joue le simple rôle d'indice de répartition des habiletés dans une collectivité ? Dans ce cas, il faudrait s'en souvenir pour rendre compte de la situation qui régnait dans les manufactures du XVIII ${ }^{\mathrm{e}}$ ou même du XIX ${ }^{\mathrm{e}}$ siècle, où les femmes et les enfants occupaient des emplois bien déterminés. Or, chacun le sait, la division « basée sur l'âge et le sexe » est reconnue dans sa particularité uniquement jusqu'à la constitution de l'artisanat et des sociétés fondées sur la propriété privée. Loin d'être arbitraire, cette coupure délimite un stade de notre évolution, pour lequel l'appartenance au

172 V.G. CHILDE : L'Europe préhistorique, Paris, 1962, p. 13.

173 «Aussi longtemps que la production d'un groupe d'hommes suffit à peine pour maintenir en vie les producteurs, aussi longtemps qu'il n'y a point de surplus au delà de ce produit nécessaire, il n'y a pas de possibilité de division du travail, d'apparition d'artisans, d'artistes ou de savants ». E. MANDEL : Initiation à la théorie économique marxiste, Paris, 1964, p. 3.

174 «La division du travail entre les deux sexes est conditionnée par des raisons tout autres que la position de la femme dans la société ». F. ENGELS : L'Origine de la famille, Paris, 1954, p. 51. 
sexe masculin ou féminin n'entrainait pas seulement la préparation à l'exercice d'une partie quelconque du même travail mais aussi, nécessairement, l'appartenance à un groupe défini de possesseurs de talents et de ressources. Les hommes étaient chasseurs ou pasteurs, les femmes se consacraient à la cueillette et — du moins au commencement de l'époque néolithique -à l'agriculture. La masculinité ou la féminité n'étaient pas les signes d'une activité bornée : elles exprimaient chacune un mode singulier, prédominant, d'interaction avec le milieu matériel.

Une césure a eu lieu là où le classement naturel et un classement biologique des individus ont cessé de coïncider. Les subdivisions sociales et techniques ont pris un relief inconnu auparavant, refoulant à l'arrière-plan la séparation des hommes et des femmes, la spécificité de leurs attributs dans l'interaction avec les parties du règne matériel. Mais la division naturelle, suite de coupures et de réordinations biologiques des capacités, ne disparaît pas pour autant. Son contenu se renouvelle à la fin de ce qu'il est convenu d'appeler la préhistoire. Si la division dite 'naturelle' du travail n'est plus basée sur l'âge ou le sexe, elle paraît l'être sur la spécialisation de la main et du cerveau. D'un côté on classe les hommes et les femmes qui mettent à contribution de façon courante essentiellement leur énergie musculaire, l'agilité de leurs membres et la finesse de leurs sens. Des schémas coordinateurs inconscients guident leurs opérations laborieuses et facilitent l'exécution des tâches prescrites. De l'autre côté figurent les groupes dont les aptitudes et les intérêts se situent exclusivement au niveau du raisonnement et de l'appréhension globale des phénomènes réels. Les méthodes intellectuelles sont le fruit de leurs efforts et le moyen par lequel ils abordent les questions que leur soumet la collectivité. Cette division du travail manuel et intellectuel s'inscrit, assurément, dans un contexte social. Elle a néanmoins pour objet de régir l'organisation des hommes eu égard à leurs facultés et à leurs relations dans le monde matériel et avec lui. Ses effets particuliers se manifestent dans l'espace des disciplines naturelles - sciences, techniques, arts, philosophies - et se font sentir lorsqu'il s'agit d'inventer ou de reproduire les savoirs et les habiletés. Une place à part, irréductible à celle de la division sociale ou technique, lui est réservée. A quoi pourrait-on la rapporter de manière permanente ? 
En face de l'artisan qui incarne le labeur du corps, l'agilité des doigts, l'ingénieur, le mécanicien fait valoir l'intelligence des mathématiques et la finesse de ses instruments. L'activité réflexe des mains et la démarche éclairée du cerveau, l'art de la répétition et celui de l'invention, les séparent et les identifient respectivement au travail manuel et au travail intellectuel. Dès que le savant moderne a pris la place qu'on lui connaît et que les sciences sont devenues le noyau de toute découverte, l'ingénieur, héritier de Léonard de Vinci, de Brunelleschi, de Stevin ou de Huygens, a réintégré le règne des techniques et des opérations quasi manuelles. Point n'est besoin d'insister longuement pour prouver le caractère pseudo-biologique de ces différenciations ou bien, à tout le moins, l'aspect non-historique du critère choisi. Rien n'autorise à accorder une signification trop littérale à la superposition d'un genre de travail à un autre, aux propriétés exclusives des systèmes anatomiques ou physiologiques.

Nous remarquons à ce propos une prédilection pour la qualification biologique de semblables divisions de l'humanité. Elles ont toutes reçu une fonction motrice dans la formation des rapports sociaux et naturels. Cependant, ce n'est ni à la masculinité ou à la féminité, ni à la pérennité de l'homo faber ou de l'homo sapiens, à leurs qualités organiques pures, que l'on est en droit de concéder pareille fonction. C'est au lien du chasseur avec l'agriculteur, de l'artisan et de l'ingénieur, etc., donc aux relations entre les catégories naturelles, que doit être attribuée la dynamique de l'histoire. Qu'elle ait été appréhendée sous la forme détournée de la séparation des sexes ou sous celle de l'individuation de la main et du cerveau ressort de la conception que l'on se fait de la nature. Si l'ordre naturel se confond, soit avec notre réalité biologique, soit avec la réalité posée hors de nous, indépendante de notre intervention, les différences qui en résultent sont forcément pensées dans une perspective organique et sans référence à la hiérarchie des forces matérielles.

Il n'en est plus de même lorsque cet ordre comporte un pôle humain et un pôle matériel qui participent ensemble à un mouvement historique défini. Le cloisonnement qui isole chacun de ces pôles, le recours aux notions tirées de la biologie, l'ignorance des processus 
autonomes de l'ordre naturel, sont autant d'obstacles à sa compréhension. Au contraire, tout nous invite à l'envisager d'un point de vue spécifique. Plus particulièrement, de même que la nature instituée par des forces inanimées obéit à un ou plusieurs principes - la gravité, les forces nucléaires, etc. - et que la nature issue de l'interaction des êtres animés manifeste un principe général, celui de la sélection naturelle, de même la nature constituée par les forces bio-sociales de l'homme obéit à un principe certain la division naturelle. Si celle-ci était appelée à prendre rang parmi les phénomènes auxquels on reconnaît la capacité d'expliquer et de commander l'existence humaine, il serait souhaitable que des recherches suivies apportassent tous les compléments nécessaires à son intelligibilité. Alors seulement ce qui se présente encore comme une vaste hypothèse pourrait devenir un instrument d'analyse précis et heuristique. 


\section{Chapitre VI.}

\section{La transformation des ressources}

\section{$\underline{\text { Retour à la Table des Matières }}$}

C'est afin de renforcer leurs rapports avec le monde matériel que l'humanité se différencie et que les hommes se séparent. Mais il ne suffit pas de le constater, il faut encore analyser le processus. Pour rendre compte du fait que l'artisan, l'ingénieur ou le scientifique se dissocient d'un cycle de savoirs ou de productions plus primitif et plus global, on a invoqué la présence d'un excédent de richesses, avec la possibilité consécutive d'une multiplication et d'une spécialisation des fonctions sociales. L'avantage certain d'une subdivision des occupations ou des travaux, d'une mise en œuvre de procédés particuliers, dans un champ de savoirs plus limité, contribuerait également, selon cette opinion, à garantir l'indépendance des arts et des sciences, et provoquerait la genèse de nouveaux arts et de nouvelles sciences. La division sociale ou la subdivision technique du travail fourniraient donc la réponse à la question que j'ai formulée. S'il en était ainsi, la division naturelle ne serait pas spécifique. Pour réfuter ces conceptions, il convient de confronter les suppositions théoriques sur lesquelles s'appuient les deux premières formes de division aux phénomènes qu'elles sont censées expliquer. 


\section{Distribution des richesses et éclatement du savoir-faire}

$\underline{\text { Retour à la Table des Matières }}$

\section{L'accumulation de surplus sociaux.}

La division sociale des travaux décrit la répartition des membres d'une société suivant les fonctions - productives, commerciales, politiques, administratives - qu'ils occupent, la hiérarchie des pouvoirs — de direction et d'exécution — qu'ils exercent, et leurs obligations particulières envers la famille ou l'État. Émile Durkheim, dans son célèbre ouvrage $L a$ division du travail social ${ }^{175}$ a tracé le tableau le plus circonstancié de ce phénomène universel et en a tiré les enseignements les plus précieux.

Parmi les raisons de cette division, on a surtout retenu (a) l'accroissement du volume du groupe social, qui contraint chaque individu à se cantonner dans un secteur du travail commun, secteur d'autant plus restreint que ce volume est plus grand, et (b) l'apparition d'un surplus de richesses qui permet à une fraction du groupe social de se libérer de certaines tâches et de se consacrer à une activité spécialisée dont les produits, matériels ou immatériels, s'échangent contre le supplément de produits existants. La première raison trouve son illustration dans le passage de la vie rurale à la vie urbaine, la seconde dans la séparation de l'agriculture et de l'artisanat.

Le cadre étroit de la communauté villageoise faisait un devoir à ses membres d'exercer plusieurs métiers ou plusieurs fonctions pour répondre à la demande et pallier la rareté des forces de travail. Le changement de dimension que représente la réunion, au sein de la cité, d'un grand nombre d'hommes, l'accumulation des richesses, l'étendue du marché, incitent l'individu à rester dans un domaine strictement délimité. Le maître-maçon cesse d'être à la fois architecte, sculpteur et peintre, le démiurge n'est plus homme de l'art et mar-

175 Paris, 1902. 
chand. Pour que ces remaniements aient lieu il faut également qu'une fraction de la société dispose d'un surplus, c'est-à-dire produise au delà de la quantité de denrées indispensables à la satisfaction de ses besoins. Dès lors, elle peut céder sa production excédentaire à d'autres fractions de la société, ou dispenser certains de ses membres du travail de la terre. Une conception inspirée du marxisme a fait de la présence d'un surplus de biens consommables ${ }^{176}$ la condition de la formation d'une nouvelle classe de producteurs et de sa rupture avec l'ancienne ${ }^{177}$. L'augmentation de la productivité, la disponibilité en nourriture paraissent être au cœur de la séparation de l'agriculteur et de l'artisan. Le grand spécialiste de la préhistoire, Gordon Childe, a exposé cette théorie avec beaucoup d'autorité et de cohérence :

«La possibilité de grands progrès techniques dépendait d'abord de l'acquisition d'une habileté dans l'agriculture suffisante pour faire rendre au sol un surplus de nourriture. Ceci permettait l'existence de gens, tels que le travailleur habile du silex, et d'autres spécialistes, qui ne produisaient pas de nourriture pour eux-mêmes »... « Grâce à la nourriture abondante et à la population nombreuse, il y avait beaucoup d'hommes qui pouvaient penser à d'autres choses que l'acquisition de nourriture en quantité suffisante. La spécialisation devint possible - certains devinrent fabricants d'outils, d'autres potiers, d'autres encore fileurs et tisseurs $\gg{ }^{178}$.

L'accroissement de la population et la pléthore de biens fournissent effectivement les éléments d'un modèle auquel nul ne contesterait la cohérence. Rend-il compte de l'apparition des catégories naturelles, des grandes familles de professions? Je ne le crois pas. Examinons, pour justifier ce que j'avance, cette théorie du surplus.

La constitution d'une richesse supplémentaire a, logiquement, trois séries d'incidences : augmenter le bien-être, permettre à un groupe de se spécialiser en échangeant ses produits contre ceux d'un autre groupe, encourager une collectivité ou une classe à vivre du labeur d'une autre collectivité ou d'une autre classe. Dans les deux derniers cas, le surplus explique uniquement la possibilité pour l'ensemble so-

\footnotetext{
176 P. BARAN : The Political economy of growth, Londres, 1957.

177 K.P. OAKLEY : Man the tool-maker, Chicago, 1962.

178 V.G. CHILDE : L'Europe préhistorique, ed. cit, p. 9.
} 
cial de se diviser : en lui-même, il ne commande pas plus l'apparition de nouveaux producteurs que celle de nouveaux non-producteurs. La seule vertu à son actif est de faciliter la consommation effectuée par une fraction de la société en freinant la consommation d'une autre fraction. L'accumulation en quelque lieu de biens stimule l'amour de la richesse et le culte de la pauvreté, le raffinement du loisir et la vertu $\mathrm{du}$ travail. Son influence sur l'épanouissement des arts et l'indépendance de la classe artisanale ne présente aucun caractère de nécessité. Peut-on attribuer à une même cause, l'existence d'un excédent, des effets aussi dissemblables que la séparation des catégories naturelles et l'institution des classes sociales?

Par ailleurs, le surplus est une quantité relative. L'agriculteur, s'il en a le choix, peut élargir la sphère des biens qui lui sont strictement nécessaires, en accroître le volume, et jouir paisiblement de sa production. C'est le pouvoir de la société, ou celui du maître, qui l'oblige à se priver des fruits de son travail pour les livrer en tant que "surplus ». Quant à l'artisan, c'est en perfectionnant son savoir-faire, en fabriquant avec plus d'adresse ce que l'agriculteur et sa femme produisaient couramment, qu'il les détermine à lui fournir une quote-part des biens consacrés à la nourriture, à l'habillement, au progrès de l'outillage ou à l'entretien de la terre. Ces observations convergent vers une seule conclusion: l'existence d'un surplus résultant d'une productivité accrue n'est pas purement et simplement à l'origine d'un groupe nouveau de producteurs; au contraire, la présence de ce groupe indépendant et spécifique peut avoir pour effet l'apparition d'un surplus. Le rapport entre le nécessaire et le disponible se modifie à cette occasion.

La notion de surplus est, il ne faut pas l'oublier, une notion économique. Elle exprime à la fois une abondance de richesses qui ne sont pas employées à la poursuite d'une production déterminée, et la condition de la distribution de ces richesses dans les différentes couches productives et non-productives de la société. A ce titre, elle peut aussi contribuer à l'accroissement des possibilités de création du travail, et par là même à la formation de catégories nouvelles de créateurs de travail. Toutefois, l'histoire nous l'apprend, cette formation n'est pas liée à l'existence d'un tel surplus. Les observations sont très 
nombreuses à cet égard. Peu de sociétés, jusqu'à ce jour, ont réservé, avec application et esprit de suite, des biens destinés à encourager la reproduction et l'invention des talents. Dans une étude poussée sur l'emploi théorique du concept de «surplus économique », Charles Bettelheim ${ }^{179}$ écrit :

« Comme je l'ai déjà observé, le progrès des connaissances et une meilleure diffusion des connaissances peuvent, dans certaines limites, se produire sans utilisation du surplus ».

Ceci l'amène à considérer l'existence d'une «croissance autonome » qui n'est point liée au surplus économique :

« Néanmoins, en pratique (même avec surplus utilisé au développement $=$ 0 ), certains changements peuvent toujours intervenir dans l'organisation du procès de production et dans l'efficience du travail qui permettent une certaine croissance du produit social disponible. De tels changements peuvent être dus, soit à l'initiative des producteurs eux-mêmes, soit à celle des autres couches sociales. C'est de cette façon que certaines sociétés primitives, ne disposant pratiquement d'aucun surplus, ont pu être en mesure de progresser. C'est afin de tenir compte d'une telle possibilité de croissance que l'on doit reconnaître l'existence d'un facteur de « croissance autonome » ${ }^{180}$.

Est-ce le cas uniquement dans les sociétés primitives? Non. Le phénomène est aussi observé dans les sociétés féodales :

«Ces classes (féodales) n'utilisent qu'une très faible partie du surplus pour le développement et, par conséquent, le produit social disponible ne croît que très lentement, essentiellement sous l'impact du facteur de «croissance autonome ${ }^{181}$.

Bien plus, dans les sociétés socialistes, ce facteur doit connaître un regain d'importance : 
« On peut imaginer qu'avec le développement des loisirs (i. e. avec le raccourcissement du temps de travail) ce facteur de croissance autonome pourra de nouveau jouer un rôle de plus en plus grand $»{ }^{182}$.

Force est de constater que la " croissance autonome » est un processus général et qu'elle n'est pas liée directement à l'existence d'un surplus. Donc ce n'est pas à celui-ci qu'on doit s'adresser pour comprendre la genèse des catégories naturelles, mais bien à l'existence d'habiletés, soit actuelles dans la sphère domestique ou sociale, soit potentielles, contenues dans les «secrets» des métiers, les théories, les brevets d'invention, les expériences transmises oralement ou publiées dans des ouvrages ou des périodiques, etc. qui, à leur tour, sont les véritables motifs provoquant la formation d'un surplus économique et canalisant son investissement.

Le recours à la notion de surplus pour expliquer la différenciation des classes de producteurs ou de créateurs de travail rencontre des difficultés dirimantes. La division sociale qu'elle vise à éclairer est un principe classificateur et non génétique. Elle reflète le « degré zéro » du placement des capacités et des individus dans les compartiments recensés d'une société : agriculture, industrie, police, gouvernement, armée, enseignement, etc. Rien, étant donné sa définition, ne permet d'isoler les facteurs essentiels de ce placement de ses manifestations accessoires. Par exemple, du point de vue de la totalité sociale, le travail d'exécution de l'ouvrier et le travail de direction du capitaliste incarnent certainement un ordre divisé de fonctions vitales. Toutefois ces divisions ne sont pas historiquement actives ou fondamentales. Les rapports du prolétaire au capitaliste, les caractères discriminants de la position de chacun dans la société, ont pour motif l'écart des richesses. Si l'on s'éloigne de cette désignation précise pour se borner aux effets de la division, la distribution du travail et la distribution des fruits du travail, le loisir du capitaliste et le surtravail de l'ouvrier se confondent et deviennent interchangeables :

«Les classes inférieures, écrit Émile Durkheim ${ }^{183}$, n'étant pas ou n'étant plus satisfaites du rôle qui leur est dévolu par la coutume ou par la loi, aspirent 
aux fonctions qui leur sont interdites et cherchent à en déposséder ceux qui les exercent. De là les guerres intestines qui sont dues à la manière dont le travail est distribué $\gg$.

En effet, les guerres intestines sont quelque peu liées à « la manière dont le travail est distribué » entre les classes supérieures et les classes inférieures, mais ce n'est pas là leur cause immédiate. Les antagonismes de classes naissent d'abord et essentiellement, nous le savons depuis Aristote, de l'opposition des intérêts, du contraste entre richesse et pauvreté. A cet égard, la division sociale est un aspect formel, secondaire, et la séquelle d'une contradiction profonde qui est le nerf de l'histoire sociale. Elle joue le même rôle formel et dérivé par rapport à l'histoire humaine de la nature.

Résultante de ces deux histoires, le processus de division sociale du travail est leur dénominateur commun, un effet combiné plutôt qu'une cause agissante, un quid proprium à l'une ou à l'autre. Il décrit un côté important de la réalité, mais il ne met pas son originalité en relief.

\section{Retour à la Table des Matières}

\section{La division ou la subdivision du travail.}

Élevée à la dignité de règle universelle par les savants, louée par les rhapsodes, critiquée par des esprits clairvoyants et condamnée par les prophètes de l'égalité sociale, la division du travail fut proclamée l'instrument par excellence de la richesse des nations. Le sujet ne soulève plus les passions. Nous nous y sommes habitués en même temps que son rôle diminuait. Les procédés de cette division sont généraux : un travail, un métier ou une science sont scindés suivant le nombre variable d'opérations dont ils se composent ou celui des objets auxquels ils ont trait. Soit que la scission des tâches laisse le loisir à chaque ouvrier de se consacrer davantage à la sienne, soit que le découpage préliminaire permette de confectionner l'objet en un temps moindre, l'effet attendu est une augmentation de la quantité produite 
aussi bien qu'une multiplication des producteurs. Le tailleur qui n'est plus tisseur, le métallurgiste qui n'est plus en même temps mineur, peuvent perfectionner leur outillage, améliorer la qualité des biens et produire en plus grande quantité. Par cette méthode, la productivité est accrue, l'éventail des métiers élargi. La gamme des professions s'étend régulièrement: l'Encyclopédie en dénombre 250, on en compte 846 en 1825, aujourd'hui leur nombre atteint plusieurs milliers. L'individuation des artisans, des ingénieurs, des scientifiques, etc. ne serait donc rien d'autre que le résultat d'une de ces quelconques subdivisions des travaux. Cette conclusion ne s'impose guère.

Que le peintre se sépare du sculpteur, l'architecte du maçon, ils rendent leur travail plus efficace, leurs produits plus raffinés; ils développent leurs rapports avec l'univers matériel mais ne les bouleversent pas ${ }^{184}$. Les arts se multiplient, les savoir-faire s'enrichissent, le nombre total des praticiens s'élève, les préceptes de la création du travail s'approfondissent sans pour autant que change radicalement leur assise matérielle. La subdivision des métiers stimule l'amélioration des dextérités et ouvre une voie d'organisation sociale de la production. Lorsque cette subdivision eut lieu dans le cadre de la manufacture, elle réduisit les facultés de l'artisan à un domaine étroit et les combina de façon quantitative; elle n'en continua pas moins à les faire progresser.

Ce que je viens d'observer à propos de l'artisan reste valable pour l'ingénieur, l'agriculteur ou le scientifique. Loin d'être une modalité de formation de catégories naturelles nouvelles, de talents originaux, la division du travail ne fait que favoriser leur extension. Celle-ci n'a pas un caractère purement quantitatif. Elle peut provenir, recouvrant des tendances hétérogènes, d'une division provoquée par un travail inédit, ou d'une division inédite du travail ordinaire. La division entre agriculteurs et artisans est du premier ordre, la division entre artisans dans la corporation ou la manufacture est du second ordre. Les amal-

« La division du travail permet la spécialisation individuelle, favorable à la productivité et la production de masse. Il ne s'agit pas ici d'un progrès technique, mais d'une meilleure utilisation des moyens dans un état donné des connaissances techniques ». A. SAUVY : Théorie générale de la population, Paris, 1956, t. I, p. 63. 
gamer est impossible. Tout d'abord, le détachement aboutissant à la formation d'une catégorie naturelle a pour répercussions la disparition d'un genre d'habiletés et son remplacement par un autre. Lorsque la femme se consacre aux arts domestiques (tissage, poterie) et l'homme à la culture du sol, l'ensemble de leurs savoir-faire gagne en ampleur. La démarcation de l'artisan et de l'agriculteur a eu pour effet de limiter le savoir-faire de ce dernier. De même, lorsque le peintre, le sculpteur, le maçon, le potier, le tisseur, le forgeron conquièrent l'autonomie de leur art, l'ensemble des arts en profite. Inversement, la séparation du seul art mécanique, celui de l'ingénieur, d'avec la famille des métiers et des artisanats, a eu pour séquelle la conversion d'une partie de ces derniers en techniques incarnées dans la machine. Ensuite, le potier, le peintre ou le sculpteur, l'ingénieur civil, l'ingénieur mécanicien ou l'ingénieur militaire, se sont différenciés du point de vue de l'objet, contenu concret de leur activité, ce qui a favorisé la progression de leur habileté et la productivité de leur travail. Néanmoins, potier, sculpteur ou peintre, l'artisan verra son art reproduit suivant les mêmes règles; elles lui permettent de saisir les qualités des substances, d'assouplir le mouvement de ses bras, de parfaire son adresse ou l'acuité de ses sens. En regard, qu'il construise des machines, des instruments d'optique, ou des fortifications, l'ingénieur accordera une importance explicite aux inventions, à la reproduction de ses connaissances à la fois par la maîtrise des habiletés manuelles et par celle des lois physico-mathématiques qui régissent les phénomènes matériels.

Peut-on se borner à reconnaître entre les deux séries de divisions une simple différence de généralité ? Friedrich Engels écrit que lors de «la seconde grande division du travail», l'artisanat se sépara de l'agriculture, comme si les séparations intervenues entre les diverses spécialités artisanales et agricoles traduisaient de " petites divisions » et que le processus sous-jacent fût identique. Rien ne semble prouver que cette conception tienne compte de la signification qualitative de ces écarts, de la définition distincte des totalités qui y sont impliquées.

Sans pousser cette opposition jusqu'à sa limite, ni méconnaître dans la réalité l'existence de transitions, pouvons-nous encore parler de la division du travail comme d'un phénomène unique? Elle 
s'attache à expliquer la multiplication des spécialités dans la perspective du produit et de la production, mais néglige d'envisager le renouvellement des catégories naturelles dans la perspective de l'habileté et de son invention.

«Ajoutons que, dans certains cas, écrivait déjà Bouglé ${ }^{185}$, des professions naissent que rien ne faisait prévoir, auxquelles rien d'analogue ne correspondait dans les régimes économiques antérieurs. Elles ne résultent pas d'un morcellement ; c'est l'apparition d'espèces de biens jadis inconnus qui les suscite... Il y a là, à vrai dire, non pas division (du travail) mais création véritable».

Les divisions ne sont pas « petites » ou « grandes », elle sont principalement distinctes et entraînent des conséquences contradictoires. D'une part elles expriment la dimension de la société, les courants du marché, l'augmentation de la somme des habiletés, l'accroissement de leur efficacité et l'approfondissement des rapports existant avec la matière. D'autre part, elles traduisent le vieillissement d'un type de savoir, l'apparition de facultés originales, la transformation d'un travail en un autre et la modification des circuits établis entre l'homme et le milieu matériel. Assimiler une division centrée surtout sur la particularité de l'objet, des disciplines ou des métiers - le mécanicien, le géomètre, le cultivateur ou le vigneron - à une division guidée par la diversité des modalités de création du travail, pour laquelle n'existent que les classes générales du scientifique, de l'artisan, etc. ébranle la fermeté de la notion et empêche d'apercevoir dans toute leur clarté les mécanismes mis en jeu.

A coup sûr, une catégorie naturelle peut prendre le visage d'une subdivision quelconque des travaux. Les ingénieurs, à la Renaissance, se reconnaissaient encore comme un sous-groupe parmi les artisans, sous-groupe d' «artisans-supérieurs », suivant la terminologie de Zilsel ${ }^{186}$, et qui

C. Bouglé : Revue générale des théories récentes sur la division du travail, Année Sociologique, 1901-2, 6, p. 82.

186 E. ZILSEL : The sociological roots of science, The Amer. J. of Sociol., 1942, vol. 47, p. 552. 
« avaient besoin, pour leurs travaux, de plus de connaissances que leurs collègues et reçurent donc une meilleure éducation ».

Rien d'étonnant à cela. Une espèce biologique nouvelle est, à ses débuts, une variété d'une espèce existante. Mais on n'en conclut pas que les lois directrices du développement d'une espèce constituée soient valides pour l'évolution de l'ensemble des espèces. La division du travail, elle non plus, quelle que soit par ailleurs son importance en tant que loi de différenciation interne d'une catégorie naturelle, ne doit pas être retenue en tant que principe historique de formation de la totalité des catégories naturelles. A force d'extrapoler, on risque de convertir en métaphore un processus concret, provoquant la confusion de réalités que l'intérêt scientifique commande de discriminer. 


\section{La substitution des ressources matérielles ou inventives}

Retour à la Table des Matières

\section{L'état d'équilibre.}

Le problème soulevé reste donc entier. Pour comprendre le déroulement des divisions naturelles successives, il est indispensable de dépeindre au préalable le cas idéal constamment recherché et jamais réalisé. Ce cas idéal suppose la concordance de deux situations d'équilibre :

1. Une articulation du système de reproduction des talents avec les ressources matérielles ou inventives, telle qu'il n'y ait rien dans l'organisation du premier qui fasse appel à des éléments absents des secondes, et réciproquement, aussi bien en quantité qu'en qualité.

2. Une relation étroite entre le nombre d'individus, le volume de la force de travail disponible qui doit devenir productive, et le nombre d'individus, le volume de la force de travail qui peut le devenir. Autrement dit, les impératifs de la reproduction bio-sociale coïncident avec les impératifs de la reproduction naturelle.

Le premier équilibre, s'appliquant aux facteurs propres à l'état naturel, signifie la stabilité des échanges entre l'homme et la matière d'un côté, l'adéquation des liaisons entre les catégories naturelles de l'autre. La création des dextérités se maintient à l'intérieur des limites existantes et les puissances matérielles corrélatives s'inscrivent dans un contexte pré-établi. Aucune invention ne rend complètement caduques celles dont elle procède. Toute reproduction trouve devant elle un chemin tracé avec précision. Chaque phénomène découvert confirme le tableau où est logé l'ensemble des phénomènes. La subdivision des capacités et des secteurs du monde physique resserre et affine des virtualités reconnues, sans troubler l'harmonie et la quiétude de l'ordre qui les englobe. 
Le second équilibre règle l'intervention des formes sociales et de leur fondement naturel, le parfait recouvrement des deux. Il implique la superposition des dimensions de la société et du champ de la nature, tout écart étant réduit, soit par élimination de la population et des besoins « superflus » - que cette élimination se produise par émigration, homicide, etc. - soit par l'interdit jeté sur l'emploi de certaines ressources ou l'apport de dextérités nouvelles. Le régime des castes est la tentative la plus élaborée qu'on ait faite pour identifier l'ordre naturel à l'ordre social, la reproduction sociale et la reproduction biologique avec la reproduction naturelle, bref pour atteindre l'équilibre parfait.

Comment ces bilans équilibrés sont-ils remis en question? Une explication est nécessaire, qui indique aussi les conséquences de cette remise en question. J'en donnerai une esquisse très générale, qui sera forcément au-delà et en-deçà de l'événement réel particulier, négligeant le détail et ne retenant de la division naturelle que ses traits les plus accusés.

Retour à la Table des Matières

\section{La formation des ressources complémentaires.}

En reproduisant le travail, théorique ou pratique, et en l'exerçant, les collectivités humaines productives, actives, engendrent constamment des habiletés nouvelles, conçoivent des procédés originaux, perfectionnent les opérations existantes. Cette création peut être encouragée ou découragée, elle peut avoir lieu au milieu de l'indifférence générale ou être entourée de multiples précautions : elle ne peut jamais être totalement arrêtée. Du reste, il est probablement plus facile d'aider les talents à proliférer que de stopper entièrement leur progression.

L'observation courante quant au caractère continu de l'avancée des forces productives, de l'invention, repose sur ce fait important qu'est la formation ininterrompue des dextérités et des connaissances au 
cours de l'emploi. N'est-ce pas une particularité qui contraste avec la discontinuité des effets, des changements qu'elles induisent au niveau social ? «Si la chronologie des inventions est continue, celle de leur emploi est discontinue », observe Bertrand Gille ${ }^{187}$.

Parallèlement à des habiletés nouvelles apparaissent des propriétés nouvelles de la matière, des puissances originales de celle-ci, c'est-àdire des ressources matérielles ou inventives. Cependant, ces ressources n'acquièrent pas immédiatement ni dans n'importe quelles circonstances une individualité propre ; elles ne marquent pas le courant de communication principal d'une catégorie naturelle donnée avec la matière, et pour cette raison elles ne s'expriment pas de manière ostensible dans le système de reproduction. Elles sont à la fois complémentaires et secondaires, puisqu'elles interviennent seulement de manière marginale, accidentelle, au cours de l'action sur le monde physique, et les savoirs afférents ne sont pas reproduits spécifiquement, en eux-mêmes et pour eux-mêmes. En regard des ressources qui contribuent principalement à la vie des hommes, par rapport auxquelles les facultés de ceux-ci sont réparties, entretenues, ces richesses matérielles et spirituelles demeurent périphériques. Nous les appellerons des quasi-ressources. Il en a été ainsi de l'habileté des femmes à tisser les fibres, à faire cuire les aliments, à fabriquer des poteries, ou encore de l'emploi du fer qui, avant de devenir un matériau indispensable à la production artisanale, servait, à l' " âge du bronze », à faire des ornements. Pendant des siècles, la puissance de l'eau et de la vapeur, connue des Grecs et des Romains, est restée secondaire, si elle n'était pas comme inexistante. Les ateliers artisanaux du Moyen Age regorgeaient d'inventions grandes et petites, de savoir-faire qui parfois se perpétuaient et parfois périssaient avec leur auteur.

Pour que de telles ressources marginales surgissent et subsistent, un travail complémentaire ou marginal doit être disponible. Sa virtualité réside dans les immenses capacités biologiques et intellectuelles qui existent à chaque époque et auxquelles on n'a recours que de ma- 
nière partielle ${ }^{188}$. Les facultés d'un professeur ou d'un ingénieur, d'un agriculteur ou d'un médecin, leur permettent d'exercer honorablement leur profession et de répondre aux demandes de leurs employeurs ou de leurs clients. Cependant, elles débordent d'ordinaire le champ des applications routinières, et aiguillonnées par une difficulté ou par l'appât du gain, attirées par l'étrangeté d'un phénomène ou la nécessité de compléter le cycle de certaines productions courantes, elles peuvent s'engouffrer dans la voie de la recherche. La contrainte ou la passion qui en résultent détournent le temps laissé vacant par les occupations routinières vers l'action sur les phénomènes matériels, la combinaison des idées ou le bricolage d'un outil ${ }^{189}$. Une fraction, rendue disponible, de la vie de millions d'individus, s'est dépensée, se dépense dans des activités qui semblent n'avoir pas immédiatement trait à une production établie, à un savoir reconnu. Sans arracher une parcelle de temps à celui que la société exige et rétribue, soumis à la contrainte d'un sous-groupe professionnel ou savant, mûs par le besoin d'élargir leur être, ces hommes engendrent pour ainsi dire un autre temps, où leur virtuosité se développe selon d'autres règles, espère le succès, subit l'échec. Aux yeux de la plupart ils peuvent passer pour des amateurs. Ils ont parfois nom Fermat, Descartes, Boyle, Cavendish, mais le plus souvent ils demeurent anonymes. La fortune n'y fait rien. Riches ou pauvres, ils s'exposent au mépris, au risque représenté par des essais nombreux et aléatoires. L'élan individuel et la pression d'une partie de la collectivité se conjuguent pour que le temps indispensable à cet emploi supplémentaire des facultés soit dégagé. J. Bellers ${ }^{190}$ apostrophe les artisans en ces termes :

188 «Dans la plupart des sociétés, le sous-emploi des ressources intellectuelles risque d'être massif, car la capacité biologique d'apprentissage propre à l'organisme humain est généralement bien plus grande que sa prestation effective $»$. K.E. BoULDING : The misallocation of intellectual resources, Proc. of the Amer. Philos. Soc. 1963, 107, p. 118.

189 « Je sais pourtant que, bien que j'emploie et dépense tout l'argent que je puis distraire de ma nécessité nue, ou du moins de ma consommation la plus stricte... pourtant l'expérience que, par la bénédiction de Dieu, cette industrie m'a apporté, m'apporte et m'apportera, fera vivre mon nom... tout ce que j'en retire, je l'investis dans les découverte futures, et tout cela pour faire du bien à une génération ingrate: souvent je m'endette pour acquérir des biens de consommation et des objets nécessaires, et j'ai le ventre creux pour découvrir de nouvelles expériences en médecine ». G. STARKEY : Nature's Explication and Helmont's Vindication, Londres, 1657, p. 224.

190 J. BeLLERS : Proposals for raising a College of Industry, Londres, 1696, p, 18. 
«Car, de même qu'un mécanicien, lorsqu'il atteint trente ans, est capable d'apprendre n'importe quelle partie de sa profession qui a déjà été découverte, il faut qu'il ait l'esprit bien obtus si, en trente ans de plus, il ne peut ajouter quelque chose à son art, à condition que les besoins de sa famille lui permettent de dépenser une partie de son temps et de son argent en dehors des sentiers battus de son métier $»$.

Cet appel a été renouvelé à chaque époque de l'industrie, et même aujourd'hui, où l'invention est devenue une industrie, il continue à l'être sous forme d'un conseil d'économiste ${ }^{191}$ :

«Une transformation du loisir « volontaire »... signifierait que certaines personnes qualifiées sont prêtes, moyennant quelque encouragement, à consacrer plus de temps à une activité inventive, non pas aux dépens d'une autre activité productive, mais aux dépens d'une partie de leurs loisirs ».

Encouragé par un groupe humain, découragé par un autre - que l'on songe aux guildes du Moyen Age - le mouvement qui induit les hommes à se consacrer au parachèvement de leur savoir, à multiplier les tentatives pour découvrir ou résoudre une difficulté, ne s'est jamais interrompu. Derrière le travail que, pour son importance ou sa solidité, une société estime mériter strictement cette dénomination, ce labeur extraordinaire s'efface comme non-travail, inutile et improductif. Superflu, même, puisqu'il se prolonge au-delà de ce qui est attendu pour produire au jour, reproduire ${ }^{192}$ ou entretenir une force de travail. Mais ce superflu est créé par les conditions mêmes dans lesquelles fonctionnent les capacités, et qui poussent à poursuivre une tâche au-delà d'un découpage arbitraire, d'une norme légitimée. Activité volontaire si l'on y consent, loisir laborieux, si on le préfère, tantôt gratuit, tantôt nécessaire, il porte à la longue ses fruits. On pense, évidemment, à la tension du créateur et à la transmutation des valeurs, au jour où le travail nocturne deviendra l'occupation diurne, à l'annonce des futurs travaux profitables où ce qui était jeu ou simulation de la vie devient son sérieux et sa matrice.

191 F. MACHLUP : Can there be too much research ? Science, 1958, 128, p. 1321.

192 «La possibilité pour une société d'accroître la somme de ses connaissances — ce qu'Adam Smith nomme la «quantité de science » — dépend de la présence, dans cette société, de ressources intellectuelles supérieures à celles qui sont nécessaires au simple remplacement des connaissances perdues à la suite de décès ou d'autre façon ». K.E. BouLDING : art. cit. p. 118. 
Dans le circuit des productions habituelles, les procédés neufs et les matières nouvelles qui composent les quasi-ressources obtenues, en partie, au cours de ce travail supplémentaire, sont jugés par rapport aux ressources et aux contenus des savoirs prédominants. Leur exploitation demeure donc subordonnée dans ce contexte. Mais les quasiressources se développent sous l'effet de la concentration et de l'évolution progressive des productions établies. Leur rapprochement, l'association de ce qui a été découvert de manière indépendante et dispersée, conduit à instituer une communauté des hommes attachés aux savoirs marginaux, exclus du cycle stable de la vie productive. Ils sont par là même capables de faire entrer le divers dans une nouvelle unité. L'ampleur prise par les ressources, le rythme de la reproduction des talents existants, codifiés, renforcent l'importance des ressources complémentaires, et des facultés s'ajoutent à titre auxiliaire aux facultés fondamentales et reproduites à ce titre. Ainsi, nous le savons, le savoir de l'ingénieur, pendant longtemps fut un complément aux savoirs du peintre, de l'architecte, du charpentier.

La présence de ces quasi-ressources rend inadéquats les rapports du système de reproduction avec les ressources matérielles, le rapport qui lie les qualités humaines prévalentes aux forces matérielles. Le travail reproduit révèle ses limites, puisqu'il ne peut ni s'appliquer aux exigences des facteurs matériels, ni les satisfaire, l'unité qu'il représente s'opposant à l'unité naissante. Le déséquilibre consécutif se manifeste en ce que les ressources complémentaires, se formant continuellement, se perdent ou tombent en désuétude avant d'avoir connu leur plein essor, avant d'avoir contribué efficacement à l'accomplissement des initiatives qui ont favorisé leur apparition.

\section{Retour à la Table des Matières}

\section{La lutte pour la nature.}

Ce déséquilibre porte sur les rapports de l'invention avec la reproduction et la consommation ou l'échange. Dans le premier cas, l'équilibre est rétabli lorsque le système de reproduction est modifié 
— les quasi-ressources se changeant en ressources — donc lorsqu'on bouleverse les productions essentielles. Dans le second cas, on réduit l'écart, dans un système donné, en répartissant les ressources de manière à concentrer un plus grand nombre de producteurs, donc de manière à améliorer la productivité de l'ensemble donné. La ligne de partage de la division naturelle et de la division du travail devient encore plus nette : d'un côté la séparation est liée à l'éclosion de ressources complémentaires, de l'autre côté l'équilibre dépend d'une redistribution effective de ressources du même genre. Assurément, on ne doit pas accorder à ces classifications une valeur rigide, ni leur faire correspondre des réalités trop particulières.

Néanmoins, ici et là, d'autres ressources complémentaires, par exemple l'abondance de force de travail humaine due au déséquilibre entre la reproduction sexuelle et sociale et la reproduction naturelle, ont un rôle à jouer. Le facteur démographique est important, et $\mathrm{M}$. Daumas pouvait à juste titre déplorer une carence sur ce point: «L'influence numérique des protagonistes sur le progrès technique a toujours été négligée ${ }^{193}$. En effet, nous voyons toujours ce facteur à l'œuvre. Dans toute société, dans tous les modes de production connus, apparaissent peu à peu des écarts touchant au nombre d'individus vivants disponibles et aux possibilités d'assurer leur entrée dans le cycle productif, sinon leur subsistance. Il ne faut pas envisager les causes de ces écarts séparément, d'autant plus qu'elles n'interviennent pas avec une intensité constante au cours de notre histoire. Une de ces causes biologiques nous est très familière : elle a trait au rythme de renouvellement des individus d'un groupe humain. La proportion des naissances aux décès est rarement, à long terme, égale à l'unité. Seul le législateur platonicien ou le poète peut y croire, ainsi que Charles Babbage, le génial inventeur anglais, l'écrivait à Tennyson :

« Monsieur, dans votre poème si beau par ailleurs, il y a un vers qui dit :

'A chaque instant meurt un homme,' 'A chaque instant naît un homme '. 
Il doit être manifeste que, si cela était vrai, la population du monde serait constante. En vérité le taux des naissances excède légèrement le taux des décès. Je suggérerais que dans une nouvelle édition de votre poème vous disiez :

'A chaque instant meurt un homme,

'A chaque instant naît un homme un seizième '.

Strictement parlant, cela n'est pas correct, le chiffre exact est si long que je ne puis le faire entrer dans un vers, mais je crois que le chiffre de $11 / 16$ sera suffisamment exact pour un poème $»$.

L'hypothèse d'une croissance de la population humaine implique l'accroissement des talents et des ressources mis à sa disposition, un accord entre les forces matérielles humaines et les forces matérielles non-humaines. Si ce n'est pas le cas, la reproduction naturelle n'est pas adaptée aux conditions réelles. Cet état de choses peut provenir de causes sociales. Parfois le maître prend une part trop grande du produit sans laisser à ses serfs nourriciers de quoi faire vivre et élever leurs enfants, afin de perpétuer la servitude fondée sur un même travail. D'autres fois, des coutumes, notamment dans les économies agraires, entraînent la subdivision des terres, et l'impossibilité pour une partie des enfants de la famille de poursuivre les activités héréditaires auxquelles ils étaient destinés. L'exploitation, la guerre, le dérèglement du système social ont eu invariablement pour conséquences l'épuisement, la dévastation des ressources en terres, en bois, en métaux privant l'agriculteur ou l'artisan de leurs champs ou de leurs matières premières. Enfin, la productivité du travail - et c'est là, sit venia verbo, une cause naturelle ${ }^{194}$ - peut rendre une forme de reproduction naturelle socialement et biologiquement inadéquate. Dans l'agriculture extensive sur brûlis, il y a un rapport optimum entre la surface des terres cultivées et la surface des terres cultivables, qui permet d'atteindre une certaine fertilité du sol et de produire efficacement. Lorsque ce rapport n'est pas respecté, et que le nombre des terres cultivées s'accroît démesurément, les sols s'épuisent ou sont

194 «Que la force productive du travail dans les diverses branches d'industrie ne se développe pas seulement dans des proportions différentes, mais aussi fréquemment dans des directions opposées, cela ne provient pas seulement de l'anarchie de la concurrence et des particularités du mode bourgeois de production. La productivité du travail est aussi liée à des conditions naturelles, dont souvent le rendement diminue dans la même proportion qu'augmente la productivité - dans la mesure où elle dépend des conditions sociales. D'où un mouvement en sens contraire dans ces sphères différentes. Ici progrès, là régression ». K. MARX: Le capital, Paris 1963, VI, p. 272. 
envahis par les mauvaises herbes, et il s'ensuit une dégradation, une moindre fertilité des champs. Le fonctionnement de ce système productif est incompatible avec le rythme d'expansion démographique, car, plus celui-ci s'intensifie, plus la culture devient extensive ; mais en même temps son rendement s'abaisse, ses résultats se détériorent. L'équilibre de l'ensemble est menacé et la reproduction des agriculteurs compromise. Ainsi ce qui à un moment avait permis un développement de la population au delà du niveau autorisé par la chasse ou la cueillette cesse de pouvoir l'assurer à un autre moment ${ }^{195}$. De même, le perfectionnement des dextérités prédatrices du chasseur a eu pour contrepartie l'extinction trop rapide de quelques espèces sauvages - par exemple le cheval en Amérique du Nord ${ }^{196}$ — et pour séquelle l'impossibilité ou l'inutilité pour une partie de la collectivité d'exercer ses dextérités.

Toutes ces circonstances créent une masse d'individus surnuméraires - la prétendue surpopulation - une force de travail potentielle - la réserve de travail - qui cherche une activité, et à qui il faut en fournir une. L'armée, la guerre, la famine, les hécatombes systématiques ${ }^{197}$ collectives sont des solutions locales auxquelles on a eu recours, sans toutefois trouver de remède permanent. L'élargissement de la reproduction naturelle et de la production sociale semble avoir prévalu avec nécessité. Cela est vrai, en moyenne et du point de vue général qui est le mien actuellement; seule une étude historique concrète - appuyée par une théorie de la population qui nous fait actuellement défaut ${ }^{198}$ — pourrait nous renseigner avec profit sur les

195

196

197 terres déjà occupées par d'autres paysans. Sans les perspectives ouvertes par les débuts de l'industrie métallurgique, les Européens auraient continué, sans aucun doute, à avoir recours au second terme de l'alternative, empêchant la population de s'accroître en laissant les jeunes gens s'entremet, comme le faisaient les Peaux-Rouges. Bien sûr, on avait effectivement recours à ce procédé, même en Europe, mais la métallurgie fut le modeste début de ces industries secondaires qui finirent par rendre inutile cette solution stupide». V.G. CHILDE: The bronze age, Past and Present, 1957, p. 4.

198

L'étude des ressources complémentaires en force de travail et en habiletés ou en matières soulève le problème de l'étude des phénomènes de population et de leur impact sur l'histoire de l'humanité. Problème qui n'a pas été étudié, à la fois parce que la question ne s'est pas en- 
voies empruntées dans les diverses sociétés à telle ou telle période de leur histoire. Quoi qu'il en soit, une chose est certaine : cet élargissement de la reproduction naturelle qui englobe les individus surnuméraires a lieu, soit dans la direction des talents prédominants et des forces matérielles ordinaires qu'il multiplie, soit dans celle de l'appropriation des quasi-ressources ${ }^{199}$, en bouleversant les bases matérielles de la vie collective.

Du point de vue démographique ou social, les deux directions sont équivalentes : les ressources complémentaires en forces de travail sont utilisées ; le nombre de producteurs s'accroît et la subsistance générale est assurée. Du point de vue naturel, au contraire, c'est dans le deuxième cas seulement que s'établit une relation nouvelle au monde matériel : au lieu que s'étende une réalité déjà actualisée, c'est une réalité latente qui s'actualise. L'augmentation du nombre de paysans par le défrichement de nouvelles terres ou la colonisation est une chose, la reproduction de la population paysanne surnuméraire sous forme d'artisans en est, de toute évidence, une autre ${ }^{200}$. Dans le premier cas, l'humanité se maintient en contact avec les mêmes forces matérielles et reste dans le même état de nature ; dans le deuxième, elle approfondit le contact avec d'autres forces matérielles et se prépare à s'installer dans une nouvelle nature. L'agriculteur grec quittant sa patrie pour d'autres terres, sises dans des colonies lointaines, em-

core posée avec une grande acuité, et parce que faisaient défaut les outils conceptuels pour exprimer et définir la réalité dont elle relève, à savoir, la nature. Comme l'écrit $\mathrm{C}$. BETTELHEIM (op. cit. p. 143) :

«En un sens, toute l'histoire de l'humanité pourrait être examinée sous l'angle de l'expansion quantitative de la population du monde et de ses différentes régions. Ceci conduirait à examiner les répercussions de cette expansion sur les techniques, qui doivent nécessairement se modifier en fonction de la densité du peuplement, puis à analyser les répercussions des changements techniques sur le milieu ambiant, ainsi que la façon dont les changements techniques et les transformations du milieu (action de l'homme sur la nature) entraînent à leur tour, nécessairement, des répercussions sur les besoins et sur les structures sociales (apparition des classes sociales, nature de ces classes, rôle et forces relatives de celles-ci). Finalement, on pourrait analyser aussi comment, à travers les changements des techniques, dans le milieu et dans les rapports entre les hommes, apparaissent des besoins nouveaux et des exigences techniques nouvelles et se modifient les conditions de reproduction de la population, les phénomènes migratoires, etc. »

199 M. DoBB : An essay on economic growth and planning, Londres, 1961, pp. 32 et seq.

200 «Le surplus de main d'œuvre, quand il existe pendant une période prolongée, peut chercher sur place un emploi dans d'autres occupations que la culture ». M. SORRE : Les fondements biologiques de la géographie humaine, Paris, 1943, t. II, p. 266. 
porte avec lui et prolonge l'univers d'Hésiode et des mythes de la création; son compagnon chassé du labour, s'initiant aux arts et transmettant cette initiation, prépare l'avènement de la philosophie et l'établissement de la nature organique.

C'est un fait d'observation: la constitution de nouvelles branches de la production, de nouvelles espèces de producteurs, succède à un essor démographique, en se produisant aux époques et dans les pays où il existe des réserves en forces de travail. Que l'on songe aux VII ${ }^{\mathrm{e}}$ et $\mathrm{VI}^{\mathrm{e}}$ siècles avant $\mathrm{J}$.-C. en Grèce, aux $\mathrm{X}^{\mathrm{e}}, \mathrm{XI}^{\mathrm{e}}$ et $\mathrm{XII}{ }^{\mathrm{e}}$ siècles de notre ère, ou encore à la situation de la population à la Renaissance et aux époques qui la précèdent ou qui lui font suite immédiatement. Mais il ne suffit pas de la présence d'une telle réserve d'hommes : il faut encore qu'elle rencontre d'autres ressources en habiletés, qu'elle s'amalgame aux germes d'un savoir et s'accorde à un aspect du monde matériel suffisamment mûri, pour s'épanouir sur le terrain ainsi préparé. Quel que soit le contenu de ces "germes », les caractères de ces variantes naissantes de l'humanité, nous les voyons toujours incarnés par des groupes diffus, minoritaires dans la société et dans la production, représentant pratiquement les ressources marginales. Les artisans furent longtemps des réprouvés, des individus marqués comme des étrangers, sacrés et craints, membres de tribus nomades, subsistant dans des conditions précaires et mal définies par l'ensemble des sociétés. La mobilité aventurière de l'ingénieur, l'incertitude de son insertion dans une collectivité corporative, les traits errants et imprécis de son activité, ressortent de la biographie de chaque grand ingénieur et architecte dont l'Europe moderne à ses débuts nous a laissé le souvenir. Maintenus à la périphérie de la société, ces producteurs potentiels sont aussi des "auxiliaires », dont la fortune et le destin sont liés à la guerre, à l'industrie de la mort, à la destruction et à la consommation du produit social. Les armées faisaient appel à ces " auxiliaires » spécialisés et ceux-ci trouvaient à employer leurs facultés au service des gouvernants prévoyants ou parmi les soudards et les princes ambitieux dans un milieu où les freins de la société civile ne jouaient pas directement. D'autres exigences de la société, notamment celles du pouvoir et de l'entretien de l'équipement collectif, ont concouru à préserver ces hommes et leurs talents, à rendre leur savoir indispensable. Le système oriental d'irrigation des terres, commun à de vastes régions, à 
de nombreuses communautés agricoles, exigeait des habiletés et provoquait des initiatives qui dépassaient le cadre des routines, des connaissances répandues à l'intérieur de chaque unité intéressée. L'adduction des eaux, la construction des fortifications, l'érection des édifices publics, n'étaient plus des tâches individuelles mais des tâches communautaires. Avant l'usine moderne ou la manufacture classique, les arsenaux de guerre réunissaient des artisans pour la coordination desquels un mécanicien était tout indiqué. Le travail des artisans à l'aube des grands empires orientaux, celui de l'ingénieur à une époque plus récente, était souvent directement social, dans le sens qu'ils se trouvaient aux ordres d'une collectivité et vivaient de ses libéralités, à moins qu'ils ne fussent dans la dépendance d'un potentat, ses domestiques ou ses courtisans.

Dans tous les cas, ces auxiliaires sont placés hors du cycle prédominant de production sociale ; ils peuvent le considérer de l'extérieur, comme un objet, car il leur est à la fois interdit et familier en tant que matière à laquelle ils s'appliquent et qu'ils servent accessoirement. Cet écart traduit un rapport d'exclusion et de substitution ; il rend impossibles la complémentarité et la coopération.

L'association des ressources complémentaires humaines et des quasi-ressources est sujette à de grandes fluctuations, et on ne peut en indiquer la direction ni en fixer la loi. Tantôt les ressources marginales en talents et en matières attirent une force de travail inutilisée, tantôt l'existence de cette force de travail amorce le mouvement des facultés prêtes à se multiplier autant qu'il le faudra. La circulation des hommes et la propagation des talents sont complémentaires et conduisent à deux séries d'effets : d'une part la survie d'une fraction de la population primitivement destinée à être anéantie, et d'autre part l'enracinement et la multiplication de l'ébauche d'une version nouvelle de l'humanité, entretenant avec le monde objectif une relation neuve. Le phénomène est trop fondamental pour ne pas appeler des recherches détaillées, qui feraient justice des thèses répandues sous le nom de diffusionnisme. Mais il est souhaitable de l'envisager - on n'insistera jamais assez sur ce point - dans une double perspective. Les conditions démographiques, sociales et géologiques constituent un champ favorable à l'extension des quasi-ressources, à la métamor- 
phose d'une simple ébauche en catégorie naturelle pleinement manifeste et agissante ${ }^{201}$. Ces conditions ne sont cependant pas suffisantes : elles impliquent et prennent ce sens dès lors que la création des habiletés, les ressources complémentaires et les causes climatiques qui les fortifient et les rendent efficaces ont atteint un certain stade. Songeons à l'apparition de l'agriculture et des agriculteurs. Le réchauffement du climat qui a eu lieu au huitième millénaire avant J.-C. a favorisé sans conteste la culture des plantes. D'autres réchauffements analogues s'étaient déjà produits à plusieurs reprises. On peut supposer que le dernier a eu ce rôle privilégié parce qu'il coïncidait avec la concentration de certains savoirs concernant le travail de la terre et la croissance des plantes, et une saturation des possibilités de reproduction des populations de chasseurs ${ }^{202}$. En substance, le processus biosocial et le processus naturel sont également déterminants, le premier apparaissant même comme une partie du second, puisque :

« toute transformation de matière naturelle en valeur d'usage humaine ne conduit pas à révéler de nouvelles forces naturelles, ni n'actualise de nouveaux côtés de la nature pour le processus de travail. Il est vrai que, sans processus social de production, quel qu'en soit le degré, il n'y a pas d'actualisation. Mais le travail seul ne suffit pas. Il faut que le travail reçoive la possibilité d'une occupation nouvelle. Là où ce n'est pas le cas, le processus de reproduction «piétine ». Alors il n'y a pas développement mais uniquement répétition ${ }^{203}$.

L'attrait et la sécurité de la répétition sont perturbés par l'imbrication des diverses ressources complémentaires - hommes, facultés, matières - dont naît une nouvelle humanité (et également de nouvelles assises naturelles pour la société), humanité douée de qualités particulières, attachée d'une autre façon aux dimensions de

201

"Il reste bien entendu que, seule l'habileté collective des réalisateurs, qui ne cesse de croître avec leur expérience, ne suffit pas à provoquer cette accélération (de l'évolution des techniques). Nous retiendrons seulement que les conditions économiques et démographiques ont favorisé progressivement le nombre des ouvriers et des «techniciens ». Ainsi a progressé également la somme de travail et de soins consacrés à l'invention ». M. DAUMAS : Le mythe de la révolution technique, Revue d'Histoire des Sciences, 1963, 16, p. 295.

202 politique, 1889,3 , p. 589.

203 K.A. WitTfogel : Die natürliche Ursache der Wirtschaftsgeschichte, Archiv. f. Sozialwiss. u. soz. Pol., 1932, 67, p. 483. 
l'univers. Ce qui rend son apparition possible, c'est qu'en se consacrant à ces ressources, elle se sépare de l'ordre humain existant; elle le modifie en généralisant les puissances intellectuelles et matérielles qui lui sont propres. Dès lors, au lieu de se perpétuer en tant que catégorie naturelle déjà présente, la collectivité humaine se perpétue sous une autre forme ; au lieu de se reproduire, à un moment, comme agriculteur, elle se reproduit comme artisan ; ou bien, à un autre moment, au lieu de se multiplier comme artisan, elle se multiplie comme ingénieur.

La généralisation s'opère dans deux directions. L'une consiste à instaurer et consolider un mode de reproduction original. L'artisan impose de nouvelles normes d'acquisition du savoir-faire, l'ingénieur se révolte contre la tyrannie du maître sur l'apprenti et prône la publication d'ouvrages, la création d'écoles, d'académies, d' "Instituts de mécaniciens " appropriés à ses besoins. L'autre direction d'évolution, non moins importante, a pour effet d'obliger les producteurs ordinaires, les catégories établies, à entrer de façon continue et organique en rapport avec les groupes d'hommes apparus à la périphérie du système de reproduction. Pour assurer un débouché à leurs capacités, à leurs ressources, à la gamme de leurs produits, et contraindre les autres fractions de la collectivité à leur fournir les éléments indispensables à leur activité, les groupes marginaux doivent transformer l'ensemble du travail et de ses soubassements matériels. C'est à ce prix, en cultivant méthodiquement les dextérités, les connaissances et les ressources inédites, en les opposant aux dextérités, aux connaissances et aux ressources prédominantes, qu'une catégorie en devenir accède au domaine et au travail d'une catégorie établie : l'artisan au travail manuel de l'agriculteur et de la femme, l'ingénieur à l'habileté de l'artisan, etc. C'est ainsi, en pénétrant dans des branches de production auparavant fermées, que se manifestent des liens d'articulation, et que les nouvelles relations de dépendance remplacent les anciennes. L'impératif de la coopération prend le pas sur celui de l'exclusion, la division naturelle devient la toile de fond d'une véritable division sociale du travail. Cet aboutissement survient par un cheminement spécifique pour chaque catégorie naturelle. Partout demeure sensible, toutefois, la transformation des fondements matériels ainsi que celle de l'humanité, de ses qualités physiques et spirituelles, de la quantité et 
de la qualité de ses besoins. Il devient possible à des groupes d'individus, distincts par leurs facultés, de vivre sur un même territoire en s'attachant à des matières différentes ${ }^{204}$, à l'instar des espèces biologiques susceptibles de cohabiter sur une aire commune si elles se procurent des ressources particulières. Ceci permet simultanément à l'humanité de s'étendre, non parce qu'un plus grand volume de ressources favorise la subsistance d'une population plus nombreuse, mais surtout parce que la présence d'un éventail d'habiletés plus étendu accroît les chances de survie de chacun. La multiplication signifie, en l'occurrence, passage d'une force matérielle à une autre, substitution progressive d'une force matérielle à une autre, combinaison dans un système de reproduction adéquat. Le couple artisan-agriculteur prend la relève du couple agriculteur-chasseur ou pasteur, et le couple artisan-ingénieur succède au couple artisan-agriculteur.

On considère généralement que l'œuvre de notre espèce a été de lutter contre les forces de la nature : les eaux, les vents, les fleuves, les animaux, etc. Cette lutte - si lutte il y a — ne lui a pas été imposée dans ces termes simples: l'humanité elle-même en est l'instigatrice. Les agriculteurs eurent à maîtriser les inondations, mais ils avaient fait dépendre leur vie de ces inondations, leur ayant donné une portée humaine. De même, les scientifiques s'appliquent à vaincre la pesanteur, parce qu'elle est pour eux partie de leur discipline, la raison et l'occasion d'exercer leur talent. Le combat n'est point permanent, l'adversaire n'a pas un visage immuable. Les hommes n'ont pas affronté les « forces de la nature » pour combler un manque physiologique ou intellectuel, ni pour égaler la perfection de l'accord des animaux avec leur milieu. Ils l'ont fait chaque fois qu'ils ont dû se constituer une réalité, chaque fois qu'il leur a fallu fournir un environnement à leur présence, et, par là, dépasser un état déjà présent. Lutter pour la nature et non contre la nature, tel est le sens véritable de leur effort. Si aucune partie de l'humanité n'est jamais adaptée à l'ordre naturel, chacune l'est à son état de nature où elle cherche à parachever ses facultés et à engendrer les propriétés matérielles correspondantes. Là ses talents arrivent à maturité et sont reconnus, là prend fin son errance et la menace d'une retombée dans l'indifférenciation ou le agrandi la nature ». A. SAUVY : op. cit., t. I, p. 200. 
néant. La division en catégories naturelles est simultanément la voie qu'emprunte l'humanité et sa réaction au déséquilibre entre la manière dont elle se reproduit et ce qu'elle invente, la solution qu'elle apporte au conflit de ces processus avec son organisation sociale.

$\underline{\text { Retour à la Table des Matières }}$

\section{Conclusion.}

Lorsque notre espèce fut projetée par Emmanuel Kant au centre du savoir et par Karl Marx au centre du système social, ce fut une révolution, que l'on a judicieusement qualifiée de copernicienne. Toutefois, comme pour la révolution copernicienne authentique qui lui sert de modèle, il ne suffit pas de découvrir le centre vrai de l'univers pour en restituer l'image fidèle. Il faut encore bouleverser l'univers lui-même pour fixer la position du principal agent qui y est à l'œuvre, énoncer les lois les plus appropriées à son action et lui permettre de poursuivre la tâche commencée. C'est à une pareille révolution, képlérienne cette fois, qu'invite l'insertion de l'histoire humaine de la nature dans le tableau et la vision du réel, en fixant la place de la connaissance et la fonction de la société dans l'espace ouvert par ce bouleversement.

J'ai tenté de fonder le modèle théorique de cette histoire et de la nature qu'elle concerne. Il réunit en un domaine défini et cohérent une série d'aspects de la réalité - invention, disciplines naturelles, évolution de l'univers matériel et des groupes humains, etc. - que l'on avait l'habitude de négliger ou de considérer distinctement.

La théorie sur laquelle repose le modèle, en échange, s'efforce d'analyser les contradictions ayant trait à ce domaine. En premier lieu, elle relève la contradiction qui existe entre le fait qu'aucune partie du milieu matériel ne nous soit accessible sans être au préalable associée à un savoir, amalgamée à un instrument humain, et la tendance à identifier l'ordre naturel à une masse compacte d'éléments matériels, homogène et entièrement extérieure. Les informations recueillies et les principes établis à propos de telle substance ou de tel phénomène sont liés à nos capacités d'agir, à notre organisation intellectuelle. On 
ignore la teneur des axiomes régissant le mouvement mécanique en soi - si cela a un sens - tout comme on ignore la formulation de ces axiomes par un être entièrement chimique ou électrique. On a déjà fait de l'astronomie comparative en étudiant la façon dont se présente le système planétaire du point de vue de chaque planète. Nous n'avons pas encore d'épistémologie comparative décrivant les facettes de l'univers physique à partir de chacun des termes qui le composent. Parmi ceux-ci, jusqu'à ce jour, le sujet humain est le seul repère auquel tout le reste soit relié. Il est inconcevable qu'il soit pensé, placé hors d'un réseau de relations auquel il donne un sens et qu'il constitue :

«Les dieux avaient donné à l'homme l'intelligence et les mains et l'avaient fait semblable à eux, écrivait Giordano Bruno ${ }^{205}$, lui donnant une faculté au-dessus des autres animaux qui consiste non seulement à pouvoir agir suivant la nature ordinaire, mais en outre hors des lois de celle-ci ; afin que, formant ou sachant former d'autres natures, d'autres cours, d'autres ordres, par son esprit, par sa liberté, sans laquelle il n'aurait pas cette ressemblance, il en vienne à se conserver dieu sur la terre ».

En deuxième lieu, il y a incompatibilité entre la tendance à reconnaître l'homme dans la nature par ce qu'il est biologiquement, psychiquement, et la volonté de l'exclure du contexte de celle-ci en raison de ce qu'il fait, individuellement, socialement. La majorité des facultés humaines, nerveuses, anatomiques, dans leur état actuel, sont consécutives à la découverte et à l'utilisation des artefacts. Nous les voyons participer à un processus dont l'aboutissement est un ordre naturel et non pas, comme on dit, une nature humanisée. Celle-ci serait une nature transformée par le travail humain, une réalité subsistant sur un autre mode, dans des conditions différentes, et qui aurait reçu une forme nouvelle uniquement pour répondre aux exigences d'un agent toujours extérieur. L'essentiel n'est pas ici l'acte transformateur mais l'acte constitutif, l'organisation particulière des propriétés de la matière et de nos capacités. Aucune tentative qui voudrait nous rattacher à la nature sous un premier aspect et nous en détacher sous un second ne trouvera de critère suffisamment assuré pour que l'on puisse éviter la confusion des postulats et l'incohérence des conséquences. 
En troisième lieu, la vision de l'action des hommes dans le monde matériel en tant que cette action obéit à un impératif supérieur, à un penchant irrépressible à conquérir la nature, à révéler son image définitive, est démentie par la réalité de cette action qui conduit à perfectionner l'état d'une nature particulière (mécanique, organique, etc.) à la défendre, ou à résister à tout ce qui peut la remettre en question. Pour cette raison, il est illusoire d'affirmer que l'on possède la nature en tant qu'entité autonome, fermée ou ultime. Au contraire, on l'élabore progressivement et on la réordonne périodiquement. Il n'est pas non plus exact de dire qu'il s'agit, à cet effet, d'annexer une région délimitée dans l'espace et dans le temps : ce que nous maîtrisons, c'est un mouvement, en transformant des relations dont nous sommes l'un des termes.

Enfin, non moins manifeste paraît la contradiction entre la reconnaissance du caractère historique de l'homme et de la matière, et le présupposé de la non-historicité de la nature. Sur ce point, pour confronter des théories et des résultats qui s'excluent mutuellement, il m'a fallu rejoindre une pensée que d'autres hommes, avec davantage de candeur et une acuité ne le cédant en rien à celle de notre époque, ont préfacée par des formules frappantes et durables. Ils ont en effet proclamé, à des instants privilégiés et avec une constance digne d'attention, que les êtres divins qui ont monté la fabrique de l'univers ont été des cultivateurs ou des pasteurs, des démiurges ou des ingénieurs, et qu'ils ont suivi la voie que parcourt chaque être humain dans sa rencontre avec les êtres non-humains. Ce n'est pas là, comme on le croit ordinairement, une projection aliénée dans un ciel étranger. Le monde se refuse à l'intelligence, se mue en astre mort, renie le sens de sa propre existence, si, dans l'événement de sa constitution, on ne le voit pas incarner le labeur du pasteur ou du cultivateur, de l'artisan ou de l'horloger; j'ajouterai à cette compagnie toutes les sortes de savants. Le souffle qui traverse ces visions est celui de la reconnaissance émue, violente, spontanée, du sujet naturel par lui-même.

En synthétisant les propositions résultant du travail destiné à élucider ces contradictions, j'ai énoncé et établi les notions et les rapports ou principes qui s'inscrivent dans le contexte d'une conception déter- 
minée. Pour l'instant, ils se présentent en quelque sorte comme ma construction. Il convient à présent de prouver qu'ils reflètent également le réel.

$\underline{\text { Retour à la Table des Matières }}$ 


\title{
DEUXIÈME PARTIE
}

\section{L'ÉVOLUTION DES CATÉGORIES ET DES DISCIPLINES NATURELLES}

\author{
PREMIËRE SECTION
}

\section{LA NATURE MÉCANIQUE ET LA STRUCTURE DES CATÉGORIES NATURELLES}




\section{Chapitre premier. \\ La formation des catégories naturelles et l'unité de l'histoire de leurs disciplines}

«L'esprit humain suit dans le développement des sciences et des arts une marche déterminée, supérieure aux plus grandes forces intellectuelles qui n'apparaissent que comme des instruments destinés à produire, en temps donné, des découvertes successives. Quoique cette force dérive de nous, il n'est pas plus en notre pouvoir de nous soustraire à son influence ou de maîtriser son action que de changer à notre gré l'impulsion primitive qui fait circuler notre planète autour du soleil ».

De cette marche déterminée, à laquelle Saint-Simon attachait tant de foi, nous avons acquis une vue plus précise : elle est tout entière contenue dans le processus de division naturelle. Ses concomitants biologiques, malgré les lumières de la génétique, nous demeurent cachés; quant à ses prolongements sociaux, ils restent aussi à explorer. Si l'on veut asseoir le constat propre à cet essai, un examen approfondi s'avère indispensable. Au préalable, l'étude de quelques problèmes actuellement non résolus s'impose. Ils ont trait à :

- la définition des catégories naturelles et la prise en considération des liens qui unissent les couches productives et les couches nonproductives, les intellectuels notamment ; 
- l'élucidation du rapport existant entre les disciplines naturelles sciences, arts, techniques, philosophies - en tant que matériaux véritables, tangibles, de la nature et de son histoire. 


\section{Les deux fonctions d'une catégorie naturelle}

Retour à la Table des Matières

\section{Des filiations évidentes.}

Au cours du processus de division naturelle, nous voyons surgir de nouveaux groupes d'hommes, frayant un accès à leur savoir, aux œuvres accomplies et à leurs assises objectives. A chaque état de nature - organique, mécanique, ou cybernétique, pour n'envisager que ceux que j'ai retenus - correspond une catégorie particulière de « porteurs d'invention » - l'artisan, l'ingénieur, le scientifique. Peut-on associer aux deux premiers la classe des intellectuels et des savants et justifier cet appariement? Font-ils partie d'une unité à laquelle s'applique avec une égale rigueur le principe de l'histoire humaine de la nature ? S'il n'en était rien, si le savoir de ces époques était l'apanage exclusif des clercs et des idéologues, la généralité des analyses précédentes serait gravement compromise. Il est possible de trancher la question en rappelant certains faits et en mettant en lumière les conditions d'action et la fonction d'une catégorie naturelle.

Sans conteste, les philosophes anciens sont, par leurs intérêts et souvent par leur origine, liés à la classe artisanale, car c'est là une inférence qui s'impose : les philosophes se sont formés au contact de l'artisanat ou en le prenant pour modèle, et, pour ainsi dire, dans son sein et dans son prolongement. Bien entendu, cela n'est pas vrai d'une façon absolue. Quand un groupe nouveau de détenteurs de facultés originales se détache, des hommes provenant des milieux les plus divers convergent vers lui, puisqu'ils trouvent là un débouché inespéré à leur génie, à leurs aspirations et à leurs ambitions les plus légitimes. Dans un autre ordre de réalités, les classes sociales ont souvent eu à leur tête des hommes qui ne sortaient pas de leur sein. Les doctrines révolutionnaires n'ont pas toujours été conçues par des individus appartenant à ces classes, pas plus que celles-ci n'ont sécrété ellesmêmes toutes leurs têtes politiques. Il en a été ainsi dans le monde antique, comme pour les révolutions socialistes modernes. Personne 
ne nie pourtant que ces hommes aient participé de la complexion des classes auxquelles ils ont lié leur sort. Pourquoi n'en irait-il pas de même, s'agissant de l'avancement et de la composition des catégories naturelles ? En ce qui concerne la Grèce, pour revenir à l'exemple choisi, le rapprochement du philosophe et de l'artisan, leur imbrication, sont chose évidente. A condition que, pour le premier, on ne pense pas uniquement à Héraclite et à Platon, et, pour le second, uniquement au boulanger ou au savetier. Suivant les critères des $\mathrm{VII}^{\mathrm{e}}$ et $\mathrm{VI}^{\mathrm{e}}$ siècles avant J.-C., Thalès qui construit des ouvrages d'art, Anaximandre qui fabrique des gnomons, Empédocle qui soigne et guérit sont hommes d'art. Xénophane est le représentant direct d'une des branches de l'artisanat qu'Homère mentionne dans sa liste des métiers : le ménestrel. Pythagore et Socrate ont baigné dans un milieu familial où l'on pratiquait des métiers. Aristote fut fils de médecin. On sait que le médecin faisait partie des technitai, des artisans ${ }^{206}$.

Si l'on juge ces associations adventices, il suffit de se souvenir que « sophos » signifie « le maître d'un art », et qu'il est le dernier en date d'une lignée de personnages faciles à identifier, lignée qui part de l'artisan — architecte, potier ou métallurgiste - inclut l'artiste, au sens moderne du terme - peintre, sculpteur ou musicien — c'est-àdire les créateurs ou poïetai, mais aussi le médecin et le prophète à la sagesse visionnaire. W. Nestlé écrit, à propos du sophos :

«Les types de sophos que j'ai énumérés répondent pour l'essentiel au corps de métiers qu'Homère appelle les travailleurs publics (demiourgoi) » ${ }^{207}$.

Et il ajoute à cette catégorie les hommes qui possèdent la sagesse et la parole, ainsi qu'un penseur comme Thalès que tout le monde s'accorde à reconnaître comme le premier «maître d'un art admirable $»$.

De ces rapprochements, il ne s'ensuit pas que l'on doive assimiler le philosophe à un technicien, ou voir dans son appartenance à la famille des hommes d'art l'unique motif de son apparition. Il s'agit seu-

\footnotetext{
206

H. DIELS : Antike Technik, Leipzig, 1920, p. 26.

207 W. NestLÉ : Vom Mythos zum Logos, Stuttgart, 1942, p. 15.
} 
lement de mettre en place le cercle où il se meut, les racines à partir desquelles il se différencie. Il faut aussi éviter de tomber dans l'excès contraire, qui consiste à considérer l'artisan comme un individu dépourvu de connaissances proprement intellectuelles, à oublier en Grèce l'existence d'une importante production savante due aux spécialistes. Les écrits hippocratiques restent un monument inégalable. Polyclète, le rival de Phidias, sculpteur préoccupé de la recherche d'un système de proportions idéales, composa un livre - le Canon lorsqu'avec le Doryphore (Cavalier porteur de javelot) il crut avoir atteint le but espéré. Nous savons que Themanthes, Pamphilos, Apelle, Melanthios, établirent et rédigèrent la théorie de leur art, de la géométrie, de la peinture ${ }^{208}$. Et d'Hippodamos de Milet, architecte, Aristote dit qu'il

« voulut être érudit dans toutes les sciences de la nature, et il est le premier, parmi les citoyens qui n'ont pas exercé de charges publiques, à entreprendre un traité sur la meilleure constitution ».

Le lien, que n'ignoraient pas les contemporains de Socrate, entre le philosophe et les autres hommes ayant en partage une techne est attesté ${ }^{209}$. Aristote ne cite-t-il pas Hippodamos, dont il vient d'être question, parmi les précurseurs de Platon ${ }^{210}$, et Platon lui-même ne rapproche-t-il pas Thalès d'Anacharsis ${ }^{211}$, célèbre pour avoir perfectionné l'ancre et la roue du potier? Il en fut ainsi, non seulement parce que le philosophe naturaliste semblait proche de l'artisan, mais aussi parce que l'artisan était jusqu'à un certain point proche du philosophe :

«Pour Platon, écrit Bruno Snell ${ }^{212}$, le rapport étroit de sophia et episteme avec techne et demiurgia avait une signification profonde; sa conception du savoir de l'artisan est, dans une certaine mesure, le matériau non encore travaillé de sa pensée philosophique. Dans l'artisan s'incarne pour lui le concept

A. KalKman : Die Quellen der Kunsrgeschichte des Plinius, Berlin, 1898.

A. BONNARD : D’Antigone à Socrate, Paris, 1964, p. 274.

210 P. BISE : Hippodamos de Milet, Arch. f. Gesch. der Philos., 1923, 35, pp. 53-42.

211 D.R. DiCKS : Thales, Class. Quart. 1959, 9, pp. 294-309.

212 B. SNELl : Die Ausdrücke für den Begriff des Wissens in der vorplatonischen Philosophie, Philol. Untersuchungen, 1924, 29, p. 87. 
d'episteme avec la problématique qui s'y trouve, qui consiste en cela que le mot exigeait d'une part la certitude, de l'autre la direction vers le but. »

Le philosophe grec part donc de l'artisan et lui fait écho, tout comme la philosophie part de la techne, de l'art, dont elle décèle, examine et réordonne le contenu.

Il est non moins aisé de montrer que le philosophe "mécanique » se trouve en relation avec l'artisan-supérieur, l'ingénieur, s'il n'en est pas un lui-même ${ }^{213}$. Du reste il se réclame constamment de cette relation. Torricelli, Galilée, Tartaglia, Baliani, Stevin et bien d'autres furent à la fois savants, ingénieurs et constructeurs d'instruments mathématiques. Ils possédaient parfois un atelier, employaient un ou plusieurs ouvriers, et vendaient les produits de leur ingéniosité. Peu de grands génies de cette magnifique époque peuvent être classés parmi les philosophes de profession, dans le sens que l'on donnerait aujourd'hui à ce terme. La philosophie mécanique était l'œuvre d'« amateurs », de « virtuosi » ou d'ingénieurs.

«Le nom même de scientifique (scientist) n'avait pas encore été formé, ceux qui travaillaient dans ce domaine de la connaissance étaient plutôt connus sous le nom d'artificiers, d'érudits, de mécaniciens, de praticiens, d'expérimentateurs, de secrétaires de l'art et de la nature - parfois même d'ingénieurs (...), de mathématiciens et d'astronomes — mais surtout, et de façon générale, de philosophes ${ }^{214}$.

Nous savons toutefois que ces philosophes, ces mécaniciens, sont des hommes venus des horizons les plus divers, intéressés par les mêmes problèmes, ceux de la mécanique, animés par un même idéal : l'invention. Leur intérêt se concentre sur le travail ou l'habileté du mécanicien et de l'ingénieur ${ }^{215}$, sur la nécessité, qu'il a mise au grand jour, d'expérimenter et de mesurer.

213 B. GILLE : Les ingénieurs de la Renaissance, Paris, 1964, p. 215.

214 K. MAYNARD : Science in early English Literature, 1550 to 1650, Isis, 1932, 17, p. 97.

215 «Les artistes de la Renaissance étaient à l'origine des artisans, et ils devinrent souvent des scientifiques, non point parce que leur génie supérieur anticipait les destinées modernes de la science, mais parce que certaines branches de la connaissance scientifique telles que l'anatomie, la perspective, ou la mécanique, étaient considérées comme nécessaires au développement de leur art ». P.O. KRISTELLER : Renaissance Thought, New York, 1961, p. 118. 
Le philosophe grec et le philosophe ou savant mécanicien, les faits cités le prouvent, proviennent donc chacun d'une catégorie naturelle avec laquelle ils s'articulent et qui leur correspond. L'examen de leurs fonctions, des différences profondes qui les séparent, étaie cette constatation.

Retour à la Table des Matières

\section{La fonction productive et la fonction auto-créatrice.}

Une catégorie naturelle se dégage, se pose devant une autre, au fur et à mesure qu'elle fournit ou introduit de nouvelles ressources concrétisées en objets, capacités, d'une qualité ou quantité inconnues auparavant. Elle devient également force de production sur la base de laquelle naissent de nombreuses activités économiques et des rapports sociaux. Dans tous ces cas, la création du travail et son emploi productif restent pratiquement indifférenciés. L'artisanat naît au cœur de l'agriculture et la multiplication de ses habiletés va de pair avec les besoins qu'il réussit à susciter ou qui le réclament. La technique de l'ingénieur s'affirme lentement dans le cadre artisanal où il est appelé à résoudre des problèmes limités ayant trait à la construction, à la guerre ; il formule une nouvelle manière de poser ces problèmes. Pendant toute une période de son évolution, le travail est entièrement résorbé, engendré dans le champ permanent de sa fonction productive. L'habileté, la force de travail et leurs organes de reproduction ne sont pas appréhendés en tant que tels mais uniquement rapportés à leur objet, et ils n'obéissent pas à des impératifs distincts de ceux de la production.

D'autre part, le travail peut apparaître séparé, différencié ${ }^{216}$, extérieur aux circonstances immédiates du circuit productif. L'initiation des apprentis, donc la pédagogie des arts et des techniques, ou bien l'invention lui confèrent une finalité propre, le transforment en objet

« Remarquons en passant qu'il y a lieu de faire une différence entre travail général et travail collectif. Les deux catégories ont leur rôle dans le procès de production, l'un se fonde sur l'autre et réciproquement ». K. MARX : Le Capital, t. V, p. 121. 
d'un autre travail, où les interférences entre les dispositions des hommes et les puissances matérielles acquièrent un relief particulier. Ici le travail est lui-même une œuvre destinée à être perfectionnée, une matière - biologique ou non - dont il faut connaître les propriétés afin d'en tirer le meilleur parti. Chacune des diversités dont il témoigne par ailleurs vis-à-vis des effets qu'il produit — objets d'usage, moyens de reproduction - s'avère variation de quelques relations ou opérations générales. Le travail dégage son unité, exprime son essence : la participation du milieu matériel à l'organisme humain, et vice-versa. D'une façon ou d'une autre, c'est la combinaison de ces deux termes - l'homme et la matière — qui s'impose à l'attention. La constitution ou la saisie de ce travail sous cet angle, du point de vue de sa reproduction et de son invention, quels que soient les produits auxquels il s'applique et les buts successifs qu'il sert, représentent la fonction auto-créatrice.

Toute catégorie naturelle obéit à sa fonction productive et à sa fonction auto-créatrice, reconnaît son travail dans le contexte de l'une et de l'autre. Historiquement, la fonction productive s'est manifestée en premier. La fabrication des vases, l'extraction des métaux, l'élevage des animaux, la construction des machines ou des horloges, sont des occupations qui mobilisent les artisans, les agriculteurs, les ingénieurs, de manière quotidienne, quasi-instinctive, avant de leur laisser la possibilité de dégager la signification pleine de leur action. Cette signification, au demeurant, ne peut s'imposer avant que la production ait atteint un certain stade, avant que les producteurs soient assez nombreux pour se confronter et pour rechercher une extension de leur domaine, pour établir son individualité et la leur. Dès qu'ils s'affirment comme collectivité distincte, ressentant la nécessité d'une organisation et d'une formation plus contraignante, ils recourent à l'échange généralisé des expériences et à la transmission de leur savoir, non seulement pour l'appliquer à la production, mais pour l'augmenter et le parachever. Ainsi se singularise la fonction autocréatrice.

Une fois atteint le stade où il est devenu nécessaire de consacrer du travail à la création du travail, une subdivision à l'intérieur de la catégorie naturelle s'avère indispensable. Elle sépare les individus appelés 
à appliquer productivement les habiletés de ceux qui les appréhendent dans la perspective de la reproduction ou de l'invention, les uns les assimilant en tant que moyen et les autres en tant que fin. Ces derniers constituent l'embryon de la couche non-productive ou proprement intellectuelle, savante. L'écart entre les deux groupes grandit au cours du développement historique. Les indications que nous possédons à ce sujet sont connues. On s'accorde à reconnaître aux cités ioniennes l'honneur d'avoir suscité le mouvement philosophique et d'avoir donné une impulsion décisive à l'art grec. En Ionie s'organisent, à l'instar des écoles de rhapsodes, de sculpteurs ou de médecins, des écoles où, vraisemblablement, tout en cultivant d'autres arts, on s'applique plus particulièrement à l'étude des phénomènes matériels ${ }^{217}$. Dans ces écoles - , celle de Milet par exemple - l'apprentissage prend pour point de départ des matériaux venus de sources diverses, trésor transmis par les poètes, les potiers, les métallurgistes ou les médecins, observations, recettes et conceptions relatives à ces métiers et aux différentes opérations qu'ils impliquent suivant la matière employée ${ }^{218}$. Rien qui ne soit conforme aux solides traditions artisanales. Les écoles marquent, en quelque sorte, l'arrêt du nomadisme, la coupure d'avec la démiurgie en Grèce. De même que l'ensemble de l'artisanat passe du nomadisme à la vie stable de l'atelier, de même l'élève cesse d'attendre du hasard la rencontre avec l'homme qui détient le savoir, et se met à fréquenter l'école. L'apparition du philosophe naturaliste comme entité distincte est une conséquence de ce processus de formation de centres d'enseignement, de stabilisation relative d'une part, et de diffusion des arts et des artisans de l'autre. Ses fonctions sont polyvalentes, et son rôle proprement technique ne peut être séparé de son rôle politique ou religieux. Sa mission est d'améliorer la transmission coutumière, d'accroître la cohésion des collectivités autour d'un savoir commun, et d'assurer la compétence de chacun. Les fruits en sont les technai ou les mathemata — ces termes sont parfois synonymes -

«Ce qui distingue les Grecs des autres peuples est qu'à une date précoce ces arts subirent l'influence d'individus remarquables, qui leur donnèrent une direction et une impulsion neuves. Mais ceci ne détruit pas le caractère corporatif de l'art, au contraire, il en est plutôt accru. La confrérie devient ce que nous appelons une "école», et le disciple prend la place de l'apprenti. C'est un changement essentiel. Une corporation fermée, n'ayant que des chefs officiels, est essentiellement conservatrice, tandis qu'un groupe de disciples attachés à un maître qu'ils révèrent est la plus grande force progressive que le monde connaisse ». J. BURNET : Early Greek Philosophy, $4^{\mathrm{e}}$ éd. p. 29.

218 M.J. FINLEY : The ancient Greeks, Londres, 1963, p. 118. 
c'est-à-dire ce qui peut être appris, des matières d'instruction. Ainsi les arts qui, dans le monde agraire et les empires du Proche-Orient, se fondaient sur un «mystère » fortifié par les recettes et l'évidence de la réussite, sont régis désormais par les principes qui se trouvent à leur base et légitimés parce qu'ils expriment la « nature des choses ». Telle fut donc la fonction majeure des premiers philosophes. Jusqu'au $\mathrm{V}^{\mathrm{e}}$ siècle, ils ne semblent pas s'être séparés radicalement de la famille des hommes possédant un art quelconque. M.N. Tod, examinant les épigrammes grecques, constate que le mot «philosophos » y est rare ; les termes « sophos » ou « sophia » sont beaucoup plus fréquents et utilisés

« dans des expressions qui parfois ne nous permettent pas de savoir avec certitude s'il s'agit de philosophie plutôt que de médecine ou d'une autre branche du savoir ou de l'habileté $\gg{ }^{219}$.

Le mouvement des arts, leur subdivision, la multiplication des artisans et la reconnaissance de leur place dans chaque cité, la diversification des écoles, enfin, marquent en Grèce, au $\mathrm{V}^{\mathrm{e}}$ siècle, une nouvelle époque $^{220}$. Tous ces faits renouvellent le sens même de la transmission des habiletés au sein du métier. D'une part, le travail qu'il faut consacrer à la reproduction, à l'instruction des apprentis, augmente. C'est en s'instruisant auprès d'un autre artisan que l'on devient artisan soi-même :

« Dis-moi, Hippocrate, tu vas donner cet argent à Hippocrate, en quelle qualité ? Que répondrais-tu ? - Je dirais que c'est en qualité de médecin. Et pour quelle intention? - Afin de devenir médecin $»{ }^{221}$.

Donc certains artistes trouvent un moyen d'existence, non dans l'emploi de leur talent de producteurs d'œuvres d'art, mais dans la reproduction de ce talent chez d'autres hommes. D'autre part, la for-

219

220

"Or il serait facile de montrer que le terme de techne est familier à la langue ancienne, tandis
que les mots philosophe et philosophie ne sont devenus usuels, dans leur acception classique
qu'à la suite de l'œuvre même de Platon ». L. BOURGEY: Observation et expérience chez les
médecins de la collection hippocratique, Paris, 1953, p. 35 .

"Or il serait facile de montrer que le terme de techne est familier à la langue ancienne, tandis
que les mots philosophe et philosophie ne sont devenus usuels, dans leur acception classique
qu'à la suite de l'œuvre même de Platon ». L. BOURGEY: Observation et expérience chez les
médecins de la collection hippocratique, Paris, 1953, p. 35 .

"Or il serait facile de montrer que le terme de techne est familier à la langue ancienne, tandis
que les mots philosophe et philosophie ne sont devenus usuels, dans leur acception classique
qu'à la suite de l'œuvre même de Platon ». L. BOURGEY : Observation et expérience chez les
médecins de la collection hippocratique, Paris, 1953, p. 35 .

221

M.N. ToD : Sidelights on Greek philosophers, J. of Hell. Studies, 1957, 77, p. 141.

Platon : Protagoras, $311 \mathrm{~b}$. 
mation de nouveaux artisans tend à devenir une spécialité, et l'argent réglant les rapports entre maître et disciples, le caractère public de ce qui est enseigné s'accroît. Si, comme on le soutient, le commerce a infléchi le destin de la philosophie, ce n'est pas le négoce des grains ou des vases qui a eu cet effet, mais bien le commerce des facultés humaines. Au lieu de produits, une partie de la collectivité concernée par les arts cède ses talents. Grâce à cette spécialisation, dont les sophistes sont les premiers à donner une expression concrète, l'œuvre de codification et d'organisation déjà avancée dans tous les métiers franchit une nouvelle étape :

«Sous l'impulsion du sophisme, observe W. Nestlé ${ }^{222}$, commença à se développer une littérature technique qui traitait de tous les arts ou talents particuliers, depuis la politique jusqu'à l'art du lutteur et à l'art culinaire ».

Avec ce courant, le philosophe se désigne comme l'homme d'un art particulier: l'instruction ${ }^{223}$. On ne s'en étonnera guère. Pour l'artisan, l'habileté est un objet explicite d'apprentissage. L'art est saisi comme savoir-faire et sa transmission exprime un des moments les plus importants de la pratique des métiers. Le philosophe naturaliste se propose de comprendre cet aspect reproductif du travail, d'éclaircir aussi bien ce qui est appris, la fin de l'enseignement, que les modalités propres à ce dernier. Le clivage des disciplines artistiques et des disciplines d'éducation s'impose, et a pour lui une importance primordiale. Ainsi vient en lumière un fait historique : à savoir que les disciplines productives se différencient de celles qui n'ont pas la production pour objet $^{224}$. La distance de l'artiste au philosophe grec, rendue explicite pour les raisons que j'ai exposées, s'exprime dans l'écart qui sépare l'emploi du travail à des fins productives de son emploi pour reproduire les habiletés ${ }^{225}$. En cela le second poursuit avec plus d'assiduité que le premier un objectif qui leur est commun.

\footnotetext{
222 W. NESTLÉ : op. cit. p. 491. 
L'inspiration du philosophe mécanicien à la Renaissance, au XVII ${ }^{\mathrm{e}}$ siècle, est radicalement opposée, nous le verrons, à celle du philosophe naturaliste. Comme l'ingénieur qui est essentiellement - ou veut être - un inventeur dont le travail et le talent sont tendus vers la découverte, il est animé par le désir d'inventer, l'appréhension de l'acte inventif. Les écrits mécaniques ont pour but principal de faire connâ̂tre les inventions, de proposer des méthodes plus assurées pour y parvenir, et bien moins d'organiser un savoir existant. Là encore, il y a des transitions. D'un Léonard, d'un Stevin, d'un Benedetti, d'un Tartaglia, nous ne savons pas exactement s'il faut les classer parmi les ingénieurs ou parmi les philosophes mécaniciens ${ }^{226}$; nous n'avons plus aucun doute en ce qui concerne un Galilée - bien qu'il ait encore porté le titre d'ingénieur ${ }^{227}$ — un Huygens, un Descartes.

A coup sûr, le tableau réel est plus complexe, ce qui n'oblitère pas les lignes générales que l'on vient de voir. Il projette les visées de la couche savante d'une catégorie naturelle, qui sont de deux ordres. Elle poursuit et canalise la création d'habiletés au delà de leur exercice spécifique dans le champ de la production. Le cas de l'invention de la lunette illustre cette tendance. L'idée a été émise au XVI siècle que, par un agencement approprié de lentilles, on pouvait voir plus loin et ainsi mieux surveiller le mouvement des troupes, ou peut-être observer les effets d'un tir d'artillerie. Des artisans ont ainsi conçu l'espoir que pareil instrument susciterait un grand intérêt. Quoi qu'il en soit de ces motifs, et ce ne sont pas les seuls, on sait que des artisans italiens et hollandais ont inventé cette lunette. Qu'ils l'aient inventée précisément au XVI ${ }^{\mathrm{e}}$ siècle résulte à la fois du développement de la dextérité des constructeurs d'instruments mécaniques ou mathématiques et de l'extension de l'emploi de verres de qualité supérieure. Toutefois, si cette lunette est devenue par la suite la lunette de Galilée, c'est parce que le savant florentin, à l'encontre d'autres philosophes du temps, s'étant longuement occupé de la fabrication et du perfectionnement

226

« Dès la fin du XV siècle et pendant tout le $\mathrm{XVI}^{\mathrm{e}}$ siècle, le savant est encore mal dégagé du technicien. La scission est cependant en cours ; elle va s'achever avec Galilée, le dernier savant technicien ». B. GILLE : Les problèmes techniques au XVII ${ }^{\mathrm{e}}$ siècle, Techniques et civilisations, III, p. 178.

227

«Galilée sera le dernier grand ingénieur savant, avant que le savant ne devienne indépendant du technicien ». B. GILLE : L'évolution des techniques au XVI ${ }^{\mathrm{e}}$ siècle, Techniques et civilisations, II, p. 122. 
d'instruments, a compris d'emblée les résultats que celui-ci était susceptible de fournir: il l'a détaché de la famille des objets quelconques, et a reconnu la gamme de ses utilisations et des améliorations qu'on pouvait lui apporter. En le pointant vers le ciel, il a découvert la lunette astronomique. Produit de la dextérité artisanale, elle est devenue incarnation des lois optiques, et savoir implicite de ces lois.

L'exemple de la lunette n'est nullement exceptionnel. Il illustre les attributs de l'activité qui consiste à reproduire les productions dans un contexte où elles deviennent des objets exclusifs d'analyse, et où la dextérité qui les accompagne se trouve parachevée.

«Jusqu'à présent, écrivait Voltaire dans sa Vingt-quatrième Lettre anglaise, comme nous l'avons déjà observé dans l'ensemble, c'est dans les siècles barbares que se sont faites les plus utiles découvertes; il semble que le partage des temps les plus éclairés et des compagnies les plus savantes soit de raisonner sur ce que les ignorants ont inventé ».

Les « ignorants », on le sait déjà, ne le furent jamais tellement. Ils modelaient les éléments matériels pour fabriquer ceci ou cela, ajoutant constamment de l'habileté à la force de travail indispensable à l'accomplissement de ces tâches. Hors de son emploi circonscrit dans la production, lorsque l'habileté doit être enseignée, diffusée, multipliée, elle s'avère être intelligence, capacité d'approcher et de pénétrer l'univers matériel, bref, connaissance. Reconstituer cette deuxième facette d'une même faculté, telle a été une des tâches « des temps les plus éclairés et des compagnies les plus savantes $»$.

L'autre visée de la couche savante - le scientifique mis à part c'est de fonder les artifices en nature. Qu'est-ce à dire ? Les relations avec la matière se nouent d'abord dans la production. Elles prennent de ce fait une expression technique. Les couches d'hommes occupés à la production les appréhendent sous cet angle. L'enrichissement de leurs dextérités, l'extension numérique de la collectivité sur laquelle ces dextérités se répartissent, la diffusion parallèle des ressources correspondantes exigent qu'à cette forme technique du rapport à l'univers on fournisse un fondement et une justification dans l'ordre naturel, en amenant à la lumière les puissances inanimées dans les artifices. La 
demande est d'abord interne. Un savoir-faire artisanal, par exemple, enchâssé dans l'état de nature institué par l'agriculteur, ne peut s'épanouir pleinement. Le contraste de son action avec les contraintes qui lui sont opposées de toutes parts est un obstacle intellectuel et concret à la fois. L'artisan sait et voit ses opérations basées sur la perfection des mouvements corporels, l'agilité de ses doigts ou la finesse de ses sens ; les matériaux qu'il manipule sont souvent des matériaux inanimés, sa terre est argile ou pierre, non pas humus des plantes. Or, ces dernières sont rattachées à une nature vivante de végétaux et d'animaux, où la fécondité, l'union biologique des sexes, sont des principes moteurs reconnus. Par ailleurs, le processus productif de l'artisan vise une fin atteinte par des chemins voulus et réglés, aboutissant à des objets ou à des outils, ce qui apparaît comme contrenature, en désaccord avec les perceptions et les données de ce milieu où tout semble être spontanéité, création, retour rituel des mêmes phénomènes, naissance ou renaissance. Les facultés artisanales ne représentent pas, de ce fait, des propriétés normales, reconnues, de la réalité humaine ou non-humaine, pas plus que leurs instruments ne sont considérés comme une expression seconde de la relation naturelle. Résoudre ces contradictions entre techniques fabricatrices et ordre naturel, substituer un ordre naturel à celui qui prédominait, voilà des obligations inhérentes à toute catégorie naturelle. Une fraction de celle-ci s'y destine. Dévoiler le lien de l'homme à la matière là où il paraît diversifié, réalisé en objets ou arts distincts, donc dédoubler l'artifice par la nature qui le sous-tend, contribue à fortifier la fonction productive par la fonction auto-créatrice et à les investir d'une vocation commune.

L'institution de l'état de nature est, en l'occurrence, possible principalement parce que cet état s'est manifesté et organisé dans un effet technique, de même que la reproduction et l'invention correspondantes se voient confirmées lorsque les producteurs qui les ont conçues ont réussi à percer. De la sorte, l'artificiel précède le naturel et devient naturel, l'artifice se prolonge dans la nature ; ce qui semblait être uniquement ou tout d'abord intervention fabricatrice d'un groupe d'hommes se dilate en expression ultime de la réalité de tous les hommes. A cette enseigne, toute science, toute philosophie est à la 
fois discipline des facultés prises pour fin, et idéologie naturelle d'une catégorie particulière, proposée à l'ensemble de l'humanité.

Évidemment, les philosophes et les scientifiques remplissent encore d'autres fonctions dans la société ; en ce qui concerne l'histoire humaine de la nature, celles qu'on vient de voir résument l'essentiel. Elles indiquent aussi bien la correspondance des couches productives et des couches non-productives, leur subdivision eu égard à la fonction productive et à la fonction auto-créatrice des groupes porteurs d'invention. Ainsi, ce ne sont pas les mêmes philosophes, les mêmes savants, s'adaptant à une situation nouvelle, mais de nouveaux philosophes, de nouveaux savants quant à leur origine qui, à une certaine époque, traduisent la refonte de l'humanité et de son insertion parmi les pouvoirs effectifs de l'univers. 


\section{Deux conséquences de la division naturelle}

Retour à la Table des Matières

\section{Arguments contre une histoire universelle et séparée des} sciences, des arts, des philosophies et des techniques.

On peut trouver une confirmation de ce que je viens d'exposer en étudiant l'évolution de la terminologie ${ }^{228}$. Le scientifique actuel n'a pas d'équivalent en Grèce, et le philosophe grec diffère de notre philosophe encore davantage qu'il ne différait du mécanicien philosophe de la Renaissance. Une telle méthode d'approche aurait cependant l'inconvénient de laisser intact ce que je m'efforce de combattre, à savoir l'idée de la continuité essentielle de ces classes durant toute notre histoire. On a cru, on croit encore, qu'il est plus honorable, moins dégradant d'agglutiner la communauté de " ceux qui savent» aux classes sacerdotales, que de les joindre aux artisans, artistes ou mécaniciens. C'est normal, dira-t-on. Ne voyons-nous pas les classes sociales se bâtir une généalogie, rechercher dans les temps les plus reculés la justification d'une permanence, d'une unité dont la seule réalité est, par exemple, l'appartenance au clan de ceux qui ont maîtrisé la richesse et le pouvoir? S'agit-il de la même richesse, du même pouvoir? Assurément non. Ce qui sépare un seigneur féodal d'un seigneur du capital est beaucoup plus considérable que la similitude dont ils peuvent se réclamer. Entre un philosophe ancien et un savant mécanicien, il y a autant de rapport qu'entre un baron franc et un baron d'Empire. Ces deux derniers portent le même titre : chacun d'eux est le résultat, le symbole d'un processus social distinct.

Toutefois, si l'évolution du contenu et de l'organisation des disciplines ne suppose pas l'appartenance de ceux qui s'y consacrent à une seule lignée historique, accorder un poids excessif aux relations à

On pourrait être enclin à supposer que je veux prouver la supériorité du producteur sur le nonproducteur ou l'unité des sciences et des philosophies avec la technique ou l'art. Mon propos est tout autre : il s'agit d'approfondir les modalités à travers lesquelles le genre humain constitue et modifie les coordonnées de sa nature. 
l'intérieur d'une catégorie naturelle — par exemple entre l'ingénieur et le philosophe mécanicien - aurait pour conséquence d'isoler une relation historique de sa propre histoire. Ce serait, indûment, concéder un privilège excessif à la production et à la technique eu égard à ce qui se passe dans le cercle des disciplines naturelles, de l'invention et de la reproduction des connaissances. Mais cela ne correspond pas à la réalité. En effet, si les techniques et les arts sont corrélatifs des sciences et des philosophies, si les hommes qui exercent les arts et les techniques ont pour associés et successeurs des hommes créateurs de sciences et de philosophies, ce mouvement n'a rien d'irréversible ni d'unilatéral. A aucun moment il n'y a eu de pratique qui n'ait été accompagnée d'une construction intellectuelle, fût-elle magique. La philosophie ionienne, choisie ici pour illustration, se constitue aussi bien à partir des arts qu'à partir des mythes qui l'ont précédée. Empédocle est l'élève et l'héritier du potier, du médecin et du musicien, autant que celui d'Homère et d'Hésiode. La philosophie mécanique - le fait est connu - s'approprie l'héritage de la philosophie aristotélicienne en même temps que les produits du savoir de l'ingénieur.

Les deux dimensions sont présentes à la fois. L'une accentue la spécificité d'une catégorie naturelle et des disciplines qui lui correspondent, l'articulation de ses couches productives et non-productives. L'autre rétablit la perspective ces disciplines, ces couches productives et non-productives sont des moments d'une même histoire, des métamorphoses des formes qui les ont précédées. Je ne conclus cependant pas à leur équivalence : ce qui tient à la spécificité d'une catégorie naturelle - le philosophe mécanicien regarde davantage vers l'ingénieur que vers un autre philosophe du passé - est sélectif et prédominant. Ce faisant, je mets l'accent sur la communauté du principe qui les domine et les explique, dès l'instant où on les envisage dans le courant de l'histoire humaine de la nature. Il y a plus. La discontinuité fortement soulignée implique aussi une discontinuité de leurs disciplines. Le savoir apparaît davantage soumis et caractérisé par un processus de transformation que par un processus d'accumulation ${ }^{229}$. Quelles sont les incidences de cette façon de voir 
sur les groupements de disciplines - techniques, arts, philosophies, sciences - et sur leur histoire?

La première incidence est, bien entendu, le caractère historique de l'apparition de ces disciplines. Telle quelle, cette proposition semble n'être que l'expression pédante d'une formule familière. Il n'en est rien. En fait, elle s'oppose d'une part au postulat généralement accepté de l'autonomie et de l'universalité de l'art, de la technique, de la philosophie ou de la science, et d'autre part à la saisie de leur histoire comme évolution et non pas en tant que réordination de structures définies. Dans les conceptions actuelles, cette autonomie et cette universalité sont maintenues aux dépens du point de vue historique réel et grâce à une détermination arbitraire de l'objet de chaque domaine historique. Elles consistent à juxtaposer les mêmes divisions des activités intellectuelles ou pratiques à chaque période du développement de l'humanité, en présupposant la quasi-fixité de leur organisation, la pérennité de leurs idéaux et la permanence du substrat qui les détermine. Les disciplines sont traitées comme si, aux différentes époques, elles se différenciaient par rapport à des critères constants et étaient entendues de manière identique. Leur individualité étant assurée, elles ne se démarquent pas les unes relativement aux autres et en regard du contexte réel qui les entoure, et chacune se voit attribuer la possibilité d'une histoire séparée.

Si cette façon de voir était appliquée à l'étude des langues, elle reviendrait à suggérer que les mots gardent une signification unique au cours de l'évolution de l'idiome dont ils font partie. Ou encore, dans la comparaison de plusieurs langues contemporaines, le vocable d'une langue aurait pour correspondant dans un autre idiome un mot et un seul, ayant un sens similaire. La valeur et la signification de chaque signe linguistique seraient univoques et invariantes. Les transformations temporelles, ramenées à l'état de pure contingence, comme on le fait pour les groupements de disciplines, se réduiraient à des permutations de termes caractérisés par leur stabilité sans que cela puisse porter atteinte à leur intégrité ou leur ajouter des acceptions supplémentaires. Une langue vivante, véhiculée par des sujets parlants, se référant à des réalités mouvantes, ne se conforme pas à ce schéma. Les mots qui, à une certaine époque, sont associés à une signification, fi- 
nissent par se référer à des réalités différentes, voire antagonistes. Jusqu'à il y a deux ou trois siècles, les termes industrie, art, dextérité étaient synonymes et exprimaient tout ce qu'en anglais on nomme le skill de l'ouvrier. Par une évolution dont il est inutile de retracer ici les étapes, ces mots en sont venus à acquérir des sens distincts et même opposés, si bien qu'aucun d'eux ne peut plus être exactement rapporté au domaine commun qu'ils désignaient autrefois. Ce phénomène affecte n'importe quel vocabulaire, y compris celui qui a trait aux disciplines :

«Dans nos universités, il y a des cours d'arts et de sciences... On comprend généralement que, dans ces appellations, sciences signifie les sciences de la nature et arts les humanités. Mais si nous essayions de traduire ces appellations en grec ancien, la science serait episteme, qui signifie la philosophie, et l'art deviendrait techne, qui signifie la technique ; par conséquent la distinction entre arts et sciences peut prendre le sens exactement opposé à celui auquel nous sommes habitués » ${ }^{230}(1)$.

Le sens d'un vocable dans une langue dépend du sens des autres vocables de cette langue, et chaque unité linguistique connaît plusieurs valeurs sémantiques, de même que tout champ sémantique se concrétise dans plusieurs unités linguistiques. La volonté de signifier absolument un objet impose des conditions très strictes, adaptées surtout à une langue formelle ou à une langue artificielle, à une langue d'indices abstraits plutôt qu'à une langue d'événements. Les sciences, les philosophies, les arts ont été soumis à une pareille volonté, ce qui les a soustraits à la considération de leur véritable devenir. Sur le plan de l'analyse historique, on a transposé le successif dans l'ordre du simultané, introduit l'hétérogénéité aux endroits où il y avait des ensembles organiquement homogènes, découpé en fragments ce qui présentait une unité manifeste. Venons-en aux faits. C'est une pratique courante de reconstituer l'histoire des sciences depuis l'antiquité babylonienne ou grecque et de la conduire jusqu'à nos jours. L'hypothèse sous-jacente est celle d'une augmentation ininterrompue, d'une filiation unique des sciences. Conjointement, on détache et on hypostasie le corpus scientifique auquel on parait attribuer des contours précis et des propriétés communes, notamment l'emploi des 
mathématiques, le recours à l'observation ou à l'expérience. En apparence, l'entreprise est justifiée. Néanmoins, à l'examiner de plus près, on constate que ce corpus réunit sous la même rubrique des éléments disparates qui se retrouvent simultanément, suivant les périodes envisagées, dans l'histoire de la philosophie et dans celle de la technique. La répartition des groupements de disciplines distincts, négligeant l'analyse de leur différenciation, des liens variables entre "théorie » et « expérience », a pour effet la constitution de fausses totalités et de croisements redondants.

Ainsi, pour décrire les matériaux propres à l'histoire des sciences, à des époques où celles-ci n'avaient pas, comme on va le voir, d'existence effective, un des procédés courants est de les isoler artificiellement. René Dugas le signale dès le commencement de sa monographie sur la mécanique au XVII ${ }^{\mathrm{e}}$ siècle $^{231}$ :

«Certes, ces classiques (de la mécanique) appartiennent presque tous et avant tout à l'histoire de la philosophie... Mais tous ont fait œuvre de mécanicien, tous ont contribué au mouvement qui a abouti à la création d'une science à la fois fondée sur l'expérience et rationnellement organisée, et c'est à ce titre que nous les suivons ici ».

Mais à quel titre, justement, ces classiques appartiennent-ils à l'histoire de la philosophie? N'est-ce pas pour avoir prôné une connaissance mathématique et expérimentale, ce qui fait l'originalité d'un Descartes, d'un Leibniz, d'un Galilée, par rapport à un Aristote, un Platon ou un Démocrite? La mécanique a-t-elle été un à-côté de leur activité philosophique? Non, elle formait le cœur de celle-ci, le fondement et le trait commun de leur philosophie. Quel sens y a-t-il à détacher leur œuvre de philosophe de leur œuvre de mécanicien? $\mathrm{Ne}$ rend-on pas incompréhensible la philosophie de Descartes en lui enlevant sa partie mécanique, en séparant le célèbre Discours des trois Essais qui le suivent ? La conception de l'espace, du mouvement, du rôle de la force gravifique, chez Newton, est-elle vraiment étrangère à ses préoccupations métaphysiques ou à sa théorie de la connaissance ? Seulement, pour reconstituer une histoire de la mécanique ramenée 
aux contours que cette science a reçus au $\mathrm{XX}^{\mathrm{e}}$ siècle, il est nécessaire de recourir à de semblables amputations, et de considérer comme équivalentes des disciplines différant par leur structure.

L'autre procédé est celui de la répartition arbitraire du contenu à l'intérieur de l'histoire de la science. On constate de la sorte que, toutes les fois qu'il s'agit de prolonger et d'étudier la «science grecque », les savants cités, les théories analysées, les classifications proposées sont exactement ceux qui appartiennent spécifiquement à l'histoire de la philosophie. La distribution dans des cadres distincts de la " philosophie » et de la «science » grecques n'aurait pas eu de sens, cela est évident, pour ceux qui sont censés les avoir établies et pratiquées.

«Les Grecs ont inventé le terme de «philosophie», mais il n'est pas facile de donner une réponse simple et concise à la question : qu'entendaient-ils par là ? En fait ce terme recouvrait une quantité remarquable d'activités intellectuelles dont quelques-unes que nous n'estimerions pas faire partie de la philosophie. Le chapitre VI traite de la science grecque ; mais si un philosophe ancien l'avait lu, il aurait dit qu'il a trait à la philosophie, et il aurait trouvé tout à fait bizarre de notre part de vouloir séparer les deux $»{ }^{232}$.

Le philosophe grec n'aurait pas seulement jugé regrettable de séparer les disciplines scientifiques des disciplines philosophiques, il n'aurait pas compris pourquoi nous voulons le faire. Le dilemme lui était étranger comme il l'était à tous les anciens ils ignoraient jusqu'à l'opposition du philosophe et du savant ${ }^{233}$. On le sait :

«Les anciens n'avaient pas de terme pour désigner le savant, ils l'appelaient philosophe ${ }^{234}$.

Pour cette époque, l'histoire de la science et l'histoire de la philosophie se recouvrent totalement. Que retrouve-t-on lorsqu'on veut établir les diverses étapes de la «science grecque»? Les étapes de la

H. LLOYD-Jones (ed.) : The Greeks, New York, 1962, p. 123.

233 L. EDELSTEIN : Motives and incentives for Science in Antiquity, in A.C. CromBIE : Scientific Change, ed. cit.

234 J.R. ForbeS, in C. SINGER (ed) : A History of Technology, t. II, Oxford, 1957, p. 603. 
philosophie grecque. Voici comment Marshall Clagett les présente $^{235}$ :

«Il est commode de diviser la période de la science grecque en quatre divisions chronologiques principales. La première période, celle de la formation, est généralement appelée par les historiens de la philosophie la période présocratique, d'environ 600 avant J.C. jusqu'à environ 400 avant J.C. La seconde est le siècle de Platon et d'Aristote, » etc.

Mon propos n'est pas, ici, de plaider pour l'unité de la science et de la philosophie, ni de soutenir que les Grecs étaient des hommes universels, encyclopédiques, exercés dans les sciences et les philosophies. Cela ne serait pas exact. Je veux simplement donner plus de poids à un fait connu : les Grecs n'avaient pas de science, au sens précis du terme. Aussi M. Clagett, présentant une division chronologique du développement des disciplines, est-il obligé de reprendre celle de la philosophie. Les travaux qu'il décrit et analyse sont, bien entendu, ceux de Démocrite, d'Héraclite, d'Empédocle, de Platon, d'Eudoxe, d'Aristote.

Les répercussions de ce procédé sur le plan scientifique sont néfastes. D'une part on considère les divers aspects traités hors de l'enchaînement intellectuel et pratique auquel ils se rattachent et dont ils dépendent. Les critères qu'on leur applique sont totalement extrinsèques. D'autre part on refuse de remarquer, en prenant prétexte d'une convention, combien sont disparates les données que l'on réunit dans une histoire des "sciences", de la " philosophie », et jusqu'à quel point l'acception qui leur est conférée est syncrétique. Bref, on renonce à tracer les frontières de l'entreprise historique, puisque la matière à laquelle elle est censée se consacrer ne peut être déterminée clairement :

«La science a tellement changé de nature au cours de l'histoire humaine, écrit J. Bernal ${ }^{236}$, qu'aucune définition ne pourrait s'y adapter exactement ».

M. Clagett : Greek Science in Antiquity, New York, 1955, p. 22.

236 J. BERNAL : Science in History, op. cit. p. IX. 
A coup sûr, dans l'antiquité elle se ramène à la philosophie naturelle ${ }^{237}$, et, à une époque plus récente, à la philosophie mécanique. Pour maintenir la fiction de son existence à travers toute l'histoire humaine, il faut renoncer à la définir. Le choix est simple : ou bien nous réclamons une énumération rigoureuse des critères de la science, et alors son histoire cesse d'être indépendante, universelle, puisqu'elle se confond avec d'autres disciplines; ou bien nous maintenons envers et contre tout l'indépendance de cette histoire, son universalité, et alors nous devons renoncer à exiger des critères rigoureux de la réalité qu'elle embrasse.

Les choses se passent de la même façon pour l'histoire de l'art et de la technique. Le champ de la technique est déterminé par deux conditions: l'emploi des instruments et des dispositifs physicomécaniques dans l'action sur la matière, et l'extension de la mesure à ces instruments et à cette action. Le domaine de l'art trouve son unité essentiellement dans l'emploi d'une habileté acquise à l'aide des dextérités manuelles, sensorielles, auxquelles s'ajoute, suivant le besoin, un outil. Aujourd'hui nous appelons arts la peinture, la sculpture, l'architecture, savoirs où l'imagination se donnerait libre cours et se proposerait d'atteindre l'idéal de la beauté. Ce sont les «beaux-arts ». Durant plus de quatre millénaires, ces arts ne se sont guère distingués, par leurs principes et leurs méthodes, des autres arts "mécaniques » ou « utiles », celui du cordonnier, du forgeron, du tisseur, du médecin, etc. C'est donc à tort, lorsqu'on retrace l'histoire de l'art, qu'on s'intéresse uniquement à la peinture, à la sculpture, à la céramique, à l'architecture et à d'autres modes de fabrication d'objets sacrés ou d'ornements. Cela équivaut à projeter dans le passé une séparation dont l'apparition est toute récente. O. Kristeller le marque, en ces termes, au sujet de l'ensemble des interprétations qui ont été élaborées à propos de l'art ${ }^{238}$ :

« De plus, alors que l'esthétique moderne souligne le fait que l'art ne peut s'apprendre et ainsi s'engage souvent dans la tentative curieuse d'enseigner ce qui ne saurait s'enseigner, les anciens entendaient toujours par art quelque

J.E. HEIDE : Die Bedeutungsverhältnisse von $\varphi \bullet \lambda$ обо $\bullet \bullet \alpha$ und Philosophie, Philosophia Naturalis, 1962, 7, pp. 144-156.

238 P.O. KRISTELLER : The modern system of arts, J. of Hist. of Ideas, 1951, 12, p. 498. 
chose qui pouvait être enseigné et appris. Les énoncés des anciens sur l'art et les arts ont été souvent lus et compris comme s'ils devaient être pris dans le sens moderne de « beaux-arts ». »

Mieux encore, certains arts sont envisagés dans le sens moderne de technique. Rien ne justifie cette façon de voir, même s'il s'agit d'outillage ou de métallurgie, puisqu'il n'y a pas application consciente d'une démarche géométrique, introduction d'instruments de mesure ou combinaison mécanique conduisant à la poursuite des fins choisies. Lorsque cette introduction a lieu, dans le cadre de la totalité artistique, à la Renaissance, nous voyons ces moyens à l'œuvre non seulement dans la construction des moulins et des forteresses, mais aussi dans la peinture, l'architecture, la médecine, etc. L'ensemble subit un changement radical.

Le mot grec techne, on l'a vu, est proprement intraduisible en langage moderne. Il ne signifie pas «technique », puisqu'il a beaucoup moins trait à une coordination instrumentale qu'à une habileté ou à un talent exercé par celui qui le possède. La techne, c'est aussi bien l'habileté du médecin que la dextérité du cordonnier, c'est le savoir de l'architecte et encore l'art du musicien. Négliger ces significations, c'est s'exposer à commettre des erreurs historiques. Des esprits délicats voient quelque chose de particulier et de divin dans le fait que Pythagore se soit intéressé à la musique, art noble, et en ait tiré sa conception de l'harmonie cosmique. Pour un Grec, cela était aussi normal, aussi urgent que pour un savant du XVII ${ }^{\mathrm{e}}$ siècle de s'intéresser aux lentilles, aux horloges, à l'aménagement du cours des eaux, à la balistique ou à l'art des fortifications. L'univers horloger et l'univers musical participent de la même dignité. Inversement, des penseurs technophiles manifestent de l'étonnement et de la réprobation parce que des ingénieurs de l'époque hellénistique, aguerris à la pratique hydraulique, se sont abaissés à inventer des instruments musicaux. Ils ne faisaient cependant qu'obéir aux injonctions de leur profession : 
« D’abord, un homme occupé de la théorie et de la pratique hydraulique, répond Drachmann ${ }^{239}$, ne pouvait guère mieux employer son temps qu'à inventer un instrument musical fort complexe $»$.

On pourrait ajouter : la tradition d'un Pythagore ou d'un Archytas l'y invitait.

La différence entre beaux-arts et arts mécaniques — ou techniques - est récente. Elle ne se réfère ni au contenu symbolique, ni au but que nous leur assignons, et n'a trait qu'à la méthode, aux effets. Nos arts modernes sont aussi éloignés et distincts des arts classiques que l'est la technique de ces arts modernes de leurs correspondants dans le passé. Il n'y a pas un développement historique particulier aux arts lire : beaux-arts - et un développement historique particulier aux techniques entendues stricto sensu. Le même développement d'une classe de disciplines ayant trait aux artifices a abouti aux uns et aux autres et à leur réorganisation. Refaire le film de l'histoire sur deux registres distincts, voire opposés, en se laissant guider par les vagues critères du beau et de l'utile, c'est enlever à l'unité sa réalité et à la réalité son unité. N'est-ce pas là une des tentations de l'anachronisme qui conduit à archaïser ou à moderniser, à éliminer les écarts là où il s'agit de les expliquer? Il nous oblige à attribuer, à transférer à la totalité du mouvement historique, le classement et les normes qui régissent la science, la technique ou la philosophie à un moment seulement de ce mouvement ${ }^{240}$.

Partant, des séparations qui ont une raison d'être à une époque sont introduites à une autre, où elles sont inconcevables et incompréhensibles. La contradiction prend ainsi corps : on veut faire l'histoire d'une discipline, d'un secteur d'activité humaine, mais ni cette discipline ni ce secteur ne sont appréhendés historiquement. Le philosophe fait l'histoire de la philosophie de son temps, le technicien l'histoire de la

G. Drachmann : Ktesibios, Philon und Heron, Copenhague, 1948, p. 15.

240

«Avant tout notre science elle-même n'est pas un étalon absolu. Quiconque connaît son évolution sait quelles transformations ont déjà subies des concepts tels que « important » et « sans importance ». Ce qu'on considérait comme pratique et théorique a aussi beaucoup changé. » H. WIELEITNER : War die Wissenschaft der alten Aegypter wirklich nur praktisch ? Isis, 1927, 9 , p. 12. 
technique de son temps, etc. Le passé est censé préfigurer ou justifier le présent, lui servir de prétexte et de mémoire. La forme, les mobiles et la structure d'un groupement de disciplines sont censés persister d'un bout à l'autre de l'évolution : seul le contenu paraît changer et se diriger vers une perfection et une richesse plus grandes. Pour cette raison, les savoirs les plus progressifs sont réputés être aussi les plus cumulatifs, quand c'est l'inverse qui est vrai. L'histoire décrit ce qui devait nécessairement arriver, et non pas ce qui arrive par nécessité. Sa véritable mission ne laisse pas de doute : donner des lettres de noblesse à ce qui existe, faire l'apologie de ce qui a réussi ou survécu. Telle est l'origine du gauchissement de notre jugement et de notre respect pour la vérité historique.

\section{$\underline{\text { Retour à la Table des Matières }}$}

\section{Groupements de disciplines et états de nature.}

La deuxième incidence du point de vue proposé ici est l'intégration des groupements de disciplines à une histoire unique, celle de notre nature. L'existence autonome et la pluralité de leurs histoires séparées - histoire de la science, histoire de l'art, histoire de la philosophie, histoire de la technique - n'ont été possibles que dans l'ignorance des liens réels qui les associent. Dans la mesure où un même principe, celui de la division naturelle, paraît leur être commun, on aboutit à envisager les disciplines comme agissant entre elles et se transformant les unes dans les autres. Ceci oblige, pour reprendre la comparaison avec la langue, à accepter le fait qu'un groupement, comme un vocable, peut avoir plusieurs significations qui s'ajoutent au fur et à mesure que d'autres groupements apparaissent et que lui-même se transforme. Ces significations ne sont pas censées avoir été présentes, prédéterminées, ni en réalité, ni en puissance, lorsque le groupement s'est constitué. La philosophie naturelle de l'antiquité peut avoir aussi la signification de science à l'époque où elle naît et s'impose, sans pour cela avoir été véritablement une science et sans qu'une science distincte, reconnue, ait coïncidé avec elle. De même, à l'art, à la techne de l'antiquité, peut s'ajouter la signification de technique ou de science appliquée, sans qu'on y délimite des compartiments qui correspondraient effectivement à ces acceptions. Les catégories d'une 
totalité historique n'ont pas à se substituer aux catégories d'une autre totalité pour concourir à l'intelligibilité : celle-ci est pleinement accessible, une fois les relations de ces catégories dégagées.

A cette fin, nous devons, bien entendu, admettre la mutabilité des articulations qui, au cours de l'évolution, cernent une discipline, et, par voie de conséquence, l'abondance de ses significations. Formellement, ces articulations nous sont fournies par les classifications et les divisions des sciences et des arts qui ont été instituées. Comme dans une langue, chaque science, chaque art ou chaque technique équivaudrait à une unité lexique, et les systèmes de classification des sciences, des arts, des techniques, à son code général. L'unité lexique ne peut changer de position ou de valeur sémantique sans que le système change, et réciproquement. Le problème historique n'est pas de réduire tous ces systèmes de classification à un seul, ni de prouver la supériorité d'un système sur les autres, mais d'établir les régularités qui leur sont propres, et le principe de leur transformation. Ce qui a été reconnu depuis longtemps par P. Tannery, sans qu'on l'ait com$\operatorname{pris}^{241}$ :

«Au moins en ce qui me concerne... je me suis convaincu que la classification des sciences est une question historique, et que, pour se rendre compte de l'état d'esprit scientifique d'une époque donnée, il faut classer les matières sous les rubriques dont on les affectait alors et dans l'ordre de leur enseignement. Même pour Descartes, vouloir, par exemple, exposer à part ses idées en mécanique, en astronomie, en physique, en chimie, et décomposer à cet effet l'unité singulière qui règne dans les Principes de la Philosophie, c'est une entreprise essentiellement contraire au véritable point de vue historique ».

La base réelle et le cadre objectif auxquels correspond un tel système de classification des disciplines est l'état de nature, tandis que la réorganisation de ces systèmes, la traduction de l'un dans les termes et les normes de l'autre, représente l'histoire de ces états de nature ${ }^{242}$

P. TANNERY : Mémoires scientifiques, t. X, p. 203.

242 Jusqu'ici le rapport de l'histoire des disciplines à l'histoire de la nature a été saisi de façon abstraite. «L'étude de son histoire montre que la science, à chaque époque, est caractérisée par un concept de nature défini et particulier, qui est intimement lié à la méthode et au dessein de poser des questions à propos des phénomènes naturels et d'y répondre. Le concept de nature prédominant et la méthode et la conception du dessein de la science qui y sont associées, 
(2). Ainsi toute discipline, tout ensemble de disciplines, peut être déterminé, et doit l'être, dans une relation de différence et dans une relation d'équivalence à un autre ensemble de disciplines, du point de vue de la simultanéité et du point de vue de la succession. La confusion de ces deux points de vue conduit à l'effondrement des systèmes qu'ils considèrent et à une incertitude quant à l'identité des disciplines envisagées.

Le tableau des groupements de disciplines en rapport avec les états de nature que j'ai énumérés se présente ainsi :

\begin{tabular}{lll}
\hline Nature organique & Arts & Philosophies naturelles \\
\hline Nature mécanique & Techniques & Philosophies mécaniques \\
\hline Nature cybernétique & Sciences appliquées & Sciences ${ }^{243}$ \\
\hline
\end{tabular}

La particularité d'une discipline provient tout d'abord de la particularité de l'état de nature auquel elle appartient. Les traits différentiels de la reproduction et de l'invention des habiletés, des connaissances, dépendent des échanges de l'homme et de la matière et s'accordent aux caractères spécifiques de ces échanges. Cela est vrai aussi bien des processus de création des facultés, des talents, directement axés sur les forces matérielles, que du transfert, de l'emploi de ces facultés dans la production, et de la conception des moyens de travail et des artifices. Les assises naturelles et les formes techniques obéissent à des exigences parallèles et contrastent avec d'autres assises naturelles ou d'autres formes techniques en fonction de critères analogues.

bien qu'échappant rarement à la critique caractérisent les principaux mouvements ». (A.C. CROMBIE : art. cit. p. 56). On remarque surtout la coordination parfaite qui existe entre le contenu et les procédés de la science ou de la philosophie d'une part, le concept de nature d'autre part. Comme deux versions d'une signification unique, la science de la nature renvoie à sa vision et réciproquement. Sans postuler un esprit qui, de par ses lois immanentes, s'y applique, on ne peut comprendre les raisons de cette duplication, ni le jeu de miroirs qu'elle exprime. Peut-on envisager, par exemple, l'idée de la société féodale en oubliant que le seigneur féodal qui exprime cette idée de société et obéit à ses règles a fait aussi la société de l'idée ? Comment ne pas voir que le savant en élaborant la science ou la notion de la nature a dû contribuer à instituer la nature de la science et de son concept L'observation de Crombie prend toute sa valeur si l'on dit que c'est l'histoire des états de nature qui caractérise les principaux mouvements de la science et de la philosophie.

243 La distinction qui sépare les sciences des philosophies, notamment mécaniques, sera établie au début de la deuxième section de cette partie, chap. VII. 
L'écart qui sépare disciplines naturelles et disciplines techniques ne se situe pas à ce niveau : il se manifeste à l'intérieur de chaque état de nature. Pour cette raison, ce qui est discipline naturelle dans un état peut fort bien être discipline technique dans un autre, et vice versa. La science moderne peut parfaitement avoir pour répondant dans l'antiquité un champ d'activité qui recouvre à la fois la philosophie et les arts. Ce qui a été implicitement reconnu :

«Il est difficile, écrit L. Edelstein ${ }^{244}$, de tracer (dans l'antiquité) la ligne de démarcation entre les sciences et les arts et métiers, de même qu'entre la science et la philosophie ».

Et lorsqu'on dresse la liste des savants, on y inclut ceux que les Grecs auraient appelés des artisans - Hippocrate, Galien - et des philosophes :

« Au sommet du monde scientifique se trouvaient des génies tels que Hippocrate, Démocrite, Eudoxe, Euclide, Aristarque de Samos, Archimède, Eratosthène, Apollon de Perge, Hipparque, Hérophile, Erasistrate, Ptolémée et Galien, hommes de talent extraordinaire qui réussirent à faire de leur époque une des plus décisives de l'histoire des sciences » ${ }^{245}$.

De cette définition relative des disciplines naturelles et techniques, il s'ensuit que nous ne devons pas chercher entre elles un rapport d'identité, mais établir des relations d'équivalence eu égard aux rôles qu'elles jouent et aux écarts qui les marquent dans un état de nature particulier. «La plus sûre définition d'un dieu, écrit G. Dumézil ${ }^{246}$, est différentielle, classificatrice ». Cela est également vrai pour un groupement de disciplines.

On voit mieux à présent pourquoi il ne peut y avoir d'histoire séparée des sciences, des arts, des philosophies et des techniques, pourquoi il ne saurait y avoir d'histoire indépendante d'une série de disciplines

246 G. DuMÉzIL : L’héritage indo-européen à Rome, Paris, 1949, p. 65. 
techniques ou naturelles. Leurs frontières n'ont rien de permanent, et leur ordre est soumis à des remaniements continuels. Nous le constaterons en étudiant la formation de la nature mécanique et la transformation de la nature organique. A la Renaissance, la totalité des arts a été ordonnée à nouveau, faisant place à la famille des techniques. Conjointement, la philosophie naturelle, invention des Grecs, a changé pour se conformer aux nouvelles facultés humaines, au nouveau commerce avec le monde matériel. Ce changement entraîne aussi une révision de la hiérarchie et de la signification des disciplines philosophiques, dont le centre est occupé par la mécanique. Les mathématiques cessent d'être des disciplines quelconques pour se substituer à la logique comme «organon » commun aux techniques et à la philosophie. Pour rendre compte de cette vie réelle qui unit et sépare sciences et arts, techniques et philosophies, la manière dont ils confluent dans des ensembles organiques et se diversifient à partir des unités préexistantes, il est indispensable de les présumer solidaires dans l'histoire dont ils modèlent le contenu et l'organisation, l'histoire de notre nature.

Nous arrivons ainsi à une autre observation : toutes les activités intellectuelles et pratiques ne font pas partie du groupement de disciplines. Comme les «humanités » qu'elles reflètent, elles cessent à un moment donné d'infléchir et de traduire nos relations avec le monde matériel. Les «beaux-arts» participent de ce groupement jusqu'au $\mathrm{XVIII}^{\mathrm{e}}$ siècle, mais en sont exclus par la suite. Sans conteste, jusqu'à la révolution dite copernicienne de Kant, jusqu'aux inventions électriques et chimiques du $\mathrm{XIX}^{\mathrm{e}}$ siècle, la séparation de la science d'avec l'ensemble de la philosophie est aussi impossible qu'impensable. Depuis, les disciplines philosophiques se sont spécialisées dans la théorie de la connaissance et l'édification des systèmes idéologiques. La laïcisation des sociétés a favorisé ce glissement, la transformation des échanges avec les forces matérielles a consolidé le terrain acquis par les sciences. Nous devons reconnaître ces cheminements avec sérénité. Point n'est besoin de les nier, de recourir aux armes habituelles, à cette terreur qui dresse la technique contre l'art, la science contre la philosophie et inversement. Pourquoi sciences ou techniques devraient-elles s'affirmer par un «règlement de comptes », l'abaissement méthodique d'un passé qui est leur origine tout autant 
que leur négation? Pourquoi arts et philosophies verraient-ils dans ce qui est leur aboutissement et leur transposition actuelle une dégradation ou une limitation de leur être original ? La fonction de l'analyse historique n'est pas d'étayer ces réactions mais de leur donner un sens, de les situer à l'intérieur d'un mouvement général. Ce à quoi, bien entendu, elle a failli.

Les disciplines sont liées entre elles et remplissent des tâches spécifiques à chaque étape de la transformation de l'ordre naturel qu'elles expriment et constituent. L'histoire humaine de la nature ne peut être conçue et comprise que dans la mesure où nous préservons cette solidarité et l'envisageons historiquement, au lieu d'y voir un état ayant atteint ou susceptible d'atteindre une forme définitive, à l'abri des révisions périodiques. Lorsqu'on replace les groupements de disciplines dans son cycle qui est aussi celui de la création du travail, des savoirs, la liberté qu'on a prise de faire leur histoire morcelée, disjointe, ne paraît pas fondée. Ce n'est donc pas un canon arbitraire qui nous enjoint de compter parmi les arts, les techniques, les philosophies, à des périodes distinctes, des méthodes, des dextérités ou des connaissances variées : seul est déterminant le mode d'interaction naturelle.

Les sciences et les arts ont été comptés parmi les événements les plus élevés de la culture, et cet excès d'honneur semble avoir légitimé le droit de les tenir pour secondaires quant à leurs répercussions sur le plan des conditionnements du monde matériel, des affaires humaines connexes. La possibilité de cette sublimation a été préparée par la scission opérée entre les produits intellectuels et l'intention, indéniablement concrète et positive, de reproduire et d'inventer les talents indispensables à la vie de toute collectivité. Nous avons des raison suffisantes pour abolir cette scission, comme nous avons des raisons suffisantes pour soustraire le savant à l'hypostase du clerc et de l'idéologue, et le classer avec son travail particulier parmi les subdivisions des catégories naturelles. Certes, les relations qui unissent ces subdivisions, leurs disciplines respectives, les fonctions productives et auto-créatrices qu'elles remplissent, sont, à leur tour, historiques. Jusqu'au XIX ${ }^{\mathrm{e}}$ siècle, la connaissance savante est née de la conversion de l'habileté, à des fins d'enseignement ou de découverte. Les conditions naturelles de notre activité, les qualités des puissances matérielles, les 
patrons intellectuels, s'ordonnent d'abord dans le creuset de la production. Le penseur les dégage et s'en dégage : il les sépare, retrouve leur essence et leur unité. A partir du moment où la science - ce fait devra être expliqué - appréhende directement nos capacités et les forces matérielles, et contribue à les combiner, les prolongements productifs sont ses conséquences, et la démarche s'inverse. Les subdivisions ultérieures partent du savant et non plus du producteur, il ne s'agit plus de dévoiler le fondement naturel de l'artifice, mais au contraire de multiplier les métamorphoses artificielles des liens naturels. La différence entre ce qu'on appelle légitimement, à partir du $\mathrm{XIX}^{\mathrm{e}}$ siècle, la science, et la philosophie qui existe à partir $\mathrm{du} \mathrm{VI} \mathrm{VI}^{\mathrm{e}}$ siècle avant J.C., est une différence révolutionnaire dans l'histoire humaine de la nature.

Pour comprendre cette révolution et celles qui l'ont précédée, il est indispensable de débarrasser l'esprit de certaines associations qui ont vidé de sa substance ce qui s'est fait dans l'enthousiasme et l'innocence historiques. Libérés des formules ayant épuisé leurs vertus, nous pouvons inclure, dans la définition d'une catégorie naturelle, les «savants » à côté des «producteurs ", Socrate avec les artisans, Galilée avec les ingénieurs. Parallèlement, la continuité qu'on s'efforce de démontrer pour un groupement de disciplines particulier déplace le point d'appui habituel d'une discontinuité au lieu d'être une ségrégation, un compartimentage dans l'espace, elle se présente comme une suite de sauts, de bouleversements dans le temps. Le dépérissement et le devenir sont ici les termes de l'alternative, préférables à la perdurabilité. Ils nous incitent à expliciter les nombreux recommencements en tant que résultats, au lieu d'enregistrer les versions successives d'un donné immuable ${ }^{247}$.

Dans ce chapitre j'ai illustré mon propos à ce sujet. Ce n'est toutefois pas sur des illustrations que l'on fonde une théorie. Celle-ci tire sa

Cette perspective a, bien entendu, des implications directes au plan de la théorie de la connaissance, pour autant que les sciences, les philosophies, les techniques ne sont censées ici ni projeter un sujet, ni refléter ou dévoiler un donné, mais créer, constituer nos facultés et les propriétés du monde matériel. A cet égard, on se tromperait en croyant qu'il s'agit uniquement d'effets pratiques, quand en réalité c'est une fonction aussi bien théorique que pratique qui se trouve redéfinie. Je ne m'arrêterai pas dans le cadre de cet essai sur les répercussions d'ordre épistémologique qu'il faut envisager : elles feront l'objet d'un travail ultérieur. 
sève et sa vigueur autant de la démonstration plus circonstanciée du modèle proposé que de l'éclatement des faits et de la reconstitution heuristique de leur mouvement. L'analyse de la nature mécanique et de la nature cybernétique, de l'émergence de la technique, de la philosophie mécanique, des sciences répond à ce souci. La recherche érudite a, de nos jours, accompli un travail admirable qui permet d'étayer démonstrations et reconstitutions. Elle a incidemment signalé les lignes historiques auxquelles j'accorde une grande attention : celle qui conduit de l'artisan au philosophe naturaliste, celle qui mène de l'art de l'ingénieur à la philosophie mécanique, etc. Fidèle à sa vocation, l'érudition y a vu des rapprochements de circonstance et les a observés inlassablement, sans vouloir conclure. Je ne censure pas cette attitude, surtout je crois, avec Copernic qu'

« il ne sert pas à grand'chose de rechercher les fautes, car c'est la marque d'un esprit sans vergogne de préférer le rôle du critique qui blâme à celui du poète qui crée ».

Je tire les conséquences nécessaires des faits afin de donner une gravité et un sens aux filiations historiques mentionnées et à d'autres moins bien aperçues. Je ne les poursuis cependant pas jusqu'à leurs dernières limites. Ce serait en effet transgresser les buts de ce travail qui sont : la définition d'un domaine du réel, la découverte d'un instrument conceptuel approprié à son intelligibilité, et la confirmation de l'autonomie de l'histoire humaine de la nature. La certitude des résultats ne saurait être étayée que par de nouvelles recherches, et non pas par l'adhésion aux formules qui l'inspirent. Si ce n'était pas le cas, les conceptions sur lesquelles je m'appuie resteraient un échafaudage où tout s'imbrique mais où rien ne tient, où la vie a fui devant la réalité, comme ces bâtisses imaginées avec ingéniosité, exécutées avec minutie, et qui demeurent pourtant obstinément inhabitables. 


\section{Chapitre II.}

\section{L'originalité de l'ingénieur}

\section{$\underline{\text { Retour à la Table des Matières }}$}

La technique est l'œuvre de l'ingénieur, elle le représente et il l'anime. Le sentiment de sa prééminence, le respect et la crainte dont il est l'objet, durent depuis plusieurs siècles déjà. Comme nous le rappelle Pierre Francastel, l'imagination et la conviction hypostasient l'ingénieur, le placent aux commandes de la vie matérielle, lui réservent le rôle d'un agent créateur :

« Actuellement, un schéma très populaire, qui correspond assez bien à l'idée que se fait du développement général de l'humanité l'hominien moderne dans les différents compartiments de la planète, tend à hypostasier l'œuvre toujours un peu mystérieuse de l'ingénieur » ${ }^{248}$.

Mais, emportés par leur élan, ses doctrinaires ont oublié qu'il est un agent historique : son apparition est datée et soumise à la pression de certaines circonstances. Rien ne nous autorise à le situer à l'aube de la civilisation ${ }^{249}$, ni à considérer que tout ce qui a été créé depuis est son fait ${ }^{250}$. Cette propension apologétique risque d'oblitérer sa spécificité. Quant à la signification dont il est porteur, au mystère qui

\footnotetext{
248 P. FRANCASTEL : Art et technique, Paris, 1956, p. 52.

249 «La technique de l'ingénieur sert à pourvoir aux besoins matériels de l'homme : dans ce rôle, elle est aussi ancienne que la civilisation ». J.K. FINCH : The story of engineering, New York, 1960, p. XXXI.

«La profession de l'ingénieur est si ancienne qu'on n’a jamais pu en découvrir l'origine ». J.H HAMMOND : The engineer, New York, 5925, p. I.

250 L. SPRAGUE DE CAMP : The ancient Engineers, New York, 1963, p. 25.
} 
l'entoure, ils s'ouvriraient plus largement à nous si l'on voulait bien se rappeler qu'il est apparu à un moment précis, qu'il s'est différencié de l'artisan ou artiste ${ }^{251}$ (termes synonymes à l'époque) pour finir par se substituer à lui. La technique n'est assurément qu'une forme historique que prennent les arts, certains arts. L'ingénieur a transformé une partie des facultés de l'artisan et, ce faisant, les a synthétisées. Il en est résulté une attitude originale envers le monde matériel et la construction d'un groupe humain qui s'y reflète et l'adopte. Trois phases principales marquent avec netteté ce processus :

- La première est caractérisée par la formation d'un corps de spécialistes du moulin et des engins de guerre, possédant un art qui se distingue des autres ;

- Dans la seconde phase, l'engin devient un moyen général de transformation des forces matérielles et de création des habiletés, et l'ingénieur, tout en remplissant d'autres fonctions - il peut aussi être peintre, sculpteur, architecte, etc. - est un artisan reconnu à la fois dans sa particularité et dans son universalité ${ }^{252}$. Pour parachever ses talents et perfectionner les machines, il a recours aux savoirs mathématiques ou mécaniques, au dessin, et il s'efforce d'assurer l'indépendance et la cohérence d'une discipline technique qui lui est propre.

- Dans une troisième phase, enfin, on enregistre l'ascension du mécanicien qui pénètre dans les branches importantes de la production textiles, mines, métallurgie - et la création d'une nouvelle branche, celle de la construction des machines. L'ingénieur devient l'agent social de la production, et la technique l'expression générale de celle-ci. De manière systématique, il transforme la dextérité de l'artisan en celle de la machine. De plus en plus, l'artisan apparaît comme une partie de la machine, l'artiste s'éloigne du champ des techniques, tan-

251 «Par conséquent, le technicien et l'ouvrier, qui étaient unis dans l'artisan, se sont séparés, et le technicien est devenu l'expression vivante de la technique en tant que telle - en un mot, l'ingénieur ». J. ORTEGA Y GASSET : op. cit. p. 153.

252 «Enfin, l'on peut dire qu'un bon ingénieur est un homme universel». B.F. BELIDOR : La science des ingénieurs, Paris, 1729, p. 2. 
dis que l'ingénieur concentre en lui toute la subtilité et l'intelligence du travail des mécanismes, toute la richesse des nouveaux matériaux dont il impose l'usage. La reproduction sociale se transforme à son tour. Il se constitue un secteur des moyens de production, secteur autonome et révolutionnaire, qui reste par excellence celui de la dextérité et du génie inventif du mécanicien.

A chaque époque, la société intègre différemment l'ingénieur et le soumet à ses exigences particulières. Les rois et les princes le mettent surtout à contribution dans le domaine militaire, et dans celui du divertissement. Les cités l'appellent afin de résoudre les questions ayant trait à la défense ou à l'aménagement de la vie urbaine. Les capitalistes reprennent une des perspectives qu'il a entrevues, celle de l' " économie de travail », et la transforment en un impératif exclusif, qui leur sert de devise, pourrait-on dire. Après s'être approprié les moyens de travail de l'artisan, ils entrevoient là une possibilité de rendre caduc son talent.

La modification constante des conditions sociales n'est pas sans influer sur le développement - le rythme et l'orientation — de la catégorie naturelle et sur le recrutement de ses membres ${ }^{253}$. Il faut cependant noter une continuité remarquable dans l'évolution de son habileté, des découvertes qu'elle a faites, entraînant l'intervention décisive de l'ingénieur dans le bouleversement de nos assises économiques et l'aménagement des échanges avec le milieu ambiant. Pierre Francastel nous a informés judicieusement de l'importance de la situation à laquelle cette catégorie accède au $\mathrm{XX}^{\mathrm{e}}$ siècle. Quant à moi, je me propose d'en retracer la genèse et de fixer les caractères qui lui confèrent sa valeur et son sens dans l'histoire humaine de la nature.

Je n'ai pas cru devoir m'arrêter dans cet essai sur les corrélations économiques ou sociologiques de l'apparition des ingénieurs. Ces corrélations ne feraient que compléter ma description sans lui ajouter des aspects fondamentaux. Il est assez fréquent que l'on agrémente les analyses historiques dans le domaine de la science ou de la technologie de quelques tableaux peignant la société et la culture du temps. Tant que l'on n'a pas correctement étudié les rapports de la société et de la nature, cela est parfaitement superflu : il ne faut introduire des considérations sociologiques que là où elles expliquent et font comprendre les échanges d'une catégorie particulière avec la matière, et les formes sociales qu'ils prennent ou la manière dont ils déterminent ces échanges mêmes. 
Serge Moscovici — Essai sur l'histoire humaine de la nature (1968) 241

Retour à la Table des Matières 


\section{Les nouvelles ressources complémentaires}

Retour à la Table des Matières

\section{La renaissance de l'artisanat.}

La période qui succède à l'éclipse d'Athènes marque une sorte de retour, à un niveau bien supérieur, aux modes de vie des empires qui se sont longtemps maintenus en Asie ${ }^{254}$. L'Égypte de Ptolémée offre le modèle grandiose d'un tel hybride ${ }^{255}$, Alexandrie témoigne du perfectionnement de tous les arts. On y connaît l'existence d'un important groupe de mécaniciens qui, pour la guerre ou pour la religion, le levage des vaisseaux ou leur construction, améliorent considérablement les engins connus et en inventent probablement de nouveaux. Sur le pourtour de la Méditerranée, à Syracuse notamment, des activités analogues se poursuivent. Si nous nous tournons vers le monde romain, nous le voyons proposer une synthèse politique, sociale, plus originale que celle de l'Égypte. Son extension propage, sous une forme appropriée, les acquisitions intellectuelles et matérielles de la Grèce, d'Alexandrie et d'Asie. On sait quelles furent les étapes suivantes: affaiblissement de l'empire romain, invasion des barbares, « âges sombres ». L'Europe devient un continent agraire où s'ébauche le régime social de la féodalité. Les arts disparaissent, ou plutôt leur rôle et leur importance s'amenuisent. Le rétablissement de l'artisanat domestique est nettement marqué. Entre le VIII ${ }^{\mathrm{e}}$ et le $\mathrm{X}^{\mathrm{e}}$ siècles après J.C. on note une amélioration des méthodes de l'agriculture, le développement de sa production d'ensemble. C'est aussi de cette époque qu'il faut dater la réapparition des artisans comme facteur notable de la vie productive.

254

serait intéressant de procéder à une étude comparative des deux lignees de développement qu'a suivies l'artisanat. L'une, partant des grands empires asiatiques, conduit à la technique chinoise. L'autre, qui jaillit à peu près au même point, mène, par la Grèce, les empires alexandrins, romains et les cités corporatives du Moyen-Age, à la technique européenne. On sait que de l'une à l'autre les emprunts ont été nombreux ; mais chacune de ces évolutions suit néanmoins une ligne particulière, et la comparaison serait riche d'enseignements.

255 M.I. RostovtzeFF : Social and economic history of the hellenistic world, Oxford, 1941, 3 vols. 
Ils réapprennent à travailler de manière autonome et se séparent de la communauté agricole au moment où celle-ci défriche de vastes territoires, diffuse l'assolement triennal, le hersage régulier, le collier d'attelage, le joug frontal. Le mouvement historique tend à se répéter dans une situation nouvelle. Dans les villages, les artisans retrouvent une situation de démiurges ; auprès des seigneurs, ils s'intègrent dans l'ensemble du domaine : ce sont les serfs de cette économie domaniale qui demeure une annexe importante de la culture. Mais il suffit de la présence des artisans au sein d'une campagne surpeuplée ${ }^{256}$, où l'oppression sociale est sensible, où les échanges sont possibles, pour que leur habileté joue le rôle de ferment : dès lors le mode de vie urbain s'impose. Aux XII ${ }^{\mathrm{e}}$ et XIII ${ }^{\mathrm{e}}$ siècles, l'air libre des villes les attire, et les artisans se retrouvent dans leur élément et se reconstituent en tant que groupe ${ }^{257}$.

Ce cheminement a été décrit plusieurs fois, bien qu'il nous échappe par de nombreux côtés :

«Une véritable révolution, écrit Henri Pirenne, dont nous ne pouvons malheureusement saisir le détail, accompagne la transformation de l'industrie rurale en industrie urbaine. Le tissage, qui avait jusqu'alors constitué une occupation dévolue aux femmes, passa aux mains des hommes ${ }^{258}$.

A peu près partout en Europe les artisans deviennent plus nombreux, les foyers d'activité artistique se multiplient ${ }^{259}$. Un historien anglais a dénombré au $\mathrm{XI}^{\mathrm{e}}$ siècle 31 centres ou communautés d'artisans, au XII ${ }^{\mathrm{e}}$ siècle 89 ; au XIII ${ }^{\mathrm{e}}$ siècle, les artisans, en Angleterre, sont reconnus dans 277 centres. Ces faits montrent bien qu'en

256 «Il faut voir un second élément d'instabilité dans la croissance de la population. La structure du manoir est telle qu'elle impose des limites au nombre de producteurs qu'elle peut employer et au nombre de consommateurs qu'elle peut entretenir, tandis que le conservatisme inhérent au système freine son expansion globale. Cela ne signifie bien entendu pas qu'aucune croissance n'est possible, seulement celle-ci demeure en-deçà de l'accroissement de la population. » P.M. SwEEZY : The transition from feudalism to capitalism, Science and Society, 1950, 14, p. 136.

257 P. BoISSONNADE : Le travail dans l'Europe chrétienne, Paris, 1930.

258 H. PIRENNE : Histoire du Moyen Age, Paris, 1941, t. VIII p. 42.

259 P. WolfF, in Histoire générale du travail, ed. cit. t. II p. 118. 
l'espace de quatre siècles le travail artisanal et celui de l'agriculteur se sont séparés - séparation qui rappelle, par bien des côtés, celle qui s'était produite en Grèce. Toutefois, l'habileté même que l'artisan a réussi à dégager pour son compte a subi des transformations multiples. La discontinuité dont l'écroulement de l'empire romain a marqué l'histoire européenne contraste avec la création continuelle de nouveaux savoirs et leur relative extension ${ }^{260}(3)$.

Ceci apparaît notamment dans l'emploi des forces animées ou inanimées. On utilise la force des animaux de façon plus efficace ; parallèlement, la qualité de l'outillage agraire s'améliore. L'utilisation de la force hydraulique, dans le moulin, s'étend, de façon lente peut-être mais régulière. $\mathrm{Au} \mathrm{IV} \mathrm{e}^{\mathrm{e}}$ et $\mathrm{au} \mathrm{VI}^{\mathrm{e}}$ siècles après J.C. son usage est attesté ; au $\mathrm{X}^{\mathrm{e}}$ siècle, le moulin apparaît dans le paysage comme un élément familier. L'emploi de la force hydraulique, sans se généraliser encore, commence à s'imposer en tant que solution technique. Il suppose, pour pouvoir s'appliquer à la meunerie, un maniement plus courant du mécanisme en général et des engrenages en particulier. La variété d'utilisation de ces moulins, employés d'abord dans tous les cas où l'on a besoin du mouvement circulaire, devient une école de mécanique pour les paysans qui doivent s'en servir, soit pour moudre le blé, soit pour la pression des oléagineux. Rien donc d'étonnant si, devenus artisans, ils ont recours à un outillage en partie mécanique.

Des documents nous permettent d'en prendre connaissance. Le martinet hydraulique est connu dès le XIII' ${ }^{\mathrm{e}}$ siècle. La force hydraulique l'actionne sans autre intervention. A ce titre, c'est un instrument semi-automatique. Le manche du marteau tourne autour d'un axe. D'autre part, une roue pourvue de cames est rendue solidaire de l'arbre d'un moulin. Pesant sur l'extrémité du manche, les cames contribuent à soulever le marteau, qui retombe grâce à son poids propre. Conjointement, on tente de régler les effets. Les cames sont fixées à un anneau qui est articulé au moyen d'un coin avec l'arbre du moulin. En variant le nombre de cames ${ }^{261}$, on peut varier l'intensité recherchée du coup. Dans le carnet de Villard de Honnecourt, on relève aussi l'existence d'une scie mue par l'énergie hydraulique, et à Trentino, en 1214, on signale des soufflets de forge actionnés de la même façon.

Ces coordonnées technologiques sont significatives. S'il se mécanise partiellement, et si, en se détachant de l'agriculture, il s'assimile

B. GILlE : Esprit et civilisation technique au Moyen-Age, Paris, 1952. 
certaines dextérités mécaniques, ${ }^{262}$ dans l'ensemble l'artisanat du Moyen Age n'innove pas :

«Aucune différence frappante des formes industrielles, constate P. Usher, ne distingue l'industrie classique de l'industrie médiévale ${ }^{263}$.

Toutefois, il est indispensable d'envisager les circonstances nouvelles. Tout d'abord, l'extension considérable de la classe artisanale qui, un peu partout, devient une force productive importante. Ce facteur quantitatif a des répercussions sur la vie sociale et les institutions ${ }^{264}$. Dans la vie urbaine, fortement organisés, les artisans acquièrent un poids qui leur permet d'orienter leur propre destin, d'assurer la réalisation de leurs fins. Le système corporatif tend à devenir la règle. $\mathrm{Si}$, dans la cité antique, les catégories sociales élevées se réclamaient de l'agriculture, dans la cité médiévale, chacun, noble ou bourgeois, à l'exception des gueux, fait partie d'une confrérie. La pratique des arts est, jusqu'à un certain point, hautement prisée et recommandée à tout un chacun. Dans sa Doctrina pueril, Raymond Lulle conseille aux bourgeois, aux princes, aux prélats même d'acquérir une dextérité artistique ; au cas où leur fortune viendrait à décliner, ils seraient en mesure de pourvoir à leur subsistance.

L'artisanat atteint un degré très élevé de perfection. La formation, l'organisation et la répartition du travail sont strictement codifiées. L'habileté même se trouve réglementée, et le travail reçoit une dignité et une individualité marquées. Les conditions d'usage et d'exploitation des ressources inventives ou matérielles, les rapports de ceux qu'elles concernent, sont strictement énoncés. Fait plus important encore, les villes corporatives peuvent s'assurer un débouché stable dans les campagnes environnantes et, en y interdisant l'exercice de tout métier, s'approprier de façon plus consciente le savoir-faire agricole :

262

on étudie la technique médievale dans la suite des operations techniques auxquelles elle donne lieu, on est frappé de voir que le Moyen-Age ne diffère de l'antiquité que par une mécanisation plus poussée et par le développement de certains procédés chimiques ». B. GILLE, Les développements technologiques, art. cit., p. 76.

263

264

R. LATOUCHE : Les origines de l'économie occidentale, Paris, 1956. 
«Par-dessus tout, observe Max Weber, cependant, la cité (des confréries) cherchait à éliminer la concurrence de la campagne qui était venue sous sa domination. Elle essayait de supprimer l'exercice des métiers à la campagne et de forcer les paysans à satisfaire leurs besoins à la ville ${ }^{265}$ (1).

L'artisan, à la différence de son homologue de l'antiquité, s'installe ainsi de manière stable et puissante dans un univers social qui, au départ, ne lui est pas favorable. Il prend mieux conscience de sa situation et de ses perspectives. Il reprend à son compte et reproduit l'habileté du monde agraire avec plus de ténacité et d'esprit de suite. Le système de reproduction des facultés qui, de l'agriculture à l'artisanat, s'élaborent en métiers déclarés, se trouve clairement défini et rigoureusement réglementé. La cité est le domaine des arts, la campagne celui de l'agriculture. C'est du moins la théorie que l'on peut tirer de la pratique du temps. Elle sanctionne socialement et exprime économiquement la division naturelle qui s'opère, jusqu'à la rendre rigide. Une telle rigidité ne pouvait aller sans tension. Les frontières qui séparent les différents métiers ne sauraient être aussi nettes qu'on le voudrait et les traditions - celles de la campagne notamment — ne se pliaient pas aussi facilement aux intérêts des communautés. Quand celles-ci faisaient pression sur le pouvoir politique, elles avaient tendance à figer le cours des événements, sans y parvenir entièrement. Malgré les heurts, les dommages subis, les transformations imposées, l'ordre artisanal, dont j'ai tracé le tableau simplifié, s'est maintenu jusqu'au XVIII ${ }^{\mathrm{e}}$ siècle.

La réalisation en Europe du schéma dont je viens de tracer les grandes lignes ne fut, il faut le rappeler, jamais complète ni uniforme. Il nous permet néanmoins de voir comment, de manière constante et avec des analogies réelles, le processus de division par lequel se constitue une catégorie naturelle se répète dans un autre milieu géographique et social, mais de façon à la fois plus ferme et plus affinée ; les comparaisons avec la division qui avait eu lieu au sortir du néolithique, et avec celle qui s'est produite en Grèce, où le modèle s'est élaboré pour la première fois en toute liberté, sont instructives. A cette 
fin, il est utile de rappeler que l'artisanat a été à l'origine de trois grandes découvertes historiques: il a fait connaître le prix de l'habileté, la valeur de sa conservation et de sa reproduction, et l'importance de l'individu comme unité technique. Si son activité a pu se développer, c'est parce que l'agriculture avait acquis une forme stable, au terme d'un mouvement amorcé au septième millénaire. Quelles furent les conséquences de ce mouvement? En premier lieu, l'accroissement des unités de production et de cohabitation jusqu'à la taille d'une proto-cité ; en second lieu, la fixation géographique des populations; et enfin le reflux des femmes de la culture du sol vers les occupations domestiques. Ce secteur domestique acquiert de l'importance et gagne en autonomie. L'équipement indispensable à la conservation des céréales, du lait, de la viande, se complique et se multiplie. Il faut emmagasiner le grain, tisser des vêtements, tresser des paniers, confectionner des jarres, construire des maisons et des dépendances. La production artisanale s'épanouit, surtout grâce à ces produits secondaires de la culture et de l'élevage qui fournissent à une main-d'œuvre disponible un apport assuré de matières premières. A côté du travail des champs commence à exister un autre travail qui, de façon embryonnaire mais distincte, se concentre sur la poterie, le tissage, les métaux, bref sur toutes les ressources complémentaires de l'agriculture qui ne sont ni consommées immédiatement, ni réservées à la continuité de sa production. C'est ainsi que la sphère domestique, si peu différenciée qu'elle soit de la sphère agricole, joue désormais un rôle certain. Les travaux artisanaux, apanage des femmes, s'ajoutent aux travaux des champs de façon accessoire. Entre le quatrième et le troisième millénaires, les conditions changent; ces sphères se séparent, leurs travaux se différencient, l'artisanat "démiurgique » est né. Les circonstances sociales et matérielles de l'exploitation agraire avaient effectivement créé, dans la région qui allait devenir celle des empires du Proche-Orient, une population instable, faite d'étrangers, d'affranchis, de fermiers sans terre ou pauvres, qui servaient de main-d'œuvre à des maîtres occasionnels et cherchaient un débouché dans tout travail, y compris le travail artisanal. Aux Indes, par exemple, les artisans sont, aujourd'hui encore, des petits fermiers qui, faute de pouvoir subsister à l'aide des seuls produits de leur champ, se tiennent à la disposition de quiconque réclame leur concours ; à ce titre, ils sont attachés au village. Ici intervient un phénomène que nous avons analysé précédemment: l'agriculture, qui 
avait donné le jour à cette force de travail surnuméraire, a aussi engendré par elle et pour elle les ressources complémentaires qui se sont accumulées en quantité importante au niveau local, à celui des États et des villes naissantes. Tandis qu'une partie de l'humanité devenait sédentaire, s'accroissait, et, grâce à la charrue et à la traction animale, décuplait sa puissance, une autre partie commençait à se déplacer. Elle allait à la quête des à-côtés de la production agricole : les fibres, le cuir et même la pierre ou les métaux, toutes ces substances qui restaient viles ou inessentielles tant que des savoir-faire et des forces de travail ne surgissaient pas pour, en les employant, les tirer du néant ${ }^{266}$. La différenciation de l'artisan et de l'agriculteur s'accomplit lorsque le premier ne se consacra plus à la fois à la transformation des matières premières et à leur préparation, lorsque, ces matières étant à sa disposition en quantité suffisante, il put se concentrer sur le perfectionnement de son activité. Dans la collectivité rurale, une grande partie du temps et des énergies était dévolue à la recherche, à l'attente du matériau approprié ou à sa formation : fibre, bois, etc. Comme le notait Homère, le charron doit commencer par être bûcheron, par abattre les arbres dont il taillera le bois. Détaché du processus de création des matériaux, allant les chercher là où ils se trouvent, l'artisan s'affranchit d'une limite, affine ses procédés, fixe mieux ses gestes et conçoit plus d'objets ou d'outils. En appliquant ses capacités à ce que j'ai appelé des quasi-ressources, il conserve son droit à l'existence ${ }^{267}$ dans un univers où il lui faut changer le superflu en indispensable, donner corps à ce qui est voué à la destruction, instaurer la vie là où la mort est l'issue rigoureuse. Si la collectivité laisse une place à l'artisan, c'est une place marginale ${ }^{268}$, puisqu'il est, soit expulsé, soit parqué, et peut-être se définit-il autant par sa qualité d' "étranger» que par celle de spécialiste. Sa particularité est d'être un démiurge, c'est-à-dire de produire pour les autres, pour le public. Outre sa portée de distinction sociale, cette définition connote une condition objective

« Il (l'homme) n'avait pas besoin de métaux avant de les avoir découverts, et jusque là ils ne pouvaient pas exister, pas même dans son imagination ». H.S. HARRISON, in C. SINGER (ed) : A History of Technology, t. I, Oxford, 1954, p. 65.

« Dans la pratique, naturellement, la production locale de nourriture n'était pas interrompue, mais la nouvelle richesse (en minerai) était employée à entretenir une nouvelle population qui, dans l'ancienne économie, aurait été en surnombre et condamnée à la famine ou à l'émigration ». G. CHILDE : Man makes Himself, Londres, 1948, p. 170.

268 G. DUMÉZIL : Métiers et classes fonctionnelles chez les divers peuples indo-européens, Annales, 1958, 13, p. 717. 
de l'activité de l'artisan, puisque son travail ne saurait avoir d'autre destination. Aussi doit-il se déplacer en quête de sa clientèle et de ses matières premières, et il est surtout itinérant. Lentement, la plupart des travaux domestiques deviennent des travaux à caractère artistique : l'artisanat croît au fur et à mesure qu'il accomplit cette conversion à l'échelle du village et de la ville. Ce qui lui permet de la réaliser, c'est sa situation extérieure, le fait qu'il n'est pas engagé tout entier dans le cycle agraire. De la sorte, ce que faisait la femme cultivatrice, l'homme artisan se met à le faire. Hérodote ne s'étonna-t-il pas de voir en Égypte des hommes assis devant des métiers à tisser? Toutefois, au cours de cette période qui aboutit à la formation de l'artisanat, l'on ne saurait dire que l'artisan ait réellement supplanté l'agriculteur dans une partie importante de ses activités habituelles. Il n'est pas davantage devenu l'assise de la vie urbaine. Il élargit, dans un sens, le cercle de la vie agraire en favorisant l'établissement des villes, mais l'ensemble de la production agricole ne s'en ressent pas. L'agriculteur continue à fabriquer lui-même ses outils en pierre ou en bois, et comme auparavant la femme tisse les vêtements et confectionne des récipients en argile pour les grains, le vin ou l'huile. L'homme de l'art n'a pas rendu caduques les activités semblables aux siennes, qui avaient été son point de départ. Ces deux variantes pleinement constituées d'un même travail coexistent. Il y a parallélisme, dédoublement, et non point partage des efforts qui les rendrait nécessaires les uns aux autres. Cependant la condition et les traits particuliers de l'artisan sont reconnus. A l'époque que nous considérons, celle des dynasties égyptiennes et des royaumes mésopotamiens, il constitue un nouveau type d'homme et de producteur, une catégorie naturelle dont la division d'avec l'agriculteur se fait sur la base du travail en tant qu'exercice d'une habileté. Sa réputation et sa singularité proviennent de la conjonction de l'outil et de la main. Signes distinctifs que l'errance à la fois masque et renforce.

La désagrégation - à partir du deuxième millénaire — ou la stagnation de ces empires, rongés par la guerre, démembrés par les invasions, ruinés par l'exploitation des paysans, talonnés par la famine, ne témoignent pas seulement de leur impéritie en matière d'administration ou de défense des terres conquises, mais aussi de leur incapacité à favoriser l'épanouissement des potentialités productives 
engendrées par les artisans et de leur prolongement, les commerçants. Pour que cet obstacle fût franchi, pour que le travail artisanal pût devenir un facteur essentiel, il fallait tout d'abord que fût découvert un matériau plus répandu que le cuivre ou le bronze pour la fabrication de l'outillage et de certains objets usuels. Le fer répond à cette demande, il permet de perfectionner l'outillage, car il est plus facile à travailler et existe en quantités plus abondantes. Par voie de conséquence, non seulement chaque artisan améliore ses instruments et les diversifie de façon assez économique, mais encore le nombre global des artisans est susceptible d'augmenter, étant donné que les moyens de travail deviennent plus accessibles ${ }^{269}$. Conjointement, l'invention du fer ouvre la possibilité d'une articulation, d'une interdépendance de l'artisan et de l'agriculteur. Sa grande «banalité » permet de le substituer à la pierre comme outil agricole. Le fermier laboure désormais avec un coultre de fer, grâce auquel il parvient à cultiver des terres auparavant impossibles à mettre en valeur. L'appel au travail artistique s'intensifie donc. Ensuite, l'extension de la crise des empires dans une aire géographique et sociale où l'emprise et la prééminence de la force agricole offraient relativement moins de résistance au développement de ce travail a eu un effet décisif. La diversification des communautés politiques, des villes, contraint chacune à s'assurer volontairement une certaine population artisanale. A cette fin, il est impératif de pourvoir à la reproduction des talents et de leur faciliter une activité régulière. Ces processus convergent entre le $\mathrm{XIV}^{\mathrm{e}}$ et le $\mathrm{XII}^{\mathrm{e}}$ siècles avant notre ère dans l'empire mycénien ${ }^{270}$ et dans les cités grecques ultérieurement. Dans ces cités, l'artisanat s'institutionnalise, se reconstitue sans référence directe à l'univers du mythe et de la fécondité agraire, donne libre cours à ses forces intellectuelles et matérielles. Les démiurges, porteurs des «mystères» de l'art, se sont

269 «Le fer a par conséquent été appelé le métal démocratique, par contraste avec le cuivre et le bronze aristocratiques », car il fournissait à l'artisan ordinaire de meilleurs outils qui lui permettaient de faire un travail plus efficace. Le métal commença alors à conquérir le monde et à supplanter les outils et les armes de pierre ou de silex qui survivaient encore ». R.J. FORBES and E.J. DiJKSTERHUIS : A history of science and technology, Hatmondsworth, 1963, t. 1, p. 72 .

«Le véritable âge du fer ne commença guère avant 1200 avant J.-C., son développement s'associant à une grande migration de peuples qui troubla presque tout l'ancien Proche-Orient, et à une hausse temporaire de beaucoup de produits de première nécessité, en particulier du blé ». R.J. FORBES : Extracting, smelting and alloying, in C. SINGER : A history of technology, ed. cit. t. I, p. 592. 
transformés en technitai. J.P. Vernant a bien montré ${ }^{271}$ comment leur travail vient à se distinguer jusque dans le langage et la doctrine. Le labeur agricole se réalise par sa vertu spontanée, tandis que la racine «tech» du labeur artisanal indique qu'il s'agit d'une production de l'ordre de la "poïein », de la fabrication artistique, et non de l'ordre de la «pratein », de l'activité non-contrainte. Dans ce dernier cas, l'effet du travail ou " ergon » n'est pas projeté au-delà ou en dehors de la chaîne d'actions qui l'ont suscité, il est confondu avec cette chaîne elle-même dans son exercice et son accomplissement.

A travers les transpositions nécessaires, l'Europe du Moyen Age connaît la généralisation de ces attitudes et de ce modèle dans des conditions semblables à celles où s'était créée en partie leur ébauche, à savoir la prédominance de l'agriculture, et la présence d'une classe à la fois guerrière et religieuse. Seulement il n'y avait plus d'esclavage qui pût freiner l'essor de l'artisanat en rendant secondaires les efforts industriels. Les Arabes et les Byzantins ont assuré les transitions nécessaires. Il a fallu que la catégorie artisanale se reconstituât, qu'elle atteignît un certain stade et accomplît son mode de reproduction et ses liens avec la matière, qu'elle étendît et restituât au travail cette autonomie et ce caractère spécifiquement humain, qu'enfin le monde de la ville s'identifiât à celui des arts, pour que l'ingénieur se dégageât dans son individualité. En ces reprises continuelles réside probablement l'objectivité de l'histoire, et la certitude qu'elle possède des principes généraux.

Retour à la Table des Matières

\section{La convergence des arts et les agents inanimés.}

L'installation de l'artisanat dans la vie urbaine signifie un changement de dimension. D'une part, les travaux nécessaires à l'aménagement des villes et à leur défense s'amplifient. D'autre part, les arts, en y contribuant, engendrent une coopération accrue des hommes qui se consacrent à eux. Cette interdépendance est très sensi-

271 J.P. VERNANT : Travail et nature dans la Grèce ancienne, journal de Psychologie, 1955, pp. 129. 
ble là où leur combinaison est imposée par le volume, la complexité de l'ouvrage (construction, drainage, approvisionnement en eau) et leur présence massive exige aussi davantage de sources énergétiques - l'eau par exemple — d'une efficacité au moins équivalente à celle des sources d'énergie humaine et animale. La poursuite de cet effort collectif engendre et renforce une nouvelle fonction qui est celle de direction, de mise en œuvre de l'ensemble des spécialités indispensables à l'exécution. Cette fonction est remplie par l'architecte et plus tard par l'ingénieur :

« Vous aurez pour tâche de diriger le maçon, le sculpteur, le peintre, le travailleur de la pierre, du bronze, du plâtre, de la mosaïque. Ce qu'ils ne savent pas, vous le leur enseignerez. Les difficultés qu'ils rencontreront dans leur travail, vous les résoudrez à leur place. Quel savoir varié vous devez posséder en conséquence, pour instruire ainsi les artisans de toute espèce! »

C'est en ces termes que s'adresse le roi des Ostrogoths, Theodoric, à son architecte en chef Aloysius. Voilà en effet une direction qui exige un savoir bien étendu ; mais il ne s'agit pas de posséder chaque art à fond, il suffit d'être capable d'en saisir la teneur afin d'aider les hommes de métier à s'adapter aux conditions particulières du travail commun et de coordonner leurs efforts. L'habileté artistique, son contenu fait de règles et de recettes, ses instruments apparaissent au maître d'œuvre de manière objective et dans leurs liaisons réciproques. Aussi doit-il appréhender ces savoir-faire, ces outillages artisanaux, en les dissociant, dans la mesure du possible, de tout objet particulier. Il doit les transformer, d'une certaine façon, en ses savoirs propres, afin de pouvoir commander et instruire les différents corps de métiers.

Dans la direction ainsi exercée, le côté instrumental contribue de manière décisive à la constitution de l'habileté de l'ingénieur. Sur les chantiers des bâtisseurs, dans les arsenaux de guerre, dans les mines ou les travaux de fortification, partout où les artisans affluent, certains mécanismes spécifiques sont indispensables à la bonne marche de l'ensemble. Étant donné le volume des matériaux à transporter, la hauteur ou la profondeur à laquelle on travaille habituellement, les engins de levage doivent être relativement importants. Les pompes sont une 
nécessité absolue de l'exploitation des mines dont l'eau envahit les gisements et les galeries, et le sont d'autant plus qu'on s'enfonce davantage dans le sous-sol, à des profondeurs où l'on ne peut plus utiliser les animaux de trait. L'efficacité requise de ces engins et de ces pompes pose le problème de l'amélioration de leur mécanisme et de son adaptation à des circonstances variées. Les instruments de précision sont aussi appelés à jouer leur rôle, soit pour aider aux opérations de mesure, soit pour permettre un dessin plus exact des plans, une exécution plus rigoureuse des modèles qui sont ensuite reproduits à grande échelle.

Cette double obligation de coordonner les travaux les plus divers et de leur fournir les moyens adéquats en énergie ou en mécanisme stimule la découverte des talents et des ressources correspondants. Dans ce contexte, le moulin cesse d'être un outil combinant action énergétique et engrenage, c'est-à-dire un moulin au sens strict, pour devenir l'expression générale que prend l'emploi de la force motrice. Une question nouvelle surgit parallèlement : celle du contrôle de la force inanimée et de l'adaptation du mécanisme qui y pourvoit. Ainsi s'achemine-t-on vers une utilisation plus raffinée de la force musculaire de l'homme ou de l'animal, et vers le perfectionnement du mouvement que peut accomplir un outil ${ }^{272}$. De là proviennent des inventions décisives, notamment l'emploi de la manivelle pour la conversion du mouvement de va-et-vient en mouvement circulaire. L'amélioration des engrenages, l'attention apportée aux roues dentées, le recours à des dispositifs à cames permirent de diversifier considérablement les mouvements que l'on pouvait obtenir. La transformation du mouvement circulaire en mouvement rectiligne reçut un commencement de solution avec la découverte, vers le $\mathrm{XV}^{\mathrm{e}}$ siècle, du système bielle-manivelle. Entre le $\mathrm{X}^{\mathrm{e}}$ et le $\mathrm{XV}^{\mathrm{e}}$ siècles, les mécanismes, les « engins » se multiplient et se combinent de façon inédite. Parallèlement le «meunier» se détache de plus en plus de sa spécialité originelle pour se consacrer aux applications différentes du moulin, maintenant partie motrice d'un ensemble technique. Le fabricant d'engins de toutes sortes s'appelle en anglais « constructeur de moulins », bien

B. GILlE : Le moulin à eau, une révolution technique médiévale, Techniques et civilisations, 1953, III, pp. 1-15.

A.P. USHER : A History of mechanical Inventions, Cambridge (Mass.), 
que la meunerie soit la seule chose dont il ne s'occupe plus. En outre le terme de moulin désigne n'importe quel genre de machine; ainsi, en allemand, « Wasser- » ou « Windmühle » se dit de moulins qui ne servent pas à moudre le grain mais à actionner des pompes ou d'autres mécanismes. Le tour vient à s'appeler « Drehmühle», et l'on entend par «Bandmühle» un métier à rubans sur lequel plusieurs rubans peuvent être tissés à la fois. Les variations de la nomenclature font écho à des changements plus profonds les «hommes de l'engin» s'affirment, avec leurs créations, à côté des artisans, ceux-ci « hommes de l'outil » ${ }^{273}$.

A bref délai, l'énergie hydraulique pénètre dans la construction des instruments mécaniques, notamment des horloges ${ }^{274}$. Au XII ${ }^{\mathrm{e}}$ siècle, l'horloge était à eau. D'après une description un peu plus tardive, elle se composait d'une corde munie d'un flotteur à une extrémité et d'un contrepoids à l'autre. La corde s'enroulait autour de l'axe qui faisait tourner le cadran. Parfois on recourait à des roues dentées. Elles servaient à multiplier la vitesse de la roue qui divise le temps et accroissaient la durée des révolutions de la roue motrice, en transmettant le mouvement à plusieurs roues. Mais, pour assurer à l'appareil une certaine régularité, il fallait pouvoir contrôler l'action du poids et se libérer des aléas du débit de l'eau. Il restait à l'horloge à se constituer comme mécanisme autonome, comme mécanisme pur. Avec l'emploi d'un corps pesant à action constante, l'invention de l'échappement et de la manière de régler les poids, cet idéal fut atteint. Plus tard, on y adapta le ressort, et l'on conçut ainsi un mécanisme propre à emmagasiner l'énergie ${ }^{275}$.

La métallurgie elle aussi profite de l'avènement de l'énergie hydraulique comme de la diligence des mécaniciens. Au cours des XIV et $\mathrm{XV}^{\mathrm{e}}$ siècles, le procédé indirect remplace le procédé direct de fabrication du fer; celui-ci est associé au bas fourneau, produisant une loupe de fer spongieuse, qui est ensuite martelée pour que le métal reçoive la contexture exigée. Lorsque, afin d'obtenir des quantités plus importantes de métal, on dut agrandir les fourneaux, et consécutivement utiliser des soufflets actionnés par la force de l'eau, des marteaux plus puissants devinrent nécessaires, et une puissance motrice

L. WHITE Jr : Medieval technology and social change, Oxford, 1962.

274 F. Berthoud : Histoire de la mesure du temps, Paris, 1802 ; J.D. de SOlla Price : On the origin of clockwork, perpetual motion devices and the compass; Contributions from the museum of history and technology, Washington, 1959, pp. 81-111.

275 J. CARDAN : Opus novum, Paris, 1550, pp. 152-156. 
hydraulique adéquate leur fut fournie ${ }^{276}$. Les mines devinrent l'atelier où se développa lentement tout un ensemble de mécanismes métallurgiques. Là non plus l'apparition des machines n'a pas eu pour résultat, du moins au début, la substitution des forces inanimées à la force animée de l'homme, mais, au contraire, la séparation de cette force et des habiletés qui la métamorphosent, et l'affirmation de son caractère purement énergétique. En effet les engins construits à ce moment-là par les mécaniciens ne sont pas suffisamment automatisés, réguliers, et ne peuvent guère compter sur l'alimentation d'une force motrice inanimée constante, le niveau et le débit de l'eau variant suivant le cycle des saisons et la configuration géologique. La puissance musculaire pouvait y suppléer, et l'on peut dire qu'elle fut utilisée de façon plus raffinée que dans l'antiquité. Les dessins de Georges Agricola dans son célèbre ouvrage consacré aux mines, De re metallica, montrent que les hommes étaient employés avec les animaux et l'eau à mouvoir les machines. L'utilisation de la force brute de l'homme semble donc avoir augmenté avec la mécanisation des opérations productives.

C'est aller au delà du nécessaire que de détailler davantage ces inventions, notamment celle de la machine énergétique à l'état pur - le canon - qui absorbe beaucoup de talents et impose de nombreuses révisions dans le milieu social et matériel. La plupart se situent entre la fin du $X^{\mathrm{e}}$ et le début du $X V^{\mathrm{e}}$ siècles. Toutefois elles n'ont pas occupé le devant de la scène au Moyen Age. Le labeur et les œuvres qui tissent la vie et définissent cette période sont ceux de l'agriculteur et surtout ceux de l'artisan, maître de son habileté, transformateur de la matière première, muni de son outillage si divers et si bien agencé, tant admiré et si souvent dépeint. Là se trouvent les ressources principales de l'humanité médiévale. A ce point de vue, l'eau et le vent, les engins qui leur correspondent, sont des quasi-ressources qui deviennent marginales. Chose remarquable, c'est dans les arts de la guerre opposés aux arts de la paix, dans ceux de la destruction et non dans ceux de la production, que la différence des ressources complémentaires et des ressources pleinement effectives est le plus sensible. D'une part des richesses matérielles qui ne pénètrent que lentement dans le cycle productif des habiletés destinées à se vulgariser, et des échanges insoupçonnés entre l'homme et la matière ${ }^{277}$; d'autre part des richesses

C. Singer et E.J. Holmyard (eds) : A History of Technology, t. II et III, Oxford, 1956 et 1957.

277 « Si la technologie médiévale est profondément enracinée dans la tradition classique, elle en diffère par un aspect important, l'introduction de moteurs premiers remplaçant l'énergie mus- 
matérielles dont la présence est ostensible, active, des facultés assurées dans la plénitude d'une interaction indiscutée du pôle humain et du pôle matériel de la nature. Le savoir-faire qui accompagne les quasi-ressources est lui aussi complémentaire de l'exercice des métiers courants. Il est à la fois pure capacité d'organiser, de commander le travail d'autrui, et relatif à une famille d'arts incertains. D'où l'aspect troublant de la faculté de l'ingénieur, de son ingenium : il est en même temps universel, c'est-à-dire non différencié, destiné à coordonner tous les métiers, et particulier, c'est-à-dire qu'il tend à se spécialiser dans la construction des engins. A cet égard, un homme n'est ingénieur que par surcroît, remplissant par ailleurs les fonctions de peintre, sculpteur, charpentier, architecte. Les facultés mécaniques progressent sur la périphérie ou à l'ombre des arts accomplis. C'est ce qui imprime au Moyen Age cette figure de Janus bifrons, époque de calmes cheminements traditionnels, de majestueuse obscurité, d'ordre soutenu, et en même temps époque traversée d'extraordinaires fulgurances, de courants inventifs, d'appétits de jouissance et de violence, sur lesquels la Renaissance va dire la vérité. 


\section{Une catégorie naturelle indépendante : l'ingénieur}

$\underline{\text { Retour à la Table des Matières }}$

\section{Le maître d'engins, artisan-supérieur.}

$\mathrm{Au} \mathrm{XII}^{\mathrm{e}}$ siècle de notre ère, lorsqu'il reçoit une signification technique et acquiert la spécificité terminologique, le titre d'ingénieur qualifie toujours une profession dont la réalité fluctue entre celle d'artisan et celle de directeur d'artisans. Domingo Gundisalvo, auteur du temps, parle de la scientia de ingeniis et de son praticien nommé ingeniator, architector ou geometricus et carpentarius. Diversité intéressante par ailleurs, qui montre que cette science des engins, disons plutôt cet art, s'adresse à l'ingénieur militaire, à l'architecte ${ }^{278}$, au géomètre, au charpentier. Le premier, pour le perfectionnement des moyens militaires, le second dans le domaine de la construction et de l'organisation de plusieurs métiers - celui de tailleur de pierre, d'imagier, de tailleur d'images (sculpteur), de maçon - le troisième pour la fabrication des instruments mathématiques et le quatrième enfin pour la mise au point des machines dont la matière première est le bois, font chacun appel à la scientia de ingeniis et l'annexent au savoir qu'ils possèdent déjà.

Mais les fonctions de cette classe d'hommes sont encore loin d'être consolidées, et son autonomie n'est pas pleinement reconnue. Le mot architecte apparaît rarement au Moyen Age, où l'on parle plutôt d'artifex, d'operarius, de cementarius. La structure lexicale de la dénomination est incertaine : on dit tantôt architectus, tantôt architector et tantôt architectarius. Rien ne prouve qu'il soit très éloigné, par sa position, du maçon, sinon cette appréciation désabusée d'un administrateur :

«Les maîtres des maçons, tenant à la main la règle et le compas, disent aux autres 'par ci me le taille', et ne travaillent rien; et reçoivent cependant une plus grande rémunération que bien des prélats modernes ${ }^{279}$.

N. PeVSNER : The term « architect» in the Middle Ages, Speculum, 1942, 57, pp. 549-562. 1929 , t. II, p. 291. 
Quelques témoignages nous sont parvenus, tel celui d'un architecte qui, au XIII siècle, se vante d'être "grand géomètre et charpentier, ce qui est supérieur au maçon », mais il s'agit d'une différence entre deux artisans, et non point d'un homme qui se proclame ingénieur face aux autres artisans. Assurément, depuis longtemps, les maîtres maçons accordaient beaucoup d'importance à la géométrie et aux instruments : l'équerre, le compas, la règle graduée. Nous sommes sur un terrain plus sûr avec ce personnage d'Ailnoth, maçon charpentier, peut-être, qui emploie, semble-t-il, des engins de levage ; responsable de la construction de Westminster Abbey, il est désigné dans les comptes comme «ingeniator». D'autre part, dans une chronique génoise (1195) des indications lapidaires mentionnent un encignerius. Il nous est resté aussi la désignation de Calamandinus (1238) en tant que meilleur «insignerius » de Brescia, ou celle de Jocelin de Cornant-Français en tant que « maistre engigniere ».

Ces documents jalonnent l'histoire de l'apparition de l'ingénieur. On ne peut guère affirmer que son influence, ses exigences se fassent pleinement sentir. Se consacre-t-il totalement à sa profession? Ne s'agit-il pas plutôt d'un homme que son métier de maçon, de forgeron, de meunier, de charpentier, d'artisan attaché aux fabrications militaires oblige à connaître la construction et l'entretien des machines, l'utilisation de l'énergie hydraulique ? Villard de Honnecourt, dont nous est resté l'Album de croquis, représente ce type intermédiaire entre le maître-artisan du Moyen Age et l'ingénieur de la Renaissance. La rupture avec le passé, la séparation d'avec l'autorité intellectuelle et sociale n'a sans doute pas été consommée. Les capacités mécaniques, le rôle de l'ingénieur demeurent surtout des capacités et un rôle auxiliaires de ceux qui existent déjà.

La transition se dessine au XIV ${ }^{\mathrm{e}}$ siècle qui fut marqué par un foisonnement d'inventions techniques anonymes et un ébranlement de l'assise institutionnelle de l'artisanat. Celui-ci enregistre les symptômes d'un double échec économique et technique qui va en s'accentuant. Sur le plan économique, le marchand qui, au début, servait de simple intermédiaire entre la ville et la campagne, ou n'était qu'un aventurier rapportant des pays lointains de nouveaux objets de consommation, tissus, épices, s'est enrichi et cherche à devenir maître de la production. Il crée un artisanat secondaire parmi les paysans qui travaillent pour lui dans leur temps disponible, concurrençant ainsi l'artisanat urbain. La réaction normale des collectivités d'artisans est la stricte défense de leurs intérêts, le renforcement du domaine réglementaire. 
Sur le plan technique, le système des corporations fait la preuve de son incapacité à féconder ${ }^{280}$ les habiletés quotidiennes créées par ses membres : "Personne ne doit trahir l'amour fraternel en imaginant, inventant, ou employant quoi que ce soit de nouveau », proclament les confréries de Torum. C'est là non seulement demander l'impossible mais souhaiter l'improbable. Et pourtant toutes les corporations s'efforcent de suivre une ligne semblable, dans des conditions qui ont changé. La pénétration des mécanismes, des moulins, dans le milieu artisanal, a été un facteur dissolvant du pouvoir des confréries ${ }^{281}$. De nombreux artisans, à des titres divers, travaillent à la construction ou au fonctionnement des moteurs et des instruments mécaniques chaque fois qu'ils apparaissent. Plus encore, lorsque se manifestent, au $\mathrm{XV}^{\mathrm{e}}$ siècle, les signes d'un rétablissement économique, la population augmente et il se forme une réserve de forces de travail ; les corporations sont incapables d'absorber ce surplus ${ }^{282}$ et même de répondre aux besoins existants. Maîtres et compagnons émigrent ${ }^{283}$. Une masse d'habiletés prêtes à s'employer dans des moules non-traditionnels et à s'adapter à de nouveaux modes de travail se constitue ${ }^{284}$. Avec les hommes circulent les savoirs; et les codes qui tentent de les arrêter, comme les interdits par lesquels on s'imagine les fixer, ne font que masquer l'inadéquation d'une forme de travail périmée, l'impuissance d'une classe de producteurs qui ont fait leur temps. Les limites dans lesquelles la «fraternité » artisanale prétend contenir cette foule de talents ${ }^{285}$ auxquels elle n'assure aucun débouché, la nécessité d'exercer les dextérités apprises, ne laissent d'autre choix aux porteurs d'habiletés que de multiplier les occasions de créer des arts nou-

280 Dans un tel système (d'apprentissage) la portion de savoir et d'expérience acquise en une génération est perdue ou oubliée dans la transmission à la génération suivante, pour être quelquefois, mais pas toujours, redécouverte plus tard ». W.B. PARSONS : Engineers and Engineering in the Renaissance, Baltimore, 1939, p. 579.

281 L.F. SAlzman : English industries of the Middle Ages, Londres, 1923.

${ }^{282}$ «Si les confréries continuent à exister (aux $\mathrm{XV}^{\mathrm{e}}-\mathrm{XVI}^{\mathrm{e}}$ siècles) elles ne dirigent plus l'organisation de la main-d'œuvre ». H. PIRENNE : The stages in the social history of capitalism, Amer. Hist. Rev. 1914, 19, p. 512.

283 « Bien qu'il y eût à ces migrations de nombreuses raisons, deux d'entre elles étalent décisives : l'apprentissage et la pression économique ». R. et M. WiTTKOWER : Born under Saturn, New York, 1963, p. 44.

284 J.A. HOBSON : op. cit. p. 57.

285 G. UnwIN : Industrial organisation in the 16 th-17 th centuries, Oxford, 1904, p. 118. 
veaux ${ }^{286}$ et de s'intéresser à des aspects négligés des arts anciens. Une grande partie de l'effort inventif est tournée vers cette fin. Les guerres dont les cités et les royaumes $d u X V^{e}$ et $d u X V I^{e}$ siècles sont friands font le reste.

C'est la Renaissance, le temps des richesses qui s'accumulent, de l'expansion des continents et de l'essor de la vie urbaine, de l'exacerbation des antagonismes politiques et des entreprises belliqueuses. Tandis qu'un ordre s'écroule sans qu'un autre prenne sa place, une carrière immense s'ouvre devant les découvertes mécaniques qui n'ont cessé de se consolider. Elles sont en quelque sorte le facteur actif et le signe avant-coureur de l'époque qui s'annonce.

L'artisan-supérieur ou l'artiste ingénieur est le produit de cette fermentation. En son personnage se combinent et confluent deux courants : d'un côté l'homme des métiers qui ont jusqu'ici cheminé en marge et en dehors de l'organisation traditionnelle des arts, de l'autre côté l'homme de l'art qui est de plus en plus absorbé par la technique mécanicienne.

L'architecte, le maître d'engins et l'ingénieur militaire ${ }^{287}$ ont toujours, de par leur vocation, échappé aux règlements et à la routine, à la fixité géographique et à l'isolement intellectuel. C'est un fait constant que la construction des cités, des cathédrales, des châteaux, était confiée à des artisans qui, en raison de leur mobilité et de la complexité de leur tâches, ont tardé à s'intégrer dans les confréries et le système corporatif. Du maçon médiéval on a pu dire qu'il était « francmaçon ». La loge des maçons était, au Moyen-Age, l'unité coopérative où deux ou trois personnages essentiels, le maître d'œuvre et le maître maçon (ou architecte) ou encore le maître des pierres se rencontraient en un seul. Les plus brillants d'entre eux, les plus passionnés par leur art, ont pu se consacrer davantage à une réflexion sur les modes habituels du travail, ouvrir les yeux sur les transformations ap-

\footnotetext{
286 J. CLAPHAM : op. cit. p. 78.

287 «A cette époque, le technicien type sera, comme au XV ${ }^{\mathrm{e}}$ siècle, l'ingénieur militaire, architecte, machiniste ». B. GILLE : L'évolution des techniques au XVI ${ }^{\mathrm{e}}$ siècle, Techniques et civilisatios, 1953, II, p. 122.
} 
portées par la balistique et les moyens mécaniques. Voyageant et étant d'autant mieux rémunérés que leur œuvre était plus réussie, toute leur énergie spirituelle et toute leur ambition humaine les poussaient à s'instruire, à accroître leur savoir et à faire état de leur acquis dans des échanges féconds. Villard de Honnecourt était un de ces hommes. Son célèbre Album, par ses dessins et même par ses maladresses, porte témoignage sur cette liberté et sur la compréhension des grandes œuvres dont il a été le spectateur.

Le constructeur de moulins ne pouvait que travailler pour les grands domaines ou se déplacer fréquemment. Sa tâche était de faire une installation solide et d'user raisonnablement de l'eau disponible. Pour accroître son industrie et réaliser ses possibilités, il construisait toutes sortes de moulins qui le familiarisaient avec la dynamique de l'eau, du vent, etc. La renaissance des cités et le fait que de nombreuses agglomérations s'installaient le long des cours d'eau mirent cellesci dans la dépendance de l'habileté des mécaniciens, et posèrent à ces derniers des questions nouvelles : approvisionnement en eau, construction de moulins plus puissants, adaptation de ceux qui existaient au débit et au niveau variable des rivières.

D'autre part, il fallait adapter les divers outillages existants à la puissance motrice inanimée, aux mouvements de celle-ci. Les mines constituaient aussi un domaine qui échappait dans une certaine mesure au pouvoir des confréries - ne serait-ce que parce qu'elles étaient situées hors les murs de la cité - et l'introduction des pompes, leur perfectionnement, la maîtrise de l'eau, provoquèrent la recherche de solutions nouvelles - recherche lente et tâtonnante mais ininterrompue.

L'ingénieur militaire ou celui qui offre ses services aux princes à cette fin ne connaît, quant à lui, qu'une seule récompense : le succès pour lui-même, la victoire pour son commanditaire. C'est dans ce champ d'activité, à en croire les notes des techniciens du début du $\mathrm{XV}^{\mathrm{e}}$ siècle, que l'imagination s'est dépensée sans compter. Toutes les machines qui sont entrées pour nous dans le domaine de la réalité y sont préfigurées à l'état de chimères. Les expériences imaginaires, qui, un peu plus tard, peuplent les ouvrages de philosophie mécanique, sont 
déjà anticipées dans ces traités de pratique mécanique, manuscrits pour la plupart. L'homme y apprend, non seulement à transfigurer le réel, ce qui est le propre de l'art, mais à concevoir l'impossible, ce qui est l'apanage de la technique. Les réussites sont manifestes : les pompes, le système bielle-manivelle, la métallurgie mécanique, les tours, les canons, etc.

Le développement de la métallurgie et de l'artillerie attire bientôt le sculpteur : n'est-il pas tout indiqué, en effet, puisqu'il sait fondre le métal ? Le voici qui se rapproche de l'architecte et de l'ingénieur militaire. Florence commande à des sculpteurs réputés - Simone dal Colle, Maso di Bartolomeo, Michelozzo - la fonte de ses canons. S'étonnera-t-on dès lors qu'un des plus grands ingénieurs de la Renaissance, Francesco di Giorgio Martini, ait pratiqué la sculpture? Que l'on examine la biographie de n'importe quel grand ingénieur du $\mathrm{XV}^{\mathrm{e}}$ siècle, et on verra que chacun a fait un apprentissage ou même a excellé dans les divers arts : orfèvrerie, peinture, sculpture, etc. ${ }^{288}$ Léonard de Vinci n'est pas l'exception, il est la règle.

L'essentiel n'est pas la rencontre fortuite de talents variés, unis dans une même personne. L'art de l'ingénieur n'est plus un complément dans le sens où il l'était auparavant: il se diffuse et laisse son empreinte dans les arts qu'il attire à lui, il en est devenu l'âme ${ }^{289}$. Une solidarité de contenu se crée entre ceux-ci et la faculté mécanique, entre la dextérité de la main et la finesse du mécanisme ${ }^{290}$. Une osmose a lieu. Confronter l'art et la technique de cette époque, comme des éléments extrinsèques, est éminemment fallacieux et arbitraire. La pratique de l'engin apporte une inspiration nouvelle :

«Francesco di Giorgio représente bien le type de l'ingénieur de la Renaissance. Artiste, sculpteur d'origine, il devient vite fondeur, artilleur, et par conséquent ingénieur militaire. Toutes ces activités l'ont conduit aux problèmes de mécanique qui intéressent ou amusent si fort les gens de cette époque ». B. GILlE : Les ingénieurs de la Renaissance, ed. cit. p. 110.

289 «Le côté, disons presque scientifique, de Brunelleschi ne peut être séparé de son activité artistique. Sans les connaissances de mathématiques et de mécanique qu'on lui attribue unanimement, il n'aurait pu résoudre les problèmes de perspective et de technique comme il l'a fait ». P. SANPAOLESI : Brunelleschi, Milan, 1962, p. 100.

290 A. HAUSER : La modernité du XVI ${ }^{\mathrm{e}}$ siècle, Paris, 1963. 
— par le lien qu'elle suppose avec les forces matérielles inanimées et la possibilité de les transformer ;

- par le genre d'intelligence requis, essentiellement consacré à la conception et à la construction des mécanismes, habileté qui s'affirme peu à peu dans son originalité ;

- par le prix attaché au savoir physique et mathématique et aux moyens destinés à le traduire dans les faits, c'est-à-dire les instruments ${ }^{291}$. L'instrument géométrique et mécanique remplace désormais l'engin comme symbole de l'artiste-ingénieur, et celui-ci a pour mot d'ordre la mesure.

«La peinture, dit Piero della Francesca, renferme trois parties principales : dessiner, mesurer et colorer ${ }^{292}$.

Les premiers arts véritablement mécanisés - on l'oublie trop facilement - ne furent pas le tissage ou l'art du cordonnier mais la peinture, la sculpture et l'architecture ${ }^{293}$. Si dans les ouvrages auxquels s'applique l'artiste-ingénieur, son habileté joue un rôle, ce n'est pas pour constituer leur objet. L'ingénieur ne fait pas un moulin comme un potier fait des pots; ni la dextérité de sa main, ni la force de ses muscles, pour importantes qu'elles soient, n'interviennent de façon décisive dans les opérations de l'outil. Son art est plutôt d'arraisonner les forces matérielles, afin qu'elles opèrent sans son intervention constante, et de diriger, c'est-à-dire de prévoir et de calculer :

«Et pourtant le jugement du Mécanicien, écrit B. Lorini, qui doit ordonner et commander aux exécutants de l'ouvrage, consiste en très grande partie à savoir prévoir les difficultés qu'apportent les diversités des matériaux avec lesquels il faut opérer ${ }^{294}$.

\footnotetext{
291 A.R. HALL : The scientific revolution, New York, 1954.

292 P. della FrancesCa : Prospectiva pingendi, ed. C. WitenBerg, Strasbourg, 1899, p. I.

293 F. SAXL : Lectures, Londres, 1957, t. I, p. 116.

294 B. LoRINI : Delli fortificazioni, Venise, 1597, p. 196.
} 
Il faut donc qu'il établisse entre les matériaux, les mécanismes, les puissances motrices et l'opérateur humain des rapports objectifs sans l'aide corrective de la sensibilité et de l'agilité. Comme l'a noté Alexandre Koyré dans une formule célèbre, la précision doit prendre la place de l'à peu près. L'instrument mathématique, le moulin ou l'horloge ne sont pas des pièces qui fonctionnent en prolongeant un organe, ils sont eux-mêmes des organismes, ou plutôt des mécanismes, dont la marche ne peut être assurée qu'en accord avec les lois, les règles ${ }^{295}$ qui y sont à l'ouvre et peuvent être vérifiées et maîtrisées. L'instrument, à l'encontre de l'outil et séparé de lui, n'agit pas sur les matériaux: il représente un modèle et un mode de contrôle. C'est l'instrument qui aide l'ingénieur artiste, et celui-ci tient à se reconnaître dans cette distinction. L.B. Alberti le souligne avec une certaine emphase :

«Je ne fais pas métier d'énumérer les erreurs des maçons, j'étudie l'architecte qui travaille avec le niveau, le fil à plomb, l'équerre ${ }^{296}$.

L'instrument d'un côté, les machines de l'autre, voilà les éléments qui permettent à l'architecte de faire un travail utile en épargnant la dépense et la peine des hommes. Ceux qui procèdent autrement ne sont pas des novateurs mais des routiniers qui ne réfléchissent pas aux cas particuliers, ni ne s'entourent de tous les conseils nécessaires. Avec l'instrument se fortifient l'esprit de méthode et l'esprit d'invention. De l'artisan, charpentier, forgeron, maçon, qui s'initiait au secret des machines, à l'artiste-ingénieur dévoré par le désir d'inventer et animé par la volonté de manifester la prééminence de l'art instrumental, de l'artisan étroitement spécialisé à l'artisansupérieur au savoir encyclopédique, la métamorphose est profonde. Avec violence éclate à la Renaissance la rupture, longuement préparée, de l'artisan et de l'artisan-supérieur ${ }^{297}$, et cette époque voit l'éclosion d'un nouveau type d'artisan, d'un art qualitativement nouveau. La division naturelle accomplit son œuvre lorsque l'habileté

Idem « Nous disons que la science des mécaniques est la pratique de fabriquer, à l'aide de règles très certaines, divers instruments et machines pour soulever, au moyen d'une petite force, des poids très grands ». 
complémentaire de l'ingénieur, jusqu'alors diffuse ou informelle, se concentre et se formalise pour s'affirmer dans toute son autonomie. Reconnaissance d'une intelligence originale, découverte éblouissante d'un rapport inconnu à l'univers matériel, sentiment profond de sa distance à l'ensemble des hommes d'art auquel il appartenait — sa catégorie naturelle - tout concourt à séparer l'ingénieur de son entourage coutumier. Les liens qui demeurent sont purement superficiels. Certes, de retour à Florence, Léonard de Vinci s'inscrit à la guilde des peintres : c'est l'ingénieur cependant qui cherche un emploi digne de ses talents.

\section{$\underline{\text { Retour à la Table des Matières }}$}

\section{Les grands affrontements.}

Les différences se transforment en véritables oppositions historiques. Elles se marquent dans le mode de reproduction des savoir-faire - l'apprentissage - et la manière de résoudre les problèmes pratiques.

Il faudrait y ajouter l'exigence d'inventer, trait spécifique de l'ingénieur et objet de son attention particulière, si l'antagonisme avec l'artisan à ce propos ne se situait sur un autre plan. Je m'en tiendrai donc à deux exemples.

\section{Premier exemple : la réponse de Paggi.}

Un des motifs les plus importants de son originalité est le fait que, par rapport à la division du travail artisanal, au cloisonnement des compétences, l'artisan-supérieur est un non-spécialiste, ou plutôt que son domaine apparaît comme une non-spécialité. On en comprend les raisons. Pour pouvoir construire un engin, il doit savoir travailler le bois, le verre, le métal, etc. D'autre part, un grand nombre de mécanismes doivent pouvoir s'adapter soit aux besoins de la guerre, soit à ceux de métiers très divers, qui ne sont pas ceux de l'ingénieur, et qu'il ne peut pas se permettre d'ignorer. Aux dextérités manuelles s'ajoutent nécessairement des connaissances d'ordre mécanique, 
géométrique, sans lesquelles il n'y a pas, surtout dans la construction, de calcul ou de plan possible ${ }^{298}$.

Voici par exemple un extrait de la préface des Mécaniques de Guidobaldo del Monte ${ }^{299}$.

« Là, il est nécessaire de considérer cette doctrine de deux manières : l'une pour autant qu'elle est affaire de réflexion, et de raison discourant sur les choses qu'il faut faire, en se servant de l'arithmétique, de la géométrie, de l'astronomie, et de la philosophie naturelle; et l'autre qui les met à exécution et a besoin de l'exercice et du travail des mains, en se servant de l'architecture, de la peinture, du dessin, de l'art des forgerons, des charpentiers, des maçons et d'autres métiers semblables, de sorte qu'elle devient mixte, et en partie composée de philosophie naturelle, de mathématiques, et d'arts manuels. Pour cette raison, quiconque se trouve doué d'un esprit ingénieux, et dès l'enfance a commencé à apprendre ces sciences et sait dessiner et se servir de ses mains, pourra devenir très bon mécanicien, et inventeur, et réussir des travaux dignes d'admiration ».

J'aurai à revenir sur certains des traits soulignés dans cette préface. Pour l'instant, retenons comme significative l'insistance avec laquelle il recommande cette information nécessaire puisée à plusieurs métiers qui font partie du bagage du mécanicien, de l'artiste-ingénieur. Si l'on songe à Ridolfo Fioravante surnommé Aristote à la Renaissance architecte, ingénieur, fondeur, médailleur, hydraulicien et pyrotechnicien - à Léonard, à Francesco di Giorgio Martini, à Ghiberti, à Brunelleschi, on voit que cette information n'a rien d'exceptionnel. Comment concilier les conditions nécessaires à l'apprentissage, à la transmission d'un tel savoir avec les circonstances régnant dans le monde artisanal ? Pour des raisons matérielles et sociales, il faut que le travail de l'artisan supérieur soit renouvelé, entraînant la formation d'une habileté originale. C'est seulement en tant que telle qu'elle peut

« Tous les artificiers ingénieux sont aussi chacun d'autant plus parfait en son art qu'ils emploient davantage des principes mathématiques, dont l'usage est appris par les peintres, les tailleurs de pierre, les forgerons, les ouvriers du bois et architectes militaires, et tous ceux enfin qui, dans leurs opérations, emploient les règles, les compas et les gnomons, sans l'aide desquels de nombreux artifices ne peuvent être exécutés ». S. MUENSTER : Rudimenta mathematica, Bâle, 1523. cf. J. GIMPEL : Sciences et techniques des maîtres maçons du XIII siècle, Techniques et civilisations, 1952, II, pp. 147-152. 
offrir un débouché aux forces de travail existantes et répondre aux nécessités qui appellent cette nouvelle classe d'artisans. Tout ce qui n'entre pas dans son cadre est à la fois inadéquat et clos. Le travail artisanal traditionnel et sa reproduction sont non seulement limités, réglementés, mais encore ils ne s'accordent pas avec le travail inédit qu'exigent la construction et l'invention des machines, l'emploi des instruments. En fait, l'ingénieur tire relativement peu d'enseignements de la tradition, car ces instruments sont conçus sur des modèles dont les principes n'ont aucun rapport avec les principes des modèles anciens. L'ingéniosité courante chez l'artisan ne suffisait plus, par exemple, à la confection des pinnules ou des alidades, à celle des échelles graduées avec exactitude. Où prendre cette ingéniosité et cette habileté ? Il fallait recourir à une instruction plus poussée. D'où l'importance que revêt la capacité d'apprendre et de s'instruire par ses propres moyens. A côté du maître, véritable père professionnel de l'artisan, apparaît une autre source de savoir-faire, le livre, et aussi l'échange intellectuel. Lorsque le livre imprimé remplaça le manuscrit, il répondit à un besoin évident.

Dans la mesure où l'habileté de l'ingénieur, du constructeur d'instruments, n'est ni fixée, ni susceptible de se fixer, l'échange, l'essai, la recherche de solutions faisant appel à des pratiques différentes deviennent coutumiers. La reproduction du travail change : la pure initiation par habituation et observation progressive, conduisant à la répétition de ce qu'on a appris à faire ${ }^{300}$, devient impossible, coûteuse, inefficace. L'apprentissage auprès du maître est encore capable de fournir une certaine disponibilité, une certaine accoutumance au travail manuel, mais cesse d'être l'élément déterminant. Du reste, l'ingénieur n'est pas destiné, au moins en principe, à faire exactement ce qui avait été fait avant lui par d'autres ou par son maître, mais à appliquer ce qu'il sait, et, en même temps, à enrichir et diversifier ce savoir. compte en premier lieu de la tradition, et ensuite seulement de la réalité ». E. PANOFSKY : Meaning in the visual arts, New York, 1957, p. 277. 
Cette inadéquation de la reproduction établie aux qualités nouvelles du travail s'affirme à la Renaissance par le précepte de l'ouverture aux leçons de la nature. L'artisan ordinaire se forme d'après l'exemplum, c'est-à-dire ce que son maître enseigne et fait, sans se laisser confronter à d'autres façons d'œuvrer; c'est cet exemplum qu'il répète et multiplie sa vie durant. Lorsque les artisans supérieurs affirment qu'il faut retourner à la nature, s'instruire auprès de la nature, c'est contre cet apprentissage qu'ils s'élèvent, contre la limitation de leurs pouvoirs nouveaux. Leur doctrine n'a pas le ton de l'initiation à une recherche scientifique mais appelle à une autre modalité d'acquisition des arts. Leur nature, ce sont les anciens, les livres des mécaniciens d'Alexandrie, et aussi les machines et à travers elles les rapports renouvelés avec l'univers matériel. Tel est le sens de cette affirmation de Léonard de Vinci :

« Heureux ceux qui prêteront l'oreille à la parole des mots; lire les bons ouvrages et les mettre en pratique $»$.

Les ateliers de ces artistes-ingénieurs se muèrent donc en lieux de rencontre et de discussion où l'on s'initiait à la peinture, à la sculpture, à l'orfèvrerie, sans cependant se fermer à ce qui avait trait à l'horlogerie, à la construction des ponts ou au drainage des eaux ${ }^{301}$. Les professeurs de mathématiques y pénétrèrent quand ce ne furent pas les apprentis qui allèrent les chercher. Rien ne pouvait être plus contraire à l'intérêt et à l'esprit des guildes. Elles voyaient là, à juste titre, au delà de la menace dirigée contre leurs privilèges, la négation flagrante de leur conception de l'art et de l'artiste. Aussi combattirentelles pied à pied le bouleversement des règles liées au mode de reproduction du talent, et refusèrent-elles de reconnaître la conception nouvelle. Changer le lien millénaire de l'apprenti à son maître, mettre fin au transfert muet des gestes, des coups d'œil et des tours de main, revenait à vider leurs talents de leur substance vive, à retirer à leur intelligence et à son action toute base objective. Ce qui fut fait, en réalité. Lorsque Paggi revenant à Gênes après un exil de quelques années

301

«Les artistes individuels qui, à cette époque, commencent à se séparer de la masse des artisans, étaient, fait suffisamment caractéristique, ceux-là mêmes qui s'intéressaient surtout aux questions scientifiques et techniques ». F. ANTAL : Florentine painting and its social background, Londres 1957, p. 376. 
voulut reprendre son travail de peintre, il se vit opposer l'interdit corporatif. A quoi il répondit, entre autres :

« que l'art peut fort bien s'apprendre sans maître, parce que son étude exige avant tout une connaissance de la théorie, fondée sur les mathématiques, la géométrie, l'arithmétique, la philosophie et autres sciences nobles, qui peuvent être acquises dans les livres ${ }^{302}$.

Et c'est sa réponse qui, à la longue, triompha.

\section{Deuxième exemple : la construction de la cathédrale de Milan.}

A partir de ces connaissances nouvelles en plein essor se développe un concept original du métier et du savoir-faire. Il est bien illustré par l'épisode de la construction de la cathédrale de Milan, qui a été magistralement analysé dans deux articles par Paul Frankel et James S. Ackerman ${ }^{303}$.

Les maîtres maçons savaient concevoir le plan de leurs constructions ; ils se servaient du déplacement des figures planes pour prévoir les relations et faisaient les élévations de manière visuelle au jugé des rapports de surface entre les figures. Le procédé était tout empirique et n'appelait aucun rapprochement des épures géométriques et des nombres. La proportion employée était une sorte de "secret de métier » purement pratique, faute d'un étalon de mesure, d'une appréciation quantitative. Il ne semble pas non plus que les constructions aient suivi un programme établi à l'avance, autre que celui des enchaînements routiniers. En l'absence d'une vue d'ensemble, on tâtonnait et on bâtissait partie après partie, ce qui ne manquait pas de soulever des problèmes et des controverses, et entraînait une révision constante des plans initiaux.

302 R. et M. WITTKOWER : op. cit. p. 11.

303 P. FrANKEL : The secret of the medieval masons, Art. Bull. 1945, 27, pp. 46-61. J.S. ACKERMAN : "Ars sine scientia nihil est », Gothic theory at the Cathedral of Milan, Art Bull. 1949, 35, pp. 84-111. 
Ainsi pour la cathédrale de Milan. Au début on avait pensé bâtir un édifice aussi haut que large, ad quadratum. Puis, on se rallia à une autre formule, ad triangulum. Dans cette conception, le faite de l'ouvrage aurait dû être le sommet d'un triangle équilatéral qui avait pour base la largeur de l'église. Lorsque la question de la section de la nef vint à l'ordre du jour, on se trouva devant une situation complexe. Dans la section dessinée, ad triangulum, comment connaître la hauteur, incommensurable avec la base ? La réponse dépassait la compétence d'un maître maçon. On fit donc appel à un mathématicien, Gabriele Stornaloco ${ }^{304}$. Nous voyons s'affirmer ici ostensiblement, en raison des conditions objectives, un lien entre les mathématiques et l'architecture, et l'idée de recourir à un expert

« en l'art de la géométrie.., afin de discuter avec les ingénieurs (inzigneriis) dudit ouvrage les doutes que l'on avait sur la hauteur et d'autres questions au sujet desquelles le doute régnait parmi lesdits ingénieurs ».

Une fois les résultats de la consultation de Stornaloco connus, on envoya chercher — c'était à la fin du $\mathrm{XIV}^{\mathrm{e}}$ siècle — un maximus inzignerius pour les appliquer.

L'habitude était que ce maximus inzignerius exposât aux maîtres et aux autres ingénieurs ses projets et la manière dont il concevait la finition de la cathédrale, projets qui devaient être adoptés avant de pouvoir être exécutés. Les comptes rendus de ces réunions mentionnent « Nos sopradicti inzignerii e operarii masonariae» (Nous susdits ingénieurs et ouvriers en maçonnerie) ou encore « le magistri e inzignerii » (les maîtres et ingénieurs), expressions qui montrent que l'ingénieur est reconnu comme ayant une individualité et une fonction propres. Jean Mignot, l'ingénieur appelé, fait ses propositions qu'il juge rationnelles et circonstanciées, et critique l'opposition des mâ̂tres maçons milanais, en concluant: "Ars sine scientia nihil est»" (L'art n'est rien sans la science). Il fonde ses arguments sur des raisons géométriques. C'est sa façon de répondre à leur affirmation que la géométrie ne doit pas être mêlée à l'art, à l'architecture. Assuré- 
ment les théories de ces maîtres d'œuvre nous paraissent bien bizarres. Ils soutiennent que ni le poids, ni la taille des tours, ni le nombre, ni la masse de leurs supports n'ont l'importance qu'on leur attribue. Et ils estiment l' « art » capable de se passer de « science », entendant par là que la valeur du plan est secondaire et que seule compte la bonne pratique : ces Lombards sont à juste titre fiers de leur habileté. Des documents reproduits il ressort qu'en fait les maîtres milanais ne comprennent pas grand'chose aux arguments de Jean Mignot.

Toutefois, pour fonder leur attitude, et cédant à la pression de la situation, ils tentent à leur tour de fournir une justification doctrinale.

«Mignot, écrit J.S. Ackerman ${ }^{305}$, force les Milanais honteux à tenir un discours scientifique qui dépasse de loin leurs capacités. Pour pallier leurs insuffisances, les maîtres se sont retranchés derrière des citations inappropriées d'Aristote, pensant conférer de l'autorité à leurs prétentions par cette simple référence. La première de leurs preuves "géométriques » est empruntée à un passage de la Physique qui a trait au mouvement perpétuel, choisi parce qu'il se réfère aux lignes droites et courbes. Ils l'interprètent abusivement comme une rationalisation des lignes droites et des arcs de la cathédrale... Les maîtres se pressent tellement de paraître scientifiques qu'ils choisissent les passages inadéquats ou invoquent les autorités à tort et à travers pour rationaliser leur travail a posteriori. Ayant grossièrement mésusé d'Aristote, ils appliquent le même traitement à Mignot, et, renversant son affirmation, pour l'adapter à leur propre philosophie, ils concluent par cette citation abusive : «La science n'est rien sans l'art ».

Pour bien situer le débat, il faut d'abord faire la part des choses. Les connaissances de Jean Mignot ne sont pas très étendues, et si sa démarche se veut systématique, face à la simple justification de recettes, elle n'a guère la possibilité de l'être. L'art auquel il veut ajouter la science est l'art artisanal, celui des maçons et non pas celui que nous désignerions sous ce nom ou sous celui de technique. Quant à la « science », il s'agit plutôt d'un savoir-faire inspiré par la géométrie, d'une démarche méthodique et instrumentée, susceptible d'offrir un schéma aux habitudes de métier, et nullement d'un corps de connaissances apte à résoudre un problème, à se substituer aux procédés existants. De leur côté, les maîtres lombards s'appuient sur leur tradition, 
sur les exemples qu'ils connaissent. La cathédrale, telle que nous la voyons aujourd'hui, est leur chef-d'œuvre, un chef-d'œuvre qui tient. Son plan primitif diffère de ce qui a été bâti en réalité. Leur démarche a suivi un cheminement tel que les piliers et les arcs-boutants se sont érigés vers un faîte non prévu, et la question première - celle de la structure des voûtes - a été résolue en dernier. La discussion ne porte donc pas sur les problèmes de réalisation, mais sur la conception du métier, le contenu du travail de l'artisan. Jean Mignot, ingénieur, veut obéir aux normes de la géométrie, introduire une systématisation, regarder la construction comme une œuvre individuelle et non pas comme la répétition dans un endroit de procédés qui ont réussi dans un autre et ont été, de ce fait, transmis de maître à apprenti. C'est le sens qu'il donne à l'union de l'art et de la science. Les maîtres milanais défendent la démarche artisanale qui étend les règles empiriques à la totalité des cas sans se préoccuper d'analyser les conditions physiques et mécaniques; ils proclament leur confiance dans les dextérités conventionnellement assimilées. En disant que la science n'est rien sans 1'art, ils refusent la science elle-même. Quand ils ont recours à elle, contraints et forcés, ils le font de manière arbitraire, et plutôt pour justifier ce qui est que pour examiner et comprendre le nouveau.

La référence à Aristote est significative, car, autour de cette cathédrale, nous voyons s'affronter les tenants, obligés, de sa philosophie, et les hommes qui se veulent munis d'une connaissance taillée sur le patron mathématique. Derrière ce débat des maîtres maçons et d'un ingénieur appelé à appliquer la formule d'un géomètre, on voit se profiler celui qui se déroule un peu plus tard, au XVII ${ }^{\mathrm{e}}$ siècle, entre les scolastiques et les Galilée, les Benedetti, les Descartes. On ne saurait insister assez sur cette similitude, puisqu'elle dévoile d'emblée le sens d'un mouvement qui va s'amplifiant, d'une exigence commune à l'ingénieur et au philosophe mécanicien, qui combattent à la fois la tradition et son corollaire, l'autorité dans la pensée et la simple recette dans l'art.

L'habileté à laquelle aspire le "maître d'engins » — l'ingénieur n'est plus celle de «l'homme de l'outil»-1'artisan. Leur travail aussi diffère non seulement par l'objet, mais aussi par l'ordre interne qui y est à l'œuvre. A la fin du XIV et au début du XV siècles, les re- 
lations de reproduction du travail subissent une réorientation: l'artisan ne s'oppose plus à l'agriculteur mais à l'ingénieur.

Les deux exemples que j'ai analysés font ressortir avec éclat les conséquences de la division naturelle qui se produit lorsque la catégorie des ingénieurs s'éloigne de celle des artisans. La nouvelle catégorie entreprend de transformer les facultés artistiques, là où elles interviennent, pour en extraire l'essence et les faire siennes. Ceci mérite mention si l'artisan, en évoluant, se sépare de l'agriculteur principalement dans la sphère domestique, l'ingénieur se distingue de l'artisan en ce qui concerne le domaine social, afin d'assurer la coopération des divers métiers et de fournir les moyens communs à l'exercice orchestré de leur totalité. A la base de la dextérité qui s'y rapporte, il propose de placer les règles et le concept, règles et concepts mesurants, calculateurs, incarnés dans l'instrument associé au monde des artifices mécaniques.

«La science instrumentale ou mécanique, dit Léonard de Vinci, est très noble et s'élève sur toute autre par son utilité ».

La dextérité purement manuelle, guidée par des recettes dont on ne connaît pas le pourquoi mais dont on voit l'effet dans la perfection de l'ouvrage et l'accomplissement de l'homme de l'art, ne reçoit plus d'hommage, elle encourt même le blâme. Le modèle n'est plus le mâ̂tre auprès duquel on a appris les premiers rudiments dans sa jeunesse. Archimède a pris sa place, qui représente la jeunesse de l'humanité. Quel plus beau titre pour un artiste-ingénieur que d'être comparé à Archimède ou surnommé l'Archimède siennois ou florentin ? Cependant la certitude se fait jour que ces maîtres lointains, alexandrins, romains, arabes ou byzantins, ont été dépassés par la volonté inventive et l'ampleur de vues de leurs disciples. Certes, les techniciens de la Renaissance ne sont pas les premiers à avoir construit des forteresses et des ponts, drainé les eaux, conseillé les princes, fabriqué des instruments, ou perfectionné ceux-ci pour la musique, l'astronomie, la navigation et l'arpentage. Qui cependant, avant eux, avait su les adapter avec tant de ténacité, sinon de maîtrise, à la domestication des puissances matérielles ? Une attitude toute nouvelle est née à cette époque. Alexandre Koyré l'a montré de façon pertinente : dans leurs 
aqueducs, les Romains laissaient couler l'eau. C'était une solution d'architecte ${ }^{306}$. La solution de l'ingénieur, mûrie $a u X V^{e}$ et au XVI siècles, a consisté à pomper et élever l'eau, à la traiter comme un poids quelconque. Dans les pompes, les moulins, les canaux, dans l'espace d'une peinture conçue suivant la perspective artificielle, les ingénieurs découvrent cette nature, lien de l'homme au monde matériel, qu'ils reprochent à leurs contemporains — artisans et philosophes — de ne pas voir, de ne pas prendre pour sujet d'inspiration.

Le savoir de l'ingénieur, complémentaire, comme les ressources auxquelles il a trait - forces hydrauliques, pondérales, etc. — prend désormais figure ${ }^{307}$ et s'avance sur le théâtre du monde à l'instar de ses inventions sur les théâtres des machines, si nombreux et si populaires. Son étude va nous retenir encore quelque temps.

«Or, les ingénieurs antiques ne me semblent pas avoir beaucoup cherché ; ils ont développé, amélioré, étendu les méthodes traditionnelles ; ils ont rarement innové. Au fond, ils ont été des architectes, et même des bâtisseurs, bien plus que des ingénieurs proprement dits ». A. KoYrÉ : Études d'histoire de la pensée philosophique, Paris, 1961 p. 304.

307 Le XV ${ }^{\mathrm{e}}$ siècle avait cependant dépassé les belliqueuses préoccupations et bâti tout un système technique, comme il avait construit un nouveau système scientifique ». B. GILlE : Les ingénieurs de la Renaissance, ed. cit. p. 225. 


\section{Chapitre III.}

\section{Les origines de la technique}

\section{La méthode de l'ingénieur}

\section{Retour à la Table des Matières}

L'art mécanique, ou plutôt l'art des instruments mécaniques, cessant d'être un art parmi les autres, s'impose comme organisation originale des habiletés à partir du moment où l'architecte-ingénieur définit aussi bien ses méthodes que le champ de ses techniques. Sur la démarche de ceux qui se consacraient aux travaux d'ingénieur avant cette époque - le $\mathrm{XV}^{\mathrm{e}}$ siècle - et la conception qu'ils se faisaient de ces travaux, nous n'avons que peu d'indications ${ }^{308}$. Le chroniqueur Domingo Gundisalvo nous dit que

«La science des engins nous enseigne le moyen d'imaginer et d'inventer la manière d'ajuster les corps naturels par un artifice ad hoc conforme à un calcul numérique, de sorte que nous en retirions l'usage que nous désirons. »

La formule est assurément élaborée et l'accent mis sur le calcul, prémonitoire. Ce n'est toutefois pas une formule de praticien, car elle ne correspond pas aux faits. Personne ne dispose à ce moment-là de règles permettant de procéder à des comparaisons numériques et à des prévisions chiffrées. Du moins nous n'en trouvons pas de traces, et le calcul est introduit bien plus tard dans le domaine des mécanismes.

308 A.G. KELLER : A Byzantine admirer of 'western' progress : Cardinal Bessarion, Cambr. Hist. J. 1955, XI, pp. 343-348. 
Nous sommes plus près de la réalité de ce métier quand nous considérons les manuscrits et les carnets de notes. Là nous constatons un effort d'observation systématique d'une classe particulière d'objets : les machines ${ }^{309}$, les instruments, et d'une forme particulière de force motrice : la force des eaux et du vent. Les dessins ne sont pas encore adaptés à leur fin qui est l'exposition de la structure des machines ; mais le travail d'observation détaillée des moyens techniques s'affirme comme un procédé courant. Les croquis et les annotations inaugurent une ère nouvelle. Ils nous font voir l'homme d'art attentif aux divers outils, aux applications machinales variées qu'il réunit pour les examiner et en faire ultérieurement son profit. Dans cette lignée s'inscrit le célèbre carnet oblong, $L$, de Léonard de Vinci, où celui-ci, ingénieur de la suite de César Borgia, enregistre des informations de tous ordres. Elles comportent aussi bien le relevé des bastions pour la défense des côtes à Cesenatico que des croquis de machines existant dans la bibliothèque de Pesaro, ou des études sur les fontaines de Rimini et le système de distribution d'eau. Ce genre de carnets où voisinent côte à côte des renseignements purement livresques et des observations faites soit au cours de la réalisation de travaux propres, soit au cours de voyages professionnels, ont inspiré des recueils du XIV siècle dont il nous reste des témoignages.

Parmi ces traités manuscrits, le Bellifortis, de Konrad Keyser (1366) a atteint une très grande diffusion. Des machines de guerre, des moulins, des machines à creuser les fossés y figurent en bonne place. Jacomo Fontana, médecin $\mathrm{du} \mathrm{Xv}$ siècle, rédige un Bellicorum Instrumentorum Liber qui paraît être l'œuvre d'un amateur plus que d'un praticien. Un manuscrit allemand, datant à peu près de la même époque, conservé à Munich, décrit des treuils démultipliés avec poulies, des machines à percer, des moulins à bras, des moulins à manège et un scaphandre. Le De Machinis Libri $X$ de Marianus Jacobus Taccola est un recueil dû à un grand ingénieur, dont le surnom d'Archimède siennois nous fait mesurer le prestige ${ }^{310}$. Outre les machines de guerre, on y trouve dessinés des engins destinés à lever des poids, à puiser de l'eau, etc. Les inventions et les artifices ou les recettes des artisans sont ainsi l'objet d'une attention systématique. Lentement se dégage des autres savoirs un sa-

«Le travail le plus distingué de la mécanique ou du mécanicien, ce sont les machines ». J. LEUPOLD : Theatrum machinarum generale, Leipzig, 1724, p. 2.

310 L. THORNDIKE : Marianus Jacobus Taccola, Arch. Int. His. Sc. 1955, VIII, pp. 7-26. 
voir consacré aux machines ; ses contours se précisent tandis que se développent et se marquent les directions d'un ensemble cohérent de modes d'action sur le monde matériel. Ceci répond simultanément aux nécessités de la transmission et de la reproduction des talents propres à l'ingénieur, et à l'impératif de son affirmation comme classe distincte d'artisans.

Cependant, c'est uniquement à partir de la Renaissance que les principes essentiels de cette classe sont énoncés avec clarté. Tout d'abord nous remarquons l'importance que revêt, dans l'emploi de ses facultés, la familiarité avec les mécanismes. Antonio Manetti, le biographe de Brunelleschi, nous dit qu'il avait appris la fabrication des horloges et y était fort habile. Ce savoir-faire a dû lui permettre d'imaginer les diverses machines de halage et de levage de son invention, indispensables à la construction de la coupole de Santa Maria di Fiori à Florence ${ }^{311}$. Là, pour la première fois, le génie mécanique s'est affirmé à la face du monde; on sait en effet que le fait mémorable n'est pas le style ou la forme de cette coupole mais la manière de l'ériger ${ }^{312}$, au moyen de machines conçues à cette fin. Et on ne peut guère songer qu'un architecte apporte une solution aux difficultés rencontrées par des générations d'artisans s'il n'est pas rompu à la pratique des instruments mécaniques.

Mais il ne faut pas supposer des connaissances très savantes ${ }^{313}$, il s'agit avant tout de rudiments de géométrie et d'arithmétique qui permettent de rendre le dessin rigoureux et d'apprécier les dimensions des ouvrages. On comprend la nécessité de cette quantification : étant donné l'autonomie des machines, il est indispensable de connaître les poids, les proportions et les formes, fût-ce de manière grossière et approchée. Très tôt, c'est la possession de notions mathématiques qui devient le caractère distinct du nouvel art et de ceux qui l'exercent.

G. SCAGLIA : Drawings of Brunelleschi's mechanical inventions for the construction of the Cupola, Marsyas, 1961, 60, pp. 45-68.

312 «C'est sa science (de Brunelleschi) de constructeur qui lui permit de mener à bien l'audacieuse conception de ses devanciers ». M. REYMOND : Brunelleschi et l'architecture de la Renaissance italienne, Paris, 1914, p. 8.

313 B. GILLE : Léonard de Vinci et son temps, Techniques et civilisations, II, 1952, p. 77. 
« Eupompio de Macédoine, écrit Francesco di Giorgio Martini dans le Prologue de son Traité ${ }^{314}$, remarquable mathématicien (dit qu') aucun art n'était parfaitement déterminé chez les hommes sans arithmétique et géométrie ».

L'emploi de l'arithmétique et de la géométrie se borne, au début, à permettre une meilleure description des machines, à discipliner le dessin. Dans une phase ultérieure, leur rôle s'accroît et elles deviennent moyens d'étude et de calcul. Ainsi Léonard de Vinci recourt à la géométrie pour l'analyse du tracé des roues dentées, des engrenages coniques et hélicoïdaux ayant un moindre frottement. Dans ses recherches aérodynamiques, les mathématiques sont employées à des fins de calcul. Ayant estimé que les ailes de la chauve-souris sont plus propres à être reproduites artificiellement que celles de l'oiseau, il calcule l'aire portante capable de soutenir un poids défini. La fonction des mathématiques dans toutes les branches où l'artiste-ingénieur est appelé à intervenir est reconnue. C'est encore Alberti qui le dit :

« Mais les arts qui profitent à l'architecte et sont nécessaires à tous sont la peinture et les mathématiques. Je ne me soucie pas qu'il sache d'autres disciplines ou non ${ }^{315}$.

Déclaration à laquelle fait écho, un peu plus tard, l'ingénieur militaire B. Lorini, lorsqu'il dit, de l'art de fortifier :

«C'est une science sans aucun doute, ayant ses fondements et toute la perfection formelle des mathématiques qui sont une science connue pour ses démonstrations sûres ») 316 .

Les mathématiques, sous leur forme la plus simple, sont donc diffuses dans le savoir-faire de l'ingénieur, et viennent à être estimées en tant qu'élément constituant de ce savoir ${ }^{317}$.

314 F. di Giorgio MartinI : Trattato di Architettura civile e militare, ed. C. Saluzzo, Turin, 1841, I, p. 152.

315 L.B. AlBERTI : op. cit. p. 214.

316 B. LORINI : op. cit. p. 62.

317 D.J. STRUIK : Mathematics in the Netherlands during the first half of the 16th century, Isis, 1936, 25, pp. 46-56. 
Un autre élément est représenté par les modèles et les expériences, qui répondent à une nécessité évidente : lorsqu'il s'agit de créer des ouvrages de dimensions importantes, ou bien d'améliorer ou de construire une machine observée, de préparer un projet pour résoudre une difficulté technique, il est indispensable de procéder à des essais et à des expériences. Ceux-ci permettent de choisir entre plusieurs solutions concurrentes. Léonard de Vinci l'exprime clairement :

«Avant de faire d'un cas une règle générale, on doit répéter deux et trois fois l'expérience, en observant chaque fois les mêmes effets se produisant ».

Pour la construction de la célèbre coupole de Florence, les deux architectes concurrents, Ghiberti et Brunelleschi, furent amenés à concrétiser leurs projets et leur savoir dans deux modèles représentant des aspects de la future construction. Par ce moyen, chacun pouvait faire ressortir la supériorité de sa démarche, permettant à la guilde des commerçants commanditaires de l'ouvrage de se prononcer en pleine connaissance de cause. Dans La fortification du Sieur Antoine de Ville ou l'ingénieur parfait, il est dit que :

«C'est une chose commune à tous les arts qu'avant de commencer l'œuvre, l'artiste fait premièrement un modèle, ou type sur lequel on voit les commodités ou incommodités qui se trouvent à son dessin, accommode les défauts s'il y en a, et le travaille jusques à ce qu'il l'ait réduit à sa perfection pour s'en servir d'exemplaire qui le guide jusques à l'accomplissement de son ouvrage $\gg{ }^{318}$.

L'intelligence de l'homme d'art ne se cantonne plus dans l'observation en vue de la copie qu'il s'agit de retoucher, ni dans la formule qui ne permet pas d'en savoir davantage. Il procède à des mises à l'essai des effets observés, à une prédiction relative des règles auxquelles obéissent les forces matérielles, enfin à une analyse des facteurs déterminant la réussite d'une entreprise. Voici Léonard de Vinci qui a proposé maint projet pour le drainage des eaux, la bonification des terres, grand problème technique et économique des $\mathrm{XV}^{\mathrm{e}}$ et 
$\mathrm{XVI}^{\mathrm{e}}$ siècles. N'est-il pas amené à une réflexion soutenue sur la formation du lit des rivières, et la circulation de l'eau dans le cadre d'une structure géologique donnée ? Entre autres questions, le dépôt d'alluvions, lorsqu'une entrave existe au fond du lit d'une rivière, le préoccupe. Pour comprendre ce qui se passe et ce qu'il faut faire, il construit un petit canal en bois dans lequel il propulse de l'eau chargée de sable, et remarque à la fois que l'eau se divise pour contourner l'entrave, et que de nombreux dépôts se constituent en amont de celleci. La résistance des matériaux attire également son attention, et il recourt aussi à l'expérience pour l'étudier.

Dans chaque domaine, la méthode remplace l'habitude ; en effet, ce que reproduit l'artiste-ingénieur n'est pas ce qui lui a été transmis par un maître mais ce que lui ont enseigné l'expérience des autres et la sienne propre. Le recours aux mathématiques, et la pratique de l'expérience, dont il est le découvreur, sont les fondements de cette méthode qui conduit à systématiser les opérations, à examiner leur utilité et à se guider sur ce qui est essentiel à l'œuvre projetée. La théorie elle-même est un élément indispensable à cette démarche, puisqu'elle sert à éviter les travaux superflus, les productions vouées à l'échec et même les expériences inutiles. Elle constitue une sorte d'économie de travail, qui supprime les tâtonnements, les répétitions, et accélère la modification des habitudes dont l'artisan ordinaire était trop souvent prisonnier. La théorie, pour l'ingénieur, est pratique, c'est une pratique. Léonard de Vinci dit dans un aphorisme :

«Il n'y a pas dans la nature d'effet sans cause; saisis la cause et ne t'inquiète pas de l'expérience $»$.

Cette déclaration peut paraître mystérieuse ou contradictoire avec la conception générale de Léonard. Son sens s'éclaire si on la rapproche de l'exemple suivant, présenté par Simon Stevin :

«Il est parfois arrivé que l'on désire faire certains vaisseaux avec des échelles dressées à la verticale à l'intérieur, d'environ 20 pieds de haut, destinées à permettre aux soldats d'y grimper. Mais comme on se demandait si ceci ne causait pas un excès de charge en hauteur, qui ferait basculer les vaisseaux et tomber les soldats à l'eau, on fit un vaisseau afin de s'en assurer, avec son 
échelle et ses accessoires; par la suite il fut mis à l'épreuve en pratique. Cela me fit réfléchir s'il ne serait pas possible de connaître ceci par des calculs statiques, de forces et de gravités supposées, sans avoir d'abord à faire la chose sur une grande échelle et à la mettre à l'épreuve de la pratique » ${ }^{319}$.

Cette réflexion a amené Stevin à écrire un petit traité autour du théorème De l'excès de charge flottante en hauteur, dans lequel il s'applique justement à « saisir la cause » de l'ensemble de la construction avant de s'inquiéter de «l'expérience».

La théorie et l'expérience deviennent ainsi parties intégrantes de l'habileté, du travail de l'ingénieur; ce sont des composantes de sa méthode, tout comme l'instrument et les mathématiques sont ses moyens. Le dessin s'y ajoute en tant que technique de collecte des observations, d'étude ${ }^{320}$ des cas particuliers, et de langage ${ }^{321}$ destiné à transmettre les résultats de ses travaux.

« De même, dit Francesco di Giorgio Martini, non seulement lui (Eupompio de Macédoine) mais de nombreux autres hommes d'expérience ont estimé que n'était pas moins nécessaire l'art du dessin dans toute science opérative, que les arts déjà cités » ${ }^{322}$.

Progressivement, l'ingénieur vient à concevoir son art comme un ensemble de règles quantitatives et de mesures. Dans les machines, dans les expériences sur l'agencement ou la résistance des matériaux, les rapports sont censés être quantitatifs et généraux. Ils remplacent les recettes d'artisans. Si Léonard examine la solidité des poutres, il propose (par un calcul relativement insuffisant), des normes de résistance des poutres à section cylindrique ou carrée, libres ou encastrées à une extrémité ou aux deux, lorsqu'une pression variable s'exerce sur elles, etc. Il énonce même des règles : dans le cas des poutres horizon-

319

320 von Schlosser, Berlin, 1912, p. 5.

321 «Le dessin mécanique est l'alphabet de l'ingénieur. Sans lui, l'ouvrier n'est qu'une main; avec lui, il indique qu'il est en possession d'une «tête».» J. NASMYTH : Autobiography, Londres, 1883, p. 125.

322 F. di Giorgio MARTINI : op. cit. p. 152. 
tales, de section carrée, appuyées à leurs deux extrémités, la résistance varie comme le carré du côté et en proportion inverse de la longueur. Toutes ces règles proviennent d'expériences, ou peuvent y conduire. La mesure s'impose en tant qu'opération indispensable. Elle réunit dans un seul mouvement les quantités mathématiques et les expériences guidées par la règle, le dessin géométrisé et le calcul vérifiable à l'aide des instruments. Son empire semble s'étendre à tous les arts sans exception. Piero della Francesca morigène vigoureusement les peintres qui

«blâment la perspective parce qu'ils ne comprennent pas la force des lignes et des angles qu'elle produit; mesurés (je souligne), ceux-ci servent à décrire chaque contour et chaque trait; il me semble nécessaire de montrer que cette science est très nécessaire à la peinture » ${ }^{323}$.

Ceci ne signifie pas que l'art de l'ingénieur soit un art savant, ni que dans tous les travaux, dans toutes les œuvres de l'artiste influencé par l'ingénieur ou dans ceux de l'ingénieur tout court, on perçoive la présence active d'un esprit philosophique, au sens de l'époque. Comparé au savant, l'ingénieur est le plus souvent un homme «sans lettres », un praticien animé par la volonté de se donner les facultés indispensables à l'exercice de son métier et soucieux d'assurer sa subsistance. Francesco di Giorgio Martini, dont la stature est comparable à celle de Léonard de Vinci, l'a dit très simplement :

«Mais plusieurs fois poussé par des raisons qui ne sont pas soumises à des inclinations corporelles, j'ai voulu m'exercer dans d'autres arts vils et mécaniques, espérant avec un moindre poids d'âme sinon de corps pouvoir subvenir aux besoins de ma vie ${ }^{324}$.

Mais il diffère notablement de l'artisan, car, d'une certaine façon, tous les éléments que je viens de décrire, utilisation des instruments, dessin, calcul, recours à la réflexion théorique débouchant sur des expériences (dont Stevin faisait « la base solide sur laquelle il faut édifier les arts ») et des mesures, même élémentaires et simples, se com-

P. della FRANCESCA : De prospectiva pingendi, op. cit. p. 31.

324 F. di Giorgio MARTINI : op. cit. p. 127. 
Serge Moscovici — Essai sur l'histoire humaine de la nature (1968) 283

binent de manière originale pour constituer le contenu et l'orientation de son travail instrumental.

$\underline{\text { Retour à la Table des Matières }}$ 


\section{La création des facultés mécaniques}

$\underline{\text { Retour à la Table des Matières }}$

\section{Un nouveau mode de reproduction naturelle.}

Dans la dispute que j'ai rappelée, autour de la construction du Dôme de Milan, on voit apparaître, comme deux mondes déjà séparés, celui de l'artisan et celui de l'artiste-ingénieur. Du premier au second, l'évolution a parfois été brusque et même brutale. Dans son admirable ouvrage sur Albrecht Dürer, Erwin Panofsky ${ }^{325}$ montre comment s'opèrent dans la vie d'un seul individu la rupture avec l'ancien et le passage d'une catégorie naturelle à une autre, comment un peintre qui, dans le sens médiéval, « produit des tableaux comme un tailleur faisait des manteaux et des costumes », devient un "artisan supérieur », connaissant les mathématiques et les mettant à la base de son art, un « esprit universel» par ses connaissances et par les points d'application de son talent, écrivant des ouvrages de géométrie pratique ou des traités de fortification, et laissant transparaître dans son œuvre ce que son intelligence a intériorisé au contact de l'acquis des grands maîtres italiens. De retour dans sa patrie, Dürer a l'ambition de montrer à quel point l'emploi de l'instrument mathématique, l'habitude de la mesure et l'intelligence de la géométrie peuvent profiter à tous les arts et les améliorer :

«Et puisque la géométrie est le véritable fondement de toute la peinture, écrit-il, j'ai décidé d'en enseigner les rudiments et les principes à tous les jeunes épris d'art... Cela peut bénéficier non seulement aux peintres mais aussi aux orfèvres, sculpteurs, maçons, charpentiers, et aussi à tous ceux qui doivent s'appuyer sur la mesure ».

La nouvelle conception de l'art, des qualités nécessaires à sa réussite, prétend triompher dans tous les domaines. Dès lors se crée tout un système de relations, d'institutions, de réseaux de communica- 
tion ${ }^{326}$ qui ont pour fin d'entretenir et d'améliorer les facultés de la classe des artistes-ingénieurs. La reproduction de ces facultés se situe au cœur de l'activité quasi générale. Le cycle de l'apprentissage s'inspirant du travail artisanal n'en constitue qu'une partie, et sa signification est transformée dans le contexte fourni par le contenu de l'art de l'ingénieur que je viens de décrire. Les rudiments de la géométrie et de l'arithmétique s'acquièrent dans les écoles d'abaque. Les mathématiciens (Recorde, Dee, Toscanelli) y enseignent aux ingénieurs les éléments d'Euclide et le calcul, et parfois les artistes ingénieurs se font les professeurs des mathématiciens, tel ce Luca Paccioli, élève de Piero della Francesca. Le chantier de l'architecte, les arsenaux de l'ingénieur militaire, les ateliers des peintres et des sculpteurs, les boutiques des orfèvres et des horlogers, deviennent des lieux d'échange, de recherche et d'enseignement, de véritables centres d'instruction qui battent en brèche le milieu et le curriculum des corporations. L'apprentissage manuel tout seul devient inutile, voire néfaste. La formation de l'ingénieur, de l'artisan supérieur, de même que l'organisation de son travail — donc sa reproduction - changent et sortent des limites de l'atelier, de l'horizon immédiat de l'artisanat.

Ces conditions provoquent l'apparition de toute une littérature technique, d'une activité intense de traduction des traités anciens, si bien que ces artistes ingénieurs se muent progressivement en leurs propres pédagogues. La plupart des écrits de Simon Stevin ont pour objet de propager un " art », de le faire connaître, comprendre et apprendre. L'immense trésor des Carnets de Léonard de Vinci constitue une collection de notes, de raisonnements, d'expériences destinés à servir à la rédaction de traités sur la percussion, la résistance des matériaux, l'hydraulique et l'aérodynamique. L'accroissement du savoir de l'ingénieur, la diffusion et l'application de ce savoir sont des points de mire.

« Si tu coordonnes tes notes sur la science des mouvements de l'eau, écrit Léonard de Vinci au début du carnet $F$, souviens-toi d'inscrire au-dessus de chaque proposition ses applications, pour que cette science ne demeure sans emploi ». 
Léonard de Vinci, on le sait, n'acheva aucun de ces traités. Son cas n'est pas unique. Lorenzo Ghiberti compila des écrits des ingénieurs alexandrins ou byzantins, fit probablement des observations expérimentales, réunit des renseignements sur l'optique et la perspective, et se promit de composer un traité d'architecture ${ }^{327}$, sans y parvenir. Son neveu Zibaldone a laissé un recueil de notes concernant la métallurgie, l'architecture, la fonderie, notes auxquelles se mêlent des fragments ayant trait à l'arithmétique et à la géométrie. Le symptôme est assez général pour qu'on le remarque. Ces artistes-ingénieurs sont tous animés par le désir d'organiser leur art, de faciliter son extension, mais ne peuvent y parvenir, d'une part faute de préparation, d'autre part en raison de l'état du savoir. Une chose est certaine : ces traités prennent les mathématiques pour modèle, et les raisonnements qui guident souvent la formulation des questions empruntent aux mathématiques leur style et leur structure. Léonard de Vinci est encore celui qui nous a laissé les témoignages les plus précis à ce sujet :

« Si un canon porte à des distances différentes avec des courbes différentes de mouvement, je demande à quelle partie de la portée sera le sommet de l'arc »?

Ces traités étaient destinés, dans l'esprit de leurs auteurs, à enseigner aux ingénieurs, outre ce mode de raisonnement, la théorie du mouvement dans les machines qu'ils décrivent et classent, et aussi des règles opératoires se substituant aux anciennes recettes pour distinguer le possible de l'impossible.

«Si vous me demandez, dit Léonard de Vinci, ce que ces règles accomplissent ou quelle en est l'utilité, je répondrai qu'elles freinent les ingénieurs et les chercheurs, en leur enseignant à ne pas promettre l'impossible à euxmêmes et aux autres, ce qui risquerait de les faire passer pour des fous ou des imposteurs ».

327 «Nous ferons un traité d'architecture et nous traiterons de cette matière ». L. GHIBERTI : op. cit. p. 51. 
S'il fallait attendre encore deux siècles avant que ces entreprises ambitieuses puissent s'accomplir et que l'ingénieur montre son savoir ou l'apprenne dans des manuels aussi achevés que ceux de ManessonMallet ${ }^{328}$, Blondel ${ }^{329}$ ou Belidor ${ }^{330}$, des ouvrages plus modestes voient le jour. L'imprimerie, première industrie fondée sur la technique mécanique, facilite aussi la diffusion des ouvrages techniques ${ }^{331}$ et la traduction des œuvres anciennes ${ }^{332}$. Traductions ou originaux, tels ces Théâtres de Machines ${ }^{333}$ nombreux à l'époque, ces livres nous entraînent loin de l'Album de Villard de Honnecourt et des divers manuscrits qui circulaient aux $\mathrm{XIII}^{\mathrm{e}}$ et $\mathrm{XIV}^{\mathrm{e}}$ siècles. Pour pouvoir être reproduit et se fixer, l'art de l'ingénieur suscite une activité littéraire importante, tend à organiser en un ensemble cohérent les diverses connaissances auxquelles il a recours : 1'architecture et les mathématiques, les inventaires de machines et les théories mécaniques, les résultats de leur activité et les œuvres de ceux qu'ils estiment être leurs maîtres dans l'antiquité.

Retour à la Table des Matières

\section{Les impératifs de l'invention.}

Si le mode de reproduction du travail se modifie, ce n'est pas uniquement parce qu'il s'agit d'une spécialité inédite ou d'un contenu

328

329

330

331

la technique et est nettement associée avec la place toujours croissante occupée par les techniciens supérieurs au cours du Moyen-Age ». J.D. De Solla PRICE, Science since Babylon, New Haven, 1962, p. 50.

M. BOAS : Hero's Pneumatica : A study of its transmission and influence, Isis, 1949, 40, pp. 38-48.

A. MANesson-Malet : Les travaux de Mars, Paris, 1685.

F. BLONDEL : L'art de jeter les bombes, Paris, 1683.

B.F. BELIDOR : Architecture hydraulique, Paris, 1737.

M. ClagetT : Archimedes in the Middle Ages, Osiris, 1952, 10, pp. 587-618.

Les ouvrages les plus connus sont ceux de R. VALTURIO : De re militari, 1472 ; A. RAMELLI : Le diverse e artificiose machine, Paris, 1588 ; V. ZONCA : Novo theatro di machini e edifici, Padoue, 1607, F. Verantio : Machinae novae, Venise, 1617 ; S. De CAUs : Les raisons des forces mouvantes avec diverses machines, Francfort, 1615; G. BRANCA : Le machine, Rome, 1629. 
ignoré auparavant, mais aussi parce que l'accent est mis sur le processus qui était, jusque-là, subsidiaire l'invention ${ }^{334}$.

Celle-ci acquiert une importance historique extraordinaire et vient imprimer aux facultés de l'ingénieur une grande partie de leur originalité ${ }^{335}$. L'invention doit être entendue d'abord par opposition à la conception qui avait cours dans la guilde et chez l'artisan. Pour ce dernier, ce qui naît au cours de l'exercice ordinaire de l'habileté a certes pour effet de l'améliorer, mais n'est pas l'objet d'un soin particulier. Au contraire, l'ingénieur, saisissant son habileté en tant qu'elle s'objective dans des opérations extérieures, les préserve et en souligne la particularité. C'est pour lui une nécessité, puisque le métier auquel il se consacre ne peut jamais être jugé achevé au sens artistique courant.

Ensuite, l'invention d' " arts nouveaux » correspond aussi à la situation marginale de l'ingénieur par rapport à l'artisanat. Comment son talent pourrait-il être reconnu, de quelle façon son métier pourraitil se situer face aux autres métiers, par quel moyen pourrait-il forcer usagers et commanditaires à s'intéresser à ses travaux, sinon parce que ceux-ci sont originaux, et qu'il en est lui-même l'inventeur? On connaît les termes de la lettre dans laquelle Léonard de Vinci offre ses services à Ludovic Sforza :

« Ayant, très illustre Seigneur, vu et considéré les expériences de tous ceux qui professent être maîtres dans l'art d'inventer les machines de guerre, et ayant trouvé que leurs engins ne différaient pas essentiellement de ceux qui sont généralement employés, je me hasarde, sans vouloir léser qui que ce soit, à faire connaître à Votre Excellence certains de mes propres secrets... »

A la Renaissance, l'invention fait l'objet d'un art, c'est un art. L'artiste-ingénieur veut y passer maître et crée autour de lui une atmosphère de passion et de grandeur. A vrai dire, inventer, ce n'est pas toujours faire une découverte, c'est parfois seulement donner forme à 
des pratiques existantes, ou les appliquer dans un contexte différent. Si l'on examine le carnet de notes de Léonard de Vinci, ce n'est pas le rabaisser que de remarquer, en maint endroit, une nouvelle combinaison de procédés existants, ou, simplement, une meilleure ordination ou encore une observation plus systématique. Oui, si l'ingénieur doit être éduqué en vue de l'invention, cela signifie surtout qu'il doit avoir acquis l'esprit d'observation critique de ce qui est fait par lui ou par d'autres, avoir saisi la possibilité d'introduire des instruments ou des mécanismes dans d'autres métiers, ou dans la solution des problèmes qu'on lui soumet. Brunelleschi ${ }^{336}$ est un des premiers à avoir ouvert la voie dans cette direction, de même qu'il est un des premiers à avoir obtenu des patentes qui sont autant de contrats entre lui et ses commanditaires. L'exemple a été imité par Venise, les cités allemandes, et suivi aussi en France et en Hollande. Le travail de l'ingénieur commence à s'affirmer comme un "travail privilégié », c'est-à-dire s'exerçant en vertu d'un privilège dans le domaine de l'invention. Ainsi arrive-t-on non seulement à envisager différemment l'art en général, mais aussi à reconnaître à l'art de l'ingénieur un trait particulier, celui d'être inventif. Les professions ne sont plus jugées stables et fixes, on commence à reconnaître qu'elles évoluent et se transforment. Vue qui est exprimée par L. B. Alberti comme suit :

«Il ne s'en trouvera jamais aucun (parce que celui-ci y aura été rendu apte par ses facultés) qui ne soit très désireux de bâtir ; et qui par son industrie n'ait trouvé quelque moyen nouveau dans l'art de bâtir, ni ne le mette plus volontiers à exécution; et comme si la nature l'y contraignait, il le rendra manifeste à l'usage des hommes $»{ }^{337}$.

Ouverture envers ce qui croît et se renouvelle dans l'art, mise en application, voilà ce qui s'oppose à l'ignorance et au refus de la nouveauté, voilà en quoi consiste l'esprit inventif à ses débuts. Non seulement la formation de talents au cours de l'exercice des facultés productives n'est pas découragée, mais encore on lutte contre la perte des découvertes infimes qui se font quotidiennement dans la vie de l'atelier. L'artisan les rejette comme superflues ou dangereuses. 1940, 9, pp. 455-554.

337 L.B. Alberti : op. cit. Préface. 
L'ingénieur, c'est un fait marquant de cette classe, fait la chasse à ces petites inventions, aux ressources en talents, pour l'instant complémentaires, qu'elles constituent. Bien plus, ajuster, changer ou projeter quelque invention est un caractère inhérent au travail de l'architecte ou du mécanicien, à tout travail, selon eux, et il faut en prendre conscience, l'utiliser et le manifester pour le bien des hommes. Dans cette optique, on ne peut prétendre posséder entièrement les arts, ni les fixer; de plus, l'ignorance est le corollaire du savoir, et l'invention, l'issue de ce conflit.

Une fois cette difficulté reconnue, on aperçoit non seulement que les arts se sont constitués et se constituent continuellement dans le temps, mais encore on sous-entend que chacun y a droit. Car les hommes, par milliers, les inventent et les réinventent :

«C'est le défaut commun de l'ignorance de nier qu'il y ait quelque chose que tu ne saches pas. Il paraît qu'on enlève une telle erreur en voulant que l'on cherche de façon plus approfondie quel commencement ont eu les arts, pour quelle raison ils ont pris naissance, comment ils se sont accrus. Il n'est pas hors de propos de dire que le père des arts a été le hasard et la réflexion, le nourricier en a été l'usage et l'expérience, et que la connaissance et le raisonnement leur ont permis de grandir. Ainsi la médecine a été trouvée en mille ans par mille milliers d'hommes, et de même la navigation et les autres arts semblables se sont augmentés peu à peu ${ }^{338}$.

Il s'ensuit que l'art n'est pas seulement l'apanage de certains, mais encore qu'il s'élabore par l'effort de tous les hommes qui le reprennent les uns des autres; et dans ce processus il s'enrichit avec le temps. De la sorte, si la dépendance d'un artisan envers l'autre et envers toutes les générations précédentes se marque mieux au plan de la reproduction, cette dépendance apparaît, aux yeux de l'ingénieur, de façon claire au plan de l'invention ${ }^{339}$.

Cet élargissement du sens du travail et de la définition de l'ingénieur implique la séparation des arts en deux catégories. La dif-

\footnotetext{
338 L.B. AlBerTI : idem, p. 118.

339 «L'acquisition se fait par l'esprit mécanique pour ce qui est de l'invention et de l’organisation ». J. ALSTED : Encyclopedia, Herbornae Nassoviorum, 1630, p. 1861.
} 
férence entre les arts que l'on constitue et apprend par invention et ceux que l'on constitue et apprend par imitation ${ }^{340}$, donc aussi entre les fins en vue desquelles on reproduit le travail, est nettement affirmée :

« D'après ceci on comprend, écrit Daniele Barbaro ${ }^{341}$, qu'il y a deux manières d'expériences, l'une qui devance l'art c'est-à-dire qui se fait avant qu'on acquière l'art, comme quand on dit je fais une expérience et je veux éprouver si j'obtiens quelque résultat; et celle-ci est comme la source et le fleuve de l'art. L'autre manière est celle qui est suscitée et dirigée par l'art, qui se trouve en nous, et nous l'exerçons de façon diverse suivant les domaines de l'art. Il découle de ce qui a été dit que l'expérience sert beaucoup plus aux arts qui s'acquièrent par invention qu'à ceux qu'on apprend par imitation ».

Les arguments exposés dans ce texte expriment bien la séparation qui s'opère entre artisans imitatifs et artisans inventifs, entre les qualités de l'art des premiers et les qualités de l'art des seconds, non seulement quant à l'objet auquel ils s'appliquent, mais aussi quant à l'habileté et à son contenu.

De là aussi, dans l'organisation des disciplines particulières à l'ingénieur, une impulsion et des facteurs propres à l'activité inventive, qui le déterminent. Non seulement l'expérience est orientée en ce sens, mais le dessin, le raisonnement, la structure de la théorie technique en subissent l'influence. Car, s'il y a un art de l'invention, il a justement pour but d'améliorer les efforts du praticien qui l'exerce, et de mettre fin - c'est du moins son idéal - aux tâtonnements et au hasard, au caractère accidentel des découvertes. Le recours au concept et à la règle intellectuelle, dans la technique mécanique, est dû en grande partie à ce besoin d'efficacité accrue dans le domaine inventif. Les frais qu'engage l'artisan et les efforts qu'il déploie l'obligent à ne pas se contenter d'une démarche aveugle. L'aspiration à une exploration plus méthodique des possibilités, le besoin de quelques principes clairs se font sentir même des moins savants. Je rappellerai ici, à titre d'illustration, le traité Tre discorsi sopra il modo d'alzar acqua da'luoghi bassi. (Trois discours sur la façon d'élever l'eau à partir de

C. DuPIN : Effets de l'enseignement populaire, Paris, 1826, p. 15.

341

D. BARBARO, in VITRUVE : L'architettura, Venise, 1641, p. 40. 
bas-fonds) publié à Parme en 1567 par G. Ceredi. Ce petit traité n'a pas de prétentions savantes. Il est publié pour procurer à son auteur les bénéfices d'une prétendue invention, et Ceredi y fait imprimer la lettre-patente, valable dans l'État de Piacenza et de Parme pour une durée de vingt-cinq ans, qui lui en concède la propriété. L'intérêt de l'ouvrage est de montrer que le travail de conception et de construction d'une machine appelle un "discours » systématique, un savoir approprié. Faute de quoi les ignorants marcheront au hasard :

«Parce que les hommes ingénieux qui ne sont pas savants ne feront jamais rien de bien, sinon par hasard; et ne sachant pas démêler les raisons des erreurs qui découlent de leurs travaux, effrayés enfin par les difficultés et les accidents, ils abandonneront leurs entreprises en invoquant ensuite mille fables et mensonges pour s'excuser ${ }^{342}$.

Les philosophes et les mathématiciens sont aussi invités de manière pressante à pallier ces inconvénients, à aider les découvertes mécaniques à venir au jour, car, sans règles, rien de certain ne peut être réalisé, et le génie de l'inventeur demeure imparfait. Pour rendre son discours plus persuasif, G. Ceredi assure les mathématiciens qu'ils seront matériellement récompensés :

«J'espère aussi que la preuve convaincra certains qui à présent sont occupés à des ouvrages mathématiques, en leur découvrant que les hommes savants entre lesquels j'avoue être le moindre, s'ils voulaient appliquer leur pensée et employer avec prudence leur savoir, retireraient un gain très honnête pour eux-mêmes et un grand bénéfice pour les autres, de la pratique de la science ${ }^{343}$.

La mathématique est appelée, par l'activité de l'inventeur, à jouer un rôle capital, afin de modifier et d'accélérer les procédés routiniers qui freinent le progrès de l'art. Descartes, plus tard, partage cette crainte de laisser les découvertes se faire au hasard, et non pas comme le résultat d'une initiative délibérée et rationnelle. 
Les instruments intellectuels et matériels indispensables à la réalisation de cette aspiration - à côté de ceux qui sont indispensables pour reproduire les capacités de l'ingénieur - élargissent, en lui ajoutant une dimension importante, cette " science de l'ingénieur». Outre les encyclopédies qui donnent un aperçu de la vie des professions et présentent les machines déjà inventées, les manuels contenant les informations utiles à la résolution des divers problèmes, les inventions elles-mêmes engendrent une littérature spécifique, un trésor de ressources complémentaires disponibles et d'informations sur les phénomènes objectifs. Les conditions dans lesquelles on obtient un privilège pour une découverte, une pseudo-découverte ou une découverte originale, stimulent la prolifération des écrits techniques. Certains sont l'œuvre d'hommes ayant une véritable maîtrise de la langue et de leur métier, d'autres, à peine lisibles, témoignent de l'existence d'individus qui se donnent pour but clair et pour profession avouée ce qu'on nommera plus tard la production de la connaissance :

«Si quelqu'un veut faire cette expérience pleinement qui a une meilleure occasion de le faire que je n'ai, écrit Platters, et ensuite la publier pour le bien général, il sera mon frère ; car nous sommes tous deux d'un métier ou d'une profession qu'on doit nommer marchand de savoir, différent des marchands de poisson ou marchands de fer, etc. en ce que nous payons nos marchandises fort cher et les distribuons gratis $»{ }^{344}$.

C'est muni d'un tel privilège que paraît en France le célèbre Théâtre des Instruments mathématiques et méchaniques de Jacques Besson, à Lyon en 1578. Et c'est la même raison qui pousse S. Sturtevant à publier son ouvrage Metallica à Londres en 1612.

Les fabricants d'instruments mathématiques, les constructeurs de machines ont encore un autre motif d'écrire. Pour se vendre, leurs instruments doivent être connus, mais aussi être accompagnés d'un mode d'emploi ${ }^{345}$. De Michel Coignet à Galileo Galilei, ils rédigent tous de petits traités destinés à montrer comment on utilise, par exemple, le

344 G. Platters : A discovery of infinite treasure hidden since the world's beginning, Londres, 1639, p. 71.

345 E. ZINNER : Deutsche und niederländische astronomische Instrumente des 11-18 ten Jahrhunderts, Munich, 1956. 
compas de leur invention et à en souligner la supériorité sur les articles existants. La publicité entre donc pour une grande part dans cette activité littéraire technique dont on peut dire encore qu'elle apporte souvent des connaissances inédites. On voit qu'elle fait directement partie des investissements propres à ce métier.

«L'argent des essais, écrit Sturtevant ${ }^{346}$, doit être dépensé d'abord en instruments théoriques et moyens d'invention, c'est-à-dire toute la description de l'invention, que ce soit au moyen d'écrits manuscrits ou de traités imprimés. Ensuite en modèles de l'invention, qu'ils soient en plan, ou en volume, de mouvement ou de direction. Et enfin dans la confection du protoplaste (prototype) auquel devront se conformer toutes les autres grandes mécaniques ».

Un autre élément pousse l'ingénieur ou le constructeur d'instruments mathématiques à rendre publics les résultats de ses travaux : il désire s'assurer le fruit de son labeur ${ }^{347}$. En fait, la propriété réelle et morale de ses travaux lui est rarement garantie. Une fois un objet produit ou une idée lancée, divulguée, n'importe qui peut s'en emparer, privant l'auteur de la gloire et du bénéfice de son effort. Même Watt dans une lettre du 17 août 1773 à Small se propose d'écrire un ouvrage afin de s'assurer la priorité de ses essais et de ses expériences :

« J'ai lu De Luc récemment et j'ai tenté une curieuse expérience pour déterminer la température à laquelle bout l'eau à chaque pouce de mercure à partir de l'air vide. Les observations de Luc et les miennes concordent; mais sa règle est fausse. J'ai quelque pensée d'en faire un livre, les «Éléments de la théorie de la Machine à Vapeur », dans lequel je me bornerai cependant à donner l'énoncé de la machine parfaite. Ce livre pourrait me servir, moi et mon projet, et laisser cependant le monde dans l'ignorance quant à la véritable construction de la machine. C'est en quelque sorte nécessaire, comme Smeaton travaille dur sur ce sujet; et si je ne puis en tirer de bénéfice, je ne devrais pas perdre le mérite de mes expériences ».

On sait que Watt n'écrivit pas ce traité de thermodynamique, et qu'il fit le bénéfice qu'il craignait de perdre. Au contraire Galilée avait été forcé de puGUNTHER, Early Science in Oxford, vol. VIII, Oxford, 1931, p. XIII) d'autres avantages non moins considérables que les précédents parmi lesquels figure l'assurance que les inventions seront attribuées à leur premier auteur, ce qu'il n'est guère possible de faire par d'autres moyens ». 
blier une brochure pour décrire son invention du compas, parce qu'un artisan prétendait l'avoir conçue avant lui.

La communication des inventions, celle du savoir-faire et des connaissances théoriques, devient un phénomène général, bien qu'il subisse des restrictions, mais sans commune mesure avec la situation et les routines de l'artisan qui jouaient un rôle tout différent. Un élément révolutionnaire entre dans la constitution du travail, anime l'esprit des producteurs et leur dicte leur intérêt. Ces artisans d'un genre nouveau s'aventurent à écrire des livres sur des sujets de leur profession qui leur tiennent à cœur, exigent que le monde savant les serve et s'associe à leurs idéaux, estiment que les connaissances doivent leur être partagées et qu'il faut que l'on reconnaisse leur mérite dans l'ordre de la découverte et la maîtrise des sources matérielles d'énergie. Pratiquant des métiers qu'ils ont proclamés savants, donc sans privilèges corporatifs, ils se procurent d'autres privilèges. A juste titre, puisqu'ils ont, dans leur travail, institué un nouveau style de relation entre l'homme et la matière.

«Être Méchanicien, donc, et Ingénieur, à l'exemple de ces hommes remarquables c'est ainsi que Guidobaldo avertit ses lecteurs - est un emploi de personnes honorables et nobles, et Méchanique est un mot grec signifiant une chose faite par l'artifice comme, par miracle, hors de la puissance humaine de mouvoir de grands poids à l'aide d'une petite force. En général la Méchanique comprend tout outil, instrument, machine, treuil, baliste, tout ce qui a été inventé de façon magistrale et élaboré pour de tels effets, et de nombreux autres dans lesquels on voit à l'œuvre la science, l'art et l'expérience ${ }^{348}$.

Quatre siècles nous ont beaucoup éloignés de la définition de Domingo Gundisalvo, qui ne voyait dans l'art de l'ingénieur que sa propension au calcul. Non seulement les ressources complémentaires en énergie, mécanismes et dextérités se sont affermies, mais les modalités de création du travail ont aussi subi un changement assez profond pour qu'on se trouve en présence de deux formes de création radicalement différentes et ostensiblement antagonistes. Ce qui était uniquement l'ébauche d'un art parmi les autres, qui s'ajoutait à eux et leur servait d'auxiliaire, est devenu un genre d'art distinct. La division 
en deux catégories naturelles, dont tout le monde s'accorde à reconnaître l'existence au $\mathrm{XVI}^{\mathrm{e}}$ siècle, n'instaure pas une distance entre l'« artisan supérieur » et l'artisan tout court, comme entre deux hommes d'art dont le premier aurait, de surcroît, la connaissance mathématique : elle transforme le second en ressource du premier, fait de l'habileté de celui-là l'objet des facultés de celui-ci, et met en concurrence le travail symbolisé par la main et le travail symbolisé par l'instrument, le travail artistique et le travail instrumental.

C'est vrai tout d'abord dans l'ordre de la reproduction. La combinaison des découvertes ayant trait aux machines, leur classement et leur rapprochement ont permis le transfert plus rapide d'un domaine à l'autre : de la construction des horloges à celle des machines-outils, des fabrications de guerre à l'application de l'énergie hydraulique, de celle-ci à la métallurgie, etc. De même s'est constitué le cadre d'une assimilation des résultats déjà obtenus par les mécaniciens alexandrins ou byzantins. L'organisation et la transmission de ces savoirs a suscité l'appel à la géométrie, au dessin et finalement aux instruments de mesure. L'horizon de l'apprentissage, de l'acquisition des habiletés, dépasse celui de l'atelier. La relation du maître au disciple éclate, car le maître est amené à dispenser plusieurs enseignements, et le disciple doit s'instruire auprès de plusieurs maîtres dans des sujets différents. De toute manière, de par sa fonction, un ingénieur est obligé de connaître plusieurs arts : c'est ce qui fait précisément sa spécialité.

Ensuite, dans une phase ultérieure, le processus inventif s'affirme déterminant dans la création mécanicienne du travail ; c'est lui qui est le foyer de l'activité expérimentale ; il précise la méthode, encourage la formulation de règles quantitatives, stimule la formation de théories à partir desquelles on peut concevoir des projets et s'engager dans la voie de la découverte. Là se trouve aussi l'origine de la critique portée contre nombre de doctrines ou de conventions qui constituaient autant d'obstacles intellectuels, ayant des effets pratiques néfastes pour le mécanicien, l'ingénieur, dont la renommée ou les débouchés professionnels dépendaient de leur capacité à proposer des solutions originales. 
Toutefois, au moment où la division naturelle prend cette tournure révolutionnaire, la production, que ce soit dans l'atelier ou dans la manufacture, reste à prédominance artisanale, et il en sera ainsi jusqu'à la création de la grande industrie ${ }^{349}$. Le secteur conquis par l'ingénieur se situe relativement à l'extérieur de la production, dans la sphère directement sociale, que ce soit celle de la guerre ou celle de la construction, ou encore là où les mécanismes apparaissent non pas comme des outils de travail, mais comme des objets mêmes : instruments mathématiques, horloge, etc. Dans ce dernier cas, on remarque une certaine intégration au cadre artisanal. Les fabricants d'instruments mathématiques, les horlogers, constituent des confréries en Allemagne et en Angleterre. En France, les difficultés à suivre cette voie semblent avoir été plus grandes ; certains de ces mécaniciens, ainsi que l'a montré Maurice Daumas dans un livre érudit et profond, finirent par s'associer à la compagnie des fondeurs.

\section{Mais :}

« Dès la fin du XVII ${ }^{\mathrm{e}}$ siècle, certains constructeurs ( $d$ 'instruments mathématiques) prirent la dénomination d'ingénieurs puis l'habitude d'user de ce terme se répandit de plus en plus au cours du XVIII ${ }^{\mathrm{e}}$ siècle pour devenir générale ${ }^{350}$.

L'extériorité des champs respectifs d'activité de l'ingénieur et de l'artisan n'est pas le seul fait historiquement marquant. L'apparition, en face d'un monde de matières premières, de formes et d'outils, d'un monde de forces, de mécanismes et d'instruments, annonce la nouvelle nature, la nature mécanique. G. Ceredi formule assez clairement cette impression lorsqu'il écrit :

«La nature même, devenue pour ainsi dire mécanicienne, semble s'être ingéniée avec un beau zèle à produire à chaque instant davantage d'organes

« L'art de l'ingénieur en tant que tel (jusqu'au XVIII ${ }^{\mathrm{e}}$ siècle) n'avait eu que peu de part aux industries de fabrication - domaine des biens de consommation. C'est la révolution industrielle du XVIII ${ }^{\mathrm{e}}$ siècle en Grande-Bretagne qui mit pour la première fois l'ingénieur en contact avec la fabrication et l'industrie et donna un nouvel essor à la construction mécanique ». J.K. FINCH : op. cit. p. XVIII.

350 M. DAUMAS : Les instruments scientifiques au XVII ${ }^{\mathrm{e}}$ et au XVIII ${ }^{\mathrm{e}}$ siècles, Paris, 1953, p.14. 
pleins d'art, dans la fabrique du monde et de toutes les formes des choses $\gg{ }^{351}$.

Elle transparaît à travers l'art de l'ingénieur qui synthétise à la fois le caractère de ses échanges avec les ressources matérielles ou inventives, et la méthode de création du travail, la reproduction individualisée et la prééminence de l'invention. Pour y parvenir, la construction de modèles, le dessin, l'expérience et les théories physicomathématiques ainsi que la dextérité manuelle indispensable à la réalisation des prototypes, à la saisie des règles de métiers, sont transformés en facultés de l'homme de l'art et examinés dans ses ouvrages. Discipline de ces facultés, la mécanique apparaît très tôt comme le grand facteur novateur, elle ne fait pas bande à part mais au contraire est capable de pénétrer et de bouleverser tout autre savoir, tout art existant. Ce qui pour nous a aujourd'hui un sens injustement péjoratif, exprimait à ce moment-là un sentiment d'exaltation, l'entrée dans la vie pleine d'une figure originale de l'humanité et d'une réalité qui semblait lui convenir. L'ingénieur élargit les fondements de cette réalité et veut agir sur elle. Dans ses rapports avec l'ordre matériel, il aspire à maîtriser et guider les forces et les mouvements, au lieu d'imiter leur résultat achevé. Cette attitude qui fait progresser son savoir lui confère, pour une grande part, son importance historique.

\section{De l'art mécanique à la technique}

Retour à la Table des Matières

Dans les pages qui précèdent j'ai décrit le processus qui a abouti à la formation d'un système de reproduction du savoir-faire dont l'artisan et l'ingénieur sont les termes. Le devenir technique des arts du premier est ainsi commencé. Le second prend en quelque sorte la relève et devient l'élément directeur, actif, des rapports au monde objectif. La mécanisation de la production, le remplacement des forces productives de la société où prédomine encore l'habileté manuelle par des forces productives où s'illustre la commande des sources 
d'énergie et du mouvement, la mutation qui sépare les beaux-arts des arts tout court, représentent la fin, bien connue, de ce devenir. Arrêtons-nous sur quelques-unes des étapes qui l'ont jalonné.

Le sens originel des arts mécaniques est purement social. Il dénote une classe d'activités où l'homme emploie, pour produire, son énergie physique, ou sous-entend que seuls s'y adonnent les individus appartenant aux couches inférieures de la société. A ce titre, la médecine comme l'agriculture, la sculpture comme l'art de construire des engins, les mathématiques comme la peinture y sont inclus. A ce stade, la dénomination de mécanique désigne un statut de la société. Elle change de portée et d'acception lorsqu'elle commence à se référer à un contenu plus spécifique, à une discipline et à une famille de pratiques qui toutes sont plus ou moins liées à la machine et à l'invention. Donc, à une signification sociale s'ajoute — pour la remplacer par la suite - une signification pour ainsi dire naturelle, qui exprime un mode particulier d'échange avec les forces matérielles, une création spécifique des dextérités afférentes. La pluralité de ces critères est attestée dans les définitions qu'on essaye de donner à partir du XVII ${ }^{\mathrm{e}}$ siècle, dans les encyclopédies des arts mécaniques :

«On les appelle arts mécaniques, écrit J. Alsted, parce qu'ils se proposent, par l'emploi de l'ingéniosité, l'utilité et l'agrément de la vie quotidienne des hommes ; aussi parce que ceux qui sont habiles et industrieux dans l'optique, tirent d'eux leur nom, même si chez d'autres on nomme l'artisan d'après le travail qu'il fait. D'un autre nom, on les appelle manuels, sédentaires et nonlibéraux ; ce dernier nom doit être compris à titre de comparaison. En effet Zwinger dans son Théâtre rappelle que, entre les arts mécaniques, les uns peuvent être dits libéraux et libres, les autres serviles et bas. Et les arts mécaniques sont aussi dits non-libéraux parce que jadis ils n'étaient pratiqués que par les esclaves, tandis que les hommes libres s'abstenaient de ces professions et les abhorraient » ${ }^{352}$.

Si elle en vient à changer de portée et de rôle, la construction des machines ne sort toutefois pas complètement du domaine général des arts. Elle est longtemps comptée parmi les disciplines composant l'architecture. Dans son traité de peinture, P. Lomazzo distingue deux 
parties : l'architecture accidentelle et l'architecture substantielle. Cette dernière comprend un art gnomonique (ayant trait aux horloges et aux instruments), un art de l'édification et un art «machinatoire », dont il dit qu'il contient :

«les organes, les engins hydrauliques, les machines mues par le feu, les sources, les organes aériens, les machines que l'on chasse par la force de l'air, et enfin les instruments militaires ${ }^{353}$.

Ceci n'efface cependant pas l'individualité de l'ingénieur et de son art. Les différents pays l'ont intégré de manière diverse. En France, le système militaire et le pouvoir royal ont contribué à lui donner un statut institutionnel à part, et ont agi sur sa formation. En Angleterre, il a été plus lent à se dégager du milieu artisanal ${ }^{354}$. Les développements de la philosophie mécanique, les inventions d'un Galilée, d'un Descartes, d'un Pascal, d'un Huygens, d'un Newton, ont heureusement retenti sur ses activités, non seulement en augmentant son prestige social, mais aussi en donnant un fondement plus solide à son travail et, ce qui n'est pas négligeable, en élargissant le marché, l'éventail des fabrications comme le nombre des usagers. Les instruments mathématiques connaissent une grande vogue et permettent l'ouverture de nombreux ateliers et le perfectionnement des procédés. L'artillerie adopte plus hardiment les enseignements de la mécanique; en s'améliorant, l'art de l'invention facilite l'essor des projets, tandis que des artisans toujours plus nombreux s'y consacrent pour assurer leur subsistance. Les talents et les hommes devenus surnuméraires par

353

«Le constructeur de moulins (millwright) de l'époque précédente était dans une grande mesure le seul représentant de l'art mécanique, et considéré comme faisant autorité dans toutes les applications du vent et de l'eau, dans quelques conditions qu'ils fussent employés, en tant que force motrice, pour le besoin de la manufacture. C'était l'ingénieur de la région où il vivait, un homme à tout faire qui savait travailler avec la même facilité au tour, à l'enclume et à l'établi... Ainsi le constructeur de moulins du siècle dernier était un ingénieur itinérant et un mécanicien en renom ». W. FAIRBAIRN : Treatise on mills and millwork, Londres, 1871, t. I, p.IX.

«Les premiers « ingénieurs» se recrutaient dans de nombreux métiers — forgerons, charpentiers, fondeurs de fer, serruriers, horlogers et surtout le constructeur de moulins, capable de faire beaucoup de choses diverses - tous artisans manuels, ayant l'expérience du travail du métal ». A.E. MusSON : James Nasmyth and the early growth of mechanical engineering, Ec. Hist. Rev. 1957-8, 10, p. 121. Voir aussi : J.B. JEFFERYS : The story of engineers, Londres, 1945. 
suite de la crise sociale profonde des guildes, éliminés de la production, cherchent un débouché dans le vaste domaine ouvert par les constructions mécaniques. Réciproquement, ressources et facultés mécaniques modifient les méthodes de travail artisanales, là où la coopération s'avère nécessaire pour des raisons objectives dans les arsenaux, les mines ou pour l'architecture - et se développent sur une échelle inconnue auparavant. La rationalisation de la production, l'amélioration et la mécanisation des moyens de travail, l'uniformisation du produit, s'ébauchent dans ce cadre. La recherche de nouvelles puissances motrices - la vapeur par exemple - inspirée par l'artillerie et les idées des mécaniciens alexandrins, l'accroissement de la dimension des pompes, la progression des connaissances en matière d'horlogerie, d'engrenages, d'automatismes, s'en trouvent stimulées.

L'idée de la production mécanique fait son chemin, bien que les réalisations naissantes soient souvent repoussées. Thomas Powell relate qu'à

« Dantzig, en Pologne, on établit une invention rare pour tisser quatre ou cinq tissus à la fois sans aucune aide humaine; c'était un automate ou engin qui se mouvait tout seul et travaillait nuit et jour; l'invention fut détruite, parce qu'elle portait préjudice aux pauvres gens de la ville, et on fit secrètement disparaitre l'inventeur ${ }^{355}$.

On peut douter que l'invention ait eu l'efficacité qu'on lui prête, mais on voit que les mécaniciens concevaient déjà clairement le mode de production de l'avenir.

Ce cas n'est pas unique. Les inventions mécaniques ne pouvaient connaître un autre sort, ${ }^{356}$ avant que les conditions qui avaient prévalu dans certains secteurs d'activité, tels que la construction ou la guerre, se fussent reproduites dans le cycle productif principal, à savoir la so-

355 T. POWELL : Human industry, or a history of most natural arts, Londres, 1661, p. 85. 
cialisation du travail artisanal et le développement de la coopération des artisans dans un cadre unitaire. Or, la généralisation des manufactures et la division technique du travail qu'elles supposent préparent la voie à la pénétration du mécanisme là où prédominait la dextérité manuelle. C'est l'œuvre des artisans-ingénieurs ou fabricants d'instruments mathématiques, et ils étaient les seuls à avoir les capacités pour le faire.

Quelques exemples nous le montrent. La chaîne des perfectionnements qui de Branca et Papin à Savery, Newcomen et Watt tendent à fournir une puissance motrice réglable et mobile - celle de la machine à vapeur - et une source d'énergie ayant un rendement supérieur aux moulins (dont Smeaton, à la fin du XVIII ${ }^{\mathrm{e}}$ siècle encore, voulait améliorer le fonctionnement) se situe entièrement dans la sphère du mécanicien. Les outils de l'horloger, en se généralisant, fournissent le modèle de nouveaux moyens de travail. Le tour de précision commence à être connu au $\mathrm{XVI}^{\mathrm{e}}$ siècle et se perfectionne considérablement au XVII ${ }^{e}$. Au siècle suivant, les horlogers emploient des outils guidés de façon mécanique. Les machines à découper les rouages d'horloge, dont Robert Hooke est l'inventeur, et celles à couper et fileter des vis pour confectionner des fusées de montre, enrichissent le domaine si important des machinesoutils, prêtes à trouver de nouveaux emplois. Vaucanson et Gombey améliorent ces méthodes pour des machines travaillant sur une grande échelle. Bramah, Maudsley opèrent la transition hardie qui, de l'horlogerie à d'autres fabrications, fait de la machine-outil l'instrument productif par excellence. La mécanisation de l'art textile remonte, elle, au Moyen Age. Le moulin à fouler, le bobinage et le retordage mécaniques de la soie y sont déjà connus. Léonard de Vinci est le premier à faire une étude technologique des machines textiles. Les inventions de Lewis Paul, Wyatt, Kay, J. Taylor, Bouchon, Cartwright, tant de fois décrites, continuent un mouvement qui s'est considérablement amplifié au cours des XVII et XVIII ${ }^{\mathrm{e}}$ siècles.

Si la « révolution industrielle » a eu lieu au XVIII ${ }^{\mathrm{e}}$ siècle, ses prémisses n'en existaient pas moins depuis la Renaissance. Sa fonction a été de permettre la transformation de la structure des forces productives, l'institution de la force productive de l'ingénieur et de ses ressources jusque-là complémentaires. En transférant méthodiquement les habiletés des artisans à la machine ${ }^{357}$, les ingénieurs accroissent leurs propres « facultés mécaniques ». Dans une mesure croissante, ils font apparaître les hommes d'art et l'art lui-même comme parties de la 
machine, et s'approprient pour leur art la finesse et les règles du mécanisme. La reproduction sociale subit des modifications en conséquence. L'industrie de l'ingénieur, secteur des moyens de production, accède à l'indépendance, en concentrant les talents et l'ingéniosité de l'inventeur, et bouleverse le rythme jusqu'alors coutumier du travail.

Les historiens de la révolution industrielle ne semblent pas avoir aperçu correctement son rôle, ni s'être rendu compte qu'elle ne constitue nullement, du point de vue de l'état naturel et technique, une véritable révolution ${ }^{358}$. De plus, ils ont adopté une optique déformante, en prenant en considération uniquement l'exploitation du prolétaire par le capitaliste, la dépossession de celui-là et l'enrichissement de celui-ci. Parallèlement, ils ont observé la déperdition constante d'habileté de l'artisan en faveur de l'industrie mécanique. Mais ils ont négligé de voir, à travers celle-ci, l'homme qui s'y incarne et l'a créée comme son champ d'action et le lieu d'exercice de son talent. Ils auraient pu, s'ils l'avaient fait, saisir le développement de cette transformation des arts, le déplacement de l'habileté de l'artisan vers l'ingénieur, manifestation de la dynamique du système de reproduction établi entre deux catégories naturelles. Tandis que le travail artistique perd son rôle de force productive, le travail instrumental le remplace; et si, d'un côté, dans des conditions sociales nouvelles et dramatiques, les facultés artisanales dépérissent, d'un autre côté les facultés mécaniques ne cessent de se développer. Ceux qui ont étudié la révolution industrielle n'ont pas accordé suffisamment d'importance à ce groupe qui, avec une ténacité extraordinaire, cherche à accroître ses talents et s'organise en vue de cette fin. Ce ne sont pas des savants, ils ne font pas de la science appliquée ${ }^{359}$. Leur capacité est orientée vers les engins qu'ils connaissent bien et qu'ils conçoivent et construisent admirablement. Par ailleurs, du point de vue de la préparation libérale et de l'éducation scolaire, on peut les considérer comme des « hommes sans lettres ». Ce sont des autodidactes - et ce terme n'a rien de péjoratif - qui s'instruisent dans la compagnie des engins autant sinon plus que dans celle des philosophes-mathématiciens. L'horlogerie est la

\footnotetext{
358 M. DAumas : Le mythe de la révolution technique, Rev. d'Hist. des Sc. 1963, 6, pp. 300 et seq.

359 J.D. BERNAL : Science, industry and society in the nineteenth century, Centaurus, 1963, 3, p. 145.
} 
première industrie à bénéficier de ces efforts, à appliquer les connaissances théoriques de la physique et de la mécanique. Mais en général la plupart des travaux mécaniques n'ont pas un lien aussi étroit avec les mathématiques théoriques.

«Les engins et les machines qui constituent les pièces exposées à l'Exposition de Londres en 1851, écrit Tom Burns ${ }^{360}$, étaient pour une large part l'œuvre de mécaniciens et de maîtres qui, grâce aux connaissances de base acquises pendant leur apprentissage, aux mathématiques qu'ils avaient apprises tout seuls, et à une conception claire des principes du nouveau génie, avaient saisi les occasions qui se présentaient tout autour d'eux ».

Ce qui est vrai pour le milieu du XIX ${ }^{\mathrm{e}}$ siècle l'est encore davantage pour le XVIII ${ }^{\mathrm{e}}$. La célèbre machine de Marly, œuvre d'art et de mécanique, qui rendit de grands services pour le pompage de l'eau, était l'œuvre d'un tel mécanicien. Nous voyons cependant ces mécaniciens, au lieu de se cantonner dans le cadre établi des connaissances artistiques, se préoccuper des moyens propres à accroître leur capacité et leur domaine d'activité ${ }^{361}$. Ce sont eux qui, avec des fortunes diverses, essaient de propager «les connaissances utiles». Les hommes tels que John Harris, John Bird et John Harrison, inventeurs, forgerons, fabricants d'instruments, publiant des essais dans le domaine de l'optique, de l'astronomie, des mathématiques, de la navigation, sont la règle plutôt que l'exception dans la multitude d'hommes qui ont entretenu cet esprit. Les Mechanics Institutions du XIX ${ }^{\mathrm{e}}$ siècle ne font que prolonger les bibliothèques d'artisans, les "sociétés du dimanche », les sectes de « philosophes de la fonte », à l'instar de la « Spittfields Mathematical Society », où les artisans-ingénieurs confrontent leurs idées et accroissent leur savoir ${ }^{362}$. A partir du moment où ils

$$
\text { mentron }
$$
membres afin qu'ils puissent «devenir des inventeurs et des découvreurs utiles ». Bien que tables que les instituts de mécaniciens ouvrent leurs portes à tous les ouvriers, néanmoins c'est aux mécaniciens, le type nouveau d'ouvriers qui était sorti des nouvelles méthodes de l'industrie, que le mouvement s'adressait tout spécialement, et il en reçut son nom. C'est à cette époque approximativement que le mécanicien et ses compagnons commencèrent à être 
sont devenus des agents essentiels de la production, le cœur et le cerveau des forces productives, ce qui avait lieu auparavant de façon lente, incertaine, apparaît clairement comme le résultat d'une intention. Tandis que l'ancien artisanat devient main-d'œuvre non qualifiée et disparaît peu à peu, la stature et la proportion des ingénieurs augmente régulièrement. Si on ne compte, aux États-Unis, en 1880, qu'un ingénieur sur 30900 personnes, on en compte en 1900 un sur 8900 personnes, et en 1920 un sur 2 120. L'accroissement général de la productivité, directement proportionnelle au nombre d'ingénieurs et inversement proportionnelle à celui des autres producteurs, exprime cette substitution de la capacité de l'ingénieur à celle de l'artisan, la reproduction naturelle du premier en lieu et place du second. La loi de la productivité moderne n'est en fait que la forme particulière de la division naturelle propre au système de reproduction qui caractérise la nature mécanique. Elle traduit le fait suivant : au fur et à mesure que le talent artistique est reproduit par le mécanisme, le talent instrumental, celui de l'ingénieur, se fortifie et se parachève. Dans ce transfert, celui-ci acquiert les facultés de celui-là, structurées de manière neuve. C'est là l'invention du mécanicien : la reproduction des facultés artistiques sous une forme matérielle. Ce qui était fait par un type d'homme est réalisé par la machine. En ce sens l'ingénieur se veut créateur de procédés qui économisent le travail. Ce moyen indirect lui permet d'enrichir son propre travail, en faisant apparaître un travail humain comme mécanique, afin d'augmenter son utilité, son propre savoir-faire machinal. On dit à tort que la machine remplace l'homme ; en réalité, un homme se substitue à un autre homme, une faculté humaine à une autre.

L'importance de la technique industrielle, du point de vue du développement de la division des catégories naturelles, est donc d'avoir marqué l'entrée de l'ingénieur et de ses ressources matérielles ou inventives dans le circuit productif primordial. Tandis que les arts mécaniques y trouvent leur plein accomplissement, la transformation des autres arts, des autres artisans - ce qui est le fond de la productivité mécanique - s'accélère, sur des bases qui ont été posées plusieurs siècles auparavant. Ces arts perdent leur individualité pour s'intégrer

reconnus en tant que classe séparée et à prendre conscience d'eux-mêmes ». M. TYLECOATE : The Mechanics' Institutes of Lancashire and Yorkshire before 1851, Manchester, 1951, p. 34. 
dans une nouvelle unité ${ }^{363}$, et la manifester dans le cadre qui leur est particulier. Le savoir instrumental n'est plus un savoir parmi d'autres, il en est la quintessence, et les savoirs particuliers ne sont que des applications ou des apparences. Dès cet instant, ce savoir est technique dans le sens que nous donnons à ce mot depuis le XVIII ${ }^{\mathrm{e}}$ siècle, ou désigne un ensemble de techniques. Assurément, la notion existait sous forme diffuse depuis longtemps. En 1737, B. Martini, opticien, publie une Bibliotheca Technologica, et J. Alsted appelle Technologie « la doctrine des propriétés, de l'ordre et du nombre des disciplines $\gg{ }^{364}$. Cependant, c'est seulement à l'époque que j'ai indiquée, et pour accentuer son originalité, que l'on parle de technique et de technologie, comme de l'ensemble des pratiques fondées sur le savoir mécanique. Consciemment, un J. Beckmann ${ }^{365}$ forge le terme de technologie pour désigner la discipline qui décrit et ordonne les métiers et les industries existants ${ }^{366}$. Elle doit se distinguer de l'histoire et de l'encyclopédie des arts tels qu'ils étaient conçus et classés antérieurement, et se substituer à elles. Karmarsch le dit expressément :

«Le nom de technologie fut employé pour désigner ce qu'on appelait jusque-là de façon courante mais impropre l'histoire des arts » ${ }^{367}$.

Ces changements de terminologie traduisent une réalité plus profonde. S'ils se manifestent lorsque la technique a atteint sa maturité, ils en attestent l'origine. Celle-ci remonte aux premiers essais faits en vue de produire un effet indépendant par la combinaison des mouvements et des instruments, sans intervention du travail de l'homme, de la dextérité humaine. L'agent humain y est présent au mieux en tant

Le terme de technologie, signifiant une branche de la profession d'ingénieur, bien qu'il en soit venu à se référer aux arts utiles ou mécaniques par opposition aux beaux-arts, est un simple dérivé du terme grec employé pour l'art». Th.J. HoOver et J.C.C. FISH : The engineering profession, Palo Alto, 1947, p. 12.

364 J. ALSTED : op. cit. p. 62.

365 J. BECKMANN : Beiträge zur Geschichte der Erfindungen, Leipzig, 1783-1803.

J. BECKMANN : Anleitung zur Technologie oder zur Kenntnis der Handwerke, Fabriken und Manufakturen... nebst Beiträge zur Kunstgeschichte, Gottingen, 1780.

W.F. EXNER : J. Beckmann, Vienne, 1878.

E.O. v. LIPPMANN : Beiträge zur Geschichte der Naturwissenschaften und Technik, Berlin, 1953, t. II, p. 201.

366 J.H.M. PopPE : Geschichte der Technologie, Göttingen, 1807.

367 K. Karmarsch : Geschichte der Technologie, Münich, 1872, p. 5. 
que source d'énergie animale. Le moulin moud, la presse broie, l'automate amuse, l'horloge indique l'heure en vertu d'un agencement interne qui exige tout au plus la chiquenaude, mais nullement la présence constante de l'opérateur humain. Ces instruments ou machines, dès leur apparition, timide à Alexandrie ou Syracuse, relativement massive au $\mathrm{XV}^{\mathrm{e}}$ siècle, ont requis une certaine expérimentation, quelques calculs, des règles de quantité ou de proportion, permettant de déterminer leur régime. Vouloir étendre la définition de la technique, en les incluant dans son domaine, aux travaux tels que l'agriculture, la chasse ou l'art dans lesquels, au contraire, le produit dernier dépend du soin constant de l'homme, et pour lesquels sa main, son habileté ne sauraient être absentes du processus matériel productif, conduit à méconnaître et à estomper les particularités structurelles et historiques de chacune de ces grandes activités. De même qu'il serait erroné de conclure à l'existence du commerce partout où il y a échange - ce qui serait confondre une fonction générale avec une de ses formes spécifiques - de même on ne peut soutenir que la technique soit présente partout où il $\mathrm{y}$ a interaction positive et pratique de l'homme avec la matière. Une telle erreur aurait pour conséquence de vider chacune des modalités d'interaction de sa substance propre.

Dans cet esprit, j'ai étudié ici l'origine des arts mécaniques comme une classe particulière d'arts, et la technique comme leur expression générale et leur aboutissement. L'ingénieur en est la contre-partie humaine et le créateur; il est également, avec son savoir-faire, le point de départ et l'inspirateur d'un ordre naturel. 


\section{Chapitre IV.}

\section{La révolution philosophique}

\section{La hiérarchie des disciplines naturelles}

\section{Retour à la Table des Matières}

$\mathrm{Au} \mathrm{XVI}{ }^{\mathrm{e}}$ et au XVII ${ }^{\mathrm{e}}$ siècles s'est formé un nouveau groupement de disciplines, que ses auteurs ont volontairement désigné du nom de philosophie mécanique. Comme pour toute formation, il s'agit d'une transformation, à savoir celle de la philosophie naturelle que les Grecs ont constituée et le Moyen Age reprise, en philosophie mécanique, ou, en d'autres termes, de la métamorphose d'une philosophie qui s'efforce de justifier, de classer logiquement des observations ou des témoignages et de saisir qualitativement des substances dans un cosmos fermé ${ }^{368}$, en une philosophie hardiment déductive et créatrice d'expériences, dominée par le souci de quantifier le mouvement des corps dans un univers infini.

Quels sont donc les caractères que revêt ce passage dans le champ des disciplines naturelles?

En premier lieu, il faut noter que la révolution du XVII siècle est une révolution philosophique et non scientifique ${ }^{369}$. Ceci veut dire que la philosophie est le théâtre d'une mutation radicale, la science, au sens précis, actuel et technique du terme étant le fruit d'une évolution

A. KOYRÉ : From the closed world to the infinite universe, Baltimore, 1957.

369 Voir Chapitre VII de la $2^{\mathrm{e}}$ partie. 
qui l'institue uniquement au XIX ${ }^{\mathrm{e}}$ siècle. La philosophie naturelle est une organisation du savoir dont les traits essentiels ont été définis plus d'un millénaire auparavant. On connaît les circonstances de cette mise en ordre. Les philosophes anciens ont eu pour souci à la fois de définir leur spécialité et de déterminer le champ de leur activité. Le modèle dont ils disposaient pour parvenir à leurs fins était celui des arts, ayant pour loi la subdivision. De cette donnée ils ont fait le principe de répartition de toute connaissance et de toute application humaines. Les répercussions de ce principe se devinent aisément. La matière d'un art s'organise autour d'un objet, et l'artiste affirme son individualité grâce à cet objet et à son art. Pourquoi le philosophe ferait-il exception ? N'est-il pas tenu comme tout homme, comme tout artisan - le peintre ou le sculpteur, le géomètre ou le médecin - de délimiter le champ de son savoir, la faculté qu'il devra acquérir et qu'il lui faudra enseigner? Aristote propose une codification des disciplines, arts et philosophie, qui répond à ce souci et couronne les tentatives antérieures de Platon ou des Sophistes. Dans ce but, il détache avec netteté le savoir philosophique (episteme) de l'habileté artisanale (techne) : ce savoir peut être enseigné, il a trait aux causes, et, ayant pour seule fin la connaissance intellectuelle, il commande aux autres disciplines. Orienté par de vrais principes (archai) son mouvement intime le conduit à démontrer l'ordre des phénomènes, les raisons de leur existence, bref, à appréhender le pourquoi. La connaissance du «pourquoi » permet d'enseigner ce qui est vrai de façon claire et cohérente. Partant, une fois définie la discipline philosophique en général, on s'efforce de dégager l'objet de chacune de ces disciplines.

La métaphysique est consacrée à la recherche sur l'être : «Qu'estil pour autant qu'il est »? - délié des conditions particulières et contingentes $^{370}$; la philosophie seconde ou physique étudie la réalité du mouvement, les relations de la forme et de la matière, les causes des phénomènes, leur principe interne dans la nature. Les mathématiques à leur tour et d'autres corps du savoir sont, bien qu'imparfaitement, qualifiés et définis. Leur réunion et leur classement, qui s'imposaient, donnent sa figure presque définitive au grou-

«Sur l'objet de la métaphysique Aristote n'est pas ferme: s'agit-il de l'être commun, de l'Être ou d'êtres immatériels ?» J.M. LE BLOND : Logique et méthode chez Aristote, Paris, 1939, p. 51. 
pement de disciplines de la philosophie naturelle. En premier lieu viennent les philosophies théoriques : la philosophie première - dénommée depuis métaphysique ou théologie ${ }^{371}$ - la philosophie seconde ou physique, et la philosophie mathématique. En second lieu sont placées les philosophies pratiques qui ont trait à la conduite politique et sociale. En troisième lieu figurent les technai — les savoirs productifs de la philosophie, et non pas poétiques, comme on a tendance à les interpréter - qui contribuent à fournir les moyens nécessaires à la vie ${ }^{372}$.

La classification d'Aristote paraît à première vue claire et linéaire. Cependant, au fur et à mesure que la réflexion progresse, d'autres thèmes interviennent qui infléchissent le tableau initial. Comment peut-il séparer absolument le savoir théorique du savoir productif quand, dans son Éthique à Nicomaque, il proclame :

«L'artisan ou l'artiste, dont le travail est le produit de l'habileté exercée mise au service d'idées conçues dans la vérité, le fabricant qui sait ce qu'il doit produire et comment le produire et dans les opérations duquel la connaissance est vivante, est un scientifique, opposé au producteur qui réussit par hasard, ou grâce à un tour de main purement irrationnel ».

La physique elle-même, bien qu'elle soit intégrée aux philosophies théoriques ${ }^{373}$, est parfois incluse dans la catégorie des disciplines productives :

«Le genre de démonstration et de nécessité est différent dans la physique de celui qui est le propre des sciences théoriques ».

Affirmation que J. M. Le Blond commente ainsi :

J. OwENS : The doctrine of being in the Aristotelician Metaphysics, Toronto, 1951, pp 85 sq.

Voir les commentaires de H.H. JOACHIM sur les ouvrages d'Aristote, On coming to be and passing away, Oxford, 1922, et The Nicomachean Ethics, Oxford, 1962.

Il serait plus approprié de traduire episteme ou epistemai par «philosophie» ou «philosophies ", le pluriel n'indiquant pas une adversité de systèmes philosophiques, mais une diversité de disciplines appartenant à la philosophie naturelle. 
« Il (Aristote) attache même tant d'importance à cette démarche (des arts) qu'il lui échappe de déclarer que la physique est plutôt une science poïetique, un art, qu'une science théorique $\gg{ }^{374}$.

Ce n'est point la faiblesse du classement qui est ainsi attestée, mais la solidarité de ses parties. Au XVII ${ }^{\mathrm{e}}$ siècle la mécanique commence à le contester et tend à détrôner la physique de la place qu'elle occupait, celle de théorie des processus de changement et des modifications des corps en général. La révolution philosophique est tout entière résumée dans cette réordination de la philosophie autour de la discipline mécanique nouvellement établie.

En deuxième lieu, on assiste à une conversion des fins des disciplines naturelles. Leur objet n'est plus tant d'enseigner, c'est-à-dire d'interprêter le savoir et les phénomènes, de fournir un tableau exhaustif des informations possédées à un moment donné, que de faciliter ou de préparer l'invention.

En troisième lieu, cette philosophie inspirée par la «science de l'ingénieur », la mécanique ${ }^{375}$, exige à la fois la mesure et

374 J.M. LE BLOND : op cit. p. 330.

375 Plus fallacieuse est la perspective suivant laquelle la philosophie scolastique aurait préparé les moyens conceptuels de la philosophie mécanique. Certes, le savant ne part pas uniquement de l'expérience ou des données que fournit le monde réel immédiat. Dans la culture intellectuelle qui le précède et qui, métaphoriquement, tend vers lui, il trouve des solutions partielles, un langage, la formulation des questions. La philosophie scolastique contient de tels éléments qui ont été indispensables à la nouvelle pensée. Au cours du Moyen-Age, certains problèmes de mécanique - trajectoire des projectiles, chute des graves dans un milieu résistant — ont donné lieu à des études intéressantes, notamment celles de Thomas Bradwardine (Tractatus de proportionibus velocitatum in motibus) (Voir en général M. ClaGETT : The Science of Mechanics in the Middle Ages, Madison, 1959). On peut aussi affirmer que les critiques formulées contre les thèses d'Aristote, la représentation graphique des formes du mouvement par Nicolas Oresme sont des conquêtes durables de la connaissance. Il est cependant erroné de conclure que (a) ces acquisitions constituent le point de départ de la révolution mécanique ; (b) qu'elles ont joué un grand rôle dans l'ensemble de la philosophie naturelle et (c) ont inspiré les ingénieurs de la Renaissance et, par là, les philosophes mécaniciens.

Contra $(a)$ et $(b)$ on peut prouver que les concepts mécaniques n'occupent pas le centre de la réflexion philosophique. Les mathématiques ne sont que des sous-produits de l'exercice logique et ne conduisent pas à « des développements nouveaux et créateurs » (J.E. MURDOCH : Rationes mathematicae, Paris, 1961, p. 35). Les notions et les problèmes qui deviennent essentiels au XVII ${ }^{e}$ siècle n'ont qu'un intérêt limité au Moyen-Age ou chez Aristote. F. Solmsen observe justement : «La célébrité ou la notoriété que les doctrines de proportionnalité inverse (entre la vitesse d'un corps et la densité du milieu résistant) ont acquise est elle-même inver- 
l'instrument de mesure ; elle suppose donc l'usage de la méthode expérimentale et des règles quantifiées. Elle acquiert ainsi une unité très grande, une communauté de théories et de réalités auxquelles elle se rapporte. La philosophie naturelle était censée englober des phénomènes très divers : biologiques, chimiques, physiques, car, ainsi qu'on l'a remarqué ${ }^{376}$, elle se rapprochait des « arts pratiques » qui sont destinés aussi bien à la guérison des maladies qu'à la fabrication des objets, à l'" imitation » de la nature (peinture, sculpture) comme à son aménagement (perspective, statique, etc.). Le philosophe mécanicien s'attache à des processus matériels d'un seul ordre, tandis que le philosophe "physicien » avait à rendre compte de processus matériels appartenant à plusieurs ordres.

En quatrième lieu, les instruments mécaniques sont le résultat d'une combinaison de force et de mouvement ; tous les aspects qualitatifs des substances et des matières premières deviennent secondaires. Ceci permet la mathématisation d'une part, et la réduction de tous les changements physiques au mouvement spatio-temporel, donc la mécanisation, d'autre part. On ne traite plus de la «nature des choses », de natura rerum, mais du mouvement, de motu. Les titres des ouvrages publiés traduisent bien le déplacement de perspective.

Ascension de la mécanique, approfondissement des facultés de l'ingénieur, intérêt porté à l'invention, limitation du domaine de la recherche aux forces et aux mécanismes, sont les traits d'un renouveau dont la philosophie mécanique est l'expression ${ }^{377}$.

sement proportionnelle à leur importance dans son propre système » (celui d'Aristote). (Aristotle's system of the physical world, New York, 1960, p. 138).

Contra (c) on peut simplement rappeler que Léonard de Vinci était ingénieur, et que ces philosophes n'étaient pas ses maîtres, car il n'aurait pas trouvé chez eux l'aliment essentiel à la pratique de sa profession. C. Beaujouan a parfaitement raison quand il conclut: " Ainsi les précurseurs de Léonard de Vinci ne seraient pas tellement, comme le croyait Duhem, les scolastiques parisiens qu'il n'a pas lus, mais plutôt les ingénieurs de la fin du Moyen-Age » (in R. TATON, La science antique et médiévale, Paris, 1957, p. 572).

376 A. CROMBIE : Robert Grosseteste and the origins of experimental science, Oxford, 1953.

377 S. Moscovici : Signification de la mécanique pré-galiléenne à la Renaissance, in Saggi su Galileo, Florence, 1968. 


\section{La mécanique au centre de la philosophie}

$\underline{\text { Retour à la Table des Matières }}$

\section{Le problème historique.}

Celui-ci a été formulé ainsi : «Pourquoi les sciences mathématiques et mécaniques, en particulier l'étude des lois du mouvement, en sont-elles venues à dominer $\left(\mathrm{au} \mathrm{XVII}{ }^{\mathrm{e}}\right.$ siècle) la dernière partie de la révolution scientifique ? ${ }^{378}$. Les raisons de s'interroger à ce sujet sont évidentes, Un observateur impartial constate que, depuis le $\mathrm{XV}^{\mathrm{e}}$ siècle, l'effervescence intellectuelle et technique est générale. Tout comme les arts mécaniques, les arts chimiques, la médecine, la zoologie, connaissent un essor sans précédent. Pourtant, seules les disciplines mécaniques et mathématiques provoquent une modification ${ }^{379}$ assez radicale et assez remarquable pour être qualifiée de révolution.

Pour comprendre les causes de ce développement, il est nécessaire de le rapporter au processus de transformation, par division, des catégories naturelles. A la période dont nous nous occupons, il se produit, (ainsi que je l'ai décrit), une séparation de l'artisan-ingénieur d'avec l'ensemble de l'artisanat existant. Une expression individualisée est également conférée aux liens qu'il entretient avec le monde matériel et à ses disciplines spécifiques, à savoir les disciplines mathématiques et mécaniques. Il en résulte nécessairement une réorganisation, en fonction de celles-ci, de la totalité du groupement de disciplines naturelles. Les connaissances et les facultés qui ne sont pas en relation directe avec cette catégorie naturelle, les ressources complémentaires

378

379

A. CROMBIE : art. cit. p. 66.

Il n'est pas question d'attribuer exclusivement ce fait à des facteurs sociologiques. Le capitalisme naissant s'intéresse davantage au commerce qu'à la production, ses investissements dans l'extraction de l'alun, donc ce qu'on pourrait appeler aujourd'hui l'industrie chimique, sont aussi importants, sinon plus, que dans l'invention des mécanismes. La navigation a encouragé la fabrication des instruments mathématiques et les travaux d'astronomie. Cependant, aucun grand artiste ou ingénieur n'a fait de contribution active à l'amélioration des constructions navales, ou aux questions relatives à la navigation en général. Quant aux écoles, importantes, d'Espagne et du Portugal, qui se sont préoccupées de ces questions, elles ne constituaient pas des centres techniques ou philosophiques marquants. 
auxquelles elles sont associées, restent à l'état embryonnaire et ne participent pas à l'institution des fondements de l'état de nature correspondant, la nature mécanique. D'où, malgré leur importance, l'écart constaté.

Par voie de conséquence, les communautés de savants qui portent au plus haut point les connaissances et les inventions qui ont marqué cette époque s'inscrivent dans la continuité de l'ingénieur, du mécanicien, établissant une subdivision de la catégorie naturelle ${ }^{380}$. Dans la création de son travail, dans la structure des habiletés indispensables à la construction des instruments, au pompage des eaux, au levage des poids ou à la balistique, apparaît l'exigence d'une procédure expérimentale et quantitative et de règles mathématiques :

«Les artistes de la Renaissance étaient en premier lieu des artisans et ils devinrent savants, non parce que leur génie supérieur anticipait les destinées modernes de la science, mais parce que certaines branches de la connaissance scientifique, telles que l'anatomie, la perspective ou la mécanique, étaient considérées comme des exigences nécessaires au développement de leur métier ${ }^{381}$.

Ce mouvement interne oriente les mécaniciens vers l'amélioration de leur savoir-faire, et ils prennent ainsi un grand intérêt aux connaissances existantes, notamment dans les écrits d'Archimède, de Héron

L'échange entre philosophes et artisans est particulièrement intense au XVII ${ }^{\mathrm{e}}$ siècle. Les intérêts réciproques, l'unité des idéaux sont reconnus, les différences aussi. Beaucoup de savants qui ne font pas partie de l'université ou y sont mal rétribués trouvent auprès des artisans un nouveau public. Les artisans, de leur côté, considèrent les branches de la philosophie mécanique comme un domaine qui leur est ouvert pour exprimer ou expliquer leur point de vue. Ces philosophes eux-mêmes leur sont nécessaires. Les besoins en matière de mathématique et de mécanique sont évidents, et la difficulté d'acquérir des connaissances est grande pour ceux qui ne savent ni le latin ni le grec. Ils demandent qu'on écrive pour eux. Ni Descartes, ni Galilée, ni Torricelli, ni Roberval n'hésitent à le faire. Recorde, Dee et Digges, en Angleterre, savants et ingénieurs, écrivent pour ceux qui manquent de l'éducation nécessaire à leur art. Robert Norman le dit : "Car bien qu'ils n'aient la possibilité d'employer la langue grecque et la langue latine pour étudier les auteurs variés dans ces arts, ils ont en anglais, pour la géométrie, les Éléments d'Euclide, avec des démonstrations absolues; et pour l'arithmétique des Cuvres de Recorde, la première aussi bien que la seconde et divers autres, aussi bien en anglais que dans d'autres langues vulgaires, qui ont aussi écrit sur ce sujet, livres qui suffisent au mécanicien industrieux pour le rendre parfait et le préparer dans ces sciences, mais en particulier pour les appliquer à l'art ou à la faculté dont il fait principalement profession ».

381 P.O. KRISTELLER : Humanism and scholasticism, Byzantion, 1944-45, 17, p. 373. 
ou de Vitruve. S'ils renouent avec l'antiquité, c'est avec une partie de celle-ci, avec cette partie qui, à Alexandrie ou à Syracuse, a vu s'établir les premières notions et les premières méthodes indispensables au talent de l'artiste-ingénieur. $\mathrm{Au} \mathrm{XV}^{\mathrm{e}}$ et au XVI ${ }^{\mathrm{e}}$ siècles, ce sont eux qui, détenant les connaissances essentielles, prennent l'initiative d'inaugurer une façon originale de saisir la réalité.

«C'est Brunelleschi, dit Giorgio di Santillana ${ }^{382}$, qui semble définir le chemin de la science pour sa génération ».

Et il démontre, à l'aide d'arguments convaincants, jusqu'à quel point la démarche expérimentale, la mathématisation des arts, contiennent in nuce les éléments décisifs du renouvellement ultérieur de la philosophie.

« Derrière elle (la pensée galiléenne) on pouvait voir à l'œuvre des facteurs très différents : le travail de l'ingénieur et la ligne archimédéenne de pensée, par exemple $»{ }^{383}$.

Léonard de Vinci, Cardan, Tartaglia, Benedetti, Stevin, ingénieurs et inventeurs, soutiennent cette progression constante de l'activité savante, avant qu'un Galilée, un Descartes, un Huygens, en fassent un champ spécialisé, en liaison avec celui des hommes qui se vouent à l'art mécanique, mais distinct de lui ${ }^{384}$. Le siècle de la révolution mé-

382

383

384

G. de Santillana: The role of art in the scientific Renaissance, in M. ClagetT, Critical problems in the history of science, Madison, 1959, p. 34.

Ibidem, p. 39.

De ce chevauchement entre le domaine du nouveau type de philosophe et celui de l'ingénieur, nous avons maint exemple. D'une part on remarque la volonté du mécanicien d'être assimilé, d'être considéré comme philosophe. Zeising (op. cit. p. 21) le revendique clairement : «On vient d'indiquer que la mécanique emprunte ses vrais principes à la mathématique et à la philosophie naturelle. On peut en conclure que celui qui invente de telles machines artistiques n'est pas inculte et doit être adroit ; c'est pourquoi les inventeurs des choses artistiques étaient rangés parmi les philosophes ». D'autre part, il semble que le fait, pour un savant, un philosophe mécanicien, d'être qualifié de mathématicien, suffise à le rapprocher de la classe des ingénieurs et à l'y associer. Ainsi lorsque Louvois écrit à Christian Huygens en lui décernant l'épithète de mathématique, le père de celui-ci s'indigne : «Je ne croyais pas avoir des gens de métier parmi mes enfants. Il (Louvois) semble le prendre pour un ingénieur de ses fortifications ». Et John Wallis pouvait écrire rétrospectivement : «Les mathématiques à cette époque chez nous n'étaient guère considérées comme études académiques, mais plutôt comme mécaniques ». 
canique est aussi, strictement parlant, le siècle du partage de la catégorie naturelle en couche productive et en couche savante, avec pour conséquence l'apparition de deux groupes de disciplines distincts. Se dégageant de l'art de l'ingénieur au XV ${ }^{\mathrm{e}}$ et au XVI ${ }^{\mathrm{e}}$ siècles, les mathématiques et l'expérience systématique prennent leur essor et acquièrent de l'importance. L'invention et la constitution de l'habileté jouent un rôle primordial, les notes de Léonard de Vinci, les écrits de Benedetti sont là pour nous en convaincre. Les couches sociales, pour lesquelles l'action de l'ingénieur s'intègre aux moyens dont elles tirent leur richesse sur le plan social et leur pouvoir politique, ne peuvent qu'encourager ces tendances, visant à rendre intelligible le monde matériel sur lequel elles assoient leur domination et à leur permettre de le maîtriser.

C'est de là que vient l'impulsion qui anime la philosophie mécanique et sa rupture avec la quintessence de la philosophie naturelle a pour cause directe la situation de ces « artisans supérieurs », lorsque le processus naturel atteint un certain stade d'évolution.

Retour à la Table des Matières

\section{La crise de la hiérarchie des disciplines dans la philosophie na- turelle.}

La mécanique prend, disais-je, la place de la physique, tel est le signe du renouveau. Dans l'architectonique de la philosophie naturelle, à laquelle Aristote a donné une forme durable, les disciplines ou « epistemai » sont classées, on vient de le voir, en théoriques, pratiques et productives. Parmi les disciplines théoriques, celles qui ont trait aux phénomènes "physiques » sont la clé de voûte. Elles décrivent et expliquent toutes les variétés de changement, y compris le mouvement, les rapports généraux de la forme et de la matière, ouvrant la voie à la métaphysique qui, d'un certain point de vue, est un degré supérieur de la physique, son noyau le plus abstrait. La mécanique ne figure pas au nombre des matières contenues dans la physique. Au Moyen Age ${ }^{385}$ pas plus que dans l'antiquité, les phénomènes rela- 
tifs à l'optique, la statique, les machines simples ne sont traités dans le cadre de la discipline théorique principale. Ce n'est point un hasard. Chez Aristote, la mécanique est une connaissance inférieure, qui reste

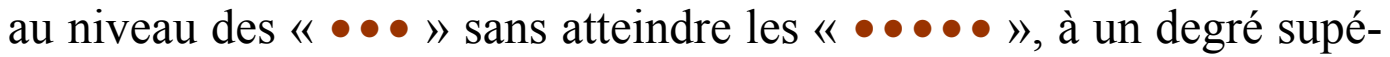
rieur. Pourtant, dans l'école aristotélicienne même, d'autres savants s'en sont préoccupés; le fruit de leurs études est un petit recueil, un écrit mineur dans le corpus de la philosophie, intitulé Problèmes mécaniques. Très longtemps négligé, cet écrit accompagné de commentaires commence à reparaître au XVI ${ }^{\mathrm{e}}$ siècle. Sa publication correspond sans nul doute à l'importance qu'a prise le mécanicien, à la multiplication d'une littérature qui lui est consacrée. On remarque ainsi l'éclosion d'un centre d'intérêt original, une volonté de "moderniser » la pensée d'Aristote ou, tout au moins, de mettre, l'accent là où l'époque l'exige. N'est-ce pas aussi l'indice d'un besoin de réorganiser l'architecture du système des disciplines philosophiques, de procéder à une révision de leur classification? Ceci se révèle d'entrée de jeu à quiconque lit la préface rédigée par le commentateur d'un de ces ouvrages intitulés «In mechanicas questiones Aristotelis ».

L'auteur de la préface se fixe pour première tâche de justifier la Mechanicam facultatem ${ }^{386}$, la faculté mécanique, de prouver sa noblesse et d'inciter à la prendre en considération. Qu'est-ce que la mécanique ? Essentiellement une science construite autour de l'instrument mathématique.

« Donc, puisque la discipline mécanique, écrit A. Piccolomini, emploie un instrument et un moyen mathématiques, il ne doit faire de doute pour personne qu'elle se range très commodément sous la géométrie. Or j'appelle discipline des ouvrages mécaniques celle dont peuvent être tirés les causes et les principes qui ont trait à plusieurs arts sédentaires, arts qui, du reste, sont couramment appelés mécaniques, mais à tort ; car ils devraient plutôt être appelés sédentaires, ou artisanaux, ou vils. C'est pourquoi ces arts doivent beaucoup au secours des mécaniciens, puisque c'est avec leur aide que sont inventés de très nombreuses machines et de très nombreux instruments, pour le foyer et pour la guerre ${ }^{387}$. 
La description du contenu de la mécanique, si on la compare à celle qu'en a donnée l'auteur des Problèmes mécaniques, est neuve. Elle reconnait l'importance de l'instrument, de l'invention, et l'ascendant du mécanicien. Si le savant aristotélicien en tient compte, c'est à cause de l'ampleur prise par cette nouvelle classe qui avant lui, a publié des ouvrages sur les machines et les instruments "pour le foyer et pour la guerre ». Reconnaître le rôle particulier de l'ingénieur, embrasser le domaine de ses connaissances, la faculté mécanique, prôner une nouvelle hiérarchie des disciplines, ce sont les symptômes d'une adaptation indispensable de la philosophie naturelle.

Une fois cette tendance signalée, consignée, le commentateur nous fait pénétrer au cœur du sujet en exposant le contenu de l'écrit aristotélicien. Parfois, il s'agit d'une paraphrase, parfois d'une traduction de l'ouvrage grec, ou d'un traitement différent des mêmes questions, assimilant certains travaux extérieurs à la tradition, ceux d'un Guidobaldo, d'un Tartaglia, d'un Cardan. De Piccolomini à Bernardino Baldi, toutes les combinaisons se rencontrent dans ces ouvrages. L'esprit cependant n'en est pas véritablement neuf. Ainsi Piccolomini dispute sur la «dignité de la figure du cercle», afin de rendre compte des propriétés des machines simples. Il attribue toujours l'incomparable efficacité du levier aux propriétés du cercle, c'est-à-dire à la possibilité d'être engendré simultanément par quelque chose qui se meut et par quelque chose qui reste en son lieu. Contre cette idée, Simon Stevin, armé des principes de la statique, réagit vigoureusement. Nulle part on ne sent le commentateur animé par la volonté d'apporter une contribution originale, de mesurer ou d'inventer, d'exposer une loi ou une invention. La mise en ordre, la discussion, la transmission d'un savoir enseveli paraissent seules le préoccuper. En cela il fait œuvre utile. On observe toutefois une mise en commun des résultats de l'école du Stagirite, de ceux de Pappus et des mécaniciens modernes, c'est-à-dire une confrontation, une réunion en un corpus de travaux d'ordre mécanique. Le commentateur ne fait pas que gloser en marge d'Aristote, il met à la disposition de son lecteur les diverses solutions données à un même problème et rapporte, plus rarement, des observations, s'il y a lieu. 
Une étude attentive des ouvrages de ces commentateurs montre qu'ils ont eu le triple mérite de systématiser les informations ayant trait à la mécanique, d'avancer quelques hypothèses à propos de certaines manifestations du mouvement, et surtout d'évoquer l'existence d'un tournant, d'un effort d'adaptation à l'intérieur de la philosophie naturelle. L'orientation de leurs études est claire : rendre la mécanique philosophique.

«Qu'est-ce que la mécanique? se demande Monantholius. C'est la somme de tout ce qui est expliqué dans ce premier chapitre mais moins parfaitement ; parce qu'on montre la raison, non de ce qu'est la mécanique, mais que c'est un art admirable, et le cercle de toutes les choses admirables qui s'y font; en outre on enseigne aussi que les problèmes de mécanique sont en partie physiques, en partie mathématiques ${ }^{388}$.

Cependant, tout n'est pas aussi simple. La mécanique, du point de vue du classement aristotélicien des disciplines, est une science productive et socialement inférieure, comme tous les arts productifs. A coup sûr, elle est liée aux mathématiques, à la physique, mais quelle est sa place entre ces deux sciences philosophiques, théoriques ? L'obligation est évidente de situer la mécanique dans l'ensemble des disciplines naturelles où elle ne figurait pas auparavant. Mais la difficulté est tout aussi évidente, et nous en trouvons un témoignage, entre autres, dans la copieuse introduction mise par G. de Guevara en tête de son ouvrage In Aristotelis mechanicas Commentarii, qui fait ressortir quelques caractères intéressants de la situation nouvellement créée lorsque la mécanique devient une discipline importante.

Pour lui, il faut commencer par définir clairement, la « faculté mécanique » qui vient d'affirmer son individualité, afin de déterminer

« si une telle attitude ou faculté est vraiment en soi et peut porter à juste titre le nom d'art ou de science $»{ }^{389}$. 
Autrement dit, il s'agit de savoir si elle peut être acceptée parmi les disciplines philosophiques ou parmi les disciplines productives. Les textes d'Aristote sur lesquels s'appuie le commentateur ne sont pas explicites, et, selon l'optique adoptée, la "faculté mécanique » peut être classée dans les deux familles de disciplines. Guevara accorde à la mécanique le statut non d'un art mais d'une discipline pratique :

« Il faut dire que la faculté mécanique n'est pas une science théorique mais pratique... Car aucune proposition mécanique, prise en soi, n'est théorique, en ce sens qu'elles peuvent résider dans la seule vérité, néanmoins, en raison de la connexion qu'elles ont avec d'autres pratiques et de l'ordre qu'elles incluent en même temps pour la pratique, en vérité elles constituent une science tout entière pratique ${ }^{390}$.

N'étant pas théorique, la mécanique ne peut pas atteindre un rang très élevé comparée à la logique, à la philosophie morale. Dans le classement existant, elle n'est pas subordonnée à la physique mais aux mathématiques ${ }^{391}$.

Le développement d'une faculté spécifique, la constitution d'une «science de l'ingénieur» est donc un facteur de crise pour l'édifice de la philosophie naturelle. Auparavant, elle n'était ni un art ni une discipline philosophique, maintenant elle semble être l'un et l'autre.

Par ailleurs, comment lui faire une place parmi les disciplines naturelles ? Dans la perspective de la nature organique, de la philosophie qui en élabore le contenu, la mécanique n'a pas trait à ce qui est naturel mais à ce qui est artificiel.

« Pour cela, dit-il, les problèmes mécaniques et les problèmes naturels ou physiques ne procèdent pas de la même façon ni suivant la même raison » ${ }^{392}$.

390 des mathématiques, en vue de prouver que c'est une science tirée de l'une et de l'autre : si on l'examine bien, cela n'a aucun poids ». Idem p. 24.

G. de GuevarA : op. cit. p. 5. 
La différence est d'importance : pour le savant qui suit les principes établis, les connaissances mécaniques ne concernent pas les processus matériels; elles sont surtout cantonnées dans le domaine des instruments inventés. Les associer à la physique, ce serait contester les soubassements de l'ordre naturel, la structure même du groupe de disciplines, accepter un rapport dissymétrique de l'homme à l'univers objectif. Bref, ce serait attribuer à la nouvelle catégorie naturelle une prééminence qu'elle n'avait pas aux yeux de ce philosophe et lui reconnaître la capacité de dire le vrai au sujet des lois du monde.

\section{Retour à la Table des Matières}

\section{La place de la mécanique.}

Cette prétention à dire le vrai et à le prouver par leurs œuvres était commune à tous les mécaniciens et philosophes mécaniciens. Ils reprochaient à leurs adversaires de tourner le dos à la nature, et de se fier uniquement à l'autorité des livres. C'est qu'entre temps, dans leur champ d'action, l'état de nature dont parlaient ces livres commençait à perdre pied et ne correspondait plus à leur expérience, à leurs habitudes intellectuelles, aux ressources matérielles et inventives dont ils avaient connaissance. Les carnets de notes, les manuscrits et les traités consacrés aux fortifications, aux machines, à l'architecture, à la perspective, leur avaient déjà fait prendre de l'espace et de la matière une vue qui ne concordait plus avec les préceptes admis. L'invention leur avait désappris l'imitation, et la reproduction de leur talent les avait détachés de l'obéissance au maître. Cette dernière était une erreur à laquelle il fallait porter remède, comme allait dire Thomas Spratt, car

« jusqu'ici le siège de la connaissance n'a pas été dans les laboratoires, comme il devrait l'être, mais seulement dans les écoles, où certains ont enseigné et tous les autres souscrit ». ${ }^{393}$

De même que le moulin a introduit la mécanique dans le milieu où seules dominaient la force et l'agilité, le canon a fait pénétrer la dy-

393 Th. SPRATT : The history of the Royal Society, Londres, 1734, p. 68. 
namique dans la mécanique, et l'horloge a donné à l'instrument et à la mesure un domaine d'application universel. Les mathématiques ont suivi le mouvement. Mais tout ce qui avait trait à cette vaste zone d'intérêts était taxé de " mécanique » et donc étranger à la philosophie ou exclu d'elle. Les ingénieurs furent aussi de véritables mathématiciens, et parfois la réciproque était vraie. Qualifier quelqu'un de mathématicien ou le qualifier d'ingénieur revenait à peu près au même. Durant les siècles précédents, les mathématiques étaient une matière d'étude accessoire et sa pratique n'était nullement encouragée. Son seul mérite était d'occuper les loisirs des étudiants, et l'université de Vienne (ce n'est qu'un exemple) les recommandait pour empêcher la débauche :

« Nous estimons préférable, dit un décret, que nos étudiants passent leurs jours de congé à fréquenter les écoles plutôt que les tavernes et disputent au moyen de leur langue au lieu de combattre avec leur épée ; nous désirons par conséquent que les jours de congé, après dîner, les bacheliers de notre université disputent et s'instruisent «gratuitement», pour l'amour de Dieu, sur le computus et autres branches des mathématiques, en insistant toutefois sur tout ce qui peut servir l'Église catholique ».

Les « hommes sans lettres» avaient une obligation plus pressante, celle de résoudre les problèmes de leur profession, d'améliorer leur art d'inventer, afin d'assurer leur subsistance ou leur gloire. Dans cette voie, ils ont fait de grandes découvertes. Les lois de la matière commençaient à poindre à travers leurs règles, et quelques-unes de cellesci étaient destinées à se muer en principes essentiels. Ils savaient, parce qu'ils en faisaient chaque jour l'expérience, que les artifices leur ouvraient la porte de réalités inconnues. Galilée fut le premier à pointer la lunette vers le ciel, mais bien avant, Léonard de Vinci avait songé à cette possibilité de découverte, en s'interrogeant sur l'usage de simples lentilles ${ }^{394}$.

Les mécaniciens ne cherchaient donc pas à savoir, comme les savants commentateurs, si la mécanique s'occupait de phénomènes naturels ou artificiels, ou si on pouvait bâtir une connaissance théorique

394 Voir C. PEDRETti : Leonardo on curvilinear perspective, Bibl. d'Humanisme et Renaissance, 1963,25, p. 85. 
sur les mathématiques, celles-ci partageant le sort de celles-là. Au contraire, ils paraissaient convaincus de la nécessité de rendre la philosophie mécanique, c'est-à-dire de l'asseoir sur le calcul, la mesure, la règle, d'instituer, selon l'expression de Benedetti, une " philosophie mathématique ». Leur intention n'était pas de «commenter» les Problèmes mécaniques — c'est là un idéal d'enseignant, non pas d'inventeur - ils critiquaient ces problèmes et voulaient leur substituer ceux d'une autre mécanique.

L'œuvre maîtresse de J. B. Benedetti, « Diversarum speculationum mathematicarum et physicarum liber », parue en 1585, ne débute pas par une «Défense et illustration » de la mécanique, une revendication de sa place parmi les disciplines. J. B. Benedetti nous dit comment, sans avoir suivi les écoles — n'est-il pas en premier lieu mathématicien et ingénieur ? - il est arrivé à savoir ce qu'il sait, et auprès de qui il a appris les mathématiques et la mécanique. Il ne paraît pas pressé de présenter sa philosophie. Son ouvrage emprunte la forme d'un recueil de questions et de réponses d'ordre mathématique et mécanique. Aussi expose-t-il, pour commencer, des théorèmes d'arithmétique. Ensuite il traite De Rationibus operationum perspectivae. L'écrit De Mechanicis qui suit résume les connaissances du temps et présente une critique de Tartaglia dont Benedetti relève les erreurs. D'Aristote, il dit « il s'est trompé », et il ne lui ménage pas les sarcasmes. La pièce de résistance de l'ouvrage, ce qui lui donne son poids historique, ce sont bien ces Disputationes de quibusdam placitis Aristotelis. La teneur des arguments est connue.

Ils débutent par la réfutation de la thèse aristotélicienne au sujet de l'impossibilité du vide : "Volens Aristotelis probare vacuum non esse in rerum natura » (Aristote voulant prouver que le vide n'existe pas dans la nature...) Ici point de détour, aucune paraphrase. La proposition vise à l'essentiel. Une fois l'existence du vide théoriquement c'est-à-dire géométriquement — démontrée, avant qu'elle le soit expérimentalement, l'ensemble des conceptions d'Aristote quant aux propriétés du mouvement peut être confortablement mis en question. La critique de Benedetti n'est pas physique, mais elle est mécanique et mathématique. En effet, elle n'envisage pas tous les mouvements, tous les changements qui sont étudiés de façon solidaire dans la physique 
d'Aristote. Seul lui importe le mouvement local. L'erreur commise à son sujet suffit à discréditer l'ensemble.

Désormais, le progrès de la mécanique est déterminé par cette critique : en avaliser les résultats constitue la tâche d'avenir. Une chose est certaine les corsi e ricorsi des siècles précédents ne sont plus possibles. N'a-t-on cependant pas dit à Benedetti que ces «sciences mécaniques », nourries de calcul et de notions relatives aux artifices, n'ont aucun titre à faire valoir sur le plan de la théorie, de la philosophie ? A quoi il riposte, dans une épître à Dominique Pisano ${ }^{395}$, qu'elles ont ces titres; c'est une erreur de méconnaître leur importance philosophique et d'exclure le mathématicien du cercle des philosophes, car il en est un, et sa philosophie est des plus prometteuses de certitude :

« Je m'étonne que toi, qui es versé dans Aristote, tu sépares dans tes écrits le philosophe du mathématicien, comme si le mathématicien n'était pas tellement philosophe naturel (physicien) et métaphysique qu'il mériterait bien plus que celui-là le nom de philosophe si nous considérons la vérité de ses conclusions. Il est vrai que tu n'es pas seul dans cette erreur ; mais elle est plus grave parce que, alors que vous voyez que même les choses morales tombent sous l'appellation de philosophie, vous ne remarquez pas que les divines sciences mathématiques doivent être aussi honorées du nom de philosophie. Si nous voulons mieux examiner le nom, nous trouverons qu'il convient au mathématicien bien mieux qu'à n'importe qui d'autre... »

J. B. Benedetti revendique la dignité qu'on lui refuse et proclame que son savoir, celui du mathématicien et du mécanicien, est la véritable base, la véritable matière première de la philosophie. C'est en se fondant sur lui et sur toute cette cohorte de nouveaux philosophes que Descartes entreprend de bouleverser la philosophie :

« Je me plaisais surtout aux mathématiques, raconte-t-il dans le Discours de la Méthode, à cause de la certitude et de l'évidence de leurs raisons ; mais je ne remarquais point leur vrai usage, et pensant qu'elles ne servaient qu'aux

395 J.B. BENEDETTI : Diversarum speculationum mathematicarum et physicarum liber, Turin, 1585 , p. 298. 
arts mécaniques, je m'étonnais de ce que, leurs fondements étant si fermes et si solides, on n'avait rien bâti dessus de plus relevé ${ }^{396}$.

Benedetti et Descartes s'accordent sur l'essentiel. Le premier a revendiqué l'attention pour les fruits de ses inventions intellectuelles, les siennes et celles de ses semblables, le second a blâmé la philosophie d'avoir négligé ce qui était si fécond dans les arts mécaniques, et de ne pas s'être attaché ouvertement à ceux-ci, en se donnant les mêmes moyens qu'eux. Que l'un affirme le caractère philosophique de son art, et que l'autre sente la nécessité de bâtir une philosophie à partir justement de cet art et non pas d'un autre ce sont deux moments de l'évolution d'une conscience commune.

Dans le monde des artifices et celui du calcul, réunis, ils aperçoivent à la fois le monde de la nature et celui de la raison ${ }^{397}$. La voie avait déjà été ouverte par Nicolo Tartaglia qui, dans la «Science Nouvelle» avait dévoilé le caractère théorique, philosophique, de l'artillerie et du canon. Avant lui, les ingénieurs décrivaient des machines, des bombardes, ou en donnaient les recettes d'utilisation. Les philosophes naturalistes considéraient le cas de la trajectoire d'un boulet comme un exemple, un cas parmi d'autres. D'une façon générale, les machines constituaient un monde à part, soit comme activité technique, soit comme objets propres à nourrir la méditation du philosophe. On énumérait leurs effets et on remarquait leur incompatibilité avec les enseignements courants de la physique aristotélicienne. Personne ne cherchait dans ces artifices, et seulement en eux, les lois de l'ordre naturel. Or, Nicolo Tartaglia crée sa « science nouvelle » à partir d'une analyse du mouvement et de sa génération, dont le moyen lui paraît être précisément le canon, machine et instrument de mesure car le canon en est un. Son travail complète celui de l'ingénieur en ce qu'il ne considère pas l'instrument technique comme instrument pur et simple, et s'éloigne de celui du philosophe naturaliste par le choix

396

397

R. Descartes : Euvres, t. 6, p. 7.

«L'un des objets pratiques, et le principal, de la Mécanique et de la Physique, a été précisément, dès l'origine de ces sciences, de reconnaître quels sont les divers corps qui peuvent être substitués à l'homme ou à l'animal pour favoriser ou pour entraver une certaine modification ; quelles sont les machines qui peuvent remplacer les ouvriers ou les bêtes de somme dans l'accomplissement d'un certain ouvrage. La mécanique s'est d'abord appelée la science des mécaniques ». P. DuHEM : Traité d'énergétique, t. I, Paris, 1911, p. 81. 
qu'il fait en recherchant dans cet instrument les assises sûres d'une connaissance des phénomènes matériels. Ce faisant, il inaugure un courant de pensée qui a pour fin de dévoiler les principes de l'univers dans les mécanismes et de rendre ces mécanismes en quelque sorte naturels. Archimède n'avait pas franchi ce pas. En effet, dans ses traités, il ne considérait pas le mouvement en lui-même, mais la machine qui le produit, et, conformément à l'esprit grec, non pas la machine en action mais la machine au repos. D'emblée, dans son écrit, Tartaglia rompt avec ces arguments traditionnels fondés sur les qualités physiques, les éléments, etc. Il envisage les mobiles suivant leur gravité ou la résistance qu'ils rencontrent. Il s'engage ainsi sur la voie d'une sorte d'homogénéisation de la matière, dont ne sont plus retenues que les variations quantitatives. Les effets de cette homogénéisation sont visibles : la distinction entre les diverses formes de changement et les mouvements spatio-temporels disparaît. Ceux-là se réunissent à ceuxci, la physique devient mécanique. Le mouvement local, c'est-à-dire le déplacement dans l'espace, espèce particulière de mouvement dans la philosophie naturelle, devient le mouvement tout court.

Descartes en tire les conséquences ${ }^{398}$ et, à l'encontre de ceux qui excluaient la mécanique, pour les motifs que j'ai examinés plus haut, il l'installe au centre de la philosophie, la substituant à la physique, dont le contenu subit un bouleversement radical.

« Mais encore que, écrit-il le 30 avril 1639 à Debeaune, toute ma physique ne soit autre chose que mécanique $» . .$.

Rien ne l'empêchait de voir dans celle-ci l'expression de l'état de nature. Il ne pouvait pas, il ne pouvait plus, faire siennes les réticences d'un Guevara. Il n'était plus question d'opposer les artifices et leurs principes à ceux de la nature, d'écarter du domaine de la physique l'art des mécanismes : 
«Et il est certain que toutes les règles des Méchaniques, déclare Descartes dans un passage justement célèbre, appartiennent à la Physique, en sorte que toutes les choses qui sont artificielles, sont avec cela naturelles $\gg{ }^{399}$.

$* * *$

Aucun individu, aucune classe sociale, aucune catégorie ne veut ni ne peut voir, puisqu'ils en sont les sujets, le caractère éphémère, convertible, de sa personnalité, de sa société, de sa nature. Et lorsqu'ils regardent vers leur histoire, ils n'observent que sa venue vers eux, forme achevée d'un passé qui les préfigure et d'un avenir qu'ils symbolisent. Le philosophe naturaliste et l'artisan, héritiers et auteurs de tant de réalités accomplies, se sentaient de droit dans leur nature, et n'avaient à douter ni de sa perdurabilité, ni de sa généralité. En près de trois siècles, l'art de l'ingénieur s'augmente, se transforme, se cristallise. Son lien à la matière, son état naturel et technique est là, prêt à éclore. Pour ce faire, il est nécessaire, et c'est une exigence de l'évolution historique et du sujet qui la porte, que le groupement de disciplines éclate et se structure à nouveau. La mécanique au lieu de la physique $^{400}$, voilà le point de départ d'une controverse qui n'avait rien de théorique. La lutte d'un Jean Mignot ou d'un Brunelleschi contre les méthodes de travail et l'esprit des maîtres-maçons n'est pas différente de celle d'un Galilée ou d'un Descartes contre les philosophes de l'École. Si la première a pour prétexte une cathédrale, la seconde a pour cadre l'univers. La réussite de celle-là a pour résultat une nouvelle délimitation des frontières qui séparent les arts ; l'éclat de celle-ci entraîne la refonte des disciplines naturelles dans leur ensemble ${ }^{401}$.

399

400

¿ Ce n'est guère avant le XVII ${ }^{\mathrm{e}}$ siècle que la mécanique — qui au siècle précédent n'était guèr plus qu'une branche subordonnée de la connaissance traitant des problèmes élémentaires relatifs à l'équilibre des forces d'un corps et à leur application technique ne dépassant pas de simples types d'outils — se développa en une vaste étude du mouvement occupant la position centrale dans le monde des sciences naturelles ». R. J. FORBES et E. J. DiJKSTERHUIS : op. cit. p. 322.

401 Tout observateur de cette « révolution philosophique » est forcé de reconnaître ce phénomène de transformation fondamentale de l'ordre naturel, parallèle à la transformation du groupement de disciplines. Le P. Lenoble écrit : «Le passage d'un type de Nature à l'autre, d'un type de science à l'autre, suppose donc, on le conçoit sans peine, une modification « en pro- 
Dans nos manuels, on dit que la technique a exercé une influence sur la philosophie. Expression bien pauvre et erronée à la fois. Nous l'avons montré, c'est une véritable transformation. Le personnage réel de l'ingénieur donne naissance à celui du philosophe mécanicien. En apparaissant, ces savants se séparent de leur milieu antérieur pour s'intéresser à la création du travail centrée sur les forces matérielles non-humaines, les instruments et les mécanismes. Dans la faculté qui y est à l'œuvre, ils n'ont pas de peine à reconnaître une faculté naturelle, et c'est leur mission d'en faire la preuve et d'en tirer les conséquences.

Retour à la Table des Matières

fondeur », de la mentalité scientifique, — et de la mentalité tout court ». in M. DAUMAS : Histoire de la science, Paris, 1957, p. 370. 


\section{Chapitre V.}

De l'univers de la machine à la machine de l'univers :

\section{Le philosophe mécanicien}

I. Le philosophe constructeur d'instruments mathématiques et doctrinaire de l'art d'inventer

Retour à la Table des Matières

\section{Le but du philosophe mécanicien.}

On sait en quoi consiste la révolution philosophique : la mécanique est venue au centre des disciplines philosophiques, et les mathématiques, sur lesquelles elle s'appuyait, se sont substituées à la logique en tant qu'organon commun «aux sciences et aux arts ». Il ne faut cependant pas perdre de vue que cette révolution affecte le sens qui s'attache désormais à l'ensemble de la philosophie, et que le but de celle-ci se trouve défini de manière nouvelle. C'est encore Descartes qui, dans une de ces formules concises dont il a le secret, nous informe que

« ce mot philosophie signifie l'étude de la sagesse, et que par la sagesse on n'entend pas seulement la prudence dans les affaires, mais une parfaite connaissance de toutes choses que l'homme peut savoir, tant pour la conduite de sa vie que pour la conservation de sa santé et l'invention de tous les arts $\gg{ }^{402}$. 
Le philosophe n'écrit donc pas pour enseigner ou systématiser un savoir existant. Sa plus grande gloire est d'ouvrir la chaîne des découvertes, de rendre possibles celles des générations ultérieures. La manière dont Descartes conclut sa Géométrie en est une indication précieuse. Après avoir fourni les éléments qui peuvent mener à la découverte, comme les instructions et les règles qu'il a données dans la Dioptrique, il termine :

«Car en matière de progressions mathématiques, lorsqu'on a les deux ou trois premiers termes, il n'est pas malaisé de trouver les autres. Et j'espère que nos neveux me sauront gré, non seulement des choses que j'ai ici expliquées, mais aussi de celles que $\mathrm{j}$ 'ai omises volontairement, afin de leur laisser le plaisir de les inventer ${ }^{403}$.

Tous les philosophes pratiquent l'art d'inventer et en célèbrent les bienfaits. Ils se voient octroyer des privilèges pour des inventions et cherchent à en établir la priorité. L'époque des combats d' " écoles » en philosophie, suivant le vœu de Leibniz ${ }^{404}$, touche à sa fin. Celle de la concurrence entre savants commence. Les contestations de priorité, les défis lancés, les concours dont le lauréat est couronné par la reconnaissance de ses pairs, prennent la place des anciennes disputes. Voici Pascal qui intitule un opuscule Lettres de A. Dettonville contenant quelques-unes de ses Inventions de Géométrie (Paris 1659), et le destine à ceux qui pourraient retrouver ces «Inventions de Géométrie ». Ces manifestations d'une philosophie consacrée à l'invention ne sont pas superficielles mais traduisent une tendance profonde, tandis que le philosophe, à la face du monde, se proclame inventeur. Galilée, pour quitter l'enseignement au service de la République de Venise et entrer à celui de la Cour de Florence, se targue de cette qualité :

« Mais je ne voudrais pas, Seigneur, écrit-il, que mes paroles vous incitent à penser que j'élève des prétentions déraisonnables, en réclamant une solde

403

Idem, t. 6, p. 485.

404

la philosophie, les écoles auront disparu tout comme elles ont disparu de la geométrie. Nous voyons, en effet, qu'il n'y a pas des « Euclidiens », des « Archimédéens ou des « Apolloniens », comme Archimède pas plus qu’Apollonius ne s'étaient proposé de renverser les principes de leurs prédécesseurs, mais de les augmenter». G. LEIBNIZ : Schöpferische Vernunft, ed. Marburg, 1956, p. 255 
sans la mériter ou sans rendre service, car ce n'est pas ma pensée. Au contraire, en ce qui concerne le mérite, je dispose de mainte invention dont une seule, si elle atteint un grand prince qui y prenne plaisir, peut suffire, non seulement à me protéger ma vie durant de la misère; car l'expérience me montre que des choses qui étaient peut-être bien moins préservables ont apporté à leurs auteurs de grands avantages; et j'ai toujours pensé les offrir plutôt à mon prince et souverain légitime, afin qu'il disposât d'elles et de leur inventeur selon son bon plaisir; et s'il le jugeait bon, de ne pas seulement prendre le minerai mais aussi la mine ; car tous les jours je découvre de nouvelles choses et j'en trouverais bien davantage si j'avais plus de loisirs, et plus d'ouvriers à ma disposition, qui pourraient me servir dans différentes expériences » ${ }^{405}$.

A quelles inventions le philosophe mécanicien songe-t-il, de quelles inventions part-il pour parachever son œuvre philosophique? Il s'agit des instruments et des mécanismes ${ }^{406}$.

Si la plupart des savants, de Galilée à Descartes, de Pascal à Leibniz, de Huygens à Newton, ont découvert des instruments mécaniques et en ont fait la théorie, ce n'est point un hasard. La conception de la lumière et la doctrine mathématique des couleurs, de Newton, sont conjointes à l'invention d'un télescope perfectionné. De la même façon, les découvertes astronomique de Galilée illustrent sa contribution à la construction de la lunette qui porte son nom. N'est-il pas significatif que, dans la série d'opuscules auxquels le Discours de la Méthode sert d'introduction, le premier soit consacré au télescope et s'adresse aux artisans ? Il s'agit là vraiment d'un traité de construction d'un instrument d'optique, où sont indiqués les procédés de travail et les recettes propres à assurer le succès de l'industrie des artisans. Descartes n'épargne aucun effort pour décrire les machines nécessaires,

405

406

G. GAlilei : Euvres, t. X, p. 233.

Les philosophes, au XVII ${ }^{\mathrm{e}}$ siècle, s'intéressent beaucoup aux travaux des artisans. Cependant l'expression reste vague et traduit une sorte d'optimisme technologique propre à notre époque. En fait ils s'intéressent surtout à une catégorie d'artisans, les mécaniciens. Comme le dit Galilée, parlant de l'arsenal de Venise : "L'activité constante que vous autres Vénitiens déployez dans votre célèbre arsenal propose à l'esprit studieux un vaste champ de recherche, en particulier la partie du travail qui implique la mécanique; car, dans ce domaine, toutes sortes d'instruments et de machines sont sans cesse construits par de nombreux artisans, entre lesquels il doit s'en trouver qui, en partie par l'expérience dont ils ont hérité, et en partie par leurs propres observations, sont devenus très experts et habiles à expliquer ». (Opere. t. VII. p. 49.) Ce sont ces artisans qui fournissent la doxa essentielle au philosophe 
les qualités du verre et les opérations indispensables qui, lui semble-til, peuvent concourir à la construction d'une lunette selon ses vues :

«Et d'autant que l'exécution des choses que je dirai doit dépendre de l'industrie des artisans, qui pour l'ordinaire n'ont point étudié, je tâcherai de me rendre intelligible à tout le monde, et de ne rien admettre ni supposer qu'on doive avoir appris des autres sciences ${ }^{407}$.

Programme qu'il remplit scrupuleusement, en accumulant ce qu'il estime être invention sur invention pour convaincre de l'utilité de sa démarche et rassurer l'artisan constructeur d'un tel instrument.

« Mais à cause que les artisans jugeront peut-être qu'il y a beaucoup de difficultés à tailler les verres exactement suivant cette figure hyperbolique, je tâcherai encore ici de leur donner une invention, par le moyen de laquelle je me persuade qu'ils en pourront assez commodément venir à bout $\gg{ }^{408}$.

Descartes attribue la découverte même du télescope à Jacob Metius, mathématicien; il se présente donc comme le continuateur d'un « artisan supérieur » et c'est à cette catégorie d'hommes qu'il dédie son opuscule. Sa géométrie apparaît, en partie, liée à cette recherche d'amélioration des lunettes. Les courbes qui donneraient la forme des verres les ovales de Descartes - qui, dans la Dioptrique, sont le but de l'industrie de l'opticien et, dans la Géométrie, l'objet de la démonstration du mathématicien, sont aussi le premier cas de résolution du problème inverse des tangentes.

Sans conteste, c'est 1'Horologium oscillatorium ${ }^{409}$ de Christian Huygens, paru en 1673, qui représente avec le plus de perfection le prototype d'un traité élaboré autour d'un instrument ${ }^{410}$, en l'occurrence, l'horloge à pendule. Entre 1655 et 1658, Huygens a

407

408

409 DUGAS : La mécanique au XVII siècle, ed. cit. p. 283. Non, il ne se double pas, c'est la définition même du philosophe mécanicien à cette époque.

410 La Micrographia de Robert Hooke (ed. R.T. GunTHER, Oxford, 1938) fait aussi partie de cette famille d'ouvrages écrits à partir d'un instrument ou autour d'un instrument. 
conçu son horloge dont la régulation est assurée par un pendule. L'invention est sienne et reçoit un privilège qu'il se propose d'illustrer et de défendre. D'emblée, il marque le double caractère de son ouvrage :

«En partie c'est une invention mécanique, et en partie différente ; et celleci bien remarquable repose sur des principes géométriques; pour ce qui est de la seconde, au prix d'un grand effort, il a fallu faire des recherches dans les parties cachées de l'art $\gg{ }^{411}$.

Ensuite, il présente son « automate » et l'emploi de celui-ci pour la mesure du temps, l'appréciation des longitudes en mer, et les expériences qui prouvent ses propriétés. Après quoi il donne un véritable traité de mécanique où les différents mouvements du pendule — leurs principes et leurs lois - sont expliqués théoriquement. Les courbes décrites par le mobile au cours de son oscillation sont analysées et démontrées géométriquement. L'ajustement de la longueur du pendule et l'étude du centre d'oscillation forment une autre partie importante de l'ouvrage. Je n'ai nullement besoin d'ajouter que chacun des chapitres de ce traité est original et constitue une contribution impérissable aux mathématiques et à la mécanique. Leur thème unique et leur point d'ancrage est l'instrument qui a joué un rôle déterminant dans le développement théorique et pratique de la mécanique : l'horloge.

La philosophie naturelle mettait au centre de son enquête sur le monde physique - l'œuvre d'Aristote le prouve - l'homme de l'art, son habileté, ses opérations et leur produit. Pour le philosophe mécanique, on peut affirmer que son propos est l'analyse et l'emploi de l'instrument, le fonctionnement et les effets de celui-ci. L'homme c'est-à-dire le mécanicien - intervient dans le cycle des forces matérielles en leur proposant un objectif qu'elles s'avèrent capables d'atteindre. Il ne fait plus partie de l'enchaînement des phénomènes matériels, ni de leur agencement causal, car l'ensemble des êtres qui les constituent doivent être dépourvus de raison. L'instrument, le mécanisme, expriment la nouvelle relation avec les forces matérielles, et, 
en inventant ceux-là, le philosophe prouve qu'il a appréhendé correctement celles-ci.

\section{$\underline{\text { Retour à la Table des Matières }}$}

\section{La méthode philosophique et l'art d'inventer.}

La supériorité du philosophe et celle de sa philosophie réclamaient des preuves. Pour y parvenir, le meilleur moyen était de contribuer à quelque découverte et d'en tracer les principes généraux, d'indiquer le danger des voies sans issue poursuivies par d'autres.

Dans le préambule de son écrit sur les Mécaniques (c'est-à-dire consacré aux instruments mécaniques) Galilée nous instruit de son propos en ces termes:

«Il m'a semblé digne d'intérêt, avant que nous descendions à la théorie des instruments mécaniques, de considérer en général et de placer sous nos yeux pour ainsi dire les avantages que l'on peut tirer de ces instruments. J'ai jugé qu'il était d'autant plus nécessaire de le faire que j'ai vu, si je ne me trompe, la plupart des mécaniciens être dupés en essayant d'appliquer les machines à de nombreuses opérations impossibles de par leur nature, avec pour résultat qu'ils sont demeurés dans l'erreur, tandis que d'autres ont été pareillement frustrés de l'espoir qu'ils avaient conçu d'après leurs promesses. Il me semble que ces duperies ont été surtout dues à la croyance qu'ont ces artisans, et qu'ils maintiennent, qu'il est possible de soulever de très grands poids à l'aide d'une petite force, comme si par leurs machines ils pouvaient forcer la nature, dont l'instinct, non, bien plus, la constitution même, veut qu'aucune résistance ne puisse être vaincue par une force qui n'est pas plus puissante qu'elle ${ }^{412}$.

L'importance de la question n'échappe à personne. L'emploi accru de la force motrice de l'eau permettait d'observer quotidiennement que le mouvement est le prolongement de cette force et qu'il ne peut y avoir plus de mouvement qu'il n'y a de force. Concevoir une machine supposait en effet que l'on respectât une certaine proportion entre les deux termes, entre la cause et son effet. Le constructeur de moulins ne 
pouvait prétendre ou espérer produire des machines dont les roues tournent pendant un laps de temps indéterminé ou à une vitesse qui ne tienne pas compte des disponibilités énergétiques. Cependant, si la plupart des mécaniciens l'ignorent encore, ce sont certains d'entre eux qui ont découvert cette règle. Léonard de Vinci et Cardan la signalent et nient la possibilité du «mouvement perpétuel », tandis que Varro affirme :

«La nature ne souffre pas que dans tout ceci une force naisse, en effet, si la proportion de cette façon pouvait être brisée par quelque moyen, il y aurait « mouvement perpétuel», ou, ainsi qu'on le nomme, « mouvement perpétuel dans la matière perpétuelle ${ }^{413}$.

Galilée énonce avec plus de vigueur cette règle mise en tête de son opuscule sur les instruments mécaniques, et la transforme en axiome universel. Le philosophe dépasse le constat et y voit un postulat qui s'applique autant au fonctionnement des machines qu'à celui du monde matériel. Les ingénieurs s'égarent lorsqu'ils s'engagent dans une direction contraire, et la philosophie est là pour les en avertir. A ce sujet, Christian Huygens écrit explicitement :

«Si les inventeurs de nouvelles machines qui s'efforcent vainement d'obtenir le mouvement perpétuel savaient faire usage de cette hypothèse, ils découvriraient eux-mêmes leurs erreurs et comprendraient que ce mouvement ne peut aucunement être obtenu par des moyens mécaniques ${ }^{414}$.

Il est digne d'intérêt de voir un Galilée, un Huygens se préoccuper des conditions qui permettent aux ingénieurs de construire raisonnablement une machine, d'étudier les critères de leurs opérations et l'étendue de leurs chances d'inventer eu égard aux propriétés des forces matérielles. Au savoir de quelques hommes d'art, le philosophe mécanicien fournit la théorie. Et ainsi une norme possible du métier, un avertissement à l'inventeur, devient une loi de la nature qui soustend le mécanisme. Bien mieux, dans la mesure où la règle de l'impossibilité du mouvement perpétuel se change en principe de

413 Voir S. Moscovici : Notes sur le De Motu tractatus de Michel Varro, Revue d'Histoire des sciences, 1958, XI, pp. 108-129.

414 C. HuYgens : E Euvres complètes, t. XVIII, La Haye, 1934, p. 250. 
conservation, qui sert d'indice au découvreur du mécanisme, ce principe devient une source d'analyse théorique du mouvement et pénètre toute la mécanique. Non seulement il permet de définir un système, il montre aussi que l'existence du système suppose un équilibre quantitatif de l'ensemble force-mouvement, sans qu'aucun élément extérieur intervienne. L'introduction dans le domaine de la dynamique est facilitée. L'énoncé du principe d'inertie, l'étude de la loi de la percussion, du déplacement des centres de gravité, et l'idée de causalité (sous la forme la cause : est égale à l'effet) découlent de la recherche et de la justification d'une règle qui préside à l'invention et au fonctionnement des machines.

Ces analyses indiquent à l'habileté du mécanicien une direction précise, un canon d'économie et d'honnêteté ; celui qui n'en tient pas compte est un charlatan ou gaspille sa peine sans profit. Le mobile auquel obéit le philosophe est l'accélération du processus inventif, l'élimination du hasard et la diminution des essais inutiles. Les recherches de Descartes sur la courbure des verres rentrent dans cette catégorie. Elles conduisirent à la conclusion que l'art de l'opticien autorisait uniquement la taille de verres sphériques. De la sorte, les constructeurs d'instruments d'optique furent dispensés d'efforts qui auraient été infructueux.

Chaque philosophe mécanicien possède un atelier et fait valoir, avec des fortunes diverses, l'excellence de son produit. S'ils légifèrent sur ce qui est possible ou impossible, souhaitable ou non dans la technique, ils organisent les savoirs et les facultés de l'ingénieur. Toutefois, cela ne suffit pas à constituer le centre de la méthode philosophique, car, pour atteindre ses sommets et remplir sa fonction, elle se devait de pénétrer et de commander le processus inventif dans son ensemble. Les instruments découverts, les théorèmes démontrés étaient autant d'apports positifs et de témoignages d'une démarche qui se voulait à la fois plus profonde et universelle.

« Dans ces siècles, on parle constamment, avec une insistance qui tourne à la monotonie, d'une logique de l'invention », note un historien ${ }^{415}$.

${ }^{415}$ P. Rossi : I Filosofi e le macchine, Milan, 1962, p. 49. 
Comment n'en parlerait-on pas, puisqu'il s'agit d'un trait majeur de la " philosophie nouvelle », de la philosophie mécanique ? La philosophie et le philosophe ne se consacrent plus à l'enseignement, la structure de leurs ouvrages ne porte plus cette marque. Si l'on s'adresse à l'artisan-mécanicien, comme on le fait fréquemment, c'est pour lui indiquer les voies dans lesquelles il peut s'engager afin d'améliorer ses facultés mécaniques. Toutefois, si l'on s'efforce de l'aider positivement à faire des découvertes qui ne soient pas le fruit du hasard, on désire aussi aiguiser ses talents à cet effet. Leibniz se préoccupe de l'accroissement des inventions et imagine un Théâtre des métiers inventifs :

«Les personnes qu'on aurait en gage seraient des peintres, des sculpteurs, des charpentiers, des horlogers et autres gens semblables. On peut ajouter des mathématiciens, ingénieurs, architectes, bateleurs, charlatans, musiciens, poètes, libraires, typographes $»{ }^{416}$.

Voilà pour la compagnie. Quant à la fonction :

«L'usage de cette entreprise serait plus grand qu'on ne pourrait l'imaginer, tant en public qu'en particulier. En public, il ouvrirait les yeux aux gens, animerait aux inventions, donnerait de belles vues, instruirait le monde d'une infinité de nouveautés utiles ou ingénieuses » ${ }^{417}$.

Le spectacle et l'échange des inventions sont proposés à titre de stimulants. L'enseignement doit avoir une fin identique. Dans le projet de «Conservatoire des arts et métiers », qui nous est rapporté par l'auteur de La vie de M. Descartes ${ }^{418}$, cette idée est soulignée expressément :

«Les professeurs doivent être habiles en Mathématiques et en Physique, afin de pouvoir répondre à toutes les questions des artisans, leur rendre raison

417 Idem, p. 255.

418 BAILlet : La vie de Monsieur Descartes, Paris, 1691. 
de toutes choses, et leur donner du jour pour faire de nouvelles découvertes dans les arts ».

Le cheminement que suit la philosophie mécanique accentue ainsi un des éléments qui définissent le savoir-faire de l'ingénieur: l'invention. Dans le processus de création du travail, à la place de l'apprentissage et de la reproduction des dextérités, l'adoption de procédés inédits et leur multiplication sont devenus les moments dominants. Leibniz insiste sur la distinction des deux processus :

«Au reste, écrit-il, j'avoue qu'il y a souvent de la différence entre la méthode dont on se sert pour enseigner les sciences et celle qui les a fait trouver... Quelquefois, comme j'ai déjà observé, le hasard a donné occasion aux inventions. Si l'on avait remarqué ces occasions et en avait conservé la mémoire à la postérité (ce qui aurait été fort utile), ce détail aurait été une partie très considérable des arts; mais il n'aurait pas été propre à en faire des systèmes $\gg 419$.

De son côté, Descartes, dans une lettre à Mersenne, du 27 février 1637, déclare «Je n'ai pas dessein de l'enseigner» (la méthode), et dans le Discours de la Méthode, effectivement, il n'expose que l'histoire de son esprit, de ses découvertes :

« Ainsi mon dessein n'est pas d'enseigner la méthode que chacun doit suivre pour bien conduire sa raison, mais seulement de faire voir en quelle sorte j'ai tâché de conduire la mienne $»{ }^{420}$.

On voit ici se dessiner la trame de la plupart des recherches méthodologiques. Celles-ci ont pour visée le moyen de faire des observations plus exactes et de procéder à des découvertes qui ne soient pas fortuites. Pourquoi le Discours de la Méthode est-il illustré par trois opuscules - ayant trait à l'optique, à la géométrie et à la météorologie - sinon pour attester la valeur des règles de raisonnement auxquelles Descartes attachait tant de prix ? Le but de ce Discours n'est-il pas de proposer une pédagogie de l'inventeur? Leibniz, de son côté, a 
écrit un Discours touchant à la méthode de la certitude et l'art d'inventer pour finir les disputes et pour faire en peu de temps de grands progrès. Il s'efforce de nous convaincre qu'entre les démonstrations et les inventions il n'y a pas de différence essentielle :

«Car les vérités qui ont encore besoin d'être bien établies sont de deux sortes, les unes ne sont connues que confusément et imparfaitement, et les autres ne sont point connues du tout. Pour les premières, il faut employer la Méthode de la Certitude ou l'art de démontrer, les autres ont besoin de l'art d'inventer. Quoique ces deux arts ne diffèrent pas tant qu'on croie, comme il paraîtra dans la suite ${ }^{421}$.

Là où Descartes songeait à l'individu ${ }^{422}$, Leibniz vise l'art d'inventer dans toute son ampleur et son essence. En regard, l'induction baconienne, dont l'influence sur les opinions a été grande, laisse peu de traces dans la structure de la philosophie nouvelle. L'« art combinatoire », de Leibniz, lui est infiniment supérieur quant à l'ampleur de vues et de moyens intellectuels mis en jeu. Il s'agit d'un véritable système complet destiné à servir d'orient aux inventeurs et à appuyer leurs tentatives. Le programme en est vaste : d'un côté Leibniz ébauche le plan d'un inventaire encyclopédique apte à ordonner les «sciences et arts ", à dégager les parties qui pourraient servir de base à la recherche de nouvelles inventions; d'autre part il indique la discipline fondamentale qui serait susceptible d'étendre les découvertes dans chaque « science » ou « art ». A cet égard, l'art d'inventer est aussi le principe organisateur de sa logique et de sa mathématique ${ }^{423}$. Son champ d'application s'étend également à l'étude des mécanismes. Par cette voie, Leibniz rêve de compléter la méthode cartésienne. L'éloge qu'il décerne à cet art, les espoirs qu'il met en lui, témoignent de son emprise sur la pensée du siècle, comme de sa place dans l'œuvre du grand philosophe, qui écrit au duc Ernest Auguste :

421

422 cherche, ce qui est différent, une clef de l'art d'inventer et forge un art combinatoire ». Y.
BELAVAL : Leibniz, critique de Descartes, Paris, 1960, p. 34 . 23 «Aussi voit-on souvent Leibniz identifier la science générale tout entière à l'art d'inventer ». L. Couturat : La logique de Leibniz, Paris 1901, p. 579. 
«Je ne fais pas grand cas des découvertes particulières, et ce que je désire le plus, c'est de perfectionner l'art d'inventer,et de donner plutôt des méthodes que des solutions des problèmes $\gg{ }^{424}$.

Nous sommes ainsi amenés à reconnaître l'importance de ces « considérations philosophiques », que les historiens ont si vite écartées pour ne retenir de la nouvelle philosophie que le rôle des mathématiques et de l'expérience. Elles constituent, en quelque sorte, la toile de fond, car mathématiques et expériences ${ }^{425}$ sont destinées à aider à faire des découvertes. La démarche de l'esprit, les processus intellectuels mis en jeu, la conception de la connaissance qui les corrobore, sont animés par le génie inventif. Aux méthodes et à la logique pré-existantes, parcourues par un esprit différent ${ }^{426}$, à la dialectique platonicienne et à la logique analytique — démonstrative ou syllogistique — d'Aristote se substituent les règles de la méthode cartésienne, et l'art combinatoire ${ }^{427}$ ou art d'inventer (logicae inventionis semina) de Leibniz. L'un et l'autre s'inspirent et sont extraits de la pratique du mécanicien ${ }^{428}$, dans laquelle Leibniz voit, à juste titre,

424

425

L'utilité des expériences est cependant double : le premier aspect sert à divers agréments de la vie, et on le découvre lorsqu'on conclut de la cause à l'effet; l'autre aspect sert à la recherche des principes vrais, et on le trouve en retournant de l'effet à la cause. La première façon de conclure est combinatoire, la seconde analytique ». G. LEIBNIZ : Schöpferische Vernunft, p. 311.

426 «A l'idéal de connaissance formel et abstrait de la pensée scolastique, Descartes oppose un autre idéal de connaissance productif et constructif. Là, il s'agissait de mettre en rapport des contenus de savoir donnés, de les classer et de les subsumer; ici, la tâche consiste à acquérir et fonder un savoir nouveau ». E. CASSIRER : Descartes Wahrheitsbegriff, Theoria, 1937, p. 164.

427 «Car quiconque ne travaille qu’à une seule chose découvre rarement quelque chose de nouveau, parce qu'en effet son sujet est rapidement épuisé, mais de ceux qui examinent de nombreuses choses très différentes entre elles et qui sont doués d'un génie combinatoire, on peut attendre beaucoup d'enchaînements nouveaux et utiles des choses. Lorsque les hommes s'attaqueront à un tel inventaire des découvertes déjà connues, il contiendra en germe de nouvelles découvertes dans toutes les sciences et dans chaque technique ». G. LEIBNIZ, op. cit. p. 309.

Le modèle du génie combinatoire est, encore un coup, l'ingenium de l'ingénieur. N'est-il pas, par définition, un artisan « universel », qui rencontre et combine les différents arts, et fait ses découvertes grâce aux analogies qu'il établit et aux transferts qu'il opère ? Mais, en même temps, il se consacre à un certain type d'invention, celui qui s'apparente aux mécanismes. De là le double aspect de son art d'inventer, combinatoire et mécanique à la fois.

428

« Cette méthode, dit Descartes, imite celle des professions mécaniques, qui n'ont pas besoin du secours des autres, mais qui donnent elles-mêmes le moyen de construire les instruments qui leur sont nécessaires », VIII ${ }^{\mathrm{e}}$ Règle, Euvres, t. 10, p. 397. 
une expression de la théorie. Il espère de la sorte aider ceux qui sont, de par leur état, obligés de résoudre des difficultés techniques et pallier leur ignorance :

« De là vient, écrit-il, que les mécaniciens ignorent l'usage de leurs observations, les érudits par contre ignorent que leurs désirs peuvent déjà être satisfaits par le travail des mécaniciens. C'est le propre de l'art combinatoire de produire de nouvelles commodités en comparant des choses différentes, qui ne peuvent venir à l'esprit de ceux qui examinent peu ${ }^{429}$.

Il tente par conséquent d'établir un lien entre le savant et le mécanicien, de jeter une passerelle entre les disciplines productives et les disciplines philosophiques.

J'ai rendu très brève une histoire très longue ; mais, même ainsi résumée, elle nous permet de constater à quel point le programme de Leibniz exprimait des habitudes nouvelles dans la vie de l'art et de la philosophie. Si, d'une part, grâce à des analyses théoriques, il établit des principes mécaniques et fait de la mathématique l'instrument par excellence de l'analyse qu'il recommande pour guider les découvertes particulières, d'autre part il aborde directement la question du perfectionnement de la faculté inventive, de l'individu et de son art, et en propose la doctrine qui paraît la plus féconde. Les deux « instruments " se complètent; tandis que l'un imprime sa marque à chaque discipline, l'autre détermine l'ensemble de la philosophie mécanique. Le premier dirige le résultat, le second l'acte d'inventer dans sa totalité.

La méthode expérimentale ${ }^{430}$ ne fait que traduire, sur un autre plan, ce double mouvement. Le philosophe mécanicien, nous l'avons vu, est un inventeur. Ce qu'il recueille auprès de l'artisan ou d'autres savants, il ne se contente pas de le saisir et de l'examiner, il veut aussi le parachever, établir une proposition géométrique, améliorer un instrument insuffisamment connu. Il ne peut donc se satisfaire

G. LEIBNIZ : Philosophische Schriften, t. VII, p. 69.

430 H. Dingler: Das Experiment, Munich, 1928. A. GewirTZ: Experience and the nonmathematical in the Cartesian method, J. of the Hist. of Ideas, 1941, 2, pp. 183-210. 
d'expériences indirectes, il fait lui-même des expériences, non pas tant pour corroborer ce qui existe que pour proposer des conséquences nouvelles. Dans la mesure où elle est invention, emploi de l'action instrumentale, qui se donne pour fin de produire des effets inconnus auparavant, la méthode expérimentale, à l'intérieur de la philosophie mécanique, diffère de celle qui aurait pu exister dans la philosophie naturelle. Jouant sur deux tableaux, elle tranche les nœuds théoriques et aboutit à des découvertes.

La célèbre expérience à laquelle procéda Torricelli ${ }^{431}$, appelée « expérience du vide», devait établir si l'espace était plein d'une " matière subtile », ou s'il était dépourvu d'une telle matière. Elle a conduit aussi bien à la découverte du baromètre qu'a celle de la pompe atmosphérique. Ce n'est point là un effet imprévu. A coup sûr, Torricelli songeait à ces deux conséquences. Sa lettre à Ricci du 11 juin 1644 l'affirme expressément :

« J'ai déjà fait allusion à quelque expérience philosophique qui était faite au sujet du vide; non point simplement pour produire un vide, mais afin de faire un instrument qui puisse montrer les changements de l'air, tantôt lourd et épais, tantôt léger et subtil » ${ }^{432}$.

L'aboutissement est digne du commencement. Les premiers essais se trouvent chez les fontainiers, les ingénieurs qui travaillent dans les mines ou ceux qui s'occupent d'adduction d'eau. Ils rencontrent beaucoup de difficulté à élever l'eau au-dessus d'un certain niveau. C'est en vain qu'ils s'efforcent de construire des pompes plus commodes, les effets attendus ne se manifestent pas. Ils soumettent leur difficulté à des philosophes mécaniciens, tels que Galilée et Baliani. Celui-ci, après avoir étudié le problème ${ }^{433}$, conclut que l'impossibilité d'élever l'eau au-dessus d'un certain niveau est due à la pression atmosphérique. La solution consiste à construire non des pompes plus solides, mais des pompes où l'on puisse faire le vide et obtenir une impulsion

Une expérience est considérée comme «inventée » par son auteur. "Cette expérience fut l'invention de Torricelli ». J. GLANVILL: Essays on several important subjects, Londres, 1676, p. 27.

E. TORRICELLI : Opere, ed. Faenza, 1919-1944, t. 3, p. 186.

433 S. Moscovici : L'expérience du mouvement, Paris, 1967. 
suffisante pour chasser l'eau. Torricelli, on le sait, en fait l'expérience, et prouve la justesse de la conception de Baliani.

$\mathrm{Au}$ reste toute invention requiert de nombreuses expériences qui ont trait aux phénomènes impliqués dans l'instrument recherché. La construction d'un pendule battant la seconde a mis à l'épreuve la sagacité d'une ou deux générations d'expérimentateurs, avant que Huygens, à l'aide de son horloge, résolve les difficultés et achève l'ouvrage. Les expériences de Newton qui ont abouti à établir la théorie classique de la lumière sont en relation directe avec les travaux de perfectionnement du télescope. $\mathrm{Si}$, au lieu de choisir le critère chronologique pour classer les écrits et les recherches expérimentales de ces grands philosophes, on prenait le critère instrumental - la lunette, l'horloge, les pompes, les moulins - on obtiendrait un ordre également satisfaisant, parce qu'il exprimerait fidèlement leur inspiration et la succession de leurs découvertes. 


\section{Habileté mécanicienne et connaissance philosophique}

Retour à la Table des Matières

\section{L'expérience en tant que méthode analytique.}

A l'aube de la révolution philosophique, le recours à l'expérimentation avait pris, à bon droit, l'aspect d'une protestation véhémente contre l'autorité. On se plaisait à opposer, avec conviction, à la fascination des livres la puissance impérieuse des faits. C'était là une tendance de l'époque qui exaltait les vertus de la nature face aux vices de l'enseignement des maîtres. De la sorte, confrontant théories et expériences, on espérait réduire à néant les doctrines généralement acceptées ayant trait au mouvement des corps terrestres et célestes, à ses causes et à ses formes. On croyait avoir découvert le moyen irréfutable de trancher entre les opinions adverses, en substituant aux éternelles « disputationes » la violence du réel.

On ne saurait cependant soutenir que toutes ces expériences protestataires furent de la plus haute qualité, ni qu'elles illustrèrent avec honneur la religion dont elles se réclamaient. Elles portaient parfois à faux, car elles suivaient des principes fort anciens et aboutissaient à défaire le but qu'elles s'étaient proposé. Bien plus, on ne devait pas tarder à le remarquer, la philosophie naturelle n'était pas aussi coupée de la vie qu'on le prétendait, ni aussi ennemie de l'observation. On pourrait même dire avec raison qu'elle était encline à en abuser.

En effet, la philosophie naturelle ordonne ses connaissances en partant d'observations, en accumulant des informations sur le plus grand nombre de cas possibles, et elle tente de les accorder entre eux, elle se montre avide de témoignages et fait fond sur eux. Cela ne lui paraît pas être une limitation, mais au contraire une manière de pénétrer davantage le réel auquel elle se réfère. Si le philosophe recourt à des témoignages, c'est pour s'assurer de la certitude de ce qu'il a vu, de ce qu'il a appris. La direction qu'il suit et le modèle dont il se sert sont ceux du médecin clinicien ou de l'homme d'art qui se fie surtout à ses 
sens, à sa perception des choses et aux dires de ses collègues. Il s'agit pour le philosophe de se familiariser avec un objet, de relever les accidents qui se répètent et les effets qui découlent des opérations identiques. Les essais, les comparaisons ont pour but de confirmer la justesse des remarques; les erreurs faites peuvent être évitées par la suite. L'habitus aristotélicien, qui est à la base de tout ce savoir, n'est rien d'autre que l'imprégnation lente, la fusion de souvenirs autour de quelques phénomènes rapportés ou constatés. Le recours à la reproduction expérimentale des processus n'a pas une importance décisive pour la théorie. Prenons pour illustration l'étude du son. Il sert au forgeron à contrôler la qualité d'un métal, au musicien à apprécier la justesse d'un instrument. Archytas propose une théorie selon laquelle il est produit par «concussion » de l'air, la hauteur du son dépendant de la vitesse du mouvement qui l'engendre, suivant un rapport de proportionnalité exprimé par des nombres simples. Les applications qui en sont faites montrent que le philosophe s'est assuré lui-même de la réalité des phénomènes observés. Sont-elles toutefois nouvelles ? Apportent-elles quelque chose de différent eu égard à ce que chacun pouvait voir et savoir? Point du tout. Karl von Fritz écrit à ce sujet :

«Les arguments par lesquels ces théories sont étayées sont fondés sur des observations qu'on peut faire dans la vie quotidienne sans expérimentation; mais la façon dont les observations sont introduites suggère fortement que, bien qu'à l'origine elles aient pu être faites accidentellement, elles ont été du moins contrôlées par une répétition sur le mode expérimental » ${ }^{434}$.

Si ce mode n'a rien d'impérieux, selon les clauses de cette philosophie, plus on fait d'observations, plus on fournit d'exemples, et plus on estime avoir assuré la valeur des concepts et des interprétations. Le critère de la fréquence est premier, puisqu'une théorie est établie sur la base du plus grand nombre de cas qu'elle embrasse, l'induction complète étant un stade limite de l'exploration. Dans ce processus d'appréhension du réel, la médiation de l'instrument n'est pas obligatoire, institutionnalisée. Le contrôle exercé par les organes humains de la vue ou du toucher sur le déroulement des phénomènes doit rester entier. 
L'expérience correspondant à la nouvelle philosophie rompt avec ces habitudes. D'emblée, elle refuse de collectionner exhaustivement les exemples ou de les ordonner en un inventaire à partir duquel peut être extrait un corps de connaissances communes. Elle ne surestime pas non plus l'importance d'une somme d'illustrations variées des phénomènes matériels. Pour cette raison, elle critique les témoignages et les observations qu'elle ne peut ni contrôler ni, surtout, reproduire. A la généralité statique des faits, elle préfère l'assurance de leur universalité. Celle-ci entraîne le seul consensus souhaitable et prépare le cadre d'une déduction rigoureuse, éliminant les controverses dues au choix arbitraire d'indices, donnant à chacun la possibilité, s'il le désire, de retrouver les effets en question. Dans l'Essayeur, Galilée pose cette condition expresse lorsque son contradicteur Sarsi se réfère à des observations et à des témoignages.

«Si Sarsi désire que je croie, sur la foi de Suidas, que les Babyloniens faisaient cuire les œufs en les faisant tournoyer rapidement dans une fronde, je le croirais volontiers, mais je dirai que la cause d'un tel effet est éloignée de celle à laquelle on l'attribue, et, pour découvrir la vraie cause, je raisonnerai comme suit : si un effet qui a réussi chez d'autres, à une autre époque, ne se produit pas chez nous, il s'ensuit nécessairement qu'à notre expérience il manque quelque chose qui était la cause du succès dans la tentative précédente; et s'il ne nous manque qu'une chose, cette chose unique est la vraie cause; nous ne manquons aujourd'hui ni d'œufs, ni de frondes, ni de gens robustes pour les faire tournoyer, et pourtant ils ne veulent cuire; et, puisqu'il ne nous manque rien — sauf d'être Babyloniens - il s'ensuit que le fait d'être Babyloniens, et non le frottement de l'air, est la cause de la cuisson des œufs - ce que je voulais démontrer » ${ }^{435}$.

L'ironie de ce texte est meurtrière. La contestation ne porte pas sur l'existence, chez le philosophe naturaliste, du souci de prendre en considération les phénomènes, mais bien sur la façon de les considérer et de s'y référer.

Nous avons déjà vu la technique de l'expérience apparaître chez Léonard de Vinci; elle était commune à tous ceux qui pratiquaient 
l'art de l'ingénieur. On cherche, par son truchement, un modèle, une machine unique, construite de manière à répondre à certaines exigences d'efficacité ou de dimension ${ }^{436}$. L'artifice, l'automate, est indépendant de son créateur et présuppose qu'aucune force intelligente ne commande son mouvement. Les instruments de mesure, auxquels il faut se fier, permettent seuls d'intervenir pour proportionner les parties et régler les forces à leurs effets. Le philosophe mécanicien accorde une confiance totale aux mesures, à l'information que des combinaisons instrumentales lui présentent. Qu'il y ait eu là une mutation nécessaire au triomphe de la méthode expérimentale, l'exemple de l'invention de la lunette astronomique nous le prouve. Lorsque Galilée la pointa vers le ciel, il vit des planètes, des taches sur le soleil dont les images variaient en grandeur et que personne ne pouvait observer à l'œil nu. Les lentilles ne semblaient donner qu'une image déformante, ce que le sens commun philosophique avait dénoncé sous le nom d' "illusions d'optique ». Les savants condamnaient l'usage de l'instrument et doutaient des phénomènes, car « on ne peut faire de la science au moyen de la seule vue » (Non potest fieri scientia per visum solum). La condamnation était sévère ${ }^{437}$ : la lunette paraissait plutôt multiplier les apparences trompeuses qu'ouvrir les chemins de la vérité.

«Le but de la vue, disait le chœur de ces savants, est de faire connaître la vérité. Or les « figures » qui apparaissent à travers les lentilles sont plus grandes ou plus petites que les objets réels, plus proches ou plus éloignées, parfois renversées tête en bas, parfois irisées. Elles ne sont donc pas la vérité. Il ne faut donc pas regarder à travers les lentilles ».

Galilée, au contraire, partage avec les ingénieurs l'habitude d'utiliser instruments et mécanismes et accepte l'idée d'opposer un artifice aux sens pour appuyer ses convictions quant à la structure de l'univers. Ce faisant, il inaugure une nouvelle époque de l'astronomie.

L'expérience du technicien avait encore d'autres caractères que ceux de la fidélité à l'instrument. Pour parvenir à fabriquer des modè-

\footnotetext{
436 P. WIENER : The tradition behind Galileo's Methodology, Osiris, 1936, I, p. 733-46.

437 «Les philosophes, porte-parole de la culture officielle, nièrent donc le sens et la validité des observations faites par les techniciens et les artisans ». P. RossI : op. cit. p. 15.
} 
les ou automates, il est indispensable d'isoler les parties et les phénomènes essentiels, d'écarter, au cours des essais, les causes perturbatrices, et de vérifier l'exécution au moyen des résultats attendus. Ceux-ci peuvent soit être prédits par une règle, soit ressortir de la comparaison avec les effets produits par une machine semblable. Dans les deux cas, la mesure intervient pour corroborer le jugement définitif. Avec la mesure et avec la sélection préalable des propriétés que doivent posséder les opérations du mécanisme, se fait sentir le besoin de la théorie. L'expérience est un moment de l'organisation de celle-ci et se justifie lorsque cette organisation propose des alternatives claires :

«Je remarquais, touchant les expériences, dit Descartes, qu'elles sont d'autant plus nécessaires qu'on est plus avancé en connaissance. Car, pour le commencement, il vaut mieux ne se servir que de celles qui se présentent d'elles-mêmes à nos sens » ${ }^{438}$.

Le premier moment, la source de la connaissance, n'est donc pas l'expérience. Celle-ci, on ne l'a pas oublié, a une double signification de technique inventive et de méthode servant à établir les propriétés du réel. Les expériences qui, aux dires de Descartes, "se présentent d'elles-mêmes ", ce sont des découvertes : la lunette, l'horloge, les pompes, et ce sont elles qui déclenchent toute une série d'analyses d'ordre géométrique, optique, mécanique, dont les conséquences imposent des vérifications circonstanciées, permettant de comprendre l'inconnu et de saisir l'inattendu. La méthode expérimentale intervient au niveau de ce mûrissement de la théorie et de ses possibilités de prédire quelque chose de nouveau. La machine ou l'instrument dont on est parti se perfectionne, et quelques lois de l'optique ou du mouvement sont établies conjointement. L'esprit de cette démarche est amplement illustré par les travaux d'Isaac Newton dans le domaine de l'optique. Les premières études qu'il a publiées à ce sujet ont eu pour motif le perfectionnement du télescope. A cette occasion, il fait sa découverte mémorable sur la décomposition de la lumière blanche en sept couleurs élémentaires. D'une part, il la prouve à l'aide d'une série d'expériences, et d'autre part il applique le calcul pour formuler la 
théorie. L'annonce de ses découvertes est caractéristique du style général ; elle doit surprendre.

«A présent, écrit-il, je vous ferai part d'une autre difformité plus notable où se trouve incluse l'origine des couleurs. Un naturaliste ne s'attendrait guère à voir la science de celles-ci devenir mathématique, et pourtant j'ose affirmer qu'il s'y trouve autant de certitude qu'en n'importe quelle autre partie de l'optique $» 439$.

D'où vient cette certitude ? Non point de la multiplication des phénomènes, ni d'une conclusion tirée de l'absence d'exemples contraires à ses propositions, mais de l'expérience, qui établit exclusivement les effets au sujet desquels il a proposé quelques déductions intéressantes :

«Car ce que je vais dire à leur sujet (au sujet des couleurs) n'est pas une hypothèse mais une conséquence très rigide, non pas conjecturée en inférant simplement c'est ainsi parce que ce n'est pas autrement, ou parce que cela satisfait tous les phénomènes (argument universel des philosophes), mais montrée par la méditation des expériences en concluant directement et sans l'ombre d'un doute ${ }^{440}{ }^{\prime}$.

Lorsque Newton eut rendu publiques sa doctrine et son expérience sur la lumière, quelques philosophes naturalistes s'efforcèrent de les mettre à l'épreuve et conçurent des expériences de tous ordres, parfois sans lien entre elles, pour l'embarrasser. De tous ces philosophes, Lucas fut le plus industrieux. Voici ce qu'écrivit Newton à Oldenburg à son sujet :

«Par ceci je puis supposer qu'il (Lucas) désire vraiment savoir quelle vérité il y a dans ces choses. Mais pourtant il atteindra plus rapidement la pleine satisfaction s'il change un peu la méthode qu'il a proposée et qu'au lieu d'une multitude de choses il tente seulement l'expérience cruciale. Car ce n'est pas burg. 
le nombre d'expériences, mais leur poids qu'il faut considérer; et là où une seule fait l'affaire, qu'est-il besoin d'en avoir beaucoup ? ${ }^{441}$.

Le nœud de la controverse est visible : faut-il faire une expérience ou plusieurs? Si une seule expérience répond à la question théorique posée, il n'est point nécessaire de les multiplier. Le nombre n'ajoute rien à l'affaire, c'est leur poids, c'est-à-dire leur signification eu égard à la théorie des phénomènes étudiés, leur valeur démonstrative, qui sont décisifs. Si l'expérience cruciale n'est pas confirmée, il est inutile de poursuivre dans cette voie. Si elle est confirmée, toute autre expérience est superflue. Newton dit : il faut examiner principalement la réfraction différente de la lumière.

«Et je l'ai démontrée par l'expérience cruciale. Or, si cette démonstration est bonne, il n'est pas besoin d'examiner la chose plus avant ; si elle n'est pas bonne, la faute doit en être démontrée, car la seule façon d'examiner une proposition démontrée est d'en examiner la démonstration ${ }^{442}$.

Une expérience est comme une proposition mathématique : l'enchaînement qu'elle démontre est le résultat qu'on peut en attendre. Et c'est là une innovation l'expérience se discute à l'instar d'une théorie. La réponse indirecte de Lucas renseigne sur sa méthode :

« J'ai lu votre lettre du 23 avec la réponse de $\mathrm{M}$. Newton à mes objections expérimentales à sa nouvelle théorie... pourtant je ne puis estimer que ce soit une preuve démonstrative de cette nouvelle théorie sans l'aide d'expériences supplémentaires. J'estime qu'on peut faire ressortir ces faits en les déduisant de cette nouvelle théorie selon une méthode syllogistique rigoureuse », et il affirme vouloir «faire un certain nombre d'expériences dans plusieurs milieux réfringents » ${ }^{443}$.

Le langage et les idées sont on ne peut plus éloignés du langage et des idées de Newton, de la nouvelle philosophie. Lucas oppose des objections aux expériences, c'est-à-dire des cas particuliers qui ris-

\footnotetext{
441 I. NEWTON : Correspondence, t. II, 1960, p. 79, Lettre à Oldenburg du 18 août 1676.

${ }^{442}$ Idem, p. 80

443 op. cit. p. 104, Lettre de Lucas à Oldenburg du 13 octobre 1676.
} 
quent de s'écarter de la règle. Pour s'en convaincre, il veut multiplier les expériences dans des milieux physiques différents, donc établir la généralité de la théorie par la fréquence des observations. C'est ce qu'il estime conforme à la «méthode syllogistique». Newton ne peut pas l'accepter. Une expérience suffit à confirmer ou infirmer une théorie.

«Et de plus la pleine vérité de ce que j'ai dit dans ma première lettre des couleurs à propos de l'impossibilité de faire progresser beaucoup plus les télescopes catadioptriques dépend de la longueur de l'image, et a une grande importance, que la théorie soit vraie ou fausse ${ }^{444}$.

Lucas envisageait donc les expériences hors de leur contexte et de leur fin : la construction du télescope catadioptrique. Le degré de vérité de la théorie ne présentait pas pour lui un caractère aussi aigu que pour Newton, lequel voulait, par son intermédiaire, aboutir à des effets rigoureux et spécifiques de son instrument. Cette fin fait aussi ressortir l'importance nouvelle des mathématiques. Il ne s'agit pas simplement de poser des chiffres, d'exprimer par l'arithmétique des quantités quelconques. Dans l'expérience, on mesure, et l'instrument, à propos duquel on expérimente, est lui-même un instrument de mesure. Ce que Lucas et bien d'autres — n'ont pas compris.

« Dans la dernière proposition de la lettre de M. Lucas, où il dit que j'ai calculé la longueur du spectre au moyen de divers prismes : le mot calculer est une représentation erronée de ce que je lui ai envoyé dont la force se trouvait dans le fait qu'ils n'étaient pas calculés mais mesurés » ${ }^{445}$.

Sobrement, mais fermement, Isaac Newton laisse voir que l'expérience constitue une démonstration des relations que la théorie aperçoit entre les phénomènes. Une fois ces relations établies, un petit nombre d'expériences, ou même une seule, ayant trait à la proposition essentielle, sert de preuve à l'ensemble des inférences déduites de la théorie, car celles-ci désignent la cause, l'inconnue. Le dispositif instrumental a pour fin de manifester ces phénomènes, la cause, et de les 
vérifier par des mesures effectuées sur les effets escomptés. Le calcul, loin d'être une opération adventice ou autonome, un indice parmi d'autres, s'intègre dans l'opération de mesurer. Quant aux diverses expériences, elles sont liées entre elles, et il ne saurait être question que certaines soient vraies et d'autres fausses. Elles sont toutes vraies, ou alors aucune ne l'est. La valeur de leur enchaînement sera appréciée à la solidité de la conception et à la qualité de l'instrument au perfectionnement duquel le savant travaille. En vertu de cette connexion intime, il n'est pas nécessaire de faire toutes les expériences possibles. Lucas rejette cette opinion méthodologique de Newton, si opposée à la sienne :

«Il (Newton) nous dit qu'il a l'intention de prendre en considération une ou deux de mes expériences que je lui recommanderai comme étant les meilleures; et quand il apparaitra qu'elles n'ont pas de poids, que d'autres jugent ce qu'il peut y avoir dans la quantité qui reste. Mais je ne puis pas ne pas m'élever contre cette méthode de réponse, la jugeant illégale, à moins que l'on ne montre que le défaut de ces deux expériences qu'il considère est partagé aussi par le reste ; car autrement le grand nombre d'expériences se maintiendra avec toute sa force en opposition à son expérience cruciale, et, pour autant que je sache, aura autant de poids ${ }^{446}$.

Non, le grand nombre de ces expériences ne s'est pas maintenu, et l'expérience princeps d'Isaac Newton est enseignée aujourd'hui à chaque enfant de par le monde. Le philosophe naturaliste n'a pas compris l'esprit expérimental que nous observons ici dans sa pureté acérée et extrême.

L'expérience, la «bonne expérience », comme disaient les artistes ingénieurs, est devenue un art précis, codifié, les connaissances mathématiques et mécaniques contribuent à l'articuler et à lui conférer une grande certitude. La technique expérimentale que Brunelleschi, le premier, a appliquée à l'étude de la lumière ${ }^{447}$ en bouleversant la perspective, se métamorphose, dans les mains de Galilée, Descartes et Newton en méthode expérimentale, forgeant à l'optique son image

op. cit. p. 191, Lettre de Lucas à Oldenburg du 23 janvier 1676/7.

447 P. SANPAOLESI : Brunelleschi, ed. cit. 
classique. Il en est de même dans les autres secteurs de la philosophie mécanique.

Le mouvement a été continu. Il a renouvelé les deux facteurs de la connaissance, ainsi que leur relation interne. L'expérience est apparue comme incarnation de la théorie, parce qu'on a fait de celle-ci la préparation à l'expérience ${ }^{448}$. On ne se préoccupe pas d'atteindre directement la structure intime de la matière ou d'agir sur cette structure. L'essentiel est de produire et de quantifier les effets que les différents artifices mécaniques manifestent. A l'aide des mesures, à partir de leur expression mathématique, on énonce des règles et des lois. Le concept et la pratique de la mesure sont un concept et une pratiqueclés, puisqu'ils rattachent la démarche expérimentale à la démarche mathématique, la quantité à la loi. L'ordre des phénomènes qui est retenu, et la théorie qui lui correspond, sont quantitatifs, pourvus de dimensions et soumis à des principes explicites dont se déduisent les règles particulières. Quant aux expériences significatives, elles sont presque toujours inspirées, occasionnées par les divers instruments et la nécessité de les parfaire par des inventions appropriées. Donc, si cette « nouvelle philosophie » se traduit par des traits inédits, ceux-ci ne sont pas exprimés de façon adéquate lorsqu'on la qualifie de mathématique et expérimentale, sans plus. Pour être plus près de la réalité historique, on doit parler de philosophie mesurante et instrumentale, se rapprochant ainsi des idéaux des hommes qui l'ont conçue et des intérêts des groupes qui l'ont reçue. Sinon, on oublie qu'elle tire son origine de la mécanique et on ne peut plus la distinguer des disciplines naturelles qui la précèdent et lui succèdent. C'est seulement à ce titre qu'elle a acquis le lustre du savoir et le pouvoir du réel.

\section{$\underline{\text { Retour à la Table des Matières }}$}

\section{La mesure et l'unité du savoir.}

Les formules heureuses sont souvent des formules inexactes : elles frappent sans porter au but. 
«Toute la logique de l'empirisme croule, écrivait Léon Brunschvicg, du moment qu'il s'est avéré que connaître, c'est mesurer ».

L'empirisme auquel le philosophe mécanicien espère porter un coup de grâce n'est-il pas en réalité un mode bien particulier d'approcher les phénomènes, historiquement daté et correspondant à un contexte précis? Arrêtons-nous un instant sur ce point. L'acte par lequel l'homme connaît devait intéresser au premier chef la philosophie naturelle, qui se trouve, dans ce XVII ${ }^{\mathrm{e}}$ siècle, battue en brèche. Comment en serait-il autrement puisque ce sont les sens, la capacité de combiner les données du milieu ambiant, d'organiser les opinions émises par autrui qui, ensemble, forment pour cette philosophie un instrument privilégié, l'organisme humain, permettant d'appréhender le monde ? La théorie de la connaissance a pour elle la signification que la théorie de la mesure revêt dans les sciences. Celle-ci s'applique aux instruments qui enregistrent et organisent les renseignements fournis par l'expérience et les articulent avec la théorie : celle-là précise les conditions dans lesquelles l'individu humain, luimême organe d'observation et de jugement, remplit des fonctions analogues. Les disciplines philosophiques anciennes n'en connaissent pas d'autres. De là, pour elles, la nécessité de définir la démarche de l'homme connaissant avec précision. Elles ne considèrent cependant pas un individu quelconque, une conduite quelconque mettant en jeu les sens et l'intelligence. La pure contemplation naïve et la description des couleurs, des harmonies sonores, le foisonnement des impressions et des sentiments qui assaillent tout un chacun dans la rencontre des objets et des décors, cette phénoménologie qui peut être l'œuvre spontanée de chaque sujet, de chaque être, ne s'inscrit pas parmi leurs visées. Avec force, le philosophe naturaliste repousse la valeur des renseignements, des constats dus au simple exercice des appareils sensoriels. L'habitude créée par répétition des gestes ou des observations, l'expérience accidentelle, fruit d'une pratique sans maître ou guide la tribé et la mélété — sont des voies inappropriées pour asseoir la connaissance. Seul l'individu humain qui se donne et possède un savoir, des facultés définies, attestées, et dont le jugement et la perception sont commandés par ces facultés, est véritablement le lien et l'outil suprême par lequel quelque chose de vrai peut être reconnu. A 
ce titre, on peut attendre de lui qu'il nous fasse pénétrer davantage dans la texture du monde réel, car les préceptes qui le dirigent lui permettent de s'orienter et de tirer tout le bénéfice de ce qui lui advient. Les opérations pratiques et intellectuelles étant commandées par la méthode et non par le hasard - comme en témoignent, nous dit Platon, celles d'Hippocrate, le médecin — l'examen de leurs aboutissants se fonde sur une grille, procède d'une discipline qui permettent d'attribuer un sens, un enchaînement à l'observable et au connaissable. Autant dire que cet individu, sujet de la connaissance, possède l'art ou la techne ou, ce qui revient au même, la discipline philosophique, l'episteme. Les règles propres à l'exercice de tout art sont un appui sûr lorsque l'homme est confronté avec le monde des phénomènes et des objets. Le philosophe naturaliste qui considère le sujet connaissant et veut en faire la théorie ne vise donc pas n'importe quel organisme susceptible de percevoir et de réfléchir, mais celui qui lui apparaît doué d'une compétence fondée sur ce qu'il a appris, soumise à une norme, sanctionnée par l'expérience et l'efficacité. La présomption de validité, d'universalité des démarches et des inférences tire sa force de cette compétence. Qu'elles soient établies par un individu et obtenues au cours de son activité particulière ne les entache pas $a$ priori d'arbitraire. Cet individu ne possède-t-il pas un savoir spécialisé, et l'art, ou la philosophie, ne sont-ils pas justement ces capacités qui n'existent nulle part ailleurs que dans ceux qui les acquièrent ou les pratiquent, comme état potentiel et préfiguration de ce qui doit être ou apparaître dans l'œuvre? Leur réalisation est une possibilité et non pas une certitude, sans que pour cela ils soient moins vrais, et moins accordés avec la réalité à laquelle ils peuvent tendre ou qu'ils soutiennent.

«On aura le droit de prétendre, écrivait Nausiphanes ${ }^{449}$, que le philosophe naturaliste (physikoi), après cette démonstration, possède la capacité de l'orateur, même s'il ne s'est jamais manifesté en tant qu'orateur, parce qu'il est demeuré loin de la vie publique. Nous prétendons cependant aussi que quelqu'un possède la capacité de bâtir, non seulement lorsqu'il exerce cette capacité, eu égard à cette activité en tant que telle, mais aussi eu égard au pouvoir d'exécuter le bâtiment à l'aide de matériaux de construction et des outils nécessaires, tout comme pour l'art des médecins et les autres savoirs. » 
Que l'homme soit porteur du savoir, que l'on pénètre l'ordre des êtres par son intermédiaire, voilà ce qui met les outils, les instruments dans la dépendance directe de son activité sensorielle et réduit l'importance d'une évaluation quantitative mesurante précise. Dès lors l'argument selon lequel les philosophes anciens n'avaient pas emprunté la voie de l'expérimentation exacte parce que seule la spéculation les attirait et qu'ils tournaient le dos au fait comme à la pratique, perd la puissance qu'on lui prête. Il serait trop facile de démontrer sa fragilité. Plus fondée à première vue, mais seulement à première vue, parait la thèse qui voit dans l'absence d'instruments la raison de l'empirisme ou de l'impossibilité, pour la plupart des philosophes grecs, de procéder à une exploration plus «scientifique » des phénomènes. W. Heidel a exposé cette thèse avec toute la précision souhaitable :

«Il est certain pourtant que les moyens employés par les grands artistes étaient extrêmement simples, bien que des mains habiles les trouvassent appropriés à leurs desseins. Le fait est que la civilisation grecque était aussi peu mécanique que possible, si l'on tient compte des résultats. Les instruments de précision manquaient, dans l'ensemble » ${ }^{450}$.

En est-il vraiment ainsi ?

Les tenants de cette thèse ne semblent pas avoir pris en considération le fait que l'appareillage instrumental des premières expériences réalisées par Galilée, Baliani, Mersenne, Torricelli ou Pascal n'aurait guère excédé les possibilités des Anciens. Pour mesurer la longueur d'un pendule battant la seconde, le mécanicien du XVII siècle n'a utilisé qu'une tour, une corde et des poids ${ }^{451}$. Ou encore, ainsi que l'affirme Galilée, la loi de la chute des graves pouvait se vérifier à l'aide d'un plan incliné et d'un récipient d'eau muni d'un robinet d'écoulement approprié. La fameuse expérience barométrique, si l'on ne tient pas compte de la qualité des matériaux dont on confectionnait

W.A. HEIDEL : The heroic age of science, Baltimore, 1933, p. 72.

451 S. MosCOVICI : Sur l'incertitude des rapports entre expérience et théorie au XVII ${ }^{\mathrm{e}}$ siècle. La loi de Baliani. Physis, 1960, I, pp. 54-43. 
les tubes, aurait déjà été à la portée du génie et des possibilités d'un Empédocle. Il en va de même des expériences de Léonard ou de Stevin. En réalité, avant l'ingénieur, personne n'a pratiqué l'expérimentation, personne ne s'est fié complètement au pouvoir des règles quantitatives. Cela est dû au fait que pour lui, la machine comme l'instrument avait une autonomie, était un automate permettant d'agir sur les forces matérielles non-humaines, et de laisser celles-ci agir. Par contre l'artisan avait uniquement confiance dans son habileté, et l'outil, de même que la précision des mesures, jouaient pour lui un rôle subordonné à ses propres opérations sur la matière première. Ce n'est donc pas l'absence ou la présence de l'instrument, son degré de précision, son rapport aux mathématiques qui sont en cause, mais le contexte formé par l'habileté à laquelle il est associé. Le philosophe naturaliste se meut dans le cadre préparé par les arts et sa tâche est de rendre l'observation plus systématique, d'affermir et d'expliciter sa méthode, elle-même conquête de l'homme de métier. Si l'idée de mesure abolit cet empirisme, elle n'abolit pas tout empirisme, notamment celui au sein duquel elle est née, le seul que reconnaissent le mécanicien, le fabricant d'instruments mathématiques, l'artilleur, comme un attribut inhérent à leur savoir, à leur industrie.

«La pratique des canons, affirmait Galilée, est relative à leurs différences, mesures et proportions ${ }^{452}$.

Quant aux inventions, elles devaient être accompagnées par la "mesure » ou la "raison», ainsi qu'il ressort du titre même de l'opuscule de Nicolo Tartaglia où il propose de récupérer le contenu des bateaux naufragés: "Inventions élaborées pour soulever avec mesure et raison tout navire coulé » (Venise 1550).

La diffusion des mécanismes a modifié les habitudes familières à de nombreux arts, introduisant le calcul mécanique et la géométrie ${ }^{453}$, la considération des rapports spatiaux, le dessin des trajectoires et les procédés d'estimation du temps et d'évaluation des poids, etc. Albrecht Dürer n'a-t-il pas redéfini les arts comme «arts fondés sur la

G. GALILEI : Opere, t. II, p. 607.

453 E.G. TAYLOR : The mathematical practitioner of Stuart England, Cambridge, 1954. 
mesure » ? La philosophie mécanique a dû parcourir une route longue et incertaine avant d'établir avec éclat, dans la connaissance, l'expérience et l'univers, ce qui s'était imposé avec évidence dans l'art. A cette fin, elle exclut d'abord de la description et de la compréhension des phénomènes, comme partie et comme moyen, le sujet, son action et ses organes sensoriels. Le monde, pour elle, est matière et quantité, et elle tient tout autre aspect pour secondaire ou réductible. Ceci peut paraître incomplet, néanmoins Descartes se fait un titre de gloire d'adhérer à une telle vision :

«Si ma philosophie lui (à Froidmont) parait trop grossière parce qu'elle ne considère que des grandeurs, des figures et des mouvements comme fait la mécanique, il condamne en elle ce que j'estime qu'on doit louer par-dessus tout et dont je suis particulièrement fier et glorieux, à savoir que j'use d'une façon de philosopher telle que tous mes raisonnements ont une évidence mathématique et que des expériences véritables confirment toutes mes conclusions ${ }^{454}$.

L'attraction et le pouvoir de cette évidence sont tels que tous les éléments de l'évidence antérieure s'estompent, se changent en sources d'erreurs et signes trompeurs. Les philosophes naturalistes qualifiaient d'illusion ce qui était aperçu à travers une lunette, et niaient le réel sous-jacent. Réciproquement, le témoignage des sens est taxé par le mécanicien de pure fantasmagorie. Ainsi le terrain solide sur lequel chacun croit se mouvoir est pour l'autre nuage fragile.

«En vérité, dit Galilée, je me sens poussé par la nécessité, aussitôt que je conçois un morceau de matière, ou substance corporelle, de l'imaginer doué d'étendue et de figure, de sorte qu'à l'égard des autres corps il soit grand ou petit, occupe telle ou telle place, à tel ou tel instant; qu'il soit au repos ou en mouvement, qu'il touche ou non d'autres corps, qu'il soit simple ou multiple ; en bref rien ne me permet d'imaginer un corps qui ne satisfasse à ces conditions. Mais que ce morceau de matière soit blanc ou rouge, doux ou amer, sonore ou non, odorant ou non, rien n'oblige mon esprit à le doter de semblables qualités; et si les sens ne leur servaient de véhicule, la raison ou l'imagination n'y parviendraient pas. D'où je déduis que ces goûts, odeurs, couleurs, à l'égard d'un objet où ils paraissent exister, ne sont rien d'autre que de simples 
noms et ont leur siège dans le sens de l'observateur ; celui-ci écarté, toute qualité de ce genre serait abolie et annihilée » ${ }^{455}$.

Qu'est-ce à dire ? Pendant longtemps on a été sensible à la couleur, à l'odeur, au son, aux formes, à tel point que l'observateur se pensait souverainement présent et aiguisait ses moyens de percevoir les phénomènes, la matière ; et brusquement on affirme qu'il est possible de négliger, voire d'anéantir toutes ces qualités, et d'imaginer le réel autrement, à savoir comme une machine dont on écarte tout ce qui dépend du jugement, de l'arbitraire de l'être humain. Les caractères que l'on envisage sont ceux qui, composant la matière inanimée, sont capables d'être mesurés, quantifiés. Les propriétés appréhendées par les sens ne pouvant se soumettre à ces opérations, on a le droit, tout au plus, de les évaluer de manière analogique :

«Bien qu'une chose puisse être dite plus ou moins blanche qu'une autre, continue Galilée, un son plus ou moins aigu, et ainsi du reste, nous ne pouvons néanmoins déterminer exactement si ce plus ou ce moins est en proportion double ou triple, sauf par une certaine analogie avec l'étendue du corps figuré » ${ }^{456}$.

L'expérience et la théorie se rapportent toutes deux à des grandeurs, à des forces qui sont présentes dans divers mouvements, sans que l'on s'arrête aux manifestations sensibles, soumises aux aléas d'une observation subjective et des conventions qui en découlent.

Le recours à l'outil mathématique et les caractères de cet outil sont définis par ces circonstances. Dans ce domaine, pour la philosophie mécanique, tout restait à faire. La géométrie conçue par les Grecs n'était immédiatement adaptée ni à l'explication d'un univers où tout est réductible au nombre, à la figure et au mouvement, ni à la description des instruments définis par l'énoncé de leurs dimensions, de leurs proportions et de leur poids. L'idée d'une géométrie quantitative, née des travaux des mécaniciens, rencontre des oppositions. Étendre les raisonnements de la géométrie aux distances et aux poids qui ne sau- 
raient être exprimés qu'en proportions et multiples d'unités jette un certain doute sur leur cohérence et sur la qualité des preuves qu'ils fournissent. Simon Stevin se sent obligé de défendre cette extension et le procédé de calcul qu'elle implique :

«Quant aux preuves du premier livre des éléments de l'art pondéraire, écrit-il, et aussi de l'hydrostatique, où les gravités sont désignées par des nombres et des poids connus tels que les livres; si quelqu'un devait tenir que ce ne sont pas là des preuves mathématiques, comme dans le premier exemple de la première proposition du premier livre, une fois que le contenu de la proposition a été montré au moyen de nombres et de poids connus, mais dans le second exemple il a aussi été prouvé mathématiquement, et de même façon pour les autres. De telle façon que la preuve pratique a parfois été ajoutée à la preuve mathématique pour atteindre une plus grande clarté » ${ }^{457}$.

Le parallélisme est étroit entre les démonstrations mathématiques et celles où se mêlent des quantités spatiales ou dynamiques. A la rationalité existante, il est indispensable d'en substituer une nouvelle, et la signification des mathématiques doit être changée. La quantification est la source de ce changement ; c'est d'elle que découle la certitude que l'on peut attendre de ces disciplines. La quantité n'est pas, pour elle, un simple nombre dans une relation de proportion, mais l'expression d'une grandeur que l'on souhaite mesurer, et qui représente une propriété particulière de l'objet. De là l'importance du concept de dimension. L'emploi des mathématiques dans le domaine des mécanismes a pour conséquence d'élargir la famille des dimensions, en y incluant celles qui ont trait au mouvement à côté de celles qui ont trait à l'espace.

«Par dimension, écrit Descartes, nous n'entendons rien autre chose que le mode et le rapport sous lequel un sujet quelconque est jugé mesurable, en sorte que non seulement la longueur, la largeur et la profondeur sont des dimensions du corps ; mais la pesanteur est la dimension suivant laquelle les sujets sont pesés, la vitesse est la dimension du mouvement, et ainsi une infinité d'autres choses de cette sorte ${ }^{458}$. 
Ceci n'est qu'un premier pas. Pour être comparée à une autre, la dimension suppose une unité, conventionnelle ou « d'emprunt».

« Je ne sais pas quel est le rapport de grandeur entre deux et trois, si je ne considère un troisième terme, à savoir l'unité, qui est la commune mesure des deux autres $»{ }^{459}$.

Mais s'il est aisé de discerner de telles unités quand la grandeur est discontinue, la continuité géométrique y fait obstacle. Or, celle-ci peut être conciliée avec la discontinuité numérique lorsque l'unité « d'emprunt » s'applique à sa détermination :

«Au moyen d'une unité d'emprunt les grandeurs continues peuvent être ramenées à la pluralité... La pluralité des unités peut ensuite être disposée dans un ordre tel que la difficulté qui était relative à la connaissance de la mesure ne dépende enfin que de la considération de la mesure ${ }^{460}$.

Un pont est jeté entre la géométrie et l'algèbre, et la quantité peut appartenir au domaine de chacune sans qu'il soit fait violence à leur rigueur et à leurs principes. Cependant, ce qui a créé la nécessité de ce pont et l'a rendu possible, c'est la mesure - ceci apparaît à chaque étape de la pensée cartésienne. Ce n'est pas uniquement un moyen, mais bien ce qui marque les sciences mathématiques, leur sens nouveau et leur essence. Dans l'esprit de Descartes, la Mathématique universelle est

« tout ce que l'on peut demander concernant l'ordre et la mesure, sans aucune application à une matière particulière ${ }^{461}$.

La philosophie mécanique peut emprunter la voie de l'analyse mathématique, parce qu'elle se donne la mesure pour critère et pour guide. L'auteur du Discours de la Méthode n'est-il pas le premier à faire de la géométrie une théorie de la mesure ? Et celle-ci n'est-elle 
pas au cœur de sa méthode et de sa philosophie ? Ne substitue-t-elle pas à la logique un autre " organon » de la philosophie, qui permet de combiner des dimensions - la vitesse et le poids, l'espace et le temps — de passer de la théorie à l'expérience, en déterminant des indices quantitatifs, d'établir, enfin, des lois et des relations rigoureuses ? Pour cette raison, la mathématique est, aux yeux de Descartes, une discipline "universelle » et indépendante de toute "matière particulière », car elle a un objet propre — commun à ces matières "l'ordre et la mesure ». Ainsi la physique — ou plutôt la mécanique - devient mathématique. Mais c'est parce que les mathématiques, elles, sont devenues mécaniques ${ }^{462}$. Descartes et Newton font mention expresse de cette fusion. Descartes s'oppose à ce que l'emploi des instruments amène à faire des discriminations entre les familles de lignes géométriques ; en effet, en géométrie, cet emploi doit être général :

« Je ne saurais comprendre pourquoi ils (les anciens) les ont nommées (les courbes de degré supérieur) Méchaniques, plutôt que Géométriques. Car de dire que ç'ait été à cause qu'il est besoin de quelques machines pour les décrire, il faudrait rejeter, pour la même raison, les cercles et les lignes droites, vu qu'on ne les décrit sur le papier qu'avec un compas et une règle, qu'on peut aussi nommer machines $\gg 463$.

Si les philosophes naturalistes voyaient dans les instruments une intrusion injustifiée des machines dans la nature, le philosophe mécanicien, habitué à elles, se refuse à exclure de la géométrie les courbes qu'elles décrivent et qui, pour lui, représentent des mouvement et non pas des formes figées.

« Décrire des lignes droites et des cercles, écrit de son côté Newton dans la Préface de ses Principes Mathématiques, ce sont des problèmes, mais non pas géométriques. La solution de ces problèmes est demandée à la mécanique ; la géométrie montre leur emploi quand ils sont résolus; c'est la gloire de la géométrie qu'à partir de ces quelques principes, pris à l'extérieur, elle puisse

« Mais, historiquement, c'est au contraire l'observation des mouvements qui a inspiré toutes les découvertes du calcul infinitésimal, et c'est sous le vêtement mécanique qu'elles se sont présentées d'abord aux regards des chercheurs ». P. PAINLEVÉ : Les axiomes de la mécanique, Paris, 1955, p. 24. 
faire tant de choses. Par conséquent la géométrie est fondée sur la pratique mécanique et n'est que cette partie de la mécanique universelle qui propose et démontre exactement l'art de mesurer ».

La géométrie et la mécanique fusionnent, la connaissance mathématique se change en connaissance mesurante par excellence. A ce titre elle assure la communication de la théorie avec l'expérience. La première est nécessairement déductive, car, cherchant à parachever le savoir existant, elle remonte des effets attestés vers leurs causes et en avançant des causes vers les effets, effets surprenants, elle provoque des inventions. Ce qui réunit les deux termes de ce cheminement est une règle. L'art mécanique est plein de telles règles. Elles expriment le rapport de l'inclinaison du canon à la puissance d'impact du boulet, décrivent les rapports entre l'angle d'ouverture d'un compas et la figure qu'il dessine, entre la convergence des droites dans la perspective et l'impression qui doit être produite, etc. Transmises d'un mécanicien à l'autre, et employées avec intelligence, elles aident à éviter l'impossible, à prédire les résultats que l'on peut espérer atteindre.

« Si tu me disais : Que produisent ces règles ? A quoi servent-elles? Je te réponds, note Léonard de Vinci dans un de ses célèbres aphorismes, qu'elles tiennent la bride à l'ingénieur et au chercheur et ne permettent pas que ceux-ci ou d'autres fassent des choses impossibles ou soient considérés comme fous inutiles ».

Projetées par le philosophe dans la machine de l'univers ${ }^{464}$, ces règles se convertissent en lois et en principes. Ceux-ci pour saisir les causes, celles-là pour préparer la déduction des effets. Les lois ont trait à des quantités et leur réalité peut être confirmée ou infirmée par l'expérience. Non pas par n'importe quelle expérience, mais par celle qui apporte des informations mesurables à l'aide d'instruments. C'est seulement ainsi qu'on atteint la certitude. Pour jouir de pareil privilège, la philosophie s'approprie et le langage mathématique ${ }^{465}$ qui, outre la mesure, signifie la relation, c'est-à-dire la règle et la loi, et

464 «Et les règles suivant lesquelles se font ces changements, je les nomme les lois de la Nature ». DESCARTES : Euvres, t. II, p. 37.

465 «C'est l'étude du mouvement, de la vitesse, de l'accélération, qui les a conduits, pas à pas, aux notions fondamentales du Calcul différentiel, et les découvertes mathématiques se muent dans leurs écrits en axiomes de la Mécanique ». P. PAINLEVÉ : op. cit. p. X. 
l'art instrumental qui, au delà de la précision et de l'exactitude des mesures, reproduit le modèle de la nature.

J'ai rappelé toutes ces circonstances pour montrer que la philosophie mécanique est comme forgée par le mouvement d'invention. C'est à l'élément véritablement révolutionnaire qui affecte son contenu, ses techniques intellectuelles - les mathématiques et l'expérience - que j'ai donné la préférence sur d'autres tendances qui me paraissaient secondaires ${ }^{466}$.

Déjà Cardan répond à Scaliger qui lui reproche : «Tu as donné à un simple artisan (Archimède) le pas sur Aristote » en ces termes :

«Sans doute ils (Guillaume d'Ockham et Guillaume de Heytesbury) ont écrit d'une manière ingénieuse et claire ; mais en eux l'invention est nulle ».

Même plus d'un siècle plus tard, la stérilité à ce point de vue restera un argument décisif contre « la philosophie aristotélicienne » jugée « inapte à de nouvelles découvertes ». ${ }^{467}$

466

On a coutume d'expliquer les traits essentiels de la philosophie mécanique en adhérant à une des grandes philosophies anciennes, soit celle de Platon (F.R. JOHNSON: Astronomical thought in Renaissance England, Baltimore, 1937 ; A.E. TAYLOR: Platonism and its influence, New York, 1932), soit celle d'Aristote (P. DUHEM : op. cit.; A. CROMBIE : op. cit. ; J.H. RANDALL : The school of Padua and the emergence of modern science, Padoue, 1965). Assurément les doctrines de Platon et celles d'Aristote ont exercé et exercent une influence sur notre pensée, comme celles d'Archimède, de Newton, de Démocrite, de Kant, de Karl Marx, et bien d'autres. Toutefois il est regrettable de voir des esprits supérieurs, faute de rechercher d'autres moyens d'explication, instituer une sorte d'antagonisme éternel entre Platon et Aristote, pour donner plus de vie à leurs monographies, et ne pas avoir d'autre ambition que de prouver que tout ce qui existe dans l'histoire des sciences ou de la philosophie est dû à l'un ou à l'autre.

La plupart des preuves apportées dans ce domaine sont fondées sur les témoignages des « influencés » eux-mêmes, Galilée, Newton, Grosseteste, etc. qui semblent souvent vouloir c'est là une tendance générale — se munir d'un arbre généalogique. A. Koyré a bien montré (Newton, Galilée et Platon, Annales, 1960, 16, pp. 1041-59) que cette référence à l'autorité d'un Platon n'est en fait qu'une simple figure de style, qui ne recouvre pas un emprunt réel de notions ou de théories.

467 J. GLANVILL : The vanity of dogmatizing, Londres, 1661. 
La philosophie mécanique, elle, se consacre assidûment à faire des découvertes, à acquérir les méthodes propres à y conduire.

Elle s'insère dans le processus de création des facultés qui manifestent une catégorie naturelle, là où celle-ci a posé son empreinte, revendiqué son originalité et systématisé ses rapports au milieu matériel. Toutefois, pour accomplir complètement son programme, cette philosophie aspire à construire également un édifice global qui inclue l'homme et le monde. L'objectif spécifique de la connaissance est bien la formulation des lois de la nature, l'établissement de l'architecture de la nature, de ses disciplines, et l'énoncé des voies par lesquelles on y parvient: le tout fondu en un système. L'invention qu'elle poursuit et qu'elle retrouve partout n'est, en dernier lieu, rien d'autre que la machine de l'univers. 
Chapitre VI.

De l'univers de la machine à la machine de l'univers :

II. La nature mécanique

\section{Le monde en question}

$\underline{\text { Retour à la Table des Matières }}$

\section{La forme et la matière.}

Nulle part il n'est possible de séparer l'instrument matériel et intellectuel qui permet aux hommes de connaître le monde, du monde qu'ils engendrent en le connaissant. A l'époque qui précède l'éclosion des techniques et des philosophies mécaniques prévaut l'impression d'une inadéquation, d'une dissolution ${ }^{468}$ de l'état naturel qui avait soutenu avec tant de force et de cohérence l'action et la vision des collectivités humaines. Dans un poème maintes fois cité, John Donne laisse éclater cette détresse devant la disparition virtuelle d'un ordre harmonieux et familier :

« L'élément du feu est entièrement éteint.

Le soleil est perdu, et la terre ; et aucun homme

$\mathrm{Ne}$ sait vers où se diriger pour le trouver,

Et les hommes avouent librement que ce monde est passé,

Alors que dans les Planètes et dans le Firmament

Ils en cherchent tant de nouveaux $\gg{ }^{469}$. ground, Cambridge, 1934 ; M.H. NICOLSON : The breaking of the circle, Evanston, (Ill.) 1950.

469 J. DonNe : Anatomy of the world : First Anniversary, Londres, 1611. 
Quelle est donc la réalité dont la structure se désagrège, dont les éléments disparaissent? Il s'agit du cosmos fini, hiérarchisé, qualitativement diversifié, dont les Grecs ont découvert et défini le modèle, la nature organique. Codifié, remanié et remis à jour, sans plus, par la philosophie naturelle - dans sa variante scolastique ou nominaliste - il s'est prorogé depuis l'antiquité. Aussi, avant d'exposer les lignes générales de l'univers que les mécaniciens - ingénieurs ou philosophes - inventent en l'instituant, n'est-il pas inutile de rappeler les grands traits de celui qu'ils ont rendu caduc.

La relation entre les processus que l'on constate dans le monde des choses faites par l'homme (techne onta) et ceux qui sont à l'œuvre dans le monde des choses données à l'homme (physei onta) a frappé d'emblée la plupart des savants anciens. Aristote, dont l'œuvre a couronné tous leurs efforts, se réfère aussi à cette intelligence artiste, au métier avec ses recettes, son labeur et l'ensemble de ses structures opératoires. Entre ce qui se passe lorsqu'on façonne un objet d'art et ce qui a lieu lorsque la nature agit, il ne voit pas de différence importante ; au contraire, tout le conduit à rechercher dans le premier processus une expression plus explicite du second :

« Si une maison était une chose engendrée par la nature - si elle croissait - elle serait produite de la même façon que l'art la produit. Si les choses naturelles n'étaient pas produites par la seule nature mais aussi par l'art, elles seraient produites par l'art de la même façon qu'elles sont produites par la nature. Chaque étape conduit à la suivante ». (Physique, II, ch. 8, 199 a).

Pour avoir rapproché aussi étroitement l'art et la nature, les choses de l'art et les choses de la nature, on ne peut s'étonner qu'ensuite il ait pris tant de soin à les différencier. Aristote les sépare essentiellement en fonction de leur origine. Ce qui est de la nature (physei) contient en soi-même la source de sa croissance, de son mouvement, de son organisation. Les paradigmes sont connus. L'être naturel est comme le médecin qui se guérit lui-même. En d'autres termes, il est comme l'artisan qui n'applique pas son savoir à quelque chose d'extérieur mais à lui-même. Ce qui est artifice suppose l'intervention d'un agent extrinsèque. Les objets propres aux divers métiers, résultant du travail 
sur la matière première, offrent d'innombrables exemples. La distinction est cependant fragile, l'argument qui la fonde pourrait être retourné facilement. Lorsque la terre se dessèche, elle ne le fait pas spontanément, toute seule. Quelque événement ou facteur externe le vent, le soleil - est présent. Donc l'action des éléments serait techne et non physei, artificielle et non naturelle. La classification à laquelle veut procéder Aristote est plus intuitive que rigoureuse et il semble en avoir été parfaitement averti (Phys. II, 199 b). Du reste il a toujours soutenu l'unité profonde de l'art et de la nature puisque chacun conduit à une fin et que le premier peut réaliser la fin que la seconde « est incapable d'avoir œuvré ».

Mais avant d'introduire la pensée d'un but dans l'ordre du monde, il faut décrire l'être (Qu'est-il pour autant qu'il est ?) Les termes de cette description sont, conceptuellement, la matière et la forme. Ils reproduisent à l'intérieur de la nature la dualité de la chose naturelle et de la chose artificielle. La matière serait en quelque sorte le donné, ce qui existe par soi, le bois, l'airain, la pierre, et la forme serait le modèle, l'organisation qu'elle reçoit et qui répond à ses possibilités internes. L'écart entre matière et forme est difficile à établir en pratique. Aristote définit clairement cette dernière lorsqu'il s'agit d'objets fabriqués, mais non pas lorsqu'il s'agit des êtres naturels au sens où il les entend. De là découle le constant chevauchement de deux visions de la nature qui sont constamment et concurremment présentes. D'un côté elle est activité, changement, mouvement, spontanéité propre aux processus matériels, et d'un autre côté elle est conjonction de la matière et de la forme, structuration cohérente des deux, guidée par quelque fin. Toutefois, c'est bien cette dernière conception de la nature qui demeure prépondérante. Ceci ressort de la façon dont Aristote conçoit tout processus. Il suppose une matière qui peut prendre une forme ou se présenter privée de cette forme. Le devenir de tout être s'inscrit dans cette apparition du sujet matériel (hylé) à la lumière de la forme (eidos) qui le transforme de ceci en cela, de bois en lit, d'enfant en adulte, et enregistre son aboutissement.

« De même, en effet, qu'on appelle art dans les choses ce qu'elles ont de conforme à l'art et de produit, de même on appelle nature ce qu'elles ont de conforme à la nature et de naturel. Or d'une chose artificielle nous ne dirons pas qu'elle a rien de conforme à l'art si elle est seulement lit en puissance et 
ne possède pas encore la forme du lit, ni qu'il y a en elle de l'art; de même d'une chose constituée naturellement : en effet la chair ou l'os en puissance n'ont pas encore leur propre nature et n'existent pas par nature, tant qu'ils n'ont pas reçu la forme de la chair et de l'os, j'entends la forme définissable, celle que nous énonçons pour définir l'essence de la chair et de l'os ». (Physique, IV, $193 \mathrm{a}-\mathrm{b})$.

L'opposition de la matière et de la forme, dans cet enchaînement dynamique, est aussi opposition du potentiel à l'actuel, car dans le cours du faire et de la croissance, tout ce qui existe existe en vue de son parachèvement. Ce qui est contenu en puissance reçoit son être plein et véritable dans une organisation actuelle. N'en va-t-il pas ainsi de l'airain qui entre dans l'atelier du sculpteur, du bois dans celui du menuisier ? Mais cela indique aussi que toute matière est toujours à l'état de mouvement et de changement, qu'il n'y a jamais, à proprement parler, de matière « morte » ou qui subsiste en soi sans rapport à ce qu'elle doit accomplir. Il n'y a pas d'être qui ne devienne et, pour cette raison, il est pouvoir, énergie, comme le savoir-faire dans les bras et l'intelligence de l'artisan.

Si la matière et la forme sont les deux termes qui embrassent tout processus naturel dans sa totalité et décrivent la figure de ce qui est $^{470}$, elles représentent aussi des modalités d'action. A ce titre elles sont des causes: la cause matérielle et la cause formelle. Aristote considère une séquence d'intervention d'ordre causal, et sa théorie, qui est parmi ses apports les plus importants à la philosophie naturelle, s'inspire de ce qui se passe dans la réalisation d'une œuvre d'art. L'artiste se propose un but (cause finale) en produisant (cause efficiente) un objet ayant certaines propriétés dont il possède le prototype (cause formelle) dans son savoir et son intellect, par l'emploi d'une substance adéquate (cause matérielle) dont l'objet sera fait. Établir l'enchaînement des quatre causes est une des tâches les plus sérieuses d'une analyse philosophique particulière, afin d'atteindre l'évidence et la connaissance, tout comme procède l'homme de métier afin de réaliser les impératifs de son art. Ce ne sont pas les principes, ni les théories préconçues, mais l'emploi conséquent de ce patron, qui permet d'atteindre la vérité et le réel : 
«Des philosophes, disait Aristote, emportés par l'amour de leurs préjugés, en sont venus, semble-t-il, à faire la même chose que les dialecticiens : ils défendent les thèses. Ils tiennent leurs principes pour vrais : ils endossent donc avec confiance tout ce qui s'ensuit. Comme s'il ne fallait pas juger des principes, au moins de certains d'entre eux, par leurs conséquences, et surtout par leur terme final. Ce terme dans le cas de la science pratique, c'est l'œuvre d'art. Dans le cas de la science de la nature, c'est par-dessus tout l'évidence sensible $»$.

Le parallélisme de l'œuvre d'art et de l'évidence sensible est formulé sans ambages : la communauté de leur finalité aussi. Le modèle artisanal ou la « cause artisanale » s'inscrivent dans le cycle de la nature comme ils s'inscrivaient dans la démonstration par le moyen du syllogisme ${ }^{471}$, leur traduction philosophique. La logique se prolonge ainsi dans la physique. Est-ce suffisant? Nous observons en fait que cette théorie de la causalité exprime et synthétise une séquence historique, la séquence des questions auxquelles la philosophie naturelle s'est efforcée de répondre, et ces questions se posent à l'origine dans le monde des métiers pour se concrétiser dans celui de la nature.

Les premiers savants ioniens ont commencé par se demander « de quoi les choses sont-elles faites ?» et ont ainsi substitué au principe animal le principe substantiel ou matériel. A travers le mythe, ils se heurtent en effet au monde agraire, monde cyclique où l'alternance du jour et de la nuit, l'union sexuelle, la croissance et le déclin des espèces végétales et animales règlent la succession et l'intelligence des phénomènes. Au contraire, ce qui a valeur d'évidence pour eux et pour les hommes de métier, ce sont les objets et les substances qui servent à les fabriquer. D'où la véritable signification de la nature : matériau à partir duquel l'habileté produit des objets, origine et ensemble des ressources et de leurs qualités. Pour la déterminer, à la place d'un principe animal, c'est un principe substantiel - eau, terre, air, feu - que l'on doit et que l'on peut désormais chercher et trouver. 
Avec les pythagoriciens, mais surtout à partir de Parménide, on s'est interrogé sur l'organisation, les proportions qui apparaissent dans tous les phénomènes. On a surtout constaté qu'il fallait rendre compte des propriétés du mouvement qui instaure cette organisation ou cet ordre réglé. A ce stade, du moins, il devait être attribué à un agent, que ce soit l'élément-artiste lui-même — le feu d'Héraclite — ou l'artisan fait élément - le nous d'Anaxagore. Celui-ci a deux aspects : c'est une cause motrice et une intelligence régulatrice, une énergie qui agit et un esprit qui connaît. C'est donc un être, une substance à part qui n'est pas mélangée aux autres.

« Les autres choses ont une part du tout, mais le nous, lui, est infini, autonome, et ne se mélange à rien ; il est seul lui-même et par lui-même, car, s'il n'était pas par lui-même et s'il était mêlé à quelque autre chose, il participerait à toutes choses dans la mesure où il serait mêlé à l'une d'elles. Car, en tout, il y a une part du tout, ainsi que nous l'avons dit précédemment. Et ce qui serait mêlé au nous l'empêcherait d'avoir pouvoir sur chaque chose, comme il l'a maintenant, étant seul par lui-même. C'est de toutes les choses la plus légère et la plus pure ; il possède toute espèce de connaissance de tout et la force la plus grande. Tout ce qui a une âme, le plus grand comme le plus petit, est sous le pouvoir du nous » (Diels, fr.12).

De toute évidence, le nous n'est pas un être divin. Ce n'est pas une substance primordiale : il est cependant essentiel. Sa présence dans une organisation matérielle dépend de la place de celle-ci dans la chaîne des êtres. Chez l'homme, il est incarné dans la main, car, aux dires d'Anaxagore, elle est le signe de la supériorité de notre espèce. Bref, le nous est une intelligence artiste, et avec lui le facteur artisanal intervient ouvertement dans l'architecture du monde et le déroulement des phénomènes ${ }^{472}$.

Enfin, pour épuiser les exigences d'une définition nécessaire, à savoir pourquoi les choses sont ainsi plutôt qu'autrement, plutôt une sta-

472

« Le plan préconçu du monde (représenté dans le nous, n.n.) est une idée digne de la physique rationnelle $\mathrm{du} \mathrm{V}^{\mathrm{e}}$ siècle. Il trouve place à une époque qui, dans tous les domaines de l'existence, accorde une importance décisive à la techne et la trouve aussi dans la nature. La construction du mouvement de tourbillon créateur est le mécanisme plein d'art par lequel Anaxagore ainsi que d'autres contemporains croient que le monde s'est formé ». W. JAEGER : Die Theologie der frühen griechischen Denker, Stuttgart, 1953, p. 186. 
tue qu'une maison, la santé plutôt que la maladie, l'invention d'une cause finale, en tant qu'art ou modèle préexistant dans ce qui conduit à la statue ou à la santé, semblait s'imposer. La concordance de la causalité et de la fabrication dans les métiers ${ }^{473}$, si ouvertement proclamée par Aristote, éclaire du même coup le sens et le substrat des réponses que les philosophes ont cherchées, des questions qu'ils ont posées à propos de l'état naturel. Et ce fut là sa grande trouvaille, le postulat à l'aide duquel il a intégré ce qui le précède, à savoir « d'appliquer à l'ensemble de la nature ce tableau des conditions de la production et de lui conférer une valeur métaphysique $»{ }^{474}$ (3). Ainsi le travail artistique devient connaissance philosophique, ce qui est fait dans l'atelier ouvrant sur ce qui est dans l'univers.

\section{$\underline{\text { Retour à la Table des Matières }}$}

\section{L'unité des espèces de mouvement.}

Deux régions se découpent dans l'univers, l'une céleste et l'autre terrestre. La région céleste comporte des mouvements circulaires, estimés simples et éternels. Le mouvement en ligne droite serait, par contre, imparfait et éphémère. A chacune de ces deux espèces de mouvement correspondent des principes matériels spécifiques. La substance capable de se mouvoir en cercle est l'éther ; c'est en quelque sorte le cinquième élément, le plus noble et le plus sublime, celui qui constitue la partie supérieure, le premier ciel, comprenant les étoiles fixes, qui s'étend jusqu'au niveau de la lune. Cette partie n'est-elle pas la plus proche du premier moteur, du moteur immobile qui ne connaît ni commencement ni fin, corps animé et nous matériel ? La sphère des astres jouit des mêmes privilèges, bien qu'elle soit moins élevée dans la hiérarchie des perfections. Chacun des astres a un orbe solide, cristallin, hérité du firmament vitrifié d'Empédocle, et pour rendre compte de leur mouvement, Aristote en a dénombré cinquantecinq. Il justifie de la sorte, physiquement, le système planétaire proposé par le philosophe-géomètre Eudoxe et adapte les observations de

\footnotetext{
473 « Des démarches de la fabrication, il ne tire pas seulement quelles sont les causes d'un phénomène donné mais l'idée même de chercher les causes, le cadre même de sa recherche ». J.M. LE BLOND : Logique et méthode chez Aristote, op. cit. p. 330.

474 J.M. LE BLOND : ibidem.
} 
Gallipe de Cyzique. L'architecture de l'ensemble est conforme aux hypothèses astronomiques de l'époque appropriées à une conception particulière de la substance et du mouvement. La terre s'y trouve, on le sait, au centre. Sa région est la moins étendue. Elle est entourée des zones de l'eau, de l'air, du feu, qui ont chacun son lieu propre. C'est une des propriétés de l'univers d'être plein - la critique du vide est constante chez Aristote - et d'être ordonné, de telle sorte que chaque corps élémentaire ait son lieu, dit lieu naturel, et que tout ce qui déplace un corps de son lieu, de son centre, engendre un effet nonnaturel ou violent. Dans ce cadre, le mouvement rectiligne se définit toujours par son sens, " en s'éloignant du centre » et « en allant vers le centre ». Le lourd et le léger s'opposent en ce que le premier se dirige vers le bas, vers le centre, le second vers le haut, en s'écartant du centre. Par extension, cette définition des qualités vient s'appliquer aux éléments. La terre et l'eau, combinaison des attributs du froid et du sec d'une part, du froid et de l'humide d'autre part, étant lourdes, ont toujours leur lieu naturel vers le bas. Le chaud et l'humide qui composent l'air, le chaud et le sec qui composent le feu, représentent la légèreté et ont leur lieu vers le haut. Il existe ainsi une chaîne continue d'équivalences allant des qualités perceptibles aux mouvements observables, en passant par les matières ou les substances sur lesquelles ou à l'aide desquelles on agit habituellement.

Nous retrouvons, dans cette partie sublunaire qu'est la terre, les éléments auxquels toute philosophie naturelle se rapporte pour expliciter les propriétés du réel, et dont Empédocle a reconnu le caractère ultime. Aristote, plus près d'Anaxagore et surtout de Platon, les décrit comme résultant d'une matière première ou protehyle qui, au gré des qualités qui l'affectent, prend des formes substantielles différentes ${ }^{475}$. Celles-ci sont les effets d'un principe extrinsèque mais inséparable qui détermine les possibilités de cette matière comme le modèle d'une œuvre dans un art particulier détermine les qualités et les manifestations de la substance à laquelle il s'applique. La transformation et la combinaison des qualités est un phénomène de permutation dont le philosophe fait un tableau complet en en définissant les modalités.

« La matière première est une pure abstraction et ne peut être autre chose, puisque, même unie à une forme, la matière n'est jamais connaissable en soi, mais seulement par analogie avec les fabrications artificielles ». L. RoBIN : La pensée grecque, Paris, 1932, p. 345. 
Quant aux opérations affectant les corps composés, ce sont celles qui sont déjà familières aux philosophes anciens et aux praticiens, à savoir le mélange, la combinaison et la solution, toutes opérations communes dans les arts et que nous appellerions aujourd'hui physicochimiques. Chacune d'elles est associée à un mode de mouvement. A l'exception des philosophes atomistes, encore que nous n'en soyons pas certains, es philosophes naturalistes ne considèrent pas le mouvement uniquement comme le changement de lieu. Ce dernier n'est qu'une espèce particulière du mouvement. Trois autres espèces s'y ajoutent : l'altération de la substance du corps qui aboutit à sa corruption ou à la naissance d'un autre corps, l'augmentation ou la réduction d'un corps par dilatation et contraction, et enfin la modification de la qualité. Tous les changements sont interdépendants. La raison de cette liaison constante des modalités de changement paraît se trouver dans les opérations à l'examen desquelles le savant s'efforce. Assurément, la séparation du mouvement d'avec les autres changements n'est possible que si l'on distingue, dans une suite d'actions, le déplacement de l'instrument ou de la force motrice. Cependant le potier qui fait tourner sa roue appréhende solidairement son mouvement, l'effet que celui-ci peut avoir sur la forme du vase, sa dépendance de la consistance de l'argile et la dessiccation plus ou moins prononcée qui a lieu à mesure que la roue tourne. Le philosophe ne pouvait guère briser cette chaîne sans se départir de l'axiome suivant lequel « dans les choses artificielles comme dans les choses naturelles, les conséquents et les antécédents sont entre eux dans le même rapport ». Donc, loin de le blâmer, comme on l'a fait, ou de voir dans sa théorie le signe d'un esprit purement classificateur, nous reconnaissons là le témoignage d'un esprit rigoureux envers les faits qu'il avait à traduire dans ses concepts et à expliquer sous l'angle de la nature.

Non seulement Aristote ne brise pas l'unité mentionnée, mais il l'encadre, si l'on peut dire, entre les deux termes qui, de l'art et de ses possibilités, en sont venus à caractériser tout phénomène matériel : la qualité et la finalité. A chaque instant, l'enchaînement est repéré ou expliqué par des combinaisons que traduisent des proportions qualitatives ou des qualités. L'air, l'eau et tout élément sont conçus à l'aide des propriétés qualitatives, chaud, humide, etc. De la matière première 
jusqu'à l'objet ultime, seules sont utilisées et utilisables les données de l'observation sensible. A la limite, le déplacement lui-même apparaît comme une qualité, par exemple le déplacement vers le bas d'un corps liquide ou d'un corps solide parce que liquide ou solide. Mais ce qui enveloppe davantage la pensée du mouvement, du changement, est l'idée d'une finalité, d'une préméditation. Chaque corps se meut vers son lieu naturel, chaque modification d'une substance l'éloigne ou l'approche de sa forme. Le principe d'ordre dans l'univers est celui des fins; il est aussi le garant de son unité et la voie privilégiée par laquelle on peut le connaître.

« La science la plus élevée, et qui est supérieure à toute science subordonnée, est celle qui connaît en vue de quelle fin il faut faire toute chose. Et cette fin est le bien de chaque être, et d'une manière générale, c'est le bien suprême dans l'ensemble de la nature ». (Métaphysique, A 2,982 b).

Retour à la Table des Matières

\section{Le point de vue organique.}

Werner Jaeger observait que les Grecs avaient adopté, au sujet des phénomènes, un «point de vue organique ». La remarque est exacte, car nous les voyons préoccupés par l'ordre structuré et la finalité, comme par l'existence d'un plan immanent, d'une sorte d'intelligence active dans l'univers et dans les choses. Aristote manifeste ce point de vue aux deux niveaux. Au niveau du cosmos dans sa totalité, il retient la présence d'un moteur immobile, auteur et source du mouvement circulaire parfait, matière spiritualisée se conduisant avec mesure et prévoyance. Au niveau des phénomènes ordinaires - outre le mélange et la décomposition - tout ce qui vient à l'être et disparaît suit un but qui est aussi actualité et forme du sujet; lorsque celui-ci n'atteint pas encore ce but ni cette forme, il est défini par leur privation, leur absence, et à cet égard il est puissance et matière. La hiérarchie même des parties de l'univers est déterminée par l'importance de leur fin. Aristote admire la sublimité de l'arrangement céleste lorsqu'il le compare aux événements terrestres. Pourtant cet enthousiasme n'est pas permanent ni peut-être fondamental. Dans les corps célestes, il 
voit une source de plaisir, justement parce que nous les connaissons incomplètement,

« de même qu'un coup d'œil jeté sur des personnes que nous aimons est plus délicieux qu'une contemplation prolongée d'autres choses, quels que soient leur nombre et leurs dimensions. »

Il aperçoit dans les choses terrestres l'occasion de parachever nos connaissances, par quoi elles compensent largement "l'intérêt sublime des choses célestes »; c'est donc aux choses terrestres qu'il s'est effectivement consacré.

Dans le ciel règne le démiurge, dont la pensée projetée garantit la cohésion de l'ensemble et son autonomie. Sur terre, son art, concret et multiforme, offre les matériaux indispensables à tout travail philosophique - ses modèles et ses notions, ses substances et ses observations - à partir desquels ce qui est réel doit être entendu.

Aristote couronne alors le cycle commencé par Thalès de Milet et rendu conscient à lui-même par Parménide d'Elée. A bien y regarder, il a obéi à un objectif profond : fonder l'art en nature et lui donner sa portée universelle. La découverte et l'institution d'un nouvel état de nature marquent les étapes de réalisation de cet objectif. Si celui-ci est taxé d'organique, ce n'est point, ainsi qu'on l'a soutenu, parce qu'une intelligence quelconque y est supposée, ni parce qu'il décalque les phénomènes de la vie ou est envisagé dans une perspective biologique. Cette interprétation est un contre-sens, attribuant au concept fondamental d'organon, instrument animé par la main et l'intelligence de celui qui le manie au cours de ses échanges avec les pouvoirs matériels, une connotation qu'il n'a jamais eue.

C'est dans les travaux manuels et leurs effets qu'Aristote perçoit une voie - qui n'est pas une simple analogie - pour comprendre l'union sexuelle, la formation des êtres vivants. La physis des philosophes naturalistes est fabricatrice et ordinatrice, se règle suivant ses propres normes («La nature ne fait rien en vain », etc.) se donne ses outils tout comme l'art et l'artiste. Que celui-ci y soit intégré, on en 
voit la possibilité. L'homme habile, dont le savoir et le savoir-faire imprègnent l'intelligence et le corps, réserve d'énergie motrice, est un agent matériel semblable aux autres. Le sujet et l'objet n'ont pas à être arrachés l'un à l'autre, avant que celui-ci devienne un automate et que la puissance non-humaine agisse sans le guidage de la puissance humaine pour, à terme, l'éliminer. Ces philosophes s'inspirent de ce qui advient réellement dans le concert des puissances objectives - au nombre desquelles figure la main-artiste engagées dans un cycle commun d'échanges. C'est en quoi leur nature est organique. 


\section{La naturalisation des artifices}

$\underline{\text { Retour à la Table des Matières }}$

\section{Jouer et faire.}

Tandis que cet ordre naturel semblait traduire la réalité la plus profonde, le paysage de la vie ordinaire et l'imagination des hommes s'en éloignaient subrepticement. Quiconque avait la volonté et la capacité d'ouvrir les yeux, à partir de l'époque de la Renaissance ${ }^{476}$, apercevait des pompes, des moulins, des engins de guerre ou de paix, et des horloges. Les ouvrages que l'on imprimait et qui commençaient à se multiplier reproduisaient ces instruments et ces machines, proposant à leurs lecteurs moins le texte, assez pauvre, que le spectacle des inventions sans cesse répétées. S'adressant autant à la vue qu'à l'intelligence, ils contribuèrent à établir une optique commune à un nombre d'hommes toujours croissant.

Ce sont, nous le savons, des «Théâtres de Machines », un arrangement « plaisant et délectable » d'inventions et d'artifices audacieux, parfois irréalisés, souvent irréalisables. Ce n'était pas encore le sérieux du monde, mais celui-ci s'inscrivait déjà dans l'existence de chacun par l'attrait de l'insolite et la transfiguration de l'habituel. Le jeu préparait ainsi la disparition de réflexes ancrés de longue date, et l'enracinement de réflexes nouveaux. Il facilitait aussi l'acquiescement à un ordre différent instauré entre les choses, tout en évitant le conflit avec ce qui était considéré comme réel, pondéré. Les règles de l'univers matériel exprimées comme langage d'un théâtre rendaient acceptable l'étrange, et la jouissance du merveilleux maintenait une distance respectable avec les prémisses et les principes de la nature organique, unanimement partagée. La solidité de celle-ci était cependant mise à l'épreuve, bien que l'affrontement, la contradiction fussent atténués. 
Le jeu et le spectacle sont, en l'occurrence, l'expression du mouvement latent de l'histoire qui, tout en déterminant ses acteurs à agir dans la direction qu'elle poursuit, n'est pas encore parvenue à la conscience, n'a pas encore posé l'impératif de cette direction. Ils assurent, simultanément, la communication d'une humanité qui s'éveille à quelque chose de neuf, avec le domaine du faire et de l'artifice. Ceuxci ne sont pas seulement lointains, étrangers à l'état de nature commun, mais lui sont, de plus, diamétralement opposés. A cet effet, le faire du mécanicien et ses mécanismes se proclament contre-nature, en tant que non-naturels et en tant qu'incompatibles avec les fondements de l'ordre naturel. Dans les arti del disegno - les arts du dessin — avides de mathématiques et d'expérimentation, la supériorité provient de l'«art des machines», qui «était le principal en l'architecture " ${ }^{477}$; et l'unité provient de la perspective, qui allait provoquer une mutation de l'espace. Avant l'invention de celle-ci, les grandeurs étaient déterminées par les angles visuels et la fixation d'un objet observé, sur une surface ordonnée, n'exprimait pas l'écart qui le sépare de l'observateur. Les artistes-ingénieurs par contre, mettent l'accent sur cet écart, sur la distance, et la représentation des corps se fait, nous dit Piero della Francesca, « compte tenu de leur diminution ou de leur accroissement». L'espace dont, auparavant, la structure était close et arbitrairement laissée au choix du spectateur, s'organise maintenant en fonction de la distance aux points mobiles ou fixes. Tout ce qui n'est pas directement visible peut le devenir si un instrument convenablement construit dirige les rayons lumineux vers l'œil humain. Par conséquent, les objets matériels comme l'espace invisible, les éléments proches comme les éléments lointains peuvent s'intégrer à un même système et être mesurés ensemble. De plus, une construction ou une forme particulière se prolongent dans l'environnement spatial. Les surfaces des corps ne sont dès lors plus fermées : elles se définissent par l'intersection des plans qui se rencontrent en un point du milieu global. Le calcul et la géométrie font ainsi leur entrée dans la détermination des relations spatiales, les corps apparaissent réductibles des cubes et à des pyramides, ayant des di- 
mensions mesurables ${ }^{478}$. Brunelleschi et Alberti inventent des appareils destinés à éprouver la validité de cette description dans l'espace, et la façon dont elle correspond au trajet des rayons de lumière. Les œuvres d'art créent le caractère homogène et indéfini, ou plutôt non fini, de l'espace. Avant que Descartes donnât la théorie de cet espace, il existait déjà chez les architectes et les peintres ${ }^{479}$.

L'emploi de la perspective ne se limite pas à ce domaine : elle sert au dessin des forteresses comme à celui des cathédrales, dans l'art optique aussi bien que dans l'art des machines, et Galilée juge indispensable de l'enseigner :

"Quelques règles pour dessiner en perspective toute chose vue ou imaginée, entre autres les forteresses et toutes leurs parties, et même toutes machines et instruments de guerre peuvent être représentés et mis sous les yeux $\gg{ }^{480}$.

Suscitée par l'usage des instruments, cette technique intellectuelle et artistique inscrit à son tour mécanismes et mouvements dans un espace dimensionné, ayant une figure géométrique, conçu pour indiquer des variations de grandeur et de quantité. Les artifices appartiennent à un espace artificiel, il faut entendre celui que construit la «perspective artificielle $»{ }^{481}$, à laquelle on opposait la « perspective naturelle » ou «commune» qui avait été conçue par l'artiste de l'antiquité et conservée par son homologue médiéval.

Cette géométrisation - car c'est de cela qu'il s'agit - mesure le degré de perfection des facultés des " artisans supérieurs », la vigueur avec laquelle ils ont transformé le milieu avant d'être reconnus

478 P. FRANCASTEL: Naissance d'un espace: mythes et géométrie au quattrocento, Revue d'Esthétique, 1951, 4, pp. 1-45.

479 «Il est certain, en tout cas, que la conception de la qualité homogène de l'espace est mise en avant pour la première fois dans les arts figuratifs, et ensuite, par voie de conséquence, dans les sciences physiques et mathématiques ». G.C. ARGAN : The architecture of Brunelleschi and the origin of perspective theory in the fifteenth century, J. of Warb. and Court. Inst. 1946, 9, p. 100.

480 GALILEI : Opere t. II, p. 607.

481 D. GIOSEFFI : Perspectiva artificialis, Trieste, 1957 ; E. PANOFSKY : La prospettiva come «forma simbolica », Milan, 1961. 
comme les créateurs de celui-ci. Les problèmes afférents à la construction des moulins, des pompes, des horloges ou des compas, ceux que posent l'édification des fortifications et le tir des canons, ont reçu une formulation et engendré une pratique originales. Toutes ces machines offrent l'exemple de systèmes capables de produire les effets recherchés et, parfois, de se régler de façon relativement autonome. Quant aux automates, ils ont un cadre, contiennent des engrenages, exigent une certaine rigidité ou solidarité des parties pour résister à l'impulsion des forces. D'où la nécessité de tenir compte de leurs liaisons ; l'expression de cette nécessité montre bien que le niveau atteint par les ingénieurs de l'antiquité a été dépassé.

«Dans les choses où agissent deux forces, écrit Michel Varro ${ }^{482}$, et si le centre n'est pas fixe, un mouvement se produira dans la machine elle-même. C'est pourquoi elle se disloquera, et c'est pourquoi la demande faite par Archimède dans le problème «Donne-moi un point fixe pour que je soulève la terre » semble défectueuse : parce qu'elle consiste en ce qu'il réclame qu'on lui donne seulement un lieu, alors qu'il aurait dû demander en outre qu'on lui donne des liens ».

Partout, avec ces mécanismes, on voit à l'œuvre les forces, la forza qui inspire des textes d'un lyrisme exaltant. Elle symbolise à la fois les ressources de l'univers et le règne des causes actives existant en vue d'un effet et non pas d'une fin. Ce n'est plus le réceptacle des formes qui retient l'attention lorsqu'est évoquée la vision de la matière, mais le réservoir d'énergie. Serait-il exagéré de soutenir que cette matière se confond avec une substance hydrodynamique, que ce monde est un monde hydraulique ? Ce ne serait sûrement pas faux, et Léonard de Vinci s'exclame : «Eau, qui es l'humeur vitale de la machine terrestre ! »

Le bois, le fer, etc., ne sont pas pensés, agis, examinés pour leur malléabilité, leur texture, leur docilité au travail de l'artisan désireux de les convertir en objets. La propriété que l'on recherche avant tout est la résistance. Outre le poids, les chocs, les frottements sont les manifestations de la force qui préoccupent sans cesse le mécanicien et par le truchement desquelles il la regarde. Elle est alors force de per-

M. VARRO : De Motu tractatus, Genève, 1584 (non paginé). 
cussion, qui produit et accompagne le mouvement. Cependant, par opposition à la percussion due à la gravité, estimée "naturelle », celle-là paraît limitée aux machines et se voit qualifiée d'« artificielle ». Même Torricelli accepte la distinction :

«Par choc, écrit-il, on entendra alors la rencontre de deux corps lorsque l'un d'eux reçoit sa vitesse d'une cause extérieure, comme le vent, une force animale, le feu, les arcs ou des choses semblables. Ainsi, sous ce genre de percussion artificielle, on comprendra les coups d'artillerie, ceux de tous les autres projectiles, des marteaux, particulièrement lorsqu'ils frappent avec un mouvement horizontal, ou vers le haut, cas dans lequel la gravité interne ne peut rien faire $»{ }^{483}$.

La transmission de la force qui fait mouvoir un corps par ce moyen propre à la plupart des mécanismes ne fait donc pas partie des processus « naturels ».

Qu'il s'agisse de la construction de l'espace ou de la génération du mouvement, le domaine des phénomènes classés comme artificiels, limité d'abord aux artifices, s'amplifie sans cesse, et devient coextensif à tout le réel. Il ne suffit plus d'y remarquer le pouvoir des hommes et leur production : le moyen qui conduit à l'ordre du monde doit être reconnu, lui aussi. Ne sont-ils pas, pour celui qui les fabrique et les découvre, le moteur et l'aliment de son intelligence, la clé de ses rapports avec les forces matérielles, l'école la plus sûre, l'ouverture sur des horizons inconnus ? Tout ce qui existe tend à être perçu à la lumière des inventions, auxquelles on compare chaque partie du réel - comparaison qu'il ne faut pas entendre dans un sens uniquement figuré.

L'être vivant lui-même apparaît comme un mécanisme :

«Un oiseau, affirme Léonard de Vinci, est un instrument qui fonctionne suivant une loi mathématique, un instrument qu'il est au pouvoir de l'homme de reproduire avec tous ses mouvements même si ce n'est pas avec un degré 
de force correspondant, car il lui manque la force de se maintenir en équilibre $»$.

Assertion à laquelle Descartes fait écho en écrivant au marquis de Newcastle :

«Et sans doute que lorsque les hirondelles viennent au printemps, elles agissent en cela comme des horloges $»{ }^{484}$.

Non seulement l'être animé, mais l'ensemble de l'arrangement de l'univers semble préfiguré dans ces instruments. Quelle fascination l'horloge n'a-t-elle pas exercée ! Et quelle ne fut pas sa vertu libératrice par rapport aux images et aux concepts prédominants ${ }^{485}$ ! Avec l'enthousiasme dont il est coutumier, Kepler écrit, dans une lettre de 1605 à Herman de Hohenburg :

« Je suis fort occupé de l'étude de la cause physique. Mon but est ici de montrer que la machine céleste doit être comparée, non à un organisme divin, mais plutôt à un mouvement d'horlogerie ».

C'est la raison pour laquelle, se détachant d'une vue organique de la nature, il arrive, le premier, à concevoir une astronomie causale dans laquelle mathématique et physique s'articulent intimement. De la sorte, après s'être mis à l'école des artifices, Kepler peut rompre avec ses anciens maîtres et la réalité qu'ils envisageaient ${ }^{486}$.

«Pénétré jadis de la doctrine de J.C. Scaliger sur l'intelligence motrice, je croyais que la cause qui fait mouvoir les planètes était une âme. Le but que je me propose est d'affirmer que la machine de l'univers n'est pas semblable à

484

485

Dieu cesse ainsi d'être le bien suprême en quelque sens important que ce soit ; c'est un gigantesque inventeur de mécanismes, et l'on ne fait appel à son pouvoir que pour expliquer la première apparition des atomes ». E.A. BURTT : The metaphysical foundations of modern physical science, Londres, 1915, p. 90.

486

«Il s'agit essentiellement ici du remplacement d'un mot par un autre, mais ces deux mots incarnent des tendances de pensée tout à fait différentes. Kepler ne veut plus, comme il l'exprime par ailleurs, voir la nature instar divini animalis (comme un être doué d'une âme divine) mais instar horologie (comme un mécanisme d'horlogerie) ». E.J. DIJKSTERHUIS : op. cit. p. 345. 
un être divin animé mais est semblable à une horloge (celui qui croit l'horloge animée attribue à l'œuvre l'honneur qui revient à l'ouvrier), et que tous les mouvements variés y dépendent d'une simple force matérielle agissante, de même que tous les mouvements de l'horloge sont dus au pendule simple » ${ }^{487}$.

C'est à la contre-nature, aux résultats du faire humain, que l'on demande, de plus en plus, une lumière sur l'être des choses et sur l'univers ${ }^{488}$. La scène sur laquelle on contemple avec ferveur ses machines et ses instruments a changé, et les analogies qu'on en tire sont effectives et d'un usage général ${ }^{489}$. Le tout manque encore, cependant, de soubassement. Que la nature se mécanise, que la mécanique se naturalise, et les illusions qui avaient d'abord pallié ce manque finiront par le combler de leur vérité.

Retour à la Table des Matières

\section{La réalité ultime.}

La hiérarchie qui commandait la disposition de l'univers fut sérieusement atteinte, sans être ébranlée, lorsque Nicolas Copernic soutint que le soleil n'était pas un astre qui tournait autour de notre planète, mais au contraire un point fixe par rapport auquel nous nous déplacions. Par la même occasion, la voûte céleste s'éloigna, l'espace s'élargit, et l'immobilité ne fut plus l'apanage de la terre.

Malgré l'importance de cette révolution, la chiquenaude qui mit véritablement en branle le mouvement par lequel les mécanismes se métamorphosèrent en réalisations de l'ordre naturel fut la Science Nouvelle de Nicolo Tartaglia ${ }^{490}$. Avant lui, les ingénieurs, les constructeurs de canons, donnaient des recettes d'utilisation et s'efforçaient, dans les traités qu'ils publiaient, de dégager les princi-

487

488 and grounds of the mechanical hypothesis, Londres, 1674) et per conséquent (Excellency tant de choses, ils sont adaptés à inclure, plutôt que dans la nécessité d'exclure, toute autre hypothèse qui est fondée sur la nature, dans la mesure où elle l'est ».

489

490 
pes de leur art sans les rapporter à une conception plus générale du réel. Quant aux philosophes, ils ne voyaient dans l'action de ces machines, les trajectoires des boulets, que des exemples, des effets parmi d'autres. Ils ne leur accordaient aucun privilège et n'en faisaient pas le point de départ de leur réflexion. Aucun d'eux ne recherchait, dans ces mécanismes, exclusivement, les lois de la matière. Or Tartaglia, en créant sa "science nouvelle", établit l'instrument comme moyen d'analyse mathématique et empirique du mouvement, manière d'illustrer la façon dont il est engendré. Il marque ainsi et, dans un sens, inaugure pour l'époque moderne un courant de recherches qui ont pour fin de dévoiler les principes de l'univers dans les artifices mécaniques, et de transformer ces artifices mécaniques en texture et cadre de la nature et de l'univers. Dès l'instant où les lois du mouvement sont réalisées dans cette famille d'instruments et ceux-ci vus non plus comme des objets techniques autonomes mais en tant qu'expressions du mouvement et des forces, il n'est plus question d'aménager les schémas, les concepts de la nature organique pour les adapter à des réalités inédites : il s'agit bien de remodeler les assises de l'état naturel dans son ensemble.

La description par N. Tartaglia de la trajectoire d'un boulet projeté par un canon retient quelques-unes des notions familières à l'époque. Il distingue ainsi un segment rectiligne au début du déplacement du boulet, et un segment curviligne à la fin. Le premier segment représente un mouvement «violent», car le corps est arraché à son lieu propre et avance en ligne droite, tandis que le second segment exprime un mouvement " naturel », circulaire et allant vers le centre de pesanteur lors de la retombée du corps grave. Néanmoins la partie « violente » de la trajectoire reste séparée de la partie « naturelle » qui la prolonge.

Dans une nouvelle étude du problème ${ }^{491}$ Tartaglia s'aperçut qu'en théorie du moins, ce parcours était entièrement curviligne : par là s'estompait la différence qui devenait alors plus une différence d'appellation que de réalité, entre les deux genres - violent et naturel - du mouvement. Galilée, examinant la question à son tour, fait 
complètement abstraction de cette distinction. Il sait que le mouvement du projectile n'est pas un mouvement simple mais composé. Toutefois cette composition est l'effet, pour une part, de la tendance du corps à se mouvoir en ligne droite, et, pour l'autre, de son poids attiré vers le centre de la terre, qui modifie cette tendance. La résultante représente une trajectoire parabolique. Pour parvenir à justifier cette trajectoire, il fallait accorder une prépondérance au mouvement rectiligne. L'élève de Tartaglia, Benedetti, avait déjà fait sienne cette option ${ }^{492}$. La conséquence en est un renversement total des perspectives. Le déplacement en ligne droite d'un corps s'impose, à l'encontre de la vision habituelle, comme prototype du mouvement « naturel», tandis que le mouvement circulaire, estimé simple, apparait en tant qu'aboutissement d'une combinaison de forces qui accélèrent la vitesse du mobile à chaque instant. Il y a là aussi un premier pas vers l'introduction de la notion d'inertie. Celle-ci traduit tout d'abord une force interne aux corps qui leur permet de résister à tout changement qui serait susceptible de les affecter. Newton parle d'un « certain pouvoir de résister par lequel tout corps pour autant qu'il est persévère dans son état présent, que ce soit le repos ou le mouvement uniforme en ligne droite ». Corps résistants et corps actifs, telle est la nouvelle classification capitale. Ensuite, l'inertie implique aussi - Descartes est le premier à énoncer le principe dans toute sa généralité — que chaque partie de la matière garde toujours le même état si aucune autre partie de la matière ne l'oblige à passer à un autre état. Donc les corps graves n'ont pas une prédilection pour le repos, pour un retour vers leur lieu propre, comme le supposait la philosophie naturelle. Ils sont aptes également à se maintenir indéfiniment dans la sphère du mouvement et aucun des deux états, de repos en un point ou de déplacement, ne jouit d'un privilège ontologique ou cosmique. Dans les machines, cette distinction est secondaire, sinon inutile. Seuls comptent la décélération ou l'accélération des vitesses, le fait de s'opposer à une percussion ou à une pression, ou de produire une pression ou une percussion. Les corps changent alors d'état et réagissent en fonction de l'énergie initiale accumulée dans un contexte statique ou dynamique. Les modifications essentielles ont trait à la direction ou aux

F. RosenBerger : Geschichte der Physik, Braunschweig, 1882-90 ; E. WoHLWILL : Die Entdeckung des Beharrungsgesetzes, Ztschr. f. Völkerpsychologie und Sprachwiss. vol. XIV, 1914-15. 
rapports, la composition des forces internes ou externes aux parties intégrées dans le système machinal. Ces modifications peuvent toutes être formulées de manière quantitative par des règles mathématiques. Le fait qu'il s'agisse de terre, eau, air, feu, n'a plus d'importance. Les éléments ont perdu le pouvoir de qualifier la matière. Celle-ci est à présent homogène, et ses seules variations sont celles de paramètres quantitatifs (gravité, quantité de mouvement, etc).

Dans la réalité, affirment les philosophes mécaniciens, il n'y a que figure, largeur, longueur, etc. Les corps sont durs, rigides, ou mous, élastiques ou inélastiques, impénétrables par définition. Les conséquences de cette homogénéisation, du point de vue qualitatif, et de la différenciation eu égard à l'action ou à la réaction, aux phénomènes de frottement ou de choc, sont manifestes la distinction entre changements en général et mouvements spatio-temporels disparaît. Ceux-là se réduisent à ceux-ci à partir du moment où tout ce qui était attribué aux éléments doit être attribué aux forces : tout ce qui est physique est par là même mécanique.

Par un renversement général de perspective, le changement est devenu une forme particulière du mouvement, du mouvement universel, pourrait-on dire, non seulement parce qu'on n'en reconnait pas d'autre, mais parce qu'il est le même, quelle que soit l'échelle à laquelle il se produit. Au lieu d'ordonner les genres de mouvements, c'est-à-dire de les séparer suivant les propriétés particulières qu'ils manifestent, on se préoccupe de les composer, de les unifier pour saisir les attributs, les effets qu'ils déterminent. Du reste, une machine est-elle autre chose qu'un moyen de combiner des mouvements, de les transmettre et de contraindre des forces à les engendrer ?

Dans ce dernier aspect se dévoile une nouvelle question : celle de la dépense des forces. Transposée à partir du monde des artifices, elle devient le paradigme de l'ordre naturel, dont elle explique la permanence. Le philosophe naturaliste voyait dans la substance l'unité qui sous-tend la diversité, l'inchangé dans le changement. Le mécanicien cesse de s'intéresser à la réalité de la substance, non qu'il la rejette formellement, mais parce que les métamorphoses qui l'occupent ne sont plus celles des éléments, de leurs qualités, mais celles des mou- 
vements. La coordination de ceux-ci, sous l'angle de la relation du moteur au corps mû et des moteurs entre eux, appelle la notion de conservation. Ce qui demeure désormais constant à travers les transformations dynamiques, c'est une quantité de mouvement, une quantité d'énergie. Nous le savons déjà : Descartes emprunte cette idée au système artificiel et la met à la base de son monde, comme principe premier. A l'intérieur de ce monde, semblable à une immense machine, le déplacement des corps, la transmission de la lumière, la réunion des masses matérielles, aussi bien que tout autre phénomène, ont lieu par choc. Les percussions auparavant qualifiées d'artificielles représentent le mode fondamental d'action naturelle. Les règles de la percussion sont élevées au rang de lois naturelles, les premières lois naturelles - erronées, bien sûr — qu'on ait jamais édictées. L'accélération, résultat de ces chocs, s'affirme en tant qu'effet général à partir duquel il faut remonter à la cause, qui est une force. Dès lors la vitesse du corps n'est plus première mais dérivée.

Les dimensions premières, celles où s'inscrivent tout mouvement et tout mécanisme, sont l'espace et le temps. Divisibles et mesurables, sans direction privilégiée, sans structure autre que celle qui est nécessaire pour déterminer la trajectoire ou la situation des mobiles et pour mathématiser leurs relations, l'espace construit par la perspective et le temps uniforme de l'horloge sont les données les plus simples, le cadre dans lequel tout événement prend place.

L'étude des thèmes qui traversent les grands ouvrages classiques de la philosophie mécanique montrerait que d'abord la chute des corps mais surtout la trajectoire d'un boulet de canon, la machine motrice, l'horloge, ont fourni les schèmes essentiels autour desquels se sont déployées toute réflexion et toute analyse expérimentale. A la fin du $\mathrm{XVII}^{\mathrm{e}}$ siècle, il ne restait plus rien, dans le domaine de l'artifice, qui fût radicalement contre-nature et ne servît à édifier un autre ordre naturel. A ce que l'on désignait ordinairement sous le nom de nature s'était substituée la Grande Mécanique : 
« La Grande Mécanique, lit-on dans une lettre de Descartes à son collaborateur Villebressieu - lettre résumée par Baillet ${ }^{493}$ — n'étant autre chose que l'ordre que Dieu a imprimé sur la face de son ouvrage, que nous nommons communément Nature $\gg . .$.

La nature est Mécanique, mais aussi la mécanique est Nature, source d'une nature. Elle est désormais la seule que les hommes aient à connaître, et ce sont ses apparences qu'ils voient et recherchent dans leur philosophie et dans leur technique. La causalité qui s'y manifeste est uniquement celle qui relie la cause à l'effet. Comme dans l'instrument machinal, les éléments s'articulent et produisent les résultats désirés sans que l'intelligence, les intentions du sujet humain soient indispensables. Celui-ci conçoit et fabrique la machine; il la met en branle, il n'intervient pas dans son fonctionnement régulier. Les qualités organoleptiques des matériaux, la forme qu'elles prennent ne sont pas non plus décisives. Des quatre causes que reconnaissait Aristote, celles qui ont trait à l'opération artisanale, à l'action du savoir sur la substance - cause finale, cause matérielle et cause formelle - ont disparu, on le comprend, après avoir été combattues avec acharnement. Y recourir signifiait, aux yeux du philosophe mécanicien, s'écarter de la voie de la raison et de la connaissance. Par un retournement normal, ce qui, à une époque, dénotait et synthétisait le plus haut sommet du savoir et le reflet le plus pur du réel a été relégué au rang de logomachie et d'illusion regrettable. Le tableau où triomphe la vérité est celui que trace Isaac Newton ${ }^{494}$ de main de maitre, comme étant «le cadre mécanique du monde» ${ }^{495}$. Dans ce «cadre mécanique », il nous est enseigné que :

« (a) tous les corps sont impénétrables et ont une force de gravité vers eux proportionnelle à leur matière, et cette force s'écartant du corps décroît suivant le même rapport que le carré de la distance croît, et par le moyen de cette force les planètes et les comètes sont arrondies.

DESCARTES : Euvres, t. 4 p. 213.

494 M. BOAS, R. HALL : Newton's « mechanical principles », J. of the Hist. of Ideas, 1959, 20, pp. 167-78 ; L. Bloch : La philosophie de Newton, Paris, 1908 ; I.B. COHEN : Newton and recent scholarship, Isis, 5960, 51, pp. 489-514.

495 A.R. HALl, M.B. HALL : Unpublished scientific papers of Isaac Newton, Cambridge, 1962, p. 167. 
(b) le soleil est un astre fixe et des astres fixes sont éparpillés dans tous les cieux à de très grandes distances l'un de l'autre et ils demeurent dans leurs différentes régions étant de grands corps ronds extrêmement chauds et lumineux, et en raison de la grande quantité de leur matière, ils sont dotés d'une puissance de gravitation très forte $»$.

L'évidence de cet arrangement du monde, au moyen de forces et de mouvements, était tellement grande qu'il fut jugé définitif, et l'homme qui l'avait appréhendé dans sa totalité estimé un génie heureux, car, disait Lagrange,

« il n'y a qu'un univers et il ne peut arriver qu'à un homme dans l'histoire du monde d'être l'interprète de ses lois ».

Pour cette raison, la philosophie mécanique, à laquelle Isaac Newton avait conféré grandeur et cohérence, fut censée durer jusqu'à la fin des temps ${ }^{496}$. La nature semblait avoir acquis une figure stable, et l'humanité devait s'y référer comme à une réalité ultime.

\begin{abstract}
$* * *$
Il serait présomptueux de vouloir réduire l'histoire de la philosophie mécanique, l'examen de son rôle dans la constitution d'un état de nature, à ce que je viens d'exposer ici. De nombreux autres motifs ont laissé une empreinte indélébile sur son évolution. J'ai passé sous silence polémiques et ébauches, controverses religieuses ou sociales. Je n'ai pas non plus retracé la suite des événements qui ont jalonné les disputes épistémologiques, la naissance de chaque concept, la découverte de chaque loi, la mise en évidence de chaque phénomène. Je m'en suis tenu à ce qui est essentiel dans la perspective du présent es-
\end{abstract}

«Sur la mécanique est aussi fondée la philosophie newtonienne, ou seule philosophie vraie du monde ». " C'est par conséquent une simple plaisanterie que de parler d'une philosophie nouvelle. Le fondement est à présent solidement établi : en vérité on peut améliorer la philosophie de Newton et lui donner de nouveaux développements ; mais on ne pourra jamais la renverser $»$.

Ces commentaires d'Emerson, servant d'introduction à la philosophie mécanique ou newtonienne, nous permettent de voir combien était répandu à l'époque le sentiment qu'il s'agissait d'une acquisition définitive. Cf. EMERSON : The principles of Mechanics, Londres, 1775 , p. III. 
sai et au développement historique réel. A savoir, le lien entre la formation d'une catégorie naturelle, sa scission d'avec une autre, et l'établissement de ses disciplines propres. L'organisation de celles-ci au niveau de la fonction productive a été concomitante d'une division de l'artisan et de l'ingénieur. Les « arts du dessin » et la " science des mécaniques » sont l'expression la plus directe de ce processus, et d'un rapport inédit avec la matière. Comme dans l'antiquité, les disciplines philosophiques se donnent pour champ d'exploration au début de l'ère moderne la doxa, l'opinion et le savoir-faire communs. Toutefois cette opinion et ce savoir-faire ne sont plus ceux de l'artisan mais ceux de l'ingénieur, de l'architecte, du fabricant d'instruments mathématiques. Vis-à-vis de la philosophie naturelle, la philosophie mécanique accomplit ce que l'art mécanique accomplit vis-à-vis des autres arts. A l'observation quasi clinique elle oppose l'expérience qui se veut unique. A l'appréciation sensorielle des qualités par un observateur, elle substitue la mesure. A la recherche des formes et aux classifications, elle fait succéder la recherche des lois et des relations quantifiées.

Mais surtout les disciplines philosophiques fournissent un soubassement aux œuvres de l'ingénieur, et elles en assurent le développement. Non pas dans le sens qu'elles sont pratiques ou s'écartent d'une vue contemplative du réel pour se montrer utiles, aboutir à la scientia activa operativa, souhaitée par Bacon. Cette attitude ne leur appartient pas en propre, et n'est pas, comme on le croit, une caractéristique de l'homme moderne. Ces disciplines contribuent à fonder le travail, les instruments du mécanicien, par le seul fait d'édifier l'état de nature qui leur correspond. Chaque aspect de cet état s'impose d'abord en tant que fragment du monde des artifices et création d'une collectivité humaine particulière. L'effacement du rôle de celle-ci et le transfert de ses œuvres dans le contexte de l'univers ${ }^{497}$, l'oubli du sujet et l'épanouissement autonome de l'objet, paraissent être les étapes nécessaires à l'établissement assuré du savoir-faire et à sa reconnaissance au titre de savoir tout court. La subdivision des disciplines en techniques et savantes, la séparation du philosophe et de l'homme de

«La nouvelle spéculation mathématique (n.n. la perspective des peintres et des architectes) n'apparaît visiblement pas encore comme modifiant les rapports de l'homme avec le monde ; on n'y voit d'abord qu'une nouvelle méthode technique et non pas une nouvelle vision ». P. FRANCASTEL : Peinture et société, ed. cit. p. 23. 
métier, mécaniciens l'un et l'autre, sont survenues précisément pour parachever ce passage du domaine de l'artifice à celui de la nature. Ce passage, que l'on peut dater de la fin du XVI siècle et du début du XVII ${ }^{\mathrm{e}}$, n'est pas ascension du concret à l'abstrait; il signifie la révélation d'une théorie et d'une pratique destinées à rendre aux travaux de l'homme une portée universelle et à les enraciner objectivement. La dextérité se mue en connaissance, et la fonction productive s'affirme également auto-créatrice. L'invention reste le but; la mesure, l'expérience et le calcul, les moyens privilégiés. La réalité à laquelle dextérités et connaissances se rapportent change de camp - et c'est là un résultat de la «nouvelle philosophie » et de la technique. Elle n'est plus l'ensemble hiérarchisé, provenant d'une matière première ayant un dynamisme spontané, dirigé vers des structures ou formes préétablies, et peuplé de fins. Nous la voyons sous les traits d'un système, composé de forces et de mouvements, commandé par des relations quantitatives, obéissant à des principes dont les effets sont prévisibles. La transformation, à l'échelle de l'histoire, s'est avérée rapide.

« N'est-il pas évident, s'exclamait le poète John Dryden, qu'au cours des cent dernières années... c'est presque une nouvelle nature qui nous a été révélée ? ${ }^{498}$.

Ainsi, à travers des étapes successives, la vie extraordinaire qui anime le faire a fini par passer dans l'architecture et la vision de l'être. 


\section{DEUXIÈME SECTION}

\section{SCIENCE, TRAVAIL INVENTIF ET PROGRESSION NATURELLE}




\section{Chapitre VII.}

\section{L'univers froid et l'univers chaud}

\section{Les philosophies, les sciences et le nouveau rapport des disciplines naturelles}

L'ordre mécanique avait acquis un degré de perfection, une cohérence qui paraissaient lui garantir une existence indéfinie ${ }^{499}$. La majesté de l'édifice, la solidité des principes donnaient l'impression d'une correspondance idéale des concepts et du réel, d'une saisie totale des phénomènes connus et d'une assimilation sans heurts des phénomènes encore à connaître ${ }^{500}$. L'invention continuelle de machines, leur pénétration dans l'industrie et dans la vie quotidienne, confirmaient et élargissaient cette impression : le mirage des artifices était devenu reflet de la nature, manifestation de la structure profonde de celle-ci. Ce qui avait commencé avec l'invention du premier moulin était désormais censé exister autant que l'homme et l'univers.

La substitution de la nature cybernétique à cet ordre, des sciences à la philosophie mécanique, est un fait actuel, contemporain. Affirmer qu'ensemble elles ont surgi au $\mathrm{XX}^{\mathrm{e}}$ siècle serait probablement une

499

« A la fin du XVIII ${ }^{\mathrm{e}}$ siècle, les principes de la mécanique semblaient au-dessus de toute critique et l'œuvre des fondateurs de la science du mouvement formait un bloc que l'on croyait défier à jamais le temps ». E. PICARD : Quelques réflexions sur la mécanique, Paris, 1902, p. 1.

500

«Au milieu du XIX ${ }^{\mathrm{e}}$ siècle, la mécanique rationnelle semblait assise sur des fondements aussi inébranlables que ceux sur lesquels Euclide a affermi la géométrie. Sûre de ses principes, elle laissait couler l'harmonieux développement de ses conséquences ». P. DUHEM : L'évolution de la mécanique, Paris, 1903, p. I. 
exagération, ce ne serait pas une contre-vérité. Dans cette section, j'indiquerai le mouvement de cet état de nature et surtout celui des disciplines qui contribuent à l'instituer. Plus particulièrement, j'insisterai sur la transformation du processus inventif et sur ses rapports avec la réorganisation du groupement de disciplines. J'espère montrer ainsi leurs répercussions sur le principe de division naturelle, sur la démarche par laquelle les hommes édifient l'histoire de leur nature, démarche qui subit un changement profond. Mais au préalable il convient d'exposer les considérations qui m'autorisent à faire état, ici, d'une révolution scientifique au XIX $\mathrm{X}^{\mathrm{e}}$ siècle, et non pas, comme on le croit couramment, au XVII ${ }^{\mathrm{e}}$ siècle. La question est d'une grande portée théorique et historique.

La nature mécanique, dont nous venons d'examiner les traits principaux et l'originalité, s'est affirmée avec éclat dès le début du XVII siècle :

«Un nouvel univers a été découvert par les philosophes du dernier siècle, écrivait Voltaire, et ce monde nouveau était d'autant plus difficile à connaître qu'on ne se doutait même pas qu'il existât ».

En effet, qui aurait pu soupçonner que l'univers organique, fini, hiérarchisé, qualitatif, recelait un univers infini où il n'existait pas de différence entre le monde sublunaire et le monde céleste, où la matière homogène et quantitativement distribuée était composée d'atomes dont le mouvement se réduisait à un déplacement dans l'espace ? La découverte de cette machine, de cette fabrique du monde, ou, pour mieux dire, son invention, ne pouvait provenir que d'une puissante révolution de nos connaissances, des moyens de reproduction intellectuels et physiques. Les philosophies naturelles - pour ne parler que d'elles - furent bouleversées de fond en comble pour faire place à une «nouvelle philosophie », la philosophie mécanique. Celle-ci eut tôt fait valoir son contraste avec les anciennes philosophies, non seulement en ce qui concerne son contenu, mais aussi pour ce qui est de ses objectifs généraux. A la systématisation des savoirs, elle opposa l'intérêt porté à l'invention; à l'exercice logique, elle préféra l'application des mathématiques dans le traitement des phénomènes matériels; à l'observation sensorielle, elle substitua le recours aux 
méthodes expérimentales. La mesure des effets à l'aide des instruments, les lois numériques, le calcul firent leur entrée parmi les éléments qui définissent une théorie et régissent une pratique. La nature changea d'alphabet et la lecture de sens :

«Et si la philosophie était celle qui est contenue dans les livres d'Aristote, écrivait Galilée à Fortunio Liceti ${ }^{501}$, à mon avis vous seriez le meilleur philosophe du monde... Mais en vérité j'estime que le livre de la philosophie est celui qui est perpétuellement ouvert sous nos yeux ; mais parce qu'il est écrit en caractères différents de ceux de notre alphabet, il ne peut être lu de tous ; et les caractères de ce livre sont des triangles, des carrés, des cercles, des sphères, des cônes, des pyramides et d'autres figures mathématiques, tout à fait propres à cette lecture ».

Le contraste si habilement amené par Galilée entre les livres d'Aristote et le livre de la nature ne doit pas nous tromper. On a l'habitude d'opposer les vues que l'on combat à l'expérience et à la nature, en négligeant le caractère relatif de cette expérience et de cette nature ${ }^{502}$. Celui qui est engagé dans la mêlée se sent l'obligation de présenter sa vérité comme absolue. En faisant fond sur elle, il bâtit un autre système de réalités et de connaissances, et les acteurs de la révolution du XVII siècle n'ont prétendu à rien d'autre qu'à proposer une "nouvelle philosophie », une philosophie de rechange. El n'est pas indifférent de rappeler que, pour eux-mêmes, pour leurs contemporains et successeurs, Galilée, Descartes, Huygens ou Leibniz étaient des philosophes ${ }^{503}$, comme l'étaient Locke, Hobbes ou Spinoza. Newton estimait avoir apporté des «principes mathématiques » à la philosophie naturelle, et Descartes avoir bâti, grâce à la géométrie et à la mécanique, une philosophie originale. Aux yeux de tous, il semblait

501

502

P. Rossi constate le fréquent de nature et d'expérience ? » P. ROSSI : Les arts mécaniques et la science nouvelle, Arch. Europ. de Sociol., 1963, 4, p. 223.

503

Galilée ayant réclamé le titre de philosophe, E. Rosen observe que : «Dans la bouche de Galilée, le terme de philosophes signifie ceux qui étudient la nature ", surtout dans ses aspects physiques. La principale fonction des philosophes d'aujourd'hui n'est plus l'étude de la nature. Si nous évitons de donner à ce terme, de façon anachronique, une signification qu'il n'avait pas à l'époque de Galilée, nous voyons aussitôt qu'il méritait pleine ment le titre de philosophe, et qu'il n'y a rien de bizarre à ce qu'il l'ait revendiqué ». E. RosEN : Stillman Drake's Discoveries and Opinions of Galileo, J. of Hist. of. Ideas, 1957, 18, p. 445. 
qu'eût surgi un ordre naturel inconnu et une manière de philosopher qui lui correspondait. Le Discours préliminaire à l'Encyclopédie exprime cette conception :

« Newton, à qui la route avait été préparée par Huygens, parut enfin, et donna à la philosophie une forme qu'elle semble devoir conserver ».

La révolution $\mathrm{du}$ XVII ${ }^{\mathrm{e}}$ siècle fut donc une révolution philosophique, et jusqu'au $\mathrm{XIX}^{\mathrm{e}}$ siècle aucun savoir ne prétend être qualifié d'un autre nom ${ }^{504}$. Dalton publie à Manchester sa Chemical Philosophy en 1808, et Lamarck à Paris en 1809 une Philosophie Zoologique. Pourtant, lorsque l'historien d'aujourd'hui doit ordonner ces événements, les innovations auxquelles sont liés les noms de Galilée, de Newton, d'Huygens, il les classe sous la rubrique de la science et de la « révolution scientifique », et il y voit à la fois la fin des disciplines philosophiques et l'avènement, la "grande instauration» des disciplines scientifiques.

En décidant arbitrairement d'établir l'origine de la science moderne là où se trouve en fait le point de départ de la philosophie mécanique, on commet une confusion de jugement et une erreur de sens. La confusion de jugement est apparente dès que l'on veut brosser un tableau de cette origine :

«La science, en tant qu'étude séparée, autonome, date du XVII ${ }^{\mathrm{e}}$ siècle. Avant cette époque, ce qui fait le contenu de la science était objet d'attention de la part des philosophes et était considéré comme une partie de la réflexion philosophique, et lorsqu'au XVII ${ }^{\mathrm{e}}$ siècle une nouvelle manière de procéder fut introduite, ces pionniers n'y virent pas une façon de traiter un problème nouveau mais une nouvelle façon de traiter un problème ancien. La science de cette époque fut la nouvelle "philosophie », faiblement esquissée par certains philosophes médiévaux, cherchant à s'exprimer chez Francis Bacon et pleinement reconnue chez Galilée. C'est seulement plus tard, lorsqu'elle eut fait tant de progrès dans certains domaines d'étude limités qu'un nouveau corps de chercheurs fut appelé à l'existence, qui se cantonnèrent dans ces domaines,

«La philosophie au XVII ${ }^{\mathrm{e}}$ siècle était la même chose que la science, nos divisions scolaires n'existaient même pas à cette époque ». B.B. HEIMANN: L'histoire des sciences dans l’Encyclopédie, Archeion, 1937, 19, p. 203. 
que la nouvelle philosophie fut transformée en non-philosophie et généralement appelée du nom de science ${ }^{505}$.

Voilà qui n'est pas entièrement clair, ou qui est trop clair. Car, lorsqu'on y regarde de près, ce n'est pas d'une révolution scientifique qu'il s'agit au XVII siècle, mais plutôt de la naissance d'une nouvelle philosophie, à laquelle la science a succédé. C'est bien plus tard que cette dernière s'est imposée en tant que groupement distinct de disciplines et «non-philosophie ». Pourquoi cet anachronisme ? Parce qu'on s'est contenté d'envisager uniquement certains aspects superficiels - présence des mathématiques, des expériences - sans remarquer que la science, d'une part, et la philosophie, de l'autre, se divisent selon leurs relations aux disciplines techniques, les liens qu'elles constituent entre le pôle humain et le pôle matériel de la nature.

Premièrement, la science suscite directement les phénomènes matériels, assoit nos connaissances et assure nos facultés, découvre les forces objectives et remanie leur structure par un processus relativement autonome. C'est seulement lorsque ces connaissances et ces facultés ont été organisées, les lois et les instruments mis en évidence, les procédés d'action sur le cycle matériel vérifiés, bref, une fois les rapports naturels établis, que ceux-ci donnent lieu à des utilisations, suscitent les artifices indispensables à la production et conduisent à instituer les disciplines de celle-ci. On ne saurait parler d'une application de la science à l'art ou à la technique, mais plutôt d'une différenciation des procédés et des industries à partir de la science. Les inventions dans le domaine de l'électronique, de la chimie ou de l'industrie nucléaire sont essentiellement basées sur des savoirs scientifiques élaborés dans le laboratoire ou le cabinet du théoricien. Le trait marquant est bien celui-ci : création par la science, et non pas application de la science.

Les philosophies, au contraire, prennent leur essor, bien que ce ne soit pas là une source exclusive, à partir des arts, qu'il s'agisse des arts de l'artisan ou de celui de l'ingénieur, en cherchant à dévoiler, à 
travers les combinaisons artificielles, les liaisons naturelles de l'homme à la matière, en transformant et en perfectionnant les instruments intellectuels et pratiques ainsi préparés ${ }^{506}$. Leur propos est de rendre l'artifice naturel. De ce fait, les commencements décisifs leur échappent, et elles s'engagent dans le cours du monde, celui de la nature, lorsqu'il a déjà parcouru un chemin relativement long et que l'homme s'apprête à en prendre une conscience claire, à passer de la vie concrète et polymorphe à l'expression abstraite et universelle. La chouette de Minerve, symbole de toute philosophie, chante au crépuscule. En cela la philosophie contraste avec la science qui garde l'initiative et se trouve à la source des changements des disciplines techniques qu'elle jalonne et commande. Maurice Daumas est parfaitement en droit de soutenir que :

«C'est donc plus tard qu'on ne l'affirme ordinairement que les conditions de l'évolution des techniques furent bouleversées, et si nous avions à situer une révolution, nous pourrions choisir la période 1840-1860 pour le faire, et peut-être même pour plus de précision 1850-1860 » ${ }^{507}$.

En regard de ce bouleversement, qui fait que des industries productives se développent à partir des sciences, ce qu'on a coutume de nommer révolution industrielle n'en est pas une, puisqu'elle n'inaugure pas une ligne distincte de celle suivie jusqu'à son apparition. S'il en est bien ainsi, force nous est de supposer que le mouvement dans lequel sont engagées actuellement les sciences ou les techniques se déroule dans des conditions nouvelles, car on ne saurait concevoir que les unes soient affectées sans que les autres le soient. La modification des relations entre les disciplines naturelles et pro-

506

Cette hiérarchie des fonctions est décrite avec précision dans un plaidoyer en faveur de la constitution d'une philosophie mécanique : «Ces jours-ci doivent poser un nouveau fondement d'une philosophie plus magnifique, qui ne sera jamais renversée, qui discutera empiriquement et raisonnablement les phénomènes de la nature, déduisant les causes des choses de leurs originaux dans la nature que nous voyons qui peuvent être reproduits par l'art et la démonstration infaillible de la mécanique ; et certainement c'est là la façon d'édifier une philosophie vraie et permanente, et il n'y en a pas d'autre. Car l'art étant l'imitation de la nature (ou la nature de deuxième main), il n'est qu'une expression rationnelle des effets qui dépendent de lois qui sont les mêmes (quoique plus éloignées) et par conséquent les œuvres de l'un doivent prouver les découvertes les plus raisonnables de l'autre ». H. POWER : Experimental Philosophy, Londres, 1664, p. 183.

507 M. DAUMAS: Le mythe de la révolution technique, Revue d'histoire des sciences, 1963, XVI, p. 300 . 
ductives est donc le signe d'une modification de leur dynamisme historique général.

Deuxièmement, jusqu'au milieu du siècle dernier, l'homme a affronté les forces matérielles sous deux angles : en tant que puissance spécifique, et en tant que partie de ces forces elles-mêmes. La structure et la mission de la philosophie ont correspondu à cette situation. Tout d'abord, comme toute famille de disciplines, elle a fait la théorie des phénomènes objectifs, elle a conçu les moyens intellectuels, physiques et biologiques adéquats pour les ordonner et les soumettre à l'épreuve de l'observation ou de l'expérience. Ensuite, ayant pour obligation de situer l'homme, son intelligence, sa capacité sensorielle en tant que pouvoir matériel, de définir avec soin leur interaction et notre particularité, elle devait rapporter la totalité des théories à un système, y introduire ce qui a trait au mode de connaître et à l'être humain en général. Les philosophies naturelles et mécaniques présentent nécessairement ces deux aspects de la connaissance : elles sont à la fois théories particulières et système d'ensemble.

Dès l'instant où les individus humains ne se combinent plus directement aux forces matérielles, et où leurs propriétés ne s'articulent plus immédiatement avec les propriétés de ces forces, cette double exigence des disciplines naturelles, de proposer des théories et de justifier en un système leur allégeance simultanée à un sujet scindé et à un objet mixte, s'estompe. Dans la science, les impératifs de l'aboutissement de toute recherche à un système disparaissent: les connaissances théoriques suivent les lois de la combinaison des éléments matériels, et l'homme, désormais médiateur de cette combinaison, juge de leur importance selon la texture des moyens expérimentaux, matériels, qu'elles mettent en œuvre ou qu'elles créent.

L'erreur de sens sur laquelle j'ai attiré l'attention est évidente. Le mot «science » était très répandu et employé depuis le Moyen Age ; le livre de Tartaglia, précurseur de la mécanique moderne, s'intitule "Science Nouvelle »; un des grands dialogues de Galilée porte sur « Deux Nouvelles Sciences ». Néanmoins, il s'agit plus particulièrement de ce que l'on a entendu longtemps par science ou scientia, c'est-à-dire une activité régulatrice de toute technique, de tout art : 
«La science est la forme qui dirige chaque discipline à l'intérieur de laquelle les techniques sont exercées, et par l'intermédiaire de laquelle leur développement et leur changement devraient être guidés ${ }^{508}$.

La philosophie conservait une signification à part, et c'est à dessein que les savants, jusqu'au XIX ${ }^{\mathrm{e}}$ siècle, se voulaient philosophes. Notre définition de la science n'est pas identique à la leur et ne convient pas non plus à la signification qu'ils attribuaient au champ de la philosophie. Un examen des notions nous fournit une image plus précise. D'après certaines indications, la science, surtout en langue latine, paraît avoir désigné un champ de connaissances quelconques, philosophiques ou non, et s'apparentait aux vocables grecs d'episteme et de techne confondus. Ainsi Savonarole écrivait :

« La philosophie réelle se divise en deux parties, la pratique et la spéculative. Nous appelons science pratique l'état d'esprit immédiatement ordonné en vue de diriger les opérations des puissances en-deçà de l'intellect $\gg{ }^{509}$.

Comme on le remarque en maint endroit, science, philosophie ou art sont des termes interchangeables en tant que synonymes du vocable et du concept de discipline. Toutefois, une tendance se dessine qui lie davantage la signification du mot science au domaine des arts ou de la technique. Voici le titre de l'ouvrage de Nicolas Le Fevre :

«Traité de Chymie. Tome Premier. Qui servira d'instruction et d'introduction tant pour l'intelligence des Autheurs qui ont traité de la théorie de cette science en général : que pour faciliter les moyens de faire artistement et méthodiquement les opérations qu'enseigne cet Art », etc. ${ }^{510}$.

L'idée de science, qui s'assimile à l'idée neutre de discipline en général, quel qu'en soit le contenu empirique ou intellectuel, en vient progressivement à signifier cette interférence, cette application des connaissances théoriques, philosophiques, au plan des techniques. Se

\footnotetext{
508

J.S. ACKERMAN : On scientia, Daedalus, 1965, 94, p. 15.

509

510

J. SAvonarole : Opus perutile, Venise, 1542, p. 4.

Paris, 1660
} 
rapportant à l'aspect qui transcende et corrige la routine des hommes d'art, elle apparaît comme un alter ego des habiletés productives, une image parachevée de leur essence abstraite. C'est ce que semble signifier le terme dans des expressions telles que l' " Académie des Sciences », «l'état des arts et des sciences ». D'Alembert en apporte un témoignage :

« La spéculation et la pratique constituent la principale différence qui distingue les sciences d'avec les arts ${ }^{511}$.

Distinction et association qui perdent toute justification lorsque les techniques cessent d'être le produit de l'habileté, de l'homme de métier, de l'ingénieur, pour devenir les prolongements des découvertes dont l'origine se situe dans l'expérience et dans la théorie à la fois, quand il ne s'agit pas tant de parachever, d'organiser des arts constitués que d'engendrer de «nouveaux arts ». De ce fait, la dextérité et les instruments n'appellent pas l'élaboration d'un schéma général, un éclaircissement des pratiques productives par un savoir, parce qu'ils partent de ce savoir même. Les sciences ne sont plus présence de la méthode philosophique dans la sphère des techniques, ni celles-ci le fruit des dextérités qui se forment à la suite de longs tâtonnements. Conjointement, la fonction propre des diverses branches de la philosophie, qui consistait à transposer les œuvres de l'homme du contexte des artifices dans celui de la nature, à imaginer un système, cette fonction dépérit. En effet, ces œuvres sont, nous l'avons noté, immédiatement constituées dans ce dernier contexte, les disciplines créant leur objet sans avoir besoin de l'emprunter aux arts. C'est pourquoi elles n'ont besoin ni de réintroduire leurs lois matérielles parmi les lois de l'homme de métier, ni de partir d'une réalité dont les contenus auraient été prédéterminés par celui-ci. Dans ce sens, la philosophie se confond avec la science, car toutes deux opèrent au niveau des liens naturels, bien que de manière différente pour chacune. Le langage a entériné cet état de choses ${ }^{512}$ tout récemment, en donnant à la dernière la dignité d'équivalence avec la première.

D’Alembert : Discours préliminaire, ed. Paris, 1894, p. 51.

512 «Le concept de « science» a subi des changements évidents depuis la Renaissance, et il n’y a guère plus d'une génération que le terme a remplacé l'expression de «philosophie naturelle » 
La confusion de jugement, l'erreur de sens n'ont d'autre source que le fait de ne pas avoir placé les écarts entre philosophies et sciences là où l'évolution historique les a réellement placés. A savoir, dans les rapports entre disciplines naturelles et disciplines techniques, entre pôle humain et pôle matériel de la nature, rapports qui furent bouleversés $\mathrm{au} \mathrm{XIX}^{\mathrm{e}}$ siècle. On ne peut fixer d'autre date à la révolution scientifique authentique ${ }^{513}$.

On voit l'importance du débat. Les groupements de disciplines gardent leur réalité et leur individualité à une seule condition, c'est qu'on leur restitue la signification que l'histoire leur a imprimée, quand elle leur en a imprimé une. A cette condition, ils peuvent être reliés à un état de nature - la philosophie mécanique à la nature mécanique, la science à la nature cybernétique - et l'on retrouve dans leur propre transformation celle des états naturels et réciproquement. En montrant que la révolution du XVII ${ }^{\mathrm{e}}$ siècle a annoncé et réalisé la philosophie mécanique et non pas la science, j'ai répondu à ce sou$\mathrm{ci}^{514}$. Il reste à en déduire les conséquences. L'apparition des sciences

dans notre vocabulaire ». R.P. STEARNS : The scientific spirit in England in early modern times, Isis, 1943, 34, p. 293.

513 «On comprend que le mot latin scientia ne faisait pas la différence entre le savoir tiré des livres et les autres espèces de savoir : les arts et les sciences nichaient ensemble et étaient étiquetés de façon interchangeable dans le trivium et le quadrivium médiévaux. Il en fut de même pour son dérivé anglais jusque bien avant dans le XVIII ${ }^{\mathrm{e}}$ siècle, la science s'appliquait de façon plus étroite à ce qui auparavant avait figuré comme philosophie naturelle ou expérimentale ; et ce n'est guère avant le milieu du XIX ${ }^{\mathrm{e}}$ siècle que ceux qui la pratiquaient furent distingués du nom de scientifiques ». H. LEVIN : Semantics of culture, Daedalus, 1965, 94, p. 11.

514 La confusion de la philosophie et de la science, le fait d'avoir choisi par convention de situer la révolution scientifique au $\mathrm{XVII}{ }^{\mathrm{e}}$ siècle a eu pour conséquences :

(a) L'arrêt des recherches concernant la germination scientifique du siècle dernier. « $\mathrm{Au}$ nombre des lacunes remarquables de l'histoire de la science figurent les études sur la croissance de la science au XIX ${ }^{\mathrm{e}}$ siècle ». J. COHEN, in M. ClageTT (ed.) : Critical problems in the history of science, Madison, 1959, p. 357.

(b) Le manque de concepts spécifiques, de cadre, pour étudier l'histoire des sciences: L'historien des sciences aborde la physique du XIX ${ }^{\mathrm{e}}$ siècle dans un esprit précautionneux. Il a devant lui une grande histoire, la plus grande peut-être qu'il y ait dans sa partie. Mais il n'est sûr ni de savoir comment la raconter, ni de la savoir toujours avec exactitude». Ch. GILLISPIE : The edge of objectivity, Princeton, 1960, p. 352.

(c) L'absence de vue d'ensemble des sciences et de leur portée réelle. Le plus grave défaut de l'histoire de la science, la cause du plus profond désespoir pour l'historien est qu'en général il n'a aucune notion historique de la façon dont la science fonctionne depuis cent ans ». D.J. de Solla PRICE : Science since Babylon, New Haven, 1962, p. 62, 
en tant que groupement de disciplines naturelles, et le scientifique comme représentant d'une catégorie naturelle se placent au foyer de convergence de deux mouvements : l'un est commandé par la division naturelle, l'autre est une transformation progressive de la structure des facultés, de leur mode de création, et détermine les décalages que l'on vient d'observer. La description et l'analyse du premier mouvement prennent du relief à propos du savoir et des phénomènes chimiques ${ }^{515}$.

Retour à la Table des Matières

515 L'application du modèle d'analyse auquel j'ai eu recours dans la section précédente exigerait, à propos des sciences, des développements trop longs pour entrer dans le cadre du présent essai. Je ne parlerai guère de la physique quantique ni des sciences appliquées connexes. Vu leur diversité et l'ampleur des controverses épistémologiques, un volume y suffirait à peine. Aussi me limiterai-je à des indications plus succinctes que celles que j'ai données dans la première section, espérant qu'un travail ultérieur viendra heureusement compléter celui-ci. 


\section{Médecine, arts chimiques et arts mécaniques}

$\underline{\text { Retour à la Table des Matières }}$

\section{Le monde terrestre et le monde souterrain.}

«C'est une coïncidence étrange, écrit Albert Einstein ${ }^{516}$, que presque tout le travail fondamental se rapportant à la nature de la chaleur ait été accompli par des physiciens non professionnels, qui regardaient la physique simplement comme leur grand dada ».

Ce n'est pas une coïncidence, c'est un résultat nécessaire, puisqu'il n'y avait point d'autres physiciens, au sens strict, que ces amateurs, ou ces professeurs itinérants démonstrateurs d'expériences destinées à instruire et amuser le public. Parmi eux, les médecins étaient nombreux. On l'oublie régulièrement lorsqu'on ébauche les grandes fresques de l'évolution des sciences et qu'on s'évade du milieu concret, particulier, des groupes d'hommes dont elles sont l'œuvre et pour lesquels elles ne sont que ce qu'ils en font. A force de décanter, la vérité de la vie ne conduit plus à la vérité de l'intelligence, qui se situe au delà de la tragédie et en-deçà de la paix : il ne lui reste que cette mélancolie pondérée, où l'élévation de l'esprit signifie égalité de l'humeur et médiocrité de l'existence, tandis que sa création a pour contrepartie le renoncement, qui ne cherche dans le réel que les traces laissées par d'autres renoncements. Les longs fils qui relient Newton à Einstein ou à Bohr, Boyle à Lavoisier ou à Curie, nous trompent sur les liens authentiques, les tentatives passionnantes et répétées que des milliers d'individus ont eu à faire avant qu'on puisse passer des uns aux autres. Et d'ailleurs Newton n'est pas le précurseur d'Einstein, ni Boyle celui de Lavoisier ; mais ce sont, pour une grande part, Paracelse, Van Helmont, Scheele, ces médecins ou apothicaires, qui jouent le rôle de pionniers, et c'est leur savoir qui est la matrice de nos disciplines modernes. 
«La médecine surtout, écrivait G. Cuvier dans son Rapport historique sur les progrès des sciences naturelles ${ }^{517}$, s'est fait, dans tous les temps, honneur de l'appui que lui prêtent les sciences naturelles... Peut-être n'aurions-nous encore ni chimie, ni botanique, ni anatomie, si les médecins ne les avaient cultivées, s'ils ne les avaient enseignées dans leurs écoles, et si les souverains ne les avaient encouragées, à cause de leurs rapports avec l'art de guérir ».

On n'en finirait pas d'énumérer les expérimentateurs et les théoriciens qui, dans tant de domaines, furent d'abord, furent aussi, praticiens de cet art ${ }^{518}$. Berthelot, Prout, Nicholson, Mayow, Stahl, Thomas Young, médecins; J. B. Dumas, Dufay, Davy, Vauquelin, Klaproth, Oersted, pharmaciens, voilà des noms qui rappellent la continuité de l'histoire des disciplines médicales et de celle de nombreuses branches de la physique ${ }^{519}$.

Cette relation n'est pas inconnue : il faut simplement lui donner la signification d'un phénomène historique et l'élucider à ce titre. La chimie joue à cet égard un rôle privilégié. A l'époque même où la science de l'ingénieur parvient à maturité, et se situe au cœur de la connaissance philosophique, au XVI ${ }^{\mathrm{e}}$ et au XVII ${ }^{\mathrm{e}}$ siècles, la chimie accède au rang et au stade d'art. Elle le resta, ainsi qu'on le reconnaît couramment, et les textes de l'époque en témoignent, bien après le milieu du XVIII ${ }^{\mathrm{e}}$ siècle. Les manuels la définissent parfois dans le contexte de la métallurgie, mais le plus souvent dans celui des arts servant au médecin et au pharmacien ${ }^{520}$.

Assurément, on peut considérer chaque branche du savoir comme le rameau d'un arbre dont les racines plongent dans la nuit des temps. Pour nous en tenir pourtant à la stricte signification historique, nous sommes en droit d'enregistrer le décalage entre l'essor de la mécanique, qui dépasse le stade technique, et l'affirmation autonome de la

517

518 bre de découvertes chimiques fondamentales furent faites par des pharmaciens ou des hommes ayant reçu la formation de pharmacien ». H.M. LEICESTER : The historical background of Chemistry, New York, 1956, p. 102.

519 S.G. CHECKLAND : The rise of industrial society in England (1815-1855), Londres, 1964, p. 75.

520 H. GUERLAC : Quantification in chemistry, Isis, 1961, 52, p. 195. 
chimie qui l'atteint à la même époque. Fourcroy s'est opposé à ces généalogies abusives, pour inviter à s'en tenir aux indices positifs, aux traits spécifiques de cette discipline :

«Elle (la chimie), écrit-il ${ }^{521}$, est peut-être la seule (discipline) qui soit tout entière de création moderne, dont on ne trouve absolument aucune trace dans les temps reculés, et qui n'offre point dans ses faits cette progression lente, cet accroissement successif que l'observateur reconnaît dans toutes les autres branches des connaissances humaines ».

Ce constat lui permet de soutenir que :

«Tout ce qu'on a dit de l'antique origine de la chimie, sur les premiers hommes qui ont travaillé les métaux, taillé et poli les pierres dures, fondu les sables, dissous et cristallisé les sels, ne montre à un esprit exact et sévère qu'une vaine et ridicule prétention, semblable à celle par laquelle on voudrait reconnaître les éléments de la géométrie dans l'ouvrage grossier du sauvage qui use les fragments des rochers, et qui leur donne des formes à peu près régulières pour les rendre utiles à ses premiers besoins ${ }^{522}$.

La barrière qui vient d'être posée à toute régression à l'infini, et la date que j'ai mentionnée permettent de s'interroger sur les circonstances qui ont déterminé la cristallisation de la chimie en tant qu'art. J'en tiens deux pour décisives.

En premier lieu, il faut envisager le développement de la métallurgie. Grâce à la mécanisation des moyens de travail ${ }^{523}$, l'extraction du minerai a fait un véritable bond en avant, $a u X V^{e}$ et au XVI ${ }^{e}$ siècles ${ }^{524}$. L'obtention de quantités plus importantes de métal, l'exploitation de gisements plus profonds et l'ouverture de mines nouvelles, une organisation relativement systématique du travail, tous ces symptômes indiquent clairement qu'un des métiers les plus anciens se transforme.

521

522

«Les traits principaux de la métallurgie du XVI ${ }^{\mathrm{e}}$ et du XVII ${ }^{\mathrm{e}}$ siècles sont sa mécanisation et sa diffusion ». S. Smith, J. ForbeS, in C. Singer : A history of technology, Oxford, 1957, t. III, p. 30 .

524 H. BUTTERFIELD : The origins of modern science, Londres, 1957, p. 191. 
La recherche et le traitement des minerais, la connaissance de leurs propriétés et des possibilités de combinaison, appellent des talents spécifiques nouveaux. Non seulement en ce qui concerne l'essai, c'est-à-dire l'étude des proportions qui entrent dans une préparation de produits métallurgiques, mais aussi pour ce qui est de la reconnaissance des signes géologiques qui permettent de déceler la présence du métal, des savoir-faire autonomes commencent à se constituer. Parallèlement s'ouvrent des écoles spécialisées - telle la Bergschule créée par les Fugger, où enseigna le père de Paracelse — et la littérature propre aux phénomènes qui ont lieu dans le monde souterrain, découvert en même temps que l'Amérique, prend son essor ${ }^{525}$. L'enthousiasme que suscite un champ d'exploration inconnu et l'intérêt pécuniaire se mêlent pour recommander la technique propre à faire reconnaître, aux dires de Rabelais « tous les métaulx cachéz au ventre dez abysmes, les pierres de tout Orient et Midy ». Les notions sont encore obscures, la transmission des connaissances malaisée, et le langage manque à tel point qu'il faut d'abord l'inventer. Georges Agricola mentionne cette nécessité dans la préface de son célèbre ouvrage De re metallica :

«Puisque l'art des mines ne se prête pas au langage châtié, mes livres manquent de raffinement dans le style. Les choses dont je traite dans cet art des métaux manquent parfois de noms. Pour cette raison, j'ai été contraint par une nécessité, pour laquelle il faut me pardonner, à en décrire certaines au moyen de combinaisons de mots, et à en distinguer d'autres par des noms nouveaux $\gg{ }^{526}$.

Ce travail de description, de classement et d'analyse des opérations d'ordre métallurgique conduit à la réunion des dextérités, des dialectes ou des recettes de métier, des procédés de travail portant sur les qualités des minerais, pierres et sels de toutes sortes, en un corpus qui deviendra celui de la chimie. Avant qu'on y aboutisse - et même lorsque la chimie sera constituée, la métallurgie n'en profitera pas avant le $\mathrm{XIX}^{\mathrm{e}}$ siècle ${ }^{527}$ - l'attention est attirée sur les éléments accessoires que l'on trouve dans les mines ou qui entrent dans le traitement des mine-

P. Delaunay, in R. TATON : Histoire générale des sciences, Paris, 1958, t. II, p. 120.

G. Agricola : De re metallica, ed. Hoover, New York, 1950, p. 6.

527 F.S. TAYLOR : A history of industrial chemistry, Londres, 1957, pp. 174 et seq. 
rais estimés à cette époque essentiels, à savoir le fer et l'or. Il s'agit notamment du mercure, de l'arsenic, de l'antimoine, de divers sulfures, d'acides, de sels, etc. Des ressources complémentaires se dégagent et deviennent disponibles, ressources en matériaux et en savoir, dont l'ampleur quantitative fait augurer de l'éclosion de nouvelles pratiques.

En deuxième lieu, le renouvellement de la médecine est un facteur décisif pour la naissance de l'art chimique. Il résulte à la fois de la dissolution du cadre monacal et de l'accroissement de la population urbaine. A partir du moment où les liens avec la vie monastique se relâchent, où fonction religieuse et fonction professionnelle ne se confondent plus, où les préceptes philosophiques et le rituel perdent de leur autorité intellectuelle, les médecins peuvent à la fois affronter d'autres aspects du réel et rétablir l'identité de leur profession ${ }^{528}$. Le discrédit dans lequel était tombé le respect du secret des arts, le déclin des guildes, ouvraient justement devant eux une carrière immense de connaissances que leur éducation supérieure à celle de bien des artisans leur permettait de saisir. Le mouvement déclenché, ils se hâtèrent d'extraire de leur milieu tout ce qui pouvait servir à leur fonction : remèdes de bonnes femmes ou drogues de guérisseurs, pratiques de barbiers et conseils d'épiciers. Le contact avec les mécaniciens d'une part et les peintres ou les sculpteurs d'autre part leur permit, en faisant fond sur l'anatomie, l'art de la dissection, de s'affranchir de l'obligation de choisir entre un diagnostic bavard et une médication routinière. Le corps humain redevint l'organisme qu'il fallait comprendre, et que l'on pouvait examiner.

L'accroissement de la taille des villes exigeait une hygiène plus stricte ; il créa aussi une clientèle qui ne se contentait plus de l'empirisme traditionnel. Les hôpitaux, en particulier après la réforme de la religion, passèrent souvent dans des mains laïques. L'enseignement clinique se développa de pair avec le milieu hospitalier. Les guerres ne furent pas étrangères à cette renaissance médicale. L'apparition de nouvelles armes plus meurtrières, notamment des armes à feu, la taille des armées et leur organisation rendirent nécessaire la multiplication des médecins et des chirurgiens. Ces derniers ne se bornent pas 
à soigner le corps, ils s'efforcent d'être utiles à plus d'un titre. On les voit pratiquer conjointement l'astrologie, la pharmacie et même le métier d'ingénieur. La recherche d'un protecteur, d'un employeur, d'une clientèle, et l'appel des cités les portent constamment d'un endroit à l'autre, les contraignant à exercer leurs capacités de manière polymorphe.

Cette condition itinérante et cette multiplication des médecins professionnels ne pouvaient manquer de provoquer une augmentation de la découverte et de la consommation des remèdes. Le pharmacien se sépare de l'épicier et commence à rechercher son autonomie, sa dignité d'homme de métier : il lui faut bien deux siècles pour y parvenir ${ }^{529}$. La connaissance des herbes et des simples, la préparation et l'usage des teintures, l'action de divers sous-produits métallurgiques, tout cela devient son domaine. Il ne comprend pas seulement la collecte et le traitement des produits animaux et végétaux, mais aussi la préparation des «esprits» (de vin, etc.) et des produits de la distillation, la concoction des extraits actifs et la combinaison des composés que nous nommons aujourd'hui chimiques. La découverte de l'Amérique a permis l'élargissement de la pharmacopée végétale des préparations extraites de nouvelles plantes - tabac, ipecacuanha, quinquina, théier, caféier — entrent dans la composition de médicaments inédits. L'amélioration du travail du verre et de la porcelaine facilite la conservation des «matières médicales », des substances servant à les préparer. Cependant, la découverte qui a eu le plus de retentissement, du point de vue qui nous occupe ici, est celle de la vertu curative des minéraux. Ce n'est peut-être pas tout à fait un hasard si nous devons l'emploi des produits minéraux en médecine à Paracelse, qui était le fils d'un médecin exerçant dans une école des mines, et qui a lui-même fait un apprentissage dans l'univers souterrain ${ }^{530}$.

C'est en tout cas lui qui a donné une impulsion décisive à l'emploi de médicaments à base de métaux dans le traitement des maladies ${ }^{531}$.

Certes ; il serait absurde de prétendre que Paracelse a été le premier à concevoir cette idée ; il est toutefois le premier à lui avoir donné l'éclat et la force nécessaires pour s'imposer. Lorsque ces ressources secondaires de l'art minier devinrent partie principale de la médecine, l'art chimique était né. Assurément, on peut bien noter la présence d'une multitude d'arts dits chimiques, qui se sont développés à cette

529

530

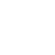

531

R. de Rosemont : Histoire de la pharmacie, Paris, 1932.

« Il (Paracelse) était réellement un chyrurgus, un homme de la pratique, du métier, non de l'étude ». A. KOYRÉ : Mystiques, spirituels, alchimistes, Paris, 1955, p. 48.

G. AGRICOLA : op. cit. p. 14. 
époque ${ }^{532}$; mais l'évidence historique nous oblige à les négliger et à voir dans cette interférence le moment historique décisif.

$\underline{\text { Retour à la Table des Matières }}$

\section{Le sommeil de l'alchimie.}

La régression de l'alchimie (dont le domaine se confinait exclusivement à la métallurgie) incapable d'atteindre ses fins complexes ou ténébreuses et d'étendre son champ d'action, en est un signe. Non pas que son esprit, son aspiration à la transmutation des métaux aient disparu d'un seul coup. De très grands chimistes, jusqu'à la fin du XVIII siècle, respectèrent son idéal et le crurent irréfutable. Les recettes qu'elle celait, le langage qu'elle avait créé, ont imprégné toute la chimie à ses débuts. Elle correspondait à une période où l'on n'avait pas encore réussi à utiliser les matériaux accessoires de l'exploitation des mines et où les connaissances minéralogiques obtenues à leur propos ne suffisaient pas non plus à provoquer une amélioration des opérations propres à la métallurgie. Pour cette raison, dans ses limites et malgré sa richesse obscurcie par un ritualisme étrange, elle ne se constitua pas en art véritable. Léonard de Vinci a tracé un parallèle saisissant entre l'alchimiste et le mécanicien qui cherche le mouvement perpétuel, en disant que celui qui veut faire fortune en un jour vivra dans la pauvreté,

« comme il arrive et arrivera jusqu'à la fin des temps aux alchimistes qui voudraient créer de l'or et de l'argent, et aux ingénieurs qui croient amener l'eau morte à s'éveiller à la vie grâce au mouvement perpétuel ».

Il est probable que les alchimistes se recrutaient dans toutes les classes de la société, parmi les artisans, les commerçants, etc., mais, s'il faut en croire un dicton rapporté par Cornelius Agrippa de Nettesheim, " chaque alchimiste est soit un médecin, soit un fabricant de savon ». La carrière désormais ouverte au premier ${ }^{533}$, par

532 P. BAUD : L'industrie chimique en France, Paris, 1932.

533 «L'apparition de la chimie médicale, de l'iatrochimie, a en effet arraché la chimie aux alchimistes pour la placer entre les mains des médecins. Elle a ainsi donné à la chimie de labora- 
l'enseignement de la pharmacopée, l'engagea sans doute dans une voie plus médiocre que le rêve d'une fortune instantanée, mais plus sûre : la voie de l'art chimique. Et à son centre, comme son principal objet, se place la médecine ou la pharmacie ${ }^{534}$. Pour s'en convaincre, il n'est que de parcourir quelques titres ou sommaires d'ouvrages ou de lire quelques définitions de cet art. Le traité de Nicolas Lémery s'intitule

Cours de Chymie, contenant la manière de faire les opérations qui sont en usage dans la médecine ${ }^{535}$,

et celui de W. Davisson, le premier professeur de chimie du Jardin du Roi à Paris

Les Elemens de la Philosophie de l'Art du feu ou Chemie. Contenant les plus belles observations qui se rencontrent dans la résolution, préparation et exhibition des Végétaux, Animaux et Minéraux, et les remèdes contre toutes les maladies du corps humain, comme aussi la Métallique (...) très nécessaire à tous ceux qui se proposent ietter de bons fondements pour apprendre la Philosophie, Médecine, Chirurgie et Pharmacie ${ }^{536}$.

Pour répondre à ce qu'on attend d'elle et faire la preuve de son efficacité, la chimie s'applique d'emblée à tous les éléments des règnes animal, végétal et minéral. Le feu et la distillation permettent d'agir sur eux et d'en obtenir les qualités désirées. La réussite thérapeutique, autant que l'expérimentation, constitue une vérification de la justesse des procédés et des notions qui s'en dégagent, un mode de connaissance ${ }^{537}$ des propriétés des corps mis à l'épreuve. Le désir de guérir l'emporte sur la curiosité pour les phénomènes naturels, chez les fer-

toire un usage pratique qu'elle n'avait pas encore connu. Elle en a fait une activité rémunératrice qui lui a acquis un personnel nouveau ». M. DAUMAS, in R. TATON : op. cit. p. 134.

534 F.S. TAYLOR : op. cit. p. 170.

535 Paris, $1675-77$.

536 Paris, 1651.

537 « Il ne sera pas plus étranger à notre propos présent de traiter brièvement aussi de la vertu médicinale du fer; car c'est un remède premier pour certaines maladies du corps humain, et par ses vertus, aussi bien celles qui sont naturelles que celles qu'il acquiert par une préparation adéquate, il opère des changements merveilleux dans le corps humain, de sorte que nous pouvons d'autant plus sûrement reconnaître sa nature à travers sa vertu médicinale et à travers certaines expériences manifestes ». W. GILBERT : De magnete, Londres, 1600, I, XV. 
vents de cet art, de l'aveu même de Robert Boyle qui pourtant n'était lui-même ni médecin ni pharmacien :

«Mon but principal, en étudiant la chimie, est de soulager plus facilement de leurs maux des patients qui souffrent, car assurément nos remèdes communs sont inefficaces $\gg{ }^{538}$.

Inversement, ce désir, joint à l'intérêt professionnel, attire vers l'art chimique un nombre relativement élevé d'adeptes, rendant sa connaissance obligatoire dans l'enseignement médical; et, dans la mesure où il leur assure la subsistance, ils s'y consacrent et en accélèrent l'évolution. Bien plus, afin de pouvoir le communiquer à un groupe plus large pour lequel cet art est d'usage quotidien, une clarification du langage, une systématisation des informations, une explication des opérations s'avèrent indispensables et ainsi rendent possible une élaboration théorique rationnelle. Néanmoins pendant longtemps encore, il s'agit d'un savoir accessoire de celui du médecin et du pharmacien - comme le savoir mécanique était accessoire pour l'architecte et le peintre - et c'est dans le cadre de la pharmacie et de la médecine que, tout en gardant une individualité qui leur est désormais acquise, se constituent ses moyens institutionnels, théoriques et pratiques. Nous le constatons à tous les niveaux.

A l'intérieur du cadre professionnel tout d'abord. A des fins d'enseignement de la matière médicale et de production des médicaments, qui sont en grande partie préparés à l'aide de végétaux, on voit un peu partout en Europe se répandre les Jardins de Plantes médicinales. Un des premiers et des plus célèbres est celui que fonde Ulysse Aldovrandi à Bologne. Dès le $\mathrm{XVII}^{\mathrm{e}}$ siècle, à Erfurt, on cultive des plantes exotiques dans un jardin botanique, afin d'apprendre aux élèves à les identifier, ainsi que les drogues qu'elles ont servi à préparer. Les résultats des efforts faits

« pour donner un tour pratique à l'enseignement se montrent aussi dans le domaine de la pharmacologie, dans la plantation de jardins botaniques. A côté 
des amphithéâtres d'anatomie, ils appartiennent aux institutions universitaires les plus précoces $\gg{ }^{539}$.

En France, un édit de Louis XIII créa un Jardin des Plantes Médicinales tant pour l'instruction des Ecoliers en Médecine qu'autres utilités publiques. Installé sur l'emplacement du jardin de Jacques Gohorri, paracelsiste et alchimiste, il allait, pendant près de deux siècles, devenir un centre de recherche où la plupart des sciences des êtres organisés se sont formées ou se sont manifestées avec vigueur ${ }^{540}$.

Ayant trait à l'art de guérir, la chimie se développe, soit dans l'enceinte de ces jardins, soit dans le cadre, plus vaste, des facultés de médecine ${ }^{541}$. Ainsi le Jardin Royal des Plantes Médicinales ${ }^{542}$, dès sa création, s'assure les services de trois démonstrateurs chargés de faire, selon l'édit fondateur

« la démonstration de l'intérieur des plantes et de travailler à toutes les opérations pharmaceutiques, tant ordinaires que chimiques ».

Ces dernières impliquent des expériences, et la présence de laboratoires. Pendant tout le XVII ${ }^{\mathrm{e}}$ siècle, en Europe, on voit s'ouvrir un peu partout des laboratoires spécialisés : 1'Institut Hermétique de Glauber, le Laboratoire alchimique de Frédéric-Guillaume de Brandebourg, celui d'Elias Ashmola à Oxford (1683), le laboratoire de J.D. Hoffmann à Altdorf (1683), ceux de Hjärne à Stockholm (1683), de J. Becher à Munich, etc. Une tradition prend corps, celle du laboratoire, où

539 F. DIEPGEN : Geschichte der Medizin, Berlin, 1949, t. I, p. 272.

540 J.P. COUTANT : L'enseignement de la chimie au Jardin Royal des Plantes médicinales, Cahors, 1952, p. 13.

541 C. Singer, E.A. UnderWOOD : A short History of Medicine, Oxford, 1962.

542 Assurément, l'introduction des médicaments tirés des métaux, la création des Jardins de Plantes médicinales, ont rencontré beaucoup de résistances et donné lieu à des disputes et à des controverses. Je n'en ai pas tenu compte ici, non que cela fût dénué d'importance pour mon propos, mais parce que l'origine historique de ces disputes et controverses est loin d'être claire. L'histoire de la médecine et de la pharmacie, comme celle de la plupart des disciplines pratiques, est encore du domaine de la chronique, des res gestae — d'une grande utilité pour qui veut rapporter des anecdotes, mais d'un faible secours pour veut comprendre l'évolution de ces disciplines. 
l'activité se concentre sur une discipline, sur son progrès, dans des conditions parfois précaires et souvent malsaines. Voici le maître de Georg Stahl, Johann Becher, se décrivant dans sa Physica subterranea comme

« un homme que n'attire ni un foyer somptueux, ni la sécurité de l'occupation, ni la gloire ni la santé ; car je leur préfère mes produits chimiques parmi la fumée, la suie et la flamme des charbons attisés par le soufflet ».

Mais le laboratoire n'est pas seulement un lieu de découverte, il est aussi, et surtout, pour les hommes de métier, un outil et le centre où leur collectivité se rassemble ${ }^{543}$, à des fins aussi bien productives qu'éducatives. La Société de l'Art et du Mystère des Apothicaires de la Cité de Londres fonde, sur une base corporative, un laboratoire destiné à produire des médicaments «galéniques » et «chimiques ». De leur côté, les pharmaciens de Nantes déplorent l'absence de jardin botanique et de laboratoire, qui faciliteraient aux candidats à la maîtrise la confection de leur " chef-d'œuvre ». Aussi installent-ils un jardin et un laboratoire communautaire. Au XVIII ${ }^{\mathrm{e}}$ siècle même, la Pneumatic Institution, où travailla Humphrey Davy, est le résultat d'une souscription volontaire des hommes d'art faite en vue d'étudier les effets physiologiques de l'inhalation de divers gaz.

$\mathrm{Au}$ fur et à mesure que ces centres prennent de l'importance, ils rassemblent non seulement des praticiens, des professeurs et des élèves, mais aussi concentrent des moyens d'observation et d'expérimentation. Aux appareils de distillation, à ceux de traitement des minéraux, s'ajoutent, quand ils deviennent utilisables, le thermomètre, et, notamment pour l'examen des propriétés des gaz, le baromètre et la pompe pneumatique.

La médecine et la pharmacie ne se sont pas contentées d'encourager l'organisation des laboratoires et de contribuer à leur équipement. Elles ont aussi stimulé la découverte, en facilitant l'élaboration d'habitudes intellectuelles. Non seulement la purification et l'isolement des éléments sont dus à des pharmaciens et à des médecins, le chrome et le béryllium à Vauquelin,

543 W.H. ARmytage : The Royal society and the apothecaries, Notes and Rec. of the Roy. Soc, of London, 1954, II, N $\mathrm{N}^{\mathrm{I}}$, pp. 22-38. 
1'uranium et le zircon à Klaproth, le palladium et le rhodium à Wollaston et le cobalt, le bismuth, le manganèse, le nickel à leurs confrères du XVIII ${ }^{\mathrm{e}}$ siècle, mais les controverses d'ordre médical ont conduit à des découvertes cruciales dans l'histoire de la chimie. L'exemple de Joseph Black, professeur de chimie et d'anatomie, est particulièrement révélateur.

A l'époque, on traitait les calculs de la vessie au moyen de soluté de chaux, et un certain Docteur Whyte prétendait que celui qu'il préparait à partir du calcaire des écailles d'huître était bien plus efficace que le soluté ordinaire. Black s'efforça de trouver un solvant qui, à la différence de la soude caustique, n'attaquerait pas le tissu de la vessie, et ses expériences portèrent sur le carbonate de magnésium. Il s'aperçut que, si l'on faisait chauffer celui-ci, il se dégageait un gaz, tandis que le carbonate se changeait en «magnésie calcinée ». Celle-ci pouvait se combiner à divers acides pour produire les mêmes sels que le carbonate de magnésium (ou « magnésie blanche ») mais non effervescents. On retrouvait la magnésie blanche si l'on traitait la magnésie calcinée par des alcalis (sodium ou potassium).

Black répéta ses expériences sur la chaux. Il obtint le même gaz, et de la chaux vive, qu'il réussit à régénérer au moyen d'un alcali. Il donna le nom d'air fixe à ce gaz, parce que la chaux ou la magnésie le fixaient sous forme solide. Il établit aussi qu'un gaz pouvait participer à une réaction chimique au même titre qu'un liquide ou un solide: ainsi se trouva ruinée la théorie contraire de Van Helmont, et la recherche en ce domaine fut vivement stimulée.

Toutes ces découvertes sont autant de prémisses de la révolution de Lavoisier, et l'on peut mesurer la répercussion de ces intérêts proprement médicaux sur l'avènement de la science chimique. Pour ce faire, il faut les saisir dans toute leur ampleur et voir qu'ils s'intègrent à une conception plus générale des phénomènes matériels et de l'ordre naturel. Sinon, on ne prendrait qu'une vue bien limitée de l'art, des ambitions qu'il nourrissait alors et aussi des apports qu'il pouvait fournir lorsqu'il débouchait sur le terrain spécifique de la philosophie mécanique prédominante. Car, à proprement parler, l'horizon du chimiste dépassait celui de la manipulation laborieuse et de l'observation méticuleuse. Ayant purifié, combiné tant d'éléments, il ne croyait pas œuvrer uniquement dans le domaine des artifices commodes, mais agir sur les processus et découvrir les principes mêmes de la nature. Il en fut ainsi dès l'instant où l'éloignement de l'alchimie prit un caractère définitif. 
A partir des processus observés, on pouvait inférer ceux de l'ordre naturel ${ }^{544}$ dans son ensemble et, pourrait-on ajouter, dans son unité, car les règnes animé et inanimé s'y trouvaient solidement articulés. Dans le détail, au niveau des phénomènes particuliers, le chimiste est parfois atomiste, parfois non. Dans la totalité, il conçoit l'univers comme un être unique en évolution, et comportant des stades ou des étapes d'organisations qui se métamorphosent les uns dans les autres. Il pose à l'origine de l'évolution un ou plusieurs principes ou racines destinés à subir les diverses combinaisons. Cette doctrine moniste, qui implique surtout une évolution ascendante, veut expliquer et comprendre, telle la Chimie philosophique de Nicolas Lefèvre, les cieux, les météores, la genèse des minéraux et l'alimentation des plantes ou des animaux. Elle accepte l'idée - que Boyle lui-même n'a pas rejetée - que certains métaux croîtraient dans la terre comme les êtres vivants, et Hoffmann, par exemple, admet l'influence des planètes sur le climat, le corps humain et les phénomènes qui ont pour siège les éléments. Réminiscences de l'alchimie, dira-t-on. Mais les vues de celle-ci ne furent-elles pas acceptées par un grand nombre de chimistes, ne pénétrèrent-elles pas la science? L'essentiel est de constater que la chimie porte en elle une vaste vision de la matière et de l'univers, qu'elle associe constamment les découvertes particulières à des principes généraux et qu'en conséquence elle prétend s'appliquer à toutes les parties de l'univers. Un titre comme «Meditationes physico-chemicae de origine mundi » (1779), du professeur de chimie enseignant à Uppsala, en dit long sur ses ambitions. Simultanément elle veut étendre son domaine à beaucoup d'arts. Il n'est, pour s'en rendre compte, que de jeter un coup d'œil sur l'œuvre publiée de Georg Stahl, le premier à avoir donné à la chimie une utilité théorique. Les matières médicales et pharmaceutiques y sont bien entendu représentées ${ }^{545}$, la métallurgie ou la teinture y figurent également ${ }^{546}$. Porter un jugement sur la qualité réelle de cette littérature technique n'aurait pas plus d'intérêt que de critiquer l'extravagance des hypothèses qui development of corpuscular theory, Arch. Int. Hist. Sc. 1948, I, pp. 640-651.

545

546 Metallurgi
lis (1703). 
la soutiennent ou l'image des processus matériels qui l'accompagne. Elle est avant tout l'expression de la conviction intime du chimiste, de la vision répandue avec la chimie, de l'empire qu'elle exerce sur une fraction importante des arts et de la technique dont elle est conjointement la source et la synthèse. En 1726 déjà, Réaumur affirmait ${ }^{547}$ :

« La chimie, dont les recherches paraissent assez vaines à ceux qui ne connaissent pas son véritable objet, pourrait devenir une des plus utiles parties de l'Académie (des Sciences); ne vantons point le secours que la médecine en pourrait tirer, ne la regardons que par rapport aux arts, à qui elle pourrait être plus utile que les mechaniques mêmes ».

La prophétie, car c'en est une, ne se fonde pas seulement sur l'existence d'attaches évidentes avec la métallurgie ou la verrerie : elle jaillit de la possibilité d'insérer dans le champ du laboratoire, de l'expérimentation, de soumettre à leurs méthodes, à leurs modèles et à leurs notions la plupart des procédés et des habiletés empiriques. Réorganisés quant à leurs routines particulières, enchaînés les uns aux autres quant à leur contenu, ceux-ci peuvent se manifester en tant qu'ils sont centrés sur quelques opérations générales - mélange, séparation, distillation, fermentation etc. - en constituant des variantes d'un art - la chimie — et sont saisis, par ce biais, essentiellement comme arts chimiques.

Ceci suppose qu'on les ait réunis, pénétrés, et reconstitués sur un autre mode. L'assimilation de tant de métiers par la connaissance chimique sous-entend le pouvoir de les engendrer à nouveau, de les « détruire » en tant que tels — suivant l'expression de Liebig — et en même temps de s'élever au-dessus d'eux. A la fin du XVIII siècle, on a pris fermement conscience d'un terrain réservé à la chimie et d'un rayon d'action étendu pour ses opérations ${ }^{548}$, d'une spécificité et d'une supériorité, intellectuelle d'abord, opératoire ensuite. Le temps est venu pour elle de se dissocier de la médecine, d'injecter ses ressources et ses savoirs dans tout le corps de la société, et d'en créer le besoin.

547

548

H. GUERLAC : Some French antecedents of the chemical revolution, Chymia, 1959, 5, pp. 99 et sq. 
Serge Moscovici — Essai sur l'histoire humaine de la nature (1968) 419

$\underline{\text { Retour à la Table des Matières }}$ 


\section{L'opposition à la mécanique}

$\underline{\text { Retour à la Table des Matières }}$

\section{L'ébauche d'une nouvelle catégorie naturelle.}

Si la chimie et le chimiste affermissent leur position, ils le font en partie à côté des disciplines mécaniques, en partie contre elles. A partir du moment où celles-ci avaient pris un sens naturel et technique, qualifiant les phénomènes sous l'angle de la force et du mouvement, envisageant les habiletés dans la perspective de l'emploi des instruments mathématiques et de la mesure, les effets proprement chimiques, qui ne pouvaient se ramener au schéma général, devaient être considérés séparément, une fois qu'une certaine maturité avait été atteinte dans ce domaine. La seule unité qui pût encore les englober était d'ordre social, résultant de la communauté de tous les métiers, de tous les savoirs, faisant appel au travail manuel. Ce que Boerhaave, savant jouissant d'une très grande autorité au XVIII ${ }^{\mathrm{e}}$ siècle, juge nécessaire de rappeler :

«Par les arts mécaniques, on entend ici ceux qui demandent qu'on mette la main à l'œuvre, et non pas cette mécanique qui fait partie de la physique, et qui explique les forces des corps par des propriétés communes à tous : celle-ci est du ressort de la géométrie, et elle ne tire aucun secours de la chimie; au lieu que cette dernière contribue beaucoup à la perfection des arts dont il s'agit; et qui consistent à travailler et à changer les corps ${ }^{549}$.

Les signes de cette cassure et de cette compartimentation sont nombreux, de même que ceux qui montrent la réserve à laquelle se heurtent la chimie et les chimistes. Leur savoir parait rude et peu conforme aux canons mécaniques. Les raisonnements mathématiques y tiennent peu de place, les doctrines ne sont pas partagées unanimement, leurs énoncés ne découlent pas de quelques principes clairs et assurés. Fontenelle traduit vraisemblablement une opinion générale lorsqu'il dit : 
«L'esprit de chimie est plus confus et plus enveloppé ; il ressemble plus aux mixtes où les principes sont embarrassés les uns avec les autres : l'esprit de physique est plus net, plus simple, plus dégagé, enfin il remonte jusqu'aux premières origines et l'autre ne va pas jusqu'au bout $»$.

On serait tenté d'en voir la raison dans une différence d'évolution, de s'arrêter à la comparaison frappante, dans ses résultats, entre une connaissance presque parfaite et une autre qui l'est beaucoup moins ; mais cela serait insuffisant. Cela n'expliquerait pas pourquoi, malgré sa présence évidente dans la pratique, dans l'enseignement, dans les académies des sciences, les philosophes, les savants de cette époque, n'accordaient pas d'attention à la chimie ou même s'en désintéressaient. Boerhaave le constate :

«C'est de la Chymie qu'il faut vous entretenir. De la Chymie! Quoi, d'un art dont les dehors paraissent si bruts, et grossiers, qu'il a pour ainsi dire rompu tout commerce avec les philosophes, qu'il est inconnu et même suspect aux sçavans $\gg$ "

Les philosophes ne se flattaient-ils pas, justement, de s'associer à des opérations manuelles, de pénétrer dans les ateliers des artisans, de suivre leur exemple et de faire mieux qu'eux ? Mais comment ne pas voir qu'une philosophie mécanique élaborée à partie de la science des engins, appréhendant le monde à l'image d'une horloge, trouvait dans la chimie un champ de réalités inassimilables à elle, étrangères et, somme toute, accidentelles ou inessentielles ? La seule tentative rigoureuse pour associer processus mécaniques et processus chimiques, celle de Robert Boyle, demeure sans lendemain bien qu'elle ne soit pas un échec. Un fossé séparait les deux domaines. Émile Meyerson observait avec raison :

«Il est, en général, malaisé de se rendre compte quelle était la véritable opinion des physiciens des $\mathrm{XVII}^{\mathrm{e}}$ et XVIII ${ }^{\mathrm{e}}$ siècles au sujet de ce que nous appelons les phénomènes chimiques. Il y avait là un domaine mal connu, nous dirions mal famé, constitué par un amas formidable de faits mystérieux... Robert Boyle est le seul homme de cette époque qui fasse exception. A la fois grand 
comme physicien et comme chimiste, il cherche à réunir les avantages des deux méthodes. Mais Boyle ne fit pas école : après lui la séparation entre physiciens et chimistes continua comme auparavant $\gg{ }^{551}$.

Mépris et ignorance, incompatibilité entre le contenu de la philosophie mécanique et celui de l'art chimique décrivent des conditions qui ont subsisté pendant plus de deux siècles. Si l'art chimique est méconnu ou décrié, si on n'entend pas sa parole, c'est que la grammaire de son discours est aussi inaccessible à un mécanicien que l'est le swahili aux oreilles d'un Français ou d'un Allemand. Aussi les chimistes vivent-ils, travaillent-ils et se développent-ils dans un monde à part.

«Les chimistes, écrit Venel ${ }^{552}$, forment un peuple distinct, ayant sa langue, ses lois, ses mystères, et vivant presque isolé au milieu d'un grand peuple peu curieux de son commerce, n'entendant rien à son industrie $»$.

Mais ce « peuple distinct» cherchait-il vraiment à prouver son affinité avec les autres groupes scientifiques, à souligner les traits qui apparentaient son travail aux techniques alors prédominantes? Non pas. A l'intérieur de la médecine déjà, deux écoles s'affrontaient: l'iatromécanique et l'iatrochimie. La première, dont le maître fut le mathématicien italien Borelli, concevait le corps, son fonctionnement et son dysfonctionnement, sur le modèle des machines et de leur mouvement. La seconde, dont l'origine remonte à Van Helmont, explique les phénomènes vitaux à l'aide de représentations empruntées à la fermentation, à la distillation ou à l'activité des acides et alcalis. Plus généralement, les chimistes ont une manière propre, nous l'avons constaté, d'aborder les processus matériels, et, dans le domaine qui est le leur, les principes mécano-mathématiques leur sont d'un faible secours. Un chimiste anglais, Lewis ${ }^{553}$, exprime une conviction partagée ${ }^{554}$ par nombre de ses confrères :

\footnotetext{
551 E. MEYERSON : Identité et réalité, Paris, 1951, p. 179.

552 L'Encyclopédie, 1753, t. III, p. 408.

553 Cité par J.R. PARTINGTON : A history of chemistry, Londres, 1962, II, p. 763.

554 P. DUHEM : Le mixte et la combinaison chimique, Paris, 1902.
} 
«Les propriétés des corps font l'objet de deux sciences, la philosophie naturelle et la chimie ; qui, bien qu'en de nombreux cas elles soient si étroitement entretissées et alliées de si près qu'il est peut-être impossible d'établir des frontières entre elles, apparaissent en d'autres comme ayant des différences importantes et essentielles... La philosophie naturelle ou mécanique semble considérer les corps principalement comme étant des agrégats entiers ou des masses entières... soumis à des lois mécaniques et réductibles à des calculs mathématiques... La chimie considère les corps comme se composant d'une espèce particulière de matière » dont les propriétés ne sont «soumises à aucun mécanisme connu, et qui semble gouvernée par une loi d'une autre sorte... Il semble important que ces deux modes d'affections des corps soient maintenus distincts, comme de nombreuses erreurs ont été commises du fait qu'on a appliqué à l'un les lois qui sont valables seulement pour l'autre ».

La matière, telle est la teneur de ces déclarations, n'est pas la même pour le mécanicien et pour le chimiste, n'est pas saisie dans une perspective analogue par l'un et par l'autre. Ce qui pour l'un est existence pleine est pour l'autre abstraction : ce qui pour le premier est loi générale applicable en toutes circonstances n'est pour le second que règle particulière ayant un champ de validité déterminé. Le réel est différent pour chacun, propre à chacun. Et aussi le mode d'action sur ce réel.

«Les chimistes, déclare Venel, ${ }^{555}$ ne s'honorent d'aucun agent mécanique... Ce n'est pas par le goût contraire, par un courage affecté, que les chimistes n'admettent point de principes mécaniques, mais parce qu'aucun des principes mécaniques connus n'intervient dans leurs opérations ».

Effectivement, le développement de la technique mécanique, du mécanicien, qui a précédé celui de l'art chimique et du chimiste, s'est répercuté sur la plupart des métiers dans la mesure où les artisans qui les exerçaient, partant de matériaux, dépensant une certaine énergie physique et s'aidant d'outils, donnaient une forme à ces matériaux. Il a aussi laissé apercevoir l'existence d'un secteur qui ne relevait pas d'elle, celui de la transformation des matériaux, des propriétés des matières premières, des propriétés conférées à une seconde matière dont la constitution n'est plus la même : ainsi la graisse qui se change en savon, le sel en soude. La substitution d'une substance à une autre 
- avant la création de l'industrie chimique, les pharmaciens ont remplacé des matières organiques par des matières inorganiques - leur séparation, l'élimination des impuretés, participent d'une même catégorie de travaux. Celle-ci n'a pas pour facteur décisif «l'agent mécanique », que ce soit la force de l'homme ou l'intervention de l'instrument. Nous sommes donc en présence de deux familles de techniques possibles que l'évolution de la science de l'ingénieur a rendues plus évidentes. En soulignant l'originalité de chacune, Robert Boyle recommandait l'une et l'autre à l'attention du philosophe expérimental ${ }^{556}$ :

«Bien que ce qui a été représenté de l'utilité de la philosophie expérimentale des métiers appartienne surtout à ceux où les productions de la nature sont employées à des usages humains par ces opérations où la nature elle-même, plutôt que l'artificier, semble jouer le rôle principal, tels que les métiers de brasseur, boulanger, jardinier, tanneur, je n'en exclurais pas les métiers mêmes où l'artificier semble être l'agent principal, et dans la production dernière desquels la chose essentielle que l'on a coutume de considérer est la forme ou figure adventice que l'artificier, en tant qu'agent intelligent et volontaire, donne, à l'aide de ses outils, à la matière qu'il travaille, comme dans les métiers du forgeron, du maçon, du coutelier, de l'horloger, et d'autres métiers manuels. Car ils consistent plutôt en dextérité manuelle des hommes, qu'en une ordination habile des productions de la nature par leurs opérations matérielles réciproques ».

Le chimiste, devant jouer par rapport à la première espèce d'arts le rôle du mécanicien par rapport à la seconde, se trouve d'emblée confronté à un mode particulier d'action sur les phénomènes matériels, héritier présomptif d'une somme de savoirs et de pratiques qui l'orientent vers d'autres attitudes et d'autres relations avec le monde objectif. Les facteurs actifs, découverts ici, sont distincts des facteurs propres à la technique dont l'ingénieur est l'initiateur et le guide. Il n'est donc guère étonnant que cette impossibilité d'assimilation des deux domaines, de réciprocité, ou encore de transgression des frontières qui séparent les zones respectives, soit signalée avec autant de netteté. En même temps qu'apparaît la chimie, se profile à travers elle phy, Oxford, 1663, t. II, p. 20. 
l'ébauche d'une nouvelle catégorie naturelle ; la division dont j'ai décrit les symptômes devient manifeste.

\section{$\underline{\text { Retour à la Table des Matières }}$}

\section{L'instrument chimique, l'univers froid et l'univers chaud.}

Deux impératifs jalonnent l'histoire humaine de la nature : que la nature soit là où est l'artifice; l'avenir d'un ordre naturel est un autre ordre naturel. Ils jalonnent également celle de la chimie et de ses rapports avec la réalité instituée, au moment où l'on voit des phénomènes apparaître de tous côtés. Une fois son territoire délimité, même imparfaitement, une fois les distances prises, la nécessité devait s'imposer, pour ses agents propres et les processus objectifs dont elle était le règne, de déboucher, à travers ce qui était considéré comme agencement artifactuel, sur l'univers et l'état naturel présents au cœur de l'œuvre.

Pour l'ingénieur et la mécanique, avant qu'on en arrive à décortiquer la substructure, leviers et roues dentées, poids et chocs, règles géométriques et calcul s'appliquent à un univers de forces, abrasant les autres aspects d'un monde sans variations de couleurs ni de température, pareil à une immense et majestueuse machine hydraulique. Mais quel est l'instrument principal du chimiste, le milieu avec lequel il s'articule? Son appellation ancienne nous le dit : c'est le feu.

« Un chimiste est par tradition un « travailleur du feu » et l'élucidation de la nature de la combustion a constitué la démarche décisive de la fondation de la chimie moderne ${ }^{557}$.

On sait que Van Helmont, le créateur de l'iatrochimie médicale, se considérait comme un philosophe par le feu ${ }^{558}$, et le manuel de Davisson porte le titre : Philosophie de l'art du feu ou Chemie. On sait aussi que, dans la réalité et dans l'imagerie commune, ce qui faisait la particularité du travail concret et de l'action du chimiste, comme de

F.S. TAYLOR : op. cit. p. 101. 
l'alchimiste avant lui, c'était de soumettre à l'épreuve du feu la plupart des matériaux, de vivre dans une atmosphère où tout était destiné à une transformation des propriétés par combustion. Avec véhémence et précision, Paracelse trace le portrait de l'homme de l'art, tel qu'il l'entendait et le voulait :

« Je fais l'éloge des physiciens chimistes spagiriques, car ils ne fraient pas avec les oisifs ni ne se promènent somptueusement vêtus de satin, de soie et de velours, un anneau d'or au doigt, un poignard d'argent suspendu au côté, des gants blancs aux mains, mais ils effectuent leur travail particulièrement au feu jour et nuit. »

Les chimistes conçoivent le feu comme l'élément le plus important de l'univers, l'adjuvant le plus efficace des opérations humaines. Il symbolise l'attribut de l'homme de métier et de l'homme en général; il est également l'instrument technique qu'il faut maîtriser en priorité ${ }^{559}$. Parmi les moyens auxquels il est indispensable d'avoir recours pour purifier ou isoler une substance particulière, la première place lui revient :

« Je commencerai, écrit Boerhaave ${ }^{560}$, par le feu, sans lequel aucune opération chymique ne s'est faite ou ne pourra se faire; ce qu'on ne peut dire assez généralement des autres instruments ».

Pratiquement, toute interrogation devait partir de lui, s'y rapporter, le prendre pour modèle ou paradigme principal. La méthode expérimentale, en chimie, semblait être entièrement fondée sur son emploi, sur son intervention à l'intérieur même de la structure de la matière ${ }^{561}$.

On comprend dès lors que ce soit à son sujet que s'élabore la première théorie chimique, qu'il lui fournisse son motif et son schème. Qu'est-ce que le feu ? Comment agit-il ? Voilà les questions primordiales auxquelles il faut répondre. Les opinions ont varié et il a été

H. BOERHAAVE : op. cit. p. 268.

561 A.F. FOURCROY : op. cit. p. 137.
} 
tenu tantôt pour un produit artificiel, tantôt pour un élément capable de se combiner avec d'autres éléments. La chaleur, la combustion, la lumière, la vaporisation, etc. étaient ses attributs sensibles ${ }^{562}$, et c'est à partir d'eux qu'il convenait de l'analyser. Mais comment sont-ils produits? Quelle relation existe-t-il entre le feu et ses attributs ? La littérature chimique abonde en essais destinés à éclaircir un problème aussi mêlé de présupposés d'origine aristotélicienne ou atomiste. Donner une réponse correcte apparaît comme une exigence capitale :

«Si nous nous trompions, disait Boerhaave ${ }^{563}$, dans l'exposition de la nature du feu, notre erreur s'étendrait sur toutes les branches de la physique, et cela, parce que, dans toutes les productions naturelles, le Feu, comme je l'ai déjà remarqué, est toujours le principal agent ».

Les phénomènes vitaux, la respiration par exemple, étaient également conçus par analogie avec le feu, et l'explication physiologique donnée à leur propos prolongeait et élargissait l'explication physique. Puisque tout tourne autour de la combustion, c'est elle que la théorie se propose d'élucider, c'est à travers elle que s'éclairent les processus naturels. La place nous manque ici pour décrire la très longue succession d'essais entrepris dans cette direction ${ }^{564}$, et aussi pour les examiner par le détail. Dans la combustion, on considère à la fois l'agent qui la produit et l'élément qui la rend possible, à savoir l'air ou un gaz quelconque. Ceci nous paraît évident. Mais, avant Georg Stahl, les chimistes ou bien adoptaient les quatre éléments d'Aristote (terre, air, eau, feu) ou bien en concevaient de nouveaux. Là où prédominait l'inspiration atomiste ou mécanique, le recours à des corpuscules de feu s'imposait. Le grand mérite de Stahl fut de rompre avec ces tentatives dictées par d'autres modes de transformation et d'existence de la matière, de se situer à l'intérieur des phénomènes essentiels à l'action chimique et d'en expliciter les conditions.

562

563

564

H. MetZger : Newton et l'évolution de la théorie chimique, Archeion, 1928-9, IX, p. 55.

H. BOerhaAVE : op. cit. t. II, p. 3.

Je pense notamment aux travaux de Jean Roy, John Mayow, dont la contribution à l'avènement de la théorie chimique moderne a été décisive. Cette filiation a été étudiée par de nombreux historiens de la chimie, et si elle n'est pas entièrement établie, elle est déjà largement connue. 
Telle est la signification qu'il faut attacher au fait qu'il ait placé la combustion au centre de la chimie. On connaît sa conception. Tout d'abord, il réunit dans une seule classe des phénomènes aussi dissemblables, en apparence, que la calcination d'un métal et l'ignition des matières organiques. Chaque corps était doué de combustibilité, qualité que l'on estimait se transporter d'un corps à l'autre. De là à y voir l'indice d'un transfert de substance matérielle, il n'y avait qu'un pas. Pas franchi en imaginant une substance particulière, le phlogistique, responsable des actions du feu, principe du feu. Présent dans les corps, il se sépare d'eux lors de la combustion, et cette soustraction explique la modification des propriétés des corps lorsqu'ils s'enflamment. Le soufre privé de son phlogistique donne naissance à l'acide vitriolique, le métal calciné à l'air perd le sien et se transforme en chaux :

«En résumé, dans l'acte de la combustion, déclarait Stahl, intervient comme instrument et se montre très puissant le feu, fervent, ardent : mais dans la substance même du composé intervient comme ingrédient, ainsi qu'on le nomme couramment, comme principe matériel, et comme constituant de tout le composé, le matériau et le principe du feu, non le feu lui-même. C'est celuici que j'ai été le premier à nommer phlogistique ».

Par rapport à ce principe, l'air ou un autre gaz joue le rôle d'un « absorbant », puisque c'est à eux qu'il s'unit. On remarque certes une variation concomitante du poids des corps: un métal calciné, par exemple, devient plus lourd ${ }^{565}$. Mais, en regard des autres propriétés, des modifications proprement physico-chimiques, la variation de poids paraissait secondaire, elle ne constituait pas un indice des procédés que l'on supposait à l'œuvre. G. Stahl déclarait qu'on pouvait négliger le poids du principe d'inflammabilité. Bien plus, l'air et le gaz restaient pour ainsi dire en dehors de la réaction, rien n'ayant prouvé jusqu'alors qu'ils entraient dans la composition des substances.

La révolution chimique de Lavoisier ${ }^{566}$ se produisit dans ce contexte. Le fait capital a été certes la découverte de l'oxygène. Non

565 H. MetzGer : La philosophie de la matière chez Stahl, Bruxelles, 1925.

566 H. GUERLAC : The origin of Lavoisier's work on combustion, Arch. Int. Hist. Sc. 1959, 12, pp. 113-35 ; H.E. FIERZ-DAVID : Die Entwicklungsgeschichte der Chemie, Bâle, 1945. 
moins capitale a été la démonstration, par Joseph Black, du fait qu'un gaz, l' " air fixe », pouvait se combiner avec un solide. Dès lors il devenait possible d'admettre que l'air, le gaz interviennent dans une réaction, et que le feu n'est que l' « instrument» qui déclenche cette réaction. Au cours de la combustion, on n'assiste pas à la soustraction d'un "principe d'inflammabilité », mais à l'addition d'un principe matériel ; bref ce n'est pas le phlogistique qui est retiré du métal au cours de sa calcination, c'est l'oxygène qui s'y ajoute. Fait prouvé par l'augmentation de poids des corps qui brûlent. La quantité de matière représente alors un indice important des processus chimiques. Toutefois ni Lavoisier ni la plupart des chimistes ne renoncent à l'idée qu'il existe des corps impondérables, à l'hypothèse du caractère substantiel du feu ou de son correspondant, la chaleur. Assurément, on considère l'oxygène comme la « cause » de transformation des acides ${ }^{567}$. Quelle est la « cause » des gaz ? C'est le calorique - la « matière de la chaleur », suivant l'expression de T. Bergman ${ }^{568}$ — puisque la saturation en calorique impose aux corps l'état gazeux. Nous sommes toujours dans un univers où subsistent des fluides impondérables. Et c'est bien le fait marquant à côté du monde mécanique, formé de corps graves et de mouvements, se place le monde chimique des substances sans poids et des fluides inflammables. A côté d'un monde discontinu, où les solides matériels ont l'impénétrabilité pour propriété commune, on aperçoit ${ }^{569}$ un monde qui accepte la continuité et la pénétrabilité des substances par un corps privilégié ${ }^{570}$, le calorique lavoisiérien, ou tout simplement le feu, « matière subtile qui pénètre les corps les plus denses $\gg{ }^{571}$.

Le fait de concevoir la chaleur comme un fluide ou une substance était-il une déficience de la part des chimistes? Ne connaissaient-ils

567

568

569

570 d'abord diphlogiste, puis air vital, le gaz inflammable et l'air phlogistique ». MM. de Morveau, LaVoisier, etc. Méthode de nomenclature physique, Paris, 1787, p. 30.

571 L'expression est de J.H. WINKLER : Institutiones mathematico-physicae experimentis, Leipzig, 1738, p. 516. 
pas la théorie cartésienne, n'attendaient-ils pas quelque confirmation expérimentale à l'instar de celle que fournit Rumford plus tard ? En vérité, la chaleur en tant que mouvement, le processus en tant que résultat mécanique restaient étrangers à leur horizon, ne répondaient ni à leur expérience, ni à leurs exigences conceptuelles. T. Bergman connaissait l'option :

« Dès les temps les plus reculés, la nature du feu a exercé le génie des philosophes, et jusqu'à présent l'on n'est pas encore parvenu à concilier les différentes opinions sur ce sujet. L'on a même mis en question si les phénomènes que l'on attribue au feu dépendent d'une matière particulière ? Ou s'ils ne sont dus qu'au seul mouvement des molécules qui composent les corps ${ }^{572}$.

En bon chimiste - et partisan de G. Stahl — il rejette la possibilité d'une explication mécanique du principal agent et phénomène de sa discipline. A. Fourcroy, partisan de Lavoisier, pense de même. Pour lui, la matière qui engendre la chaleur est le calorique, le corps qui, avec la lumière, est le plus répandu dans l'univers ${ }^{573}$. Il proteste donc fermement contre son assimilation au mouvement et considère que les preuves apportées en faveur de cette conception sont peu convaincantes.

Voici donc opposées, on ne peut plus clairement, les opinions chimiques et les opinions mécaniques au sujet d'un phénomène aussi essentiel que la chaleur, les uns l'insérant dans le monde des fluides impondérables, les autres dans celui des corps en mouvement et se frottant les uns contre les autres, résistant les uns aux autres. Et si, pour rendre raison des réactions chimiques - de l'affinité des corps, comme on disait - on fait appel à un modèle de la philosophie newtonienne, qui était prépondérante et si rigoureuse, c'est à la loi d'attraction qu'on a recours. On a pu dire, avec à propos, qu'en l'occurrence

«la loi de gravitation universelle pour rendre compte de la chimie s'assouplissait en s'altérant : en douant chaque substance de propriétés spéci-

T. BERGMAN : op. cit. p. 185.

573 A.F. FOURCROY : op. cit. p. 121. 
fiques, de qualités que l'énoncé de Newton ne laissait aucunement prévoir, les savants, tout en rendant son application plus facile, lui firent perdre de sa pureté, de son homogénéité, de sa grandeur ${ }^{574}$.

Pouvait-il en être autrement? La loi de Newton, dans la philosophie mécanique, était la seule loi véritablement non-mécanique ${ }^{575}$, l'action à distance se prêtant aux interprétations les plus diverses. Même ainsi, la traduction de l'abstraction en affinité, la tentative pour imaginer un modèle qui empruntât quelque chose à celui des forces gravifiques ${ }^{576}$, est restée longtemps sans écho ${ }^{577}$.

Ce serait aller trop vite que de négliger les possibilités offertes, l'ascendant et la fascination exercés par les schémas atomistiques et mécaniques ${ }^{578}$. Non seulement ils fournissaient un langage plus élaboré et une armature plus puissante, mais encore ils semblaient ouvrir la porte à une application féconde des mathématiques. Pour une partie des chimistes, la philosophie mécanique était le critère du savoir, le signe de l'épanouissement total d'une forme de connaissance. Mais, à vrai dire, on ne dépasse pas le stade des déclarations d'intentions, et on se contente d'exprimer le désir d'égaler le savoir le plus élevé, de profiter de son acquis et de se mettre à son école. Le feu demeure « le plus étonnant de tous les phénomènes ${ }^{579}$, et lorsque Rumford démontre expérimentalement le caractère mécanique de la chaleur, on le réfute, car :

« si l'on examine les faits dans leur ensemble, on voit bientôt que la théorie mécanique nous mènerait à des conséquences peu conformes avec la nature des choses. En effet si nous voulons suivre avec rigueur ses principes, on devrait regarder toutes les actions chimiques comme une suite de mouvements

H. MetZGer : Newton, Stahl, Boerhaave et la doctrine chimique, Paris, 1930, p. 57.

idem, p. 52.

C. Berthollet : Essai de statistique chimique, Paris, 1803.

577 L. MEYER : Les théories modernes de la chimie, Paris, 1887, t. I, p. 3.

578

Voir notamment ce qu'écrit J. DALTON : «L'opinion la plus probable, en ce qui concerne la nature du calorique, est qu'il s'agit d'un fluide électrique, de grande subtilité, dont les particules se repoussent mutuellement, mais sont attirées par tous les autres corps. » A new system of chemical philosophy, Manchester, 1808, p. i.

579 H.C. OERSTED : Recherches sur l'identité des forces chimiques et électriques, Paris, 1813, p. 75. 
intérieurs. C'est même cette conséquence naturelle qui a fait triompher la théorie du calorique, lorsque les faits chimiques, bien examinés, n'ont plus permis de les déduire des propriétés purement mécaniques $»{ }^{580}$.

La coexistence de ces deux états de la "nature des choses», l'évidence sur laquelle reposait chacun, le mode de relation qui leur était respectivement propre, eu égard aux pouvoirs matériels, complètent l'esquisse de la division en catégories naturelles que j'ai décrite, et correspondent à la nécessité de fonder l'opération des artifices.

$\underline{\text { Retour à la Table des Matières }}$

580 idem, p. 197. 


\section{Chapitre VIII. \\ L'annonce de la révolution scientifique}

\section{Les deux visages de l'art expérimental}

\section{$\underline{\text { Retour à la Table des Matières }}$}

Le processus inventif associé à l'activité des philosophes mécaniciens, dès le XVI ${ }^{\mathrm{e}}$ siècle, se voit fixer deux orients. D'une part viser au développement, au parachèvement de ce qui a été trouvé, expérimenté, sur le plan productif, diversifier, surpasser les découvertes tant théoriques que pratiques de l'ingénieur, de l'opticien, etc., représentait un intérêt majeur. Les expérimentateurs se savaient outillés pour améliorer à la fois le contenu des techniques et leurs propres procédés d'invention ${ }^{581}$. Muni des matériaux recueillis dans les ateliers artisanaux, inspiré par les conceptions propres à la philosophie et les opinions des mécaniciens, aiguillonné par les questions soulevées par les uns et les autres, le philosophe pouvait espérer découvrir des rapports inédits, et ainsi enrichir le domaine de la technique et de la nature.

« J'ai traité le sujet de la discussion qui précède, nous avertit Robert Boyle ${ }^{582}$, avec beaucoup plus de particularités que je ne l'aurais fait si ma plume n'avait été entrainée par l'espoir que les choses que j'ai représentées fournissent des excuses à bien des hommes curieux qui peuvent être entraînés par là à apporter des matériaux philosophiques tirés des ateliers aux érudits, et divulguer les expériences des hommes d'art, en vue de l'amélioration des mé-

R. HOOKE : Micrographia, Preface, in Early Science in Oxford, ed. cit.

582 R. BOYLE : Some considerations concerning the usefulness of Experimental Natural Philosophy. Oxford, 1663, t. II, Preamble. 
tiers eux-mêmes et du grand enrichissement de l'histoire des Arts et de la nature $\gg$.

Mieux inventer, éviter le tâtonnement et le hasard, voilà ce qu'on attendait du philosophe mécanicien, et ce que lui-même estimait pouvoir réaliser.

D'autre part, les disciplines philosophiques, en observant la méthode expérimentale, explorent des phénomènes inconnus ou méconnus pour cerner les conditions de leur existence et établir leur fonction. Sous cet angle, elles se proposent d'aboutir à la création de nouveaux arts :

«Le philosophe expérimental, affirmait Robert Boyle ${ }^{583}$, peut non seulement améliorer les métiers mais les multiplier ».

Dès lors, l'entreprise du philosophe ne diffère point de celle de n'importe quel inventeur, ni l'objectif de la philosophie de celui des techniques ou des arts, puisqu'elle se propose d'obtenir « des résultats analogues ». C'est-à-dire de provoquer des effets, de manier des matériaux, de multiplier les processus, là où ces effets, ces matériaux, ces processus étaient inexistants, même au niveau de la technique ${ }^{584}$.

Le passage essentiel ne serait donc pas celui qui va de l'habileté à la connaissance, mais d'une connaissance à une autre ou à un savoirfaire original. L'expérience, dans ce cas, ne chercherait plus ses moyens et ses modèles dans les ateliers ou sur les chantiers, elle n'est pas la transposition d'une habileté commune; elle est son propre commencement et se nourrit de sa propre tradition.

Bien que la philosophie mécanique soit caractérisée par l'esprit de découverte, elle reste marquée par le souci immanent à toute philosophie de fournir une explication, de dévoiler l'essence des réalités qui sont apparues ou se sont affirmées, soit dans la production - celle de

R. BOYLE : idem, p. 30.

584 T. SPRATT : cit. p. 109. 
l'ingénieur, en l'occurrence — soit dans la société, avant que la réflexion dont elle est l'incarnation vienne à s'instituer. Il est conforme à la vocation des disciplines mécaniques de reprendre et de soumettre à l'examen toutes les nouveautés que proposent l'ingénieur, l'opticien ou l'horloger. Leur champ s'élargit de la sorte et leurs méthodes sont, parallèlement, validées. Par exemple, lorsque la machine à vapeur fut d'une application courante, le rapprochement avec d'autres mécanismes s'imposa, et la généralisation des axiomes acceptés conduisit à la création de la thermodynamique. Celle-ci fut, probablement, la dernière branche du savoir à se constituer de cette manière, en partant de la nécessité de transposer, sur le terrain des fondements naturels, ce qui s'était déjà solidement cristallisé dans la technique. La succession des opérations et la distribution des fonctions étaient prévues : les phénomènes mis au jour par l'art mécanique étaient transférés, saisis par la philosophie mécanique, et assimilés au modèle prédominant qui déterminait aussi bien les cadres de l'étude théorique que ceux de l'expérimentation ${ }^{585}$. Une tendance que je qualifierai ici de façon purement conventionnelle comme étant celle de la philosophie expérimentale continue parallèlement à faire l'inventaire des phénomènes curieux, à proposer des expériences destinées autant à étonner qu'à faire avancer le savoir. Elle se consacre aux aspects du réel qui ne se sont réalisés ni dans la philosophie ni dans l'art mécanique, elle a l'ambition d'ouvrir de nouveaux horizons, de fonder de nouvelles disciplines, de pousser l'élan inventif jusqu'à ses limites. Ce visage de la pensée et de la préoccupation philosophiques n'était pas absent de l'œuvre des grands mécaniciens. A cet égard, Isaac Newton apparaît comme un Janus bifrons : d'une part il rédige les Principes mathématiques de la philosophie naturelle, le paradigme de la connaissance assurée, et d'autre part il traite, dans son Optique, de questions qui, précisément, ouvrent sur l'univers inexploré de la lumière, du magnétisme, de l'électricité, de la chimie. Dans une étude très documentée,

585 « Mais malgré ce sentiment d'unité, la distinction était bien entendu manifeste entre les sciences mathématiques et surtout déductives qui s'occupaient de la matière inanimée, et où se posaient les principaux problèmes de l'époque, et, d'autre part, les sciences dans lesquelles les mathématiques ne jouaient pas encore un rôle important, et qui reposaient surtout sur l'observation et l'induction - la chimie, à ce stade, et les sciences de la vie ». M. d'ESPINASSE : The decline and fall of Restoration science, Past and Present, 1958, n ${ }^{\circ}$ 54, p. 71. 
J.B. Cohen ${ }^{586}$ a montré que chacun de ces aspects a été embrassé par un groupe distinct de savants - le premier par les mathématiciens et les mécaniciens, le second par ceux qui se livrent justement à des expériences sur l'électricité et le magnétisme. L'écart était tel que les travaux d'un Benjamin Franklin, qui faisait manifestement partie de ce dernier groupe, suscitaient les commentaires suivants :

«Un homme qui a passé le plus clair de son temps à étudier les Principes de Newton et les sciences nécessaires à la compréhension de ce livre, pouvait entendre parler de gens qui frottaient des tubes de verre sans éprouver de curiosité ardente pour ce qui en résulterait. Mais plus particulièrement s'il était convaincu que Newton avait moissonné une récolte si complète qu'il ne laissait à la postérité que bien peu de chose à glaner ${ }^{587}$.

Le même chroniqueur ajoute que le grand livre d'Isaac Newton

« semble n'être que peu prisé ou compris de la race actuelle des philoso-
phes » ${ }^{588}$.

Quelle est cette race de philosophes dont on disait, par ailleurs, en exagérant, qu'elle agit, écrit, conceptualise

« comme si l'on n'avait jamais entendu parler ni rien lu de Sir Isaac et de sa philosophie ${ }^{589}$.

Nous pouvons, certes, la rattacher à Gilbert, à Guericke, à Robert Boyle, à Réaumur, savants qui, au XVII et au XVIII ${ }^{\mathrm{e}}$ siècle, se sont particulièrement intéressés au magnétisme, à la chimie, à l'électricité, aux phénomènes de la vie. Cependant, si nous y regardons de plus près, nous les voyons très souvent se recruter parmi les fabricants d'instruments mathématiques, parmi les hommes qui ont fait de la diffusion des connaissances leur métier, et aussi, bien entendu, parmi les

\footnotetext{
586 J.B. COHEN : Franklin and Newton, Philadelphie, 1956.

587 cité par J.B. COHEN : op. cit. p. 357.

588 idem, p. 318.

589 idem, p. 414.
} 
amateurs. Un public s'était créé, au XVIII ${ }^{\mathrm{e}}$ siècle ${ }^{590}$, qui s'intéressait aux phénomènes matériels, aux expériences plaisantes, et cherchait, outre l'amusement, une instruction qui n'était pas autrement à sa portée. Artisans désireux de parachever leur savoir, manufacturiers attirés par la nouveauté, femmes du monde et gentilhommes, médecins ou rentiers se pressaient aux conférences régulières organisées par ces entrepreneurs de la connaissance. Dans plusieurs classes de la société, mais surtout dans la classe la plus aisée, le goût pour l'expérimentation, pour ce qu'on nommait les "cabinets de physique », s'était répandu ${ }^{591}$. De même que les fondateurs de la Royal Society de Londres ont commencé à se réunir dans des cafés et ceux de l'Académie des Sciences dans des demeures particulières, le nouveau public, avide de distraction et de savoir, se réunit dans des clubs et constitue des sociétés à cette fin. De ces sociétés philosophiques, répandues un peu partout, et pour satisfaire l'intérêt, répondre à l'engouement et agrémenter les loisirs en province, on passe aux foires où, comme à Saint-Germain, des "professeurs de physique » composent des numéros d'illusion en utilisant des effets acoustiques et hydrostatiques, ou les étincelles des globes électriques ${ }^{592}$.

La popularité des démonstrateurs est partout attestée et la quête de spectacle est générale ${ }^{593}$. Pour mettre en évidence les effets de la condensation de l'électricité dans une bouteille de Leyde, l'abbé Nollet prend pour sujets de ses expériences les gardes du roi, ou bien les moines d'un couvent de Paris; il les range en ligne et les lie par du fil de fer : la décharge les fait tous sauter en l'air en même temps. Aux conférences de la Royal Institution, à Londres, se pressent les admiratrices de la chimie et de Sir Humphrey Davy ${ }^{594}$. Au Lycée des arts, à Paris, ingénieurs et artisans, avides d'inventions et de découvertes, s'essaient aux expériences les plus curieuses, où le plaisir du jeu a sa part autant que la préoccupation purement philosophique ${ }^{595}$. Des cours, un embryon

A. Wolf : A history of science, technology and philosophy in the eighteenth century, New York, 1939.

591 «La mode des cabinets de physique allait de pair avec celle des laboratoires de physique». M. DAUMAS : Lavoisier, Paris, 1955, p. 7.

592 M. DAUMAS (ed) : Histoire de la science, ed. cit. p. 927.

593 F. CAJORI : A history of physics, New York, 1929, p. 125.

594 G. Foote : Sir Humphrey Davy and his audience at the Royal Institution, Isis, 1952, 43, pp. 612.

595 W.A. Smeaton: The early years of the Lycée and the Lycée des Arts, Annals of Science, 1955, II, pp. 309-319. 
de laboratoire et un cabinet de physique y suffisent. Ce serait se tromper lourdement que d'ignorer le caractère public de ces expériences, de négliger la personnalité de leurs auteurs. Des historiens pour qui la science se confond avec la culture mélancolique de l'esprit et le cérémonial académique dédaignent souvent le fait qu'elle est passée par les réunions mondaines et le champ de foire, et qu'elle a eu pour apôtres des démonstrateurs tantôt besogneux, tantôt charlatans, dont le génie a suppléé à ce qui pouvait alors être taxé d'ignorance. Bref, que la physique ludique s'est amalgamée à la physique sérieuse, et que de nombreuses découvertes se situent à leur point d'interférence. Il importe d'en tenir compte, car cette situation non seulement a eu pour conséquence de stimuler la publication d'ouvrages ${ }^{596}$, mais a imprimé son sceau à leur contenu et a infléchi le style d'activité de ces démonstrateurs et philosophes. Nous ne saurions les regarder autrement, et nous commettrions une grave erreur en leur refusant le titre de véritables savants ou de créateurs de science, quand leurs contemporains les ont estimés tels. En tout état de cause, on ne devrait pas oublier qu'une chaîne continue relie le « professeur de physique » de la foire Saint-Germain au physicien des salons mondains et à celui de l'Académie des Sciences, et que chaque individu joue plusieurs rôles. Avant d'être démonstrateur au Jardin du Roi et d'avoir pour auditeurs Diderot, Rousseau et Turgot ${ }^{597}$, G.F. Rouelle faisait des cours libres ${ }^{598}$. L'abbé Nollet publiait dans les Mémoires de l'Académie des Sciences et faisait courir les snobs à ses séances de physique. Charles Morazé observe à juste titre :

« Entre cette forme élevée d'artisanat et l'homme de science (ne l'eût-on pas appelé en France aussi bien philosophe ?) il n'est pas de différence de nature. Sans doute, astronomie et mathématiques ont déjà un acquis antérieur trop riche pour que la compétence puisse s'improviser. Mais en physique, chimie et médecine même, l'amateur éclairé ou l'artisan adroit font plus que le pédant, grand réciteur d'autorités, grand liseur d'élucubrations révolues $\gg{ }^{599}$.

Évidemment, l'amateur éclairé et l'artisan adroit se devaient de faire davantage, sinon, comment auraient-ils pu attirer les auditeurs? Une expérience originale est souvent conçue comme une attraction, destinée à capter l'attention; une invention utile, outre le prestige

B. RAPPAPORT : G.F. Rouelle : An eighteenth century chemist and teacher, Chymia 1960, 6, pp. 68-101.

598 G.F. RouELLE : Cours d'expériences chimiques : les plantes, les animaux et les minéraux sont l'objet de ces expériences, Paris, 1759.

599 C. MORAZÉ, in R. TATON : Histoire générale des sciences, ed. cit. t. II, p. 429. 
qu'elle confère, peut apporter à son auteur bénéfice et sécurité, lui ouvrir l'accès à la communauté philosophique ou littéraire ${ }^{600}$.

Un ouvrage représente à la fois une brochure publicitaire, une suite de leçons et un agent propagateur qui permet au lecteur de refaire les expériences décrites. L'auteur y expose avec prolixité ses démarches et ses procédés, inaugurant de la sorte une tradition qui demeurera dans la littérature scientifique, à savoir la présentation des données et des manipulations expérimentales de manière à ce que tout un chacun puisse les contrôler et les reproduire. Dans ces livres, on trouve moins d'analyse théorique que de recettes empiriques, ayant trait à l'appareillage, à sa construction et à son agencement en vue de provoquer les phénomènes auxquels on prend intérêt. Parfois un ouvrage constitue la charte intellectuelle d'une société que le démonstrateur tente de fonder pour poursuivre la réalisation du programme annoncé. Bryan Higgins, le précurseur de la théorie atomique en chimie, édite

«Un programme de recherches chimiques et philosophiques composé à l'usage des nobles et gentilshommes qui ont souscrit aux propositions faites pour l'avancement des connaissances naturelles ${ }^{601}$.

Les lecteurs éventuels et les participants aux cours et démonstrations sont invités à souscrire cinq guinées. Avec leur aide, et sur la base de son "Programme », Bryan Higgins constitue en 1793 une Society for philosophical experiments and conversations qui publie régulièrement des comptes rendus de ses activités. C'est dans ce cadre non seulement que s'insère une découverte comme celle de l'acétamide, mais que l'on conçoit aussi un harmonium chimique : les notes de musique y sont produites par la combustion d'un jet d'hydrogène dans un tube de verre placé verticalement.

John Dalton, lui aussi, exerçait la profession d'enseignant et démonstrateur, et faisait partie d'une association analogue, The Manchester literary and philosophical society, dans les locaux de laquelle 1960, 13, p. 233.

601 Londres, 1776. 
il avait son laboratoire. Le grand J.B. Priestley, pour subvenir à ses recherches et à ses propres besoins, donnait des leçons à Nantwick (Cheshire), et à cette fin avait acheté une pompe pneumatique et une machine électrique. F. Hanksbee, Desarguilier ont également gagné leur vie de cette façon.

L'《 expérience philosophique » devient familière, les phénomènes qu'elle traite ne se rattachent plus strictement au domaine de la mécanique. Les démonstrateurs itinérants et les professeurs de physique ou de philosophie expérimentale répandent la nouvelle manière de voir et d'aborder la réalité. Comme les autres artisans et philosophes, ils préservent et propagent l'intérêt pour l'invention dans de larges couches de la société ${ }^{602}$. Mais, à l'encontre des ingénieurs et des philosophes mécaniciens, ils ne sont que faiblement attirés par la discipline rigoureuse des mathématiques, l'élaboration de modèles théoriques stricts, ou les phénomènes qui ont principalement pour source la transformation du mouvement et la combinaison des forces. Ils ne s'occupent point de parachever des techniques ou des instruments qui existent déjà. Leur connaissance se veut utile et vise non seulement à instruire, mais aussi à révéler des événements et des processus qui n'ont pas encore reçu d'expression théorique ou productive. Les «expériences philosophiques » auxquelles ils se livrent touchent aux pouvoirs matériels qui ne s'inscrivent pas encore parmi les ressources habituelles de la société, notamment l'électricité, le magnétisme et la chimie.

Profitant de la capacité d'étonnement et du désir de jouer de la plupart des hommes, possédant la fraîcheur de l'imagination et la volonté de quitter les domaines trop chargés d'acquis, ils engendrent des savoirs nouveaux, qui donnent un autre sens au rapport avec l'univers. A l'abri de ce simulacre de gratuité, concepts et spéculations se ramifient et prolifèrent avec une surprenante profondeur et une grande liberté, exprimant davantage la fascination devant l'organisation des êtres que la crainte de leur rencontre. Comme s'il s'agissait d'un jeu, où l'on essaie et éprouve les phénomènes matériels avant de vérifier leur existence réelle et de les mettre au travail «pour de bon », on se 
risque à faire des esquisses successives, des ébauches et des brouillons, on se livre à des manœuvres et à des répétitions, qui présentent le spectacle du monde comme un monde du spectacle.

Assurément, ces doctrines, ces notions, comme la démarche qui sert à les établir, malgré une volonté de cohérence, restent souvent prisonnières de préjugés et de représentations toutes faites, ce qui empêche de les qualifier de scientifiques ou de théoriques. L'étude qu'a consacrée Gaston Bachelard ${ }^{603}$ à l'élucidation de leur structure a mis en relief tout ce qui les éloigne de la vision assurée et triomphale d'une pensée déductive, capable de contrôler ses démarches et de respecter les règles de sa constitution. Scories et déchets abondent : mais la raideur scolastique et le formalisme mathématique n'ont-ils pas eu les leurs ? Et, pour être organisés, ils n'échappent ni à la tentation de la poésie, ni au risque d'errer sans issue.

Cependant, l'irruption d'une connaissance qui s'accepte - ou se veut - tâtonnante, imparfaite et même inachevée, à un moment où le modèle du savoir intégré et réfléchi - le modèle de la philosophie mécanique - était si manifeste et normatif, prend l'allure d'une provocation et d'une innovation. A travers elle, la philosophie tente d'appréhender non pas ce qui est ignoré, je veux dire ce qui est fait sans qu'on sache pourquoi, mais ce qui est inconnu, c'est-à-dire inexistant et au delà des limites imparties à ses possibilités d'action. Y étant parvenu, après avoir maîtrisé et modelé l'activité inventive, à son tour elle commence à être maîtrisée et modelée par cette activité. Ainsi la philosophie se montre sous un autre jour, non pas tant par la transposition et la subdivision des connaissances ou habiletés qui existent que par la mise en évidence directe, l'institution des réalités auxquelles elles correspondent. 


\section{Un nouvel ordre de philosophes : la prophétie de J. B. Priestley}

\section{$\underline{\text { Retour à la Table des Matières }}$}

Les philosophes expérimentaux apparaissent donc comme un groupe à la fois particulier et nouveau. Leur action a un effet transformateur sur l'ensemble d'une catégorie naturelle, sur son système de reproduction, et s'exerce d'emblée au niveau de la fonction autocréatrice de facultés et de savoirs. La fonction productive ne sera modifiée, établie, qu'ultérieurement. C'est là un renversement de la hiérarchie dans l'apparition des fonctions qui prévalait dans l'évolution des rapports entre l'homme et les forces matérielles.

Qu'il s'agisse là d'un événement historique important, J.B. Priestley en a eu conscience dès le début. Principal acteur d'une histoire dont il a été un des plus perspicaces historiens, il a embrassé d'un regard sûr les courants qui la traversaient. Ainsi fut-il en mesure, sinon d'en prévoir l'avenir, du moins d'exprimer les promesses contenues dans les disciplines naissantes. Il voyait que le changement de l'état naturel mécanique était inévitable, et qu'un autre état, ayant ses propres acteurs, se dessinait déjà avec vigueur.

«En suivant donc cette nouvelle lumière, on peut parvenir à étendre les bornes de la physique au-delà de tout ce dont nous pouvons maintenant nous former une idée. On peut découvrir à notre vue de nouveaux mondes, et la gloire du grand Isaac Newton lui-même et de tous ses contemporains peut être éclipsée par un nouvel ordre de philosophes, dans un champ de spéculations tout à fait nouveau $»{ }^{604}$.

Le ton est ferme, l'indication précise. Au monde tel qu'il est conçu, consolidé, d'autres mondes sont prêts à se substituer. J.B. Priestley, électricien et chimiste, entrevoit les prodromes de cet événement, qui aura son Newton, au moment précis où son contemporain Lagrange, mécanicien et géomètre, déplore l'existence d'un ordre unique, dont le 
célèbre philosophe anglais a eu l'insigne fortune de donner les lois, laissant pour seule tâche à toutes les générations suivantes le soin de les parachever. Le contraste est extrêmement frappant, et la vocation de ces nouveaux philosophes on ne peut plus claire : assurer la suprématie des pouvoirs matériels et intellectuels qui se manifestent dans leurs découvertes. Nous avons vu qui ils sont : démonstrateurs, amateurs, propagateurs de connaissances utiles, expérimentateurs habiles à émerveiller leur public ou théoriciens au sens le plus strict du mot.

«Les expériences électriques, dans presque tous les pays d'Europe, ont fourni à l'occasion un moyen de subsistance à de nombreuses personnes ingénieuses et industrieuses, qui ne jouissaient pas d'une grande aisance et qui ont eu l'habileté de tourner à leur profit la passion du merveilleux qu'ils voyaient être si forte chez leurs semblables ${ }^{605}$.

L'acception du philosophe s'élargit à mesure que les sociétés philosophiques, les disciplines auxquelles elles se consacrent, se multiplient et prétendent accéder à un rang intellectuel plus élevé et même concurrencer académies et établissements royaux reconnus.

Le signe distinctif de l'appartenance à la classe des savants est la capacité inventive que l'on déploie dans un domaine, quel qu'il soit. L'érudition, la maîtrise des mathématiques ou de l'une des branches de la philosophie mécanique ne suffisent pas pour qui veut être, suivant la terminologie de Whewell, "philosophe physicien ». Le nombre de ceux-ci n'a pas cessé de croître. Leurs journaux et leurs revues ont une audience certaine, ils intensifient les échanges, enregistrent les contributions majeures ou mineures.

Si la valeur des découvertes originales est le critère suprême, alors un ignorant, sit venia verbo, est l'égal d'un homme très savant; bien plus, si le philosophe veut répondre à ce critère, il a intérêt à diriger ses efforts vers les domaines les moins explorés, ceux qui sont encore en friche. Et même à en créer de nouveaux. Le novateur n'a aucun avantage à parcourir jusqu'à son terme le chemin ouvert par d'autres, car, justement, il n'y a pas de terme. Il se distinguera le plus là où, 
sans être alourdi par les bagages du passé, il s'aventurera sur des voies inconnues. Cette vision apparaît clairement à travers les arguments avancés par J.B. Priestley pour stimuler l'étude de l'électricité ${ }^{606}$ :

«Dans l'électricité, en particulier, il y a la plus large place pour faire de nouvelles découvertes. C'est un domaine qui vient seulement de s'ouvrir, et qui ne demande pas un grand bagage de connaissances préparatoires particulières : de sorte que quiconque a une assez bonne habitude de la philosophie expérimentale peut être bientôt à égalité avec les électriciens les plus experts. Bien plus, cette histoire montre que plusieurs aventuriers sans préparation se sont acquis autant de considération que d'autres qui sont, à d'autres égards, les plus grands philosophes $»$.

Cette description de l'entreprise philosophique rappelle, par maint côté, des constatations que nous avons faites à propos du XVII ${ }^{\mathrm{e}}$ siècle. Dans un cas comme dans l'autre transparaissent l'injustice nécessaire envers le passé, les signes de l'identité qui s'affirme face à ce qui peut la masquer. Mais la ressemblance s'arrête là. Le philosophe mécanicien proteste contre l'amoncellement de livres scolastiques parce qu'ils forment écran entre lui et le réel qu'il estime pouvoir saisir par le seul moyen de son intelligence. Ces autodafés périodiques, indices du surgissement de nouvelles totalités d'action et de pensée, sont indispensables. L'ignorance triomphante tourne le manque en un pouvoir, la mise à mort en une naissance. J.B. Priestley se réfère à un tel rafraîchissement, à une telle sélection des savoirs. Cependant, il ne s'y réfère pas comme à un franchissement d'obstacles que la réflexion saine tente de contourner. Ce n'est pas son propos, il ne veut pas écarter les hommes des livres. Pour lui, comme pour bon nombre de ses contemporains, c'est la permanente conquête de "nouveaux mondes » qui s'écarte des livres, dispense de s'en trop soucier.

En somme, l'idéal poursuivi est autant de changer le monde que de le connaître. Si, auparavant, découvrir ou systématiser sur un autre mode était une démarche que l'on reconnaissait satisfaire aux normes, maintenant la véritable règle de l'invention devient : dépasser ce qui est. En cela l'invention est recherche. Conséquence inévitable, le nom 
même de savant s'avère ambigu. Un de Candolle le juge franchement inadéquat puisqu'il condense deux sens désormais contradictoires :

« Ne désigne-t-il pas deux classes distinctes de travailleurs qui ne peuvent plus être confondus, ni associés : la classe de ceux qui savent et la classe de ceux qui découvrent ${ }^{607}$.

Pour dissiper la confusion :

« Il faudrait avoir un mot pour ceux qui cherchent, qui découvrent, qui inventent, ou plutôt d'une manière générale qui font faire des progrès » ${ }^{608}$.

Créateur de l'objet de la connaissance en même temps que de la connaissance de l'objet, tel est le philosophe, dont Priestley voulait être le prototype ou le prophète, tel est pour de Candolle le savant qui n'a pas encore reçu de nom. Le scientifique représente l'un et l'autre. Ainsi se trouve fondé le «nouvel ordre » de philosophes. 


\section{Le regroupement des disciplines naturelles}

$\underline{\text { Retour à la Table des Matières }}$

Le $\mathrm{XIX}^{\mathrm{e}}$ siècle s'est annoncé comme révolutionnaire dans la sphère de la nature. La différenciation des créateurs de savoirs et d'habiletés l'atteste. La succession des découvertes capitales, la diffusion des expériences et des notions dont elles procèdent, le nombre, relativement important pour l'époque, de laboratoires de chimie ou de cabinets de physique, sont des signes qui ne trompent pas. Ils n'ont pas trompé Diderot $^{609}$ :

« Nous touchons, déclarait-il, au moment d'une grande révolution dans les sciences. Au penchant que les esprits me paraissent avoir à la morale, aux belles-lettres, à l'histoire de la nature, et à la physique expérimentale, j'oserais assurer qu'avant qu'il soit cent ans, on ne comptera pas trois géomètres en Europe $»$.

Prémonition juste et prévision fausse nous font voir quelle révolution il a entrevue : celle qu'ont provoquée les savoirs biologiques et physiques. Comment échapper à cette impression de renouvellement en voyant la perspective ouverte par les multiples recherches dans le domaine de l'électricité, du magnétisme ou de la chimie ${ }^{610}$ ? Lorsque la Mécanique analytique de Lagrange continue et clôt trois siècles de mathématiques et de mécanique, Lavoisier lance dans une nouvelle direction la connaissance des phénomènes chimiques. Une vision hardie, une relation que l'on pressent en train de muer, tout fait présager un contact original avec le monde matériel :

«Il me semble, écrit Herder, que nous approcherions d'un nouveau mode de connaissance, si les observations qui ont été faites par Boyle, Boerhaave, Hales, s'Gravesande, Franklin, Priestley, Black, Crawford, Wilson, Achard, etc. sur la chaleur et sur le froid, sur l'électricité, sur les différentes espèces d'air et d'autres agents chimiques, et sur l'influence que ces principes exercent

${ }^{610}$ C.A. BeCQuerel : Résumé de l'histoire de l'électricité et du magnétisme, Paris, 1858, 
sur le règne animal et le règne végétal, sur les hommes et sur les minéraux, étaient rassemblées en un seul système ${ }^{611}$.

L'enthousiasme que soulèvent chez les observateurs les changements en cours, la précision de leurs idées quant au contenu susceptible d'être rassemblé, le pronostic sur lequel ils s'accordent, sont inspirés par plusieurs séries de faits.

D'une part - et ceci de manière incontestable - la chimie a franchi une étape importante. Ses expériences sur l'état interne des corps, la cohérence des doctrines qu'elle propose, le schéma des puissances matérielles qui s'en dégage, la situent au-delà du cadre de l'art, de la technique. Sa discipline se révélant entièrement naturelle, au même titre que les autres disciplines, le chimiste entend désormais participer de la philosophie et se veut philosophe. Cette option ${ }^{612}$ va cependant beaucoup plus loin. Le chimiste situe son savoir à la racine des phénomènes objectifs. Toute la physique - ou la philosophie naturelle, ainsi que la qualifient les Anglais, même de nos jours - doit être révisée et établie sur d'autres principes, les principes chimiques. Shaw, l'éditeur anglais de Boerhaave, déclare ${ }^{613}$ :

« La chimie, dans son étendue, n'est rien moins que le tout de la philosophie naturelle ».

Faute de quoi, elle demeure non seulement incomplète mais surtout erronée. Venel dans l'Encyclopédie déjà citée, vient à la rescousse :

«Toutes les erreurs qui ont défiguré la physique sont provenues de cette unique source : savoir que les hommes ignorant la chimie se sont donné l'air de philosopher et de rendre raison des choses naturelles, que la chimie, unique fondement de toute la physique, était seule en droit d'expliquer ».

La prétention est excessive. Cependant, l'apport intellectuel et pratique de la chimie, l'importance croissante, du point de vue social, des

\footnotetext{
611 J.G. HERDER : Idées pour la philosophie de l'histoire de l'humanité, Paris, 1827, t. I, p. 31.

612 J. BLACK : Lectures on the elements of chemistry, Edinburgh, 1803, p. 5.

613 J.B. COHEN : op. cit. p. 223.
} 
hommes possédant ce savoir particulier justifient pareille demande. Une chose est évidente : l'autonomie une fois conquise, ce n'est pas à une place quelconque parmi les disciplines philosophiques qu'aspire la chimie, elle réclame la première place.

« Et sa méthode, enfin indépendante, doit devenir tôt ou tard la boussole de plusieurs branches de l'histoire naturelle, plutôt que de continuer à en paraître un simple accessoire, comme elle avait paru l'être depuis si longtemps $\gg .{ }^{614}$.

L'aire de jonction ou d'expansion de la communauté des savants ou des hommes de métier, le courant de recherches ou la tendance philosophique dans lesquels le chimiste est assuré de trouver l'écho désiré, sont virtuellement prédéterminés. C'est, bien entendu, le domaine de ces philosophes expérimentaux avides d'étendre leurs possibilités d'action, de créer de nouveaux savoir-faire. Entre leurs mains l'électricité - et le magnétisme - se sont remarquablement développés et sont devenus des secteurs relativement délimités, ayant leur langage, leur littérature, et leurs applications. Les phénomènes électriques prennent leur place parmi les phénomènes matériels. Cela peut nous sembler aujourd'hui absurde ou étonnant. Il y a juste deux siècles, tout effet électrique était jugé résulter d'une opération de frottement, donc artificiel. On n'imaginait pas qu'un état analogue se retrouverait parmi les états ordinaires des corps abandonnés à l'action de leurs lois propres. Le but des expériences de Benjamin Franklin (et une des raisons de leur grand retentissement) a été de prouver que la décharge de l'éclair était un phénomène électrique. Du même coup s'est trouvé démontré le caractère non artificiel de celui-ci. Les résistances à cet égard furent tenaces ${ }^{615}$. Bien entendu, les machines génératrices d'électricité ou les condensateurs — la bouteille de Leyde notamment - ont stimulé l'expérimentation, enrichi l'appareillage des cabinets de physique et se sont avérés aussi variés que les instruments optiques ou mathématiques. Les découvertes de Franklin sont allées plus loin; elles ont mis en évidence une lacune dans l'ordre naturel constitué :

614 A.F. FOURCROY : op. cit. p. XLIII.

615 «Le préjugé était si fort que les noms d' »électricité naturelle » et d' »électricité artificielle» se sont maintenus pendant une partie du XIX ${ }^{\mathrm{e}}$ siècle. » J.B. COHEN : op. cit. p. 281. 
«Galilée et Newton avaient construit ce qu'ils considéraient comme un système presque complet de l'univers sans accorder à l'électricité plus qu'une mention au passage ${ }^{616}$.

L'association des connaissances chimiques et électriques faisait ressortir les failles de ce système. Elle aboutissait à contester la manière dont la philosophie, surtout mécanique, appréhendait le réel :

«Jusqu'ici, écrit J.B. Priestley ${ }^{617}$, la philosophie s'est surtout préoccupée des propriétés les plus sensibles des corps ; l'électricité, avec la chimie et la doctrine de la lumière et des couleurs, semble nous permettre d'accéder à leur structure interne, dont dépendent toutes les propriétés sensibles ».

Tous ces témoignages concordent, ils expriment une attitude commune, ils sont l'indice d'une position prise par un groupe relativement homogène, celui que constituaient les chimistes et les électriciens. Les exemples ne manquent pas, depuis Dufay jusqu'à Priestley, Davy, Faraday ou Oersted ${ }^{618}$, d'hommes qui ont fait des travaux ou des découvertes d'importance dans les deux branches du savoir.

La mise en relief du côté philosophique de la chimie ${ }^{619}$, l'articulation de celle-ci avec les disciplines à l'état naissant de la philosophie expérimentale ${ }^{620}$, ont donc pour effet visible la constitution d'un corpus de théories ${ }^{621}$, d'expériences, et d'un groupe d'hommes qui les embrassent de conserve. Cette agrégation n'entraîne pas de confusion. Assurément, il y a bien des incertitudes. G. Cuvier ${ }^{622}$ traite de l'électricité dans un chapitre consacré à la Chimie générale; on

616

617 J.B. PRIESTLEY : The history and present state of electricity, Londres, 1767, p. XIII.

618 L.P. WILliAMS : Faraday's education in science, Isis, 1960, 51, p. 530.

619 «C'est du reste une chose toute moderne que la philosophie de la chimie ». P. de RÉmUSAT : Les sciences naturelles, Paris, 1857, p. 56.

620 «La chimie devient ainsi pour moi la seconde partie de la physique générale ». A. AMPÈRE : Essai sur la philosophie des sciences, Paris, 1856, p. VIII.

621 «Le terme de physique pendant la première moitié du XVIII" siècle, et souvent jusqu'à la fin, désigne l'ensemble des sciences de la nature ». D. MORNET : Les sciences de la nature en France au XVIII siècle, Paris, 1911, p. 2.

${ }^{622}$ G. CUVIER : Rapport historique sur les progrès des sciences naturelles, ed. cit. pp. 56 et seq. 
peut estimer que Lavoisier a renouvelé la physique ${ }^{623}$; rien de tout cela ne constitue vraiment un objet de controverse à l'intérieur du champ dont les contours se dégagent nettement et dont la nouveauté est accusée ${ }^{624}$. N'espérait-on point parvenir à lui donner une structure unitaire?

« Nous terminerons, écrit H.C. Oersted ${ }^{625}$, par cette observation, que la chimie, enrichie par tant de nouvelles découvertes, doit maintenant s'emparer de plusieurs chapitres de la physique qu'elle a jusqu'à présent ou partagés avec cette science, ou qu'elle lui a entièrement abandonnés (telles sont les recherches sur l'électricité, le magnétisme, la chaleur et la lumière). Peut-être suivra-t-on encore mieux le développement de la science en réunissant en un tout ce qu'on a jusqu'ici appelé physique ou chimie ».

En attendant de voir se réaliser cet espoir, des solutions provisoires sont nécessaires et elles se dessinent dès l'instant où l'on veut inclure la mécanique dans le nouvel ensemble. Pour le décrire, J. B. Biot le divise, divise la physique, en deux parties. La première partie traite des actions mécaniques permanentes et générales. La seconde renferme des changements dus à des forces variables (la chaleur, l'électricité, le magnétisme). L'articulation concerne, on le voit, une discipline - surtout mécanique - ayant trait aux causes invariantes essentielles et une discipline — surtout physico-chimique — destinée à étudier les causes variables et accidentelles.

De ces deux parties ou disciplines, l'une, quoique plus élaborée, reste relativement stationnaire, l'autre, incertaine, pleine de matériaux épars, ne cesse de progresser ${ }^{626}$. Elle manifeste même au sujet des phénomènes chimiques, électriques et calorifiques ${ }^{627}$ un souci de quantification et mathématisation. L'exemple de la philosophie méca-

623 (e projet de realiser une nouvelle physique particulière sur les débris l'ancienne ». A. LIBES : Histoire philosophique des progrès de la physique, Paris, 1810, t. IV, p. 53.

624 J.B. BIOT : Traité de physique expérimentale et mathématique, Paris, 1816, p. II.

625 H.C. OERSTED : op. cit. p. 257.

626 «Mais la partie de cette science qui traite des causes accidentelles a fait surtout des pas remarquables » J.B. Bı̈ : Essai sur l'histoire générale des sciences, Paris, 1803, p. 17.

627 D. ROLLER : The early development of the concepts of temperature and heat, Cambridge (Mass), 1950. 
nique et les nécessités internes ont joué leur rôle à cet égard. Avec Lavoisier et Coulomb, la balance et la loi quantitative pénètrent rigoureusement là ou leur présence avait été longtemps tenue pour inutile ${ }^{628}$. J. B. Richter dans une dissertation qui inaugure un courant qui ne cessera de s'amplifier - De usu mathéseos in chymia (De l'emploi des mathématiques en chimie) — propose une méthode de détermination des poids spécifiques d'une substance en solution ou de ses composés. La théorie de Proust, selon laquelle chaque combinaison chimique traduit une structure stable spécifique, indépendante des conditions dans lesquelles cette combinaison a eu lieu, permet de calculer les proportions des corps qui entrent dans une réaction et de faire une prévision rigoureuse. Le monument le plus beau, un des plus beaux de la science, a été dressé, à partir de cette physique, par J. Fourier dans sa Théorie analytique de la chaleur. Développant une théorie des dimensions, dont l'esquisse est due à Descartes, il donne, on le sait, une formulation rigoureuse de la conduction de la chaleur à l'intérieur d'une masse matérielle. Cependant, et ceci est caractéristique, il adhère à la doctrine substantielle de la chaleur ${ }^{629}$. Par conséquent, il se désintéresse des effets mécaniques et les déclare sans rapport avec les phénomènes thermiques :

«Mais quelle que soit l'étendue des théories mécaniques, elles ne s'appliquent point aux effets de la chaleur. Ils composent un ordre spécial de phénomènes qui ne peuvent s'expliquer par les principes du mouvement et de l'équilibre $»{ }^{630}$.

Géométrisé, ou en passe de l'être, ce réel demeure composé de matières fluides impondérables, et le feu — la combustibilité ou le calorique - y prédomine. L'électricité est classée dans la famille des « feux » et obtempère à la règle qui veut que « tous les corps que nous saisissons par les sens enferment le feu ${ }^{631}$. Ne sert-elle pas à la combustion de l'«esprit-de-vin » ordinaire et aux mélanges ? Et la

«Beaucoup de personnes en France et ailleurs croient que la physique doit être présentée sous la forme expérimentale, sans aucun appareil algébrique ». J.B. BioT : Traité de physique, op. cit. p. XI.

629 J. FOURIER : Théorie analytique de la chaleur, Paris, 1822, p. I.

${ }^{630}$ idem, p. II.

631 J.H. WINKLER : op. cit., pp. 516 et seq. 
machine électrique n'est-elle pas considérée comme une «pompe à feu ${ }^{632}$ ?

Ainsi, les constitutions matérielles envisagées du point de vue chimique et du point de vue électrique embrassant donc une grande partie de la physique sont similaires ${ }^{633}$. Elles ont en commun le principe qui concerne la combustion, les effets calorifiques ${ }^{634}$, et non pas le mouvement et la détermination des forces ou des vitesses. Il conduit à reconnaître partout des fluides impondérables non soumis à l'attraction gravifique, et qui tendent à se répandre uniformément dans l'espace, sans se fixer dans un milieu privilégié ( «L'électricité, dit Cuvier ${ }^{635}$, est encore un de ces principes impondérables, qui jouissent du pouvoir de modifier les affinités »). L'ensemble de ces substances représente, Henry Cavendish le note expressément, une autre sorte de matière ${ }^{636}$ :

«A l'avenir, je voudrais qu'on comprenne que je n'entends pas le fluide électrique sous le nom de matière, mais seulement comme une sorte de matière $»$.

La fécondation des savoirs est évidente lorsqu'on voit les emprunts fréquents que font les méthodes électriques à la chimie et réciproquement. Celle des concepts ne l'est pas moins. L'invention de la pile de Volta incita immédiatement Carlisle et Nicholson à procéder à des expériences qui aboutirent à la décomposition de l'eau par électrolyse. Plus systématiquement, Davy découvrit le sodium et le potassium en soumettant la soude et la potasse fondues à l'action des courants électriques. Les spéculations antérieures sur l'assimilation des forces électriques et des forces chimiques, celles de Priestley ou Oersted d'une

632 raison qu'on donne celui de Pompe à air aux machines d'Otton de Guericke et de Boile ». W. WATSON : Expériences et observations, Paris, 1748, p. 128.

633 J. DAUZAT: Origines et formation de la théorie des phénomènes électriques et magnétiques, Paris, 1943.

634 J.G. Biot : Traité de physique, op. cit. p. 19.

635 G. CUVIER : op. cit. p. 6.

636 J.C. MAXwELl (ed) : The scientific papers of the hon. Henry Cavendish, Cambridge, 1921, t. I, p. 34. 
part et celles - de Winterl ou Ritter - relatives au classement des métaux suivant leur facilité d'oxydation ou leurs propriétés électriques, prirent de la sorte consistance. Dans cette lignée se situe la célèbre tentative de Berzelius d'attribuer à toute parcelle d'un corps deux pôles opposés mais contenant des quantités inégales d'électricité, de sorte que chaque élément ou partie de cet élément apparaisse polarisé positivement ou négativement. Partant, il croit percevoir dans chaque combinaison chimique une constitution binaire, comme celle de ces sels qui possèdent deux composantes matérielles, l'une positive et l'autre négative. Il ordonne donc tous les éléments en une série allant du potassium, le plus positif, à l'oxygène, le plus négatif. Lorsque deux corps s'unissent, leurs parcelles se juxtaposent avec les pôles opposés en regard et procèdent à un échange de leurs électricités libres : l'effet en est un phénomène thermique ou lumineux. Quand, au contraire, on fait passer un courant électrique par un corps composé, ce courant restitue aux éléments composants leurs polarités originelles, et la molécule se décompose. Cette théorie dualiste, ainsi qu'on l'a qualifiée, se situe dans le prolongement de la tradition de Stahl et Lavoisier - le principe oxygène, ayant remplacé le principe phlogistique, est à son tour remplacé par l'électricité — et son propos est assurément d'expliciter aussi le processus de combustion à la fois chimique et électrique ${ }^{637}$.

Si J. J. Berzelius reprend des thèmes traditionnels, sa conception n'en offre pas moins l'exemple d'un changement radical et profond de la définition ${ }^{638}$ la plus générale de la structure matérielle du monde : à l'universalité de la gravité, il substitue celle de l'électricité. A partir de là, il n'était point de retour, car l'état naturel ne pouvait plus être maintenu tel qu'il était, pondérable pour les uns, tout en fluides pour les autres : pour les uns une horloge perpétuelle, pour les autres un feu éternel. Les rapports entre les disciplines qui traduisaient ce dédoublement, l'activité de l'homme de métier ou de science qui éprouvait

J.J. BERZELIUS : Essai sur la théorie des proportions chimiques et sur l'influence chimique de l'électricité, Paris, 1819 p. 70.

638 «L'électricité, dont la nature nous est encore inconnue, et qui n'a d'analogie avec aucun autre corps dans la sphère de notre expérience (si l'on excepte le fluide magnétique) semble donc être la cause première d'action dans toute la nature qui nous environne ». J.J. BERZELIUS : op. cit. p. 92. 
cette ambiguïté, en subissaient le contrecoup de manière trop accusée pour qu'on ne ressentît pas la nécessité de faire un choix parmi les termes d'une alternative désormais clairement définie. 


\section{Chapitre IX.}

\section{La science des effets}

\section{Systèmes stables et théories périssables}

\section{Retour à la Table des Matières}

Les traits accusés du nouveau type de savant déterminent la structure des disciplines auxquelles il se consacre, la nature des réponses qu'il ambitionne de donner. Selon leur constitution antérieure - et en tant qu'ébauches de la philosophie naturelle ou mécanique - ces disciplines correspondaient directement les unes avec les autres, et l'organisation des informations propres à chacune était subordonnée à l'unité de la totalité ${ }^{639}$. L'existence de systèmes cohérents, partant de principes ou de modèles universellement validés, se déployant à travers toute la gamme des phénomènes divers, paraissait être une nécessité. Elle découlait de la dualité des rapports entre les savoirs - verticaux et horizontaux, hiérarchiques et linéaires - qui les enchaînaient les uns aux autres. L'harmonie interne et la symétrie des parties représentaient des critères suffisants pour signaler l'action de cet enchâ̂nement unitaire, l'ampleur du système.

Les raisons de cette architecture ne sont pas entièrement clarifiées. Il faut, selon toute vraisemblance, les attribuer à la fonction de la philosophie. Celle-ci, quel qu'ait été son contenu, prend son essor lorsque l'art ou la technique sont déjà constitués. La réalité naturelle dont elle se réclame se trouve à sa disposition incluse dans les artifices et les

${ }^{639}$ E. NAGEL : The Structure of science, New York, 1961. 
habiletés des hommes. Elle tend à dégager ce qui leur est commun, à réunir les membres disjoints, à conjuguer des efforts à première vue dispersés. Sa raison d'être est de fournir un cadre, de conférer l'être conceptuel à ce qui a déjà une existence incontestable, une configuration concrète stabilisée. D'où la recherche de convergence, d'où la tendance à introduire l'ordre, à unifier plutôt qu'à diversifier. Le rôle de la philosophie est d'ajuster, de faire prévaloir une méthode là où l'on procédait par tâtonnements. A travers la classification, la comparaison des termes ou des alternatives, le choix d'un guide universel, pointe la systématisation. Bref, un schéma définitif virtuel se dessine toujours à l'horizon ou en pointillé, puisque c'est bien l'être, la mâ̂trise du devenir et non pas le jaillissement provoqué de celui-ci qui paraît imposer la mission particulière du savoir philosophique. Pour celui qui en use, qui conçoit son effort en tant que colligement de phénomènes variables et pénétration par paliers successifs jusqu'à une réalité définie, la fixation d'un principe explicite, d'indices qui signalent les enrichissements progressifs, sont des avantages inestimables.

Les conditions changent dès qu'il s'agit d'engendrer phénomènes et processus, dès qu'il faut assurer le devenir et que les propositions théoriques doivent, non seulement clarifier ce qui est, mais encore préparer les circonstances de leur propre dépassement. Une proposition qui se contenterait d'ordonner le connu, sans aucunement annoncer son bouleversement, ou du moins dénoncer son incomplétude, manquerait d'intérêt. Un théorème qui énonce — par réduction une loi est d'autant plus puissant qu'il se combine immédiatement avec d'autres théorèmes pour faire découvrir une conclusion inattendue, laisser déceler la présence d'un phénomène inconnu. Que l'on pense aux théories de la physique quantique. L'introduction des considérations relativistes a permis de supposer l'existence d'électrons positifs, insoupçonnable auparavant. D'un seul coup, tout un domaine s'est trouvé ouvert, où théoriciens et expérimentateurs durent s'engouffrer pour explorer ce que l'on est convenu d'appeler l'anti-matière.

Cette attitude rend à la fois plus difficile et moins urgente la recherche d'une interdépendance des branches particulières du savoir. Elle produit l'unité par combinaison et non point par systématisation, 
conformément à des cadres préétablis. G. Bachelard a observé à bon escient que :

«Le progrès scientifique marque ses plus nettes étapes en abandonnant les facteurs philosophiques d'unification tels que l'unité d'action du créateur, l'unité du plan de la nature, l'unité logique » ${ }^{640}$.

Cela ne suppose pas une dispersion totale, une non-coordination patente. Au contraire, une concordance étroite est maintenue entre théories, notions et concepts, et la communication, sans passer par un schéma central, hiérarchiquement supérieur, facilite une régulation réciproque des domaines et des disciplines. L'articulation de celles-ci fait penser à ces tableaux contemporains où d'éblouissantes taches de couleur restent prisonnières, inexplicablement à première vue, d'un sévère quadrillage. L'établissement d'une autre unité, plus contraignante et normative, risque toujours d'être tenu en échec. Émile Meyerson le constatait :

«C'est qu'en effet la tendance à la mathématisation du physique... est, sinon combattue, du moins primée, par cette autre tendance, qui est véritablement caractéristique de la science, en tant que distincte de la philosophie proprement dite, et qui cherche à maintenir la réalité de l'image par laquelle la théorie vise à remplacer celle du sens commun » ${ }^{641}$.

L'accord de la pensée avec le réel a en effet pris un autre sens. Il ne s'agit pas d'élaborer, soit le reflet, soit l'image idéale d'un contenu concret donné, mais de le faire jaillir, de le constituer ou de le reconstituer par des expériences successives. Le contenu concret est produit pour convenir à une pensée et être adapté à ses exigences ${ }^{642}$; les règles valides auparavant ne s'appliquent plus à cette fin, le monde extérieur étant le résultat ultime et non pas le point de départ du cheminement théorique. Les apparences, loin d'être données, sont suscitées. On ne peut invoquer aucun plan caché, aucune unité dissimulée derrière les phénomènes; au contraire il s'agit d'ordonner, d'inventer les

E. Meyerson : La déduction relativiste, Paris, 1924, p. 16.

642 H. HERTZ : Gesammelte Werke, Leipzig, 1894, p. I.
} 
choses visibles et sensibles. Au XIX ${ }^{\mathrm{e}}$ siècle, les témoins des débuts de cette transformation en avaient parfaitement conscience :

«L'unité de la connaissance, l'ordre et l'harmonie, même la complétude et la symétrie, la vérité et la beauté, ne servent plus directement de canons au chercheur scientifique, pas plus que les mystères que l'on supposait jadis être inhérents à certains nombres » ${ }^{643}$.

Cette réorientation de l'activité intellectuelle n'entraîne ni le scepticisme ni la relégation de la théorie au rang de suivante de l'expérience. Au contraire, la théorie subit une mutation remarquable. Elle n'est plus regard, vision, saisie de ce qui est manifeste à un autre niveau, mais au contraire production continuelle de concepts qui, ipso facto, n'ont plus le répit de s'hypostasier, de se faire mutuellement écran. Parallèlement, tout le travail de formulation des lois, des propositions théoriques, leur renouvellement, l'essai des différentes variantes, acquièrent une dynamique propre. On propose les notions et les concepts avec la même liberté et la même abondance que l'on projette et réalise des expériences. L'intensité de cette création des théories n'est pas due à leur caractère hypothétique ni à leur incomplétude, mais à leur fonction qui est d'ouvrir constamment des brèches dans les perspectives établies, de mettre en relation un nombre croissant d'ébauches théoriques. Ainsi approche-t-on le but qui est

« de nous orienter vers des faits nouveaux, de suggérer de nouvelles expériences et de conduire à la découverte de nouveaux phénomènes et de nouvelles lois » ${ }^{644}$.

Les axiomes posés, les paradigmes qui les complètent ne sont pas l'objet essentiel de la recherche. La marche de celle-ci est constamment dirigée vers d'autres axiomes et d'autres paradigmes, pour autant qu'ils stimulent un dépassement.

Ici s'introduit une dimension temporelle. Le rapport de la théorie au réel est un rapport d'à venir. Aucun des termes n'est considéré 
comme ayant une constitution définitive. Il s'agit, pour la première, moins de légiférer et d'abstraire que d'exploiter et de concevoir un programme. Le second est l'incarnation de cette théorie et sa confirmation, une fois réunis les moyens qui permettent de l'instaurer. De l'électricité, de la physique, on peut répéter ce que disait G. Bachelard de la chimie qui

«multiplie et complète ses séries homologues jusqu'à sortir de la nature pour matérialiser les corps plus ou moins hypothétiques suggérés par la pensée inventive ${ }^{645}$.

La contrepartie ou le contrepoids de cette productivité théorique est son caractère périssable et immédiatement historique. En effet, si lois et concepts sont destinés à transformer les vues prédominantes, à presser le pas de la découverte, il faut reconnaître qu'ils peuvent être tout aussi vraisemblablement remplacés et assimilés par des lois et des concepts différents.

Cette dégénérescence potentielle, cette mortalité prévisible accompagnent toute connaissance, rendant aiguë la conscience de sa temporalité, sa référence à un moment, son insertion dans une succession :

"Quand nous faisons une théorie générale de nos sciences, constate Claude Bernard ${ }^{646}$, la seule chose dont nous soyons certains, c'est que toutes ces théories sont fausses absolument parlant. Elles ne sont que des vérités partielles et provisoires qui nous sont nécessaires, comme des degrés sur lesquels nous nous reposons, pour avancer dans notre investigation $»$.

Rien ne s'oppose davantage à l'ordination en systèmes, à la réduction à un modèle premier et régulateur de tout le savoir, qui suppose une phase de perfection ultime, que cette production luxuriante de théories et leur substitution non moins certaine et rapide.

Les frontières des disciplines ne sauraient non plus rester figées, tendre vers un équilibre et une détermination statique du contenu et

${ }^{646}$ C. BERNARD : Introduction à l'étude de la médecine expérimentale, ed. Paris, 1940, p. 59. 
des relations qu'elles enferment. A un développement que l'on envisageait ou souhaitait continu et confirmant des principes ou des modèles permanents, fait face un développement discontinu et générateur de principes et modèles adaptables ou transformables.

«Dans les sciences expérimentales, Claude Bernard en était averti, au contraire, les vérités n'étant que relatives, la science ne peut avancer que par révolution et par absorption des vérités anciennes dans une forme scientifique nouvelle $»{ }^{647}$.

Ainsi, ce qui pour un ordre du savoir était le but suprême, le signe de son accomplissement — enchaînement hiérarchisé des notions, possibilité d'expliquer la totalité des phénomènes à l'aide d'un nombre fini de propositions - est, pour un autre ordre du savoir, stagnation ou épuisement. Il faut alors rechercher une autre direction, de peur de voir la fonction du savant et son savoir frappés d'une condamnation à mort. Comme le mineur qui, après avoir épuisé une veine, doit en ouvrir une autre, comme un peuple qui, ayant consommé une partie de ses ressources, doit découvrir des ressources nouvelles, ainsi le travailleur scientifique doit constamment poursuivre des voies inédites ou en frayer là où il n'y en avait aucune, et parier sur la possibilité que ces voies existent. Son labeur théorique - et expérimental - ne débouche pas, ainsi qu'on l'a cru, sur un acosmisme, une dissolution du monde matériel dans et par la science.

«La science est réaliste, écrit Émile Meyerson ${ }^{648}$, mais nous savons cependant que, d'explication en explication, elle ne peut aboutir qu'à l'acosmisme, à la destruction de la réalité ».

C'est là confondre à tort sa tendance avec celle d'une certaine philosophie ${ }^{649}$. La vérité est autre. La science explique pour diversifier,

C. BERNARD : op. cit. p. 67.

648

E. MEYERSON : op. cit. p. 205.

649 «Enfin la théorie scientifique, nous le savons, tend, autant que la philosophie idéaliste, à détruire la réalité du monde de notre perception, puisqu'elle finit par le résoudre en un tout indistinct. Il y a donc là un accord entre les deux tendances, ou plutôt, manifestement, c'est une seule et même tendance qui veut le monde intelligible et qui ne peut se satisfaire qu'en le détruisant ». E. MEYERSON : De l'explication dans les sciences, ed. cit. t. II, p. 199. 
déployer cette réalité où l'homme et ses disciplines jouent le rôle de médiateurs et d'initiateurs, au lieu d'être l'autre pôle qui cristallise et traduit l'objet dans le sujet. Croire que son travail n'a pas de terme définitif, qu'il pourra dévider, comme le héros du mythe ossète, la pelote des secrets du monde sans que celle-ci diminue jamais, est aussi indispensable au scientifique que la croyance inverse semblait autrefois nécessaire, à savoir que la variété des phénomènes matériels se transvaserait complètement dans l'univers de la raison et que l'esprit finirait par atteindre son but. Le savant doit supposer, ainsi que le faisait Humphrey Davy en 1825, que

« La science, comme cette nature à laquelle elle appartient, n'est limitée ni par le temps ni par l'espace. Elle appartient au monde et n'est d'aucun pays ni d'aucun siècle. Plus nous savons, plus nous éprouvons notre ignorance, plus nous sentons combien de choses nous demeurent inconnues; et en philosophie le sentiment du héros de Macédoine ne peut jamais s'appliquer — il y a toujours des mondes nouveaux à conquérir ».

Cette déclaration aurait pu être faite à n'importe quelle époque. Cependant, ce n'est que dans le contexte de ces disciplines naissantes qu'elle reçoit sa pleine et entière signification. La philosophie mécanique s'est approchée de leur idéal en s'employant à l'invention. Les sciences ont fait de celle-ci un élément de leur structure profonde. L'historicité organique de leur création théorique, leurs attributs qui conduisent à les regarder comme constructrices et non pas uniquement révélatrices de leur objet, de notre substrat matériel, sont les manifestations les plus sures de cette pénétration. 


\section{L'assimilation des modèles mécaniques}

Retour à la Table des Matières

Au moment où il soutenait la possibilité de les conquérir, les nouveaux mondes décrits par Humphrey Davy ne projetaient sur l'avenir que leur ombre. Du calorique ou de l'électricité, on n'aurait su dire si c'étaient des entités matérielles véritables ou des phénomènes manifestant, sous une forme gauchie, d'autres entités. Si la pondérabilité passait pour l'indice par excellence de la réalité des corps, que signifiaient ou que représentaient ces fluides? La question se posait avec acuité, et un savant de l'importance de Berzelius - et il n'était pas le seul - mettait en œuvre toute son ingéniosité pour la clarifier et y répondre. Conjointement, l'impression subsistait que les connaissances et les expériences physico-chimiques, tout en enrichissant la science, brouillaient l'image de l'univers et restaient en deçà d'une appréhension correcte des principaux processus matériels :

«Une fois sortis des phénomènes du choc, écrit G. Cuvier, nous n'avons plus d'idée nette des rapports de cause et d'effet $\gg{ }^{650}$.

Bien que ces phénomènes et les théories qui les embrassaient fussent situés en dehors du cercle des effets ou des notions assurés, ils constituaient un ensemble autonome de plus en plus cohérent. L'articulation des agents chimiques avec les agents électriques ne faisait plus de doute depuis la découverte de la pile voltaïque, et l'énoncé du système de Berzelius. Le pas suivant devait être l'extension de la chaîne aux forces magnétiques. L'expérience d'Oersted constitua à cet égard un événement dont le retentissement a rarement été égalé. Dès que l'on apprit que le savant danois, en plaçant les fils d'une batterie galvanique parallèlement à une aiguille aimantée, avait fait tourner celle-ci d'un angle de près de $90^{\circ}$ par rapport au méridien magnétique, l'idée de l'unité des deux «fluides »s'imposa. Répétée un peu partout, l'expérience donna naissance à un grand nombre de travaux, dont 
ceux d'Ampère furent les plus féconds et les plus décisifs. Bien entendu, une fois la certitude enracinée que l'on peut produire des effets magnétiques à l'aide de l'électricité, on essaya de provoquer le phénomène inverse. L'induction électromagnétique, découverte révolutionnaire à laquelle est attaché le nom de Faraday, est le résultat de cette recherche. L'expérimentateur anglais trouva qu'en envoyant un courant de valeur variable à travers une bobine de fil métallique, on faisait naître un courant passager dans une bobine voisine : le même effet était obtenu si l'on employait un courant constant parcourant une bobine mobile ou, ce qui revenait au même, un aimant permanent installé à proximité d'une deuxième bobine de fil métallique. Dans ces expériences, Faraday a mis en évidence le principe fondamental de la dynamo de même qu'Oersted avait dégagé celui du moteur électrique. Ces deux savants - ou philosophes, ainsi qu'ils se désignaient euxmêmes - qui ont jeté les bases de l'industrie électrique, et révélé les phénomènes qui allaient former le cœur de la science de l'électricité sont, fait digne de remarque, chimistes de formation et d'instinct.

Ces liens établis entre les «fluides» ne sont pas les seuls. Faraday tente d'y associer la lumière. Pour ce faire - en 1845 - il place un morceau de verre de forme oblongue entre les pôles d'un puissant électro-aimant, et constate que ce morceau de verre s'oriente perpendiculairement au champ magnétique. Il renouvelle son expérience mais en dirigeant un rayon de lumière polarisée, qui traverse le verre parallèlement aux lignes de forces magnétiques. Il observe que le plan de polarisation de la lumière est changé. Cette action du magnétisme sur la lumière lui suggère, en 1846, l'hypothèse que la lumière se compose de vibrations ondulatoires qui se produisent suivant les lignes de force. A cette date avait déjà été démontrée l'identité de la lumière et de la chaleur rayonnante. En 1800, William Herschel avait constaté que, sous l'action des rayons solaires, un thermomètre enregistrait des variations sensibles au delà du rouge visible. Les expériences effectuées par Melloni entre 1830 et 1840 montrèrent que la chaleur rayonnante, tout comme la lumière, pouvait être réfléchie, réfractée ou polarisée. Quant à la capacité de l'électricité de provoquer des effets calorifiques, elle avait été établie dès 1801 par l'emploi du courant électrique pour amorcer l'explosion de la poudre à canon.

L'ensemble de ces recherches démontre à la fois l'unité des agents matériels et leur transformation. 
D'autre part, l'hétérogénéité de ces phénomènes et des phénomènes mécaniques ne pouvait plus être soutenue avec la même rigueur — et il n'était pas question d'exclure ceux-ci de l'unité recherchée. Le rapprochement fut opéré à la suite de l'intrusion de la force électromagnétique, capable de produire des actions équivalentes à celles de la force mécanique et de se substituer à elle, en tant que force motrice, dans le domaine industriel. De la sorte, un pont fut jeté entre le mouvement en général, le magnétisme et le courant électrique, et l'on s'efforça de leur trouver une mesure commune. La voie de leur substitution réciproque était ouverte, et l'on ne mit pas longtemps à s'en apercevoir. A. Becquerel pouvait prévoir que :

«En présence de tant de faits, dont chaque jour fait mieux apprécier l'importance, on comprend facilement tout ce que l'avenir réserve à l'emploi d'une force dont la puissance est pour ainsi dire infinie, qui existe enchaînée, silencieuse, partout où il y a de la matière, et dont l'homme saura peut-être un jour se rendre complètement maître $»{ }^{651}$.

Et il ajoutait qu'à côté d'elle la puissance « de la vapeur n'est rien » ${ }^{652}$.

Cette confiance n'était pas unanime, mais l'attrait exercé par les possibilités offertes devait vaincre toutes les appréhensions ${ }^{653}$. La double série de rapports, maintenant affermis, entre forces matérielles d'un côté et machines motrices de l'autre stimula les travaux destinés à leur donner une expression adéquate. Les expériences de Joule méritent d'être considérées les premières, car elles illustrent cette conception d'une conversion des phénomènes. Partant de la découverte toute récente des courants d'induction faite par Faraday, il voulut mesurer la quantité de travail mécanique qu'il fallait dépenser pour produire une certaine quantité de courant électrique, devant se transformer à son tour en chaleur. Cette transformation devait s'exercer non pas directement, mais par l'intermédiaire des courants d'induction. La conviction qu'il existe un lien entre tous ces processus est chez lui profonde :

«Et je ne doute pas qu'en interposant un moteur électromagnétique sur le circuit d'une batterie, il en résulterait une diminution de la chaleur développée par l'équivalent du changement chimique, et ceci en proportion de la puissance mécanique développée $\gg{ }^{654}$.

idem p. II.

653 «Cette comparaison (avec la machine à vapeur) est si défavorable que j'avoue que je désespère presque du succès de l'attraction électromagnétique en tant que source économique d'énergie ». P. JOULE : The scientific papers, Londres, 1884, t. I, p. 48.

654 P. JOULE : op. cit. t. I p. 120. 
Les observations de Joule font ressortir que la quantité de chaleur produite est toujours la même, que le travail mécanique soit employé à produire la chaleur mécanique par frottement, ou qu'il soit dépensé à alimenter la machine électromagnétique, le courant créé se muant en chaleur à son tour ${ }^{655}$.

En d'autres termes, il essaya de trouver l'équivalent mécanique de la chaleur, et nous savons qu'il y réussit.

Néanmoins, au-delà de l'établissement de cette relation quantitative, c'est une conception plus générale qui connaît un regain de faveur. Elle avait déjà été avancée et partiellement démontrée par Rumford et Davy : à savoir que la chaleur n'est pas une substance - car une substance ne peut être engendrée par un autre agent physique - mais un mouvement ${ }^{656}$. Les expériences de Joule confirment absolument cette hypothèse et lui confèrent une valeur heuristique et épistémologique. W. Thomson le déclare expressément :

«Considérant ainsi comme établi que la chaleur n'est pas une substance mais une force dynamique d'effet mécanique, nous percevons qu'il doit y avoir une équivalence entre le travail mécanique et la chaleur, comme entre la cause et l'effet $\gg{ }^{657}$.

La balance ayant ainsi vigoureusement penché du côté de ce rapport causal, il fut possible de généraliser les principes mécaniques du mouvement à l'ensemble des processus thermiques ${ }^{658}$. Parmi ces principes, celui de la conservation des forces vives ou de l'impossibilité du mouvement perpétuel, de par sa généralité, s'imposa d'emblée. J.R. Mayer, W. Thomson, et H. Helmholtz furent les premiers à s'y consacrer. Les recherches de Helmholtz, notamment, traduisent avec la plus grande clarté l'application du modèle newtonien dans un domaine dont il paraissait exclu. Le savant allemand prend deux points de départ : (a) il est impossible d'accumuler indéfiniment du travail qui serait l'effet d'une combinaison quelconque de corps ; (b) il est nécessaire d'exprimer toute action dans la nature par des forces d'attraction et de répulsion dont l'intensité ne dépend que de la distance séparant les points qui agissent les uns sur les autres :

P. JOULE : op. cit. p. 149. 
« Le problème des sciences physiques consiste à ramener tous les phénomènes naturels à des forces invariables, attractives et répulsives, dont 1'intensité dépend de la distance des centres d'action $\gg{ }^{659}$.

Le caractère original de ces travaux ${ }^{660}$ réside dans le sens accordé à la conservation, qui dénote moins l'invariance de la quantité d'énergie que la conversion des forces mouvantes. En effet, on peut imaginer un système isolé, perméable uniquement aux échanges énergétiques et déterminer l'énergie qui est fonction de son état l'énergie interne. Selon le principe de conservation, l'énergie interne est égale à l'énergie totale qui a été échangée avec l'extérieur sous forme de travail ou de chaleur, et ceci dans un processus physique, chimique, etc. On en conclut que l'énergie interne ne saurait être ni gagnée ni perdue sans échange, donc elle ne peut se conserver sans se transformer. L'énergie mécanique, par exemple, ne se conserve pas ${ }^{661}$. Les oscillations d'un pendule se ralentissent : mais l'énergie se convertit en chaleur, et l'énergie totale se conserve si l'on fait le bilan des transformations d'une énergie en une autre. Donc, ce qui est exprimé foncièrement, c'est une corrélation entre les diverses forces matérielles. Cependant, cette corrélation n'aurait pas pu être affirmée si une autre idée n'avait subi une modification profonde. Le passage de l'électricité à la chaleur, au magnétisme, mettait à rude épreuve la conception de ces corps en tant que fluides, car il était impossible d'imaginer un processus susceptible de le concrétiser. La liaison reconnue entre ces différents phénomènes et le rôle de la chaleur comme dénominateur commun, la négation du caractère substantiel de celle-ci, ont entraîné le dépérissement de la notion de fluide impondérable ${ }^{662}$. Cette entreprise fut le couronnement de tout le mouvement des études thermodynamiques. Ce ne fut pas la seule. A vrai dire, le principe de conservation ne donnait aucune indication sur le sens des transformations physiques et sur l'action de la chaleur, aucune proposition ne la qualifiant avec précision. Sadi Carnot ${ }^{663}$, en étudiant les

\footnotetext{
659 H. Helmholtz : Mémoires sur la conservation de la force, Paris, 1869, p. 62.

660 J. TYNDALL : La chaleur, Paris, 1857, p. XVIII.

661 J.M. RANKINE : On the general law of transformation of energy, Phil. Mag. 1853, v, p. 106 ; G. HeLM : Die Lehre von der Energie, Leipzig, 1889 ; E.N. HIEBERT : Historical roots of the principale of conservation of energy, Madison, 1962.

662 J.R. MAYER : Mémoire sur le mouvement organique, Paris, 1872, p. 37.

663 S. CARNOT : Réflexions sur la puissance motrice du feu, Paris, 1824, p. 8.
} 
machines à vapeur, s'avise de la nécessité de le faire. On sait la solution qu'il préconisa en appliquant l'axiome de l'impossibilité du mouvement perpétuel aux phénomènes calorifiques. Un moteur hydraulique ne peut fonctionner, c'est là une donnée d'observation courante, que si l'eau passe d'un niveau élevé à un niveau moins élevé; de même, pour qu'un moteur thermique puisse fonctionner, il faut que la chaleur passe d'une température élevée à une température plus basse, d'une source chaude à une source froide. Il en découle que, si le travail mécanique peut être intégralement transformé en chaleur, l'inverse n'est pas vrai. Clausius a repris ce principe sous une autre forme. La chaleur ne peut pas d'elle-même se transporter d'un corps froid à un corps chaud. Par conséquent si un tel transport a lieu, il est obligatoirement accompagné d'une autre modification physique. L'examen d'une suite de telles modifications a montré que les formes d'énergie tendaient à se dégrader en chaleur et que l'on ne pouvait rétablir les conditions ou les états initiaux dans lesquels s'était trouvée une force matérielle. De la sorte, le second principe qui détermine le sens des processus physiques est aussi un principe d'évolution. Le monde ne se caractérise pas par un cours circulaire, et la croyance suivant laquelle le bilan des changements matériels est invariable perd toute justification :

«Quand le premier principe fondamental de la théorie mécanique de la chaleur fut énoncé, écrit Clausius ${ }^{664}$, on pouvait peut-être le considérer comme une confirmation éclatante de l'opinion mentionnée (celle de la réversibilité des transformations, n.n.) Le second principe fondamental de la théorie mécanique de la chaleur contredit cette opinion de la manière la plus formelle... De là résulte que l'état de l'univers doit changer de plus en plus dans un sens déterminé ».

Ce résultat théorique, faisant apparaître l'ordre naturel comme une suite de transformations ayant une direction et manifestant une évolution, constituait une promesse et un scandale. Une promesse : car, une fois les fluides impondérables évanouis, tous les phénomènes exprimaient l'action des forces et des mouvements (et la conservation de l'énergie à travers leurs effets ); le moment paraissait donc propice pour employer les lois mécaniques à rétablir l'explication véritable du 
monde ${ }^{665}$. Les essais se proposant d'y parvenir se comptent par centaines ${ }^{666}$. Leur but était de soumettre les principes physiques à ceux de la mécanique ${ }^{667}$, et de réduire les processus électromagnétiques à des manifestations de solides élastiques ou à des mouvements de liquides visqueux, bref, au choc, à la figure et au mouvement ${ }^{668}$. Il serait alors possible d'assimiler les diverses forces à la force de gravité et de les soumettre à ses lois. La pluralité des disciplines se dissoudrait dans l'unité retrouvée — et enrichie — de la philosophie mécanique ${ }^{669}$. Malgré les preuves du contraire, cet idéal a nourri tout un siècle, et si on désespérait de lui donner une réalité, on espérait cependant arriver à imaginer des fictions plausibles. Quelles que fussent les concessions sur le plan de la rigueur, les impatiences sur celui de l'épistémologie, on n'aboutit qu'à l'impasse et au découragement :

«... A aucun moment, depuis que les phénomènes électriques font partie de la science, on n'a rien formulé qui pût, de près ou de loin, passer pour une théorie mécanique consistante de ces phénomènes. Ce n'est pas faute de l'avoir cherché $»{ }^{670}$.

Tandis que, d'un côté, on s'efforçait, sans beaucoup de bonheur, de remplir le programme auquel le principe de conservation de l'énergie avait donné un regain de vigueur, de l'autre côté on s'empressait d'atténuer le scandale provoqué par le second principe, celui de la déperdition de l'énergie, et par la direction imprimée à la transformation des forces naturelles. La mécanique a toujours défini les phénomènes comme réversibles. Tous les corps qui subissent un changement doi-

665

666

667

668

669 attacher plus qu'une valeur symbolique ou idéale ; elles ont cependant l'effet souhaité de pro-
duite dans l'esprit de celui qui les étudie, du praticien inventeur ou d'un auditoire populaire,
une forte conviction que tous les phénomènes physiques peuvent être décrits en tant que pro-
cessus de mouvement, et que la solution finale du problème de la philosophie naturelle se
trouve dans une vue cinétique ou mécanique des phénomènes. La physique et la chimie sont,
selon cette opinion, destinées à devenir en fin de compte de simples chapitres de la dynami-
que, en tant qu'elle est la doctrine du mouvement mécanique ». J.T. MERZ : op. cit. t. II, p. 90.

W. THOMSON : op. cit. t. V, p. 11.

J.J. ThOMSON : Applications of thermodynamics to physics and chemistry, New York, 1880, p.

J.C. MAXWELL : op. cit. t. I, p. 564.

P. TAIT : La théorie dynamique de la chaleur, Paris, 1870, p. 69.

«Aucun des physiciens qui ont dépensé leur ingéniosité à inventer ces fictions ne semble leur

E. MEYERSON : op. cit. p. 58. 
vent pouvoir revenir exactement à leur état primitif. L'étude de l'énergie calorifique - et, par extension, celle de la plupart des processus physiques - a, au contraire, accrédité le fait de l'irréversibilité foncière des changements. Comment concilier deux réalités, deux conceptions aussi contradictoires, et, finalement, remédier à une situation aussi dangereuse pour la mécanique ? Et d'abord, pourquoi vouloir ramener tous les phénomènes électriques, magnétiques, optiques, à des lois qui expriment des modifications impossibles ? Pour résoudre ces problèmes ${ }^{671}$, dans une série de mémoires auxquels sont attachés les noms de Maxwell, Boltzmann, et Gibbs, on postula que l'organisation de la matière était la cause de l'irréversibilité. L. Boltzmann, en particulier, démontra que l'énergie calorifique était, non pas une énergie produite par le mouvement ordinaire, mais une énergie cinétique d'agitation désordonnée, et que c'était l'altération des mouvements moléculaires, évoluant vers le désordre, qui se trouvait à l'origine de la déperdition stipulée par le second principe thermodynamique. Ainsi fut provisoirement résolue l'opposition entre les lois des phénomènes physiques observés et les lois des processus mécaniques supposés. A cette occasion, une véritable révolution s'accomplit; les processus imaginés sont des processus statistiques on considère des grandeurs moyennes qui traduisent au niveau macroscopique les paramètres définis au niveau microscopique - et les lois prennent un caractère probabilitaire. L'instrument mathématique subit une mutation décisive, puisque le calcul des probabilités - à l'encontre des conceptions antérieures ${ }^{672}$ — commence à pouvoir être appliqué aux interactions matérielles. Le succès de la connaissance mécanique est avéré là où elle paraissait être mise en échec, à propos du sens des transformations physiques. Sa défaite n'est pas moins accusée là où, lors de l'établissement de l'aspect dynamique, nonsubstantiel de la chaleur, elle pouvait espérer rétablir son autorité et sa généralité.

E. WHITTAKER : A history of the theories of aether and electricity, Londres, ed. 1951, t. I; R. DUGAS : La théorie physique au sens de Boltzmann, Paris, 1959; M.B. HeSSE : Forces and fields, Londres 1961.

672 Un historien des mathématiques écrivait à la fin du XIX ${ }^{\mathrm{e}}$ siècle : La théorie des chances a excité l'émulation des plus grands géomètres, et exercé au plus haut degré leur perspicacité. Nous n'en avons pas parlé jusqu'ici, parce que cette théorie n'avait pas avant Laplace pris de développements suffisants. Nous n'y attachons, du reste, qu'un intérêt relatif. Nous croyons toutefois devoir en dire quelques mots ». M. MARIE : Histoire des sciences mathématiques et physiques, Paris, 1887, t. X, p 54. 
Mais, à supposer que cela fût possible, comment pouvait-on y prétendre quand les notions essentielles de la mécanique étaient battues en brèche? Le paradoxe est bien là : c'est de vouloir recourir à un modèle du réel pour expliquer les « nouveaux mondes » à l'instant même où les propriétés de ce modèle sont contestées. Et ce n'est pas une des moindres contradictions du mouvement historique que de voir les mêmes hommes poursuivre avec ténacité le but de la restauration de l'unité explicative, et ruiner la validité du cadre spécifique de l'explication. J. C. Maxwell en donne un exemple éminent, lui qui écrit :

«Par une étude attentive des lois des solides élastiques et des mouvements des liquides visqueux, j'espère découvrir une méthode pour former une conception mécanique des états électroniques adaptée au raisonnement général $\gg{ }^{673}$.

Sans entrer dans les détails, et sans reproduire des descriptions déjà classiques, j'indiquerai deux des directions dans lesquelles l'approfondissement des processus électromagnétiques a ébranlé les bases de l'ordre naturel conçu en rapport avec les forces gravifiques et mécaniques.

La première direction a trait à la saisie de l'action physique. Dans la philosophie newtonienne, les corps sont envisagés comme des agrégats de points matériels agissant à distance et de manière, pourrait-on dire, instantanée, la vitesse de la lumière elle-même étant infinie dans l'univers mécanique. Le milieu dans lequel les impulsions agissent et se propagent n'entre guère en ligne de compte. Certes, il y avait là quelque chose de difficile à admettre, mais les lois étaient respectées malgré cette difficulté, ou grâce à elle. Faraday, le premier, conteste vigoureusement cette idée, du point de vue expérimental.

L'induction électromagnétique, qu'il a découverte, l'amène à imaginer une diffusion de l'action dont l'effet dépend du milieu, et à concevoir le milieu qui entoure une charge comme porteur d'impulsions électriques et magnétiques. Il 
avait maintes fois constaté que la charge induite entre conducteurs dépendait quantitativement de la nature de l'isolateur. En tranchant celui-ci, et en séparant les deux parties, on voyait apparaître des charges opposées sur les deux surfaces. Enfin les lignes d'induction, l'étincelle de la décharge le montre, sont recourbées. Ainsi s'accumulaient les faits prouvant que le milieu où se déroulaient les phénomènes électromagnétiques ne jouait pas un rôle passif ou accidentel. Il n'était pas concevable que la force électrique située en un point déterminé pût agir instantanément sur une autre force électrique située en un autre point. L'action des forces électriques et magnétiques traduit des changements - déformations ou transformations - propres au substrat matériel. Les attributs de celui-ci doivent donc être envisagés en priorité, car il est le siège de processus définissant les phénomènes que nous observons. Toute action à distance est purement et simplement impossible ou irréelle.

Les intentions et les spéculations de Faraday, appuyées sur de nombreuses expériences, prirent une forme mathématique dans les équations de Maxwell. Ces équations de type différentiel, remplaçant celles qui se fondaient sur les lois de Newton, expriment une propagation de proche en proche des charges, des impulsions. Toutes les grandeurs qu'elles embrassent se réfèrent à un même point de l'espace. La valeur de la grandeur en un point et à un instant donnés est fonction de la valeur des autres grandeurs dans une aire infiniment petite autour du point choisi, au même instant ou à l'instant immédiatement antérieur. Les équations de Maxwell décrivent l'organisation d'un champ, en appréhendant non seulement les points où sont concentrées matière et charge, mais aussi l'ensemble de l'espace et des actions, conformément aux postulats mécaniques. Importance du milieu, propagation de l'action de proche en proche, nouveau type de lois - lois de structure - telles sont les conséquences d'une saisie plus correcte des phénomènes électromagnétiques. Si les fluides disparaissent en tant que substances - et à ce titre ils ouvrent la voie aux considérations mécaniques - ils ressuscitent comme champs, systèmes matériels, pour rendre ces considérations impossibles.

La deuxième direction, qui s'est développée conjointement, porte atteinte aux concepts fondamentaux d'inertie et de masse. L'invariance de l'une et de l'autre constituait un dogme inébranlable de la mécanique newtonienne. Cette invariance est mise à l'épreuve lorsqu'on envisage les transformations chimiques ou les phénomènes électromagnétiques dont un corps est le siège. En effet, si l'on consi- 
dère un élément matériel qui acquiert ou cède de l'énergie, on constate une modification de sa masse. La combinaison de $2 \mathrm{~g}$ d'hydrogène et de $16 \mathrm{~g}$ d'oxygène dégage $2,87.10^{12}$ ergs de chaleur; on n'obtient pas, ainsi qu'on s'y attendait, $18 \mathrm{~g}$ d'eau, mais une valeur inférieure de $3,2 \cdot 10^{-6} \mathrm{mg}$. Bien plus, la variation de la masse n'est pas seulement accidentelle, mais nécessaire, pour rendre compte des écarts à une loi aussi importante pour la chimie que la loi de Prout. Celle-ci postule que les poids atomiques des corps sont des multiples entiers d'une même quantité. Cependant les expériences ont toujours prouvé l'existence d'écarts à la loi. La possibilité d'une diminution de masse, résultant de la fluctuation de l'énergie interne, au cours de la formation des atomes à partir des éléments primitifs, est une possibilité théorique étayée par des constatations empiriques, avant d'être définitivement consolidée par la découverte d la radioactivité.

D'autre part, une fois que l'électricité était considérée comme une propriété de la matière, la masse elle-même devait être saisie comme un phénomène électrique. L'étude du mouvement des électrons fut décisive à cet égard. Quand l'électron se meut sur une trajectoire de manière uniforme, la réaction du champ engendré est nulle, et l'inertie dont il est doué ne le différencie pas d'une particule quelconque envisagée du point de vue mécanique. Il n'en va plus de même si son mouvement est, soit accéléré et rectiligne, soit uniforme mais curviligne. Dans le premier cas, le champ produit par l'électron réagit sur lui avec une force proportionnelle à son accélération et dirigée dans le sens inverse de celui de cette accélération. Dans le deuxième cas, la force du champ est proportionnelle à la sienne, mais de direction contraire. Dans chacun de ces cas, nous avons affaire à une masse électromagnétique, l'une longitudinale et l'autre transversale ${ }^{674}$. Comme on le voit, un électron mobile diffère foncièrement d'une particule décrite par les lois mécaniques en ce qu'il possède deux masses, c'est-à-dire réagit aux actions des champs extérieurs suivant que celles-ci modifient sa vitesse en grandeur ou en direction. Au terme d'une discussion étendue et serrée. P. Langevin ${ }^{675}$ remarquait que l'inertie n'apparaissait plus comme une propriété générale de la ma-

(i) M. Abraham : Die Grundhypothesen der Elektronentheorie, Phys. Ztschr. 1904, 5, p. 576 ; P. LANGEVIN : La physique des électrons, Rev. gén. des Sc. pures et appl. 1905, 16, p. 257. 
tière, telle que l'avait considérée Newton ; au contraire, elle paraissait dépendre des phénomènes électromagnétiques :

« Il a donc paru plus fécond depuis une dizaine d'années de chercher une interprétation électromagnétique de l'inertie plutôt qu'une explication mécanique des lois de l'électromagnétisme ».

Cette mise en question a été un processus relativement rapide. En l'espace d'un demi-siècle, l'accumulation des données expérimentales, l'obligation de doter les nouvelles disciplines d'une structure cohérente, ont imposé une limitation de plus en plus stricte à la sphère de validité des connaissances portant sur l'ordre naturel tel qu'un Galilée l'avait entrevu et un Lagrange ou un Laplace parachevé :

«Ainsi, écrit à ce sujet E. Meyerson ${ }^{676}$, par un processus d'évolution, l'élément mécanique a fini par se résorber, pour ainsi dire, dans l'élément électrique ».

Les tendances à l'œuvre dans ces découvertes devaient se révéler dans toute leur originalité et s'accomplir dans toute leur généralité à travers la théorie de la relativité. Le premier mémoire d'Einstein qui la propose, en $1905^{677}$, est aussi le signe de la venue du nouveau Newton, pressenti par J. B. Priestley environ un siècle plus tôt. On connaît les grandes lignes de cette théorie, et il ne saurait être question de la présenter ici, a fortiori sans se servir du formalisme mathématique. Même si je réussissais à le faire avec une clarté suffisante, mes commentaires seraient trop incomplets - comme ils le sont, d'une façon générale, dans toute cette partie qui ne pourrait être développée de manière satisfaisante sans un recours plus abondant aux techniques intellectuelles spécifiques que j'ai été obligé de sacrifier, pour m'en tenir au minimum compatible avec les limites de l'exposé.

Je rappelle cependant qu'en 1864 J.C. Maxwell présente sa conception du champ électromagnétique. Prenant appui sur les théories de la chaleur et de la lumière, associant les phénomènes optiques,

676

677 A. EINSTEIN : Zur Elektrodynamik bewegter Systeme, Ann. der Physik, 1905, XVII. 
électriques et magnétiques, il suppose que ceux-ci sont source de perturbations qualitatives de l'éther, qu'il renonce à décrire mécaniquement. Ces fluctuations des particules de l'éther sont de nature énergétique. Allant plus loin, il avance une hypothèse merveilleuse et hardie : l'énergie électrique d'un côté et l'énergie magnétique de l'autre représenteraient, respectivement, l'énergie potentielle et l'énergie cinétique de l'éther. Vingt équations déterminent le champ électromagnétique, et il en déduit la théorie électromagnétique de la lumière. Dans l'espace vide, et c'est là une proposition très neuve, bien qu'attendue, la vitesse de propagation d'une onde de ce champ est égale à celle de la lumière. Corrélativement, dans cet espace, la lumière se propage avec la même vitesse, quels que soient sa source ou son état de mouvement; cette vitesse a un caractère d'universalité pour tous les systèmes physiques.

Dans une série d'expériences demeurées célèbres et d'une immense portée pratique, $\mathrm{H}$. Hertz réussit à mettre en évidence la présence d'ondes magnétiques provenant de la bouteille de Leyde ou des étincelles des spires, et parvint à les réfléchir, les réfracter et les polariser. Ainsi se trouva démontrée l'identité du domaine de l'électricité et de celui de la lumière (et de la chaleur rayonnante). Le résultat négatif des expériences de Michelson et Morley permit de généraliser la seconde conséquence des conceptions de Maxwell. Comparant, à l'aide d'un interféromètre perfectionné, la vitesse de la lumière suivant deux directions, celle du mouvement de la terre autour du soleil, et une direction perpendiculaire à la première, les physiciens américains tentèrent de prouver que l'« éther », le « vent d'éther », perturbait la propagation de la lumière. A l'encontre des prédictions théoriques, les deux vitesses s'avérèrent identiques, et la perturbation indécelable. Des conséquences graves en découlaient. D'une part, le mouvement de la source ne semblait pas influer sur la vitesse à laquelle se propage la lumière; d'autre part, les notions d'espace et de temps, sur lesquelles se fonde l'influence présumée, n'étant pas valables pour les phénomènes optiques observés, ne sauraient non plus convenir aux phénomènes électromagnétiques - le lien entre les deux familles de phénomènes ayant été fermement établi par J.C. Maxwell et H. Hertz. Les axiomes de la théorie de la relativité dressent le constat, en s'appuyant sur ces résultats expérimentaux, positifs et négatifs, et les présupposés théoriques dont ils sont le fruit ${ }^{678}$.

A. EINSTEIN : art. cit. p. 891 ; M.B. WeINSTEIN : Die Physik der bewegten Materie und die Relativitätstheorie, Leipzig, 1913 ; H. LorEnZ, A. EInSTEIN, H. MinKOWSKI : Das Relativitätsprinzip, Berlin, 1913 ; A. EINSTEIN : Uber die spezielle und allgemeine Relativitätstheorie, Braunschweig, 1920 ; J.L. SYNGE : Relativity, the special theory, Amsterdam, 1958. 
Tout d'abord, la vitesse de la lumière, représentant celle de tous les phénomènes physiques dans lesquels a lieu une transmission d'énergie, reçoit le rôle d'une constante universelle. Ensuite on abolit la notion de transmission instantanée d'un signal et d'une action. Compte tenu de l'existence des perturbations du milieu est réintroduite l'idée - après tout familière, mais rejetée par la mécanique qu'un certain temps est nécessaire pour la propagation d'un signal ou le déplacement d'une impulsion d'un point à un autre. Il en découle qu'il ne peut y avoir de mesure unique du temps indépendante du système de référence. Chaque système a son temps propre, perçu et mesuré par un observateur qui se déplace avec lui, de même qu'un point de ce système possède des coordonnées relatives à lui, perçues et mesurées par l'observateur qui s'y trouve placé. La dissymétrie qui était propre à la mécanique, entre un temps absolu et un espace conçu pour admettre un mouvement inertial, relatif à un système de référence, s'estompe. C'est là une conséquence qui découle d'un second axiome implicite : la valeur finie de la vitesse de la lumière, et son indépendance par rapport au mouvement de la source.

Dès son premier mémoire fondamental, en 1905, Albert Einstein redéfinit les relations entre la masse et l'énergie; celle-ci, démontre-t-il, possède une inertie ; celle-là n'est pas une constante, car elle dépend de la vitesse. Il montre notamment que la masse d'un projectile s'accroît avec la vitesse de celuici, et qu'elle deviendrait infinie si cette vitesse atteignait celle de la lumière. Rien ne paraissait plus scandaleux du point de vue de la mécanique que cette proposition et celles qui en découlaient, à savoir : toute masse au repos suppose une provision d'énergie immense; et, d'autre part, les deux principes de conservation respectifs se fondent en un seul, qui établit la conservation de l'énergie dans l'univers. Désormais, la masse et l'énergie ne sont plus des réalités distinctes, mais constituent les deux aspects d'un processus matériel unique.

La théorie de la relativité généralisée traite du mouvement accéléré et de la gravitation, et donne plus d'ampleur aux résultats nouvellement acquis. Les deux théories établissent de façon solide les concepts, les processus objectifs, la structure des lois que les sciences avaient mis en évidence dans le domaine de l'électricité, du magnétisme, de l'optique, et dans le domaine thermique. 
L'ère est close où l'on espérait pouvoir ramener toutes ces disciplines à la mécanique, et où un Whewell pouvait écrire ${ }^{679}$ :

«Et si les phénomènes du magnétisme et de l'électricité ne nous ont conduits qu'à de telles lois (d'attraction, de choc), les sciences qui leur correspondent doivent être ordonnées comme des branches de la mécanique ».

Au contraire, ce n'est pas, ce n'est plus à la mécanique qu'incombe désormais le soin d'expliquer tous les phénomènes ; ce sont les principes qui régissent les phénomènes de l'électromagnétisme, de l'optique ou du rayonnement qui doivent fournir la base permettant d'appréhender chocs, mouvements, attractions et répulsions. Un renversement s'est produit : ce qui, au début du XIX ${ }^{\mathrm{e}}$ siècle, apparaissait aux yeux d'un Georges Cuvier comme le particulier, est le général ; ce qui lui semblait général est le particulier. L. Brunschvicg ${ }^{\mathbf{6 8 0}}$ a bien décrit le contraste :

«Laplace partait de la théorie newtonienne de la gravitation pour aborder, et pour tenter d'assimiler, les domaines divers de la physique et de la chimie suivant le plan tracé dans la dernière question de l'Optique newtonienne. M. Einstein, au contraire, fait fond sur les doctrines élaborées en thermodynamique, en électro-optique, pour réviser, corriger et faire entrer dans des cadres tout nouveaux la théorie de la gravitation $»$.

Ainsi, au lieu d'être la science vers laquelle retournent toutes les autres, la mécanique n'est plus qu'une des parties du groupement de disciplines nouvellement formé.

Mais ce renversement se situe aussi dans une autre perspective. La théorie relativiste ne constitue pas le reflet d'une réalité ultime. Les lois ou les processus auxquels A. Einstein a donné tant d'éclat ne représentent pas le cadre obligatoire auquel tout doit être intégré ou dont doivent être déduits chaque effet et chaque règle. En effet, dans le même temps, à partir de l'étude thermodynamique de l'émission et de l'absorption du rayonnement, la théorie quantique s'ébauche, tandis que la radioactivité commence à inaugurer, entre les mains des physiciens, la chaîne des découvertes qui a conduit à celle des particules élémentaires et des forces nucléaires. La cosmologie elle-même, jusque-là pur domaine de spéculation, devient une science relativement rigoureuse et complète cette contexture de l'état naturel dans lequel les transformations des forces matérielles dénotent une évolution et s'inscrivent dans une histoire. 
Il faut observer que celle-ci impose une dimension temporelle, donne un caractère d'événement à tout ce qui compose l'univers physique. La présence de cette dimension témoigne d'un apport constant d'éléments, de mesures, de même qu'elle traduit la conversion nécessaire des rapports avec la matière au fur et à mesure que leurs termes changent. Ceux du monde mécanique et du mécanicien se sont trouvés ainsi être absorbés et réduits à figurer un cas particulier, un moment d'un système physique et d'un mouvement plus généraux. Les disciplines qui sont nées de la philosophie expérimentale, les groupes de créateurs de facultés auxquelles elles sont associées ont poursuivi, comme on a pu le voir, ce résultat. Si l'état naturel cybernétique s'est avéré historique, ce n'est pas sans lien avec l'aspect inventif et périssable que j'ai signalé des savoirs propres à ces disciplines. Si ces savoirs ne s'étaient pas combinés, s'ils ne s'étaient pas succédé de façon aussi intense, il se serait produit une stabilisation autour de certaines relations et de quelques structures matérielles, et tout ce qui n'était pas compatible avec elles, ou qui était moins développé, aurait été, sinon exclu, du moins tenu pour secondaire. Telle est bien la situation qui avait régné au XVII ${ }^{\mathrm{e}}$ siècle. A cette époque, on s'efforça avant tout de consolider l'édifice entrevu à travers les inventions de la mécanique. L'ensemble des phénomènes liés à la chimie, au magnétisme, semblaient, sinon négligés, du moins maintenus à l'écart du courant principal.

La science se fixe pour règle que chaque découverte expérimentale doit ouvrir sur une autre. Pour y contribuer, pour participer à sa vie, il est indispensable d'adopter cette attitude heuristique. L'acte de susciter le réel - et non pas celui qui vise à l'ordonner - devient l'objet premier de la connaissance. Ainsi, elle ne cherche pas à dévoiler les mondes cachés, mais à réaliser des mondes nouveaux; elle n'aspire pas à l'exhaustion des chaînes des phénomènes, mais à leur éclosion ; elle travaille à leur changement, non point à leur ossification. L'historicité de l'état de nature répond à la manière dont le savoir s'est organisé à partir du rapport à l'univers matériel défini par le scientifique. 


\section{La primauté de l'effet}

$\underline{\text { Retour à la Table des Matières }}$

Au terme d'une analyse circonstanciée de l'activité scientifique, G. Bachelard voyait dans celle-ci «moins une science de faits qu'une science d'effets $\gg{ }^{681}$.

La science qui se bornerait à décrire les phénomènes, à classer leurs conséquences, à systématiser leurs liaisons, serait assurément incomplète ${ }^{682}$. Au contraire, il nous est déjà apparu que le savoir théorique est orienté vers la production de propositions destinées à lui permettre d'aborder des phénomènes toujours inédits. La méthode expérimentale, qui se rattache à ce savoir et le prolonge, se conforme à ce principe. Elle intervient, bien entendu, dans un but de vérification des lois et des concepts énoncés dans une discipline particulière. En cela, elle remplit une fonction habituelle. De plus, elle doit concrétiser, actualiser ces forces, ces processus, auxquels se réfère la connaissance scientifique. Sa vocation est double: décider entre plusieurs théories concernant le réel donné, matérialiser les êtres de raison imaginés par celles-ci.

Dans le premier cas, la recherche se cantonne essentiellement dans le domaine des faits, c'est-à-dire des événements ou processus censés exister tels quels ou préexister à une notion. Les expériences destinées à vérifier sur les corps les lois mécaniques du choc, les observations concernant l'apparition d'une planète inconnue déduite de la loi de la gravitation, illustrent le caractère analytique de cette démarche. La connaissance qui en résulte est une connaissance des faits, et la méthode a pour objet de les révéler. Cette forme d'appréhension du réel a été solidement établie par les mécaniciens. Les physiciens - et surtout les chimistes - ont accentué une autre forme, celle où les phé- 
nomènes se dessinent justement comme des effets consécutifs à l'action du savant. Ainsi le chimiste décomposant l'eau en hydrogène et oxygène est presque leur inventeur :

« A suivre dans son histoire l'effort de la chimie vers le corps simple, défini, pur, on se rend compte qu'on a presque le droit de dire que l'expérience chimique moderne crée les substances, que du moins, en les épurant, elle leur rend leurs véritables attributs $\gg{ }^{683}$.

Dans cette perspective, l'intervention expérimentale, l'instrument qui y participe, ne sont pas, au premier chef, des modes de représentation concrète et visible d'un fonds abstrait et invisible (l'horloge qui concentre en elle les lois de la mécanique), ni des procédés propres à aiguiser et accroître la capacité sensorielle (le télescope dont le pouvoir discriminateur dépasse celui de l'œil). Bref, ils ne sont pas les intermédiaires pratiques grâce auxquels le sujet agissant ou connaissant aborde et saisit un objet ou une réalité déjà formés. L'intervention expérimentale en question atteint et constitue, jusqu'à un certain point, l'objet et le réel, en les métamorphosant ou en les recomposant après en avoir détruit les états antérieurs ${ }^{684}$.

Débouchant sur des propriétés entièrement différentes, donnant corps à celles qu'il a conçues, le savoir du scientifique - que celui-ci se consacre à la chimie ou à une autre branche de la connaissance exprime sa tendance essentielle, à savoir créer des substances, des processus matériels qu'il intègre à son fonds. La distinction qui s'était maintenue entre organisation ou élément naturel et organisation ou élément artificiel s'estompe et cesse d'avoir une raison d'être. L'effort intellectuel et expérimental n'étant plus dirigé vers la définition du champ de validité ou l'appréhension des faits établis à l'extérieur des disciplines naturelles, tous les effets peuvent être attribués d'emblée à ces disciplines et reconnus à ce titre. Parallèlement, dans la mesure où elles engendrent directement la réalité de leur objet, elles ne servent plus de médiatrices entre l'homme et quelque chose qui existe : leur rôle est la formation évidente des termes eux-mêmes. Connaître, dé-

G. BACHELARD : op. cit. p. 36.

684 A.F. FOURCROY : op. cit. p. XLII. 
terminer les propriétés d'un système matériel, c'est jusqu'à un certain point l'engendrer :

«La science factice déborde nettement la science naturelle ${ }^{685}$.

Ceci revient à constater que l'expérience est une expérience constitutive, combinatoire, qu'elle est à la fois un moyen qui dirige l'activité scientifique vers une structure définie, une extension de nos dispositions subjectives, et l'échafaudage qui permet d'obtenir d'autres structures résultantes, de poser le cadre objectif lui-même. Sous ce dernier éclairage, la méthode qui l'inspire est synthétique.

C'est en chimie, et plus particulièrement en chimie organique, que cette méthode s'est imposée tout d'abord ${ }^{686}$. Des découvertes bien connues y ont joué un rôle décisif : par exemple celle de l'urée, par évaporation du sel ammoniacal de l'acide organique, due à Wöhler. La reproduction au laboratoire des roches et des minéraux - notamment celle du marbre en partant du calcaire - s'inscrit dans cette perspective de création de propriétés identiques à partir de substances différentes. Toutefois ce sont deux principes plus généraux qui ont servi à établir les procédés de synthèse sur des bases solides. Le premier est celui de la substitution, selon lequel le remplacement, dans un composé, d'un élément chimique par un autre n'altère pas gravement ses propriétés. Si l'on verse une petite quantité d'acide acétique cristallisable dans un récipient rempli de chlore sec et qu'on expose le mélange à la lumière, les parois du récipient se couvriront, au bout d'un certain temps, de cristaux; à l'analyse chimique, on constate que ces cristaux diffèrent de ceux de l'acide acétique parce qu'ils ont trois équivalents d'hydrogène en moins et trois équivalents de chlore en plus : ce sont ceux de l'acide trichloracétique. Les deux acides, malgré la présence de chlore à la place de l'hydrogène, ont des propriétés rigoureusement semblables. Cette expérience, due à J.B. Dumas, eut un très grand retentissement, parce qu'elle réalisait une combinaison interdite alors par la théorie, notamment la théorie électrochimique de Berzelius. En effet, un élément électronégatif, le chlore, y produisait des effets analogues à ceux d'un élément électropositif, l'hydrogène. Elle prouvait aussi que ce ne sont pas les éléments qui déterminent le déroulement des manifestations d'un corps quelconque, et qu'il ne suffit pas de les retrouver par l'analyse, mais que c'est leur arrangement, leur articulation dans une totalité, qui est responsable de ces manifestations, et qu'on peut les reproduire par voie de synthèse. 
Le deuxième principe découle de cette conception: les corps chimiques constituent des familles ou types chimiques. Un type embrasse tous les composés qui dérivent les uns des autres par voie de substitution d'un élément ou d'un groupe d'éléments. Le génie poétique de Laurent a conçu cette idée, une des plus fécondes de la science. J.B. Dumas l'a formulée de manière vigoureuse, et Gerhardt a décrit et classé minutieusement les types : l'hydrogène, l'acide chlorhydrique, l'eau et l'ammoniaque. Il suffisait dès lors de connaître l'équation constitutive d'un corps, le type auquel il appartenait, pour le reconstituer au moyen d'autres éléments que l'on possédait déjà, donc effectuer une synthèse ${ }^{687}$.

On est passé rapidement de la théorie des types et des substitutions à la notion de valence, en particulier grâce aux résultats obtenus par l'expérience. En 1850, Frankland, Wurtz, réalisent la synthèse de certains hydrocarbures, et A.W. Hofmann celle des amines. Dix ans plus tard, M. Berthelot accomplit un progrès décisif : en effet, ce n'est plus en partant de corps simples, déjà constitués, mais en partant d'éléments — hydrogène et carbone — qu'il fait la synthèse de l'acétylène au moyen de l'arc électrique. De cette opération il élimine complètement la notion d'intervention d'une force vitale dans la composition des matières organiques, force supposée échapper à l'analyse. Le chimiste se trouve libéré d'une entrave, et, confiant dans ses déductions, il propose désormais de réaliser dans son laboratoire toutes les substances qu'il peut concevoir.

« La connaissance de cette loi (générale), écrit Berthelot, permet de réaliser une infinité d'autres effets semblables aux premiers ; de former une multitude d'autres substances, les unes identiques avec les substances naturelles déjà connues, les autres nouvelles et inconnues, et cependant comparables aux premières. Ce sont là des êtres artificiels, existant au même titre, avec la même stabilité que les êtres naturels : seulement, le jeu des forces nécessaires pour leur donner naissance ne s'est point rencontré dans la nature ${ }^{688}$.

Ce n'est donc plus à la faiblesse, à l'imperfection de l'homme que suppléent l'expérience et son appareillage, mais à la faiblesse et à l'imperfection des forces matérielles, de la nature. Renversement si-

P. DUHEM : Le mixte et la combinaison chimique, Paris, 1902.

688 M. Berthelot : La synthèse chimique, Paris, 1876, pp. 273-274. 
gnificatif de perspectives, aux conséquences prévisibles. La possibilité de découvrir des propriétés, de les retrouver par d'autres voies ou dans d'autres contextes, s'est traduite par l'accroissement continu du nombre des combinaisons utiles. On en connaissait 20000 en 1883, 74000 en 1899,100000 en 1902 et 144000 en $1910^{689}$.

J. B. Dumas auquel nous devons véritablement le fondement de la méthode synthétique pouvait écrire dès 1840 :

« Comparés aux physiciens, aux mécaniciens et aux géomètres, les chimistes nous paraissent les véritables inventeurs de l'art d'expérimenter ${ }^{690}$.

La proposition n'aurait pas ce caractère excessif si elle s'était contentée de mentionner l'orientation que les chimistes ont donnée à la méthode expérimentale, et son originalité ou sa supériorité par rapport aux démarches empiriques des mécaniciens. Elle correspond effectivement à une réalité, à une attitude qui n'a pas manqué d'influer sur l'ensemble des sciences, notamment sur la physique.

Cette influence ne s'est manifestée nulle part avec autant d'éclat que dans le domaine des hautes énergies, et dans l'emploi du tableau de Mendéléeff. Comme on le sait, partant des 65 éléments alors connus, compris entre l'hydrogène et l'uranium, Mendéléeff les ordonne dans un tableau où figurent dans la même colonne ceux qui ont des propriétés semblables, et sur des lignes différentes ceux qui ont des propriétés dissemblables. Avec une audace intellectuelle extraordinaire, il modifie les poids atomiques admis pour faire entrer les éléments dans les cases du tableau périodique, en même temps qu'il laisse des cases vides pour de éléments, encore inconnus, dont il prédit l'existence. Le programme qu'il proposait était clair; son tableau devait servir

« au système des éléments ; à la détermination du poids atomique des éléments insuffisamment étudiés; à la détermination des propriétés d'éléments jusqu'ici inconnus ; à la correction de la grandeur du poids atomique ${ }^{691}$.

A. KIRMANN : La chimie d'hier et d'aujourd'hui, Paris, 1928, p. 48.

690 J.B. Dumas : Leçons sur la philosophie chimique, Paris, 1840, p.4. 
La rectification postulée des poids atomiques se justifiait dans bien des cas, ainsi que les expériences l'ont prouvé par la suite. Les éléments manquants furent identifiés, le gallium grâce à Lecoq de Boisbaudran, le scandium par Lars Nelson, le germanium par Winckler, le rhenium par Walter et Ira Noddack.

Jusqu'à la découverte de la radioactivité, la démarche suivie conserve tous les aspects de la méthode analytique. Dans une première phase, on propose une loi régissant les rapports entre les éléments; dans une deuxième phase, la recherche expérimentale s'efforce de compléter la gamme des substances connues et de confirmer la loi. La découverte des propriétés radioactives a permis de déceler d'autres éléments et de parachever ainsi la série. Elle est cependant allée au-delà dans la voie de la synthèse. De ce fait, le tableau de Mendéléeff a été élargi pour pouvoir y introduire et classer les véritables «espèces physiques » nouvellement créées, pour lesquelles les conditions d'existence n'ont peut-être encore jamais été réunies dans l'univers. Parmi ces "éléments synthétiques », outre le technitium et le prometheum, dont le nom indique suffisamment l'origine, les transuraniens compris entre le neptunium et le laurencium, tous radioactifs, sont constitués essentiellement au cours des réactions nucléaires. Le neptunium fut préparé à partir de l'uranium par addition à celui-ci de plusieurs neutrons qui ont eu pour effet d'augmenter sa masse sans modifier son nombre atomique. Néanmoins, à un moment donné, un nouvel élément se dégage, car l'« espèce » devenue trop riche en neutrons tend à métamorphoser un de ceux-ci en un proton qui reste dans le noyau et un électron qui est libéré. Cette transformation a pour résultat une " espèce » nucléaire ayant une charge positive supérieure d'une unité.

L'histoire de ces découvertes a été maintes fois relatée ; elle nous intéresse ici à deux points de vue. D'une part, elle montre la réalité de la transmutation: si l'on modifie l'architecture atomique d'un corps simple, celui-ci peut devenir autre. Plus précisément encore, une rela-

D. MENDÉLÉEFF : Die periodische Gesetzmässigkeit der chemischen Elemente, Leipzig, 1895, p. 64. 
tion génétique est mise en évidence - si un noyau d'helium se dégage du noyau de polonium, il reste un noyau de plomb. La matière elle-même est donc capable d'évolution, puisqu'on peut considérer que les éléments dérivent les uns des autres par une série de transformations temporelles. S'insérant alors dans cette histoire, d'autres corps peuvent être formés qui ont une place bien déterminée, ajoutant à la série qui nous a précédés une série qui est la conséquence de notre existence. D'autre part, la loi périodique qui, à l'époque où elle fut proposée, avait trait à un spectre limité d'espèces physiques, s'étend maintenant à toutes les espèces qui se trouvent dans l'univers, celles qui y étaient avant nous et celles que nous avons inventées. Dès lors il est certain que la méthode expérimentale, à des degrés divers suivant les disciplines, témoigne de sa fonction constitutive des processus et des phénomènes. La voie synthétique complète et valide la voie analytique - ce dernier exemple l'illustre abondamment — et le produit de l'art s'associe, pour ainsi dire, au naturel, jusqu'à se confondre avec lui. La science donne une réalité matérielle aux phénomènes et aux concepts, que les conditions qui servent à les produire dans l'univers aient été réunies ou non. L'originalité de cette méthode, telle que l'ont forgée les sciences, se dessine clairement. Elle découle de la possibilité de créer les propriétés et l'organisation des structures naturelles, de recombiner celles qui existent déjà, d'inventer celles qui n'existent pas encore. Cette action constitutive des substances et des phénomènes fait disparaître, nous en avons vu maint exemple, l'écart qui sépare les êtres artificiels des êtres naturels. Corrélativement s'estompe l'hétérogénéité entre la théorie et la démarche expérimentale, dans la mesure où celle-ci devient, jusqu'à un certain point, également déductive. Assertion qui peut sembler à première vue paradoxale, puisque l'expérience est supposée relever, au contraire, du domaine de l'induction.

Le parallélisme de la "déduction » expérimentale et de la déduction purement notionnelle se comprend lorsque celle-ci s'inscrit dans le contexte de celle-là. Mais cette insertion ne manifeste pas, à elle seule, l'atténuation de l'hétérogénéité dont j'ai parlé plus haut. Je me suis davantage référé au fait que l'expérimentateur peut varier ou combiner les expériences de manière systématique, pour obtenir des résultats analogues à ceux de l'analyse théorique. Quels sont les mo- 
tifs de cette convergence? Lors de son élaboration par la philosophie mécanique, l'expérience avait souvent pour point de départ une observation, un instrument (lunette, horloge, etc.) dont il s'agissait de dégager les lois de constitution et de fonctionnement. Ces observations ne sont pas nécessairement nées les unes des autres, pas plus que l'invention d'un instrument n'a conduit génétiquement à l'invention d'un autre. On ne saurait donc les ordonner dans un ensemble cohérent de liaisons, et les expériences auxquelles ils ont donné naissance ne sauraient être ordonnées non plus. Par contre, les expériences des diverses sciences, les appareils imaginés pour les réaliser, forment un corpus ayant une très grande homogénéité et se sont engendrés réciproquement. La découverte des corps chimiques de synthèse, celle de la radioactivité, manifestent une telle solidarité interne et une telle continuité. Dès lors, le cours des expérimentations indispensables ou des phénomènes qu'elles sont obligées de découvrir se trouve déterminé, en grande partie, par le mouvement qui les embrasse, les fait apparaître dans leur succession. A ce titre elles sont susceptibles d'aboutir, grâce au développement déductif implicite, aux mêmes phénomènes que la théorie.

La découverte de l'électron positif, examinée de manière détaillée par N. R. Hanson ${ }^{692}$, nous laisse voir qu'il en est bien ainsi. Dans une série de brillants mémoires, en 1927 et 1928, le physicien anglais Dirac se proposa de définir les conditions que les principes de la relativité restreinte imposaient aux ondes décrites par la mécanique ondulatoire. Les équations auxquelles il aboutissait présentaient un caractère fantastique; en effet, l'énergie totale déterminant le mouvement de l'électron était négative. Ceci ne pouvait avoir qu'une seule cause : le caractère négatif de la masse. Une particule de masse négative aurait un comportement bien singulier. Soumise à une force, elle aurait une accélération de direction opposée à la force. Deux électrons de charge électrique négative et de masse opposée se repoussent mutuellement en raison de leur charge. Cette force de répulsion a pour effet d'accélérer l'électron de masse positive en le dirigeant vers la droite. L'autre électron ayant une masse négative, la force qui s'exerce sur lui CONNELL : Quantum particle dynamics, Amsterdam,1960, pp. 255 et seq. 
l'accélère aussi vers la droite, et ils se déplaceront de concert, avec une vitesse qui augmentera constamment.

Cette situation extraordinaire n'a jamais pu être observée, pas plus que l'on n'a pu mettre en évidence de particule ayant une masse négative. Cependant, à mesure que les électrons subissent une déperdition d'énergie au cours de collisions, ou émettent des rayonnements, leur énergie devrait finir par tomber au-dessous des valeurs négatives admises ; la plupart des électrons devraient occuper ces états, même s'il est impossible de les observer. C'est alors que Dirac proposa une hypothèse hardie. On connaît le principe selon lequel il est impossible que deux électrons occupent le même état quantique. Si donc tous les états où les électrons ont une masse négative sont normalement occupés, il est impossible que d'autres électrons accèdent à ces états. Dirac postula que l'espace vide, dépourvu de propriétés matérielles, était en réalité un espace dans lequel tous les états accessibles aux électrons de masse négative étaient occupés. Puisque l'on ne voit jamais un électron de masse positive abandonner une fraction de son énergie telle que sa masse devienne négative, Dirac supposa l'existence d'une autre particule, de masse identique à celle de l'électron mais de charge opposée, c'est-à-dire un électron positif ou positron. Ce fut là la première découverte purement théorique de cette particule, découverte des plus audacieuses.

La découverte expérimentale eut lieu par d'autres voies et fut l'œuvre d'Anderson. En 1932, ce physicien observa, dans une chambre à vapeurs, des tracés surprenants, qu'il ne pouvait attribuer à des protons, en raison de leur longueur dix fois plus grande que la trajectoire des protons. Il n'était guère possible de supposer que deux électrons aient produit au même instant deux trajectoires qui donnaient l'impression d'une seule. Anderson supposa alors qu'il s'agissait d'une particule venant d'en bas, perdant une partie de son énergie dans la plaque, et qui arrivait à proximité du pôle négatif du champ magnétique transversal entourant la chambre à vapeurs. A cause de sa portée, il ne pouvait s'agir que d'un électron, mais de charge positive.

Cette conclusion fut accueillie avec scepticisme par des savants aussi peu prévenus contre les nouveautés que Bohr et Rutherford. Il 
s'agissait d'une découverte purement expérimentale, présentée comme telle par Robert Millikan en 1935, disant qu'elle

« avait été faite sans le guidage d'aucune théorie, tout comme la découverte de couples de trajectoires, l'une positive, l'autre négative, qui se produisaient souvent $»{ }^{693}$.

Il restait à montrer que la particule postulée par Dirac et celle qu'avait découverte Anderson étaient une seule et même particule ; ce fut l'œuvre de Blackett et Occhialini, qui mit fin aux incertitudes et aux controverses, en établissant que la déduction théorique n'était pas pure spéculation, ni l'observation de l'expérimentateur pure illusion ${ }^{694}$.

L'assurance que l'on retire de la démarche autonome de l'expérience, capable de prolonger la connaissance théorique mais aussi d'avancer seule sur la voie de la déduction, est un indice de sa puissance de dépassement de l'acquis, du connu :

« Dans tous les cas, observe Berthelot ${ }^{695}$, il est essentiel de remarquer que notre puissance va plus loin que notre connaissance ».

De cette manière, l'expérience s'articule avec la théorie pour accroître le champ et les probabilités d'invention : elle ne la connaît ni comme limite ni comme aboutissement. Animées par cette perspective, les sciences échappent à la disparité de l'artificiel et du naturel, de ce qui est ou de ce qui n'est pas le résultat de l'intervention humaine, pour créer leurs objets. Elles assimilent conjointement, grâce à leur activité régulatrice et génératrice de processus ou de phénomènes — de faits ou d'effets - les possibilités qui étaient celles des arts et des techniques. A l'encontre de la philosophie naturelle ou mécanique, les sciences ne poursuivent pas la transposition conceptuelle ou expérimentale des réalités fournies par l'habileté de l'artisan ou de l'ingénieur: leur action s'apparente, en quelque sorte, à celle des arts

\footnotetext{
693 cité in N.R. HANSON : op. cit. p. 136.

694 idem, p. 135.

695 M. BERTHELOT : op. cit. p. 275.
} 
et des techniques. Berthelot reconnaît ce rapport d'emblée et ce qu'il dit de la chimie reste valable pour toute discipline scientifique :

«La chimie crée son objet. Cette faculté créatrice, semblable à celle de l'art lui-même, la distingue essentiellement des sciences naturelles et historiques $\gg{ }^{696}$.

Dans une puissante fresque, qui aurait pu passer pour une prophétie dont nous voyons quotidiennement la réalisation, œuvre du scientifique, le savant français décrit les aspects démiurgiques de cette création ${ }^{697}$ :

«C'est ainsi que, non contents de remonter par la pensée aux transformations matérielles qui se sont produites autrefois et qui se produisent tous les jours dans le monde minéral et dans le monde organique, non contents d'en ressaisir les traces fugitives par l'observation directe des phénomènes et des existences actuelles, nous pouvons prétendre, sans sortir du cercle des espérances légitimes, à concevoir les types généraux de toutes les substances possibles et à les réaliser : nous pouvons, dis-je, prétendre à former de nouveau toutes les matières qui se sont développées depuis l'origine des choses, à les former dans les mêmes conditions, en vertu des mêmes lois, par les mêmes forces que la nature fait concourir à leur formation... »

Qu'est-ce à dire, sinon que les « êtres de raison » de l'expérience et de la théorie peuvent constamment se changer en réalités, que nous devons, en quelque sorte, multiplier nos sciences afin de multiplier les réalités auxquelles elles donnent vie et qu'elles précèdent? Le trait constitutif «artificiel» des disciplines naturelles réside essentiellement dans cette capacité de provoquer des phénomènes originaux, de créer des domaines du savoir et du réel, inconnus auparavant, et de les développer.

$* * *$ 
Jusqu'ici je me suis servi indistinctement des termes de science ou de philosophie pour définir le même groupement de disciplines, de même que j'ai employé les vocables de scientifique, savant ou philosophe pour parler de la même catégorie naturelle. J'ai, ce faisant, suivi les habitudes des époques que j'ai examinées, et exprimé les fluctuations de sens surtout lorsqu'elles marquaient une transition. Au milieu $\mathrm{du} \mathrm{XIX}^{\mathrm{e}}$ siècle, le partage devint plus net, lorsque fut pris le tournant caractéristique d'une transformation profonde. Il est symptomatique qu'en $1840 \mathrm{~W}$. Whewell ait exprimé la nécessité de désigner d'un nom spécifique les hommes qui se consacraient aux sciences. Il proposa de les appeler scientists (scientifiques) ${ }^{698}$ au lieu de « savants » ou «natural philosophers », par une dérivation analogue à celle qui a donné l'appellation de l'artiste.

« Nous avons grandement besoin d'un nom pour décrire un homme qui cultive la science en général. Je serais enclin à l'appeler un scientifique $»{ }^{699}$.

La proposition fut adoptée. Elle venait à son heure pour symboliser une réorganisation des rapports entre les disciplines, entre les collectivités qui possédaient et exerçaient les diverses formes de savoir. La terminologie souligne un événement historique, enregistre une évolution, en introduisant un usage qui était auparavant, sinon impossible, du moins inutile. A une époque antérieure, on n'aurait pas compris que l'on pût qualifier de "scientifique » une classe d'individus. L'Encyclopédie française est catégorique :

«On dit un traité scientifique, par opposition à un ouvrage de pratique... Il ne se dit guère de personnes $»{ }^{700}$.

Le titre de philosophe était seul usité. La diffusion de la distinction souhaitée par Whewell et l'opposition qu'elle a suscitée traduisent l'une et l'autre un changement évident. Les sciences en sont venues à signifier un corps de connaissances original par sa structure, équivalent à la philosophie; le scientifique, une catégorie plus large, égale

K. MAYNARD : Science in early English literature, 1550 to 1650, Isis, 1932, 17, pp. 94-126.

W. WHEWELL : Philosophy of the inductive sciences, Londres, 1840, Aphorisme XVI.

Article SCIENTIFIQUE, t. XIV, p. 789.
} 
en dignité à celle du philosophe mécanique ou naturaliste. Le remaniement du vocabulaire traduit un clivage entre les sciences et la philosophie. Ce clivage n'est pas dû à des motifs superficiels, tels que la subdivision nécessaire des connaissances, consécutive à leur accumulation, l'unité de la philosophie et le morcellement des sciences. La particularité de celles-ci tient surtout à la convergence de deux mouvements qui ont abouti à les établir en tant que groupement indépendant de disciplines naturelles. D'un côté, l'évolution de la division naturelle dans le contexte de la chimie, de l'autre côté la transformation du processus inventif de la philosophie mécanique telle qu'elle s'est exprimée dans la physique électromagnétique, sont en cause. Leur convergence a non seulement bouleversé le mode de création des facultés humaines, les rapports avec la matière, elle a simultanément modifié les relations avec les disciplines productives, techniques. A cette occasion, la démarche philosophique a été profondément réformée. J'ai souligné, dans ce cadre précis, ses caractères, à savoir : en premier lieu, elle s'efforce de fonder les liens naturels, de les révéler, de les ordonner en partant des objets et des actions concrétisés dans et par les techniques, de reconstituer sous une forme conceptuelle rigoureuse ce qui est apparu sous une autre forme, en tant qu'habileté et instrument, intellectuel ou non. En deuxième lieu et cela est vrai surtout de la philosophie mécanique on peut reprendre ultérieurement ses résultats afin d'organiser et d'améliorer les méthodes courantes dans la pratique des techniques. Visiblement, les sciences s'éloignent de cette attitude; elles ne sont plus destinées à servir de médiation à la philosophie et à l'art ou à la technique, symboles de celle-là, ombres de ceux-ci. Celui qui s'y consacre n'est ni un philosophe qui essaie de découvrir à travers le donné les règles du monde matériel et de les analyser systématiquement, ni un homme d'art qui s'élève à partir de l'empirie pour saisir ses opérations comme les reflets de ces règles ; c'est un scientifique, qui étudie et maîtrise des phénomènes en tant qu'ils expriment directement les forces matérielles, et leur impose une structure qui peut prendre des aspects variés suivant les exigences des diverses actions, lesquelles sont autant de prolongements de la science, autant de sciences, s'il le faut, appliquées. En cela sa connaissance est le couronnement de la connaissance inventive, dans la mesure où celle-ci se veut génératrice de formes et de substances. Ses artifices sont annonciateurs directs de rapports naturels, et ses rapports naturels, préludes d'artifices. Ainsi la science qui était autrefois savoir 
intercesseur entre les philosophies et les techniques ou les arts s'est substituée aux unes et aux autres pour devenir la matrice d'une nouvelle unité autonome.

Je n'ai pas eu l'ambition de faire un exposé complet des circonstances dans lesquelles les disciplines philosophiques et les disciplines scientifiques eurent à se différencier. Ces circonstances ne se sont pas toutes présentées exactement de la même manière partout. Le développement historique que j'ai indiqué représente en quelque sorte une ligne d'évolution générale, ramenée à ce qu'elle a d'essentiel. 


\title{
Chapitre X.
}

\section{La transformation opérée par les sciences}

\author{
dans l'histoire humaine de la nature
}

I. Le dépérissement des techniques

$\underline{\text { Retour à la Table des Matières }}$

\section{Les nouvelles ressources complémentaires.}

Les sciences, on l'observe et on le déclare, témoignent d'une mutation de nos relations avec l'univers matériel. Les prodromes de cette mutation sont manifestes. Ce sont tout d'abord la différenciation des savoirs chimiques, leur convergence avec les résultats de l'activité inventive de la philosophie mécanique, notamment à propos de l'électricité, du magnétisme et des forces motrices en général. Corrélativement se détache et se regroupe un "nouvel ordre de philosophes », celui des scientifiques d'aujourd'hui. Ensuite, à l'état naturel mécanique se substitue un état naturel distinct, que j'ai désigné ${ }^{701}$ sous sa forme développée du nom d'état cybernétique. Enfin la pénétration de la démarche théorique et de la méthode expérimentale par le processus d'invention, la conversion subséquente de celui-ci, ont profondément modifié les rapports à l'intérieur du groupement de disciplines. Les disciplines naturelles et la couche savante de la catégorie naturelle instituent directement le fondement réel de leur recherche. Les disciplines productives leur sont subordonnées. Le fait est incontestable. Il convient de montrer ses conséquences. A coup sûr, il

${ }^{701}$ Chapitre IV de la I ${ }^{\text {re }}$ partie. 
faut situer parmi elles la modification du système de reproduction des facultés et de leurs qualités. Toutefois, cette modification a également trait aux propriétés essentielles de la création du travail, aux liens que les hommes y établissent. Elle affecte dès lors, en fin de compte, le principe même de l'histoire humaine de la nature. Pour mieux comprendre le rôle que les sciences ont joué à cet égard, il est indispensable de revenir en arrière et de scruter le mouvement qui leur a permis d'acquérir leur identité et leur indépendance.

Deux facteurs ont principalement déterminé cet événement. Le premier est, de toute évidence, la présence de ressources complémentaires, la disponibilité en hommes et en matières. Au XIX ${ }^{\mathrm{e}}$ siècle l'accroissement de la population est un phénomène marquant ${ }^{702}$.

L'Europe qui, en 1800, ne comptait que 187 millions d'individus, en compte 266 en 1850. En 1900, ils sont 401 millions ${ }^{703}$. Non seulement la densité augmente, mais grâce au prolongement de la durée de la vie, la population active constitue un pourcentage de plus en plus important du total. Les chiffres, faute de données démographiques sûres, sont sujets à caution : la tendance elle-même ne l'est pas. Pas plus que ne le sont la désertion des campagnes et sa contrepartie, l'urbanisation ${ }^{704}$. Pour ne prendre qu'un seul exemple en 1890 , en Allemagne, $11,4 \%$ de la population habitent dans des villes de plus de 100000 habitants; en 1910 , ce pourcentage est de $21,3 \%{ }^{705}$ (4).

Une évolution de même nature se déroule en France, quoique à un rythme plus lent. Les courants de migration, vers les États-Unis notamment, sont un signe de cette disponibilité en hommes. Il faut voir une cause de surpopulation constante dans la mécanisation de l'industrie, avec les bouleversements qu'elle entraîne dans les campagnes, dans la production artisanale, et l'impulsion qu'elle donne à

702 tion au cours du dernier quart du dix-neuvième siècle » in H.J. HABAKKUK, M. POSTAN (eds) :
The Cambridge Economic history of Europe, t. VI (I), Cambridge, 1965, p. 62.
R. SCHNERB : Le dix-neuvième siècle, Paris, 1957.
M. LEVY : Histoire économique et sociale de la France depuis 1848, Paris, 1952.
J.H. CLAPHAM : Economic development of France and Germany (1815-1914), Cambridge,
1963. 
l'activité capitaliste. Le capital s'efforce de diriger cette industrie suivant ses fins propres, dont l'une est de se passer de main-d'œuvre, et l'autre d'employer celle-ci le plus intensément possible. De la sorte, il provoque l'existence d'une force de travail supplémentaire, d'une " armée de réserve » à laquelle il convient de trouver un emploi, d'une part pour en extraire la richesse potentielle, d'autre part afin d'atténuer le contrecoup des crises et du chômage qui ébranlent les fondements mêmes de la société capitaliste. La ressource que représente cette force de travail disponible constitue une tentation et une menace permanentes. Une tentation, parce qu'elle est un appel à l'investissement, et que la possibilité de la «faire travailler » conduit à des profits croissants. Une menace, puisque l'existence de milliers, voire de millions d'individus sans travail aiguise la lutte des classes, et que le départ ou la défection de bras et de cerveaux affaiblit chaque groupe national dans l'âpre concurrence pour la conquête des marchés.

Les inventions qui améliorent le système productif donnent à cette conquête plus d'ampleur, obligent à reculer les frontières de ces marchés, et n'ont pas de meilleur compagnon que le chômage - qualifié, par la suite, de technologique. Elles entraînent une autre conséquence : le déséquilibre entre les différents secteurs de la production. Le phénomène a été particulièrement sensible dans l'industrie la plus caractéristique de l'époque : l'industrie textile. Celle-ci utilisait, pour le blanchiment des fibres, des produits végétaux, onéreux, et disponibles en trop faibles quantités. On a donc cherché d'autres procédés. Roebuck conçoit des chambres de plomb de dimensions importantes pour la préparation de l'acide sulfurique, Leblanc découvre un procédé permettant d'obtenir de la soude artificielle, Tennant fait breveter un produit de blanchiment efficace ${ }^{706}$.

Par ailleurs, avec le développement des matières nécessaires à l'industrie, s'accumulent des déchets dont la conservation représente une dépense importante, et la présence même un manque à gagner non moins considérable. En 1852, un observateur signale qu'il y a là 
« une source de gros ennui pour les fabricants, ces déchets sont volumineux et on ne leur a pas encore trouvé un emploi utile. Ils s'accumulent en tas immenses au voisinage des soudières, et il est parfois nécessaire d'acheter des terrains uniquement pour les entreposer $\gg{ }^{707}$.

Une production qui commence à s'organiser suivant des exigences de rationalité économique et d'efficacité technique s'efforce d'exploiter systématiquement tous les facteurs qu'elle met en œuvre. La présence de sous-produits en vastes quantités aux abords des usines ou des mines incite l'industriel et l'ingénieur à leur trouver une utilisation profitable. Les théoriciens démontrent le juste emploi qu'on peut en faire, et les doctrinaires rappellent les principes d'une saine économie :

«C'est un des plus importants devoirs de l'industrie manufacturière que de trouver un emploi utile des déchets. On a défini la poussière, avec un grand bonheur d'expression, en disant que ce n'était que «de la matière en un lieu inapproprié $»{ }^{708}$.

La mécanisation des procédés artisanaux, la recherche d'une productivité sans cesse accrue, ont provoqué l'accumulation massive de ces deux ressources extraordinaires : la force de travail et la « matière en un lieu inapproprié ». Ces ressources constituaient, virtuellement, un point de mire, et un terrain d'application pour une autre ressource extraordinaire : le talent susceptible de s'y ajouter et de les valoriser.

Les motifs indiqués ne sont pas les seuls déterminants, toutefois ils symbolisent une série de circonstances propres à intéresser à la production les «nouveaux philosophes ». Ceux-ci n'ont pas hésité à s'y engager Les chimistes surtout font valoir, et c'est devenu une opinion courante, que les transformations de leur discipline les

«mettent à même de convertir les substances qui paraissent les moins utiles en objets importants. Chaque branche d'art a senti son influence et chaque 
jour apporte de nouvelles preuves des ressources infinies que la chimie sait trouver dans les parties les plus stériles de la nature $\gg{ }^{709}$.

La réalisation de cette possibilité a joué un rôle décisif par la suite, puisqu'elle a entraîné une diversification exceptionnelle des branches de l'industrie ${ }^{710}$.

Le deuxième facteur de l'autonomie des sciences est assurément l'extension de cette communauté d'hommes qui possèdent les talents propres à constituer de «nouveaux arts ». Formés souvent en marge de la médecine ou de la pharmacie dans le cadre de ces « sociétés philosophiques » où ils jouaient le rôle de conférenciers ou de démonstrateurs, habitués à divertir ou à instruire un public de curieux, ils ont créé des disciplines relativement distinctes — l'électricité, la physique - et ont annexé la chimie. Le besoin naît de subdiviser et de se spécialiser comme aussi le besoin de donner à son activité une assise plus vaste, plus solide. J.B. Priestley, témoin avisé, exprime cette tendance :

«L'objet de la philosophie s'est tellement multiplié que tous les livres de comptes rendus philosophiques généraux ne peuvent plus être achetés par les particuliers, ni lus par les individus. Il est grand temps de subdiviser l'objet, afin que chacun ait l'occasion de voir tout ce qui se rapporte à sa recherche de prédilection, et toutes les diverses branches de la philosophie trouveraient leur compte dans cette séparation à l'amiable ${ }^{711}$.

On ne manquera pas d'observer que cette séparation vise à améliorer les conditions de travail des savants, sur le plan économique comme sur le plan scientifique. Chacun ne disposant que de ressources et de temps limités, une répartition des tâches s'impose. Une conséquence certaine en sera le développement de chacune des différentes branches de la philosophie expérimentale, aussi bien que l'apparition de nouvelles possibilités d'application. J.B. Priestley qui a décidément une vue presque politique de la question — consiproblèmes posés par la présence des déchets ». S.G. CHECKLAND : op. cit. p. 171.

711 J.B. PRIESTLEY : op. cit. p. XIV.
} 
dère que le nombre des savants doit s'accroître, et qu'ils doivent se donner les moyens institutionnels et économiques nécessaires à cette fin :

«Je veux seulement donner une indication supplémentaire, ajoute-t-il ${ }^{712}$, sur ce que je considère qui pourrait favoriser l'accroissement de la connaissance philosophique. A présent, il y a, dans les différents pays d'Europe, de vastes sociétés constituées, dotées de fonds pour l'avancement de la connaissance philosophique en général. Que les philosophes commencent maintenant à se subdiviser et à entrer dans des combinaisons plus petites. Que les diverses compagnies fassent de petites fondations et nomment un directeur d'expériences. Que chaque membre ait le droit de fixer la vérification des expériences en proportion de la somme qu'il a souscrite, et qu'on publie un compte rendu périodique de leur résultat, qu'elles aient réussi ou non. De cette façon, la puissance de tous les membres pourrait être assurée et accrue ».

Ces propositions ne contiennent rien de révolutionnaire. Elles traduisent cependant le souci d'une collectivité désireuse d'assurer sa survie et son développement, et une volonté de chercher des voies propres à l'emploi et au progrès des connaissances créées. La situation d'amateur isolé est peu confortable ; elle s'avère, de plus, incompatible avec la multiplication des hommes qui aspirent à se consacrer à la découverte des phénomènes matériels, et avec l'accroissement des investissements appropriés en livres et en appareils. Mais, semble-t-il, on ne peut compter ni sur des appuis extérieurs solides, ni sur un intérêt authentique de la société. J.B. Priestley — encore lui — le sait bien qui écrit ${ }^{713}$ :

«Les princes ne s'occuperont jamais de cette grande affaire, dans quelque but que ce soit. L'esprit d'aventure semble totalement éteint dans la race actuelle de marchands. Cette découverte est un grand desideratum dans la science; et où peut-on s'attendre à trouver l'enthousiasme noble et pur pour de telles découvertes, si ce n'est chez les philosophes, des hommes qui ne sont pas influencés par les mobiles de la conduite politique ou l'appât du gain ? »

Les circonstances en Angleterre sont particulières à maints égards, Néanmoins, elles ne diffèrent pas radicalement de celles qui existent

\footnotetext{
712 idem, p. XV.

713 idem, p. XVII.
} 
dans bien d'autres pays. On serait en droit de les croire plus favorables qu'ailleurs, dans cette patrie de la révolution et du capitalisme industriels — ce modèle auquel Karl Marx a accordé tant d'attention. Or, justement, la classe qui possède d'importants capitaux est celle qui s'intéresse le moins à la découverte - ou s'y intéresse peu ${ }^{714}$. En Angleterre, les possibilités offertes par la science, le potentiel représenté par les scientifiques, sont jugés secondaires par comparaison avec ceux de la mécanique et de l'ingénieur, alors en plein essor. L'historien E. Hobsbawn observe avec raison ${ }^{715}$ :

« Comme ce fut le cas pour toutes les forces externes qui modelaient le développement scientifique, les appels directs adressés aux scientifiques par le gouvernement ou l'industrie furent des plus secondaires. En Grande-Bretagne, les industries-clés de la période qui nous intéresse étaient les textiles de coton, le charbon, le fer, les chemins de fer et la marine marchande. Les talents qui les révolutionnèrent appartenaient à des empiristes - trop empiristes. Le héros de la révolution du chemin de fer britannique, fut George Stephenson, illettré scientifique, mais qui avait du flair pour ce qui fait fonctionner une machine - un artisan supérieur plutôt qu'un technicien. Les tentatives de savants, tel Babbage, pour se rendre utiles aux chemins de fer, ou d'ingénieurs scientifiques comme Brunel, de les asseoir sur des fondements rationnels plutôt que purement empiriques, n'aboutirent à rien ».

L'analyse historique confirme donc les assertions de J.B. Priestley. Et les sciences demeurent dans une position subalterne par rapport à la technique et aux exigences de l'industrie de la production.

Rien de plus normal que le désir du philosophe, du savant, de voir ses capacités, pleinement reconnues, s'épanouir. Il essaie donc de s'organiser - le plaidoyer du chimiste anglais en est un signe. Et aussi de faire accepter ses conceptions par l'ensemble de la société, en espérant que celle-ci lui accordera un appui plus solide et plus constant : de la sorte naîtra le climat propice à l'éclosion des germes semés

714 «Il y avait de nombreux fabricants intelligents, à l'esprit expérimental, et même cultivé, qui se pressaient en foule aux réunions de la nouvelle association britannique pour le développement de la science; mais ce serait une erreur de supposer qu'ils représentaient la norme de leur classe ». E. HOBSBAWN : The age of revolution, Londres, 1962, p. 187.

715 idem, p. 278. 
par les disciplines scientifiques ${ }^{716}$. C'est en faisant la preuve de ses capacités qu'il s'imposera à une industrie et à un gouvernement réticents, qu'il modifiera aussi de fond en comble les conditions dans lesquelles opèrent l'un et l'autre. L'apparition des facultés nouvelles est ainsi le facteur déterminant.

«Rien ne contribue davantage, observe à ce sujet $H$. Sée ${ }^{717}$, à accroître l'emprise du capitalisme sur l'industrie que les progrès du machinisme et ceux des applications industrielles des sciences, de sorte qu'en définitive c'est beaucoup moins au capitalisme lui-même qu'on doit l'extraordinaire épanouissement de l'industrie qu'à la science elle-même et même à la science purement désintéressée. La chose est visible en France comme ailleurs. »

Ailleurs, c'est-à-dire en Angleterre et en Allemagne. L'Allemagne surtout, qui voit sa population émigrer en masse ${ }^{718}$, qui ne possède pas une industrie mécanique aussi importante que l'Angleterre, offre moins de résistance, elle est aussi davantage encline à faire appel aux savoir-faire qui sont peut-être plus abondants dans ce pays que dans d'autres. Ceux de la chimie notamment, dont un témoin, Campbell, affirmait en 1753 :

«Les Allemands sont de loin les meilleurs chimistes d'Europe et les meilleurs traités sur ce sujet sont écrits en latin et en allemand ${ }^{719}$.

La pression conjuguée de ces deux facteurs - les ressources complémentaires en forces de travail et en matières premières d'un côté, les ressources en savoirs ou talents de l'autre - crée des possibilités inédites. Les hommes qui incarnent ces ressources transforment les procédés de travail et les moyens de communiquer, réussissent à

716 «En divers pays, les savants les plus convaincus de l'importance sociale de leur activité comprirent qu'un vaste effort de vulgarisation des progrès récents de la science permettrait d'éclairer l'opinion sur l'intérêt des travaux de recherche et d'obtenir ainsi un précieux appui, dans leur lutte en faveur d'une aide active à la science... Cette action des savants sur l'opinion publique se fit également par l'intermédiaire des nombreuses sociétés qui se créèrent au cours du XIX ${ }^{\mathrm{e}}$ siècle dans le but de renforcer la collaboration entre spécialistes d'une même discipline, de faciliter la publication des travaux originaux et d'assurer une large diffusion des découvertes récentes ». R. TATON : Histoire générale des sciences, Paris, 1961, t. III, p. 618.

717 H. SÉE : Histoire économique de la France, ed. Paris, 1951, p. 296.

718 F. SCHNABER : Deutsche Geschichte im 19. Jahrhundert, Freiburg, 1934, t. III, p. 354.

719 cité in J.H. ClAPHAM, op. cit. p. 103. 
s'insérer dans la réalité matérielle de la collectivité et à l'infléchir. Ils transposent également leur effort sur un terrain objectif différent, rendant nécessaire l'emploi des énergies physiques et des facultés qu'ils possèdent. Fait remarquable toutefois, avec la science et le scientifique, le processus de substitution s'opère en partant du domaine des phénomènes matériels, de la connaissance, pour aller vers celui des méthodes productives et du savoir-faire, et non pas en sens inverse comme c'était le cas précédemment.

\section{$\underline{\text { Retour à la Table des Matières }}$}

\section{Les sciences appliquées.}

La chimie et l'électricité sont les agents principaux de ce renversement ${ }^{720}$. Avant de pénétrer profondément le cycle de la production, les deux disciplines naturelles s'étaient déjà affirmées par leurs découvertes expérimentales et théoriques. La première avait parcouru les étapes essentielles de sa carrière en tant qu'art et philosophie au sein de la médecine et de la pharmacie. La seconde s'était donné les fondements les plus assurés dans le cadre des sociétés de philosophes, lesquels y trouvaient un moyen de s'instruire, de subsister, et aussi d'être acceptés dans la République des Lettres.

«L'étude de l'électricité débuta comme un passe-temps assez agréable et sans utilité, et fournit une série de nouvelles expériences intéressantes et spectaculaires ${ }^{721}$.

Certes, l'association de la chimie avec la manufacture des textiles fut un pas d'importance. Elle démontra l'utilité des savoirs cachés dans les officines et suscita également une série de recherches en vue de récupérer les sous-produits et d'éviter la pollution atmosphérique. Autour de ces activités se développa une industrie chimique ayant pour objet de préparer l'acide sulfurique, la soude et le chlore ${ }^{722}$.

\footnotetext{
720 J.T. MERZ : op. cit. t. I, p. 91.

721 J.D. BERNAL : Science in history, ed. cit. p. 363.

722 J. KolB: Sur l'évolution actuelle de l'industrie chimique, Lille, 1883, p. 3.
} 
On ne saurait pourtant reconnaître à cette association une portée décisive qui est plutôt le fait de la chimie organique, de l'application générale des procédés de synthèse ${ }^{723}$. Les travaux de Chevreul sont, à cet égard, exemplaires. Il démontra qu'en ajoutant une molécule d'eau aux suifs et aux graisses, on décomposait ces corps en glycérine et en acides organiques complexes, capables de donner des sels lors de leur combinaison avec des bases. Cette découverte marqua l'industrie du savon et permit la formation d'une industrie des bougies. Ainsi une réaction chimique d'intérêt majeur pour la théorie débouchait directement sur un emploi productif. Les expériences de synthèse qui permettent de construire des structures moléculaires complexes en assemblant des structures plus simples ont été à la base de l'industrie des colorants, dont on peut dire qu'elle procède de la science et partiellement de la pharmacie. On sait que la première teinture à l'aniline, la mauvéine, a été découverte au cours des essais de synthèse de la quinine. Les goudrons d'huile utilisés pour fabriquer les premiers colorants synthétiques servaient généralement à produire des antiseptiques. C'est leur étude qui, de Hofmann à Kékulé, a ouvert la voie à la découverte systématique des substances colorantes au laboratoire : la fuchsine en 1859, l'alizanine en 1868 et l'indigo en 1880. Ainsi naissait une nouvelle industrie chimique, proprement scientifique ${ }^{724}$.

Non sans quelque hésitation, le capital s'introduisit par cette porte ouverte. Il nous suffit de donner quelques chiffres: en 1897, l'Angleterre exportait 11000 tonnes d'indigo végétal en provenance des Indes, en 1911 elle n'en exporte plus que 860 tonnes. Pour sa part l'Allemagne qui exportait, en 1897, 600 tonnes d'indigo de synthèse, en exporte 22000 tonnes en 1911.

La filiation qui joint l'industrie pharmaceutique à celle des colorants synthétiques est presque directe ${ }^{725}$. Tout d'abord, les matières colorantes ont été employées avec succès dans l'étude histologique

723 «La fabrication de produits chimiques organiques était davantage une science et moins un art que celle des produits inorganiques, et en fait ce ne sont pas les pays qui brillaient le plus dans le domaine de la chimie inorganique industrielle qui se distinguèrent le plus dans le domaine organique ». F.S. TAYLOR : A history of industrial chemistry, Londres, 1957, p. 230.

724 L.F. HABER : op. cit. p. 81.

725 W. VERSHOFEN : Die Anfänge der chemisch-pharmazeutischen Industrie, t. I, Berlin, 1949. 
des tissus. Ensuite, il est apparu qu'elles étaient douées de propriétés qui les rendaient capables de lutter contre certains agents pathogènes. Dans ce domaine, P. Erlich, le créateur de la chimiothérapie, est un pionnier. Les expériences par lesquelles il s'est efforcé de découvrir des médicaments qui puissent détruire les bactéries et les protozoaires sans attaquer les tissus représentent un véritable tournant.

P. Erlich s'était aperçu que les teintures se fixaient à certaines fibres textiles, à l'exclusion d'autres, et il avait également remarqué qu'elles coloraient les bactéries en laissant intacts les tissus voisins. L'idée lui vint donc de trouver des teintures qui, en se fixant à ces parasites microscopiques, les détruiraient. Ses premières études portèrent sur les maladies provoquées par le trypanosome et propagées par certains insectes, notamment certaines épizooties et aussi la redoutable maladie du sommeil. Vers 1907, il réussit à mettre au point une variété de teintures qui détruisaient les trypanosomes mais constituaient elles-mêmes un poison dangereux. Son attention se porta alors sur des composés à l'arsenic, et il réussit à en préparer un, l'atoxyl, qui guérissait la maladie du sommeil - mais entraînait des accidents pouvant aller jusqu'à la cécité. La réussite des expériences prouvait cependant la possibilité de la chimiothérapie. Ces découvertes, comme celle du salvarsan, médication de la syphilis, couronnent l'entrée de la chimie dans l'aire industrielle.

$\mathrm{Si}$, dans la manufacture textile, elle demeure un savoir auxiliaire, elle engendre parallèlement des productions que l'on doit à ses méthodes propres, et finit par se rendre indispensable à toutes les autres industries, en raison de la maîtrise qu'elle exerce sur toutes les matières. Elle est mise à contribution dans des domaines aussi variés que les mines, la fonderie, le bâtiment, et aussi l'agriculture, puisqu'elle prépare des engrais et propose des méthodes de conservation des aliments. Elle va même beaucoup plus loin; dès le début du $\mathrm{XX}^{\mathrm{e}}$ siècle, elle arrive à remplacer progressivement la plupart des matières premières traditionnelles — bois, fibres végétales ou animales, métaux, etc. - par des substances synthétiques.

Toutes ces substances sont le résultat de découvertes scientifiques consécutives à un renouvellement des concepts, prolongé dans des expériences. Bien plus, étant donné les conditions de température, de vitesse ou de pression auxquelles ont lieu les réactions chimiques, l'emploi des instruments mécaniques devient de plus en plus malaisé, sinon impossible. Le changement des méthodes de travail, 
l'élimination de l'intervention directe de l'homme, résultent nécessairement de la chimisation du processus productif, comme ils résultent de l'application des inventions auxquelles l'électricité a donné naissance.

La télégraphie est sans conteste la première de ces inventions dans le domaine pratique. Elle s'installe le long des voies ferrées ${ }^{726}$ et accélère la transmission des informations de manière spectaculaire pour l'époque. Cooke et Wheatstone sont les constructeurs de l'appareil électromagnétique qui relie 5 ou 6 fils métalliques à autant d'aiguilles magnétiques pivotant entre les deux sections d'une double bobine métallique. Par leurs oscillations vers la droite ou vers la gauche, les aiguilles indiquent des lettres spécifiques, après lecture sur un cadran. La pose du premier câble transatlantique à laquelle $\mathrm{W}$. Thomson a collaboré - acheva de consolider la position de ce nouveau moyen de transmission, et celle de la jeune science électrique. Toutefois, à une époque qui se préoccupe de l'énergie et de la force, c'est la possibilité d'employer l'électricité à la génération du mouvement qui devait jouer le rôle essentiel. Les inventions destinées à répondre à ces préoccupations existaient déjà au moment où s'imposait la télégraphie avec fil. Dès 1831, Faraday avait montré que l'électricité pouvait donner naissance à un courant continu, et en 1835 le premier moteur miniature fut construit. Il se composait de bobines stationnaires entourant un arbre sur lequel était monté un aimant en forme de barreau. L'arbre était muni d'une série de contacts qui, envoyant successivement le courant d'une batterie à travers les bobines, faisaient tourner l'aimant et l'arbre. Deux ans plus tard apparurent les premiers moteurs électriques à usage industriel, servant à forer du métal et à tourner du bois. Les inventions de Gramme, Pacinotte et Siemens achevèrent de rendre la force électrique accessible à l'industrie. Bien que les espoirs mis dans la possibilité de la créer par voie chimique se fussent rapidement effondrés ${ }^{727}$, 1 'économie qu'elle permettait, la ductilité de sa transmission et de sa distribution en assurèrent le succès.

Au début de notre siècle, machines-outils traditionnelles et moteurs électriques coexistaient, et ceux-ci avaient atteint une maturité que l'on appelait, par référence à la technique prédominante, «mécanique $\gg$.

727 H.C. PASSER : The electrical manufacturers 1875-5900, Cambridge (Mass), 1953. 
«Au cours des trente-cinq dernières années du XIX ${ }^{\mathrm{e}}$ siècle, (la dynamo), ce rejeton vigoureux de souche électrique, a accédé à la pleine stature de la majorité mécanique $»$, écrit-on ${ }^{728}$.

Pour un observateur averti, il était évident que cette majorité signifiait, davantage encore, la pénétration d'une nouvelle forme d'énergie et de mouvement dont les lois et les manifestations ne pouvaient se limiter à un secteur déterminé. Le rythme des inventions, l'ampleur des modifications qu'elles provoquaient, faisaient de cette forme l'héritière directe de l'instrument mécanique en général. Un texte du grand historien de la physique F. Rosenberger, témoin de l'éclosion des applications de l'électricité, nous le confirme ${ }^{729}$ :

« Il n'a pas encore été possible d'établir qui a employé pour la première fois le vocable d'électrotechnique, et pour quelle raison Karmarsch, dans son Histoire de la technologie de 1872, n'en fait pas mention, et c'est en vain que l'on compulserait, pour le trouver, les Encyclopédies antérieures à 1880. Quoi qu'il en soit, c'est la I ${ }^{\text {re }}$ Exposition Électrique de Paris, en 1881, et le Congrès des Électriciens qui l'ont tenu sur les fonts baptismaux. Il n'est pas aisé de définir le mot, et on n'en épuisera pas le sens, si l'on se contente de l'interpréter, ainsi que le suggère l'aspect extérieur du terme, comme une branche particulière de la technique; au contraire, elle prétend actuellement embrasser la technique tout entière, du moins dans la mesure où l'électricité, partout directrice et transformatrice, devient le loyal arbitre du jeu des forces ».

La prévision de Rosenberger s'est parfaitement réalisée. La diffusion du moteur électrique a commencé par modifier l'organisation des machines mécaniques et éliminer certains modes de transport de l'énergie qui leur étaient spécifiques ${ }^{730}$. Mais le rôle de l'électricité apparait dans toute son ampleur si l'on considère le développement de l'électronique, qui se propose d'assurer le fonctionnement des instruments de mesure ou des moyens de travail par le contrôle des «porteurs d'information» d'une partie à l'autre d'un ensemble machinal intégré. On sait que les découvertes fondamentales, à cet égard, sont relatives à la transmission dans le domaine de la radio. Elles reposent sur une observation d'Edison datant de 1883: l'ampoule d'une lampe à filament de carbone se recouvre d'un dépôt noir. Il observe également que, si l'on suspend une plaque de métal à l'intérieur de l'ampoule, en la reliant extérieurement, par l'intermédiaire d'un galvanomètre, à l'extrémité positive du filament, un

F. ROSENBERGER : op. cit. t. III, p. 790.

730 P. DunShEATH : A history of electrical engineering, Londres, 1962. 
courant continu parcourt la plaque tant que le filament est chauffé. En 1904, J.A. Fleming étudiant l'effet Edison et les travaux sur la décharge dans les gaz effectués par J.J. Thomson, vit leur application dans le nouveau domaine de la T.S.F. où Marconi progressait rapidement. Il s'agissait de trouver un redresseur capable de convertir le train d'oscillations de haute fréquence en courant intermittent mais de même sens ; alors que les premières n'avaient aucun effet sur le récepteur téléphonique sensible, le courant redressé devait produire une note musicale décelable dans le récepteur, et ayant la fréquence du train d'étincelles.

J.J. Thomson avait élucidé l'effet Edison en montrant que les électrons étaient émis par le filament chauffé au rouge dans une ampoule où régnait le vide, et Fleming aperçut là la solution de son problème. Il fit faire des lampes où le filament placé dans l'ampoule était entouré d'un cylindre de métal (la « plaque ») lui-même relié à un contact aboutissant à un troisième pôle. En reliant le pôle négatif du filament à la «plaque », il trouva que, dans le circuit transportant le courant reçu à haute fréquence, le courant était redressé et pouvait être détecté par le récepteur. En 1906, Lee de Forest améliora la lampe de Fleming en lui adjoignant, entre le filament ou cathode chauffé au rouge et la plaque, une troisième électrode appelée la grille. Grâce à ce perfectionnement, la lampe triode put amplifier les signaux, ouvrant ainsi la voie aux applications que l'on sait dans le domaine de la radio-communication et de l'automation.

Si l'on ajoute à ces inventions celle de la cellule photoélectrique, on voit comment l'électron a pu se substituer aux engrenages et aux cames, avec des performances bien supérieures, uniquement limitées par les « bruits » occasionnés par les mouvements désordonnés.

«Cette supermécanique électronique a permis de reprendre sur de nouvelles bases bien des anciens problèmes auxquels la mécanique des pièces mobiles n'avait donné que des réponses limitées » ${ }^{731}$.

Elle a aussi permis de se dispenser, un peu partout, de l'intervention des agents humains, et d'établir l'autonomie de fonctionnement des systèmes techniques.

Cette évolution associe constamment chimie et électricité. Mais ce qui fait surtout son originalité, c'est l'impossibilité de trancher la par- 
tie industrielle de la partie scientifique ${ }^{732}$ et de les décrire séparément sans artifice littéraire. Pour la première fois dans l'histoire humaine, une chaîne ininterrompue relie la connaissance des lois d'un phénomène artificiel matériel à celle des règles de fabrication des objets ou instruments ; pour la première fois, il n'y a plus de solution de continuité entre la création d'une discipline naturelle et celle d'une discipline productive. Des lignes auparavant parallèles, ou qui semblaient destinées à ne se rencontrer que grâce à des aiguillages complexes, se trouvent désormais placées dans le prolongement l'une de l'autre.

$\underline{\text { Retour à la Table des Matières }}$

\section{La mutation du travail humain.}

En effet, la source de tous les changements qui affectent le travail technique et le fondement de tous ses procédés résident dans la science et les découvertes scientifiques. Assurément, les sciences sont autonomes et ne se confondent avec aucune de leurs applications. C'est après s'être dégagée du cadre de la médecine et de la pharmacie que la chimie, par exemple, a acquis une telle autonomie et une identité propre ${ }^{733}$. Mais elle doit cette situation privilégiée au fait qu'elle est devenue une discipline relativement générale, commune à une multitude de « nouveaux arts » et d'arts moins nouveaux.

Forte de cette situation, la catégorie naturelle qui avait pour savoir les disciplines physiques, chimiques, électriques, a commencé à se constituer dans le cadre de l'invention de ces savoirs, hors de la production, et ce immédiatement en tant qu'ils représentent les rapports

732 «L'industrie moderne est baignée par la science, et dans certaines branches, telles que l'électricité et la chimie, elle est dans une grande mesure une opération de la science. Il n'est plus pertinent, comme par le passé, de décrire les caractères spécifiques de l'industrie en poursuivant par l'exposé de leur influence sur la pensée scientifique. Le degré d'interpénétration est déjà trop élevé ». J.D. BERNAL, op. cit. p. 497.

« Depuis le début du XVIII ${ }^{\mathrm{e}}$ siècle, la théorie chimique est une partie essentielle et causale de la chimie industrielle, et l'on ne peut comprendre l'histoire de cette dernière qu'en fonction de cette théorie. Il est donc impossible d'écrire l'histoire des industries chimiques au XIX et au $\mathrm{XX}^{\mathrm{e}}$ siècles sans l'histoire des théories chimiques dont elles sont issues ». F.S. TAYLOR: op. cit. p. XV.

733 H. GUERLAC : Some French antecedents of the chemical revolution, Chymia, 1959, 5, p. 112. 
propres à l'ordre naturel. La subdivision, à l'intérieur de cette catégorie, entre les hommes qui se consacrent directement à ces rapports et ceux qui se cantonnent dans leur emploi productif, est ultérieure. Au début, les savants sont, dans des proportions variables, entrepreneurs et usagers de leur science dans le domaine industriel. Les Thomson et les Brewster ne sont pas seulement des savants mais aussi des ingénieurs. Fondateurs et directeurs de la Society of Telegraph Engineer, de 1'Institute of Electrical Engineers ils posent les jalons d'une spécialisation qui va s'accentuer de plus en plus. Les praticiens de ces disciplines, qui auparavant avaient un foyer commun dans une société à caractère scientifique - la Royal Society de Londres ${ }^{734}$ par exemple - commencent à se subdiviser et à se différencier. Mais cette séparation a lieu suivant des lignes inverses de celles que nous avons notées pour d'autres périodes ; ce n'est plus un ingénieur — un Benedetti, un Stevin - qui accède au rang de savant, de philosophe, mais un savant qui manifeste pour la première fois son aptitude à être aussi ingénieur. Une fois cette aptitude manifestée, débute la reproduction des talents propres à l'application des sciences. Ce ne sont plus les disciplines théoriques expérimentales qui prennent le nom des arts ou des techniques - ainsi la philosophie mécanique par exemple - mais les arts ou les techniques qui prennent celui des disciplines théoriques, expérimentales.

« La profession de l'ingénieur moderne est due, dans une large mesure, directement au progrès scientifique. Les noms mêmes des différentes espèces d'ingénieurs qui existent aujourd'hui - ingénieur électricien, chimiste, radio — indiquent que c'étaient toutes, à l'origine, des branches de la science qui sont devenues, à présent, des branches de la pratique $\gg{ }^{735}$.

Ce déroulement suivait un cours nécessaire. Les hommes de science étaient les premiers - et les seuls - à pouvoir conseiller et guider efficacement les opérations industrielles. A titre d'experts, de conseillers ${ }^{736}$ et d'inventeurs, ils prenaient part à la constitution des

734 «Pendant de longues années avant la formation d'un corps professionnel d'ingénieurs électriciens, les pionniers qui jetaient les bases de la science trouvèrent un forum adéquat à la Royal Society ». P. DUNSHEATH : op. cit. p. 319.

735 J.D. BERNAL : op. cit. p. 17.

736 F. SCHNABER : op. cit. p. 327. 
laboratoires et des usines ${ }^{737}$, et s'ils ne devenaient pas industriels euxmêmes, ils attiraient sans cesse l'attention de ceux qui pouvaient le devenir ${ }^{738}$.

Lorsque les méthodes productives furent suffisamment au point et que les découvertes à faire pour y aboutir devinrent inséparables des particularités du produit, on passa du domaine de la science à celui de ses applications, et alors se forma et se détacha le sous-groupe des hommes qui se destinaient à ce but ${ }^{739}$.

\section{Le contraste ${ }^{740}$ entre l'apparition de cette classe d'ingénieurs et} celle de la classe des mécaniciens est manifeste et a frappé tous les historiens :

«Dans le génie civil et mécanique, l'invention pratique a généralement précédé toute analyse théorique des principes d'opération — dans le génie électrique, d'autre part, et, dans une mesure moindre, en chimie, l'évolution a suivi un cours tout différent $\gg{ }^{741}$.

737

738$$
\text { GuRLAC : art. cit., p. } 108 .
$$

La division sociale du travail s'est manifestée de plusieurs manières. En premier lieu, par le fait que les industries chimiques et électriques ont été créées, surtout au début, par des savants aussi bien que par des capitalistes. La séparation nette des deux fonctions dans ce domaine, celle de scientifique et celle d'industriel, s'est produite vers la fin du XIX ${ }^{\mathrm{e}}$ siècle. (L.F. HABER : op. cit. p. 78.)

En deuxième lieu, par la séparation des productions proprement industrielles de celles qui étaient traditionnellement pharmaceutiques. Antoine Baumé, pharmacien chimiste, crée une usine de produits chimiques indépendante de son officine, tandis que la pharmacie fondée par J. Riedel, à Berlin, en 1810, donne naissance en 1874 et en 1884 aux deux plus grandes entreprises chimiques allemandes. (G. URDANG : Retail pharmacy as the nucleus of the pharmaceutical industry, Supp. Bull. of the Hist. of Med. 1944, 3, p. 327).

En troisième lieu, les capitalistes eux-mêmes, maîtres des nouvelles branches de l'industrie, une fois qu'ils se sont approprié les rôles sociaux détenus par les scientifiques, sont censés acquérir les connaissances adéquates. L'Allemagne, là encore, et surtout dans le domaine de la chimie, occupe une position d'avant-garde. (L.F. HABER : op. cit. p. 186). Comme on le voit, l'individuation des fonctions naturelles et sociales, et la transformation du contenu des classes sociales, vont de pair.

739 F. HARTUNG : Sociological foundations of modern science, Philos. of. Sc. 1947, 14, 68-95.

740 «A la différence des autres branches de la profession, qui sont nées des efforts faits pour répondre à des besoins pratiques, le génie électrique est le résultat d'une recherche menée pour trouver des applications et des emplois pratiques à des découvertes dont un grand nombre a son origine dans les sciences de la nature ». J.K. FINCH : The story of engineering, op. cit. p. 360.

741 P. DUNSHEATH : op. cit. p. 9. 
Jusqu'au XIX ${ }^{\mathrm{e}}$ siècle, l'ingénieur, le mécanicien, ont fondé, par un effort tenace et admirable, l'architecture moderne, la métallurgie, l'optique, l'industrie textile et celle des machines-outils, et les transports tels que nous les connaissons aujourd'hui, tels que, longtemps encore, ils feront partie de notre vie quotidienne, en témoignant de la puissance du génie de leurs inventeurs. Les découvertes ingénieuses, les appareils subtils et les machines motrices sont tous des résultats de cette mécanique qu'ils ont créée et qu'ils ont imposée au savant comme objet de réflexion. Toutefois, malgré le recours aux lois mathématiques et mécaniques, il ne s'agit pas, on le reconnaît couramment ${ }^{742}$, d'une industrie véritablement scientifique. De façon presque exclusive pendant cette période, tout le travail productif est basé sur l'habileté mécanique de l'ingénieur et l'intervention des sciences y demeure secondaire. Les synthèses chimiques d'abord, les découvertes de l'électromagnétisme ensuite, œuvres de la science, rompent avec les voies de la technique prédominante et préparent son remplacement.

La conséquence n'est est plus, comme par le passé, la transformation du savoir-faire de l'ingénieur en celui du savant - bien que celle-ci aussi puisse avoir lieu. Elle est d'un autre ordre. De nouvelles sciences naissent, les sciences appliquées. Ce sont là les "nouveaux arts », dont le caractère inventif, enraciné dans la philosophie expérimentale - et ensuite dans la science - a imposé la recherche. Le propre de ces sciences appliquées est de découler des sciences «pures », et non pas de l'accoutumance aux procédés de production. Leur extension dans tous les domaines provoque le dépérissement des techniques authentiques, c'est-à-dire des disciplines pratiques développées grâce à de tels procédés ${ }^{743}$. De plus en plus, la distinction qu'autrefois

742 « Ni l'industrie textile, ou charbonnière, ni les chemins de fer, ou la navigation, en tant que tels, ne dépendaient de la science, et ils n’ont pas contribué, de manière directe, son progrès (...) L'industrie mécanique, bien qu'elle soit davantage liée à la science que la fabrication du métal, est toujours restée largement en dehors des principaux mouvements scientifiques du $\mathrm{XIX}^{\mathrm{e}}$ siècle ». J.D. BERNAL : Science, industry and society in the 19th century, Centaurus, 1953, 3, p. 141 et p. 145.

743 «L'intervention de la science dans un art a l'avantage inappréciable de le détruire comme tel, c'est-à-dire dans ce qu'il y a d'individuel en lui ». J. v. LIEBIG : Le développement des idées dans les sciences naturelles, Paris, 1867, p. 40 
on voulait tranchée entre philosophie ou science, et technique, devient difficile à établir, sinon impossible. Le physicien américain Holton rappelle

« l'incapacité des intellectuels comme du public en général de trouver une différence fondamentale entre technique et science ${ }^{744}$.

Opinion assez répandue, à en juger par d'autres témoignages :

«Et aujourd'hui encore, note T. Kuhn ${ }^{745}$, une partie de nos difficultés à voir les différences entre la science et la technique doit se rapporter au fait que le progrès est une attitude manifeste dans les deux domaines ».

Certes, on se réclame, dans certains secteurs, de cette unité, pour décrier la science et la confondre avec une technique. La possibilité en est ouverte par l'ignorance où l'on se trouve du processus historique qui a conduit à la réduction de l'espace occupé par les techniques, sinon à son élimination au profit des démarches et des conceptions élaborées scientifiquement. Dans l'évolution de l'appareil productif, il s'agit d'un événement récent et qui est devenu manifeste dès l'instant où les installations machinales anciennes ont fait place à l'outillage électronique et aux substances créées chimiquement. Dans ce cadre, il devient difficile de considérer les ingénieurs comme une classe à part ou dans un contexte semblable à celui dans lequel étaient insérés les constructeurs de machines ou d'instruments mathématiques. Si, par analogie, on parle d'ingénieurs électroniciens et d'ingénieurs chimistes, la distance qui les sépare des scientifiques est d'un ordre différent et bien moindre que celle qui séparait l'ingénieur du philosophe mécanicien; et surtout, on reconnait en eux des scientifiques qui se consacrent à la science appliquée ou, suivant la terminologie moderne, au «développement» des connaissances scientifiques à des fins productives. Cela est vrai de leur formation aussi bien que de leur fonction ${ }^{746}$.

745

746

G. Holton : Introduction to the issue « Science and culture », Daedalus, 1965, 94, p. XX.

T.S. KUHN : op. cit., p. 160.

"Très souvent, en vérité, le même homme peut être à la fois "scientifique pur » et "ingénieur », lorsqu'il travaille aux différentes parties d'un problème unique. Nous ne croyons pas en une séparation artificielle entre la recherche fondamentale et la recherche appliquée ou en- 
Partant, cette communauté et ce rapprochement ont une portée double. D'une part est légitimé le rapport de la science pure à la science appliquée, de la discipline naturelle à la discipline productive, avec, pour corollaire, le dépérissement des techniques. D'autre part, le lien qu'ils révèlent se situe dans le cadre du processus d'invention, où chercheurs et ingénieurs scientifiques se conforment, ensemble, aux mêmes impératifs, aux mêmes principes. A la découverte qui résulte d'une amélioration et d'une recombinaison des instruments et des habiletés existant dans la production, ils substituent la découverte engendrée par la théorie et le laboratoire. Le mécanicien progressait en reproduisant successivement tous les arts sur le mode du mouvement machinal, et en les annexant, ainsi remaniés, à sa dextérité. Mais la science, elle, n'a pas pour moyen et pour but essentiel de reproduire les capacités d'une autre classe d'hommes. Au contraire, elle amplifie les capacités scientifiques, en transposant les propriétés d'un système matériel à un système matériel distinct, comme nous l'avons constaté à propos de la diversification des corps chimiques et du prolongement de la chaîne des éléments transuraniens. Les effets obtenus, à mesure qu'on avance dans cette voie, sont considérables, comparés à ceux de la technique des ingénieurs. Les répercussions d'une telle disproportion se sont fait rapidement sentir :

«La rénovation des transports par les ingénieurs et la mécanisation des processus traditionnels, surtout dans l'industrie textile, était chose à peu près achevée vers 1880. Par la suite, le rôle de l'ingénieur changea. Il perdit l'initiative, c'est-à-dire le pouvoir de donner naissance à de nouveaux concepts capables de transformer la société, mais devint toujours plus important à mesure que ses œuvres croissaient en taille. Les nouvelles idées révolutionnaires devaient venir à présent non des manipulateurs et empiristes, mais des zones plus élevées des mathématiques, de la physique, de la chimie et de l'électricité » ${ }^{747}$.

Le scientifique, nous en avons tous conscience, prend dans le processus de création du travail la place qui fut longtemps celle de l'ingénieur. A l'encontre de celui-ci, son activité ne s'oriente pas prin-

tre la science et l'activité de l'ingénieur ». Scientific progress and the federal government, Science, $1960, \mathrm{n}^{\circ}$ 532, p. 1804.

747 S.G. CHECKLAND : op. cit. p. 95. 
cipalement vers la conversion des habiletés existantes en habiletés propres â la machine. L'objet de son attention est, au contraire, la force matérielle elle-même, les rapports entre les forces. Plus exactement encore, le mécanicien part d'une relation donnée, d'un échange direct entre l'homme et l'instrument, qu'il s'efforce d'améliorer, d'aménager, et, finalement, de remplacer par un autre échange. Le scientifique a pour point de départ une relation entre les forces matérielles, par exemple entre la force mécanique et la force électrique ; son intervention crée d'autres relations ${ }^{748}$, provoque l'apparition d'autres forces matérielles, dans des conditions différentes; ainsi du chimiste qui découvre un équivalent synthétique des phénomènes organiques.

C'est pourquoi on peut affirmer que l'habileté de l'ingénieur, tout en ayant un contenu géométrico-mécanique, est en grande partie intuitive, tâtonnante, et dans la dépendance des contextes particuliers où elle s'exerce. La théorie des machines est née assez tardivement et sa forme n'a jamais été jugée satisfaisante. Le processus de production, tel qu'il est conçu par l'ingénieur, reste surtout axé sur le perfectionnement des moyens de production. Il trouve son programme dans l'éventail des métiers existants, et sa limite dans la force de travail de l'homme, les capacités nerveuses, sensorielles et musculaires de celuici. Pour le scientifique, le processus de production n'est qu'une autre forme du processus propre aux forces matérielles elles-mêmes. Ce sont elles qui se profilent directement à la base de la production, dont les branches particulières sont autant de versions différentes des mêmes principes généraux. Une fois définis, les procédés synthétiques peuvent être multipliés méthodiquement, tout comme le sont les procédés physiques dès qu'ils ont été reproduits à une échelle suffisamment petite et essayés au laboratoire. Si donc le scientifique répond aux demandes qu'on lui fait, la plupart du temps c'est lui qui provoque de telles demandes et suscite des besoins ${ }^{749}$.

748

«Alors que, jusqu'au tournant du siècle, la science et la théorie fondamentale s'occupaient dans une large mesure d'expliquer beaucoup de choses que les ingénieurs avaient faites en appliquant leur art et leur intuition, l'époque naissait où les découvertes des scientifiques seraient à l'origine de nouvelles théories qui prédiraient de nouveaux progrès encore à faire dans le génie ». G.S. Brown : New Horizons in engineering education, Daedalus, 1962, 91, p. 342.

749 «Les problèmes posés aux savants sont la plupart du temps ceux qu'ils ont eux-mêmes choisis. Par exemple ce n'est pas notre Département de la Défense (aux États-Unis) qui a décidé 
A cet égard, il devient, à la place de l'ingénieur, le symbole du groupe "porteur d'invention », incluant et transformant l'ingénieur dans un cadre où il n'est plus qu'un élément dont l'importance diminue ${ }^{750}$, tandis que l'invention acquiert un sens nouveau et que le savant reçoit une prééminence ${ }^{751}$ incontestable.

«A présent, le spécialiste a évincé l'inventeur, et dans de nombreuses industries il a évincé l'artisan, car il a transformé l'invention et l'artisanat en sciences exactes $\gg{ }^{752}$.

Cette part grandissante accordée à la science et au savant, cette mise en place des structures de la science appliquée là où étaient seules à l'œuvre les structures techniques, est chose récente : bien qu'elle se soit amorcée au siècle dernier, elle n'a été effective que dans le nôtre. Mais la signification particulière de cette mise en place ne vient pas de ce qu'elle consacre une catégorie naturelle, ni de ce qu'elle transforme notre vie quotidienne, ou bouleverse la production. Elle se rattache au fait qu'avec la pénétration et la reconnaissance positive de la science, l'activité proprement inventive — recherche et découverte - n'est plus le simple complément d'autres activités ou d'autres facultés ; elle s'affirme dans son indépendance et dans sa puissance, $a c$ quérant le statut du travail.

un jour qu'il voulait une bombe atomique, et a demandé ensuite aux savants d'es faire une. $\mathrm{Au}$ contraire, c'est Albert Einstein, l'homme de science, qui a dit à Franklin D. Roosevelt, l'homme de décision, qu'une bombe de ce genre était possible. Aujourd'hui plus que jamais, les savants sont aux côtés de ceux qui prennent des décisions, et ils font en sorte que les problèmes soient formulés de façon que les solutions scientifiques soient possibles ». A. RAPAPORT : Bon et mauvais usage de la théorie des jeux, Les Temps Modernes, 1963, 19, p. 681 .

750 « Autrefois ce gâteau (des investissements) était découpé au profit de l'ingénieur. La portion de la science augmente maintenant à mesure que celle de l'ingénieur diminue (...) Bref, le génie a été relégué à rôle subalterne dans l'estime publique». Scientific Manpower, Natural science foundation, Washington, 1961, p. 27 et p. 29.

«Dans la phase néotechnique, les principales initiatives viennent, non de l'ingénieur inventeur, mais du savant qui établit la loi générale. » L. MUMFORD : Technique et civilisation, Paris, 1950, p. 199.

751 D.J. De Solla Price : Science since Babylon, ed. cit. p. 122.

752 E.A. AshBy, in C. SINGER : A History of Technology, t. IV, ed. cit. p. 797. 
Avec la science et le scientifique qui donnent à l'assise matérielle de notre société ses dimensions et son contenu, le travail humain tend à se transformer en travail inventif. 


\section{La progression naturelle}

$\underline{\text { Retour à la Table des Matières }}$

\section{Les sciences institutionnalisées et leur reproduction.}

La création de cette forme du travail, de son contenu particulier, met les hommes de science en face des problèmes communs à toutes les catégories naturelles : organiser leurs disciplines, assurer la reproduction des facultés indispensables à cet effet. Le premier pas dans cette direction s'est concrétisé dans l'institution d'innombrables « sociétés » et d'organes destinés à accroître les échanges, à témoigner de la priorité des découvertes. Ainsi est né le sentiment d'appartenance à une collectivité consciente de ses fins et en possession de ses moyens. Le mouvement scientifique car il faut bien parler d'un mouvement, au sens strict du terme, avant de parler de la science - a reçu une force accrue lorsque la «Société Helvétique des Sciences Naturelles » a fait son apparition, en 1815, suivie, en 1822, par la " Gesellschaft deutscher Naturforscher und Ärzte ». En Grande-Bretagne, pour pallier les déficiences de la Royal Society et lutter contre ses principes, la «British Association for the Advancement of Science » (1831) ${ }^{753}$ s'associe pleinement aux initiatives prises ailleurs.

«Le but initial de ces sociétés, note R. Taton ${ }^{754}$, était de confronter, au cours de larges débats publics, les progrès les plus récents des différentes disciplines scientifiques, afin de mettre en lumière leurs interférences réciproques, et d'en tirer d'utiles renseignements sur l'utilisation des recherches ».

Ces échanges et les stimulations qu'on en attend complètent le tableau d'une volonté de capter l'attention et d'obtenir, avec la reconnaissance du corps social, son intéressement matériel à l'entreprise scientifique. Les disponibilités des amateurs individuels étaient variables, et, en tout cas, limitées. Les possibilités ouvertes dans chaque

O.J.R. HoRwath : The British Association for the Advancement of Science, 1831-1931, Londres, 1931.

754 R. TATON : op. cit. p .618. 
domaine exigeaient, pour se développer, un soutien constant. L'indifférence du milieu social général était un obstacle très net au recrutement de nouveaux talents, à l'élargissement du cercle des personnes disposées à s'engager dans une voie dont l'issue n'était pas encore visible.

«En Angleterre, écrivait Babbage ${ }^{755}$, ceux qui se sont jusqu'ici adonnés à la science n'ont en général pas de motifs raisonnables de se plaindre : ils savaient, ou auraient dû savoir, qu'elle n'était pas du tout demandée, qu'elle conduisait à peu d'honneurs, à moins encore de bénéfices ».

Une question qui soulevait tout autant de préoccupations était la question pédagogique, compte tenu du caractère de ces disciplines. Elles ne pouvaient guère s'apprendre uniquement à l'atelier ou au laboratoire; et l'acquisition des notions purement théoriques supposait l'assimilation d'une culture mathématique et physique poussée. Les facultés de médecine offraient un moyen convenable de reproduire les connaissances indispensables au scientifique, au chimiste essentiellement. La plupart des universités lui étaient fermées ${ }^{756}$, non seulement parce qu'elles se désintéressaient de telles matières, mais surtout parce que leur fonction première était de fournir des clercs religieux ou laïques ${ }^{757}$. Les quelques institutions techniques réservées à la formation des ingénieurs pouvaient constituer un palliatif, mais non une solution véritable ${ }^{758}$.

La France fut, sans conteste, le premier pays à constituer un centre et un enseignement scientifiques ${ }^{759}$ dont le Muséum d'Histoire Naturelle fut le noyau. L'École Polytechnique ${ }^{760}$, fondation napoléo-

C. BABBAGE : Reflections on the decline of science in England, Londres, 1830, p. 23. comme de leur devoir de conserver et de transmettre l'éducation libérale traditionnelle, fondée sur la littérature classique et la philosophie naturelle de Newton ». D.S.L. CARDWELL, in A. CROMBIE : Scientific change, op. cit. p. 662.

760 «École polytechnique et Muséum furent les premiers instituts scientifiques modernes ». M. DAUMAS : op. cit. p. 150. 
nienne, organisa la recherche et l'enseignement dans le domaine des sciences et les orienta vers des applications civiles et militaires.

« Cet établissement, écrit J.B. Biot ${ }^{761}$, avait un triple but : former des ingénieurs pour les différents services, répandre dans la société civile des hommes éclairés, exciter les talents qui pourraient avancer les sciences ».

Dans ce dernier but, on installe des laboratoires, on récompense les découvertes, et bientôt toute l'Europe y trouve son modèle ${ }^{762}$. On vient à Paris chercher l'inspiration, et les Allemands surtout en tirent grand profit. Le plus grand profit, peut-on dire, car ce sont eux qui parachèvent l'organisation de la recherche et de la pédagogie scientifiques. Hors du cadre de la médecine et des écoles d'ingénieurs ${ }^{763}$, des instituts consacrés à la physique et à la chimie et des laboratoires voient le jour. Le plus célèbre et le plus exemplaire fut celui de Liebig à Giessen (1825), imité à Marburg (1840) et Leipzig (1843 et 1868). Une séparation stricte des sciences donne à leur spécialisation un caractère de rigueur et un gage d'efficacité. La régularité des publications, la compilation des résultats et des documents, un souci de compétence ne fût-ce que dans un domaine restreint — sont les traits qui donnent à ces universités leur physionomie.

Mais quelles luttes n'a-t-on pas menées, de quelle clairvoyance n'a-t-il pas fallu témoigner, pour faire accepter la place de la science, imposer, pour ses adeptes et ses praticiens, le besoin d'une préparation théorique, intellectuelle, égale en importance à celle des philosophes et des humanistes, pour briser les résistances de ceux-ci, vaincre l'inertie des académies décadentes ${ }^{764}$, et aussi démontrer qu'on ne saurait abandonner la formation de ce nouveau groupe aux soins des techniciens, à qui cette préparation fait précisément défaut ${ }^{765}$. Il fallait donc créer quelque chose, et ce fut fait. Les sciences, grâce à la diffu-

\footnotetext{
761 J.B. BIOT : Essai sur l'histoire générale des sciences, Paris, 1802, p. 59.

762 G. PINET: Histoire de l'Ecole Polytechnique, Paris, 1877.

763 L.F. HABER : op. cit. p. 25.

764 F. SCHNABER : op. cit. p. 129.

765 idem, p. 332.
} 
sion de leurs découvertes ${ }^{766}$, à l'influence qu'elles commencent à exercer sur l'industrie, modifient profondément la carte du système éducatif, et, loin de chercher à rétablir une unité perdue pour certains, inexistante pour d'autres, accentuent la disparité :

«Sans doute semble-t-il actuellement, écrit Helmholtz ${ }^{767}$, que les rapports réciproques de toutes les sciences, qui nous font les unir sous le nom d'Universitas litterarum, soient devenus plus lâches que jamais ».

Cette marche solitaire, cet isolement ${ }^{768}$ à l'intérieur des institutions universitaires, est la rançon des oppositions antérieures à y accepter les disciplines naturelles ou techniques. Une incompatibilité profonde entre les principes qui guident le développement des connaissances sur la voie de l'invention et le mode d'obtention des aptitudes requises s'y ajoute. La signification de ce changement, de cette organisation des sciences dont les savants allemands furent les pionniers les plus assidus ${ }^{769}$ et les réalisateurs les plus efficaces, ne tarda pas à s'imposer à l'attention du monde. Tout d'abord par une productivité intellectuelle accrue. Ensuite par l'impulsion sans cesse croissante donnée à l'industrie qui y avait recours, et qui justifiait le nombre grandissant d'étudiants désireux d'acquérir un savoir scientifique. Lorsque ce développement se répercuta sur le plan de la lutte pour la conquête des marchés, on reconnut, non sans difficulté, que la bataille économique et politique se gagnait dans les universités ${ }^{770}$. La nécessité de s'inspirer du modèle que les savants avaient instauré en Allemagne s'imposait ${ }^{771}$. Les comparaisons auxquelles on procéda nous renseignent suffisamment sur les caractères, présumés nouveaux, que l'on attribuait à la science et aux scientifiques. Le premier, et le plus que j'appartiens moi-même au cercle des sciences de la nature, et que, à une époque récente, on a précisément accusé le plus fortement les sciences de la nature de s'être engagées sur un chemin isolé et d'être devenues étrangères au reste des sciences qui sont liées entre elles par des études philologiques et historiques communes ». H. HELMHOLTZ : op. cit. p. 6.

769

770

H. HeLmHoltz : Populäre wissenschaftliche Vorträge, ed. cit. t. I, p. 139.

idem, p. 3.

J. von LIEBIG : Lettres sur la chimie, Paris, 1845, p. 28.

E.S. ASHBY : op. cit. t. IV, p. 776.

H. HAUSER: Les méthodes allemandes d'expansion scientifique, Paris, 1917 ; M. ARNOLD : Schools and universities on the continent, Londres, 1868, p. 232. 
évident, est le remplacement des méthodes traditionnelles de formation des capacités de travail, par transmission directe d'un individu à l'autre, dans le cadre de production lui-même. L'apprentissage, tel qu'il est de règle pour les techniciens, paraît lui aussi insuffisant, et c'est bien à un enseignement plus général, à une formation intellectuelle prolongée, qu'il faut soumettre les individus si l'on veut qu'ils soient capables d'assimiler et d'employer les connaissances scientifiques. L'éducation autrefois réservée à ceux qui se destinaient aux professions libérales, et qui ne semblait pas s'adresser aux hommes appelés à constituer l'armée du travail, à manier les instruments matériels de la vie pratique, devient une nécessité pour tous ${ }^{772}$.

L'instruction dont il s'agit ne doit pas se limiter à l'acquisition des dispositions permettant uniquement de reprendre les techniques connues et de faire fonctionner l'appareil productif tel qu'il s'est constitué à un certain moment. Elle doit aussi et surtout rendre les individus capables de faire des travaux originaux, donc se poursuivre jusqu'à un stade avancé. Une commission anglaise le souligne expressément :

«L'Anglais est habitué à chercher un profit immédiat et doit encore apprendre qu'une éducation prolongée et systématique jusques et y compris la méthode de recherche originale, est maintenant une condition préalable nécessaire au plein développement de l'industrie $\gg{ }^{773}$.

Le deuxième caractère nouveau que l'on reconnaît lié à la science est la professionnalisation des savants. Il est certain que, même avant cette époque, la pratique de la philosophie expérimentale assurait, à un groupe restreint, des moyens d'existence précaires ${ }^{774}$, souvent complétés par l'exercice de la médecine ou d'un autre métier, ou l'apport d'une fortune personnelle. Toutefois ces hommes n'étaient ni rémunérés ni estimés en tant que chimistes ou physiciens, et ne jouissaient d'aucun des avantages qui s'attachent à la pratique d'une discipline

\footnotetext{
772 P. Magnus : Industrial education, Londres, 1888, p. 15.

773 D.S.L. CARDWELL : op. cit. p. 4.

774 G. HAINES : German influence upon English education, Londres, 1957, p. 11.
} 
déterminée ${ }^{775}$. Le système introduit dans les universités allemandes faisait voir que le pas avait été franchi, et que l'idéal prôné par les précurseurs du mouvement scientifique pouvait se réaliser, à savoir que la mise en valeur d'une connaissance particulière, dans ce domaine, pouvait assurer à celui qui la possédait un moyen de subsistance, une fonction économique et des conditions de travail confortables. Au moment où le grand Maxwell écrivait que

«bon nombre d'efforts seraient nécessaires avant que la physique expérimentale morde sur notre système universitaire qui est si continu et si complet sans elle»,

se généralise la conscience que l'on prend de l'importance de la découverte organisée en vue de l'avancement des disciplines naturelles et du rôle de la connaissance dans les progrès de l'industrie. La production de ces spécialistes commence à devenir, on l'a vu, une préoccupation partagée par toutes les nations, et des débouchés leur sont assurés, dans leur propre spécialité, tant dans le cadre des laboratoires académiques que dans les entreprises industrielles.

Il en résulte non seulement la constitution d'un esprit de corps mais aussi une définition claire - bien que rigide - des qualités qui font le savant, pour le distinguer de ceux qui s'arrogent ce titre sans y avoir droit, et qui peuvent le faire, tant que ne se dégage pas un consensus socialement sanctionné. En même temps, si chaque individu trouve sa place dans ce corps ordonné qui a une fin commune, les talents nécessaires peuvent être mieux distribués et les activités subdivisées, de manière à approfondir et cultiver un champ déterminé. Tel était le but que l'on visait et que l'on atteignit ${ }^{776}$.

En contrepartie, grâce à cette répartition méthodique des tâches et des sujets à travers les sciences, non seulement celles-ci se multi-

775

«En Angleterre, la science n’est pas une profession. Ceux qui la cultivent ne sont guère reconnus en tant que classe ». " La pratique de la science ne constitue pas, en Angleterre, une profession distincte, comme c'est le cas en maint autre pays. Elle est donc, pour cette seule raison, dépourvue des avantages qui s'attachent aux professions libérales ». C. BABBAGE : op. cit. p. 8 et p. 10.

776 P. SCHNABER : op. cit. p. 129. 
plient, mais l'entreprise devient de plus en plus collective; quoique des individus puissent continuer à travailler de façon isolée, la coopération s'instaure progressivement et s'impose à la plupart des scientifiques comme une nécessité. II est dès lors inévitable que la quête intellectuelle, l'ingéniosité expérimentale, au lieu de se manifester en tant qu'opérations inspirées et exceptionnelles, soient assimilées à un travail, au travail. La professionnalisation l'exige, la coopération le suppose.

La reproduction des facultés scientifiques assurée, la science devenue une profession ${ }^{777}$, tel est, à travers bien des vicissitudes, l'acquis du siècle dernier, que, depuis, nous n'avons cessé d'amplifier et d'approfondir. Mais quel est le sens de ce qui est reproduit, et celui de la profession elle-même? Il s'agit essentiellement du rôle qu'y jouent l'invention et la recherche ${ }^{778}$.

Retour à la Table des Matières

\section{Le travail inventif.}

En effet, si telle est bien la portée de ce résultat, l'important n'est pas que les sciences aient été enseignées et que les scientifiques aient pu accéder à la dignité universitaire d'enseignants, mais que l'activité inventive soit devenue régulière et qu'elle ait été reconnue dans sa particularité. On a pu douter que la découverte puisse faire l'objet d'une spécialité autonome :

«Poursuivre des idées ou des choses nouvelles ne sera jamais une profession régulière ni lucrative ${ }^{779}$.

777 « La professionnalisation de la science fut l'œuvre de nombreuses forces, les unes internes à la science et lentes à venir au jour, les autres s'exerçant beaucoup plus nettement dans la société en général. » E. MENDELSOHN : The emergence of science as a profession in nineteenth century Europe, in K. HILL (ed). The management of scientists, Boston, 1963, p. 40.

778 «Lorsque la recherche scientifique devint une profession distincte, le processus de découverte fut considérablement accéléré ». J. BEN DAVID : Roles and invention in medicine, Amer. J. of Sociol. 1960, 6, p. 557.

779 A. de CANDOLLE : op. cit. p. 92. 
Elle l'est pourtant devenue ${ }^{780}$. Et ceci avec d'autant plus de vigueur que transformer la science en une institution signifiait avant tout transformer l'invention en une institution. Vouloir réduire le rôle du scientifique à celui d'un éducateur, la science à une discipline reproduisant uniquement des savoirs, serait prendre une attitude contraire à leur essence et les conduire à une décadence certaine. Non seulement la vie des sciences ne se conçoit pas sans celle des laboratoires, coupée de la recherche inventive, mais cette recherche même, dès le XIX ${ }^{\mathrm{e}}$ siècle, et actuellement avec une intensité accrue, tend à se muer en une activité séparée, une occupation ayant sa propre fin. Elle n'est plus le résultat accessoire, accidentel, de la reproduction naturelle des talents, de l'éducation, comme "par le passé », lorsque « les adjonctions faites à la connaissance étaient surtout le sous-produit du système éducatif ${ }^{781}$.

Acceptée pour telle, au lieu d'être diffuse et discontinue, l'invention ou la recherche - est devenue l'emploi stable et permanent de millions de personnes ${ }^{782}$. Si toutes les autres activités humaines doublent tous les quarante ans, celle de la science double tous les dix ou quinze ans. La «petite science » cultivée dans un nombre restreint de centres isolés est devenue la $"$ grande science ${ }^{783}$ dont les résultats, au lieu d'être enregistrés par 300 journaux ou revues spécialisés (leur nombre en 1830) sont publiés par environ 100000 périodiques.

Ceci montre bien qu'au lieu de se poursuivre de manière accidentelle elle obéit à des programmes, se fixe des buts ${ }^{784}$ et prévoit, avec

780

Dans ces conditions, si la recherche demeure une vocation pour certains, elle est devenue un métier pour le plus grand nombre ». P. PIgAniol, L. VILleCOURT : Pour une politique scientifique, Paris, 1963, p. 13.

781 «Supprimez les laboratoires, les sciences physiques deviendront l'image de la stérilité et de la mort. Elles ne seront que des sciences d'enseignement, limitées et impuissantes, et non des sciences de progrès et d'avenir ». L. PASTEUR, Le budget de la science, Paris, 1868, p. 1.

782

VILLARD : Competition, oligopoly and research, Jour. of Pol. Econ. 1958, 66, p. 487. V. KOURGANOFF : La recherche scientifique, Paris, 1958 ; Scientific and technical personnel in American industry, Washington, 1959.

783 D.J. de Solla Price : Little Science, Big Science, New-York, 1963.

784 A.H. WeInBerg : Impact of large-scale science in the United States, Science, 1965, 134, pp. 161-64 ; K. GALKIN : The training of scientists in the Soviet Union, Moscou, 1959. 
quelque certitude, leur aboutissement. Des indices objectifs de son efficacité tendent à s'élaborer : ainsi le nombre de publications, leur degré de signification et d'influence, leur espérance de vie, avant qu'elles soient dépassées ou assimilées par d'autres ${ }^{785}$, etc.

Elle est également un processus collectif organisé, réunissant un grand nombre d'individus et disposant d'un système de communications international par les canaux duquel circule un nombre croissant d'informations et de découvertes. Les efforts se concentrent, se partagent et se corroborent, et les problèmes soulevés sont attaqués par des voies dont on a dessiné et discuté le tracé. Non que l'invention individuelle ait disparu, mais elle se trouve intégrée dans un courant d'incitations et d'échanges qui contraste avec l'éparpillement caractéristique de l'invention aux siècles passés. Sous cet angle, et parce qu'elles ont acquis une position prédominante - en 1960, $15 \%$ seulement des savants américains étaient surtout enseignants ${ }^{786}$ - la science et la découverte scientifique sont reconnues comme des formes du travail, organisées comme n'importe quel autre travail, et les hommes qui s'y adonnent considérés comme des travailleurs, une « main-d'œuvre scientifique »:

«C'est justement pour ces travaux (de recherche) qu'il faut de la maind'œuvre scientifique, qu'il faut des laboratoires modernes et bien outillés, des moyens puissants »,

disait-on déjà en $1917^{787}$, et l'expression, née bien avant, n'a cessé depuis de se répandre. Alors qu'elle aurait paru, il y a un siècle à peine, insultante et scandaleuse, tant les notions de labeur productif et de labeur tout court étaient confondues, tant l'identification du savant au travailleur choquait, elle est entrée dans les mœurs. Elle annonce, assurément, un déplacement des valeurs sociales, auquel les doctrines socialistes ne sont pas étrangères. Mais tout ceci s'accomplit sur un arrière-plan objectif, à savoir qu'il s'est constitué un travail qui a pour contenu la science pure ou appliquée et pour but l'invention, tout

785 WEISS : Knowledge : a growth process, Science, 1960, 131, pp. 1716-19.

786

787 
comme l'autre avait pour but la production ; qu'une partie considérable des forces physiques et intellectuelles humaines y est employée, et que la répartition du travail, qui atteint un volume important, s'opère, socialement et économiquement, entre ces deux formes.

Bien plus, si la nouvelle forme du travail, si l'invention n'est pas un sous-produit de l'éducation, un à-côté de la fonction enseignante, et en cela aussi le scientifique se distingue du philosophe - elle n'est pas non plus, comme ce fut le cas pour l'ingénieur, un sous-produit de l'insertion dans l'appareil industriel, un à-côté de l'activité productive.

$\mathrm{Au}$ contraire, en devenant la base matérielle de cette dernière ${ }^{788}$, l'invention, cessant d'être une partie de la technique dans le cadre de l'atelier pour se muer en invention des sciences appliquées, se sépare également de l'industrie et se transforme en une branche autonome qui a pour objet la création des savoirs, avec ses normes, son équipement humain et matériel :

«La partie de la recherche technique qui peut être accomplie en vue d'un bénéfice devrait être considérée comme une industrie - l'industrie de la découverte. Son produit est la connaissance $\gg{ }^{789}$.

Le travail qui est absorbé par cette « industrie » est par définition un travail non productif ${ }^{790}$. La part relative de ceux qui l'exercent s'accroît régulièrement ${ }^{791}$, tandis que la part des travailleurs directement productifs décroît, du moins dans les pays qui disposent des moyens industriels les plus puissants.

On observe ainsi que la population des hommes dont le travail est directement lié à la découverte et dont le produit est la connaissance,

788 cherche dans l'entreprise, Paris, $1960 ;$ Y. BROZEN : Automation : the impact of technological change, Washington, 1963 ; C. BETTELHEIM : Bilan de l'économie française 1914-46, Paris, 1947. S.H. SCHLICHTER : The industry of discovery, Science, 5958, 128, p. 161.

F. MACHLUP : The production and distribution of knowledge in the United States, Princeton, 1962, p. 6.

791 U.S. Department of Labor, Bull. N 1949, Dec. 1959, p. 41. 
est suffisamment grande pour marquer un tournant, une transformation dans la composition des travaux spécifiquement humains. Tant que ce travail se confondait avec l'éducation ou avec la production, tant qu'il était rejeté à la périphérie de cette dernière, on ne pouvait s'attendre qu'il devînt un secteur déterminé de la vie des sociétés, une composante essentielle des tâches humaines. De même que l'homme a été un usager d'outils avant de devenir un fabricant d'outils, de même on peut dire qu'il a été un usager d'invention avant de devenir un producteur d'invention. Telle est la portée qu'a eue le passage de l'ingénieur au scientifique, de la technique à la science appliquée, de l'industrie mécanique à l'industrie scientifique.

Il faut aussi préciser de quelle industrie il s'agit, à savoir, celle de la découverte. Mais elle l'est devenue en réunissant ce qui était autrefois séparé et éparpillé, c'est-à-dire l'invention qui naît de la théorie et de l'expérience propre aux disciplines naturelles, et celle qui naît de la pratique, pour les faire apparaitre comme les deux faces d'un processus commun: la recherche fondamentale et la recherche appliquée. Les perspectives qui s'ouvrent devant celle-ci ${ }^{792}$ montrent bien qu'il s'agit d'un secteur où,

« selon l'opinion du Pr. John Bernal, dans le cours du siècle, il se peut que $20 \%$ de la population soient directement ou indirectement engagés dans un travail scientifique d'une espèce ou d'une autre. L'académicien Sempronov a exprimé la conception selon laquelle, à l'avenir, une moitié de l'humanité participera à un travail scientifique d'une espèce ou d'une autre $»{ }^{793}$.

C'est-à-dire participera, en l'occurrence, à un travail qui s'individualise : le travail inventif.

$\underline{\text { Retour à la Table des Matières }}$

3. La matérialisation des savoir-faire.

792 A.G. Korol : Soviet education for science and technology, M. I. T. 1957 ; American science manpower (1955-58) National Science Foundation, Washington, 1958.

793 Role of science in modern society, World marxist Review, 1963, 6, p. 39. 
Cette individualisation n'est pas le seul résultat notable: les facultés mises en œuvre se transforment également. Parmi les traits marquants de cette transformation, il faut en retenir trois, qui cernent un phénomène unique, la matérialisation des savoir-faire et du travail.

Le premier trait est la disparition quasi certaine de la force de travail, de la pure dépense d'énergie humaine, et des qualités de nos sens en tant qu'éléments de la force matérielle qui ont fait de l'homme, pendant des millénaires, une annexe d'autres forces matérielles. Le résultat atteint par la mécanisation a acquis d'autres dimensions et pris d'autres aspects avec l'application des sciences. En effet, il ne s'agit pas seulement du fait que notre force physique peut être remplacée par d'autres forces physiques : celles-ci, à leur tour, deviennent capables d'exercer des fonctions et d'accomplir des travaux plus raffinés, bref d'exécuter des opérations équivalentes de celles que nous exécutons. L'emploi des calculatrices électroniques a montré qu'il était possible de concevoir des appareils capables d' " apprendre », et de « se corriger » eux-mêmes. Ceci permet d'accroître grandement l'efficacité opérationnelle de la machine traitant les informations. Par exemple, s'il s'agit d'informations concernant la chimie, la machine peut élaborer des réponses indiquant les voies de synthèse d'un composé chimique qui ne figuraient pas dans la littérature chimique; les résultats d'une vérification expérimentale du modèle de synthèse proposé par la machine sont alors introduits dans la mémoire de celle-ci. On a la possibilité de corriger automatiquement les données enregistrées dans cette mémoire, relatives aux conditions d'utilisation de chaque type de réaction prévu par le programme en cours. Cela signifie que les réponses aux questions élaborées par la machine sont de plus en plus dignes de confiance.

On voit bien comment se modifient nos rapports avec les forces matérielles, puisque notre travail s'applique dans une mesure croissante à des opérations semblables aux nôtres, ce qui le généralise dans un tout autre sens que le sens purement physique. Ces relations, cessant d'être des relations de complémentarité - comme celles de l'outil et de la main — ou de substitution - comme celles de la machine et de l'habileté - deviennent des relations de spécialisation, où s'instaure une certaine autonomie entre les diverses forces matérielles, 
y compris la nôtre. Ainsi, avec la découverte des phénomènes d'ordre chimique, où les conditions de pression, de vitesse, de température sont de moins en moins compatibles avec notre présence et notre action, il faut concevoir des systèmes matériels adéquats où l'habileté et le sens humains ne peuvent être considérés ni comme adjuvants, ni comme modèles :

«L'extension des recherches et de leurs applications dans les domaines de plus en plus éloignés de l'expérience humaine courante a conduit nécessairement à confier la conduite des appareils à des mécanismes ne dépendant pas directement de l'homme, qu'il s'agisse d'instruments de mesure ou de machines destinées à la production industrielle ${ }^{794}$.

On ne peut donc plus parler d'artifices. La différence accusée et l'antagonisme dénoncé subsistaient tant que les parties de l'appareil productif fonctionnaient en se combinant avec les nerfs et les muscles humains, tant que leur vocation essentielle était de suppléer aux déficiences des sens et de l'énergie de l'homme, et de leur fournir du renfort. Maintenant, ils commencent à se regrouper en systèmes indépendants, complets en eux-mêmes. La conséquence nécessaire en est que les facultés, le savoir-faire, pouvant être attachés à n'importe quelle force matérielle, il est possible de les répartir aussi bien entre les seuls hommes qu'entre l'espèce humaine et les autres espèces matérielles convenablement définies.

«A la racine de cette transformation, dont on ne saurait exagérer l'importance pour la pensée humaine, écrit P. Naville ${ }^{795}$, il y a l'extension du principe d'autonomie, au monde des artefacts, des structures techniques quelles qu'elles soient. C'est un principe qui va nous contraindre à réviser les divisions traditionnelles de l'économie, à réformer notre code d'interprétation des grandes branches de l'activité humaine ».

Dans ce sens, le travail s'universalise. Il peut en effet se fixer à toute force matérielle ; par là il est aussi le médiateur entre les systèmes matériels, et leur initiateur. Il peut transférer les propriétés d'un système à un autre, et, ce faisant, transformer ses qualités. En d'autres 
termes, il n'apparaît plus sous sa forme générale, comme négation de sa forme humaine, comme cristallisation objective d'une réalité subjective, mais comme une suite de variantes qui ont chacune son lieu propre de concrétisation, tantôt en un agent humain, tantôt en un agent non-humain.

Le second trait est l'institution explicite du travail comme produit, comme son propre produit. Ceci se manifeste dès l'instant où l'on établit une industrie qui a pour fin la connaissance. En effet, sa présence indique que nos talents peuvent être élaborés méthodiquement, devenir l'objet direct d'une recherche et d'une prévision des formes auxquelles ils peuvent prétendre. Elle démontre également que le besoin de savoir-faire prend la place jusqu'alors occupée par le besoin de telle ou telle matière; les facultés humaines sont ainsi reconnues comme une ressource essentielle. On continue, certes, à recenser les machines, l'énergie motrice, les " esclaves mécaniques », parmi les possessions les plus enviables ; toutefois ce n'est là qu'une apparence. La réalité est tout autre. Par le développement constant des disciplines scientifiques, des capacités qui les accompagnent et des hommes qui se les approprient, on est à même de se procurer et d'engendrer les ressources dont on affirme la nécessité. Si tel ou tel matériau fait défaut, on peut orienter le processus de création des savoirs de manière à l'obtenir à partir des matériaux existants. Par exemple, comme il est possible d'obtenir des aliments à partir du pétrole, pourquoi ne verrait-on pas des pays à agriculture pauvre, mais riches en pétrole, nourrir leur population en cultivant - le terme est approprié - les capacités chimiques nécessaires?

Bref, des solutions s'esquissent à partir du moment où l'on recherche ou fournit les facultés humaines en tant que ressources inventives :

« Si, pour un problème de cette importance, on déclare au monde scientifique qu'il existe une solution, les capacités intellectuelles des savants et les moyens actuels des laboratoires sont si largement répartis que la réalisation 
quasi indépendante de ce travail ne sera que l'affaire de quelques années, n'importe où dans le monde » ${ }^{796}$.

L'essentiel n'est donc pas la possession de telle ou telle matière première, mais la possession des facultés indispensables pour en engendrer d'autres, ce qu'on appelle la «puissance cérébrale ». Cela ne signifie point que les autres ressources soient devenues négligeables ; cependant, historiquement, le travail n'est plus seulement le médiateur qui permet à l'homme d'agir, il est devenu le levier direct à l'aide duquel on agit et sur lequel il faut agir.

Le troisième trait se rapporte au mode d'objectivation des facultés. Il est évident que, jusqu'à une date récente, la plupart de celles-ci étaient « enregistrées » par des mécanismes surtout organiques supposant le concours massif de nos muscles, de nos sens, concomitants d'une capacité mnémonique à prédominance biologique. Nombre de renseignements étaient inscrits dans le paysage, dans l'ordre des outils, dans la disposition des substances végétales, animales ou minérales, dans le relief et bien d'autres œuvres. Cette situation était plus marquée encore au début de la carrière productive de notre espèce, et l'anthropologue anglais Leach affirme que

« ce qu'apprend l'aborigène d'Australie est emmagasiné «là-dedans » dans les modèles factuels du milieu ambiant, tout comme ce que nous apprenons est emmagasiné « là-dehors » dans les modèles symboliques des livres imprimés et des bandes pour calculatrices électroniques ${ }^{797}$.

Le contraste atteint sa pleine signification de nos jours où l'information demeure de moins en moins fréquemment imprimée dans des objets pour se muer de plus en plus souvent en un objet même. Dans les grandes calculatrices, ayant des mémoires étendues et fidèles, des portions importantes d'une science peuvent être entreposées. On a conçu des techniques d'enregistrement pour fixer le contenu de centaines de milliers d'articles et les organiser suivant leur em-

\footnotetext{
796 N. WIENER : Cybernétique et société, Paris, 1952, p. 155.

797 E.R. LEACH : Culture and social cohesion, An anthropologist's view, Daedalus, 1965, 94, p. 37.
} 
ploi. Dans les livres et les périodiques qui exposent consciencieusement et rigoureusement les procédés les plus routiniers comme les plus surprenants, une grande partie du savoir-faire apparait dans son individualité comme produit de l'homme, et non pas comme partie de l'homme et de son milieu. Partant, en tant qu'unité, et en tant qu'elles sont codifiées et saisies comme science pure ou appliquée, les facultés de travail apparaissent objectivement sans référence immédiate au corrélat biologique d'un groupe particulier d'individus qui les possèdent à un moment donné et se les transmettent directement. Ceci veut dire que le travail se définit explicitement comme une organisation autonome de nos capacités, à la fois présentes et passées, celles d'Archimède, de Watt, de l'artisan polynésien, de l'ingénieur de la Renaissance ou du savant d'aujourd'hui — et l'analyse des documents le montre bien.

Cette transposition de nos facultés dans des archives somme toute maniables ouvre la voie à des combinaisons multiples, à des rapprochements rapides de savoirs, et à la découverte de solutions qui, sans cela, auraient dû attendre des migrations ou des accidents démographiques, la rencontre problématique entre les groupes porteurs des diverses dextérités accumulées. Processus forcément long et aléatoire.

La conséquence de cette situation nouvelle est que nos facultés se matérialisent dans des codes et des documents, indépendamment des hommes auxquels elles s'attachent, de leur répartition dans l'espace et dans le temps, et peuvent être traitées de manière à se croiser, s'articuler, et à donner naissance à d'autres facultés.

On a donc raison de parler de la «Produktivkraft (force de production) matérialisée dans les documents de la science et les ouvrages de la technique ${ }^{798}$. Les limites de notre constitution, notre mémoire individuelle et nos monuments techniques habituels sont ainsi à la fois exprimés et transcendés par l'immense corps du savoir scientifique et technique qui se présente comme un champ où l'activité ordinatrice et créatrice des hommes peut s'exercer sans tenir compte des rapports subjectifs. La génération de nouvelles connaissances, donc implicite- 
ment d'un nouveau travail, n'a plus un autre organisme humain pour instrument et appui, elle a trait uniquement à cette connaissance ellemême et à la force matérielle qui lui est adjointe. L'artisan qui acquiert, modifie, transfère l'habileté reprend celle de l'agriculteur, inscrite dans ses bras et son cerveau. Le savant qui transplante dans le domaine de la physique un savoir mécanique ne s'inspire pas des empreintes laissées par le mécanisme dans les bras et le cerveau de l'ingénieur mécanicien : il part des lois qui ont été concrétisées dans une discipline autonome. Non seulement le savoir-faire se dédouble et acquiert ce caractère matérialisé : il cesse aussi de s'identifier à l'individu, de se confondre avec son organisation biologique et individuelle. En effet, entraînée par le processus inventif, la quantité totale de ces savoirs n'est plus censée rester constante ni associée à une personne durant toute sa vie. La notion d'habileté doit, de ce fait, céder le pas à celle d'information; ce que l'on assimile et transmet est un certain volume de renseignements opératoires, mais non pas une structure ni un ensemble de règles propres à s'imprimer, de manière stable, dans une substance physique et mentale. D'où le caractère relativement extérieur de ce qui est appris, et la nécessité de s'adapter à ses changements :

« Le besoin d'adaptabilité dénonce une ambiguité dans le mot talent (skill) que l'on pourrait autrement employer pour résumer toute la discussion. Depuis des siècles, un travailleur qualifié (skilled) signifie un travailleur qui, dans son jeune âge, a acquis la maîtrise d'une forme particulière d'artisanat et a passé le reste de sa vie à appliquer la qualification ainsi requise $»{ }^{799}$.

Le renouvellement et la reproduction continuelle des facultés durant toute la vie de l'individu - ce que l'on appelle l'éducation permanente - dissout leur caractère particulier, ruine leur définition exclusive en tant que propriété de celui qui se les adjoint, pour les changer en termes d'un langage approprié à la communication avec les processus objectifs.

Ainsi, à l'échelle de l'individu comme à celle de l'espèce, les capacités de travail s'ordonnent comme des structures d'information et se 
matérialisent dans des documents propres, différant de l'organisme et de son milieu, et qui traduisent l'un et l'autre.

On constate donc une double mutation structurelle du travail humain, consécutive à l'apparition des sciences et du scientifique. D'une part, au lieu d'être entièrement productif, il perd en partie cet attribut qui ne lui appartient plus en propre, mais est commun à toutes les forces matérielles, pour devenir, dans une proportion croissante, travail inventif. D'autre part, les facultés qui le composent acquièrent à la fois le caractère de produits, de ressources primordiales, et d'informations constituant des ensembles homogènes, qui ont leurs propres règles, et que l'on peut traiter indépendamment de leurs concrétisations successives dans tel ou tel groupe humain, dans telle ou telle puissance non-humaine. A cette transformation radicale du travail correspond un bouleversement de sa répartition, de sa reproduction, et des rapports avec le monde matériel qui sont nécessairement différents de ce qu'ils étaient jusqu'ici.

\section{$\underline{\text { Retour à la Table des Matières }}$}

\section{Progrès scientifique et technique, ou progression naturelle.}

Les changements que $\mathrm{j}$ 'ai décrits, relativement au travail et à sa création, n'exercent pas une influence uniquement sur les structures psychobiologiques et sociales; ils impliquent aussi une révision du rôle de la division naturelle, en tant que mécanisme essentiel de notre histoire de la nature. Il fallait s'y attendre. L'action d'un principe, même très général, est liée à la présence de certaines conditions spécifiques. La sélection naturelle commence à déterminer la succession des espèces à partir du moment où se confirme la capacité d'autoproduction des organismes vivants; les systèmes colloïdaux primitifs ne sont guère soumis à son action. Lorsque les conditions régulières de fonctionnement d'un processus constitutif sont altérées, la nécessité se fait jour pour lui de se modifier, ou de disparaître. Bien entendu, celui qui le remplace ne vient pas à éclore brusquement : aucun de ces processus ne se développe sans accompagner quelque temps celui auquel il se substitue. 
Dans la constitution de l'espèce humaine, il n'y a donc pas de solution de continuité entre la sélection naturelle et la division naturelle. La première n'est pas l'apanage des êtres vivants à qui font défaut les caractères transmis de manière non héréditaire ; la seconde, ne bornant pas ses effets à cette dernière catégorie de transmission, que certains voudraient réserver de façon exclusive à notre espèce, ne va pas sans empiéter sur sa substance biologique.

On a cru pouvoir distinguer le règne animal du règne humain en se fondant sur la capacité à apprendre, à communiquer l'acquis d'une génération à l'autre : cette hypothèse est contredite par les faits, et notamment par des observations faites au Japon sur de petites colonies de singes ${ }^{800}$. Un membre d'une de ces colonies ayant découvert, par hasard, qu'une pomme de terre jetée dans l'eau avait meilleur goût, les singes se sont mis à laver les pommes de terre avant de les manger, et cette habitude s'est transmise à leurs descendants les jeunes nés dans cette colonie lavent, eux aussi, leurs pommes de terre.

D'autres études ont mis en évidence des comportements analogues. Elles nous permettent de voir combien peu nous pouvons nous fier à

« la croyance dogmatique que la particularité qui distingue un être humain de n'importe quelle autre espèce de créature vivante est la dépendance où il se trouve du comportement d'apprentissage; pour l'homme seul, l'équipement instinctuel ne suffit pas, en lui-même, à assurer la survie. En fait, l'abîme qui sépare l'homme du reste de la nature est, à cet égard, bien moins clairement marqué qu'on ne le suppose. Les insectes sociaux, les dauphins, les oiseaux, les primates et diverses autres créatures dépendent tous, dans une certaine mesure, de l'apprentissage, mais il est clair que cette faculté a beaucoup plus de signification chez l'homme que chez n'importe quelle autre créature ${ }^{801}(2)$.

Toutefois, cette disposition, même sur le plan humain, n'a pas été sans coexister longtemps avec des modifications organiques manifes-

800 J.E. FRISCH : Research on primate behavior in Japan, Amer. Anthrop. 1959, 61, pp. 584-96; K. IMANISHI : Social behavior in Japanese monkeys, Macaca fuscata, Psychologia, 1957, I, pp. 47-54.

801 E.R. LEACH : art. cit. p. 24. 
tes. Nous ne savons pas encore exactement comment s'est développée chacune des espèces humaines, ni quelle a été la cause de leur disparition. Nous pouvons seulement remarquer que mainte modification de la main, du cerveau, a suivi et non pas précédé la découverte des artifices.

L'homo habilis, l'homo neanderthalensis, l'homo rhodesiensis, c'est un fait avéré, ont possédé pendant une longue période une capacité de travail analogue à celle de l'homo sapiens, du moins à ses débuts ${ }^{802}$. Il faut donc supposer que la différenciation d'une catégorie naturelle - le passage du prédateur au chasseur — avec sa création d'habiletés, son rapport aux forces matérielles, a trouvé une résonance d'ordre biologique ${ }^{803}$, puisque les diverses filiations hominiennes en ont été marquées. On ne saurait attribuer à la sélection naturelle une action indépendante préalable ${ }^{804}$ dans la formation de l'homo sapiens; il importe au contraire de voir que ses effets se sont combinés avec ceux de la division naturelle ${ }^{805}$.

Dans l'enchaînement des espèces humaines, il est impossible, pendant une longue période, d'envisager séparément l'action de chacun de ces principes ${ }^{806}$. L'intervention de l'un et de l'autre est cependant reconnaissable. La sélection naturelle a commandé notre évolution, comme elle commande celle de l'ensemble des êtres vivants. En nous transformant biologiquement, elle nous a permis de nous conserver en

802

Toutes ces activites semblent indiquer clairement que, du point de vue culturel, les Pithecanthropes étaient peut-être presque aussi avancés que certaines des races les moins civilisées d'hommes d'aujourd'hui ». W.E. LE GROS CLARK : History of the primates, Chicago, 1961 p. 136.

803

804

$$
\begin{aligned}
& \text { outils qui sont propres à l'activité des artisans. Ce sont ces artifices, et non pas des propriétés } \\
& \text { organiques, qui différencient, en premier lieu, l'homme des espèces dont il descend le plus di- } \\
& \text { rectement: «Il est probable que ce qui distingue l'homme du singe devra reposer en dernière } \\
& \text { analyse sur une base fonctionnelle plutôt qu'anatomique, le critère de l'humanité étant sa ca- } \\
& \text { pacité de parler et de fabriquer des outils ». W.E. LE GROS CLARK, cité in M.F. AsHLEY } \\
& \text { MONTAGU : Culture and evolution of man, New York, 1962, p. } 5
\end{aligned}
$$

Il serait plus exact de parler, à propos du chasseur, de la présence des artifices que de celle des

805 G. Clarke : A la découvertes des sociétés préhistoriques, Paris, 1965 ; L.S.B. LEAKEY : Adam's ancestors, New York, 1960 ; K. OAKLEY : Framework for dating fossil men, Londres, 1964 ; S. ZUKERMAN : The social life of monkeys and apes, Londres, 1932.

806 «L'histoire des espèces, nous l'avons vu, tient à la fois de l'histoire naturelle et de l'histoire humaine ». R. ARON : Introduction à la philosophie de l'histoire, Paris, 1957, p. 32. 
interaction avec un milieu matériel qui nous était, dans une certaine mesure, donné. Toute modification importante de celui-ci se répercutait sur notre organisation interne. Les individus en qui se développaient des caractères appropriés subsistaient à travers ces variations. L'équilibre instable qui en découlait, tout en n'étant soumis à aucune orientation consciente ou pré-établie, garantissait une adaptation suffisante aux exigences de la reproduction sexuelle ou sociale, et à la coexistence avec les autres espèces végétales et animales, sur le produit spontané desquelles, en bonne prédatrice, la nôtre prélevait le nécessaire. Sa conséquence principale, à notre point de vue, est le modelage de l'organisme humain doté de traits particuliers : station debout, convergence binoculaire, spécialisation des organes de la parole, etc.

Si la division naturelle a contribué à ces effets, elle reflète surtout notre capacité à faire de l'échange avec la matière une activité réglée et finalisée, s'articulant intimement avec notre être, le travail. Grâce à ce mode particulier d'action, les espèces humaines ne font pas que se conserver - biologiquement et socialement - elles augmentent aussi le nombre des individus qui les composent, multiplient leurs propriétés, bref témoignent d'une croissance s'opérant aux dépens de l'entourage auquel elles confèrent des formes nouvelles. Simultanément l'homme apparaît en tant que puissance matérielle spécifique en face des autres forces matérielles qu'il inclut dans son milieu interne en expansion. La liaison de ces forces avec l'humanité (qui fait partie d'elles) est réciproque. La main, le sens ou l'œil s'associent des instruments ; mais le muscle ou le nerf humain font partie de tout agencement matériel — animé ou inanimé — et lui sont homogènes. Sans cette participation, nulle puissance non-humaine ne peut s'exercer. Tout animal appelle notre effort animal, tout outil réclame la force et l'habileté de nos bras, tout pouvoir mécanique se combine à nos appareils sensoriels. Aucune de ces forces n'est indépendante ni ne peut fonctionner sans nous, dans la structure complexe du milieu dont nous sommes un des éléments organisateurs. Par la division naturelle, l'homme se reproduit de manière non seulement biologique mais aussi naturelle. Les pouvoirs objectifs étant devenus des parties de son être, l'organisme humain est le grand livre dans lequel s'inscrivent les lois des diverses parties de l'univers. Aucun homme ne peut le lire sans s'en écarter et transformer ce qui y est marqué en ses propres ressour- 
ces, afin de récrire autrement cet admirable ouvrage. Les sens et l'armature musculaire de l'homme jouent ce double rôle d'être articulés avec des forces quelconques - animal avec les animaux, pouvoir mécanique avec les mécanismes - et en même temps détenteurs de leur essence, c'est-à-dire des règles et des lois qui transforment ces forces en parties de lui-même. Les habiletés et les instruments artificiels se combinent afin d'intégrer le monde matériel à notre constitution et, vice versa, de faire participer notre constitution au monde matériel. Ensemble, ils déterminent la particularité du mouvement, de l'activité qui fait du milieu objectif une composante de l'organisation et de la reproduction du travail, c'est-à-dire le caractère productif de ce dernier. Il devient, de manière fondamentale, le critère servant à différencier les hommes, leurs qualités, la façon dont ils s'inscrivent dans le cadre de l'ordre naturel et le constituent.

La nouvelle définition du rapport des hommes aux ressources matérielles dont ils sont non seulement les partenaires, mais aussi et surtout les médiateurs, la répartition de leurs savoirs qui prédominent dans le contexte de l'invention, représentent des changements radicaux. L'apparition d'un autre type de travail, le travail inventif, et la matérialisation des facultés dont il a été question, sont à la fois les conséquences et les prodromes d'un processus nouveau dans l'histoire humaine de la nature, que je désignerai du nom de progression naturelle.

La progression naturelle, cela va sans dire, embrasse la famille de phénomènes que l'on attribue d'ordinaire au progrès scientifique ou technique. Néanmoins, la convention que je propose n'est pas de pure terminologie : son but est de préciser la sphère propre de ces phénomènes. Ce n'est pas en multipliant les variétés de progrès - intellectuel, scientifique, social, productif, etc. - comme des vertus scolastiques, que nous y parviendrons. Non seulement cette multiplication les vide de toute signification réelle, mais elle conduit aussi à les hypostasier en une chaîne d'agents, dont chacun jouerait le rôle de cause autonome, de moteur sans aucun rapport avec les acteurs humains. Ainsi la science, la technique, ou toute autre entité surgirait, douée de pouvoirs inconnus et fascinants, et, se situant quelque part entre la société et un esprit indéfini et flottant, symboliserait un mouvement et une 
action mécaniques dans le fond, marqués par la fatalité quant à leur forme ${ }^{807}$.

Dans ce sens, le progrès est aperçu de l'extérieur et saisi uniquement par ses effets. Il offre le spectacle et propose le bilan des conquêtes heureuses ou des accidents inéluctables. Comment pourraitil en être autrement, quand ce changement continuel de notre monde objectif et de ses propriétés non moins objectives est coupé de tout rapport qui le montrerait pour ce qu'il est, une fonction originale de l'intervention humaine ? Cependant, — est-il besoin de le dire ? - il n'y a pas un esprit qui engendre les techniques ou en prend connaissance : il y a des hommes qui les créent et se les assimilent. Il n'y a pas de science ou de pensée scientifique : il y a des scientifiques qui pensent et font ces sciences. Si donc nous allons vers la racine des hypostases, ce sont bien des hommes, des relations humaines, qui sont à l'œuvre et dont il faut se préoccuper. Au vu de ces conditions, on ne saurait non plus oublier que le progrès est une démarche et un résultat par lesquels nous agissons à la fois sur l'univers matériel et sur les facultés de l'espèce dans ce cadre. Assurément, celles-ci se trouvent créées de manière nouvelle, et l'on reconnaît à cette création une influence directe sur notre développement historique :

«Un coup d'œil jeté sur l'époque présente, constate le grand physicien Pascual Jordan, suffit à nous convaincre que la science influe de manière décisive sur les événements historiques et ici je suis loin de penser à la seule bombe atomique, car le passé nous enseigne la même leçon ${ }^{808}$.

Une chose est certaine ; qu'il s'agisse de sciences ou de techniques, ou d'autres savoir-faire encore à venir, organisés en groupements de disciplines rigoureuses, leur avancement va de pair avec l'avancement et la transformation de nos aptitudes et du milieu auquel celles-ci correspondent. De la sorte, le domaine spécifique dans lequel se répercu-

807 « Puisque la critique note justement la fréquence d'un réalisme du progrès, j’y ajouterai que la conséquence de cette tendance est que : $1^{\circ} 1^{\prime}$ 'on se figure que le progrès se fait tout seul indépendamment de l'effort humain; $2^{\circ}$ on le réduit à ses aspects les plus mécaniques ». A. LALANDE : Vocabulaire de la philosophie, Paris, 1947 p. 888.

808 P. JORDAN : Science and the course of history, New-Haven, 1955, p. VII. 
tent les conséquences de toute progression est clairement dessiné, puisque, comme l'observait Léon Brunschvicg :

« Le progrès du savoir entraîne un progrès de la nature (souligné par moi), en tant que l'espèce humaine en a mis à profit, pour ses besoins et ses désirs, les diverses manifestations $\gg{ }^{809}$.

Faut-il s'arrêter là ? Suffit-il, pour justifier la dénomination de progression naturelle, de fixer l'ordre naturel comme lieu véritable auquel se réfère le progrès ? Certes non. Pour qu'il se manifeste en tant que réalité, principe historique, il est indispensable de souligner son caractère de processus.

En effet, le progrès représente, aux yeux de la plupart des hommes, un mouvement linéaire et sans heurts, une évolution cumulative, qui substitue le plus au moins, le mieux au moins bien, et sa marche est supposée sans retour possible. A la limite, cette conception répandue et naïve se borne à faire l'inventaire des enchaînements superficiels et à fournir un étalon arbitraire, autorisant des comparaisons avantageuses avec le passé. Liée à l'invention conçue comme une sommation unilatérale de savoirs et de ressources, elle en découle directement.

Il est toutefois évident que le terme de progrès dénote plus que cette seule extension, cette additivité, et que son trait le plus important réside ailleurs. Nous le décelons mieux si nous examinons la transformation du donné : aucun talent, aucun produit n'apparaît sans entraîner, en contrepartie, la disparition d'un autre talent ou d'un autre produit. La nouveauté et le vieillissement, en affectant des relations et des termes, instaurent des structures et rendent inopérantes d'autres structures; là où s'ajoute quelque découverte ou quelque pouvoir matériel, une autre découverte, un autre pouvoir sont rendus caducs. Le mouvement d'ensemble ne représente pas seulement un amoncellement sans fin, mais encore une combinaison et une métamorphose de ce qui existe déjà, une confrontation de réalités qui s'opposent et résistent au changement : 
« On imaginait trop simplement le progrès comme une accumulation, 》 écrit Raymond Aron ${ }^{810}$. On ne se contentait pas de l'imaginer ainsi. On éludait aussi ses tensions évidentes en parlant de ses conséquences positives, lorsque quelque chose s'ajoutait, et de ses conséquences négatives, lorsque quelque chose dépérissait, sans chercher à relier ces deux séries d'événements et sans les intégrer à une unité. Cette séparation permettait de maintenir la fiction d'une évolution déterminée - ascendante et descendante - alors que c'est précisément en une simultanéité parfaite que réside l'essence du processus en question. C'est donc une erreur de considérer le progrès comme l'épanouissement constant de la même organisation des phénomènes, du même état naturel et technique. Comment ne pas voir qu'il implique un passage, une conversion d'un état dans un autre, avec involution ou déploiement de certains aspects, et que c'est moins dans une multiplication que dans une transgression des propriétés que l'on saisit sa spécificité ?

Le bilan quantitatif n'est qu'une conséquence du bilan qualitatif et s'il exprime notre insertion dans le monde matériel, il traduit moins l'élargissement que le bouleversement de celui-ci. C'est bien ce qui s'est produit lors de l'éclosion des connaissances scientifiques :

«Depuis la première moitié du siècle (le $\mathrm{XIX}^{\mathrm{e}}$ siècle) qui vient de finir, sans remonter plus haut, le monde a étrangement changé de figure : les hommes de ma génération ont vu entrer en jeu à côté et au-dessus de la nature connue depuis l'antiquité, sinon une anti-physis, une contre-nature comme on l'a dit quelquefois ; mais une nature supérieure et en quelque sorte transcendante, où la puissance de l'individu est centuplée par la transformation des forces jusque-là ignorées — ou incomprises - empruntées à la lumière, au magnétisme, à l'électricité » ${ }^{811}$.

La formation des sciences - un acteur et un témoin viennent de l'attester - a moins reculé les frontières de l'univers qu'elle n'a imposé un univers de contenu et de structure entièrement différents. 
La solidarité qui unit l'apparition du nouveau et la disparition de l'ancien, la certitude d'un renouvellement des attributs humains et non-humains qui les accompagnent, nous obligent à traiter le progrès comme un processus - et non pas comme une pure croissance évolutive - comme une genèse impliquant naissance, lutte et mort, bref, comme une histoire, et non pas comme une généalogie. A cet égard se précisent une notion et un faisceau de faits qu'il est souhaitable de ne plus laisser se disperser ou se gauchir, faits tantôt assimilés à l'ensemble social, et tantôt tenus à l'écart, tantôt censés mesurer des rapports humains, tantôt réduits à incarner la projection objectivée de ces rapports, tantôt identifiés à toute invention et tantôt ramenés à la forme scientifique ou technique de cette dernière. Rattachés à une réalité déterminée, ils se classent sans équivoque à côté des mécanismes inhérents à l'élaboration de nos facultés, de nos ressources, et à la reproduction des unes et des autres. La progression naturelle (tel est l'esprit de la convention que je viens de motiver) subsumant leur dynamisme actuel, est replacée, par nécessité, dans la lignée des principes ${ }^{812}$ qui modèlent l'histoire de notre espèce et du monde matériel qu'elle constitue.

Retour à la Table des Matières

\section{Des phénomènes encore inexplorés.}

La progression naturelle est entièrement définie par sa position dans la suite des processus régulateurs de l'histoire humaine de la nature. La dégager de la dilution du devenir total en facteurs hypostasiés - la science, la technique, etc. — est une condition préalable à son étude. Celle-ci ne peut toutefois conduire, dès maintenant, à la clarté complète. On se heurte à une limite de fait. Nombre de particularités

${ }^{812}$ La division naturelle l'accompagne - nous l'avons constaté à propos de l'apparition de la chimie - et ne disparaîtra assurément pas d'un seul coup. Tout processus nouveau, il n'est pas inutile de le rappeler, demeure longtemps associé à un processus ancien, puisqu'il est, en fait, la réalisation d'une de ses possibilités. Toutefois, si la progression naturelle est appelée à s'enraciner et à durer - la division naturelle a subsisté pendant plusieurs centaines de milliers d'années - il est préférable de ne pas l'assimiler au groupement de disciplines, à la catégorie naturelle qui l'a imposée — la science, le scientifique — car elle les dépasse nécessairement. 
ou de conséquences du principe en question ne se sont pas encore développées. La raison en est son articulation, encore trop forte, avec la division naturelle. Même si la recherche théorique a pour vocation d'aller au-devant des phénomènes ou des événements, elle serait mal avisée d'aller au-delà. Il n'en reste pas moins qu'elle peut faire mieux que répéter des évidences - les richesses matérielles se sont multipliées grâce au progrès du savoir, l'avenir est différent du passé, etc. - c'est-à-dire que travestir les choses en mots, donner à lire ou à entendre ce que chacun peut voir.

Son rôle est au contraire de démonter les éléments du mouvement historique, afin de rappeler qu'il n'a pas surgi du néant il y a deux ou trois siècles ${ }^{813}$, mais qu'il a, au contraire, assimilé ceux qui l'ont précédé. Ouvrant une brèche à travers l'opacité des routines discursives, la connaissance passera du stade intuitif ${ }^{814}$ au stade analytique.

Je commencerai par souligner un contraste essentiel. La progression naturelle a trait au genre humain, non seulement en ce qu'il tend à assurer sa propre conservation dans un monde matériel donné, ou s'accroît en s'adjoignant des forces de ce monde - la sélection ou la division naturelle n'agissent pas autrement — mais en tant qu'initiateur, ou centre d'impulsion de l'univers dans lequel il subsiste. Qu'est-ce à dire ? Bien entendu, il ne s'agit plus de considérer cet univers comme un lieu où nous rencontrons des êtres non-humains hostiles, et pas davantage comme un territoire que nous conquérons pas à pas. Au contraire,

«pour la première fois dans le cours de l'histoire, l'homme est seul sur terre en face de lui-même, il ne trouve plus de partenaire ou d'ennemi » ${ }^{815}$.

\footnotetext{
813 J. FoURASTIÉ : Le progrès technique et l'évolution économique, Paris, 1962, p. 86.

814 «La notion de progrès technique est, dans une certaine mesure, intuitive, mais se révèle à la réflexion malaisée à définir avec rigueur ». M. BRODSKY : Production et économie industrielles, Paris, 1952, p. 230.

815 W. HeISENBERG : The representation of nature in contemporary physics, Daedalus, 1958, p. 105.
} 
Notre fonction, sous ce rapport, n'est pas d'exécuter ou de mettre à jour un plan préconçu. Comment cela pourrait-il se faire ? Des parties de la matière continuent à se transformer, et quelques-unes sont plus jeunes que l'humanité, tels les amas d'étoiles datant d'environ un million d'années. Par ailleurs, on est en droit de penser qu'il ne sera jamais possible d'entrer en contact avec certaines régions de l'ensemble cosmique. Donc, il faut y insister, nous ne vivons pas dans une nature qui était présente avant que notre espèce émergeât; compte tenu de l'évolution incessante du tout, nous ne vivrons jamais dans un monde dont le programme complet d'édification aura été déchiffré grâce à notre labeur incessant. Jusqu'à un certain point, l'homme peut se reconnaître en qualité de facteur ordinateur, source d'organisation du milieu où il se situe. Partant, la matière cesse d'être le substrat, le fonds pré-établi servant à maintenir les attributs de notre espèce, et devient explicitement le résultat des activités à elle consacrées. Telle est la signification du tournant historique provoqué par l'apparition des sciences et des scientifiques. Une aptitude à dégager, à métamorphoser ou à engendrer des qualités substantielles s'affirme. Elle permet de mettre en évidence ou de susciter des structures matérielles qui n'existeraient pas sans l'intervention humaine, sans que leur avènement soit méthodiquement préparé :

«Le chercheur se trouve maintenant, écrit P. Auger ${ }^{816}$, pouvoir atteindre sur place dans ses laboratoires des conditions qui ne sont réalisées que dans les régions inaccessibles comme le centre des étoiles ou les profondeurs du globe, ou même qui ne le sont peut-être nulle part naturellement dans l'univers ».

La pénétration profonde dans l'histoire, l'intervention dans le cours propre aux puissances matérielles animées ou inanimées est, actuellement, effective. La prolongation de la chaîne de transmutation des éléments, en accord avec le tableau de Mendéléeff, jusqu'à la formation synthétique des espèces physiques, le montre. Et ce n'est là qu'un des nombreux exemples de cette attitude vraiment créatrice du milieu objectif. 
Sur quoi repose le changement ? Pour répondre à cette interrogation, il est nécessaire d'envisager le cadre dans lequel s'établit notre rapport aux ressources. Jusqu'ici, la reproduction naturelle a prévalu. Ceci signifie que chaque découverte ou chaque substitution, au cours de laquelle étaient appréhendés les pouvoirs non-humains, demeurait attachée à une chaîne de transpositions, dont le modèle ou l'un des termes était nécessairement l'élaboration des habiletés humaines. C'est bien ce qui se produit lorsque les artisans reprennent à leur compte les habiletés de l'agriculteur - les reproduisent, donc, d'un homme à un autre homme - ou lorsque les ingénieurs s'approprient celles de l'artisan, par le truchement d'un transfert aux forces mécaniques.

La conjoncture a cependant changé du tout au tout. Nos dextérités - ce qu'il s'agit de former, transformer, répartir - ont pris un caractère à la fois tangible et moins directement organique. Je l'ai indiqué à propos de la matérialisation des facultés humaines. Celles-ci peuvent être, de ce fait, déplacées, mobilisées, combinées, sans que l'on tienne compte de leur traduction biologique ou de leur distribution spatiale. Le maniement de ces forces à l'instar d'un maniement d'information correspond à cet état. Dès lors, tous les fragments du savoir universel se présentent de façon objective, et il est possible de les stocker, de les examiner, de les traiter, de les utiliser consciemment pour résoudre un problème ou concevoir des connaissances inédites que l'on souhaite obtenir. L'exercice de nos capacités n'est plus l'exercice exclusif de quelque chose qui est fixé en nous - comme l'art de la charpente dans les doigts du charpentier - ni fondu dans le paysage ou le cycle propre au milieu ambiant - telles les conditions de travail de l'agriculteur au cours de nombreux millénaires. Il s'associe des organisations et des structures où sont condensées des lois et des règles susceptibles d'être enregistrées et confrontées sur une grande échelle sans référence directe à la constitution humaine. La calculatrice électronique, bien plus que le livre, est la marque de cette symbiose, et il est parfaitement approprié de dire que 
« la combinaison de l'homme et de la calculatrice promet d'être équivalente à un saut dans l'évolution du système nerveux de l'homme ${ }^{817}$.

Pour mieux faire ressortir la différence avec l'état passé, il faut recourir à une autre analogie, elle aussi d'ordre biologique. Jusqu'à présent, la sélection naturelle - ou artificielle — donc la transmission et l'adaptation des propriétés qui convenaient au milieu ambiant, était le seul mécanisme auquel on pût avoir recours pour individualiser des espèces. Actuellement, il est possible d'envisager cette individuation en remaniant le noyau des cellules, c'est-à-dire en variant le nombre de chromosomes du noyau de façon à modifier la structure de celui-ci, afin de provoquer les mutations désirées. On peut dire qu'il en va de même de nos disciplines et de nos facultés : nous sommes désormais capables de les renouveler, en partant de leur contenu que nous avons analysé et sérié, dont nous pouvons ordonner les parties essentielles de manière à obtenir les quantités d'information ou les talents indispensables, sans attendre du hasard ou de la chance la rencontre des individus porteurs de ces informations ou détenteurs de ces talents.

Par ailleurs, la transmission des connaissances se fait dorénavant d'une première puissance matérielle à une seconde puissance matérielle. Ces puissances apparaissent douées d'un savoir-faire destiné à être acquis, échangé, " enseigné » au sens propre du mot. L'électricité " s'est mise à l'école » de la force mécanique, dont elle a acquis notamment les qualités motrices; aujourd'hui les forces nucléaires s'approprient les capacités des forces électro-chimiques, de même qu'une matière synthétique nouvelle reprend les qualités de résistance ou de dureté d'une matière ancienne, synthétique ou non. On est en droit de considérer ces systèmes matériels comme dépendant d'une somme de propriétés qu'ils reproduisent entre eux, autant, sinon plus, qu'ils ne dépendent de celles de l'homme et les reproduisent. C'est là un signe indéniable d'autonomie, l'évidence d'un enchaînement dont nous ne sommes ni un terme ni le modèle explicite.

817 W.A. Rosenblith : On some social consequences of scientific and technological change, Daedalus, 1961, p. 507. 
Il en découle que l'invention n'a plus besoin d'être une forme de la reproduction - du fait de l'intégration des facteurs humains et nonhumains - ni un mouvement diffus, aléatoire, conditionné par la constitution partiellement biologique et la saisie subjective des habiletés ou des connaissances. Elle devient un processus naturel distinct, prépondérant, méthodique. Le travail qui lui est consacré est reconnu pour tel. Les corollaires en sont non seulement une assimilation accélérée de ses résultats là où les circonstances s'y prêtent, mais aussi un accroissement du nombre des hommes qui y participent, puisque la masse des savoirs qu'il faut ajouter ou écarter augmente en proportion. Bien plus, la reproduction lui est subordonnée, comme une de ses expressions particulières. Ce qui est acquis ou transmis, au titre des dextérités et des moyens d'action, l'est de moins en moins pour une longue durée et sous la même forme, de plus en plus sous une forme bouleversée. L'exigence d'une «éducation permanente » des adultes, le vieillissement rapide du contenu des sciences témoignent de la révolution qui s'est opérée.

Quelles sont les incidences de cette prépondérance du processus d'invention? Nous les observons dans la répartition du travail. Une première fraction de celui-ci, la plus décisive, revient au savant et à l'ingénieur scientifique. La recherche, fondamentale ou non, les occupe l'un et l'autre. En fonction de celle-ci, ils se partagent les tâches et collaborent à un même vaste programme. Qu'il s'agisse de science pure ou de science appliquée, des connaissances et des aptitudes analogues sont indispensables : seul le contexte diffère.

Certes, le partage en spécialités demeure vivace, mais la gamme des combinaisons s'accroît aussi vite que celle des subdivisions. Même lorsqu'ils œuvrent dans leur secteur particulier, les savants et les praticiens des sciences appliquées gardent des rapports similaires avec les forces matérielles, avec les ressources qui leur sont communes. Bien plus, l'opposition entre conception et production, les barrières qui séparent la découverte de sa diffusion, s'atténuent ${ }^{818}$. 
L'interdépendance des différentes catégories de travailleurs est devenue, en conséquence, plus étroite, et c'est par rapport à une information et à des savoirs constituant un corpus dont les parties semblent obéir à des principes généraux que les individus se qualifient.

Ce déplacement d'accent, l'importance nouvelle qui s'attache aux « systèmes de connaissances » soulignent, d'une autre manière, ce qui est devenu la fin d'une partie de l'effort humain, et décrivent un de ses secteurs essentiels. Les talents qui s'exercent, à cet égard, les liens qui unissent les savants aux ingénieurs scientifiques n'ont pas pour centre la production des objets mais, explicitement, la création du travail.

La seconde fraction des connaissances ou des habiletés potentielles est impartie aux forces matérielles, par rapport auxquelles notre action est régulatrice ${ }^{819}$, lorsqu'elles se reproduisent mutuellement, ou communiquent des ordres, ou exécutent des opérations. Nous le savons : ces forces ne sont pas uniquement des agents moteurs, elles possèdent une « sensibilité » et un " jugement » qui les rendent capables de produire, de manière indépendante, les effets les plus complexes. Leur rôle n'est plus de « renforcer » nos organes ou de les prolonger, de nous servir de prothèses instrumentales ${ }^{820}$ moulées à nos nerfs et à nos muscles ; dotées d'organes propres - la cellule photoélectrique, la mémoire électromagnétique en sont des exemples elles pourvoient à la réalisation de la plupart des tâches d'observation, de mesure ou de mouvement.

« Nous nous servons d'outils, rappelle P. Jordan ${ }^{821}$, depuis les temps préhistoriques. Mais aujourd'hui nous commençons à donner à nos outils une sorte d'existence indépendante ».

819 «Le travail n'apparaît plus tellement enfermé dans le processus de production; au contraire, l'homme se comporte en tant que gardien et régulateur vis-à-vis du processus de production. » K. MARX, Grundrisse der Kritik der politisehen Ökonomie, ed. Berlin, 1953, p. 592.

820 «Ce n'est plus le travailleur qui intercale l'objet naturel modifié comme chaînon entre l'objet et lui-même ; mais il intercale le processus naturel, qu'il transforme en processus industriel, en tant que moyen entre lui et la nature inorganique, qu'il maitrise ». ibidem.

821 P. JORDAN : op. cit. p. 36. 
Pour cette raison, ces outils reçoivent toute une série de dextérités qu'ils « apprennent» les uns des autres, ou de l'homme, et les pratiquent avec une efficacité supérieure à celle que nous pourrions avoir. Aussi constituent-ils des facteurs de production dont le travail jouit d'une certaine liberté, et ils se posent devant nous, à côté de nous, avec des normes et des propriétés particulières. L'automation, opposée à la mécanisation, concrétise ce changement.

La répartition des facultés entre pouvoirs humains et pouvoirs nonhumains revêt une signification qu'il est imprudent de sous-estimer, puisqu'elle affecte profondément le rôle des catégories naturelles. En effet, nous l'avons constaté à maintes reprises, lorsqu'une de ces catégories prenait son essor, elle élaborait les connaissances indispensables pour faire des découvertes et procéder à des substitutions des ressources objectives, conformes à ses dispositions et en accord avec sa vocation historique. La catégorie dont elle se séparait, à partir de laquelle étaient dégagées découvertes et substitutions, s'enfermait dans le cycle de la production, et son labeur était entièrement conditionné par la nécessité de préserver ce cyle. " Porteurs d'invention » et producteurs se cantonnaient de la sorte dans des échanges spécifiques avec le monde matériel, et se reproduisaient dans des secteurs distincts.

Parallèlement, nous l'avons également remarqué, à l'intérieur de chaque catégorie naturelle, coexistaient deux groupements de disciplines, deux branches d'activité aux fonctions clairement établies. L'élaboration des rapports avec les forces matérielles d'un côté, la saisie de ces forces en tant qu'artifices techniques de l'autre côté, représentaient les zones de clivage. Le philosophe naturaliste ou mécanicien, l'artisan et l'ingénieur et, plus près de nous, le savant et le technicien ou l'ingénieur scientifique, correspondent à la spécialisation indiquée.

Parmi toutes ces différenciations, celles du chasseur, de l'agriculteur, de l'artisan ou du mécanicien, qui se sont produites successivement, ont dominé l'ensemble de l'évolution historique. La division naturelle commande et permet cet écartèlement des catégories naturelles prises dans leur totalité. Ce qui en exprime l'essence n'est 
pas qu'une communauté d'individus fasse plus de travail qu'une autre, ou que la première fasse un travail distinct de celui de la seconde, mais que le travail de l'une apparaisse comme le lieu des ressources matérielles de l'autre, que leurs habiletés soient liées à des mondes relativement isolés. La femme identifiée à la terre et l'homme identifié à l'animal fournissent les premières images stylisées d'un partage inévitable. Par contraste, l'interaction à l'intérieur d'une catégorie, d'un groupe de «porteurs d'invention » ou de producteurs, était à la fois faible et unilatérale ; elle n'intervenait dans le développement général que de manière secondaire. Nous avons vu, à plusieurs reprises, par quels détours s'est effectuée la communication des disciplines naturelles philosophiques avec les disciplines purement techniques. Le passage des premières aux secondes est accidentel, et a surtout lieu à des moments privilégiés, sans être une règle inscrite dans leur fonctionnement et un impératif pour ceux qui les exercent.

Les sciences et les scientifiques, ayant imposé un nouveau travail et modifié nos facultés, ont bouleversé cette situation. Tout se passe maintenant comme si la différenciation qui affectait toutes les catégories naturelles affectait davantage une catégorie naturelle et des systèmes matériels autonomes; comme si la division à l'intérieur de laquelle une partie de l'humanité se rapportait à l'autre partie comme à sa ressource et à sa matière, embrassait cette dernière effectivement en sa qualité de matière et, accessoirement, eu égard à la présence humaine. La première s'attribue en priorité un travail qui lui est propre, le travail inventif; la seconde reçoit, de préférence, autant que faire se peut, la charge du travail productif.

L'essentiel n'est pas que les bras humains soient remplacés par des bras non-humains, ni que les cerveaux humains soient remplacés par des cerveaux électroniques, mais qu'ils forment, respectivement, une unité, qu'ils acquièrent et transmettent des savoirs et une mission qui est la leur et dans laquelle ils excellent. Notre écart aux forces matérielles est ainsi devenu analogue à l'écart vis-à-vis d'une catégorie naturelle, et non l'inverse.

Quelle en est la conséquence ? On enregistre un déplacement du centre de gravité de la dynamique historique. Celle-ci était condition- 
née par la séparation entre classes d'individus, le dédoublement de l'espèce et celui des rapports au réel. Avec l'atténuation des effets de la division, la tension, le courant de transformation à l'intérieur d'une même classe s'amplifie et devient déterminant. Ainsi l'interaction endogène à une catégorie naturelle prend le pas sur l'interaction exogène, qui se fond dans l'interaction avec les puissances matérielles proprement dites. Dans un article auquel j'ai déjà renvoyé plusieurs fois, Maurice Daumas souligne indirectement ce fait. Il observe avec raison que, depuis leurs commencements jusque vers le milieu du siècle dernier, les techniques ont suivi le même principe de transformation. Qu'elles aient reçu des contenus divers ou pris des aspects industriels originaux, personne ne le méconnaît. Toutefois, ces renouvellements successifs n'ont pas bouleversé leurs «conditions d'évolution ». La révolution véritable et qui touche au fondement, au principe de leur existence et de leur histoire, se déclare lorsque

« la liaison entre découverte et invention commence à s'établir dans les deux sens, et les échanges entre science et technique à devenir profitables à l'une et à l'autre » ${ }^{822}$.

Une confrontation entre ceux qui découvrent et ceux qui font l'industrie de la découverte, entre ceux qui renouvellent les systèmes matériels autonomes et ceux qui les adaptent à leur emploi productif $^{823}$ (2), la distribution des capacités et des disciplines respectives, donnent déjà une idée de ce processus qui dictera notre reproduction en tant qu'espèce et notre insertion dans l'univers. La scission n'étant plus un préalable à l'élaboration de ses qualités, l'humanité pourra se conduire comme une entité ayant ses propres fins, celles dont elle est redevable à elle-même et non pas à un agent extérieur. Déjà

«l'objet de la recherche, constate W. Heisenberg ${ }^{824}$ (3), n'est plus la nature elle-même mais plutôt la nature exposée aux interrogations de l'homme, et, dans cette mesure, l'homme ici aussi se rencontre lui-même».

M. DAUMAS : Le mythe de la révolution scientifique, art. cit. p. 298.

823

P. NAVILlE : L'automation et le travail social, Paris, 1961, p. 7.

824 W. HEISENBERG : art. cit. 
C'est probablement en cela que réside la progression naturelle, et c'est aux circonstances que j'ai énumérées qu'elle doit son avènement. Je dis probablement, puisque je me suis borné à préfacer son étude, sans prétendre l'avoir menée, ici, à son terme. 


\section{TROISIÈME PARTIE}

\section{SOCIÉTÉ ET HISTOIRE HUMAINE DE LA NATURE}


Dans les parties qui précèdent, j'ai analysé l'histoire humaine de la nature en insistant sur l'originalité des processus qui la caractérisent. J'ai fait abstraction de ses rapports avec la société ; il s'agit à présent de les reconsidérer dans une perspective renouvelée.

D'abord, l'état de nature, tel qu'il vient d'être envisagé, ne se réfère pas uniquement, comme dans ses acceptions ordinaires, aux capacités bio-psychiques de l'espèce : il englobe les facteurs sociaux parmi ses éléments. L'examen centré sur son histoire, les régularités qui lui sont propres et les actions des catégories naturelles qui y sont impliquées, ne se conçoit pas sans l'analyse des phénomènes correspondants sur le plan de la société. Celle-ci ne demeure pas extérieure à la création du travail, aux événements qui la ponctuent. L'impulsion de la collectivité figure à l'inventaire des motifs qui associent l'humanité à la matérialité. La recherche du profit, la soif de pouvoir et de prestige, la guerre et les préparatifs militaires, la vente quotidienne du talent, les intérêts politiques, aiguisent le sens de la découverte, commandent la substitution des ressources à opérer. De façon concrète, les échanges avec la matière se situent également au sein des industries et des arts : l'univers physique est ainsi répété à des millions d'exemplaires, reproduit sur toutes ses facettes, cristallisé en œuvres variées. Mobilisé dans le cadre productif, le savoir garde une jeunesse éternelle, une éclatante permanence que son usage confirme à chaque instant. Le fonctionnement des rouages de la production repose sur l'emploi tantôt ludique, tantôt contraint des appareils sensoriels, de l'énergie nerveuse des individus, en même temps qu'il assure la conservation des liens avec les forces objectives. Le système social qui s'édifie à travers ce mouvement obéit à ses normes et réalise la transposition du monde matériel dans son propre contexte. Ce qui est naturel - au sens établi dans le présent essai - prend une expression sociale, en se soumettant obligatoirement aux principes économiques, éthiques, politiques, etc. Quelle forme revêt cette expression ? Il convient de l'élucider théoriquement et historiquement. 
Ensuite, ainsi que je l'ai démontré, la nature humaine comprend tout ce qui concerne la genèse des talents et des ressources. La société humaine se manifeste par l'intermédiaire des lois de la propriété, de la distribution des richesses et des pouvoirs. Nature et société représentent deux modes de relation entre les mêmes termes, et non pas les termes différents d'une même relation qui poserait les hommes d'un côté et les forces matérielles de l'autre. Ceci interdit, dans l'étude de leurs rapports, le recours à l'hypothèse d'une discontinuité, fixée dans le temps, du devenir société de la nature, de l'histoire de la première en tant qu'abandon graduel de la seconde. Que l'on place l'événement à l'origine, passage de l'état de nature à l'état de société, ou à l'apogée, cessation de l'action naturelle de l'homme socialisé, libéré de la rareté des biens ${ }^{825}$ grâce aux découvertes scientifiques, les obstacles auxquels on se heurte demeurent. Ni la création des habiletés propres à la chasse ou au maniement de l'outil, ni l'apparition de l'outil, ni l'institution des règles de parenté, ne sont, de toute évidence, des commencements absolus, déclin de notre appartenance à l'ensemble cosmique. L'ordre social ne succède pas à un ordre purement biologique en le refoulant, il est un des paramètres de celui-ci et accompagne l'existence d'un grand nombre d'espèces :

«... Les faits de groupement à bénéfice mutuel chez les Mammifères, plus largement chez les Vertébrés, et plus largement encore dans tout le monde vivant sont suffisamment nombreux pour montrer qu'il y a, dans la vie sociale, une option biologique fondamentale, au même titre que dans la symétrie bilatérale par opposition à la symétrie radiale, ou que dans la spécialisation du membre antérieur pour la préhension » ${ }^{826}$.

Il est en effet malaisé, sinon impossible, de prouver que le règne social succède au règne biologique, et non pas à une de ses propres modalités d'être. Qu'est-ce qui permet de soutenir, si on ne le postule pas pour des raisons extrinsèques, religieuses ou philosophiques, que les lois sociales se séparent des lois bio-naturelles et s'y substituent? A propos de ces dernières, nous savons et nous pouvons simplement constater que l'humanité est passée d'un certain type de rapport bio-

J.P. SARTRE : Critique de la raison dialectique, ed. cit.

826 A. LEROI-GOURHAN : op. cit. p. 205. 
naturel à un autre type de rapport bio-naturel, d'une situation dominée par la sélection naturelle, qu'elle partage avec d'autres espèces, à une situation marquée par la division naturelle, qui lui est plus spécifique. Cette dernière situation elle-même n'est pas définitive. De nouvelles relations avec le monde matériel s'ébauchent. Elles sont susceptibles de nous éloigner de l'humanité d'aujourd'hui autant que nous nous sommes éloignés de notre animalité d'autrefois. Chaque ensemble social s'associe à une de ces configurations naturelles et réagit à sa réorganisation; par là ils interfèrent et se conditionnent réciproquement. La confusion de la réalité avec une de ses figures explique pourquoi la disparition d'un mode d'existence naturelle de notre espèce a été considérée comme la disparition de toute existence naturelle. Ainsi est né le besoin de justifier l'apparition de la vie sociale, non seulement par une différence de qualité, de concept, ce qui est nécessaire, mais aussi par une différence d'origine, ce qui l'est moins. Si par contre on les envisage dans leur évolution globale et dans leur histoire humaine, la discontinuité chronologique s'estompe, et l'on reconnaît que la société est continuellement sortie de la nature, qu'il y a passage incessant de l'une à l'autre. Tous les jours, nous recréons leurs différences et nous déplaçons leurs frontières. Aucune partie de l'humanité, à aucun moment, n'est plus proche ni plus éloignée d'un état de nature, ni dans le passé primitif, ni dans l'avenir évolué. Il n'est pas essentiel à l'homme de prouver son unicité, ni dégradant de replacer sa société et sa nature dans la succession des créations qui ont lieu ici ou là dans l'univers, grâce à son action ou à celle des autres espèces connues ou à connaître. En outre, s'il n'y a pas de commencement absolu à la présence de la société eu égard à la nature, il n'est pas indispensable de caractériser uniformément cette présence. On s'attache à cette uniformité lorsqu'on affirme que l'homme est par essence " possesseur de la nature ", et que son antagonisme vis-à-vis du reste du monde matériel est irréductible. Ramenée à sa juste proportion - celle d'une croyance commune sans véritable prolongement scientifique - cette conception veut nous signifier que les échanges avec l'univers physique s'amplifient, que les forces productives se multiplient, que la productivité du travail s'accroît, et qu'il en sera toujours ainsi. L'histoire sociale de l'humanité traduirait de la sorte une relation au monde matériel constamment identique à elle-même, à une différence quantitative près. 
Ni le rejet dans un passé reculé, ni l'unicité de sa progression ne rendent justice au contenu réel du rapport à la nature. Celui-ci est et ne peut être qu'un rapport historique, puisqu'il relie, articule l'ordre social avec l'ordre naturel, pour autant que chacun a une histoire. Sa teneur change, non pas, comme on le croit, de dimension ou d'intensité, mais de qualité. Par conséquent, il faut le décrire relativement à la période du mouvement historique à laquelle il correspond, et non pas une fois pour toutes.

Dans la première époque, si l'on envisage les sociétés primitives qui se sont maintenues le plus longtemps à la surface de la terre, on peut les définir par deux traits principaux : la propriété collective et la participation de tous les membres à la production. La structure du pouvoir et la disposition des biens autorisent la totalité des membres d'un groupe déterminé à avoir accès aux ressources du groupe. De par leur caractère social, celles-ci peuvent échoir plus spécialement aux hommes ou aux femmes ${ }^{827}$, à un clan ou à une tribu. Aucune règle ne prive pourtant les autres fractions d'une collectivité de la jouissance des forces matérielles, pas plus du reste qu'elles ne sont écartées de l'effort qu'elle exige. En d'autres termes, s'il existe des privilèges relatifs à l'emploi de certaines richesses matérielles,

« ces droits excluent simplement un groupe des ressources détenues par un autre groupe ; ils n'excluent pas l'autre groupe de la nature elle-même $"{ }^{828}$.

Dans les limites d'un territoire donné, la terre pourra être concédée aux agriculteurs, le bétail aux pasteurs, etc. Le système de subdivision peut être plus minutieux pour la chasse et la cueillette, codifiant l'attribution aux différents clans d'espèces végétales ou animales. Cependant, malgré ce fractionnement, l'appropriation de ces terres et de ces espèces est essentiellement communautaire. Il en a été ainsi, de fait ou de droit, jusqu'à la constitution des empires féodaux en Orient et des sociétés grecque et romaine, si l'on s'en tient à l'Europe ${ }^{829}$.

827

828

829

E.E. EVANS-PRITCHARD : The position of women in primitive societies and other essays, Londres, 1965.

L. WHITE : The evolution of culture, New York, 1959, p. 256.

H. Frankfort : La royauté et les dieux, Paris, 1956; R.L. MAKARIUS : L'origine de l'exogamie et du totémisme, Paris, 1961 ; M. GODELIER : La notion de mode de production 
Le rang des individus dans la société ne découle donc pas d'une division inégale de la propriété ${ }^{830}$. Au début, les liens de parenté occupent une position centrale et sont aussi religieux, politiques et économiques. La différenciation continuelle de ces liens a progressivement réduit l'importance réelle des relations de parenté, en faisant surgir d'autres critères de hiérarchisation. Toutefois, loin d'avoir le sens d'une séparation, cette hiérarchie fondée plutôt sur la distribution des fruits du travail que sur celle de ses moyens, manifeste la vigueur d'une interdépendance étroite, d'une complémentarité organique. Corrélativement, les relations entre les groupes sociaux sont en même temps des relations entre groupes de producteurs. D'emblée le mariage est le signe d'une double alliance : d'une part celle de deux collectivités (clans, familles) d'autre part celle, par exemple, d'un groupe qui chasse avec un groupe qui cueille. L'homme et la femme produisent des nourritures différentes, appliquent des procédés spécifiques pour fabriquer leurs outils. La coopération nécessaire à l'obtention d'une alimentation complète et régulière, la dépendance qui en découle, transforment l'unité familiale en cellule sociale et productive ${ }^{831}$. La superposition des liens sociaux à ceux qui subsistent entre producteurs se retrouve à un niveau plus global. Au Ruanda, les Tuvi sont pasteurs et guerriers, les Hutu agriculteurs, et les Tuva vivent de la chasse et de la fabrication des pots. Les Tuvi dominent l'ensemble de la société, méprisent l'agriculture et s'abstiennent de la pratiquer. La théocratie ou la royauté despotique, en Asie ou en Afrique, tendait à s'insérer dans le processus productif, soit au plan de la totalité des communautés, soit à celui d'une opération particulière, comme la régulation des eaux nécessaires à l'irrigation des terres. Cela se vérifie encore mieux pour certains systèmes de castes, où l'on retrouve un principe identique d'articulation des rapports sociaux avec des fonctions productives ${ }^{832}$. Dès lors, une interdépendance étroite associe les membres de la société, pour autant qu'ils produisent et répartissent les

asiatique et les schémas marxistes d'évolution des sociétés, Paris, 1963 ; K. WitTFoGEL: Oriental despotism, New Haven, 1957.

M. SмiтH : Structured and unstructured class society, Amer. Anthropologist, 1955, pp. 302305.

LÉVI-STRAUSS : Les structures élémentaires de la parenté, Paris, 1949, pp. 48 et seq.

L. DumONT : La civilisation indienne et nous, Paris, 1964, p. 18. 
habiletés, et entrent en rapport avec le monde matériel. Relations sociales et relations naturelles se correspondent ${ }^{833}$, par conséquent, immédiatement, et embrassent les mêmes individus. Les écarts que l'on constate à l'intérieur d'une collectivité paraissent relever des deux ordres de relations. Les groupes se considèrent simultanément comme des catégories naturelles en tant qu'ils sont doués de propriétés psycho-physiques particulières et en ce qui concerne leurs savoirs, et comme des catégories sociales dans la mesure où ils occupent une position donnée dans la société. La reproduction des talents indispensables à la vie collective se confond avec la reproduction des habiletés exigées par la vie matérielle. L'humanité se subdivise en fractions, les unes cultivant la terre, les autres domestiquant les animaux, d'autres encore travaillant le métal, chacune appartenant de ce fait et du même coup à une tribu ou à une caste déterminée. C'est pourquoi l'ordre des hommes peut apparaître dans le prolongement de celui des espèces biologiques ${ }^{834}$ ou physiques et être pourvu des qualités correspondantes.

Partout, la société et la nature s'imbriquent, partout on observe une assimilation concrète ou idéale des groupements sociaux et des catégories naturelles ${ }^{835}$. Leur articulation immédiate, la transparence de cette articulation, font que les institutions collectives ne se développent pas suivant un principe entièrement autonome, générateur de mouvement historique. C. Lévi-Strauss a décrit ce phénomène avec précision ${ }^{836}$ :

833 296.

834 l'ambition démesurée de ce schème, création d'une philosophie barbare. Toute la nature a été divisée en secteurs, tous les hommes ont été répartis entre les groupes correspondants, et à chaque groupe d'hommes a été assigné, avec une audace surprenante, le devoir de régir un secteur de la nature en vue du bien commun ». J.G. FRAZER: Totemism and exogamy, Londres, 1950, t. I, p. 118.

835 «Dans l'une ou l'autre perspective (du système des castes et des groupes totémiques) il faut admettre que le système des fonctions sociales correspond au système des espèces naturelles, le monde des êtres au monde des «objets ». C. LÉVI-STRAUSS : La pensée sauvage, Paris, 1962, p. 169.

836 C. LÉVI-STRAUSS : Race et histoire, Paris, 1953, p. 42. 
«En un mot, ces sociétés qu'on pourrait appeler « froides » parce que leur milieu interne est proche du zéro de la température historique, se distinguent, par leur effectif restreint et leur mode mécanique de fonctionnement, des sociétés « chaudes » apparues en divers points du monde à la suite de la révolution néolithique, et où des différenciations entre castes et entre classes sont sollicitées sans trêve, pour en extraire du devenir et de l'énergie ».

Ce qui caractérise la « froideur » en question, le mouvement de ces sociétés dont la plupart sont dites, à tort, sans histoire ${ }^{837}$, c'est le mode de création des capacités humaines, le passage d'un de leurs systèmes de reproduction à un autre, processus qui transforme les liens entre les catégories naturelles. En regard, le «milieu interne » apparaît comme stationnaire, car les relations des groupes sociaux, les groupes de parenté notamment, tout en leur correspondant, conservent un rythme d'évolution lent et décalé. Tout se passe comme si ces sociétés étaient entraînées dans un courant qui les détermine, sans leur être vraiment propre, faute d'avoir été intériorisé ou rendu spécifique. Qu'est-ce à dire, sinon que le principe de l'histoire humaine de la nature joue un rôle moteur, se manifeste directement dans l'histoire sociale ? Ce rapport entre les deux formes d'existence de l'homme était autrefois désigné du terme de barbarie, qui inclut l'état sauvage ${ }^{838}$.

La seconde époque - dans laquelle nous nous trouvons encore est marquée par la séparation des relations naturelles et des relations sociales. Celles-ci acquièrent — avec la propriété privée et la lutte des classes ${ }^{839}$ ou des rangs de la société - un principe historique propre. Le fait lui-même est incontestable. L'incertitude commence lorsqu'on veut rendre compte de l'apparition de la propriété privée, de sa domination sur la propriété collective. Si l'on reconnaît que son intervention a été décisive dans la vie de l'humanité, c'est qu'elle s'est impo-

Assurément, si une partie des sociétés peut être désignée comme étant « sans histoire », cela tient au fait que la seule histoire reconnue en général est celle des sociétés. Il n'en est pas de même si l'on envisage leur participation à l'histoire humaine de la nature.

838

On emploie couramment les termes barbarie, civilisation, etc. pour désigner des mœurs, des techniques ou des modes de pensée. Dans la conception exposée ici, mœurs, techniques ou modes de pensée sont le résultat conjoint de l'état social et naturel, comme termes autonomes et se transformant l'un par l'autre. L'emploi de ces désignations pour qualifier les rapports, l'unité de ces états, serait donc justifié.

839 A. BAUER : Les classes sociales, Paris, 1902 ; R. DAHRENDORF : Class and class conflict in industrial society, Stanford, 1959 ; S. KELLER : Beyond the ruling class, New York, 1964. 
sée grâce à un concours de circonstances, avec l'appui de ce hasard qui est comme l'accoucheur de l'histoire, bien plus que le revers de sa nécessité.

Assurément, on doit commencer par poser, parmi les prémisses de cette forme d'appropriation, l'essor de l'agriculture et le changement de dimension de la société, qui ont exigé une division stricte des fonctions. La multiplication des tâches communes, celles de la défense et de la production, l'armement et l'irrigation, la protection et le transport des matières premières, ont suscité un nouveau modèle d'organisation sociale. Les communautés et les individus qui se consacrent à la culture ou à l'élevage délèguent à d'autres le soin de coordonner les divers travaux collectifs, et bientôt ceux qui coordonnent s'arrogent le droit de disposer des bras et de l'avoir des couches de la société vouées au travail ${ }^{840}$. La trinité du roi, du soldat et du prêtre, gardiens de l'univers, de la richesse et de l'ordre, se dégage avec cette forme sociale, théocratique ou despotique. Elle annonce la naissance d'une institution originale, l'État, pouvoir et réunion des membres disjoints d'un corps de communautés et de groupements, appelés ou condamnés à vivre ensemble. Néanmoins, dans son cadre, monarques ou aristocrates religieux ou laïques conservent un rôle producteur ou un rôle social de supervision, destiné à maintenir, de façon réelle ou symbolique, le cycle des échanges matériels. La propriété collective y maintient ses prérogatives, la communauté cède une partie de ses produits, de sa terre ou de son temps, et garde jusqu'à un certain point le droit de penser qu'elle le fait moyennant une contrepartie, dans le but d'assurer une activité complémentaire de la sienne.

La société despotique ou théocratique - comme celle des castes est plutôt l'aboutissement d'une évolution des sociétés dites primitives que le prototype ou le point de départ d'une nouvelle famille d'ordres sociaux. Certes, elle suppose l'existence d'un surplus de biens et de services, affluant vers les villes naissantes, les temples et les palais, qui furent autant des entrepôts que des lieux de culte, de gouvernement ou de jouissance. Toutefois, si ce surplus est une condition de la division sociale du travail, de la hiérarchie subordonnant ceux qui 
produisent à ceux qui consomment, il n'est pas la clé de l'énigme que représente encore la victoire de la propriété privée sur la propriété collective. Nous sommes, en tout état de cause, réduits à des conjectures. Il est même probable que les classes sociales se sont constituées par plusieurs voies. L'une d'elles est la conquête, surtout lorsqu'il s'agit de peuples pasteurs, plus mobiles et plus guerriers, recherchant des terres pour leur bétail, prompts à soumettre les communautés d'agriculteurs, à les transformer en serfs ou en esclaves, s'offrant à protéger leur vie en échange de la cession, volontaire ou non, de leurs biens et de leurs bras. Progressivement ces producteurs se muent en non-producteurs, ces guerriers en administrateurs, et ils s'adjoignent une main-d'œuvre servile ou mercenaire. Leur qualité de pasteurs, par exemple, devient fictive. Ils se détachent du commun et choisissent pour fin la vie divine, c'est-à-dire le luxe, la rapine, l'organisation du corps social et le gouvernail du pouvoir. Les sociétés féodales, où la violence et la contrainte politique directe sont l'instrument de l'obéissance des classes inférieures, sont issues de cette évolution.

Dans le développement de l'artisanat et l'apparition conjointe du marchand, on peut voir une seconde racine de l'appropriation privée $^{841}$. La possession des arts et des outils impose des modes de partage et de domination différents de ceux qui accompagnent la possession de la terre ${ }^{842}$. L'individu lui-même est richesse et source de richesse. Quant aux produits artisanaux, leur fabrication régulière et le contrôle que l'on peut exercer sur leur volume et leur qualité les rendent aptes à l'accumulation et à l'échange à un degré bien supérieur à celui de toutes les productions connues antérieurement. La concentration, les migrations et la subdivision du travail artistique, implanté dans la cité, dans les palais ou dans les cellules communales, attirent

841 «Un nouveau principe d'organisation sociale fut alors introduit (avec l'artisanat). Et à mesure que ce nouveau principe s'étendait, l'ancienne base de parenté reculait. Les confréries d'artisans spécialisés avaient, bien sûr, tendance à devenir héréditaires, et dans cette mesure à conserver la parenté comme élément d'organisation. Mais la parenté était subordonnée à l'occupation et était de plus contenue dans les limites de la confrérie, de sorte que la parenté en tant que base d'organisation sociale diminuait en grandeur et en importance subordonnée ». L. WHITE : op. cit. p. 294.

842 G. DuMÉZIL : Métiers et classes fonctionnelles chez les divers peuples indo-européens, Annales, 1958, 13, pp. 756-24. 
le surplus agraire ${ }^{843}$, favorisent le commerce, le déplacement des matières premières et l'emploi de la monnaie. De plus en plus, dans les cités phéniciennes ou en Grèce, la hiérarchie personnelle, charnelle, concrète - surtout politique et militaire - est recouverte par le tissu fin et indéchirable des relations économiques et financières, où les individus ne sont plus que des débiteurs ou des créanciers. La propriété est là nue, dépouillée de l'appareil somptueux des communautés protectrices ou des rois créateurs de cosmos et générateurs de cataclysmes. L'individu est pratiquement isolé dans son atelier ou dans sa boutique ; le marché sort de l'orbite administrative, sépare le riche et le pauvre, le maître et celui qu'il a dépossédé, les obligeant à refluer vers leur sphère particulière. L'État, repris des systèmes sociaux précédents, replacé dans la cité, représente un agencement où les classes sociales, fortement individualisées, s'associent ou croisent le fer pour obtenir une fraction des biens disponibles et la domination des instruments de production.

Que ce soit par la conquête ou par la création d'une richesse matérielle particulière, engendrée par les arts, l'évolution qui va d'une prééminence de la possession collective à celle de la possession privée donne lieu à une nouvelle structure sociale. Là, les rapports qu'habiletés ou ressources instaurent entre les hommes ne s'ajustent plus aux rapports véritablement sociaux qu'établit la propriété et qui se nouent désormais entre producteurs et non-producteurs. Ceux qui dirigent les destinées et forgent les visions des sociétés ne sont engagés principalement ni dans la production des objets, ni dans celle des savoirs afférents. Les interactions avec les forces matérielles, la reproduction et l'invention du travail deviennent opaques aux yeux des classes oisives, guerrières ou thésaurisatrices, qui ne veulent connaître du travail que son produit, seul à avoir une valeur de richesse sociale. Quant aux hommes qui s'y consacrent, leur fin réelle étant prise pour un simple moyen, le sens de leurs actes n'apparaît plus en pleine lu-

843 « En règle générale, à l'intérieur même du système (propre au despotisme) mais en marge de sa contradiction fondamentale, le développement de la fortune privée, individuelle, dont le commerce est le ferment principal, [souligné par moi] tend à faire éclater cette contradiction par la suppression de l'un des termes, en l'espèce par la dissolution de la propriété collective du sol, l'entrée de la terre dans la sphère des marchandises ». J. SURET-CANALE : Les sociétés traditionnelles en Afrique tropicale et le concept de mode de production asiatique, La Pensée, 1964, 117, p. 28. 
mière. On admire l'œuvre, on ignore l'artiste. Telle est la devise d'une société où l'individu est fondamentalement esclave, serf, salarié, prince, marchand, et accessoirement agriculteur, mineur, ingénieur ou savant. Le noyau des rapports avec l'univers se présente comme étranger à lui-même puisque la valeur est déniée aux classes qui s'évertuent à les établir. Le cheminement, à cet égard, reste dans l'inconscient de l'histoire réelle. La nature apparaît ainsi comme le réceptacle des choses, l'ordre des matières où seul transparaît le produit fini, le tableau achevé des lois, des forces et des traits qui les réunissent. La double comptabilité du talent et de la richesse en masque les origines et l'initiateur, et crée une situation de schisme. Les rapports sociaux et les rapports naturels ne se répondent plus directement. Ils représentent des ordres distincts, voire opposés, ayant chacun son principe moteur. La division naturelle continue à régir la création du savoir effectif, les systèmes de reproduction à l'intérieur desquels les hommes se qualifient pour une activité déterminée et répartissent les talents disponibles. Mais la sphère de la production, du travail, s'éloigne de la sphère qui enferme la consommation, le loisir, l'appropriation. La différenciation des habiletés subordonnée à la différenciation due à la richesse, et la séparation des catégories naturelles et sociales, imposent la scission de chaque homme du point de vue du travail, de la propriété et du pouvoir. La lutte des classes se proclame l'âme de la société. Le résultat en est l'autonomie relative de l'histoire humaine de la société et de l'histoire humaine de la nature, qui se déterminent sans se dévoiler l'une à l'autre. L'État, l'administration et l'arbitrage politique en sont la résultante, le corpus de droits et de contraintes intervenant pour régler la vie matérielle et intellectuelle. La correspondance et la médiation entre société et nature sont ici celles de la civilisation.

Nous voyons aujourd'hui se dessiner, à travers l'exigence de gouverner la nature, les prémisses d'une troisième étape. Les événements auxquels je fais allusion se retrouvent au plan de l'état social comme à celui de l'état naturel. Les liens de reproduction que suppose la nature cybernétique, l'étendue des capacités qu'elle met en œuvre, la population qu'elle requiert, l'adaptation des propriétés biologiques à des milieux matériels inédits qu'elle laisse prévoir, ne s'accommodent pas de n'importe quelle forme d'organisation sociale. Savoir laquelle 
convient le mieux à ces liens ou peut en naître comme leur conséquence constitue un point focal pour la pensée et la pratique politiques. Parallèlement, et non sans rapport avec cet état naturel, s'ébauchent des systèmes sociaux originaux. Ce serait faire preuve d'une candeur excessive que de croire que la société dite capitaliste ou industrielle, parce qu'elle dure, sera perpétuelle. Malgré les limites, les vicissitudes historiques dont s'accompagne son institution, malgré la rudesse des moyens comparée à l'élévation des fins, le socialisme ne cesse d'être aujourd'hui, sur un mode ou un autre, à l'intérieur de chaque société, une de ses issues possibles. Néanmoins, quel que soit l'avenir de la société, ses deux états — capitaliste et socialiste — de par les préoccupations qu'ils expriment, témoignent d'un renouveau des relations avec le fondement naturel. Notre époque a quelque chose d'exceptionnel, non seulement parce que l'ordre social et l'ordre naturel se transforment, mais aussi parce que leurs principes tendent à changer. Ce fait, dont on prend peu à peu conscience, est signifié de deux manières en quelque sorte symétriques.

D'un côté, s'il est vrai qu'une partie de l'humanité se propose de réaliser ou réalise effectivement une société sans classes, elle s'interroge à juste titre : "Où sera le moteur de l'histoire ? " ${ }^{844}$. Jusqu'ici, il était représenté par la lutte des classes ; cette lutte cessant, on le suppose, le mouvement historique doit subir une refonte profonde. Seuls restent disponibles pour l'assurer — du moins suivant la théorie - l'échange avec les puissances matérielles, le développement des ressources inventives, bref les forces dites productives qui sont la contrepartie sociale de notre nature. D'emblée, avec la direction qui s'amorce, la création d'un type de société différent, le rapport de l'histoire sociale de l'homme à son histoire naturelle prend un caractère essentiel et explicite.

D'un autre côté, l'emprise de la progression naturelle, de ce principe qui, nous l'avons vu, anime l'expansion du travail inventif, est à tel point évidente qu'elle donne l'impression, justifiée, que les traits de l'évolution de la société vont être bouleversés. Un poids nouveau est accordé à la création de nos talents, de nos habiletés. Les produits 
de l'activité intellectuelle et pratique, faute d'avoir été envisagés à l'intérieur de leur réalité spécifique, ont été placés, soit trop bas, dans une sorte de purgatoire de l'histoire, où des millions d'êtres anonymes s'exténuent sans gloire, soit trop haut, dans l'empyrée des idées, où les inventions les plus riches et les plus nobles, celles qui ont le plus profondément pénétré notre existence, sont devenues leurs propres ombres. C'est bien le signe d'un changement radical que ce qu'il y a de plus élevé, la science, devienne le fondement positif de ce qu'il y a de plus quotidien, et que l'action sociale se voie contrainte de parler le langage de l'action naturelle. Le principe historique de la création de nos facultés, qui semblait jusqu'à maintenant cheminer de manière souterraine, vient au grand jour, et annonce un renversement des rapports avec les lois de la société :

« Désormais, écrit Claude Lévi-Strauss ${ }^{845}$ — et son allusion est nette l'histoire se ferait toute seule, et la société placée en dehors, et au-dessus de l'histoire, pourrait, une fois encore, assumer cette structure régulière et comme cristalline, dont les mieux préservées des sociétés primitives nous enseignent qu'elle n'est pas contradictoire à l'humanité ».

Qu'est-ce à dire, au delà des métaphores, sinon que le mouvement de la nature humaine devient l'élément qui donne son impulsion à la société humaine, dont l'histoire, bien loin de disparaître de l'horizon, change seulement de point d'application ? Dans la définition de ce point d'application, la progression naturelle est un facteur décisif.

Les liens entre société et nature, si l'on fait entrer en ligne de compte la convergence des deux séries d'événements, le renouvellement du contenu des termes et le déplacement du centre de gravité historique, dessinent un autre contour à notre réalité. Ses dimensions sont connues. L'une d'elles est l'apparition d'un principe nouveau, déterminant notre histoire naturelle. L'autre est la socialisation progressive - ou brusque - des échanges avec le milieu matériel, laquelle se traduit aussi bien par la concentration des possibilités de création du travail hors du domaine de l'appropriation privée que par la remise en cause de cette dernière. Un tel développement signifie 
que le processus naturel - et ipso facto le processus d'évolution des forces productives - redevient directeur dans l'histoire humaine, de manière immédiate et ouverte. Faisant surface, l'invention et la reproduction des facultés acquièrent une portée au moins aussi fondamentale que la production et la distribution des produits. Le but vers lequel elles tendent ne s'énonce plus en termes de conquête des forces matérielles, il englobe clairement la génération de nos facultés, la coordination des disciplines et, nous l'avons vu, la constitution de liaisons spécifiques entre les hommes. Reconnus, ces mécanismes que nous savons être naturels laissent entrevoir les prodromes du système social qu'il est nécessaire d'édifier pour répondre à leur incitation.

Les orientations indiquées - c'est là une hypothèse raisonnable et non pas une prophétie - nous laissent présager que les hommes viendront à considérer leur société comme une forme de leur nature. Le principe de l'histoire de cette dernière une fois institué principe moteur de l'ensemble de l'histoire humaine, les relations sociales pourront s'apparaître à elles-mêmes comme des transformations des relations naturelles. Non que la société redevienne sans histoire, mais parce que cette histoire s'édifie en prise immédiate sur les échanges avec les parties de l'univers auxquelles elle participe. Même s'il ne s'agit encore que d'une possibilité objectivement établie et d'un idéal qui a surgi dans le passé et s'y est affirmé, il est légitime d'observer que, dans la succession des rapports entre société et nature, s'annonce un rapport virtuel, nouveau : celui qui a pu être dénommé "postcivilisation ${ }^{846}$ ou que l'on peut appeler, conventionnellement, culture.

Barbarie, civilisation et culture désignent des rapports successifs entre l'histoire humaine de la nature et l'histoire de la société humaine. En parlant des époques que parcourt l'humanité, on ne peut certes pas s'empêcher d'introduire un jugement, un ordre de préférence. Ce jugement n'a rien d'absolu, il ne rabaisse pas plus le passé qu'il ne rehausse le présent. Il indique ce qui correspond à la situation des collectivités humaines à ce jour, les voies qui leur sont ouvertes. Même si les périodes révolues semblent avoir des côtés attrayants, les 
chemins qui leur étaient spécifiques nous sont irrémédiablement fermés. Devant la possibilité qui s'offre de gouverner notre devenir, des choix s'imposent, et l'irréversibilité des événements, de leurs effets, est indéniable. Outre sa visée théorique, l'étude succincte qui va suivre de la conjonction des relations sociales et des relations naturelles, de l'expression sociale de ces dernières, se propose de pénétrer le sens de l'ère qui se prépare, et dont nous percevons les signes avantcoureurs. 


\section{Chapitre premier.}

\section{La main et le cerveau : les manifestations sociales de la division naturelle}

\section{L'illusion organique}

\section{$\underline{\text { Retour à la Table des Matières }}$}

L'écartement des orbites historiques de la société et de la nature humaines est consécutif, dans la civilisation, à l'écartement des couches productives et non-productives. Cette tendance vers l'autonomie, vers la séparation, se heurte à la réalité où chacun des termes est obligé de trouver dans l'autre son expression. Ainsi les rapports naturels entre les hommes prennent un sens social et les rapports sociaux acquièrent une physionomie naturelle. C'est notamment le cas lorsqu'un segment de la collectivité, dont la fonction est d'organiser les institutions politiques ou la production, s'arroge le travail intellectuel comme sa propriété et son activité spécifique. Il rejette au pôle opposé le travail manuel et son agent, voué aux besognes matérielles et à la soumission. Au nom de cette division entre les individus qui ont un cerveau pour commander et ceux qui ont un corps pour obéir, on estime que les seconds doivent subvenir aux besoins des premiers. Une doctrine savamment élaborée par l'esprit et appuyée par la force s'est de la sorte perpétuée de génération en génération comme une évidence :

« Il y a des travailleurs intellectuels et des travailleurs manuels, écrivait déjà le philosophe chinois Men-Tse. Les travailleurs intellectuels maintiennent l'ordre parmi les autres; les travailleurs manuels sont tenus en ordre. Ceux qui 
sont tenus en ordre par les autres nourrissent ceux-ci. Ceux qui tiennent en ordre les autres sont nourris par ceux-là. Voilà ce qui est le devoir de tous sur terre... »

Doit-on attribuer à cette répartition des «cerveaux» et des « mains » le sens d'un fractionnement ou d'une spécialisation physiologiques ? Les opinions qui ont cours à ce sujet semblent le supposer. Elles voient dans le clivage du travail « manuel » et du travail « intellectuel » une véritable césure organique, un mécanisme bio-psychique ayant des effets historiques certains.

« La conscience primitive, écrit l'historien G. Thomson ${ }^{847}$, était pratique et concrète et non-théorique. Le développement du raisonnement théorique dépendit de la division entre travail intellectuel et manuel».

Mais n'est-ce pas là prendre une métaphore pour une définition rigoureuse, et accorder le rang de proposition scientifique à un postulat d'ordre idéologique ? Selon cette psychophysiologie naïve, le cerveau est le siège de l'abstraction et la main l'instrument de l'action. Dès lors le cerveau, séparé de la main, de la pratique, contraint de fonctionner, peut devenir théoricien. Tant que la main l'accompagne, la progression de ses idéations abstraites est ralentie. Devrait-on aussi estimer que, plus il y a de métaphysique, de science, dans une société, plus le cerveau et la main sont distants l'un de l'autre ? Ce matérialisme grossier entraîne des extrapolations incertaines et n'a aucun fondement rationnel, vérifiable, dans la réalité biologique. Il porte nécessairement une empreinte non-historique. Le contenu de ce que l'on entend par travail manuel et travail intellectuel a considérablement varié, et l'on aurait beaucoup de difficulté à les identifier respectivement à l'usage exclusif de l'intelligence ou de la force physique dans l'accomplissement des divers travaux dans la société et dans la nature. Quelle est donc leur signification ? La possibilité de différenciation de l'homo faber et de l'homo sapiens est moins due à l'individualité de la main et du cerveau qu'à celle des catégories naturelles possédant des habiletés particulières, associées au fonds matériel des systèmes col- 
lectifs des classes distinctes. La hiérarchie ${ }^{848}$ et l'inégalité généralement observées entre leurs porteurs reproduisent la hiérarchie, l'inégalité, effectives ou souhaitées, des classes sociales ellesmêmes ${ }^{849}$. Dans la mesure où cet écart traduit davantage une distance entre les groupes sociaux qu'un dédoublement des fonctions psychophysiologiques réelles, on peut voir dans la division du travail en manuel et intellectuel la manifestation sociale du processus de division naturelle.

Retour à la Table des Matières

\section{Un modèle abstrait.}

La richesse d'une société et d'une classe particulières provient de son habileté et du travail d'une catégorie d'individus qui lui est entièrement vouée, et son mode d'appropriation se reflète dans l'architectonique des relations économiques et spirituelles. Les rapports du propriétaire à ses esclaves, du noble féodal à ses serfs, etc. définissent les procédés d'organisation du corps social et d'enrichissement de ses maitres. Une richesse s'incarne toujours dans des ressources précises auxquelles elle s'attache : terres, cours d'eau, mines, etc. Elle a son répondant objectif dans l'habileté, les forces physiques, les routines de consommation, de loisir et d'exercice de la violence. Pour la classe des possédants, la forme sociale de la proprié-

848

« En remontant plus haut dans le passé, on trouverait que telle ou telle civilisation faisait aussi le choix entre les techniques nobles et les techniques non-nobles : l'histoire du peuple hébreu accorde un véritable privilège aux techniques pastorales, et considère la terre comme maudite. L'Éternel agrée les offrandes d'Abel et non celles de Caïn: le pasteur est supérieur à l'agriculteur. La Bible contient une multitude de schèmes de pensée et de paradigmes tirés de la manière de faire prospérer les troupeaux. Les évangiles au contraire introduisent les modes de pensée tirés de l'expérience de l'agriculture. Peut-être pourrait-on, aux origines des mythologies et des religions, trouver un certain parti-pris technologique consacrant comme noble une technique et refusant le droit de cité aux autres, même quand elles sont effectivement utilisées ; ce choix initial entre une technique majoritaire et une technique minoritaire, entre une technique valorisée et une technique dévaluée, donne à la culture qui incorpore les schèmes techniques ainsi découverts un aspect de particularité, de non-universalité ». G. SIMONDON : Du mode d'existence des objets techniques, Paris, 1958, p. 86.

«Ainsi la conception selon laquelle la pensée est le but final et complet de la nature est devenue la rationalisation d'une division existante des classes sociales. La séparation des hommes en non-pensants et chercheurs fut prise pour l'œuvre même de la nature. En fait elle s'identifiait à la division en travailleurs et hommes jouissant du loisir ». J. DEWEY : Experience and nature. Londres, 1929, p. 119. 
té et ce répondant matériel sont conformes à la «nature humaine » et coïncident parfaitement, l'un assurant la perpétuation de l'autre. Même la classe dépossédée est fidèle à cet agencement, car sa vie, ses réflexes psychologiques, son équilibre mental et ses possibilités d'agir y sont intégrés. Considérons maintenant l'apparition d'une catégorie naturelle. Au début, le travail qu'elle crée reste associé au travail existant - par exemple le travail de l'ingénieur à celui de l'artisan — et ne s'en distingue pas socialement. Néanmoins, de par son développement, lorsqu'il devient suffisamment abondant, il se fait source d'une richesse exigeant des moyens de production propres et une organisation distincte de la société.

Le premier signe en est le dépérissement progressif qui s'empare du soubassement matériel de la richesse existante, le risque qu'il lui fait courir d'être vidé de tout contenu. De la sorte, une classe sociale qui soumettait un ordre particulier de producteurs et voyait sa propriété incarnée dans une force matérielle spécifique - terre, charbon, eau, etc. se sent menacée. En face d'elle se trouve son antagoniste, administrant et agissant au nom d'une nouvelle ressource matérielle, donc au nom d'une autre catégorie naturelle et d'un rapport à la matière différent. La substance solide de son univers se dissout à vue d'œil, tandis que les facultés correspondantes se racornissent et se dévaluent. Toute une nature recule, tout un monde est englouti. Les besoins changent ou se déplacent, ce qui formait un être plein et consistant se moule en creux et devient l'enveloppe d'un autre noyau réel, dont la possession échappe aux maîtres habituels. La lutte contre cette érosion est aussi lutte d'intérêts, conflit entre des classes dont les biens s'incarnent dans des ressources matérielles d'origine différente — et dans les habiletés qui y sont associées. Les oppositions qui s'affirment sont toujours, dans ces circonstances, des oppositions à cette origine elle-même.

Le deuxième signe est le renouvellement de la division sociale. Les contraintes du système social, la nécessité d'une efficacité accrue, font qu'une partie des producteurs se consacrent davantage aux échanges purement économiques, à la défense des intérêts collectifs, avant de s'instituer les maîtres de la collectivité dans son ensemble, et de l'appropriation des richesses disponibles en particulier. Ainsi la classe 
marchande est sortie du sein de l'artisanat pour le décharger du travail requis par l'écoulement des produits. Tantôt cette spécialisation, cette division sociale à partir d'une catégorie naturelle aboutit à la constitution d'une classe sociale nouvelle - celle des capitalistes, par exemple - tantôt elle consolide la catégorie en question, fait épanouir ce qui est implicite dans les lois qui la dirigent, et en métamorphose le contenu. Henri Pirenne a observé ce changement de composition pour la classe des seigneurs du capital :

«Je crois, écrit-il ${ }^{850}$, que pour chacune des périodes en lesquelles on peut diviser notre histoire économique, il y a une classe distincte et séparée de capitalistes. En d'autres termes, le groupe de capitalistes d'une époque donnée ne provient pas du groupe capitaliste de l'époque précédente. A chaque changement de l'organisation économique, nous trouvons une solution de continuité ».

La cause de ces solutions de continuité se trouve dans le passage de l'art à la technique, de l'artisan à l'ingénieur, passage qui, à l'époque considérée, modèle le visage du capital et donne naissance à des capitalistes liés tout d'abord à la première catégorie, ensuite à la seconde. Nécessairement, à l'intérieur de la même classe, se cristallisent des antagonismes à l'égard des forces matérielles, des capacités productives, des relations avec le monde matériel qui se substituent aux forces, aux capacités et aux relations coutumières. Les machines et les inventions mécaniques n'ont pas rencontré uniquement la résistance des hommes de métier qu'elles remplaçaient ; si ceux-ci les ont brisées, ils l'ont fait en accord tacite avec les propriétaires de forces productives menacées d'obsolescence ${ }^{851}$ et les chantres romantiques d'un ordre naturel révolu.

Bref, l'ascension d'une catégorie naturelle — et d'une puissance matérielle, substance de la propriété, sa "valeur d'usage », aurait dit Karl Marx - suscite une réaction de la part des classes sociales dont la subsistance ou la fortune dépend d'autres puissances, d'un autre travail. Par contre, elle engendre des groupes capables de remplir les

H. PIRENNE : The stages in the social history of capitalism, Amer. Hist. Rev. 1914, 19, p. 494. 
fonctions sociales qui lui sont indispensables ou reçoit le soutien de ceux qui y voient un moyen d'accroître leur bien-être, de s'intégrer à la classe sociale qui accède au royaume de la prospérité. La division naturelle prend une forme sociale, et l'opposition ou la liaison à une catégorie de « porteurs d'invention » motive la désignation d'une relation à la matière, comme étant conforme ou non à la nature, qui est, en l'occurrence, la nature hypostasiée d'un ordre social où ses couches supérieures trouvent profit et aisance. Le travail manuel et le travail intellectuel sont définis dans ce contexte. Nous le verrons mieux à propos d'un exemple particulier.

Retour à la Table des Matières

\section{L'exemple grec.}

Aux $V^{\mathrm{e}}$ et $\mathrm{IV}^{\mathrm{e}}$ siècles avant J.C., en Grèce et surtout à Athènes, artisans et marchands avaient acquis une position prédominante. Partout ils déployaient une activité intense et remodelaient le visage de la cité. Avec eux, la navigation avait pris une très grande importance ; le trafic maritime était nécessaire à l'approvisionnement en denrées, à l'échange des marchandises. Il fournissait également un débouché aux hommes de métier. Mais le tableau n'est pas complet. A la place du hoplite, petit propriétaire agraire armé, du noble chevalier et de leurs authentiques valeurs guerrières, les commerçants et les artisans témoignaient d'une nouvelle puissance et d'une nouvelle stratégie basées sur la marine ${ }^{852}$. Sur le plan politique, l'art et le commerce symbolisaient la victoire des partis populaires, le choix des constitutions démocratiques, une conception définie de l'État. Cette situation était explosive. Le conflit entre oligarches et démocrates, les deux forces qui cherchaient à diriger la cité, s'exprimait d'emblée dans l'antagonisme suscité par le rôle de la marine, la forme de vie qui y

852 «La démocratisation de l’État semble conditionnée avant tout par le transfert de la puissance militaire athénienne à la marine. Eu égard à ce danger, l'opposition anti-démocratique avait attaché du prix, dès le début, à la conservation de la base agraire de la république... Contre le développement de la marine, les milieux anti-démocratiques s'étaient aussi révoltés dans la crainte que la puissance des hoplites, qui répondait à la base de leur vie agraire, ne perdît de l'importance ». G. PRESTEL : Die antidemokratische Strömung im Athen des 5. Jahrhunderts, Breslau, 1959, p. 28. 
était attachée, les valeurs militaires situées à l'opposé des vertus traditionnelles. Platon est catégorique à ce sujet :

«Les États qui doivent leur puissance ou, en même temps, leur salut à leur organisation navale, n'en reportent pas l'honneur sur ce qui, parmi les acteurs de la guerre, vaut le plus; c'est grâce à l'habileté du commandant du navire, grâce à celle du maître d'équipage, du chef des rameurs, c'est grâce à cette foule bigarrée d'hommes qui ne sont pas considérés qu'a été gagnée la victoire ${ }^{853}$.

Cependant, à travers cette opinion, se profile un souci plus profond et plus vaste. L'effet le plus radical de ce nouvel instrument militaire, et de la richesse qui le sous-tend, est l'amenuisement du statut, du pouvoir politique et de la fortune de la classe qui jouit du loisir et des dignités grâce au travail de l'agriculteur ${ }^{854}$. La flotte non seulement fortifie l'empire de l'argent opposé à la terre, elle accroît aussi l'importance de l'artisan en face de l'agriculteur, offre une solution de rechange aux paysans qui désertent la terre, et contribue à accélérer cette désertion.

La défense de l'aristocratie, c'est évident, se confond avec celle de ses biens-fonds, des coutumes et des croyances qui leur sont attachées, de la production agricole et des producteurs qui la perpétuent. A ses yeux, l'accumulation des connaissances artistiques est à la fois inutile et impossible. En ces termes s'exprime le refus d'accroître un savoir susceptible de faire avancer les arts, d'encourager une classe d'hommes à étendre et consolider leurs facultés productives. Pour arrêter cette extension, Platon aurait souhaité édicter des règles interdisant l'acquisition de dextérités nouvelles. Les conséquences de ces mesures étaient aperçues clairement, puisqu'on y répond en ces termes :

« La loi dont tu parles, qui s'opposerait à toute recherche, serait pour nous la ruine totale de tous les arts, et même à jamais l'impossibilité d'une renaissance $\gg{ }^{855}$.

PLATON : Les Lois, IV, 707 a.

854

A. ZIMMERN : The Greek commonwealth, New York, 1961, p. 230.

Platon : La Politique, 299 e. 
Bien mieux, le régime des castes, fixant les règles des métiers et maintenant ceux-ci dans un corset rigide, lui paraît propre à assurer la conservation d'un État où l'aristocratie terrienne se sente à l'abri de toute menace :

« Voici donc le premier règlement à établir dans la cité : qu'un ouvrier en métal ne travaille pas en même temps le bois, qu'un charpentier ne s'occupe pas d'ouvriers en métal plus qu'il ne fait de son propre métier, sous le prétexte que, surveillant plusieurs serviteurs qui travaillent à son profit, il est naturel qu'il donne plus d'attention à l'ouvrage qu'il fait par eux, ou qu'il en tire un plus fort revenu que de son propre métier; que chacun au contraire n'ait dans la cité qu'un métier à lui tout seul et gagne aussi, à ce métier, sa vie ${ }^{856}$.

L'attaque dirigée contre l'artisanat revêt une forme plus directe lorsque, conformément à une vieille tradition égyptienne, reprise en l'occurrence, les arts sont proclamés serviles, tandis que l'agriculture, la guerre, l'élevage des chevaux sont tenus pour nobles. Xénophon nous livre à cette occasion le témoignage d'une attitude qu'il aurait aimé voir se généraliser :

«Très bien, Cristobule, dit son Socrate, car assurément les arts illibéraux, ainsi qu'on les appelle, sont décriés et sont naturellement tenus dans le plus parfait mépris dans nos États. Car ils gâtent le corps des ouvriers et des contremaîtres, les forçant à rester assis et à vivre à l'intérieur, et, en certains cas, à passer toute la journée près du feu » ${ }^{857}$.

L'obéissant Cristobule demande alors à Socrate de définir les arts les plus nobles, et celui-ci répond :

«Devons-nous avoir honte d'imiter le roi des Perses? Car on dit qu'il donne une grande attention à l'agriculture et à l'art de la guerre, considérant que ce sont deux des fins les plus nobles et les plus nécessaires $»{ }^{858}$. 
Voilà donc le roi des Perses, maître d'un empire despotique où ne règne d'autre loi que celle de son bon plaisir, ami de la guerre, enrichi par la violence, devenu le modèle de la cité athénienne, de la cité qui justement, grâce à sa marine, l'a défait lorsqu'il menaçait la terre grecque. Aux Thermopyles et à Platée l'héroïsme des hommes leur fit honneur, et à Marathon leur volonté de vivre atteignit au sublime. Xerxès resta néanmoins vainqueur. A Salamine, la guerre fut gagnée par la flotte. Les Athéniens avaient montré la vérité de l'aphorisme de Xénophane : "Car bien meilleur est notre art que la force des hommes et des chevaux ». Cependant les témoignages de cette histoire dont il fut un des acteurs ne suscitèrent pas en Socrate - ou en Xénophon qui le met en scène - l'écho auquel on aurait pu s'attendre. Ne continue-t-il pas à propager des conceptions anciennes lorsqu'il affirme :

« Or nous croyions qu'il est impossible d'apprendre toutes les sciences, et nous étions d'accord avec nos États en rejetant les arts dits illibéraux, parce qu'ils semblent gâcher le corps et affaiblir l'esprit. Nous disions que la preuve la plus claire de ceci apparaîtrait si, dans le cours d'une invasion ennemie, on faisait se placer à part les agriculteurs et les artisans et qu'on demandât à chaque groupe s'ils votaient pour défendre le pays ou pour se retirer de la plaine et garder les forteresses. Nous croyions que, dans ces circonstances, ceux qui s'occupent de la terre voteraient pour la défendre, les artisans pour ne pas combattre mais pour rester assis, comme on leur a appris à le faire, loin de la peine et du danger $\gg{ }^{859}$.

Le laboureur n'est-il pas, en effet, associé à l'activité guerrière, n'est-il pas censé appartenir à une communauté d'hommes toujours disposés à se retrouver sur le champ de bataille? De plus l'agriculture, ressemblant en cela à la guerre, n'est pas un métier. Devrait-on classer l'une et l'autre parmi les technai ? Assurément non. La techne est un savoir spécialisé ; elle exige un apprentissage et possède des procédés secrets de réussite ; confinant les hommes dans les ateliers, elle leur fait perdre la familiarité avec les périls physiques. L'agriculture, au contraire, ne fait pas appel à un apprentissage particulier, elle n'a pas de secrets, et si les hommes y réussissent inégalement, cela n'est pas dû à l'écart de leurs connaissances mais à la différence des efforts qu'ils y déploient. Le courage est indispensable au 
cultivateur, qu'il s'agisse de maîtriser les animaux ou de faire face aux intempéries. Sur tous ces points, l'agriculture s'approche de la guerre - la guerre aristocratique, bien entendu - comme pratique et mode de vie humains, et s'éloigne des métiers et du commerce ou de la navigation.

Dans ce cadre économique, politique et philosophique, le travail artisanal, la main se chargent d'une signification qui tend à les dévaluer ${ }^{860}$. Dédaigner ce travail, ce n'est pas seulement exprimer son hostilité envers l'artisan, son activité physique ; en effet ce sentiment s'étend au marchand qui l'accompagne ${ }^{861}$. Les menaces que tous deux représentent pour la classe aristocratique sont perceptibles sur le plan économique et politique : là se trouve la racine du jugement porté sur le travail manuel. On doit y insister il ne s'agit pas de n'importe quel travail, mais de celui de l'artisan ${ }^{862}$. L'agriculteur, son labeur et ses routines sont glorifiés, tenus pour nobles et sacrés ${ }^{863}$. Sans doute les éloges s'adressent-ils à l'agriculture en général, à l'essence universelle de l'agriculture personnifiée par la terre et son propriétaire. Celui-ci ne songe pas à la diversité des travaux tels que traire les vaches, actionner les moulins, fumer les terres, labourer, qui ne semblent pas être des occupations plus nobles - ou moins manuelles - que les occupations du potier ou du forgeron. Plutarque a, de nombreuses façons, façonné cette vision qui condamne les arts serviles, le travail

«Tous les préjugés contre le travail manuel chez les Grecs sont d'origine relativement tardive ». H. MiCHELL : The economics of ancient Greece, Cambridge, 1940, p. 10.

861

« Néanmoins, dans la Grèce classique et à Rome, un autre criterium sert couramment à distinguer le travail honorable du travail méprisé : les éloges sont réservés au travail agricole, alors qu'une condamnation à peu près unanime frappe le travail artisanal et commercial». A. AYMARD : L'idée de travail dans la Grèce archaïque, J. de Psychol. 1948, 41, p. 43.

${ }^{862}$ Le mépris du travail manuel est à la lettre mépris du travail artisanal. En Ionie et en Asie mineure, le nom de l'artisan est cheirmas et traduit l'idée d'un homme qui sait commander à ses bras, l'idée de maîtrise. En Attique, le mot n'est pas usité ; on y parle, péjorativement, de banausos, qui désigne surtout les artisans familiarisés avec la technique du feu. Voir P. Chantraine :: Trois noms grecs de l'artisan, in Mélanges Auguste Diès, Paris, 1956, pp. 4147.

${ }^{863}$ « D'ordinaire, au moins, s'il s'agit du propriétaire exploitant son propre domaine, l'agriculteur est excepté de cette condamnation à la fois morale et sociale. L'exception est unique. Le discrédit frappe également tous les autres travailleurs, commerçants aussi bien qu'artisans ». A. AYMARD : Hiérarchie du travail et autarcie individuelle dans la Grèce antique, Rev. d'Hist. de la Philos, et Hist. gén. de la Civilis. 1943, p. 215 ; M.I. FINLEY (ed.) : Slavery in classical antiquity, Cambridge, 1960. 
manuel, pour exalter la noblesse du loisir et de l'agriculture. Voici comment il décrit Lycurgue :

«Car l'une des plus belles et des plus luxueuses choses que Lycurgue introduisit oncques en sa ville fut le grand loisir qu'il fit avoir à ses citoyens, ne leur permettant point qu'ils se puissent employer à métier quelconque, vil ni mécanique $\gg . . .{ }^{864}$.

Tel est le leit-motiv d'une partie de la pensée et d'une partie de la société grecques, et ensuite de la pensée et de la société romaines. Les artisans et les commerçants restent ou doivent rester des étrangers ou des esclaves, afin de justifier la visée politique ou économique fondamentale et de lui donner une signification idéale, à savoir que le travail de l'artisan est la partie méprisée du travail, exercée par la main, le corps, sans intelligence et, pour ainsi dire, sans connaissance ${ }^{865}$. En face de la vertu quasi religieuse du sol, du savoir-faire agraire, l'emploi habile de la main, la discipline imposée aux sens, sont supposés inférieurs, moins entraînés à la reconnaissance des signes célestes, à celle des lois et des nécessités de la guerre.

De toute évidence, ces arguments portent le sceau d'une interprétation unilatérale de la réalité. Objectivement, le labeur de l'agriculteur est au moins aussi sublime ou aussi borné que celui de l'artisan. L'exercice de l'art n'est pas davantage servile, c'est-à-dire du ressort exclusif des esclaves. Assurément il y a à Athènes, comme à Rome et comme auparavant en Égypte ou en Mésopotamie, des esclaves qui exercent des métiers. Cependant aucune recherche historique n'a pu établir que le travail était réservé aux esclaves ${ }^{866}$. Donc, ce n'est ni dans la structure du travail, ni dans la condition sociale de ceux qui

864

865 tion in the Near East, New York, 1962.

866

"L'etude des artisans de l'ancienne Egypte et de leur statut social devrait nous mettre en garde contre les déclarations catégoriques que l'on rencontre dans de nombreux ouvrages sur la science et la technique de l'antiquité. Si nous nous limitons à Rome, dans la période qui va de 250 av. J.-C. à 100 ap. J.-C., nous sommes en droit de parler de sociétés esclavagistes, mais ceci n'est pas valable pour d'autres périodes de l'histoire ancienne, ni même, dans la période envisagée, pour tous les artisans dans tout le bassin de la Méditerranée ». R.J. FORBES : Professional crafts in ancient Egypt, Arch. Inter. Hist. Sc. 1950, 12, p. 618. 
s'y consacrent, que l'on doit rechercher la motivation d'un tel mépris $\mathrm{du}$ travail. Celui-ci, du reste, ne trouve-t-il pas aussi ses défenseurs ${ }^{867}$ ? Dans le souvenir de tous, le nom d'Anaxagore reste attaché à la glorification de la main comme instrument essentiel de la transformation de la nature humaine et indice visible du nous, cette intelligence suprême si profondément vénérée. Malgré les partis pris de Platon, de l'aristocratie, les arts font, à partir du iv siècle, des progrès décisifs et les premiers ingénieurs apparaissent à Alexandrie. Pappus, le grand philosophe mathématicien rejette explicitement les idées qui, systématisées par une fraction de la philosophie grecque, auraient pu trouver une large audience :

«La géométrie, écrit-il à son fils Hermodore ${ }^{868}$, ne déchoit nullement lorsque, s'appliquant à nombre d'arts, elle tend à les corroborer, mais elle semble, au contraire, promouvoir les arts et en être ainsi honorée et embellie comme il sied».

Les résultats du travail intellectuel peuvent ainsi s'adjoindre au travail proprement manuel. Du reste, le caractère relativement externe de cette opposition s'affirme chez Aristote ; tout en y souscrivant, il n'en déclare pas moins que chaque homme véritablement doué aime le travail de ses mains :

«La raison en est que l'existence est pour tous les hommes une chose qu'ils doivent chérir et aimer; et que le métier manuel est, dans un sens, le producteur en activité ; il aime son métier, par conséquent, parce qu'il aime l'existence ${ }^{869}$.

La ségrégation si vivement réclamée du travail manuel et du travail intellectuel nous renvoie donc à celle des catégories naturelles pour autant qu'elles sont associées à une classe sociale et obéissent aux rapports que cette classe entretient avec les autres. Les droits conférés par les lois de la propriété enferment le maître et l'esclave, le possédant et le non-possédant, dans un cycle social, économique, où ils se 
rencontrent comme le non-travail en face du travail, le pur consommateur en face du producteur, le dirigeant en face du dirigé. Les luttes, les guerres civiles, les négociations politiques ont pour enjeu la richesse, quelle qu'en soit la provenance matérielle - agriculture ou artisanat. Parallèlement d'autres sources de conflit prennent de l'importance. De nouvelles ressources mettent en question le contenu de la propriété, sa perdurabilité, et avec elles surgissent d'autres possédants et d'autres non-possédants. Nous l'avons constaté : à côté de l'aristocrate et de l'agriculteur apparaissent l'artisan et le marchand. Une perte de substance politique et économique est la perspective immédiatement envisagée et ressentie par les premiers ${ }^{870}$. Pour contrecarrer cette perte de substance, une classe doit combattre les « nouveaux pauvres » en même temps que les " nouveaux riches », c'est-à-dire la catégorie naturelle qui symbolise les assises matérielles, les habiletés, les modes de reproduction du travail à partir desquels les « nouveaux riches », une autre classe sociale dominante, s'assurent le confort et le pouvoir ${ }^{871}$. La lutte pour ou contre cette catégorie est une forme de la lutte entre classes sociales. Elle a pour fin la maîtrise de l'état naturel, des forces productives qui l'expriment socialement, et, ipso facto, le maintien pratique et idéologique des structures étatiques et politiques qui lui correspondent.

Retour à la Table des Matières

871

G. TOzZI : Eonomisti greci e romani, Milan, 1961.

Il est donc erroné d'entendre par lutte des classes uniquement la lutte des riches contre les pauvres, et de ne pas voir la lutte des riches entre eux et des pauvres entre eux, cette guerre de tous contre tous dont parle Hobbes; il est donc faux d'affirmer, comme on l'a fait (A. AYMARD : L'Orient et la Grèce antiques, Paris, 1953, p. 300) que le conflit des oligarques et des démocrates à Athènes est uniquement la lutte « des riches et des pauvres ». 


\section{La querelle des arts et l'artisan supérieur}

$\underline{\text { Retour à la Table des Matières }}$

\section{Les arts libéraux et les arts mécaniques.}

Dans l'antiquité, l'opprobre dont était entouré le travail artistique, du plus raffiné au plus grossier, était l'indice d'une action concrète dirigée contre son épanouissement. Le monde médiéval, où l'agriculture occupait une place éminente, ne s'est pas écarté radicalement de cette attitude, à laquelle il a donné une formulation théologique et la solennité des grands rites. Il tolérait ou encourageait les métiers, mais il n'avait d'estime profonde que pour l'ancienne trinité du laboureur, du soldat et du prêtre (ou de l'orateur). La parole et la réflexion, pures de tout mélange avec ce qui concerne le monde de la main ou de la matière, sont les signes d'une activité supérieure. Dans les raffinements de toute grammaire, il faut chercher le degré de raffinement dans la servitude auquel ils correspondent. Une arithmétique étrange combine l'acte verbal et l'acte empirique, fournit les règles de leur amalgame et sert à définir un art comme mécanique ou libéral ${ }^{872}$, à le proclamer digne ou indigne d'un homme libre. Le Moyen Age a systématisé ces différences ${ }^{873}$, les a érigées en critères rigides d'une hiérarchie des arts et de leurs praticiens ${ }^{874}$. Les arts mécaniques, qui font intervenir la main et l'outil, occupent en général un rang subalterne. Les arts libéraux, ceux qui sont consacrés de préférence à la parole et à la réflexion, sont considérés comme élevés ${ }^{875}$.

872

Il faut comprendre que les arts mécaniques ont d'abord été inventés pour que, par leur moyen, se fît l'acquisition et la découverte de ce qui était nécessaire au corps, et qu'ainsi l'âme libérée pût s'adonner à l'étude des sciences libérales ». J. DACI : Opera, ed. A. ОтTO, Haunia, 1955, p. 20

874 H. SCHOPPER : De omnibus illiberalibus sive mechanicis artibus, Francfort, 1574.

875 E. GARIN : Le dispute delle arti nel quattrocento, Florence, 1947. 
C'est ainsi qu'à la Renaissance ${ }^{876}$, lorsque l'artiste-ingénieur acquiert une individualité et se constitue en catégorie naturelle, il lui faut déterminer sa place parmi les autres artisans, marquer son originalité, trouver une traduction sociale ${ }^{877}$ appropriée à son savoir, qui le différencie de l'ensemble de l'artisanat ${ }^{878}$. En d'autres termes, cette catégorie doit se distinguer aussi par un critère visible aux yeux de la société, critère qui assure la reconnaissance de son art comme majeur et même supérieur aux autres arts. Le seul recours qu'elle ait pour y parvenir est de se poser en tant que « libérale », c'est-à-dire comme ayant intégré dans son habileté la pensée théorique ${ }^{879}$, de faire passer son travail pour intellectuel. C'est de cette façon seulement qu'un développement normal de ses capacités créatrices et une rétribution convenable pourront lui être garantis.

Avec la technique de l'ingénieur, étroitement liée à elle, toute une famille d'arts est rehaussée et la rehausse. Notamment la sculpture et la peinture. A leur sujet, comme nous l'avons déjà noté pour la mécanique ${ }^{880}$, les opinions régnantes doivent être profondément bouleversées. Pour Cennino Cennini, la peinture est encore un art manuel ${ }^{\mathbf{8 8 1}}$ :

«C'est un art que l'on désigne par le mot de peindre; il demande la fantaisie et l'habileté des mains; il veut trouver des choses nouvelles cachées sous les formes connues de la nature, et les exprimer avec la main de manière à faire croire que ce qui n'est pas soit ».

C'est là le point de vue artisanal du Moyen Age. Alberti, Léonard de Vinci, Michel-Ange, Dürer et tous les artistes-ingénieurs rompent

876 L'antithèse sociale des arts mécaniques et des arts liberaux, des mains et de la langue, a influencé toute l'activité intellectuelle et professionnelle de la Renaissance ». E. ZILSEL : art. cit. p. 550.

877

Riches de leurs nouvelles méthodes scientifiques, ils (les sculpteurs, les peintres, les architectes) commencèrent à faire valoir leur supériorité sur les simples artisans et tentèrent de se donner un meilleur statut social ». A. BLunT : La théorie des Arts en Italie de 1450 à 1600, Paris, 1963, p. 75.

878

879 Inst. 1951, 54, pp. 234-58 ; O.J. GORDON : Poet and architect, J. of the Warb. and Court. Inst. 1949, 12, p. 152.

880 Voir Chapitres III et IV de la $2^{\mathrm{e}}$ Partie.

881 C. CENNINI : Traité de peinture, ed. 1843, p. 30. 
avec cette tradition. Pour eux, la peinture est un mode de connaissance, un art qui exige un savoir intellectuel, bref un art libéral. Ce n'est pas l'action manuelle, matérielle, qui est différenciation, mais la présence d'une intelligence particulière à l'œuvre. La main ne rabaisse pas un métier, la connaissance savante le relève. L'outil, l'exercice physique n'indiquent une subordination que pour autant qu'ils sont privés du secours d'un savoir éminent. D'où l'appel aux mathématiques, à la mesure, au dessin conçu à l'instar d'une science géométrique, qui donnent à un métier un titre de noblesse. Cependant, on le voit au détail, des contradictions subsistent.

Léonard de Vinci acquiesce à l'ancien critère de ségrégation des arts tant qu'il s'agit de prouver l'excellence de la peinture, notamment face à la sculpture :

«La sculpture n'est pas une science mais un art très mécanique, parce qu'elle engendre la sueur et la fatigue corporelle chez celui qui la pratique ».

C'est un des buts de son Traité de peinture que d'établir le caractère libéral de l'art, de décrire les signes du rang social qui convient à l'artisan-supérieur et de rappeler la distance qui le sépare du simple travailleur de l'atelier ${ }^{882}$.

Pourtant Léonard de Vinci, comme les autres artisans-supérieurs de la Renaissance ${ }^{883}$, est aussi sculpteur, mécanicien, ingénieur militaire, etc. Cela le détermine à revendiquer avec véhémence le caractère intellectuel de tout ce qui a trait à l'instrument et à l'opération manuelle :

«Et si tu dis que les sciences vraies et connues sont de l'espèce de la mécanique parce qu'elles aboutissent manuellement, j'en dirai de même de tous les arts de l'espèce du dessin, même de la peinture : l'astrologie et les autres passent par les opérations manuelles ; mais d'abord elles sont mentales comme

«Toutes ces discussions supposent la croyance implicite en la supériorité de l'intellectuel sur le manuel ou mechanique - et cette croyance répond chez les artisans au désir de se laver de l'accusation de n'être que des artisans - car le travail manuel était pour la société de la Renaissance chose tout aussi ignoble que pour la société médiévale ». A. BLUNT : op. cit. p. 83. 
la peinture, laquelle réside dans l'esprit de l'artiste et ne peut parvenir à la perfection sans l'opération manuelle ».

En apparence, il semble adhérer à un point de vue bien établi parmi les artisans, dont témoigne Cennini :

«Le fondement de l'art et le commencement de tout travail manuel reposent sur le dessin et sur la couleur ${ }^{\mathbf{8 8 4}}$.

Mais le dessin s'est transformé en une discipline quasi mathématique la perspective. L'application de celle-ci exige un savoir approfondi et une longue chaîne de préparations, de jugements d'ordre géométrique, de mesures, où l'exécution manuelle effective ne vient qu'en tout dernier lieu. Le contenu de ce que l'on entend par le vocable d' ' intellectuel » change. Ce serait nier l'essence même de l'habileté de l'ingénieur, son intérêt pour les phénomènes matériels, l'instrument mathématique et l'invention, que de situer la supériorité de son art dans l'excellence de la parole et la spéculation pure. La discipline du dessin remplit désormais l'office d'élément intellectuel. Francesco di Giorgio Martini lie le destin de l'art libéral à la qualité du dessin. S'il concède un aspect mécanique, manuel, il insiste sur sa grande utilité :

« Donc, bien que chez nous on l'estime (l'art du dessin) vil et inférieur à d'autres arts mécaniques, néanmoins en considérant combien il est utile et nécessaire dans toute ouvre humaine, dans l'invention, dans l'explication des concepts, dans la pratique et pour l'art militaire... ${ }^{885}$.

Avec une insistance qui ne craint pas la redite, chaque ingénieur retrouve des arguments identiques pour démontrer le caractère intellectuel de son habileté et faire litière des jugements portés contre le recours à l'instrument, au dessin, aux dextérités manuelles. Le résultat en est un retournement complet : un art, une discipline qui ne connaît pas l'intervention de la main ${ }^{\mathbf{8 8 6}}$, de la main qui guide un instrument

C. CENNINI : op. cit. p. 32.

86 E. PANOFSKY : Artist, scientist, genius, in The Renaissance, a symposium, New York, 1953 (roneo). 
mécanique, n'est pas jugé digne d'attention et porteur de certitude. Si cette combinaison a lieu, il n'est pas question de parler du caractère vil du travail manuel. B. Lorini admoneste les responsables militaires qui, bourrés de préjugés, pensent pouvoir dédaigner la connaissance de l'art du dessin :

«Et celui qui méprisera et fera peu de cas des intelligences du dessin, en disant que c'est l'œuvre des mécaniciens et des gens de basse condition, je dis sans aucun doute qu'il se trouve dans une profonde erreur, et par conséquent manque de perfection dans le commandement ${ }^{\mathbf{8 8 7}}$.

Le titre de mécanique commence à être revendiqué comme un titre honorable, ayant un passé historique solide et glorieux. Un homme qui le porte, même s'il est de rang social élevé, peut s'enorgueillir de la pratique de cet art ${ }^{888}$, et l'histoire, réinterprétée, est appelée à la rescousse. L'ingénieur Jacques Besson s'adresse en ces termes à François d'Hastings ${ }^{889}$ :

«Monsieur, outre ce que ma petitesse peut me regarder, voire me convaincre d'une hardiesse démesurée en ce que j'entreprens de mesler votre illustre nom parmi aucune chose venue de moy, ce titre attribué aux ouvriers de ce qui est descrit en ce livre, en les appelant mechaniques, descrie tellement l'ouvrage, qu'il semble que vous en tenir seulement propos soit une lourde faute et du tout inexcusable. Mais pour répondre en premier lieu à ce dernier poinct, ceux qui scavent que vaut ce mot de Mechanique en la langue Grecque, dont il a été tiré (et ne signifie autre chose qu'un inventeur ou ouvrier d'engins et machines desquelles l'usage s'estend en tout ce qui est requis en la vie presente, soit en temps de guerre ou de paix) jugeront de cette tout excellente science (je dis science vrayment demonstrative) non pas selon que porte l'abus du commun, mais selon la vérité ».

Voilà donc la dénomination de mécanique, dont on disait qu'elle vient de «moechus », bâtard, servile, appuyée par une haute tradition grecque, et tous les stéréotypes qu'elle charrie attribués à l'abus du commun. L'habitude est prise de se réclamer de cette tradition et de se proclamer descendant des grands mécaniciens d'Alexandrie et de Sy-

Idem, p. 196.

889 J. BESSON : Théâtre des instruments mathématiques et mechaniques, Lyon, 1578, Préface. 
racuse, en tournant à son profit les déclarations, si populaires, de Plutarque. Archimède, Héron, Archytas sont les grands génies dont on revendique le parrainage et dont on continue l'œuvre. La dignité des mathématiques est la dignité même des sciences de l'ingénieur. Les arts ne sont pas libéraux ou mécaniques, mais mathématiques et inventifs - ou ne sont pas. La dichotomie ancienne est provisoirement éliminée et l'univers lui-même peut se mettre à travailler de ses mains. Le triomphe d'un nouveau travail et d'une nouvelle intellectualité ${ }^{890}$, la constitution de nouvelles assises matérielles, s'imposent à une partie de la société, et, de ce fait, les antagonismes se font fluides et changent de sens ${ }^{891}$.

$\underline{\text { Retour à la Table des Matières }}$

\section{Conclusion.}

Pour les ingénieurs, on vient de le voir, prouver leur droit à l'autonomie, poursuivre la création des ressources inventives et des talents propres, forcer le corps social à les accepter, tout cela implique un combat incessant contre les pouvoirs qui leur font obstacle. D'un côté le cadre des corporations artisanales, avec des règlements et des habitudes profondément ancrés, qui entravent l'activité et les modes de reproduction des mécaniciens ${ }^{892}$. De l'autre côté, le monde compartimenté, hiérarchisé de la société féodale, qui reconnaît en eux une fraction du travail artisanal, les confine à un rang subalterne, leur dénie la possibilité d'une existence sociale indépendante. Le rapprochement avec les arts " libéraux » permet d'anoblir le contenu du savoirfaire, de fournir un critère irréversible à la séparation d'avec l'ensemble des artisans. Parallèlement, l'ingénieur se fait une place dans la société, réussit à s'intégrer au niveau qui lui correspond du point de vue de ses nécessités et des services qu'il rend. Ainsi l'écart du cerveau et de la main constitue une traduction économique des re-

890 P. FRANCASTEL : Peinture et société, Lyon, 1951, p. 127.

891 T. GARZONI : La piazza universale de tutti le professioni del mondo, Venise 1587, p. 24.

892 «Les discussions relatives aux arts libéraux constituaient donc l'aspect théorique de la lutte des artistes pour obtenir une meilleure position sociale. L'aspect pratique de cette lutte était la lutte contre la vieille forme d'organisation en corporations, que les artistes ressentaient comme une entrave ». A. BLUNT : op. cit. p. 85. 
lations entre catégories naturelles, et en conséquence, contribue à accentuer leur contenu de classe. La différence se change en inégalité sanctionnée et consolidée socialement. La coupure dont l'origine est dans la division naturelle, au lieu d'être envisagée eu égard à leur domaine matériel respectif - ainsi l'ingénieur par rapport aux forces inanimées et l'artisan par rapport à la matière — est inscrite dans l'échelle propre à la structure sociale.

Inversement - et c'est dans cette perspective que j'ai présenté l'exemple grec - une classe sociale qui, luttant pour sa richesse, combat aussi pour la force productive qui la sous-tend, se donne un contenu naturel. Il s'agit, pour elle, de fortifier les rapports collectifs qui lui confèrent le pouvoir, et ces rapports impliquent un certain type d'interaction avec les forces matérielles, un certain mode de reproduction du travail.

Toute transformation lui ôte la terre sous les pieds et rend évanescentes les bases objectives de son existence. A travers le travail manuel ou intellectuel se manifeste l'antagonisme d'une classe sociale envers une autre classe sociale et envers le groupe de producteurs dont cette dernière est issue par la subdivision sociale du travail. Réciproquement, la division des catégories naturelles s'insère dans cet antagonisme comme une de ses parties et en prend les caractères. Toutefois, en tant que telle, elle est masquée. Doublement masquée, du fait que les rapports des catégories naturelles s'affirment comme liens des classes sociales et que, inversement, les rapports des classes sociales se veulent liens entre catégories naturelles. Socialisation d'une part, naturalisation d'autre part, tendent à diminuer la distance qui les sépare. Aussi cette distance est-elle introduite entre le travail intellectuel et le travail manuel, à l'intérieur de ce qui constitue immédiatement une unité visible, pour créer l'impression qu'il s'agit vraiment de l'esprit et du corps, du cerveau et de la main. Par là, on rend homogènes deux relations hétérogènes - les relations sociales et les relations naturelles, réduites à la dimension biologique - et hétérogènes deux relations homogènes, à savoir celles qui sont propres aux catégories naturelles d'un côté, aux classes sociales de l'autre. La lutte des classes est présentée dès lors en tant que division naturelle, et la division naturelle en tant que conflit de classes. De ce fait, des fils plus fins se 
tissent, joignant ceux qui pensent la propriété et la richesse à ceux qui pensent la matière, le talent; les maîtres de la société se reconnaissent ainsi comme les maîtres de la nature. Mais ceux qui se trouvent relégués de la sorte ont toujours des motifs de réconfort, car, comme le disait Nietzsche :

«La consolation est que cette "première nature » était jadis nature seconde et que toute "seconde nature » conquérante devient première nature...».

Dépouillée de son aura organique illusoire, telle est la signification de l'opposition du travail manuel et du travail intellectuel. Elle traduit l'action de la division des catégories naturelles dans une famille de sociétés qui ont acquis un principe historique indépendant. De là découle son importance, de là aussi le genre d'unité qui se manifeste entre l'histoire de notre nature et celle des ordres sociaux animés par la lutte des classes. 


\section{Chapitre II.}

\section{Le gouvernement de la société et la conquête de la nature}

\section{Le corps naturel et le corps politique}

\section{$\underline{\text { Retour à la Table des Matières }}$}

Les juristes de la monarchie avaient établi qu'un roi possédait deux corps : un corps naturel et un corps politique. Son corps naturel était mortel, sujet au dépérissement, aux infirmités dues à l'âge et à tous les accidents dont un organisme individuel peut être victime. Son corps politique, en revanche, invisible, intouchable, était invulnérable lorsqu'il dirigeait le royaume et prenait soin du bien supposé commun ${ }^{893}$. Cette fiction symbolise l'autonomie des rapports sociaux et des rapports naturels, tout comme la disjonction de la main et du cerveau traduit de manière indirecte, opaque, l'interdépendance de ces rapports. La fiction nous présente, de plus, en filigrane, une série d'ordres sociaux partagés en rangs, les uns ayant le droit à la jouissance et les autres le devoir d'entretenir cette jouissance, les premiers étant préparés à commander et à consommer, les seconds à obéir et à produire. L'esprit afflue à un pôle, la matière se retire à l'autre. La hiérarchie et l'opposition qui en résultent sont aussi hiérarchie et opposition de l'univers social et de l'univers naturel. Le dédoublement de leurs sphères, de leurs savoirs respectifs, est la conquête de la civilisation. Ce n'est pas la seule. Dans ces ordres, la classe supérieure a, pour objet direct de son effort, la maitrise des instruments d'appropriation et de l'État, et la classe inférieure le travail et les ressources qui lui cor- 
respondent. Les arts et les sciences essentiels pour la première sont tournés vers les divers aspects de la société ; les arts et les sciences réservés à la seconde ont surtout trait au monde matériel. Le fait est digne d'attention : les collectivités civilisées connaissent deux familles de disciplines, deux systèmes d'éducation, les uns relatifs à l'état social, les autres se rapportant à l'état naturel. Plus que leurs produits politiques ou religieux, scientifiques ou techniques, les institutions éducatives sont les signes d'une situation et d'une intention des groupes sociaux. On sous-estime la valeur de ce signe ; il est peu connu et encore moins étudié, parce qu'il pointe vers une réalité particulière. Pourtant, cette réalité devrait retenir l'attention, car elle semble dessiner le tracé le plus profond d'une évolution. Elle nous permet surtout d'observer le caractère privilégié pris par un savoir, et nous laisse entrevoir à quel point les hommes ont toujours été éduqués, préparés, par des voies distinctes, pour la société ou pour la nature. Ainsi

« est laissé aux arts manuels ce qu'on tirait des choses et des animaux mêmes qu'on employait; et à la sagesse et à la vertu des grands hommes est réservé le devoir de diriger l'activité humaine en vue de l'accroissement du bien commun $\gg{ }^{894}$.

Le privilège attaché à tout ce qui touche la classe dominante a pour conséquence de donner un caractère également privilégié aux liens tissés autour des intérêts économiques et politiques, ainsi qu'à la rationalité de l'action qui s'y associe. Quant à ceux qu'engendrent les ressources matérielles, la reproduction des talents, ils se trouvent rejetés dans les régions inférieures, comme se rapportant aux rangs les moins élevés de l'État. Des deux séries de critères qui, abstraitement, différencient l'humanité de l'animalité — et, en fait, distinguent les hommes entre eux - la propriété ou le langage, d'une part, l'habileté ou le travail de l'autre, la première est mise en avant et la seconde reléguée à l'arrière-plan. Le groupe de ceux qui gouvernent veut l'homme social, politique, tel qu'il estime avoir exclusivement la vocation et les capacités de l'incarner - raffinement des mœurs, don de la communication ou de l'exercice du pouvoir, etc. Les rapports de ce groupe avec les diverses fractions de la collectivité sont les seuls qui 
méritent d'être reconnus. Le reste, notamment les relations entre «porteurs d'invention», ou simplement entre hommes exerçant leur dextérité ${ }^{895}$ — c'est-à-dire les rapports naturels - doit être banni de la conscience claire et souveraine. Ils demeurent l'apanage d'une humanité qui n'occupe jamais le devant de la scène, qui reste confinée dans la zone des efforts inconscients de leurs buts. Le fossé qui sépare la société de la nature n'a pas, on le voit, de cause mystérieuse : il est celui-là même qui sépare l'une de l'autre les classes de la société. Les traits que j'accentue ici à dessein reproduisent, en le simplifiant, un processus infiniment plus complexe. Par ailleurs, les circonstances changeant, ils sont aujourd'hui en passe de s'estomper. Néanmoins, à regarder un intervalle très long de notre histoire, leur généralité ne fait aucun doute. Ils seront parfaitement éclairés par les courants du passé qui restituent le sens exact de certains débats présents : celui de l'humanisme et de l'anti-humanisme ou du réalisme ${ }^{896}$, celui de la culture technico-scientifique et de la culture tout court, et, enfin, celui de la teneur du gouvernement des états naturels.

Retour à la Table des Matières

895

Le peu de cas que l'on fait des producteurs, des «porteurs d'invention », et l'anonymat dans lequel on les maintient, ont suscité des protestations continuelles. Ainsi, à propos de l'ingénieur, J.H. HAMMOND écrit : «Comparé à l'homme d'État ou au politique, sa gloire est bien mince relativement à ce qu'il a accompli. Son nom n'apparaît pas ». (The Engineer, ed. cit. p. 18).

896 La différenciation du monde naturel et du monde civil est un produit historique et non une donnée de l'«existence humaine », fût-elle liée à l'apparition du langage (voir p. ex. E. ORTIGUES : Nature et culture dans l'œuvre de Claude Lévi-Strauss, Critique, 1963, nº 189, p. 151). L'opposition de l'humanisme et de l'anti-humanisme est un phénomène du même ordre. Dans les discussions qui ont actuellement lieu en France à ce sujet sous l'impulsion de MM. Foucault et Althusser, ce fait est complètement escamoté. L'éventuelle disparition de l'humanisme est présentée comme une conséquence du devenir objet de science, de l'homme. Depuis longtemps, la philosophie idéaliste, notamment celle d'Émile Meyerson, a soutenu que la correspondance du réel et de l'intelligible débouchait sur l'acosmisme, le transvasement de la substance du premier dans les moules du second. La connaissance ayant donc le pouvoir de dissoudre ce qu'elle vise à connaître, du moment où un savoir scientifique des sociétés se constitue, on peut s'attendre à la «fin » de l'homme en tant que sujet autonome, et de l'humanisme, doctrine de cette autonomie. Mais ce que l'on décrit dans ces discussions est plutôt un «être de raison » qu'une réalité ayant des propriétés sociales, historiques, précises. Si l'on se référait à cette réalité, on verrait que l'anti-humanisme en question n'est qu'une forme, mandarinale, de l'humanisme, forme conçue pour appuyer une hiérarchie et affirmer son système. Quant à l'humanisme qui est combattu à cette occasion, celui de J.P. Sartre, il représente une autre forme, davantage liée au combat politique, dans une société qui rend ce combat possible et où les individus souhaitent et espèrent pouvoir agir en tant que sujets sociaux. 


\section{Le gouvernement de la société}

$\underline{\text { Retour à la Table des Matières }}$

\section{Le savoir naturel, le savoir social et la science du pouvoir.}

L'assomption du lien social et politique marque bien une nouveauté. Il traduit une coupure avec les collectivités où les rapports de parenté, les relations locales de communauté de travail ou d'appropriation étaient prédominantes. Par là le corps social dans son ensemble se conçoit comme ayant la charge de ses affaires, l'initiative de son devenir et de son histoire. Cette découverte lui enseigne la nécessité d'élaborer un savoir-faire portant sur la solution des problèmes qu'il rencontre, les processus qui lui sont propres. Parallèlement, l'antagonisme des classes avec leurs fins particulières, transformant l'autre en moyen, permet à chacun de prendre une certaine distance et de s'appliquer de manière quasi objective à l'analyse des difficultés politiques, économiques, etc. ou à la création d'instruments de domination ou de défense. La conséquence la plus immédiate de cette double autonomie de la société par rapport à la nature et par rapport à sa propre forme ancienne est l'individuation des connaissances la concernant. Dans la mesure où la philosophie grecque est un témoignage privilégié, on la voit parcourir cette trajectoire. Au début, elle cherche à comprendre et à instituer une conception globale d'un ordre socio-naturel total. Les traités sur la nature qu'écrivent les philosophes sont aussi des pamphlets politiques. Des éléments qui nous paraissent hétérogènes sont placés en relation directe et se combinent en une unité difficilement soluble ${ }^{897}$. L'idée même de cosmos provient d'une certaine conception de la vie collective ${ }^{898}$ et, transposée à l'univers ${ }^{899}$ tel que le décrit par exemple Anaximandre, manifeste une continuité parfaite du cadre social aux phénomènes matériels ${ }^{900}$. Le passage

\footnotetext{
897 F.M. CORNFORD : From religion to philosophy, Cambridge, 1914, pp. 51 et seq.

898 E. LAROCHE : Histoire de la racine Nem en grec ancien, Paris, 1946.

899 W. KrAnZ : Kosmos als philosophischer Begriff frühgriechischer Zeit, Philologus, 1938, 93, pp. 340-38.

900 J.P. VERNANT : Les origines de la pensée grecque, Paris, 1962, p. 102.
} 
constant de l'un aux autres est également un trait fondamental de la pensée d'Héraclite, de Pythagore, et Jamblique proclame ce dernier fondateur de l'art politique

« quand il affirme que, parmi les choses qui existent, rien ne se trouve sans mélange : la terre contient une part de feu, le feu une part d'eau et les éléments une part d'air. De même l'honnête est mêlé au déshonnête, le juste à l'injuste et le reste à l'avenant».

Pourtant, malgré cette impression de continuité, d'unité, l'observation historique enseigne que

« ce n'est pas l'assimilation de la nature et de la société que la philosophie était appelée à établir mais leur séparation ${ }^{901}$.

Il s'agit en réalité de la transformation d'une philosophie qui auparavant unissait dans une même vision les liens sociaux et les attaches naturelles de l'homme, et concevait des habiletés communes à ces deux domaines, en une philosophie qui distingue avec vigueur ce qui a trait à la régulation de la vie sociale et politique de ce qui advient au cours des échanges avec le monde matériel. Elle consacre une spécialisation dans la sagesse et la vertu, ou dans les arts, soutenue par l'hérédité et la propriété ; devenue spécialisation au travail et au nontravail ${ }^{902}$, elle tend à instituer un écart entre ce qui a trait à la société et ce qui a trait à la nature, donnant à l'une l'apanage de la parole et laissant à l'autre la chose. Où faut-il chercher les raisons de cette unité d'abord, puis de sa dissolution? Assurément dans la cité ${ }^{903}$ qui, à ses débuts, conserve les caractères qu'elle a hérités des modes de vie traditionnels. Les Ioniens l'ont établie, on le sait, soit par une colonisation dont le but essentiel était l'occupation des terres ${ }^{904}$, soit par la réunion de plusieurs collectivités en une seule, ou par la soumission à un intérêt commun des factions ou classes en lutte. Nous rencontrons

901

902

903

904

C. KAHN : Anaximander and the origin of Greek cosmology, New York, 1962, p. 192.

I. BYWATER : Aristotle's dialogue on philosophy, J. of Philos. 1877, 7, pp. 68-87.

H. FRANCOTTE : La polis grecque, Paderborn, 1907.

«Il est en effet certain que le motif premier des colonisations dans la grande majorité des cas ne fut pas le commerce, mais l'acquisition de nouvelles terres arables ». H. LLOYD-JONES (ed) The Greeks, New York, 1961, p. 26. 
là une société, une forme d'association inédites. L'aristocratie ayant perdu son ascendant, le hoplite - le petit propriétaire agricole - a renforcé ses positions; les classes urbaines s'étant affirmées, le monde rural doit en tenir compte : telle est la clé d'un équilibre original ${ }^{905}$. Les riches se voient obligés de partager leur pouvoir — le petit cultivateur comme le grand s'intègre dans la cité — de réfréner leurs appétits, de reconnaître l'existence du peuple en tant que partenaire et force politique. La démocratie est, à cet égard, autant militaire que sociale. La démesure, l'inégalité sont dénoncées en tant qu'ennemies de la cohabitation, du modus vivendi propre à la collectivité. Chaque classe, chaque individu observe une limite qu'il ne peut dépasser sans mettre en péril l'harmonie de la cité. Celle-ci crée son culte et sa religion pour l'ensemble des citoyens, déclarés semblables et même, en principe, égaux ${ }^{906}$. Mais en fait l'égalité demeure proportionnelle, hiérarchique, et de toute manière ne saurait s'étendre aux esclaves. Ce n'est plus le décret d'un roi, l'arbitraire d'une classe ou la coutume qui sont au centre de l'univers humain, mais la règle ou le contrat ${ }^{907}$.

A Athènes, principalement, où cette évolution apparaît de façon évidente, la cité se définit, surtout au $\mathrm{VI}^{\mathrm{e}}$ siècle, comme cité « du mélange ». La réforme de Clisthène institue un compromis entre l'ancien principe tribal qui détermine la place des citoyens dans la cité suivant les liens de parenté et la nouvelle situation découlant de l'existence de professions, d'une localisation des activités politiques et commerciales. La répartition des groupes de citoyens a lieu, dorénavant, selon un découpage purement territorial, en dix tribus réunissant la ville et la campagne, les riches et les pauvres, les artisans et les agriculteurs, les aristocrates et les commerçants. Les lignes de force de l'ensemble convergent vers un centre unique, qui a pour vertu de consacrer le mélange ainsi constitué des diverses fractions du corps civil. L'avènement de cet ordre est bien l'avènement d'un ordre humain, œuvre commune, fondée sur la solidarité et la complémentarité.

905

906

907

J. HASEBROEK : Griechische Wirtschafts-und Gesellschaftsgeschichte, Tübingen, 1931.

G. Vlastos : Isonomia, Amer. J. of. Phil. 1953, 74, pp. 337-366.

Les luttes qui accompagnent l'institution de la polis non pas comme œuvre de raison mais comme œuvre des hommes sont exprimées avec plus d'acuité par les poètes que par les philosophes qui, pour cette étape de l'histoire grecque, ne sont pas les guides les plus sûrs. 
Cependant, cet ordre n'est qu'une phase du développement urbain, il vise à synthétiser ce qui, aux dires d'Aristote, ne saurait se combiner ${ }^{908}$, à savoir la pauvreté et la richesse. Le mouvement interne de ce développement et de cette contradiction rompt nécessairement avec l'équilibre si laborieusement institué ${ }^{909}$. La cité devient le centre où s'exercent les arts, où se rassemblent les artisans. Les commerçants s'affirment et prospèrent. Leur influence s'accroît et l'argent pénètre dans les veines où circule le sang du corps social. Avec l'instrument financier, la propriété s'avère mobile et les liens interhumains reçoivent la médiation d'un signe abstrait. L'aristocratie terrienne voit sa suprématie mise en question, non seulement par le paysan, mais aussi par l'artisan et surtout par le commerçant opulent ${ }^{910}$. Les rapports entre les classes changent, et aussi les voies d'accès à la conquête des magistratures suprêmes dans l'État ${ }^{911}$. L'unité disparaît devant la différence. Le possesseur de moyens prend le dessus sur la communauté des fins, le citoyen sur la cité. Celle-ci, ainsi que l'envisage Hippodamos ${ }^{912}$, en architecte mais aussi en théoricien de la politique - le premier en date, dit-on - est une cité diversifiée où l'artisan et le commerçant, le militaire et le paysan, l'administration politique et les organismes économiques s'écartent les uns des autres pour recréer leur unité particulière, divisée, dans une portion de l'espace social, un quartier propre. La cité « de la pureté » se substitue à la cité " du mélange ", la divergence à la convergence. La paix civique est submergée par la guerre civile ${ }^{913}$, celle des classes et des fractions ; l'empire est là, la vieille polis se dissout. Avec elle s'éloigne aussi l'ancienne relation de la société et de la nature. La sphère politique acquiert une autonomie extraordinaire, approfondissant davantage les écarts sociaux ${ }^{914}$. Le pouvoir, dans un État qui règle toute la vie des citoyens, devient un objet distinct de préoccupation. Pour ceux qui veulent l'obtenir, maîtriser autrui, convaincre une assemblée, gérer les affaires publiques, il exige un apprentissage particulier, une doctrine précise

\footnotetext{
908 ARISTOTE : Politique, VI, 15.

909 V. EHRENBERG : The Greek state, New York, 1960.

910 A. FRENCH : The Growth of the Athenian economy, Londres, 1964.

911 M. CLERC : Les métèques athéniens, Paris, 1893.

912 P. LÉVÊQUE et P. VIDAL-NAQUET : Clisthène l'Athénien, Paris, 1964.

913 G. GLOTZ : Histoire ancienne, t. III, p. 20.

914 T.A. SINCLAIR : A history of Greek political thought, Londres, 1959, p. 118.
} 
de ce que doit être l'organisation du monde civil. Y a-t-il un art propre à la vie politique? Les hommes mobilisés dans le conflit social l'appellent de leurs vœux. Les classes en présence, celle des marchands et des artisans ou celle des nobles et des cultivateurs ont leurs conceptions propres, conformes à leurs intérêts, quant à la forme de la société et au groupe qui doit la diriger. L'art politique peut-il s'enseigner, ou bien l'oligarque le possède-t-il seul de naissance? Quelle est la meilleure constitution pour la cité ? Voilà les questions qui surgissent à ce moment-là. Plus profondément encore, la négation de l'être social du producteur et l'interdit jeté sur le côté productif de l'activité du citoyen tranchent dans le vif et déplacent l'horizon de chacun. Ce qui marque désormais leur coexistence, c'est qu'ils signalent l'un à l'autre un manque. L'unité de l'espace physique et de l'espace civique, de la connaissance de l'ordre naturel et de l'ordre social avec l'ensemble des facultés qui leur sont indispensables, tout cela se scinde au siècle de Périclès ${ }^{915}$, après avoir été consolidé dans celui de Solon.

La théorie philosophique a suivi le courant et détaché les deux ordres. La vision intellectuelle renonce à l'unité. Chaque domaine doit résoudre ses problèmes séparément, en créant son langage et ses méthodes de réflexion.

«Et la distinction qui fut ainsi faite de façon plus ou moins définie en pratique entre les citoyens proprement dits et la classe productive fut affirmée avec plus d'ampleur encore en théorie ${ }^{916}$.

Pour les premiers, les sophistes créent une discipline particulière, qui est l'art politique. De même que le cordonnier apprend à faire des chaussures, de même le citoyen peut apprendre à dominer une assemblée, à persuader un adversaire, à rallier ses partisans et aussi à donner des lois à l'État. Être citoyen, du reste, est en quelque sorte un métier,

Celui qui étudie la polis relie qu'elle est — c'est-à-dire une communauté — arrivera rapidement à la conclusion que le siècle même de Périclès, qui est aussi celui d'Anaxagore et de la première génération des sophistes, doit être considéré comme la période qui marque le début de la dissolution interne de la polis ». V. EhrEnBERG: When did the polis rise ? J. of Hell. Stud. 1937, 57, p. 147.

916 C.L. Dickinson : The Greek way of life, New York, 1961, p. 37. 
puisque l'on est rémunéré pour sa participation à la vie publique. La pédagogie sophiste prolonge celle de l'artisan où elle trouve son modèle et sa justification. Elle ne se cantonne pas dans l'entraînement au geste et à la parole. Le contenu de ce qui est particulier à l'activité consacrée au domaine économique et politique la préoccupe également. Comment pourrait-il en être autrement, puisque l'Athénien qui accède à une charge de l'État doit savoir armer un navire, conduire des troupes à la guerre, conclure des traités ? Par l'art politique, il acquiert une spécialité qui inclut l'administration de la cité, la possession des outils permettant de dominer les hommes, et la connaissance des exigences de la communauté dans son ensemble.

Pourtant ce ne sont pas les sophistes mais Platon qui tire les conséquences de l'autonomie de l'univers politique ${ }^{917}$ et donne une expression philosophique profonde à la société fondée sur l'individualité des classes et leur opposition. Il pense fournir à l'aristocratie les instruments intellectuels requis par les nouvelles circonstances. La cité se compose pour lui de citoyens et de non-citoyens ; les premiers, nonproducteurs, vivent uniquement en vue de cultiver la vertu politique ou militaire; les seconds, les artisans surtout, sont des étrangers ou des producteurs. Le groupe qui jouit du loisir, du pouvoir et de la sagesse est projeté dans les régions supérieures de la connaissance épanouie ; celui qui travaille se trouve éloigné de toute prérogative ${ }^{918}$ comme du droit à la direction de la cité.

«Or le principe fondamental de la politique platonicienne, observe Émile Durkheim ${ }^{919}$, c'est que la classe inférieure doit être radicalement séparée des deux autres, autrement dit que l'organe économique doit être mis hors de l'État, bien loin d'y être attaché ».

« C'est quand nous nous tournons vers l'Athènes de la fin $d u V^{e}$ siècle que nous trouvons une véritable pensée politique indépendamment de la spéculation physique ». E. BARKER : Greek political theory, New York, 1960, p. 60. « Dans la République de Platon, le besoin fonde la cité élémentaire (369 bc) mais au fur et à mesure que l'édifice se complète, il apparaît que le sort de l'économique est d'être maîtrisé ; les producteurs sont radicalement séparés des guerriers et des philosophes ». P. VIDALNAQUET : Économie et société dans la Grèce ancienne, Arch. Europ. de Sociol. 1965, II. p. 138.

919 E. DURKHEIM : Le socialisme, Paris, 1928, p. 43. 
Il n'y a là nul paradoxe. Nous savons avec quelle précision Platon parle des métiers et des artisans, et avec quelle acuité il a saisi le sens profond du labeur artistique. Toutefois, rien de ce qui a trait à leurs efforts, à leur création, à leur intelligence, ne trouve grâce à ses yeux. Pour lui, tout cela est indigne de l'homme, méprisable pour le citoyen; et seuls les esclaves ou les étrangers peuvent s'y complaire. Celui qui pratique un métier s'exclut immédiatement du cercle de la vertu pour s'abaisser à la condition subordonnée, non-humaine, du devenir et de l'accident ${ }^{920}$. Le travail entraîne cette conséquence néfaste, puisqu'il est incompatible avec le droit politique, la sagesse et le principe même de l'espèce dans ce qu'elle a de plus profond ${ }^{921}$. Il convient de rappeler, à ce propos, qu'à l'époque précédente, c'est le labeur dirigé par l'habileté, enseigné suivant les règles de l'art, qui évoquait et figurait le passage du monde animal au monde humain, la genèse de ce dernier. Par un renversement tout à fait radical, on voit ce labeur devenir au contraire ce qui ravale le monde humain au niveau du monde non-humain, et, à sa place, dans la même fonction de différenciation, apparaît la sagesse politique, le savoir qui l'imprègne. Ce n'est point une platitude que formule Aristote lorsqu'il dit que l'homme est un animal social. A ses yeux, un nouveau critère accède au premier rang, se dissociant de tous les autres ou les rejetant dans l'ombre. De la sorte, le sujet de la société recouvre et refoule celui de la nature, œuvrant dans l'univers matériel, car à la fois il est son maître et se veut sa quintessence. La mission de la philosophie, dans cette optique, est la formation de l'élite, du personnel administratif et politique, en même temps que la définition des qualités d'obéissance qui assurent la conservation du corps civil. La création de l'Académie, haut lieu de la pensée philosophique, correspond à ces idéaux :

920

On peut dire que pour Platon le travail reste étranger à toute valeur humaine et que, sous certains aspects, il lui apparaît même comme l'antithèse de ce qui, dans l'homme, est essentiel ». J.P. VernANT : Mythe et pensée chez les Grecs, Paris, 1965, p. 192.

921

«On pourrait dire que l'œuvre de Platon tout entière est sous-tendue par des préoccupations politiques; et que les problèmes que nous avons étudiés jusqu'ici — le problème du dialogue, le problème de l'enseignement philosophique, critère et moyen de formation d'une élite - ne sont, au fond, que des problèmes politiques ». A. KOYRÉ : Introduction à la lecture de Platon, Paris, 1962, p. 83. 
«En effet, écrit P.M. Schuhl ${ }^{922}$, il s'avère que, par un de ses aspects essentiels, l'Académie fut une École des Sciences politiques, orientée vers l'action autant que vers la théorie ».

Les élèves de cette école, comme ceux des sophistes, s'initiaient à la connaissance intime du comportement des hommes, des besoins qu'ils cherchent à satisfaire, des passions auxquelles ils succombent et des idéaux qui les enflamment. La possibilité de rendre forts des arguments faibles et d'édifier des systèmes conceptuels susceptibles de soutenir la pratique sociale s'incarne en une science rhétorique ou philosophique. La raison appropriée devient fondement du choix et de l'action au plan de la société. L'ignorance est dévastatrice, germe de défaite assurée d'un parti ou d'une cité - l'ignorance du maître, car celle des classes inférieures est au contraire souhaitée et encouragée.

Ces innovations intellectuelles n'ont pas trait, comme on le croit d'ordinaire, à la différence entre la philosophie d'avant ou d'après Socrate $^{923}$, et ne constituent nullement «la réaction en faveur de l'humanisme » ${ }^{924}$, le passage d'une conception relative au cosmos à une conception relative à l'homme, d'une réflexion centrée sur le monde extérieur à une réflexion centrée sur notre vie intérieure. Leurs dimensions importantes et leurs intérêts sont les dimensions et les intérêts du philosophe dont le rôle se scinde ${ }^{925}$ et s'affirme sur le plan civil. Du moins Aristote l'entend-il ainsi puisqu'il écrit :

« Pour eux (l'homme d'État et les philosophes), le point capital paraît être l'organisation de la propriété, source unique, à leur avis, des révolutions » ${ }^{926}$.

P.M. SCHUHL : Platon et l'action politique de l'Académie, Rev. d'Et. Grecques, 1946-7, 5960, p. 2.

923 J. KIRCHENSTEINER : Kosmos, Quellenkritische Untersuchungen zu den Vorsokratikern, Munich, 1962.

924 W.K.C. GUTHRIE : The Greek Philosophers, New-York, 1960, p. 63.

925 «Et pourtant ces mêmes sophistes passent de la philosophie de la nature à la philosophie de la culture et reconnaissent le pouvoir de la norme humaine et la valeur des lois ». K. JOEL : Geschichte der antiken Philosophie, ed. cit. p. 700.

«En effet, le conflit entre Physique et Éthique a été incomparablement plus important. Il a pris, depuis la fin du $\mathrm{V}^{\mathrm{e}}$ siècle av. J.-C. la violence d'un véritable combat dirigé par la philosophie socratique qui voulait évincer la philosophie de la nature, qu'Athènes avait héritée de l'Ionie ». O. GIGON : Les grands problèmes de la philosophie antique, Paris, 1961, p. 25.

926 ARISTOTE : Politique, II, ch. VII. 
Pour faire face à cette préoccupation absorbante, on se replie sur soi, sur la cité, dans ce cercle de l'existence authentique, que l'on oppose au cercle de la vie matérielle, artificielle. Chacune des deux formes du réel est objet d'une branche de la philosophie, constituant ce qu'il convient de dénommer une idéologie sociale et une idéologie naturelle. Elles ne représentent pas une totalité écartelée, déchue. Chacune, reconstituée, englobe un genre d'habileté, un type de savoir, des disciplines particulières. Née à un certain moment de l'évolution des sociétés, non pas avec la cité mais avec son éclatement, marquée par la confrontation des classes, leur dichotomie est restée consubstantielle à cette confrontation, jusqu'à prendre l'allure d'une propriété indélébile de notre intelligence, de notre espèce. Nos sciences perpétuent cette spécialisation, comme notre société ses motifs. Sur le sens de cette permanence, il convient d'insister davantage.

\section{$\underline{\text { Retour à la Table des Matières }}$}

\section{Les qualités de l'homme humain.}

Ce mouvement qui retire le citoyen du champ de la production et le producteur du champ de la cité les place dans des classes différentes. Le dédoublement qui en résulte, celui des groupes sociaux, de leurs facultés, soulève une question légitime : une fraction de l'espèce ayant pour art ou pour science la direction de la société, des rapports sociaux, et l'autre fraction se consacrant à l'art ou à la science concernant la nature, les rapports naturels, laquelle des deux revêt le plus d'importance, possède les capacités majeures de l'humanité, en exprime pour ainsi dire l'essence? La hiérarchie des pouvoirs et l'inégalité des richesses conduisent à situer cette essence, le propre de la condition humaine, dans les relations qui se tissent autour de la société civile et de l'État, dépositaire de la loi et de la force politique :

«L'État, écrit Max Weber ${ }^{927}$, consiste en un rapport de domination de l'homme sur l'homme fondé sur le moyen de la violence légitime (c'est-à-dire qui est considérée comme légitime)». 
Les responsables de cette violence prescrivent la manière dont les parties de la collectivité doivent se joindre, les intérêts qu'elles doivent servir en priorité. Ce faisant, ils fixent le principe de l'existence de l'individu dans la société, non pas dans le sens qu'il ne saurait subsister isolé, mais qu'en regard de son état - détenteur de la force ou soumis à la force - tout autre lien est secondaire ou accidentel. A la faveur d'une option aussi tranchée, il était loisible d'imaginer qu'un secteur particulier se confondait avec la sphère entière de la réalité humaine. En effet, après avoir donné du relief aux rapports sociaux noués autour des modalités d'appropriation des biens ou des privilèges - et mis entre parenthèses ce qui n'y avait pas trait directement - la création des talents, les échanges et les relations à leur propos entre producteurs - on a pris la partie pour le tout, l'homme politique et social pour l'homme tout court. Une telle substitution est la traduction du point de vue qui convient au maître, à l'État désireux de subordonner le citoyen, au parti souhaitant grouper ses membres — tous aspects de la pénétration profonde, dans la vie, de l'institution politique et de son illusion d'universalité. Partout où l'intérêt et l'activité des classes supérieures manquent à l'appel, l'humanité, identifiée à elles, serait également absente ; ainsi par exemple dans l'interaction avec le monde matériel et chez les classes subordonnées qui s'y consacrent ${ }^{928}$.

Quel est l'homme qui a part à la sociabilité, et quel est l'homme ou plutôt le non-homme - à qui elle fait défaut ? La réponse se déchiffre immédiatement, inscrite dans un espace qui a toujours un haut et un bas, une région supérieure et une région inférieure ; nul ne peut transgresser ses limites sans châtiment ou sans remords. Figurées de la sorte, sociabilité et coexistence avec autrui proposent des fins, cernent la substance de ce que doit être la vie, qu'elle soit contemplative ou active, vouée au loisir ou au travail, avide de jouissance ou, au contraire, rongée par le manque. Indiquer où se trouve la vertu, conseiller la sagesse, accompagner la mort et rendre la vie supportable, conserver l'harmonie là où règnent la volonté de puissance, le bon haft u. der Liter. Mainz, Abh. d. Geist. u. Sozialwiss. Kl. 1963, 13, pp. 1283-1310. 
plaisir et le calcul, sont les préoccupations constantes qui suscitent les grandes œuvres destinées à forger l'homme social. Nous remarquons qu'elles le différencient d'une espèce plus primitive et de l'animalité :

«Elle (l'humanitas de patriciens romains, et on pourrait ajouter celle des classes qui les ont précédés et leur ont succédé, n.n.) signifiait la qualité qui distingue l'homme non seulement des animaux mais davantage de celui appartenant à l'espèce homo sans mériter le nom d'homo humanus; du barbare et du vulgaire qui manque de pietas et de païdeia, c'est-à-dire le respect pour les valeurs et pour ce mélange raffiné de savoir et de distinction que nous désignons du nom discrédité de culture ${ }^{929}$.

Le mélange raffiné en question était destiné, nous le savons, à l'entretien de cette couche qui a acquis les moyens d'être supérieure ${ }^{930}$, passionnée par le droit et l'exploitation de ses domaines, par la vertu et l'augmentation du nombre de ses esclaves, par la guerre et la rapine, et qui, après avoir fait des philosophes eux-mêmes des esclaves, les a employés à orner ses cours. Le dédain pour ce qu'il y avait de réellement profond dans les arts et les philosophies, dont sont pourtant sortis leur pensée et leur discours, est partout répandu dans les déclarations de ceux qui prétendent au titre d'homo humanus. Refusant de s'enfermer exclusivement dans une activité particulière, ils façonnent néanmoins le contenu de ce qui doit être tenu pour vrai, beau ou convenable. Ces catégories de la société s'opposent au reste des hommes qui ne sont ni dilettantes, ni pourvus d'un savoir encyclopédique, mais exercent un art ou une science tant pour gagner leur vie que pour développer leur dextérité. Ceux-ci sont exclus du cercle de l'humanité humaine ${ }^{931}$, ou, suivant les époques, de la dignité de citoyen. Proches, par certains côtés, de l'inhumanité, comment y auraient-ils accès, quand, de toute évidence, les dons essentiels leur font défaut? Leur éducation spécifique ne les y autorise guère :

E. PANOFSKY: Meaning in the visual arts, New York, 1957, p. 2.

J.M. ANDRÉ : L'otium dans la vie morale et intellectuelle romaine des origines à l'époque augustinienne, Paris, 1966.

931 «Cicéron, Aulu-Gelle et d'autres employaient humanitas au sens d'éducation libérale, de culture de l'esprit convenant à la bonne éducation, d'élégance des manières ou du langage, de raffinement - en en faisant plus ou moins un synonyme de doctrina, litterae, eruditio. Ce concept s'opposait à ce qui appartenait aux bêtes brutes, le subhumain, et, par extension, à ce qui était servile ». W.J. ONG : Religion, Scholarship and the resituation of man, Daedalus, 1962,91, p. 418. 
«L'affirmation de Protagoras, écrit W. Jaeger ${ }^{932}$, selon laquelle l'éducation culturelle est le centre de la vie humaine, indique que son éducation visait franchement à l'humanisme. Il le sous-entend en subordonnant ce que nous appelons maintenant la civilisation — c'est-à-dire l'efficacité technique - à la culture ».

L'intelligence et l'humanité que celle-ci reconnaît sont l'intelligence et l'humanité d'une classe ou d'une élite seules capables de manifester leur sociabilité et d'en faire une discipline rigoureuse, principalement dans le domaine de l'armée, de la politique ou de l'administration, dont elles se réservent les savoirs. A qui d'autre, en effet, pourraient-ils servir, et qui d'autre aurait le droit d'en faire usage ? Ces arts ou ces sciences de la jurisprudence, de la stratégie, de la rhétorique, etc. ne sont-ils pas supérieurs, et censés commander à l'ensemble des arts et des sciences, puisque les hommes à qui ils sont destinés se comptent parmi les plus élevés dans la hiérarchie de l'État et de la collectivité ? Sous le couvert d'une généralité exemplaire, l'échelle des disciplines et des réalités recèle néanmoins une particularité de fait. Celle-ci prend sa source dans des rapports singuliers de l'ordre social et de l'ordre naturel, où le premier détaché du second est proclamé souverain, grâce à l'assimilation de l'humanité à celle de ses parties qui détient les instruments du gouvernement.

\section{$\underline{\text { Retour à la Table des Matières }}$}

\section{Les deux visages de l'humanisme.}

L'organisation et l'éducation des «professionnels » de la politique - commis, théologiens, hauts dignitaires, doctrinaires, notables, officiers, etc. - des groupes spécialisés dans le maniement des hommes, l'énoncé de la loi et la justification de la force, sont parmi les tâches les plus urgentes qu'aient dû s'assigner les États et les sociétés. Elles se sont avérées plus nécessaires encore à partir du moment où ils ont été divisés en classes et où la guerre, qui ne cessait d'être militaire que pour devenir civile, a requis une direction continue. Que ces élites ap- 
partiennent pleinement à la classe qui détient les leviers du pouvoir, ou qu'elles soient uniquement ses mains ou ses cerveaux, leurs fonctions répondent à une nécessité générale :

« Toute entreprise de domination qui recherche une continuité administrative exige d'une part que l'activité des sujets s'oriente en fonction de l'obéissance due aux maîtres qui prétendent être les détenteurs de la force légitime, et d'autre part que, moyennant cette obéissance, elle puisse disposer des biens matériels qui sont, le cas échéant, nécessaires pour appliquer la force physique. En d'autres termes, elle a besoin d'une part d'un état-major administratif, et d'autre part de moyens matériels de gestion ${ }^{933}$.

Ces besoins ont déclenché un mouvement extraordinaire de découvertes. Par exemple l'écriture. Celle-ci fut, si l'on se reporte aux empires despotiques, un instrument admirable pour procéder au relevé des possessions du roi et de ses compagnons, pour permettre aux prêtres et aux nobles de régir leurs sujets. Née avec la soumission, on la proclame savoir spécifique d'une catégorie d'individus qui, vivant à l'ombre des maîtres, les servent pour asservir les autres, infusent dans l'élégance du style l'inextinguible soif du pouvoir. Les brahmanes, les bonzes, les mandarins, les lamas, les évêques, aux Indes, au Japon, en Chine, au Tibet et dans l'Europe du Moyen Age, trouvent, grâce à l'écriture, symbole de leur fonction, une protection et un emploi qui mettent leurs capacités au service de la gloire et de la cupidité, avant de les consacrer à la philosophie ou à la science. La comptabilité passive qu'ils tiennent implique une hiérarchie stricte, un monde qui se veut cristallisé et statique, dont le système englobe chaque individu et chaque parcelle du réel dans un ordre qui semble établi de toute éternité. L'agitation des individus, la floraison des passions, les labeurs ou les impulsions de la multitude ne sont que des apparences au-delà desquelles point la souveraineté comme essence. Dans ces circonstances se développe un savoir qui se donne pour mission de déchiffrer les signes de ce monde figé, d'interpréter ou d'édicter les règles du jeu imposées aux acteurs, et enseigne au corps social non pas à agir mais à se survivre. Cet humanisme mandarinal a pour pendant l'humanisme 
« démagogique » ${ }^{934}$, tel que 1'ont compris les Grecs ${ }^{935}$. Les premiers linéaments de celui-ci, qui tourne le dos à l'écriture, au privilège des scribes «palatiaux», ont été ébauchés sur la place publique où s'affrontent groupes et intérêts divers. Ils sont tout entiers associés au travail du verbe, à la païdeia athénienne qui, à l'instar de la philosophie correspondante, est, aux yeux d'Isocrate, «l'étude du devoir, du citoyen ». Les rhéteurs, artistes de la parole et acteurs de la persuasion, remplissent une fonction nécessaire dans la démocratie où existent une procédure électorale et des négociations civiles. A 1'ordre notifié, il faut ajouter le vocable parlé, l'appel, l'argumentation. Le silence du signe ne convient plus là où il faut le scandale de la parole, et le langage, révélant les intentions d'une classe ou d'un parti, engage l'esprit dans le présent du discours qui se prolonge en échos sonores. Que ces démagogues-stratèges, dont Périclès ${ }^{936}$ est 1'illustration la plus grandiose, que ces orateurs aient un rôle précis à jouer dans la cité, est chose connue. Ils sont responsables des motions approuvées par l'assemblée et égaux aux administrateurs qui proposent les lois. De plus, les hautes charges étant électives, la position politique d'un individu ou d'un parti dépend de son habileté à influencer les électeurs. Cependant, à l'arrière-plan de cette habileté couve la conviction que le cours du monde n'est point arrêté, qu'il est destiné à changer, et que si l'homme n'a pas conscience des ressorts de son action, il en demeure, incontestablement, le sujet.

$\underline{\text { Retour à la Table des Matières }}$

\section{L'éducation de l'élite politique.}

A cet art de la rhétorique, de la politique, tous les autres fournissent de simples matériaux susceptibles de servir de substrat à la persuasion, de faciliter le modelage du discours, de meubler la conversation. Le lettré ou l'homme d'État ne les cultive pas pour eux-mêmes, il leur emprunte matériaux, formules ou exemples. On le remarque bien à

934

Depuis qu'il existe des États constitutionnels et même depuis qu'il existe des démocraties, le démagogue a été le type du chef politique en Occident ». M. WEBER : op. cit. p. 129.

935

936

M. FINLEY : Athenian demagogues, Past and Present, 1962, XI, pp. 3-24. 
Rome où les « arts libéraux » se sont cristallisés. La philosophie grecque, ses technai et ses epistemai sont considérés comme des auxiliaires précieux ${ }^{937}$, mais nullement comme des disciplines ayant une valeur intrinsèque. Les écrivains romains les recueillent dans la mesure où ils servent à l'instruction des patriciens, de leurs juristes et de leurs poètes ${ }^{938}$. Pour eux, les poèmes d'Homère ou les traités d'Aristote ont la même valeur de connaissance. Les uns et les autres font partie de cette « culture de l'esprit » qu'ils servent à orner, fondus dans des exposés agréables, aptes à entretenir l'attention sans la lasser :

«Un homme distingué à Rome voulait bien discuter des disciplines abstraites des Grecs - si elles étaient à la mode - mais il n'en désirait que les éléments, sans subtilités, sans gaspillage de ses efforts ${ }^{939}{ } »$.

Le seul domaine qui tolérât ce gaspillage était celui de la langue polie ou subtile, de la prose élégante. L'idéal grec, à travers la forme que lui a donnée le patriciat romain, a depuis servi de modèle à notre moderne science des humanités. La continuité est visible :

« Je veux indiquer simplement, écrit P.O. Kristeller ${ }^{940}$, que l'humanisme de la Renaissance doit être compris comme une phase caractéristique de ce qu'on peut nommer la tradition rhétorique de la culture occidentale. Cette tradition remonte aux sophistes grecs et est très vivace de nos jours... ».

C'est justement pour rendre vie à cette tradition que la renaissance des lettres latines, il y a cinq siècles, le retour à l'antiquité, ont récupéré un savoir longtemps enseveli ${ }^{941}$. De même, l'étude de l'histoire, l'examen des documents politiques ou économiques anciens, éclai-

937

La philosophie et l'eruditio (à Rome - et on pourrait dire partout, n.n. ) étaient les servantes des arts du gouvernement qui avaient de nombreuses facettes ». W.H. WoODWARD : Studies in education during the age of Renaissance, Cambridge, 1906, p. 9.

938 «La philosophie », romaine est exclusivement politique. L'intérêt pour l'art n'est pas très grand dans une société à prédominance agricole. On ne peut pas dire que les Romains s'intéressaient davantage à la pratique et que les Grecs étaient davantage attirés par la théorie. A la vérité, les Romains avaient de l'intérêt pour une théorie de l'administration et du gouvernement, propre à leur pratique sociale, et l'ont créée. L'œuvre de Cicéron et celle des juristes en témoigne. » W.H. STAHL : Roman science, ed. cit. p. 96.

939

940

941

Idem, p. 66.

P.O. KRISTELLER : op. cit. p. 11.

E. GARIN : L'umanesimo italiano, Bari, 1964. 
raient les problèmes vivants des nouvelles cités marchandes qui, hors ou au delà du monde de l'Église et de la féodalité, devaient se donner des institutions et des hommes aptes à gouverner ${ }^{942}$, à défendre leurs intérêts. Et, comme une vie civile inédite surgissait, l'existence sociale, le caractère social de l'homme étaient les thèmes prégnants de la pensée humaniste. Corrélativement l'action politique et la conversation — « le savoir commence par la conversation et se termine dans la conversation », disait Stefano Grozzo - but et occupation essentiels $\mathrm{du}$ nouveau patriciat, paraissaient épuiser l'être terrestre de l'humanité ${ }^{943}$, son être transcendant se révélant dans la théologie, sinon dans les belles-lettres ${ }^{944}$.

La caste des humanistes, comme on l'a dénommée, fournit l'effort indispensable pour aboutir à l'excellence dans l'utilisation des possibilités de la parole et pour l'enseigner à ceux qui entrent au service de la cité ou du prince ${ }^{945}$. Politien rappelle avec insistance la suprématie du rhéteur lorsqu'il demande :

«Que peut-il y avoir de plus utile et de plus fructueux que de persuader, par la parole, tes concitoyens d'accomplir les choses qui conviennent au bien de l'État, s'éloignant au contraire de ce qui lui est nuisible? ».

Autour de cette fonction et du langage, se renouvellent ou se constituent les arts libéraux, disciplines "dignes d'un homme libre », comme le veut Sénèque. Ils exigent, outre la pratique des vertus ou des vices nécessaires au citoyen, une maîtrise des moyens propres à préserver les liens sociaux aussi grande que celle qui permet à l'artisan de commander aux mouvements de ses mains et de percevoir les qualités des matériaux. C'est le but auquel répondent ces arts du discours - la poésie, la grammaire, l'histoire - et auquel ils se bor-

E. CASSIRER : Individuum und Kosmos in der Philosophie der Renaissance, Leipzig-Berlin, 1927 ; H. BARON : Humanistic and political literature in Florence and Venice, Cambridge (Mass.), 1955.

943 A. v. MARTIN : Soziologie der Renaissance, Stuttgart, 1932.

944 G. SAITTA : Il pensiero italiano nell'umanesimo e nel Rinascimento, Bologne, 1949- 51.

945

«Mais de même que les humanistes se considéraient comme des conducteurs spirituels des peuples, de même, d'abord, leur parole d'éducateurs était réservée aux élus, essentiellement à ceux-ci, princes et fils de princes, et fut étrangère à ceux qui s'adonnaient aux arts serviles et aux professions ». G. TofFANIN : Storia dell'umanesimo, Bologne, 1950, t. II, p. 211. 
nent ${ }^{946}$. Dans une société où, pour les rangs les plus élevés, la communication, le fait de briller "en société », le courrier diplomatique, la chronique historique, à côté des grandes théories juridiques ou morales, comptent au nombre des devoirs majeurs, les lois de l'écriture et l'ordonnance des parties de l'univers discursif sont au cœur même de toute connaissance :

«Mais la connaissance scientifique, écrivait John de Salisbury ${ }^{947}$, est le produit de la lecture, de l'étude et de la méditation. Il est par conséquent évident que la grammaire, qui est à la base et à la racine de la connaissance scientifique, implante, pour ainsi dire, les semences (de la vertu) dans le milieu de la nature, lorsque la grâce a préparé le terrain ».

De même que le mandarin apprenait avec application et prisait la calligraphie, l'humaniste, succédant aux rhétoriciens médiévaux (dictatores) et aux clerc théologiens, s'initiait à la syntaxe et faisait, de sa possession, son plus grand titre de gloire ${ }^{948}$. Les écrits et les lettres de Coluccio Salutati, disciple de Pétrarque, ou de Léonardo Bruni, tous deux porte-parole des chancelleries florentines, témoignent de ce raffinement dans la conception du discours, qu'il s'adresse aux pairs ou resserre la trame d'un pamphlet politique. Précepteurs des grands ou professeurs d'université ${ }^{949}$, marchands importants ${ }^{950}$ ou secrétaires de chancellerie, hommes politiques ou philosophes de cour ${ }^{951}$, doi-

946 «L’apprentissage de la rhétorique, qui exerça sans doute une emprise plus grande que celle de l'éducation philosophique, n'a jamais inclus plus que des rudiments de science, car tout ce qui se trouvait au-delà était considéré comme inutile. Ce qu'on appelait l'art libéral menait au seuil de la science, mais pas plus loin ». L. EDELSTEIN : Motives and incentives for science in antiquity, in A.C. CROMBIE : Scientific Change, ed. cit. p. 35.

947 J. of SALISBURY : Metalogicon, ed. Berkeley, 1962, p. 64.

948 «Le mouvement humaniste n'a pas pris naissance dans le domaine des études philosophiques ou scientifiques, mais dans celui des études grammaticales et rhétorique ». P.O. KRISTELLER : Humanism and scholasticism, Byzantion, 1944-5, 17, p. 354.

949 P.O. KRISTELLER : Renaissance Thought, ed. cit. p. II. Cf. également P. RENUCCI : L'aventure de l'humanisme européen au Moyen-Age, Paris, 1953.

950 J. LE GofF : Le temps du travail dans la «crise » du XIV siècle : du temps médiéval au temps moderne, Le Moyen-Age, 1963, p. 611.

951 «Avec Ficin apparaît le lettré de cour, qui n'est pas même professeur d'université mais au service du seigneur qui se sert de lui, non seulement pour donner de l'éclat à sa maison, mais aussi, sans aucun doute, pour des buts subtils de propagande politique ». E. GARIN : Medievo e Rinascimento, ed. cit. p. 290. 
vent tous se pénétrer de cet art précieux de la grammaire ${ }^{952}$ et de la rhétorique s'ils veulent remplir dignement leurs fonctions d'office ou de cérémonie ${ }^{953}$.

Nos démocraties parlementaires et nos monarchies constitutionnelles ont préservé cette tradition humaniste, dont la richesse nous éblouit encore, pour éduquer leurs corps politiques et instruire leurs fonctionnaires. Elle imprègne toute l'éducation classique ${ }^{954}$ qui sert de critère au recrutement des hommes destinés à sauvegarder les intérêts particuliers au sein de l'État et à veiller à la bonne marche des mécanismes sociaux ou économiques. Pouvait-on d'ailleurs concevoir un autre système, puisque, comme l'écrit Henri Marrou ${ }^{955}$,

«Quand il s'agit de former non plus une petite équipe de dirigeants mais toute l'élite d'une société, il convient mieux de se maintenir au niveau plus concret des lettres, dans la zone moyenne des idées générales, des grands sentiments généraux qu'affectionne la tradition classique, où elle voit le terrain par excellence d'une culture commune à l'ensemble des bons esprits ».

Je n'ai pas voulu écrire ici une histoire, qui de toute façon serait plus longue et plus complexe, mais rappeler, par des avances et des retours en arrière, le cadre où la spécialisation de la parole et de l'écriture marque le processus de division au cours duquel se détache un groupe d'hommes pour qui la politique, l'idéologie et les affaires de la société constituent la " profession principale » (l'expression est de Max Weber). Ce groupe s'est écarté des autres fractions de la col-

952 « Le résultat est qu'on trouve des hommes qui professent tous les arts, libéraux et mécaniques, mais ignorent l'art premier (la grammaire) sans lequel il est vain de vouloir progresser dans les autres. Mais alors que les autres études peuvent aussi contribuer aux «lettres », la grammaire seule a le privilège unique de faire d'un homme un «lettré ». J. of SALISBURY : op. cit. p. 71.

953 «On peut affirmer sans crainte de se tromper que pour Érasme comme pour les grands Italiens, l'éducation était une préparation à servir la société dans l'Église, l'État, la cité et la famille ». W.H. WOODWARD : op. cit. p. 117.

954

«Historiquement, l'humanisme de la Renaissance a déterminé, dans toute l'Europe occidentale, en liaison d'ailleurs avec la tradition transmise par les écoles médiévales, un certain régime d'études secondaires ou supérieures, basé sur la lecture commentée des œuvres littéraires grecques et surtout latines, sur une certaine notion de 1'" homme » et de son destin, sur une stratification sociale que résume assez bien le terme élite ». M. de GANDILLAC, in Mélanges Alexandre Koyré, 1964, t. II, p. 196.

955 H. MArrou : Histoire de l'éducation dans l'antiquité, Paris, 1948, p. 305. 
lectivité pour agir tantôt au nom d'une classe particulière, tantôt au nom de l'État. Pour accroître l'efficacité de ses techniques et traiter les questions qui se posent à lui, il doit approfondir la connaissance de l'objet auquel elles s'appliquent: la société. Définir, transformer et légitimer l'ordre social conduit à comprendre ses ressorts intimes, ses processus généraux. Grâce à leur familiarité avec les événements et avec les actions, historiens ${ }^{956}$ et érudits, chanceliers et philosophes, témoins et participants, ces esprits attentifs à ce qui figure dans leur champ d'activité quotidienne exposent ses données, révèlent ses lois. Pamphlétaires ou porte-parole, habiles à travestir ou à élever au niveau de la théorie ${ }^{957}$ les hauts faits, les crimes ou les arrière-pensées de leurs maitres, la vérité leur devient accessible parce qu'elle est ce qu'ils ont tantôt à révéler, tantôt à dissimuler. La poursuite de la guerre et le maintien de la paix, dans lesquels ils sont engagés comme diplomates, militaires, hommes de parti ou tribuns, aiguisent leur volonté d'édifier des doctrines, de suivre des règles, de bâtir une vision d'ensemble. Saisir d'emblée les dimensions économiques, psychologiques et politiques — voire artistiques ${ }^{958}$ — correspond bien à la vocation de conseillers, d'éducateurs, d'idéologues ${ }^{959}$ ou d'exécutants qu'ont remplie les membres des élites politiques successives. La jurisprudence et la philologie, la connaissance des arts "libéraux » et de l'économie, contribuent à expliciter et à asseoir la valeur de l'objectif suprême auquel tout est rapporté : le gouvernement.

Le gouvernement de la société se déploie sur tous ces plans et se veut œuvre de l'intelligence, dans la mesure où il est sous l'entière responsabilité des hommes que leur classe, leurs capacités, leurs des-

956

Ceux qui prenaient la charge d'écrire l'histoire parmi les anciens étaient des hommes recommandables par leur vertu et par leur doctrine, qui avaient part à l'administration des affaires publiques, ou qui vivaient familièrement avec les premières personnes de l'État pendant la paix et pendant la guerre ». J. BullaRT : Académie des Sciences et des Arts, Bruxelles, 1682, t. I, p. 121.

957 D. CANTEMORI : Rhetoric and politics in Italian humanism, J. of Warb. and Court. Inst. 1937, p. 92.

958 R.W. LEE : Ut pictura poesis : the humanistic theory of painting, The Art Bulletin, 1940, 22 , pp. 597-259.

Les humanistes de la Renaissance écrivaient leurs œuvres morales pour leurs collègues, pour leurs disciples, et pour une élite d'hommes d'affaires ou de nobles urbanisés, qui étaient tout disposés à adopter leurs idées morales et culturelles ». P.O. KRISTELLER: Renaissance Thought, ed. cit. p. 30. 
seins conduisent dans la voie du loisir et du pouvoir. Dans ces circonstances, l'état social n'apparaît pas, ne peut pas apparaître comme une donnée externe, un accident heureux qui ne dépend pas de l'intention de ceux qui y prennent part, mais comme le résultat d'un faire vers lequel toutes les passions convergent et qui absorbe nécessairement toutes les énergies de l'organisme social. La suprématie et la survivance dépendent de la force et de l'habileté déployées, la vie ou la mort d'une classe, d'un État, étant l'enjeu qui se renouvelle sans cesse. Pour infléchir l'issue, tout est mis en œuvre, savoirs et éducation, institutions et idéologies, les armes de la destruction comme celles de l'esprit.

La rationalité que l'on espère introduire - en particulier parmi les classes qui ont pour occupation principale l'accroissement de leur puissance, celles qui ont jusqu'ici établi la charte des idéaux de la société — s'inspire de cette conscience aiguë d'un déficit combler entre la possibilité d'agir et le déroulement nécessaire de l'histoire. Le reste est laissé en friche, concédé au néant, a la matérialité, puisque ce gouvernement, déguisé ou à visage découvert, est censé représenter seul la totalité et l'essence de l'homme, le fondement de son être social. 


\section{La nature externe}

$\underline{\text { Retour à la Table des Matières }}$

\section{Une pédagogie souterraine.}

La préférence donnée à la sapience sur la science, la spécialisation des uns pour l'ordre social et des autres pour l'ordre naturel, manifestent une tendance qui revêt des formes multiples. Il suffisait à mon propos d'en montrer l'existence chez ceux qui les ont le plus directement mises en pratique. Les humanistes d'hier et d'aujourd'hui font peu de cas du monde « extérieur », où ils voient un domaine d'activité inférieur, laissé au soin de ceux qui s'en accommodent par naissance ou par goût. Si la recherche des « secrets de la nature » leur paraît sublime, ce n'est point par ce qui lui est particulier ${ }^{960}$, par ce qu'elle apporte l'humanité, mais à cause des aliments qu'elle fournit à la spéculation et à la rêverie ${ }^{961}$. La démarche qui y conduit, le processus qui l'entretient et le groupe d'hommes qui s'y dévouent ne comptent pas. De toute manière, leur possibilité d'expression est réduite, et leur œuvre, comme leur histoire, demeure anonyme ${ }^{962}$.

Le système d'éducation est conçu dans ce contexte. Son état permanent est la scission. L'enseignement qui convient aux futurs citoyens, jouissant pleinement de leurs droits, régents ou serviteurs de l'État, et l'enseignement qui convient aux producteurs, aux autres

960 «De plus, les studia humanitatis (études humanistes) incluent une discipline philosophique, c'est-à-dire la morale, mais excluent, par définition, des domaines tels que la logique, la philosophie naturelle, et la métaphysique, aussi bien que les mathématiques et l'astronomie, la médecine, le droit et la théologie... Ces faits implacables semblent fournir des preuves irréfutables qui nous empêchent, comme on a voulu le faire à maintes reprises, d'identifier l'humanisme de la Renaissance à la philosophie, à la science ou au savoir de l'époque dans son ensemble ». P.O. KRISTELLER : op. cit. p. 10.

961 L. THORNDIKE : Science and thought in the fifteenth century, New York, 1929.

962 «Honneur à l'historien qui l'embrassant (l'histoire du travail) dans son application à une industrie, à un art quelconque, réussirait à montrer les victoires successives remportées dans la lutte contre la matière, par les générations d'inventeurs oubliés, de praticiens obscurs... » G. FAGNIEZ: Documents relatifs à l'histoire de l'industrie et du commerce en France, Paris, 1898 , t. I, p. LIII. 
classes de la société, sont soigneusement distingués. A vrai dire, ce qu'on nomme à proprement parler l'éducation a été confondu avec le premier genre d'enseignement ${ }^{963}$. C'est lui qui a reçu les soins les plus constants, c'est lui qui a fourni des techniques pédagogiques et proposé des critères à la formation de l'homme, l'homo humanus s'entend, opposé à celui qui ne s'occupe pas exclusivement des objets considérés comme les plus élevés. Nécessairement, le curriculum de cet ensemble éducatif exclut les matières qui se réfèrent au monde naturel ou bien assigne pour unique but à leur étude celui de former l'esprit. Autrement il tourne résolument le dos au travail productif, à la science de la matière ${ }^{964}$. N'est-ce pas le grand Pétrarque qui reproche aux médecins de se consacrer aux questions naturelles, sous le prétexte que l'homme en est absent? Ne leur signifie-t-il pas qu'ils ne sont que de vils mécaniques? «Que peut en effet le salarié et l'artiste infâme ? » écrit-il. Ou encore, dans cette même Invectiva contra medicum quemdam, n'est-il pas amené à s'écrier :

« Fais ton métier, mécanique, je t'en prie, si tu y arrives, guéris les corps si tu le peux, et autrement tue-les et fais-nous payer le salaire de ton crime. Mais comment peux-tu oser, avec un sacrilège inouï, subordonner la rhétorique à la médecine, la maitresse à la servante, un art libéral à un art mécanique ? »

Nous savons que ces médecins, contre lesquels tant de violence verbale est déchaînée, sont des savants qui s'occupent en même temps d'invention et de mathématiques, de la construction des instruments et de l'édition des ouvrages de philosophie naturelle. Pourtant chaque humaniste reprend à son compte les arguments de Pétrarque ${ }^{965}$, et tous se croient obligés de renouveler ses attaques. Le thème commun en est : les connaissances relatives au monde matériel peuvent nourrir le discours, elles sont inutiles à la vie. Léonardo Bruni dit d'elles :

963

« On persiste aujourd'hui, comme on le faisait au XVI ${ }^{\mathrm{e}}$ siècle, à considérer comme « culture » l'ensemble des humanités et comme «cultivé » exclusivement l'homme qui possède des connaissances dans ce domaine ». G. CASSINI, in Le dialogue des sciences et des humanités, Cahiers de l'Assoc. Intern. des Universités, 1960, n 5, p. 17.

964 «La nouvelle philosophie naît sur le terrain de la morale, dans une polémique de plus en plus âpre entre la nature et l'humanité, ou même si on veut entre le destin et la vertu ». E. GARIN : L'umanessimo italiano, ed. cit. p. 33-

965 «Le thème polémique contre la science de la nature parcourt donc toute l'œuvre de Pétrarque ». G. TOFFANIN : op. cit. t. II p. 124. 
«Elles ont un prix théorique peu commun, mais aucune valeur pour la vie : l'autre philosophie est, pour ainsi dire, toute nôtre ».

Elle est aussi la philosophie des hommes de loi, des juristes défenseurs de l'intérêt de la cité, de ses maîtres et des règles qu'ils édictent. La querelle qui oppose les médecins aux légistes, au $X V^{\mathrm{e}}$ siècle, est très instructive à cet égard. Les juristes voient la supériorité de leur discipline dans le fait que, comme l'art militaire, elle intéresse l'ensemble de la société, tandis que les autres sciences ont en partage un domaine plus restreint.

« La discipline et l'œuvre militaire sont pour le bien public et universel, et la science et les études seulement pour le bien particulier ${ }^{966}$.

C'est pourquoi le juriste prétend au titre de «signore », alors que le médecin n'est qu'un artisan quelconque, un maître parmi les maîtres des autres corps de métiers :

«Les médecins en fait sont maîtres comme les chausseurs, les blanchisseurs, les ouvriers, les maçons et une grande partie des travailleurs manuels, si bien que la médecine apparaît aussi vile que ces métiers ${ }^{967}$.

Les médecins ne peuvent nier que leur attention soit tournée vers les phénomènes matériels qui constituent un champ de préoccupations nettement inférieur et secondaire. Certes, si seule la vie politique et policée, la vie des hommes qui se consacrent à la société en cultivant ses valeurs, en justifiant ses errements, a de l'importance aux yeux de ceux qui y sont attachés par leur position et aux yeux de leurs commanditaires, le reste est éliminé de la zone des intérêts essentiels. Il faut être philosophe plébéien pour s'adonner aux disciplines qui n'atteignent pas la dignité requise pour être reconnues des grands, et Ermolao Barbaro dénonce explicitement le péché de ces «philosophâtres plébéiens qui séparent la philosophie de l'éloquence ». 
L'étude de l'histoire et du droit, le développement de la rhétorique et de la grammaire, bref, tout ce qui permet à la société — à la bonne société - de prospérer, de s'ancrer dans la certitude de sa pérennité, est jugé supérieur à l'étude des lois matérielles, tirées de l'expérience, trompeuses et incertaines. Le chancelier florentin Coluccio Salutati y insiste dans son De nobilitate legum et medicinae. La confrérie dont il fait partie et la doctrine qu'il propage conservent toujours la nostalgie d'une humanité purifiée par la contemplation et la conversation, dégagée de toute contingence matérielle et extérieure, avec le regret de voir altérer l'intégrité de l'homme par la poursuite d'occupations vulgaires et productives. On n'essaiera donc pas de réunir ce qui est distinct, au contraire on recherche la hiérarchie et la séparation. Assurément, on peut étudier à l'occasion les phénomènes météorologiques, mécaniques ou astronomiques, mais on ne saurait en faire son occupation exclusive, car ils ne sont pas primordiaux. On comprend que cette conception, qui a subsisté jusqu'à nos jours, se refuse à reconnaître l'honneur de ceux qui accumulent des informations tellement dénuées d'importance pour l'âme et la société des puissants, et s'efforce de les remettre à leur place. C'était le lot des médecins au sortir du Moyen Age, et celui des scientifiques jusqu'au début de ce siècle ${ }^{968}$. Sir Thomas Merton l'a rappelé récemment ${ }^{969}$ :

«Il fallait tenir les scientifiques en lisière. Il y eut un Premier Ministre pour dire « Nous devons laisser les scientifiques en perce (on tap) et les empêcher de percer jusqu'au sommet » (on top), et il y eut un secrétaire permanent pour envoyer un mémoire indiquant qu' «il n'est pas conforme aux règles d'une bonne administration de laisser siéger les scientifiques aux côtés des fonctionnaires supérieurs ». Le pire de tous fut peut-être ce membre d'un cabinet qui déclara : «Ce que j'aime chez les scientifiques, c'est qu'ils forment une équipe, on n'a même pas besoin de savoir leur nom ».

Que leur instruction, et l'instruction destinée à ceux qui pratiquent les métiers, les arts, les techniques, aient été longtemps laissées en friche n'étonne guère. Assurément les États ont réglementé la durée

G. Foote: The place of science in the British reform movement : 1830-1850, Isis, 95, 42, p. 18.

969 T. MERTON : Science and invention, New Scientist, 1965, nº 430, p. 377. 
de l'apprentissage, les conditions d'admission dans un corps professionnel. Jusqu'à une date récente ${ }^{970}$, toutefois, on ne peut pas soutenir qu'on ait accordé une grande importance à la pédagogie dans cette direction. L'agriculteur, l'artisan ou l'ingénieur se mouvaient dans leur domaine propre, assurant la production des biens, la reproduction du travail. L'habituation du jeune agriculteur à la culture du sol, l'enseignement du jeune apprenti, de l'artisan ou même de l'ingénieur se faisaient à la ferme ou à l'atelier. Les arts, qualifiés de mécaniques, suivaient leur voie hors des grands courants qui préoccupaient constamment les élites dirigeantes de l'humanité, et n'apparaissaient que rarement comme son faire et sous sa responsabilité. L'antagonisme qui sépare ces deux directions d'enseignement, en raison de leur contenu et du rang qu'on leur attribue, a été transformé en une propriété jugée inhérente à la nature humaine. Le grand historien et érudit W. Jaeger note que :

«L'opposition des deux conceptions de l'éducation (sociale et technicoscientifique) se manifeste à travers toute l'histoire, car elle est un trait fondamental de la nature humaine ${ }^{971}$.

Pour préserver ce «trait fondamental », beaucoup d'efforts ont été dépensés. En effet, non seulement les notions élevées furent inculquées aux enfants qui le méritaient, vu les positions qu'ils devaient occuper dans la société : elles furent de plus refusées, voire interdites, à tous ceux qu'une vocation inférieure, productive, allait accaparer complètement. Lorsque à partir $\mathrm{du}_{\mathrm{XVIII}}^{\mathrm{e}}$ siècle, pour ne considérer qu'une époque très récente, il parut évident que la préparation des ingénieurs constituait une tâche importante, que les scientifiques étaient nécessaires à l'industrie, qu'enfin l'ouvrier lui-même devait avoir un minimum de connaissances pour s'intégrer à la production ${ }^{972}$,

970

"Les humanités étaient donc les plus anciennes des disciplines et celles qui jouissaient généralement du plus de prestige. Elles comprenaient la fleur de l'instruction supérieure, dans tout le monde occidental, pendant très longtemps, maintenant un monopole virtuel qui ne fut pas rompu avant le milieu du XIX ${ }^{\mathrm{e}}$ siècle... Malgré l'œuvre grandiose de figures telles que Galilée et Newton... les sciences naturelles ne rivalisèrent pas de façon effective avec les humanités dans l'éducation supérieure et la culture des classes sociales les plus influentes, avant que le $\mathrm{XIX}^{\mathrm{e}}$ siècle en fût presque à sa moitié ». T. PARSONS : Unity and diversity in the modern intellectual disciplines : the role of social science, Daedalus, 1965, 94, p. 41.

971

A. LÉON : Histoire de l'éducation technique, Paris, 1956, p. 89. 
l'Europe traversa une grave crise de conscience. Les habitudes d'ignorance qu'on avait entretenues entrèrent en conflit avec l'intérêt bien compris de l'industrie et les besoins du marché. La première réaction fut de rejeter résolument l'idée de faire entrer les classes laborieuses, ou même ceux qui se consacraient à des tâches plus techniques, dans le circuit normal de l'éducation. Ensuite furent conçues les écoles destinées exclusivement à la technique et à la science, mais qui ne donnaient pas la possibilité de s'initier aux arts de la société et de la politique. Connaître davantage de choses ne convenait pas à une intelligence si proche de celle des créatures inférieures à notre espèce :

«L'éducation, écrivait un de ces hommes soucieux du bien public ${ }^{973}$, comme nous l'avons vu, a trait à la période d'adaptation ou de dépendance. Comme l'animal inférieur se développe plus rapidement que l'homme et par conséquent atteint le stade d'adaptation totale à un âge plus précoce, ainsi parmi les hommes, ceux qui possèdent une intelligence d'espèce inférieure ont un développement mental plus rapide à l'intérieur de leur cercle étroit que ceux qui appartiennent à une espèce supérieure. Par conséquent le stade d'adaptation totale et ainsi celui où ils ne dépendent que d'eux-mêmes dans leur milieu restreint est atteint par ces hommes à un âge plus précoce. Donc, pour eux, l'éducation n'est plus nécessaire — ou n'est même plus possible ».

En France, des voix vigoureuses se sont élevées contre les Écoles Centrales, en les accusant d'athéisme et d'impiété envers les bonnes études. Nous savons, par ailleurs, qu'en 1824 une commission de députés jugea les Écoles des Arts et Métiers politiquement dangereuses et inutiles. Les matières que l'on y enseignait n'étaient pas nécessaires au fonctionnement de l'État, au maintien de l'ordre et de la religion ${ }^{974}$. Les critiques de la commission des députés paraissent discutables au baron Dupin qui les rapporte, et il est intéressant de savoir pourquoi :

«Que l'on regarde comme dangereuses les écoles où l'on professe certaines théories politiques, morales ou historiques, on le conçoit facilement. Mais je demande en quoi les éléments de l'arithmétique, de la géométrie ou de la

F. WARE : Educational foundations of trade and industry, Londres, 1901, p. 116.

974 C. Dupin : Avantages sociaux de l'enseignement public appliqué à l'industrie, Paris, 1854, p. 14. 
mécanique, du dessin, de la physique ou de la chimie peuvent être dangereux $\gg{ }^{975}$.

Voilà les arguments auxquels on était acculé pour faire accepter les disciplines naturelles dans le champ de l'éducation organisée et systématique. Lyon Playfair le remarquait à la fin $d u \mathrm{XIX}^{\mathrm{e}}$ siècle :

«Et pourtant, si quelqu'un s'aventure à faire ressortir la nécessité d'une éducation améliorée dans nos grandes écoles, il est considéré comme un démocrate de l'éducation et un barbare qui écraserait la grâce de la littérature polie avec la main de la vulgarité mécanique $»{ }^{976}$.

Élaborée dans ces conditions, la pédagogie qui s'adressait aux hommes censés entrer dans le cycle productif, se consacrer à l'invention, embrasser tout le domaine matériel, ne pouvait être que limitée aux exigences immédiates de la profession. De plus, acceptée avec réticence, elle ne pouvait conférer un grand prestige.

« Il y a cinquante ou soixante ans - c'est-à-dire au début du $\mathrm{XX}^{\mathrm{e}}$ siècle on enseignait peu de science aux garçons dans les écoles, sauf à ceux qui se spécialisaient en science, alors que les lettres classiques étaient des matières obligatoires. Ce système ne semblait pas avoir de conséquences graves à l'époque parce que la plupart des découvertes de ce temps-là pouvaient être expliquées en termes simples à quiconque était doué d'une intelligence moyenne : malheureusement ce n'est plus le cas. Les fonctionnaires et les hommes politiques se recrutaient principalement parmi ceux qui avaient fait des études supérieures en lettres ou en histoire, et, à peu d'exceptions près, ils méprisaient les scientifiques qu'ils étaient enclins à considérer comme des philistins et des barbares incultes $»{ }^{977}$.

Barbares, certes, puisqu'ils n'ont pas reçu l'éducation ${ }^{978}$, la seule digne de ce nom, celle qui perpétue, en les aménageant, les routines

975

976

977

978

C. DUPIN : idem, p. 16.

L. Playfair : op. cit. p. 20.

T. MERTON : art. cit.

"L'évolution des techniques, quelles qu'elles soient, a pu longtemps passer pour un phénomène qui n'intéressait pas directement la formation ni l'éducation de la généralité des jeunes gens... Pourtant, à toutes les époques de l'histoire humaine, les techniques de tout genre ont joué un rôle essentiel, mais le plus souvent inconscient, dans la formation des cadres de la société ». P. NAVILLE : Vers l'automatisme social ? ed. cit. p. 248. 
de l'enseignement libéral. La teneur de ces conceptions, qui n'ont rien perdu de leur actualité, a l'avantage d'être familière à chacun. Ici, leurs conséquences et leur valeur nous retiennent seules. L'éducation, la transmission des talents qui est prônée, suppose l'existence de deux voies, étanches et inégalement développées, pour la formation des individus en vue de leurs rapports avec autrui et avec l'univers. Pour ce qui est des produits du travail, la première enseigne leur usage, et la seconde leur découverte et leur fabrication. Dès lors, suivant une doctrine qui remonte à Platon et à Aristote, l'usager est meilleur juge, possède la compétence indispensable et l'idée, par le truchement desquelles il fixe les cadres où s'exerce l'activité productive et créatrice. Mais il est évident que cette appréhension des produits demeure une appréhension externe. Le travail y est reconnu par ses résultats, la nature par ses éléments. Les métaux, les cours d'eau, les terres, les animaux domestiques et les talents qui accompagnent les uns et les autres se trouvent là, à proprement parler, gratuitement, produits de l'instinct et du hasard, sans que personne ait à les créer systématiquement. Tout ce qui a trait à la multiplication des richesses matérielles, aux relations entre collectivités humaines autres que les rapports de la propriété et du pouvoir - aux relations naturelles — chemine séparément, sans paraître devoir donner prise à une action ou à une réflexion qui soient centrées principalement sur elles. Si ces relations naturelles revêtent l'aspect non-humain, non-social, d'un au-delà de l'œuvre humaine, c'est parce que cette œuvre, le commandement et la vertu qu'elle visait, ont été concentrés dans les rapports sociaux et politiques, abandonnant tous les autres, dans les limites où le permettait l'intérêt, aux soins des couches inférieures de l'humanité. Celles-ci étaient proches de la nature, et la nature était leur lieu, représentant, en ce qu'elle avait d'effectif, la non-humanité, à l'instar de ces couches ellesmêmes. Bien que le travail, sa reproduction et son invention soient à la base de notre constitution objective, il reste inscrit, eu égard aux valeurs prédominantes, dans le royaume des moyens. Et si l'on déclare, par la suite, que le monde est devenu étranger, vide, a perdu tout contenu humain, c'est parce qu'on s'est situé hors de ce monde, parce que les notions inculquées, gravées dans la conscience, supposent l'ignorance, la méconnaissance de toute une partie de notre existence, dont on a détourné les yeux, tant on la jugeait inutile, dès l'instant où elle tombait hors des limites des ordres qui fixaient à la société sa conduite. 


\section{Une figure de rhétorique la conquête de la nature.}

Tout ce qui transgresse les limites établies par cette fraction de l'humanité est du domaine de la conquête de la nature. Celui-ci englobe l'univers matériel, la création des savoirs qui s'y réfèrent et les interactions des groupes humains lorsqu'ils s'y consacrent. La reproduction naturelle des talents, l'enseignement qui s'y rattache n'ont pris une forme systématique et ouverte, ayant une valeur reconnue pour la collectivité, que tout récemment:

«Les idéaux de la Renaissance et de l'Humanisme ont inspiré la pratique pédagogique jusqu'à une période avancée du XIX $^{\mathrm{e}}$ siècle et survivent même dans beaucoup d'esprits en qualité de reliques. Les sciences et les techniques étaient considérées comme étant de faible valeur formative, alors qu'en revanche les disciplines historico-littéraires se voyaient reconnaître une valeur éminente. Cependant le développement des sciences a pris de telles dimensions et une telle signification pour la vie humaine qu'il n'est déjà plus possible de les considérer comme le simple complément d'une éducation générale humaniste, comme un élément d'information étranger aux disciplines éducatives et formatives $\gg{ }^{979}$.

En effet, la situation s'est modifiée, et le contraste nous frappe plus vivement. Les causes en sont connues: socialisation de l'appareil productif d'abord, éclosion de la science et du travail inventif ensuite. Le siècle précédant le nôtre en a fait l'expérience simultanément. Dans ses usines se sont concentrés des millions d'hommes qui, dépourvus de terres ou dépossédés de leur métier, sont venus constituer l'immense armée des travailleurs de l'industrie. Chaque progrès dans la construction des machines et l'accumulation des énergies inanimées, tout en éliminant une partie de la main-d'œuvre, réunissait dans un même atelier un plus grand nombre d'ouvriers. Les diverses branches du processus industriel, stimulées par l'échange, talonnées par la concurrence, eurent besoin de se diviser et de se subdiviser, durent rechercher des combinaisons nouvelles. L'interdépendance de toutes 
les parties de cet ensemble, tant du point de vue technique que du point de vue économique, atteignit un degré d'universalité inconnu auparavant. La croissance des unités urbaines, l'intensification des communications, la mobilité des individus, la fébrilité entretenue par la poursuite du profit capitaliste et la «lutte pour la vie», rendirent plus dense le tissu des relations sociales. Dans la vie des États, la production industrielle et les conflits d'ordre économique acquirent une place éminente qu'ils n'ont plus cessé d'occuper. Rien ne pouvait échapper à la loi commune, ni la collectivité perdre ses dimensions nouvelles. Parallèlement, la science se structura et devint un terrain fécond où des forces productives inédites pouvaient apparaître à tout moment. Avec elle, l'invention se changea en un processus régulier, systématique et continu. Aucune nation ne devait plus l'ignorer ${ }^{980}$, sous peine de sombrer politiquement et économiquement. Inversement, les découvertes scientifiques bouleversent constamment les procédés et les branches de la production, affectent sans cesse les rapports entre les nations. A l'intérieur de chacune, le contenu des classes sociales a changé, car toute ressource ou connaissance nouvelle élimine certaines des ressources ou des connaissances existantes et, avec elles, les hommes qui les détenaient. Les cloisonnements et les séparations si bien entretenus et depuis si longtemps ont cessé d'être rigides et n'ont plus pu le redevenir. Les institutions et les principes éducatifs se sont trouvés violemment entraînés dans ce mouvement. Non seulement parce que, avec la science, universités et écoles, «bastions de la formation des lettrés " ${ }^{\mathbf{9 8 1}}$, ont été forcées d'admettre la nécessité du changement, mais aussi du fait que tous leurs buts se sont trouvés révisés. Destinées à la conservation du savoir et à sa redistribution, elles ont été obligées de le renouveler. Les portes qui, jusque-là, donnaient accès uniquement à la politique, à l'administration, et qui, pas plus que celles de la société ${ }^{982}$, ne débouchaient sur la production, sur l'industrie, durent ouvrir sur celles-ci également. Bien plus, ce dernier

C.P. KINDLBERGER : Economic Growth in France and Britain, Cambridge (Mass.), 1964.

J.H. HeXTER: The education of the aristocracy in the Renaissance, J. of Mod. Hist. 1950, $\mathrm{n}^{\mathrm{o}} 22$, p. 4.

982 «La complication des techniques a conduit progressivement à des différenciations dans le monde ouvrier et une nouvelle stratification sociale va correspondre à une hiérarchie des savoirs... Tout en haut de l'échelle apparaissent maintenant d'une manière plus précise les grands techniciens, mal définis et surtout mal intégrés jusque-là dans une société qui ne faisait guère de place aux préoccupations techniques. » M. DAumas (ed.) : Histoire générale des techniques, Paris, 1962, t. 2, p. 136. 
enseignement allait se substituer au premier et le dominer. La révolution était profonde, et Auguste Comte a annoncé sa venue, de même qu'il en a pleinement saisi la signification :

« Déjà, tout est préparé pour cette grande révolution. Les connaissances naturelles sont enfin devenues, à tous les yeux, et deviendront de plus en plus l'objet principal de l'enseignement ${ }^{983}$.

Si cette prophétie d'Auguste Comte et de tant de ses contemporains ne s'est pas encore réalisée, si le bouleversement entrevu n'a pas encore parcouru toutes les phases de son cycle, les conditions de son accomplissement sont déjà manifestes. L'enseignement en question, la conception du développement historique qu'il présuppose restent soumis aux contraintes que l'on sait. En effet, bien que la hiérarchie du champ social et du champ naturel, des groupes humains consacrés à l'un ou à l'autre ait changé, l'écart entre eux persiste. Cela n'a rien d'étonnant. La structure de classe des collectivités contemporaines, les rapports de l'État à l'ensemble du monde civique, la particularité de la sphère politique vis-à-vis des autres sphères de l'existence humaine, son poids et sa vigueur d'intervention, n'ont pas été radicalement et généralement ébranlés. Toutefois, l'ampleur qu'ont prise nos interférences avec le monde matériel - et à cet égard le rang auquel s'est haussée l'éducation qui vise à l'acquisition des disciplines naturelles est un signe - élargit l'horizon qu'il est indispensable d'explorer, d'appréhender dans un nouveau cadre, l'ancien étant visiblement rendu caduc. En conséquence, les limites reconnues à la société et à son gouvernement s'évanouissent, et l'élan attribué à la conquête violente, victorieuse, de la nature, se trouve relégué parmi les accessoires de la rhétorique. La dissymétrie entre ce qui était considéré comme du ressort du faire social et ce que l'on estimait relever du donné naturel éclate. Le décalage entre l'attention accordée aux rapports politiques, économiques, et le dédain voué aux autres relations, ne résiste pas aux confrontations avec la pratique générale. Les processus par lesquels se sont formés et se forment les talents, les disciplines par lesquelles sont assurés les échanges avec l'univers matériel, viennent au premier plan, occupent le devant de la scène. Nos relations à cet égard, 
l'obligation de les reproduire et de les inventer, bien que naturelles en elles-mêmes et pour elles-mêmes, commencent à devoir être gouvernées, autant que le furent et le sont les relations sociales. L'histoire des sociétés qui ont suivi un principe indépendant, celle des classes sociales qui se sont fixé pour fin d'établir les instruments conformes à ce principe, ne peut plus se dérouler en reléguant l'histoire de notre nature dans le royaume de la matérialité inerte. Au sein de cette matérialité, une vie se découvre qui est la vie des catégories d'hommes ayant la vocation de la façonner et de faire jaillir ses propriétés éminentes. De ce fait se pose un problème des plus sérieux, dont la résolution importe autant à l'humanité qu'autrefois la nécessité d'esquisser les premières ébauches permettant de saisir et de maîtriser les liens dans la communauté politique. Et il n'est pas plus incongru de se demander quel est l'état de nature le meilleur ou le plus conforme à notre situation historique qu'il ne le fut, à un certain moment, de se demander quelle était la meilleure cité ou celle qui correspondait le mieux aux exigences des forces collectives en présence.

Ce sont les traits essentiels de la civilisation - autonomie de l'ordre social, opposition de celui-ci à l'ordre naturel, droit à définir l'essence de l'espèce humaine — qui sont remis en cause par les circonstances réelles qui ont provoqué cette demande. 


\section{Chapitre III.}

\section{L'exploitation des choses}

ante fuit.

Quod nunc ratio est, impetus

OVIDE.

\section{Le gouvernement de la nature}

$\underline{\text { Retour à la Table des Matières }}$

\section{Progrès plein et progrès vide.}

A travers l'évolution que j'ai décrite, c'est le rapport de notre état social à notre état naturel qui se trouve affecté, remis en question. La totalité que constitue la civilisation est soumise, nous avons pu le constater, à deux mouvements historiques, dont l'un est propre à la nature et l'autre à la société. La séparation des catégories naturelles et l'antagonisme des classes sociales forment respectivement le noyau de chacun de ces mouvements. Ce découpage et cette opposition ont pour effet d'isoler les hommes dans des sphères de vie différentes, ne communiquant que par de multiples intermédiaires. La nature cybernétique et la progression naturelle transforment ces traits de la civilisation, annoncent de nouvelles formes d'interaction avec les pouvoirs matériels, de nouveaux liens entre les parties de l'humanité, pour autant qu'elles reproduisent et inventent leurs facultés. Bien plus, cette tendance figure parmi les conditions préalables du renouvellement de la société. Ces conditions sont réunies et il n'est pas nécessaire d'y 
insister : il s'agit là d'une donnée de la conscience commune, inscrite dans la vie politique et la volonté de millions d'hommes. Le partage de notre planète entre deux systèmes sociaux définit une situation suffisamment expressive par elle-même pour nous avertir que cette division engendre obligatoirement des structures sociales originales, dont il ne saurait être question de prévoir le contenu avec exactitude sans transgresser la frontière qui sépare l'analyse de la prophétie. Les ébauches seront forcément nombreuses : l'orientation fondamentale se maintiendra, sous la pression des causes qui lui ont donné naissance.

La conjonction que je viens de résumer a été appréhendée au moment où elle venait de s'ébaucher :

«L'exploitation de l'homme par l'homme, voilà l'état des relations humaines dans le passé ; l'exploitation de la Nature par l'homme associé à l'homme, tel est le tableau que présente l'avenir ».

Personne ne s'était mépris sur les prolongements révolutionnaires de l'idée de Saint-Simon, sur le cheminement dont il dessinait le tracé à l'avance. Formation d'une communauté ayant supprimé conflit et oppression en éliminant l'État et en abolissant l'autonomie de la fonction politique, après avoir associé ses membres à la gestion de leurs affaires, d'abord. Transfert de leurs énergies et de leurs tensions du champ des rapports qu'ils entretiennent entre eux au champ des rapports qui les lient à l'univers matériel, ensuite.

On apercevait là d'emblée une solution de rechange aux routines de la servitude, la voie à suivre une fois celles-ci bannies. A savoir, la voie de la découverte du monde extérieur, la seule où les actes, étant en accord avec les valeurs profondes de l'humanité, lui rendraient sa dignité et lui permettraient de maîtriser les ressources et les lois de la matière. L'histoire des sociétés humaines, au lieu de continuer à être le répertoire des crimes de l'humanité, de son ignorance, de sa misère, de ses illusions, deviendrait une longue chaîne d'entreprises utiles, une suite de conquêtes faites dans le royaume de la connaissance et le domaine de la technique. Absorbé par ces tâches, débarrassé du gaspillage qu'entraîne la soumission d'un homme à un autre homme, le corps social se trouverait encouragé à se libérer des guerres civiles, à 
imprimer une nouvelle direction à son histoire. De la sorte, il se préparerait à remplacer le gouvernement de la société - en tant que gouvernement des hommes - par le gouvernement de la nature - en tant que gouvernement des choses.

Certes, l'irruption de celui-ci dans la réalité n'allait pas attendre la disparition des formes anciennes. Lorsqu'il surgit, comme aujourd'hui, c'est en les chevauchant, pour accentuer avec une vigueur dramatique les problèmes communs : la lutte des classes et des nations privées du nécessaire contre les classes et les nations nanties d'un important surplus de richesses, le contraste entre les profonds bouleversements dus aux sciences et aux techniques et l'incapacité de les assimiler, etc. ${ }^{984}$.

La proximité relative du mode de gouvernement dont la venue nous a été prédite nous permet de saisir clairement les fins qu'on lui assigne : d'abord, l'unification, grâce aux progrès des sciences et des techniques, des aspects intellectuel et manuel du travail, l'éradication de l'inégalité entre les travailleurs - la troisième inégalité — qui les caractérise ; ensuite, l'accumulation de sources d'énergie, de savoirs et de machines, la formation d'une armée d'esclaves mécaniques, destinés à satisfaire la gamme croissante des besoins et à assurer les loisirs de tous par la réduction des travaux qui exigent la participation humaine. Au fur et à mesure que ces objectifs sont concrétisés, les hommes sont à même de gouverner la nature en maîtres, et de considérer avec sérénité leur action sur celle-ci.

Arrêtons-nous cependant un instant pour détailler le sens de ces formules et examiner les moyens que présuppose leur application. Pour être aptes à gouverner l'univers physique, pour exercer ce gouvernement en s'associant entre eux, il ne suffit pas que les hommes

984 « Plusieurs évolutions importantes sont parvenues à maturité à notre époque ; la révolution des classes défavorisées contre les sociétés qui ont failli à la tâche d'atténuer les injustices sociales; la révolution des nations défavorisées contre les empires qui ne se sont pas transformés assez vite en communautés de nations libres - et, donnant une terrible urgence à ces deux soulèvements, la grande révolution scientifique et technique, qui a doté l'humanité d'une capacité sans précédent de se détruire de ses propres mains, ou de s'élancer vers de nouveaux sommets du bien-être matériel universel ». E. RABINOwITCH : The dawn of a new age, Chicago, 1963, p. 48. 
écartent uniquement l'iniquité introduite par la répartition de la richesse ; il leur faut aussi en finir avec la disparité due à la structure du travail. Aux yeux de ceux qui embrassent cette perspective d'avenir, la signification différente que la société attache au travailleur manuel et au travailleur intellectuel les oppose irrémédiablement. D'un côté, malgré les sacrifices qu'on lui impose, l'individu se voit relégué dans la zone inférieure de la vie collective, tandis que sa production, quel qu'en soit le prix, est dénigrée. De l'autre côté, l'appartenance à la couche supérieure de la collectivité, la reconnaissance sociale et la possibilité d'atteindre par ses travaux à l'aisance, ou à la direction des institutions politiques, ne font pas de doute. La différence de valeur qui sépare les deux formes d'activité souligne une inégalité fondamentale, au regard de laquelle celle des classes n'est qu'un effet parmi d'autres ${ }^{985}$. La question est capitale pour les systèmes sociaux qui se réclament du socialisme. La justice tant attendue se heurte au roc des différences de qualification au travail, qui imposent une distribution hiérarchique des biens, une scission entre dirigeants et dirigés. Le désir d'associer les hommes en face de la nature rencontre les mêmes limitations. Si habiles que soient les idéologues, si fortifiée que soit la volonté politique, l'antagonisme qui sépare l'être de raison de la société et son être de fait contrecarre les principes sur lesquels elle s'est édifiée, et au nom desquels elle s'adresse au monde.

La pratique alternée des deux formes de travail paraît être, à première vue, une réponse. Elle permettrait aux couches de la société de se rencontrer, chacune faisant l'expérience de la situation de l'autre. Plus généralement, la variété des occupations, le passage d'un type d'activité manuelle à un type d'activité intellectuelle et réciproquement, est considéré comme le moyen approprié de resserrer les liens

985

\footnotetext{
« Par ailleurs, la division entre les types d'activité, et surtout la division entre travail manuel et intellectuel, malgré la croissance massive des divers types de travail intellectuel, demeure très importante [dans les sociétés socialistes]. Le maintien de cette division des forces de travail était une des raisons qui justifiaient aux yeux de Karl Marx des rapports de répartition marqués par le droit bourgeois pendant toute la première partie du collectivisme. La répartition selon la qualité et la quantité du travail, avec une égalité de droit consacre l'inégalité de fait des aptitudes intellectuelles, comme le remarque Marx. Certes toute la société est tendue par une promotion culturelle démocratique. Certes la répartition selon la fortune disparaît et le parasitisme des couches possédantes est supprimé ; mais non toute répartition inégale. » B. PAUL : Réflexions sur le mode de développement du mode de production collectiviste, Économie et politique, $1965, \mathrm{n}^{\circ} 131$, p. 95.
} 
entre les divers groupes de la société et de réduire les distances existantes ${ }^{986}$. La collectivité atteindrait ce stade de transparence, de possession des forces matérielles, lorsque la division du travail aurait fait place au cumul des spécialités, devenu la règle universelle au lieu de rester l'apanage d'une minorité.

Le raccourcissement de la durée du travail, la profusion des loisirs et la présence massive d'esclaves mécaniques sont également donnés pour des signes éminents de notre capacité de gouverner la nature, comme s'ils en dépendaient. Maîtres de leur temps — ce temps dénommé libre par opposition à celui de la servitude - les individus pourront enfin se retrouver pour se vouer ensemble à leur enrichissement et au contrôle des ressources désormais abondantes. En poursuivant méthodiquement la carrière ainsi ouverte aux talents et aux besoins qu'enferme chaque individu, l'harmonie recherchée sera rapidement atteinte. Cette circonstance fait - la leçon nous vient des classes qui l'ont cultivé longuement ${ }^{987}$ — que le loisir ne peut être abandonné au hasard. Organisé, il devient labeur de la culture ${ }^{988}$; laissé au gré des convenances personnelles, il n'est que fuite. Les machines, les sources énergétiques sont appelées à le conserver aux hommes ${ }^{989}$, leur permettant d'échapper à l'asservissement ${ }^{990}$, de vaincre la monotonie. Asservissement et monotonie qui seront le lot des admirables appareils scientifiques ou techniques, tous les jours plus puissants et parfaits. Leur travail s'affirme à terme comme notre loisir, leur soumission muette témoigne de l'emprise que nous exerçons sur eux.

986

«Pour que le travail devienne un besoin vital de l'homme, il faut qu'il soit physiquement facile, intéressant, créateur, combinant de façon harmonieuse l'activité physique et l'activité intellectuelle, et il ne doit pas durer trop longtemps. Ce résultat peut être atteint sous un régime socialiste, comme conséquence de l'énorme progrès technique qui est en cours ». E. MANEVICH : Abolition of the differences between mental and physical labor in the period of full scale construction of communism, art. cit. p. 14.

987 T. VEBLEN : The theory of the leisure class, New York, 1953.

988 P. NAVILle : De l'aliénation à la jouissance, Paris, 1957, pp. 488 et seq.

989 «Si la culture de jadis s'est édifiée pendant le temps de loisir fourni par le temps de travail des esclaves et la division de la société en catégories économiques, la culture de l'avenir peut être édifiée grâce à l'énergie illimitée disponible ». W.N. POLAKOW : The power age, New York, 5933, p. 20.

990 «A l'avenir, les machines finiront par soulager l'homme de tout le travail mécanique, qui viendra à être considéré comme indigne de l'effort humain ». E. FISCHER : The necessity of art, ed. cit., p. 128. 
Ces opinions ${ }^{991}$, qu'il ne coûte rien d'émettre ou de propager, résument la vision d'une époque - celle de la civilisation des loisirs, dit-on où toutes les figures particulières de notre espèce pourraient se confondre en un être universel, complet, et, après avoir renoncé à l'exploitation des hommes, se consacrer à celle des choses.

Quelle est la portée effective de ce programme, quelle est la teneur du contenu instillé à une conception qui s'est proclamée révolutionnaire ? Quel est son rapport avec le réel ? Sa composition traduit moins l'aboutissement d'un effort d'analyse qu'une tendance à la compensation, le désir de combler un manque. En ajoutant ce qui fait défaut, en retranchant ce qui se trouve en excès, on prétend atteindre, sans sortir de la voie de la prudence, le difficile ou l'exceptionnel. Le travail et le loisir, la main et le cerveau, le monde social et le monde naturel viennent à la rencontre les uns des autres pour se combiner heureusement et substituer les apparences positives aux apparences négatives ${ }^{992}$. La tension présente fait place, insensiblement, à l'harmonie future. Le nouveau ne prononce pas l'arrêt de mort de l'ancien ; il s'agit de récupérer ce qui a été gaspillé, et non pas de faire accéder à l'être ce qui n'a jamais été. Dès lors, le gouvernement de la nature n'est qu'une transposition du gouvernement de la société, tous deux fondés sur la co-présence de maîtres et d'esclaves. La seule différence vient de ce que l'on souhaite, après avoir longtemps fait de l'être humain un esclave - être non-humain — transformer à leur tour l'ensemble des êtres non-humains en esclaves des hommes. Ce que l'on projette ainsi dans le futur, c'est d'abord la revanche prise sur les privations anciennes.

L'instrument de cette justice distributive de l'histoire est le progrès scientifique et technique. Les considérations dont on l'enveloppe, les

991

Alors s'épanouiront pleinement les dialectiques interminables de la liberté. D'abord la conquête continuée de la nature par l'homme. Dans les chantiers sans limite de la triple infinité : celle du petit, du grand et du complexe, l'homme a la perspective des luttes sans fin; du côté de la microphysique et des désintégrations de la matière, du côté du cosmos, du côté des synthèses chimiques inédites, de plus en plus complexes, comme celles de la chlorophylle, ou de la vie ». R. GARAUDY : Karl Marx, Paris, 1964, p. 156.

992

Voir pour illustration R. GARAUDY : Karl Marx, ed. cit. 
caractères d'automatisme et de perfection qu'on lui prête ${ }^{993}$, la confiance, voire l'abandon qu'il provoque, en font, selon l'heureuse expression de Karl Marx, une catégorie « tout à fait vide de contenu et abstraite ».

C'est de l'essor considérable des sciences et des instruments cybernétiques que l'on attend généralement le surplus de durée qui permettrait à chacun d'exercer une activité en rapport avec ses dons. C'est aussi par son intermédiaire que l'asservissement des choses se substituera à l'asservissement des hommes.

Quel poids faut-il accorder à ces lieux communs rénovés? A l'instar des classes qui leur sont vouées, loisir et travail se nient réciproquement. Cette négation est considérée comme leur trait permanent. Si le premier ne passait pas pour le symbole de la domination et de la consommation exclusives, si le second n'était pas identifié à la servitude et à la production contraignantes, on n'aurait aucune raison de penser qu'ils s'excluent mutuellement, ni de faire de l'un le remède aux inconvénients de l'autre. De plus, il n'y a pas de loisir bénéfique et fécond si l'ensemble des occupations humaines ne l'est pas. On a $\mathrm{vu}$, bien à tort, dans le loisir la condition essentielle de toute vie sociale riche, de toute culture et de tout art. Sir Herbert Read l'a opportunément rappelé ${ }^{994}$ :

«Qu'entendons-nous par loisir, et pourquoi devrions-nous supposer qu'il constitue un problème qu'il incombe aux arts de résoudre ? Les grandes périodes de l'art n'ont pas été remarquables pour leur loisir — du moins, l'art n'y était pas une activité associée au loisir. C'était un artisanat comme les autres, qui avait pour but la fabrication d'objets nécessaires ».

993 994

\footnotetext{
comme sujet et comme objet de l'action. Pour servir l'homme, il faut l'asservir. Désormais on
peut ne plus asservir que des machines, et c'est la rigueur du système de communication et de
production technique qui garantit la flexibilité et peut-on dite l'humanité des systèmes de
communication et des relations entre les hommes ». A. TouRAINE : Le rationalisme libéral de
Michel Crozier, Sociologie du Travail, 1964, 6, p. 189 .

«Les contraintes traditionnelles viennent toujours de la confusion inévitable de l'homme

H. READ, in N. CALDER : op. cit. t. 2, p. 88.
} 
La confrontation des préjugés confortables avec la réalité ${ }^{995}$ nous enseigne que c'est bien dans les activités liées à l'essor de nos habiletés que se trouve la source de notre originalité. Une communauté dont chaque membre aurait son violon d'Ingres serait certes plus enviable qu'une communauté dont tous les individus en seraient dépourvus; elle n'en resterait pas moins une communauté tronquée, où seule l'évasion serait élevée à la hauteur d'une institution. Le loisir en tant que non-travail reste enfermé dans ce qu'il fuit, au lieu de se tourner vers ce qu'il construit.

La prolifération des esclaves mécaniques, le résultat tant attendu du progrès, n'est pas non plus une garantie de libération authentique du genre humain. Au lieu que l'homme devienne artisan, ingénieur ou savant accompli, on lui propose pour idéal de devenir surveillant de machines, de se conduire en maître des pouvoirs matériels venus à résipiscence. De toute manière, le noyau de la relation — déplacé de l'univers social à l'univers naturel - le contenu que l'on a pris l'habitude d'y adapter demeure identique : c'est la servitude.

« Mais il est difficile de se libérer, observe G. Simondon ${ }^{996}$, en transférant l'esclavage sur d'autres êtres, hommes, animaux ou machines; régner sur un peuple de machines asservissant le monde entier, c'est encore régner, et tout règne suppose l'acceptation de schèmes d'asservissement ».

Ce qui s'affirme en réalité, encore mal dégagé des obsessions anciennes, n'est pas l'irruption du loisir et des esclaves mécaniques, mais la mutation du travail. Cette idée doit être prise au sérieux et poussée jusqu'à ses dernières conséquences. En effet nous assistons à une évolution rapide de l'organisation des tâches. De la production

995 Nul n'ignore aujourd'hui que si la productivité est une des conditions de la réduction du temps de travail, ce n'est pas la seule. L'état économique d'une société, les rapports sociaux sont les véritables déterminants à la fois de l'étendue et du contenu des activités de loisir. Les rattacher exclusivement au nombre d'esclaves mécaniques - et les justifier ainsi - est une preuve de naïveté, sinon celle d'une intention inavouée de masquer les véritables données du problème. Celui-ci se pose uniquement dans les sociétés dites développées, c'est-à-dire riches. L'allègement des charges et de la durée du travail peut y être attribué simultanément aussi bien aux esclaves mécaniques qu'aux « esclaves humains » des sociétés moins riches. La civilisation de ces dernières sera longtemps encore une civilisation, non du «loisir », mais du travail.

996 G. SIMONDON : op. cit. p. 127. 
artisanale à la production mécanique, de la production mécanique à la production automatique, les métamorphoses sont évidentes et la continuité attestée. L'homme jouant le triple rôle de force physique, d'outil et de porteur d'outils fait place à l'ouvrier qui combine son énergie et ses appareils sensoriels avec la machine, jusqu'à ce que l'ensemble systématisé des machines s'équipe de ses moteurs et de ses organes sensoriels propres. La rationalisation progressive, la diminution proportionnelle de l'intervention des opérateurs humains, dessinent une ligne ininterrompue d'innovations techniques, d'aménagements à la limite desquels on aperçoit une "société de travailleurs sans travail $\gg{ }^{997}$. Mais ce dernier est envisagé uniquement dans le cycle de la production. Et notre retrait de ce cycle, notre résiliation d'une fonction millénaire sont jugés comme un abandon du domaine du travail. Bref, les hommes sont censés ne plus travailler parce qu'ils n'exercent pas ou parce qu'ils n'exercent plus une forme particulière de travail qui a été et est encore prédominante, à savoir, le travail productif. L'erreur a été de ne pas remarquer, en s'en tenant à une vue partielle du réel, que, si quelque chose semble dépérir, ce qui devient essentiel et proprement humain, ce qui se substitue à un travail, ce n'est pas le non-travail mais un autre genre de travail. Telle est la révolution qui s'opère. L'accroissement du nombre de savants, d'ingénieurs scientifiques, d'enseignants, la fonction de la pédagogie à cet égard, sont des phénomènes qui s'y rattachent.

La fusion du laboratoire et de l'usine - le premier commandant à la seconde - le renouvellement constant des savoirs, traduisent la réalité d'un autre faire comme faire humain. Une préparation des facultés qui lui soit adaptée s'impose : il reste à l'assurer. Quelle que soit la forme qu'elle prendra, elle n'aura pas à perpétuer — vis-à-vis du monde matériel — des modèles d'asservissement qui, édifiés par une classe particulière, seraient appelés à se généraliser. Si ces modèles présupposent que des "esclaves» mécaniques de plus en plus nombreux chassent les " esclaves » humains devenus de plus en plus rares, on ne peut oublier que ceux-là réclameront une armée de cerveaux pour être découverts, tout comme ceux-ci mobilisaient une armée tout court pour être contrôlés. Le temps et le labeur rendus dispo- 
nibles d'un côté s'investissent et s'investiront encore davantage de l'autre côté, le côté du travail inventif ${ }^{998}$. Autant dire que la somme de cette main-d'œuvre inanimée ne représente pas la longue théorie de nos serviteurs : elle manifeste l'état de nos facultés, puisque la même démarche les crée aussi bien. Ce n'est point à un âge du loisir ou de maîtrise absolue des artifices matériels qu'elle nous renvoie. La mutation du travail et le besoin d'établir sur d'autres bases le rapport à nos œuvres, voilà ce qui s'y exprime le plus directement.

Le déplacement du centre de gravité du travail modifie obligatoirement le contexte dans lequel est censé disparaître l'antagonisme de son côté manuel et de son côté intellectuel, et influe sur la fonction attribuée au progrès scientifique et technique à cet égard ${ }^{999}$. On s'accorde habituellement à reconnaître que ce dernier entraîne deux effets différents, l'un indirect: la non-spécialisation croissante des travailleurs, l'autre direct : l'intellectualisation du travail.

Le premier pas vers l'interchangeabilité des tâches a été accompli dans la production - mais ses conséquences ont peut-être été fâcheuses. La mécanisation des opérations industrielles a permis aux agents humains d'exécuter tous les travaux imposés sans faire preuve d'aucune habileté particulière, puisqu'ils devaient seulement utiliser leur capacité générale à dépenser leur énergie et à faciliter l'emploi des forces mécaniques. Les inventions successives ont encore amenuisé le rôle des aptitudes spécifiques pour ne plus laisser que l'aptitude globale à effectuer un travail machinal. Le deuxième pas s'est effectué à un autre niveau : la poursuite incessante de la recherche scientifique et de ses applications a raccourci l'espérance de vie des connaissances de tout ordre, transformé les relations entre les sciences et modifié la

On a l'habitude de négliger cette transformation de la nature du travail. Au lieu de penser que le travail productif est métamorphosé dans sa structure par la science, on préfère penser que c'est la science qui devient un travail productif : Et à mesure que se développera un nombre toujours croissant de nouvelles branches de production... le travail du chercheur acquerra une importance croissante, jusqu'à devenir la forme dominante du travail productif ». Role of science in modern society, World Marxist Review, 1963, 6, p. 42.

999

«La révolution scientifique et technique qui s'est produite au milieu du Xx $\mathrm{X}^{\mathrm{e}}$ siècle est destinée à jouer un rôle immense dans la résolution de la tâche historique d'éliminer la différence significative entre travail intellectuel et travail physique ». E. MANEVICH : art. cit. p. 14. 
configuration dans laquelle elles sont habituellement associées ${ }^{\mathbf{1 0 0 0}}$. Désormais la qualification au travail, à une discipline, ne saurait plus être fixe, le contenu de la spécialité n'est plus donné une fois pour toutes ; les combinaisons auxquelles elle participe ne cessent de changer. Une nouvelle tendance se fait jour, qui consiste à associer plusieurs disciplines. Sur le fond de cette régénération et de ce mouvement des cadres où s'inscrit toute activité, au delà de l'avancement commun des savoirs, la culture générale viendrait accentuer l'impossibilité de toute division, empêcher la cristallisation des disciplines dans les limites qui sont actuellement les leurs. Cette conviction gagne de plus en plus ${ }^{1001}$.

L'intellectualisation des tâches est une conséquence du progrès liée à la précédente. Ce qui exige dépense musculaire, coordination des mouvements, intervention de nos sens pour garantir la réussite d'une opération physique ou chimique, est concédé aux systèmes automatisés, capables d'obtenir de meilleurs résultats. La partie pénible du travail est réservée aux êtres techniques; elle exige un nombre plus restreint d'hommes et requiert, théoriquement, une fraction toujours moindre de leur effort. Ce dernier tend à s'exercer sur des informations codifiées; échappant désormais aux contraintes directes de la substance pour se soumettre à celles des méthodes logiques ou mathématiques, il s'applique à l'interprétation d'un ensemble de signes abstraits. Un tel travail se définit dès lors, non plus par son rôle dans une chaîne de corps et de mouvements, mais par sa capacité de les faire fonctionner ensemble, de contrôler des instruments déterminés par leur qualité « intellectuelle » ou « sensorielle » machines à calculer, oscilloscopes, cellules photoélectriques, etc.

Mais si ce sont là les répercussions probables d'un élan inventif incontestable, le sens qu'on leur attribue conventionnellement - triomphe de la non-spécialité sur la spécialité, victoire du cerveau sur la

1000 «C'est d'ailleurs un des caractères les plus frappants de l'effort scientifique actuel que de faire appel à ces ressources sans tenir compte des anciennes divisions séparant les anciennes disciplines ». P. AUGER : Tendances actuelles de la recherche scientifique, ed. cit. p. 23.

1001 «Il en découle par conséquent que l'éducation fondamentale devra être plus complète et plus générale. L'économie n'a plus besoin d'apprentis à un métier particulier ». J. VAIZEY : Education for to-morrow, Londres, 1962, p. 24. 
main - ne nous indique pas encore la portée véritable de ce qui est en jeu dans la division du travail en manuel et intellectuel. En effet, concevoir une activité quelconque sans séparation ni subdivision fût-ce à titre provisoire - est probablement illusoire, sinon stérile. Qu'un individu puisse comprendre la totalité des événements objectifs et agir sur eux, que dans tout cerveau se groupe le principal du savoir et du savoir-faire, est certes un idéal élevé. On serait en peine d'en trouver un exemple convaincant dans l'histoire. L'universalité espérée n'est qu'une construction inefficace. Archimède, Aristote, Darwin, Einstein ont tous été des spécialistes. L'important — et nous sommes actuellement les témoins de cette transformation — est justement d'empêcher les capacités dont on dispose de se coaguler dans des moules immuables, et, pour cela, de les relier systématiquement et consciemment entre elles. Les caractères de la subdivision des sciences et des travaux se modifient: la subdivision ne disparait pas pour autant. La culture générale paraît utile : elle n'est ni le complément ni la cause de l'arrêt de la parcellisation des facultés.

« La division du travail - Émile Durkheim nous en a avertis depuis longtemps ${ }^{1002}$ — ne change pas de nature parce qu'on la fait précéder d'une culture générale $»$.

C'est une illusion que l'on observe couramment en corrélation avec la précédente que d'envisager la disparition éventuelle du travail manuel, l'effacement de la frontière qui le sépare du travail intellectuel, sous l'angle organique, biologique. Même si certaines tâches physiques - les travaux de force, par exemple — sont de plus en plus fréquemment confiées aux machines, d'autres, liées à la fabrication des instruments, à l'expérimentation, à la construction des prototypes, ne peuvent que se développer et se diversifier. Cette prévision est légitime : malgré les écarts institués, les talents de la main et ceux du cerveau se prêtent un secours mutuel, prolifèrent et se métamorphosent simultanément.

Faut-il alors dire que l'on se trompe lorsqu'on attend des sciences, de leur avancement, la fusion du travail manuel et du travail intellec-

1002 E. DURKheIM : De la division du travail social, ed. cit. p. 364. 
tuel ? Oui, si l'on s'en tient à l'aspect banal de leur influence sur la structure des travaux et la localisation anatomo-physiologique des facultés correspondantes. Non, si c'est la signification historique que l'on met en avant. A cet égard, la distance de la «main» au «cerveau » est l'expression sociale de la division de l'humanité en catégories naturelles. Elle est l'indice d'une hiérarchie; elle dénote l'inégalité au sein d'un système social, la lutte d'une classe pour s'emparer de la source des richesses détenues par une autre classe, le besoin de dominer l'ensemble des forces productives. Une société socialiste, on l'a noté, où la diminution de cette distance a une valeur aussi grande que la limitation du temps de travail ou le changement du régime de la propriété, ressent encore plus profondément les séquelles de cette séparation. Une grande partie de la collectivité y souffre de la contradiction de se savoir et d'être proclamée sujet de la société, d'une part, et d'être, d'autre part, objet en ce qui concerne sa participation à la création du savoir-faire et les échanges essentiels avec l'univers matériel. Toutefois, on est obligé de maintenir, sous une forme ou sous une autre, aussi bien le symbolisme de ce qui est intellectuel et de ce qui est manuel que la répartition différentielle, inéquitable, sur l'échelle de la société. Procéder autrement, ce serait diffuser des talents et des connaissances condamnés à demeurer en grande partie inutilisés. Quant à penser que la solution pourrait être trouvée si chaque mathématicien, ingénieur ou philosophe se mettait à labourer la terre ou à descendre dans la mine, si tout ouvrier non qualifié pénétrait au laboratoire ou peuplait les bibliothèques, cela n'aurait guère d'effet sur le contenu des opérations quotidiennes des diverses professions, ni sur la valeur de leur travail. Cette prétendue panacée ne remédierait qu'à des manifestations superficielles. Elle ne nous aiguille pas vers la nécessité d'ordre particulier qui conduit à relâcher la tension entre " main » et " cerveau », à réduire leur écart. Nécessité qui, sans conteste, prend corps dans l'histoire humaine de la nature ${ }^{1003}$.

Tout d'abord, et je m'en tiens à l'aspect qu'elle revêt pour la société, son symptôme essentiel est l'unification des bases matérielles, des forces productives de celle-ci. L'interdépendance étroite des pouvoirs objectifs réalisée dans la production, de même que la qualité de nos

1003 Pour ce paragraphe, voir le Chapitre I de la $3^{\mathrm{e}}$ Partie. 
habiletés et de nos connaissances, manifestent une origine commune, la science, et leur fusion ne fait qu'accentuer cette évolution. Des principes et des méthodes identiques pénètrent progressivement dans les diverses sphères du travail, s'appliquant aussi bien à l'agriculture ou aux communications qu'à l'industrie. Du laboratoire et du cabinet du savant jusqu'à l'usine et au champ, on perçoit un mouvement qui conduit à spécifier, à concrétiser des lois générales, mouvement bien différent de la division parcellaire des métiers et des règles sans liaison interne entre eux, comme pouvaient l'être ceux de l'agriculteur et de l'artisan, de l'artisan et de l'ingénieur. Et en même temps - ici se manifeste pour la nature l'unité des forces productives - a lieu le mouvement d'assimilation du travail productif et du travail inventif, l'atténuation des contrastes préservés par la tradition ${ }^{1004}$.

Ensuite et corrélativement, la reproduction d'une catégorie naturelle particulière provoque le dépérissement des fondements et de la possibilité d'une scission entre travail manuel et travail intellectuel, envisagés sous l'angle historique. Nous l'avons observé en son lieu ${ }^{1005}$ : il s'agit des chercheurs, ingénieurs et techniciens scientifiques, dont le nombre s'accroît dix fois plus vite que la population générale. Et cela non point parce qu'ils ont défait la spécialisation, ou mis fin à la disparité organique de la main et du cerveau, mais parce qu'il s'agit d'une catégorie dont la constitution n'obéit pas au processus de division naturelle, et aussi parce qu'elle ne saisit pas le travail ou la force matérielle en tant qu'ils sont fixés dans l'habileté d'une autre catégorie. Ses savoirs ne s'imbriquent plus strictement à son organisme ; surtout, ils ne sont plus figés dans des relations préétablies au cours de nombreuses générations. La plasticité des rapports qui unissent les hommes, non pas à une ressource isolée ou isolable, mais à un ensemble de forces matérielles, est source de transformations fréquentes, de substitutions inévitables. Ainsi disparaît le fondement de la séparation qui, dans le rapport de l'homme à la matière, permettait à une fraction de l'ordre social de manifester son opposition à une autre fraction en tant qu'opposition des activités intellectuelles aux activités manuelles, contraste entre la substance de la richesse attachée

1004 «Un nombre croissant d'hommes est aujourd'hui directement engagé dans la production, combinant le travail productif et la recherche ». World Marxist Review, art, cit. p. 39.

1005 Voir le Chapitre X de la $2^{\mathrm{e}}$ Partie et le Chapitre II de la $3^{\mathrm{e}}$ Partie. 
aux unes et la substance de la richesse attachée aux autres. Cette substance est désormais indivisible, parce qu'elle est commune à l'ensemble de la société : tel est le résultat de la suppression des cloisons qui, dans le déterminisme interne au développement de nos facultés et de notre univers, isolaient les différentes catégories naturelles.

Au terme de ces remarques, on voit que définir l'exploitation des choses, le gouvernement de la nature, par référence aux « esclaves mécaniques ", au loisir, au développement quantitatif des savoirs, contrevient aux données les plus évidentes de la situation actuelle. Nous sommes encore fascinés par la fine broderie que le XIX ${ }^{\mathrm{e}}$ siècle a tracée autour de l'action et de l'histoire humaines concernant l'état naturel et l'état social, et leurs rapports concrets, ce qui amène souvent les penseurs à faire davantage écho aux préoccupations d'une époque révolue qu'à répondre aux problèmes de la nôtre. Ces derniers peuvent être saisis sur le plan théorique. Ils ont trait, d'une part, à l'importance et au mode de création des facultés de notre espèce, qui s'expriment dans des phénomènes tels que la mutation du travail, l'assimilation de sa forme productive et de sa forme inventive, la reproduction accélérée des travailleurs scientifiques. D'autre part, de nouvelles questions se posent qui relèvent de la politique et du gouvernement : il s'agit notamment du décalage entre l'interdépendance croissante du processus naturel et du processus social et la distance que l'on persiste à vouloir maintenir entre les modalités d'action dans la société et dans la nature.

Retour à la Table des Matières

\section{L'expression actuelle d'un thème révolutionnaire.}

Où se situe le gouvernement de la nature ? Il ne faut pas le chercher dans la domination des choses, dans le domaine des forces matérielles. Celles-ci, conditions et résultats d'action, ne peuvent donner lieu à aucune prise directe, exclusive. Elles sont agrégées à nos connaissances, à nos facultés, qui seules possèdent des qualités motrices et sont appréhensibles. Nous savons en effet que le manque de ressources physiques, tout comme leur abondance, est proportionnel 
au manque ou à l'abondance des savoir-faire qui leur correspondent : les premières ne peuvent être obtenues qu'en présence des seconds. Il faut donc mettre en avant la fonction des groupements de disciplines et l'influence des talents, les lois inhérentes à leur évolution. Aussi doit-on guider ces disciplines et ces talents, les prendre pour fins véritables de notre intervention dans l'univers, et aider les hommes qui les représentent, au lieu de vouloir agir sur des objets inertes et parfaitement opaques.

Le modèle directeur n'est pas celui qui prône la thésaurisation des éléments du monde matériel, l'asservissement de ses énergies. Son cadre cesse d'être celui des "victoires sur la matière », de la collecte des phénomènes, de l'accumulation des richesses matérielles capturées et rendues disponibles à notre commandement, comme les richesses sociales entassées dans les coffres d'une banque ou incluses dans les moyens industriels d'une entreprise. Au contraire, en percevant que chaque parcelle de matière enferme une parcelle d'habileté, de science, ou d'art, on reconnaît que l'apparition ou la destruction des substances physiques et l'apparition ou la destruction des facultés sont une seule et même chose, et que l'on ne saurait soumettre ou utiliser les unes sans soumettre et utiliser les autres. Ces observations, basées sur la pratique historique, découlent également de la conception de l'état de nature en tant que réunion de son pôle humain et de son pôle matériel, articulation des ressources matérielles ou inventives avec un système de reproduction des capacités de travail. Prétendre au contrôle, à l'intelligence du mouvement qui embrasse un tel état, implique le contrôle, l'intelligence du processus au cours duquel il est constitué, à savoir la création du travail, des savoir-faire.

Les difficultés que l'on rencontre à accroître la quantité de matière disponible, les détours par lesquels on arrive à l'énoncé de ses principes, ne sont pas le point de mire vers lequel convergent toutes nos préoccupations. La présence de connaissances, de talents, leur structure et leur combinaison, se révèle comme le véritable levier de nos rapports avec le milieu environnant et des relations entre les hommes. La question essentielle est donc moins de magnifier le monde des objets pour l'adapter aux diverses visées, que de favoriser l'éclosion de nos virtualités en tant que sujets et de les réaliser. Ainsi, gouverner la 
nature ne signifie pas gouverner des choses en découvrant leurs propriétés, mais gouverner le travail en créant ses facultés.

Allons plus loin. Si le gouvernement de la société se réfère à un lieu, à des actes spécifiques - production, consommation - à des collectivités particulières — classes sociales, élites politiques — et si celui de la nature ne peut plus demeurer au niveau abstrait de la saisie immédiate de la totalité des phénomènes et des instruments corrélatifs, quels sont les points d'application de ce dernier? La réponse est fournie par la théorie et la situation concrète. Il s'agit des mécanismes médiateurs entre les pouvoirs humains et non-humains - la reproduction, l'invention et les catégories naturelles.

Il y a longtemps qu'on l'a compris, quoique de manière détournée. La réglementation des procédés de fabrication, l'interdiction de quitter le pays notifiée à des savants ou à des travailleurs qualifiés pour un métier donné, le secret des inventions - tout comme les normes corporatives - marquent bien que ces mesures, outre leur sens social, étaient destinées à préserver un certain système de reproduction des catégories naturelles, un même rapport des hommes à leur environnement.

Toutefois, en raison de leurs dimensions et de leur portée restreinte, les processus de création de nos facultés n'appelaient pas, aux époques dont il vient d'être question, une méthode de direction particulière, distincte, qui fût aussi une méthode de direction dans l'élaboration de l'ordre naturel. Deux circonstances contribuent actuellement à donner du relief à cette méthode et à faire considérer avec un soin particulier ce qui, au cours de l'histoire, a été seulement ébauché et n'est apparu que sous une forme déguisée.

Tout d'abord, l'autonomie et le caractère systématique de ces processus. Ayant cessé d'être des sous-produits, des activités en marge de l'appareil productif et éducatif ${ }^{1006}$, la découverte et la transmission des savoirs constituent un ensemble nettement différencié. Par son

1006 Voir Chapitre X de la $2^{\mathrm{e}}$ Partie. 
intensité, sa continuité, l'invention n'est plus le résultat d'une démarche aléatoire. La recherche, l'« industrie de la découverte », la contiennent en grande partie, et le mode de reproduction des talents, dans son cadre ou en dehors de celui-ci, notamment à l'école ou à l'université, tend à forger une nouvelle unité. Aucune confusion n'est plus possible dès lors entre la sphère où se poursuit la production des choses et la sphère qui s'est dégagée récemment, celle de la création des connaissances, du travail. Cette dernière est reconnue en tant que telle, et les investissements économiques et intellectuels dont elle est le but ont acquis, pour la plupart des sociétés, une importance égale, sinon supérieure, à ceux que l'on consacre aux instruments productifs en général ${ }^{1007}$. Ayant atteint ce seuil, tant du point de vue des dimensions que du rythme de l'activité, la reproduction et l'invention prennent conscience de leurs buts, de leur individualité, et appellent une organisation, une politique propres. La définition de la première, l'étude de la seconde ${ }^{1008}$, s'imposent de toute évidence comme éléments d'un système de gouvernement et composantes de sa pratique.

Ensuite, un nombre toujours croissant d'individus a pour occupation principale ou exclusive la création du travail. Il y a là un déplacement important du cadre de vie, puisque l'homme ne se meut plus dans un monde d'objets, résistant et fermé ; désormais il se trouve dans le domaine des informations qu'il s'agit de combiner, d'ordonner et de cristalliser dans des sciences et des facultés. Indubitablement, une époque commence où une portion sans cesse accrue du travail est réservée à engendrer ce travail même, en tant que but et non pas uniquement en tant que moyen. De cette manière, l'homme sort progres-

1007 «Dans l'ensemble, le coût total de l'éducation s'est accru beaucoup plus rapidement que le coût total des ressources entrant dans le capital physique ». T.W. SCHULTZ : Capital formation by education, Journ. of polit. Econ. 1960, 68, p. 582.

${ }^{1008}$ Les processus d'invention et de reproduction sont en passe de devenir, de manière empirique d'abord, un champ d'étude. On s'en aperçoit en examinant par exemple le programme de recherches proposé pour l'organisme anglais Council for science policy, destiné à élargir et compléter les institutions semblables déjà en place : «Parmi les travaux en cours [en 1984] figurent : $1^{\circ} 1^{\prime}$ établissement de statistiques détaillées des dépenses de «recherche et de développement $» ; 2^{\circ}$ des études poussées portant sur la prévision technologique $; 3^{\circ}$ des enquêtes particulières menées dans des domaines scientifiques choisis relativement aux besoins en recherche des différents secteurs de l'économie ; $4^{\circ}$ un examen de la relation qui unit la créativité scientifique à différents types d'organisation des recherches; $5^{\circ}$ des études destinées à mieux élucider la nature et la signification économique des innovations techniques et de la sociologie du changement, etc. » A. KING, in N. CALDER : op. cit. t. 2, p. 8. 
sivement du champ de la production, où son rôle de facteur principal s'estompe ; il met au premier plan des secteurs d'activité ayant trait à l'échange avec la matière, à la constitution explicite de l'ordre naturel - secteurs qui auparavant paraissaient marginaux, improductifs ou « gratuits ».

Point n'est besoin d'insister, ni de se référer à des statistiques, pour montrer que la succession et l'étendue des inventions ont entraîné le développement des sciences, des pratiques ayant pour fonction de les transmettre, de même qu'elles requièrent, de la plupart d'entre nous, un nombre accru de savoirs, donc un cycle de formation plus long. Cette formation devient une préoccupation permanente durant toute la vie de l'individu et ne se sépare plus de l'exercice des facultés. La liaison se manifeste de multiples façons. D'une part, personne ne peut plus se désintéresser ou se détacher de ce qui se passe dans la recherche ou l' « industrie de la découverte » s'il tient à s'en assimiler les résultats à chaque étape de son existence, à rester dans le contexte de la vie sociale active. D'autre part, à côté du temps voué au travail ordinaire, donc du temps jugé non libre, la tendance se fait jour de dégager une fraction de temps disponible afin d'entretenir les savoirs acquis et de s'en procurer de nouveaux ${ }^{1009}$. Dès lors, une chaîne continue relie l'enseignant, qui est simultanément chercheur, au producteur qui se maintient dans le circuit de l'enseignement, surmontant les subdivisions instaurées et rendant leurs frontières labiles. Tout concourt à intéresser des fractions de plus en plus appréciables de la collectivité aux processus qui canalisent l'action de l'humanité à l'intérieur de l'univers. Dans cette perspective, des institutions et des principes aptes à les régir s'avèrent d'importance primordiale.

Une fois indiqués les points d'application - la reproduction et l'invention - et les raisons qui différencient le gouvernement de la nature et le transforment en une véritable division sociale du travail c'est-à-dire l'autonomie de ces processus, le temps et le volume

«L'allure de la connaissance et de la technique est si grande que l'éducation pendant toute la durée de la vie devient une nécessité pour chacun de nous ». W.J. PlatT : Economics and comparative education, Los Angeles, 1962 (roneo), p. 10. T. STELSON : Les ingénieurs devraient consacrer plus du tiers de leur temps à entretenir leurs connaissances, L'expansion de la recherche scientifique, Janvier, 1962, 5-6. 
d'énergies humaines qui leur sont consacrés - on doit aussi marquer la teneur de son changement. Celui-ci ne nous apparaît pas, à la lumière de ce qui vient d'être exposé, dépendre uniquement de l'existence d'une société qui, ayant réussi à se policer, à prendre conscience de ses aspirations, et à extirper ses conflits, se tourne vers le monde extérieur pour le courber systématiquement. Il n'est pas non plus le signe d'une maîtrise qui, étendant son règne, se contente de régler les rapports qu'entretiennent les hommes avec les pouvoirs matériels. Donc son avènement n'est garanti automatiquement ni par le remodelage des structures sociales, ni par l'ampleur des découvertes ou des instruments physiques. En effet, " exercer une plus grande action sur la nature », suivant les termes de Saint-Simon, a pour conséquence, non seulement une masse accrue de connaissances, de talents et de forces, mais aussi le fait que certains groupes humains s'adjoignent ces connaissances et ces talents, tandis que d'autres se voient dépossédés des leurs, rendus caducs. Partant, ce qui affecte le lien à l'univers matériel et la manière de l'établir — c'est là un des fils conducteurs de cet essai - atteint aussi les liens qui unissent les hommes pour autant qu'ils inventent et reproduisent leurs facultés, métamorphosent leurs relations à l'intérieur des catégories naturelles et les relations mêmes de ces catégories.

La modification qui commande l'évolution de ces relations donne une nouvelle orientation au gouvernement de la nature. Jusqu'à nos jours, les hommes se rencontraient divisés ; de ce fait, ils ne pouvaient prétendre administrer et ordonner les processus de création du travail, et, plus généralement, de création des facultés de l'espèce. Chaque ensemble de «porteurs d'invention » poursuivait une tendance qui lui était propre et qui pouvait s'opposer à la tendance intrinsèque à un autre ensemble. La voie empruntée par l'agriculteur différait de la voie suivie par le chasseur, la voie de l'ingénieur était distincte de celle de l'artisan. Orienter et diriger de concert le système de reproduction était une attitude incompatible avec le principe profond de celle-ci, sa structure réelle. Les savoirs se constituaient de façon trop lente pour être appréhendés dans leur totalité, développés suivant des lignes bien arrêtées. De plus, amalgamés aux organismes humains, concrétisés dans leur immense majorité sous forme biologique, ils apparaissaient comme des objets de l'activité inventive uniquement à la 
condition qu'une partie de l'humanité s'écartât de l'autre, et fût assimilée par elle au domaine des choses, des matières premières.

L'ampleur prise par le processus d'invention, l'accélération des échanges dont il est le lieu, ouvrent la voie à l'introduction d'une rationalité là où prédominaient l'improvisation et l'accident. Parallèlement, le travail, les connaissances qui le composent et les dextérités qu'il exige, sont concentrés continuellement dans des systèmes de stockage de l'information, des instruments et des livres. La distance nécessaire pour qu'il soit traité objectivement, expérimenté dans des combinaisons diverses, ne présuppose plus, comme par le passé, un éloignement par rapport à une collectivité humaine qui l'incarne. Cette distance est instaurée par la matérialisation, l'existence indépendante, sous forme non-humaine, de la plupart des facultés de l'espèce. La substitution de la progression naturelle à la division naturelle $^{1010}$ - transformation connexe à l'apparition de la science et du scientifique - correspond à un moment où ces phénomènes s'accentuent et où les mouvements divergents s'atténuent. L'association, désormais obligatoire, de ceux qui participent à l'état de nature cybernétique, permet aussi de le gouverner.

La conséquence en est bien l'élimination de la troisième inégalité, celle des savoirs. Cette fin pouvait avoir naguère un caractère philanthropique ; elle ne l'a plus aujourd'hui : en effet, elle s'accorde rigoureusement avec les circonstances objectives. Et ceci aussi bien du point de vue historique que du point de vue actuel. Envisagé sous l'angle historique, tant que cette inégalité se maintient - entre autres sous la forme de la différence hiérarchisée du travail intellectuel et du travail manuel - tant que les hommes sont séparés par la manière dont ils créent leurs capacités, au lieu d'être rendus solidaires grâce à elle, le changement entrevu du gouvernement de la nature ne saurait s'accomplir pleinement. Car son champ n'est pas avant tout l'administration des choses, l'univers extérieur : il concerne les hommes au premier chef.

${ }^{1010}$ Voir Chapitre X de la $2^{\mathrm{e}}$ Partie. 
Du point de vue quantitatif, la nécessité d'utiliser de plus en plus les facultés potentielles des hommes paraît impérieuse. On reconnaît ${ }^{1011}$ qu'elles se perdent, s'étiolent, si on se borne à les rechercher uniquement dans les secteurs les plus élevés de la société et de la production. La somme même des connaissances et des habiletés existantes est telle que le nombre ${ }^{1012}$ de ceux qui sont appelés à les manier ne peut plus demeurer restreint. La formation des hommes, en s'étendant, renverse les barrières soigneusement dressées à l'intérieur de la collectivité. J.D. Bernal en a noté les causes et les effets ${ }^{1013}$ :

« Aucun élément de notre culture n'a augmenté autant, au cours des dernières décennies, que la science; mais cette augmentation a atteint un stade qui n'affecte plus une élite limitée mais la population tout entière ».

Cet impératif s'impose à toutes les sociétés, puisqu'il résulte des mutations des disciplines naturelles et de celles de la production qui ont suivi :

«Le progrès accéléré des connaissances, constate un rapporteur qualifié ${ }^{1014}$, l'évolution des sciences et des techniques entraînent une transformation continue des besoins des sociétés humaines. Quelles que soient les oppositions, les contradictions qui les différencient ou les dressent parfois les unes contre les autres, il n'en est pas moins vrai qu'elles suivent des lignes à peu près semblables. Ainsi l'extension de l'instruction est un fait objectivement constatable. On peut la justifier par la justice démocratique, par les nécessités du développement économique. On peut la baser sur une sélection qui masque une inavouable ségrégation, ou sur le respect intégral de la démocratie, le fait

1011 «Il est probable que le pourcentage d'enfants des classes laborieuses qui sont dotés d'aptitudes naturelles d'ordre élevé n'est pas aussi grand que celui d'enfants de personnes ayant atteint ou reçu en héritage une situation élevée dans la société. Mais puisque les classes occupées à travailler de leurs mains sont quatre à cinq fois plus nombreuses que toutes les autres classes réunies, il n'est pas improbable que plus de la moitié du génie naturel qui naît dans un pays leur appartient ; et une grande partie de ce génie demeure stérile faute d'occasion. Il n'y a pas de dépense plus préjudiciable à la croissance de la richesse sociale que cette négligence, ce gaspillage, qui laisse le génie d'humble extraction se dépenser dans un travail humble ». A. MARSHALL : Principles of economics, ed. cit. pp. 252-3.

1012 «Nous vivons à une époque où la connaissance éclate. Pour cela, il faut donner plus de connaissances, de nouvelles techniques, et plus de nouvelles capacités à plus de gens ». A.H. HALSEY et al. : Education, economy and society, Glencoe (Ill.), 1961, p. 37.

1013 J.D. BERNAL : Education and science, The Marxist Quarterly, 1953, 3, p. 13.

1014 M. PENTZ : Bulletin de l'union des travailleurs scientifiques, 1963, n 2 et 3,p. 4. 
demeure : l'humanité tout entière est de plus en plus avide d'enseignement et d'éducation ».

C'est, pourrait-on ajouter, parce qu'elle aperçoit de plus en plus clairement le danger qu'il y a pour elle à dissiper ses énergies et ses aptitudes virtuelles.

Le génie répandu parmi toutes les couches d'une nation peut être fécondé, et sa puissance décuplée, si on le cultive à un niveau relativement élevé. Dans la conjoncture définie par le renouvellement régulier, tous les dix ans, des savoirs, le fonctionnement quasi autonome des systèmes matériels et le renforcement du travail inventif, l'accent se déplace. Les hommes qui sont enfermés ou qui restent enfermés dans le cercle des opérations peu qualifiées, à l'évolution lente souvent classées comme manuelles — demeurent aussi en-deçà du seuil d'efficacité souhaitable :

« L'homme qui travaille exclusivement ou essentiellement de ses mains est de plus en plus improductif $»{ }^{1015}$.

Ce qui était prisé lorsque habiletés et ressources étaient engendrées de façon marginale, à côté des diverses routines productives, lorsque l'invention était sporadique et partielle, signifie aujourd'hui perte de talents, sous-utilisation des énergies disponibles pour l'obtention de talents nouveaux.

La suppression progressive de l'inégalité propre à un certain système de répartition des capacités d'échange avec l'univers matériel s'inscrit dans ces perspectives. Malgré ce qu'on affirme et ce qu'on a cru longtemps, une société n'accède pas à un ordre supérieur, à la pleine possession de ses moyens, à la maîtrise de son destin, en se bornant à rejeter l'iniquité fondée sur la richesse et la domination politique, mais dans la mesure où elle procède à cette suppression; en d'autres termes, lorsqu'elle motive son intérêt pour l'avancement du

1015 A.H. HALSEY et al. : op. cit. p. 18. 
savoir ${ }^{1016}$ moins par la nécessité d'augmenter les moyens destinés à satisfaire les besoins et à préparer pour les générations futures les emplois qui leur permettront de subsister que par le dépérissement de la hiérarchie instaurée entre les aptitudes humaines. N'est-ce pas là la meilleure manière de disposer de toutes les richesses qui s'offrent? Le fait que cette hiérarchie et la disparité qui la sous-tend apparaissent comme des signes de gaspillage des dextérités virtuelles, des indices de stérilité des investissements, souligne la nécessité de les forclore, accordant ainsi ce qui est subjectivement désirable avec ce qui est objectivement déterminant ${ }^{1017}$. Tel est le contenu et le motif du passage si tôt discerné de «l'exploitation de l'homme par l'homme» à « l'exploitation de la terre par l'industrie ».

Ce passage ne doit pas être regardé comme l'au-delà d'une société qui aurait aplani ses déséquilibres internes, le signe de l'apparition d'une nouvelle race de seigneurs de l'univers. S'il atteste une tendance à renouveler le gouvernement de la nature, ce n'est pas parce que son accomplissement réclame de nous peu de travail productif, présuppose la présence d'une masse d'esclaves mécaniques, mais au contraire parce qu'il mobilise beaucoup de travail inventif et une pléiade de facultés, de disciplines, de savoirs, définissables avec précision. Sa raison d'être n'est pas davantage l'effacement d'une divi-

1016 « Il faut bien voir que cet essor de la culture n'est pas seulement une exigence morale, mais qu'il est devenu nécessaire pour la croissance de la force productive-homme en corrélation avec la force productive-instruments de production ». P. NOIROT et J. VERNES : Science, technique et production, Economie et politique, 1962, n 86, p. 43.

1017 Il nous est actuellement difficile d'accepter ou de reconnaître cette orientation au milieu des courants contradictoires :

(a) Les nations, par la concurrence économique qu'elles se livrent dans la recherche et la course aux talents veulent se donner les meilleurs instruments contre d'autres nations; (b) les scientifiques, pour faire avancer leurs disciplines, s'engagent sur la voie de la ruse et sont en proie à la peur ; (c) les collectivités s'en remettent à l'automatisme du progrès du soin de résoudre leurs difficultés les plus graves et se laissent bercer par l'illusion d'une attente qui confie à ce progrès les tâches dont elles-mêmes refusent la responsabilité.

Il en résulte que (a) les armes que les nations préparent les unes contre les autres ont pour effet de les transformer et de les engager dans un cours différent de celui qu'elles souhaitent; (b) les scientifiques placés dans une position éminente deviennent indifférents à la dégradation provoquée par l'acceptation de la ruse, et négligent de s'interroger sur leur rôle et leur fonction historique véritable ; (c) l'automatisme du progrès, l'expansion des savoirs, par les obstacles auxquels ils se heurtent, font bien voir que leur constitution réelle est incompatible avec l'absence d'objectifs et la démission des groupes sociaux. Lorsqu'on aura compris tout cela, il faudra bien cesser de contempler l'envers de la vérité pour regarder son nouveau visage. 
sion ancienne - la scission du travail en manuel et intellectuel - ou celui de l'iniquité sous-jacente. Il faut plutôt y voir l'indice concret d'une direction que prend l'histoire. A savoir, le passage d'un état qui mettait au premier rang de ses préoccupations la création des choses à un état où la première place revient à la création des hommes, de leurs facultés. Le résultat attendu, le but poursuivi, est moins la capacité d'accumuler connaissances et pouvoirs extérieurs que la volonté d'instaurer et d'administrer les rapports entre les hommes, de déterminer leur appartenance à une catégorie naturelle. En définitive, l'humanité aspire, dans la nature, non pas à maîtriser son alter ego matériel, mais à se gouverner elle-même, à conférer à cette nature les dimensions d'une réalité où elle s'affirme et non pas d'une abstraction où elle se nie. Que ce besoin ait été exprimé il y a plus d'un siècle et sous une forme détournée - n'enlève rien de sa résonance révolutionnaire à l'idée qu'il enferme. Depuis, le temps a confirmé sa vérité, en nous permettant de mieux apercevoir ses conditions et son incidence. 


\section{La société, forme de la nature}

Retour à la Table des Matières

Les prémisses d'un état de nature gouverné consciemment par les hommes semblent donc être réunies. Le rapport de la société à cet état est défini par trois séries de faits :

- les processus naturels se dégagent en tant que fondements actifs et explicites des actions collectives ;

— la création du travail, des savoirs, est socialisée ;

- l'influence des facteurs sociaux s'exerce désormais manifestement à l'intérieur des facteurs naturels.

Ces faits s'expriment d'emblée à travers la fonction que remplit notre espèce auprès des autres espèces et l'aménagement général de nos ressources et de notre milieu. L'ampleur des systèmes matériels avec lesquels nous interférons pose, de façon aiguë, la question du nombre et celle du bilan, c'est-à-dire la question de notre propre évolution démographique et celle de l'équilibre à maintenir entre les diverses espèces animales et végétales et les forces matérielles disponibles. Leur dépendance mutuelle ou vis-à-vis de nous est devenue plus rigoureuse. Modifications du climat, des propriétés du sol, emploi élargi des moyens physiques et chimiques pour infléchir les processus vitaux des animaux et des végétaux, communications d'un point à l'autre du globe - et bientôt d'une planète à l'autre - provoquent des perturbations et exigent le rétablissement de mécanismes qui permettent aux organismes de subsister ${ }^{1018}$, aux hommes de préserver leur existence biologique et sociale. Ces derniers sont devenus une force géologique qui s'exerce sur une grande échelle, et dont la mesure est donnée par les connaissances théoriques et pratiques auxquel-

1018 R. CARSON : Printemps silencieux, Paris, 1963. 
les ils ont recours en l'occurrence. La disposition de l'espace, le calcul des réserves en substances et en énergies, la prévision de leur épuisement et de leur substitution ${ }^{1019}$ accusent les caractères biomorphiques des préoccupations qu'aucune collectivité ne peut sous-estimer :

«A l'encontre d'une opinion largement répandue, les facteurs naturels ne sont pas moins importants mais plus importants que par le passé $»{ }^{1020}$.

Toutefois, l'importance des facteurs en question ne réside pas, comme on le laisse entrevoir, dans le volume des énergies ou la variété des matériaux mis en jeu. Elle tient, on le sait, aux processus décisifs dont ces aspects manifestes ne sont que l'aboutissement, à savoir ceux de la création des habiletés, de leurs disciplines particulières. Les traits de l'intervention qu'ils représentent dans l'histoire humaine de la nature diffèrent de ceux qui ont longtemps prévalu. Suivant les besoins, on est à même de susciter les talents, les sciences - et les hommes qui les détiennent - pour aboutir à des résultats, à des phénomènes ayant des attributs établis à l'avance. S'il s'agit, par exemple, de découvrir un élément transuranien, un métal résistant à certaines pressions atmosphériques, ou de construire une fusée interplanétaire, on sait dans quelles directions il faut encourager les recherches théoriques ou expérimentales, quelles disciplines on doit combiner en vue de ces fins. Avec une égale certitude, on s'attend que le travail quotidien des savants dans les divers domaines scientifiques ou empiriques provoque l'apparition de phénomènes et de substances qui auront un jour un impact sur les occupations habituelles de l'humanité. Au cours de ce cycle de découvertes et de leur transmission, on est amené à relier les objets aux sujets humains qui les revendiquent, et réciproquement à relier les sujets aux objets qu'ils constituent. La tâche première dans la création du travail et des savoirs est dès lors de former les créateurs, de les considérer solidairement et non pas, comme jusqu'à maintenant, séparément, en tant que moyens et que fins. Ceci a une répercussion marquée sur les méthodes de production et de satisfaction, sociales, des besoins. Pendant des millénaires, ces méthodes ont préservé un cercle relativement étroit d'adaptations

1019 P.C. PUTNAM : Energy in the future, Princeton, 1953.

1020 L.D. STAMP, in N. CALDER : op. cit. t. 2, p. 103. 
quantitatives et qualitatives du travail aux nécessités auxquelles il répondait. L'industrie mécanique, et, en particulier, son organisation capitaliste, ont perturbé ce quasi-équilibre en métamorphosant la consommation ou l'échange en instruments capables de grossir la demande et d'élargir le marché. Avec la naissance et la pénétration des sciences dans ce domaine, il est devenu évident que l'emploi de la main-d'œuvre, la prolifération des biens de consommation dépendent de l'activité inventive dont découle la possibilité d'engendrer des ressources et des savoirs. La variété des produits et la productivité de l'effort social ont leur source dans la diversité des sciences et la densité de leurs découvertes. Ce qui a trait à la production et à la consommation est donc venu à s'exprimer sans détours au travers de l'obligation de constituer des dextérités sans cesse renouvelées. Le centre et le moteur des mécanismes élémentaires de la vie collective est ainsi déplacé, et c'est dans ce sens que l'on chante les louanges du progrès technique. En un mot, la société démontre expérimentalement et exprime consciemment que tout ce qui se trouve dans la sphère de la reproduction sociale est un prolongement, une transposition de notre auto-création naturelle.

Parallèlement, la partie objective, matérielle, de l'appareil industriel — instruments, machines, formes techniques - ne symbolise plus le règne des artifices opposé au règne de la nature. Cet appareil voit maintenant apparaître dans son champ des systèmes automatisés autonomes ${ }^{1021}$ complets en eux-mêmes, qui se rapprochent des autres systèmes «naturels » (dans l'acception courante du terme) comme autant de réalisations particulières venant enrichir la famille de ces derniers. Cette continuité une fois affermie et généralisée, l'acte producteur ne signifie plus extraction humaine des richesses détenues par un ordre non-humain (c'est-à-dire naturel), mais se définit au contraire en tant qu'il approfondit cet ordre même. En même temps, la carte des secteurs essentiels entre lesquels nous répartissons nos efforts et nos intérêts, et dont nous attendons les résultats les plus marquants, appelle une refonte qui est déjà commencée et ne peut que s'accentuer. Jusqu'ici, pour reproduire les richesses sociales, à proprement parler, on se préoccupait surtout de perpétuer et de fournir les moyens de

${ }^{1021}$ Voir Chapitre IV de la I ${ }^{\text {re }}$ Partie. 
production et les moyens de consommation en mettant à leur disposition les formes techniques et les moyens de travail indispensables. Entre la partie de l'industrie destinée à fournir des moyens de production et celle qui était engagée dans la préparation des moyens de consommation, la ligne de démarcation était rigide et intangible.

Cette pratique doit désormais être abandonnée. L'entretien et le développement des ressources matérielles, la découverte et la répartition des savoirs avec tout ce qui pourvoit à leur reproduction naturelle — procédés de diffusion de l'information, institutions éducatives ${ }^{1022}$ - viennent peu à peu occuper la première place, tandis que les divisions inhérentes au circuit industriel - industrie lourde, légère, etc. — passent à l'arrière-plan. Il est même possible que, à l'instigation de la science et des scientifiques, le modèle qui inspire les conceptions et l'organisation de l'industrie cesse d'être celui de l'armée, adapté à la production de biens, pour devenir celui de l'école, qui marque actuellement notre création de talents :

«Il n’y a de science, observait G. Bachelard ${ }^{1023}$, que par une École permanente. C'est cette École que la science doit fonder. Alors les intérêts sociaux seront définitivement inversés la société sera faite pour l'École et non pas l'École pour la société ».

En effet, tout se passe comme si, pour continuer à produire et à consommer, l'ensemble social devait assumer ouvertement la responsabilité de la marche et de l'entretien du monde matériel, de la biosphère, et des propriétés concordantes de l'espèce. Nulle part la chaîne ne peut rompre sans compromettre ou déchirer le réseau complexe que l'homme a su établir partout, grâce à ses œuvres. Les processus sociaux, au lieu d'être la matrice ou l'écran filtrant des processus naturels, sont la prolongation et la médiation de ceux-ci. La collectivité y puise le principe qui lui sert à répartir ses énergies : elle pose nécessairement, d'un côté et ensemble, la production et la consommation, et

1022 «L'éducation a atteint une importance économique sans précédent, en tant que source d'innovation technique, et le système éducatif est orienté, dans une mesure croissante, pour servir la force de travail agissant comme un simple appareil de recrutement et de formation professionnelle ». A.H. HALSEY et al. : op. cit. p. 2.

${ }^{1023}$ G. BACHELARD : La formation de l'esprit scientifique, ed. cit. p. 252. 
de l'autre côté, associées, l'invention et la reproduction - soit, d'une part, ce qui a trait à l'industrie tout court, d'autre part ce qui se rapporte à la recherche, à l'industrie de la découverte. Ceci nous permet de voir que cette dernière commande étroitement la première et son fonctionnement : toute rupture engendre la stagnation ou le recul. A ce titre, invention et reproduction constituent le fondement actif et distinct de l'action sociale.

Elles le sont encore à un autre titre. En effet, la création du travail revêt également une expression entièrement socialisée, sous l'angle de l'organisation comme sous celui des investissements et des effets. Pour cette raison, elle se découpe nettement dans la sphère de la société. Ceci n'a guère besoin d'une longue démonstration. Prenons toutefois, à des fins d'illustration, l'exemple de la recherche scientifique pure ou appliquée. Cette recherche est l'œuvre d'équipes intégrées, se communiquant projets ou comptes rendus. Autour des appareils physiques ou mathématiques - accélérateurs de particules, calculatrices électroniques, etc. - se concentrent non seulement des dizaines de physiciens, ou mathématiciens, mais encore des ingénieurs et des savants de toute sorte, de l'électronicien au logicien, du mécanicien au biologiste. Le phénomène est amplifié à l'extrême lorsqu'il s'agit des expériences spatiales : la conception et le lancement d'un satellite ou d'une fusée font appel à des milliers de personnes, et toutes les disciplines - de la chimie à la médecine, de l'astronomie à la microphysique, de la cybernétique à l'optique, etc. - y contribuent et en bénéficient.

La circulation de l'information ne va pas sans une interdépendance étroite des diverses branches de la science, des multiples groupes de recherche qui se stimulent, coopèrent, ou se livrent une concurrence acharnée. La simultanéité des découvertes traduit la convergence des intérêts, et le fait que les articles soient signés par un nombre croissant d'auteurs ${ }^{1024}$ concrétise l'aspect collectif de l'entreprise scientifique. Par-dessus tout, l'existence de communautés de savants, de techniciens, d'ingénieurs travaillant de concert suscite le besoin d'une coordination à l'intérieur de chaque unité, entre ces unités elles-mêmes, et,

${ }^{1024}$ Voir l'ouvrage de D.J. de SOLLA PRICE : Little Science, Big Science, ed. cit. 
enfin, à l'échelon national ou international. La reproduction des savoirs revêt les mêmes caractères. L'ensemble des institutions consacres à conserver et transmettre les informations constituées est devenu social. La formation des techniciens ou des savants est conçue sur une grande échelle; elle embrasse simultanément une multitude d'individus. L'acquisition et la répartition des capacités sont de moins en moins le fruit de décisions isolées ; elles deviennent objet de programmes, résultat de coordinations qui tiennent compte de la situation des sciences et de l'état de la société. La démarche méthodique est, là aussi, de rigueur.

Les investissements, de par leur ampleur et leur origine, ne peuvent être que sociaux. Les fonds publics n'interviennent pas seulement lorsqu'il s'agit de former des individus : ils participent au financement de la plupart des inventions véritablement décisives ${ }^{1025}$. Il est facile d'en donner les raisons. Les moyens indispensables à la poursuite d'une série d'études théoriques, associées à des expériences propres à les confirmer ou à les infirmer, dépassent les disponibilités d'un individu, sinon d'une entreprise. Parallèlement, le coût de l'instruction, ou l'étendue de la population qu'elle concerne, imposent le recours au financement collectif, recours qui s'accentue proportionnellement au volume des connaissances et à leur degré d'avancement ${ }^{1026}$.

Certes, tant la recherche que l'enseignement supposent une longue durée de préparation avant que leurs fruits parviennent à maturité. Une ou plusieurs dizaines d'années sont nécessaires pour former un technicien ou un savant, une ou plusieurs générations doivent déployer leurs efforts avant qu'un problème puisse être résolu, un procédé mis au point. Les aléas sont nombreux, la prévision des risques demeure malaisée. Les dépenses engagées dépassent, de la sorte, les perspectives du calcul économique et ne peuvent plus être chiffrées en

1025 «Les plus grandes découvertes des dernières décades — l'atome, les fusées, etc... — sont les résultats d'une recherche socialisée et non d'une recherche capitaliste ». M. DUVERGER : Introduction à la politique, Paris, 1964, p. 336.

1026 «Les investissements destinés aux individus ressortent du domaine public; ces investissements deviennent de plus en plus essentiels avec le progrès des sciences et de la technologie ; et il n'y a pas de mécanisme qui puisse déterminer automatiquement la répartition entre investissements matériels et investissements humains ». J.K. GALBRAITH : L'ère de l'opulence, Paris, 1961, p. 255. 
fonction du profit ou de la productivité d'une industrie particulière. Si l'on acceptait les limites que celle-ci impose, on irait à l'encontre de l'intérêt présent ou futur de la société :

«Il semble clair, observe un économiste ${ }^{1027}$, que si l'on livrait le champ de la recherche fondamentale exclusivement à des firmes privées opérant les unes indépendamment des autres et vendant sur des marchés concurrentiels, le stimulant du bénéfice n'attirerait pas à la recherche fondamentale une aussi grande quantité de ressources qu'il est socialement souhaitable».

Et ceci à plus forte raison, il faut le reconnaître, que la substance et les gains des processus créateurs de facultés humaines ne peuvent pas faire l'objet d'une appropriation. Non seulement il est impossible de les vendre ou de les acheter, mais on ne saurait non plus les fixer de manière à rémunérer ou à augmenter le capital ${ }^{1028}$. Dès lors, les détenteurs de fonds privés, les gardiens avisés de la propriété n'ont pas intérêt à investir une grande partie de leurs moyens dans l'activité créatrice. Le feraient-ils, en prenant les mesures nécessaires pour s'assurer la pleine possession des résultats - mainmise sur la recherche, non-dissémination des découvertes - ils la ralentiraient, et leurs dépenses auraient moins d'effet que des dépenses d'un montant équivalent engagées par l'État. Les conditions de la génération et du développement des connaissances étant telles, et la participation de la richesse publique aussi considérable, on doit supposer un essor continu de la fraction collective de la propriété, une refonte de la composition de celle-ci.

On observe ainsi qu'en ce qui concerne la création du travail, la forme et le contenu commencent à coïncider. Celui-ci a toujours été social, dans la mesure où son appropriation — je viens d'y faire allusion — n'a jamais cessé d'être sociale. Les personnes ou les groupes qui s'en adjugent le profit ne peuvent le faire que de manière acciden-

${ }^{1027}$ R. NELSON : The simple economics of basic scientific research, J. of Polit. Econ. 1957, 67, p. 304.

1028 «En fait, il y a une contradiction essentielle entre les conditions nécessaires à une recherche fondamentale efficace - contrainte faible ou nulle exercée sur la direction de la recherche, libre et pleine dissémination des résultats de la recherche - et la pleine appropriation des gains provenant d'un patronage accordé à la recherche dans une économie concurrentielle ». R. NELSON : idem, p. 305. 
telle ou éphémère. Par contre, l'assimilation des habiletés et des savoirs, les efforts consentis afin de les systématiser ou de les multiplier - la forme de la reproduction et de l'invention — sont restés, jusqu'au début de ce siècle, strictement individuels. Et ceci aussi bien du point de vue de l'organisation que du point de vue des investissements. La seule récompense de l'inventeur était la gloire; son seul moyen de réussir, le sacrifice ; son seul tourment, l'échec ou le vol ; pour ces raisons, la découverte était le fruit d'un hasard et l'acte d'un héros.

La production et la consommation, elles, ont pris depuis longtemps une forme sociale. Les liens qui relient les secteurs industriels, l'interdépendance des ouvriers dans une usine en tant que membres d'un travailleur collectif, suivant la métaphore de Karl Marx, la configuration des marchés et l'intensité des échanges, l'institution de procédés destinés à produire des biens consommés par une masse d'individus, en sont autant de preuves. Cette socialisation, venant s'opposer à la substance privée de la propriété, a déjà eu pour conséquence, au gré des situations, l'apparition d'un secteur collectif de la propriété - de manière prédominante dans les pays socialistes notamment, de manière partielle ou déguisée dans les autres. De la sorte, la forme collective de nos modalités de produire, de consommer, d'échanger, rejoint son contenu social, lequel imprime sa marque sur l'état des richesses et de la possession.

Le contraste entre les processus naturels et les processus sociaux - les premiers ayant une forme individuelle et un contenu social, les seconds ayant une forme sociale et un contenu individuel - si vif jusqu'à une époque récente, est donc en passe de s'estomper. La socialisation des processus naturels permet à deux séries d'exigences de se manifester de façon plus nette et plus intense. D'une part, celles de la société, puisqu'elle y emploie directement une fraction de ses richesses, et qu'elle se donne les institutions nécessaires pour exercer un contrôle strict et procéder à des choix. Le nombre de commissions spécialisées à cet égard, de ministères et d'administrations concernés par la recherche scientifique, est en continuelle augmentation. La concurrence industrielle et économique détermine toute une floraison de découvertes immédiatement applicables, et influe sur leur rythme. 
Les tourments militaires des grandes puissances, ou de celles qui rêvent de l'être, ont imprimé leur cachet à l'effort inventif, en provoquant un afflux de moyens économiques et en suscitant l'intérêt des organismes étatiques pour le cours ordinaire de l'élaboration des connaissances. On doit cependant observer que cette interférence des cerveaux guerriers et des appétits politiques n'a fait qu'accélérer une évolution dont les prémices étaient déjà discernables avant que le sabre reposât à côté de l'éprouvette. Notamment lorsque les scientifiques, pour conquérir leur indépendance dans des circonstances historiques déjà décrites, ont voulu conseiller à l'industrie la voie qu'elle avait à suivre.

D'autre part, l'accroissement en quantité et en prestige de l'ensemble de ceux qui ont pour occupation première l'avancement et la diffusion des connaissances de tout ordre concourt à imposer à la société, comme sa tâche légitime, des préoccupations et des vues qui leur sont propres. Les systèmes pédagogiques et les sujets de recherches sont choisis ou interprétés, dans une grande mesure, par la discipline, par le mouvement collectif qui, à un moment donné, les imposent. Des dizaines, des centaines de milliers d'hommes - physiciens, chimistes, mathématiciens, électroniciens, etc. - sont promptement aiguillés vers des voies semblables ou convergentes. Les académies, les sociétés savantes, les congrès et les dizaines de milliers de périodiques renforcent cette tendance, la canalisent et légifèrent à son propos. Cela suffit à déterminer les disponibilités financières, à tisser une trame que l'industrie, l'appareil politico-militaire sont obligés d'adopter. L'exemple de tant de découvertes théoriques ou expérimentales qui ont d'abord paru curieuses et gratuites pour déployer, par la suite, des conséquences prodigieuses ou terrifiantes, incite à tempérer les jugements hâtifs portés sur l'inutilité ou l'intérêt d'une recherche spécifique. Non que la tension entre les fins que la collectivité propose et celles que les savants ou les ingénieurs défendent se soit transformée en harmonie. Cependant, les objectifs que se fixent les scientifiques sont reconnus, faute de pouvoir être contestés à partir de critères valables, et leur réalisation est soutenue, à des degrés variables. La perméabilité de l'influence exercée sur l'évolution des facultés et des ressources d'un côté par une catégorie naturelle, de l'autre côté par les organismes politiques, incite la collectivité à se 
concevoir avec une responsabilité particulière à l'égard de ces activités ayant trait à l'état de nature, auquel tant de ses membres sont expressément préposés.

Ainsi l'espèce humaine ne saurait considérer cet état comme le lieu des contingences auxquelles elle s'efforce constamment d'échapper, puisque, au contraire, il se développe continuellement comme son résultat. La société ne se prépare donc pas à sortir de la nature, mais à en être l'intériorité. Et c'est tomber dans le piège des mots que d'envisager le côté naturel de son existence essentiellement dans le prolongement biologique de ses membres, de le juger en fonction de l'intelligence ou de l'indice de cérébralité ${ }^{1029}$, paradigmes qui restent abstraits, malgré leur allure familière, parce qu'ils ne tiennent pas compte du processus d'auto-création et de ses implications. La continuité qui unit ce processus à la reproduction sociale marque un mouvement qui inaugure une époque.

L'ensemble social, sans se détourner de son travail historique, renonce à pouvoir le diriger vers la cristallisation de ses structures les relations qui l'expriment perdent leur caractère solide, substantiel, leur aptitude à entretenir la permanence des intérêts, des comportements et des situations. De la sorte, le fétichisme des collectivités hypostasiant une de leurs figures se heurte déjà et se heurtera toujours davantage aux forces qu'elles suscitent par ailleurs et qui les mettent en question ${ }^{1030}$. Longtemps, en révolutionnant leur ordre naturel, les hommes, sans en prendre conscience, bouleversaient, après d'innombrables détours, leur ordre social. Maintenant, venant à la conscience, s'intégrant à la pratique, cette évidence ébranle les sociétés qui cherchent à se bâtir sur des matériaux définitifs, à s'édifier comme autant de règnes clos.

\footnotetext{
${ }^{1029}$ Voir par exemple TeILHARD DE CHARDIN : Le phénomène humain, Paris, 1955.

1030 «On ne voit pas quel peut être l'objet des sciences dites sociales, en quoi elles méritent le nom de sciences, si elles ne se consacrent pas à cette invention des institutions sociales, basée sur la théorie et l'expérience. Faute d'être constitutives du réel, elles se borneraient à l'interpréter. Une telle tâche est davantage du ressort des idéologies que de celui des sciences. Seule une société qui leur ouvrira cette possibilité de recherche leur permettra d'être des sciences, au sens plein du terme.
} 
$\mathrm{Au}$ contraire, un lien continu autorisant la communication entre les principales sphères de la vie, révélant leur interdépendance, parce qu'elles sont notre fait et que nous sommes leur sujet reconnu, est celui qui institue la société comme forme de la nature. Il s'ensuit que leurs champs respectifs ne se manifestent pas, ne pourront plus se manifester comme deux mondes à part, mais comme deux manières différentes de conduire l'activité humaine, l'une assurant les ressources matérielles, stimulant et répartissant nos facultés, l'autre commandant l'accumulation et la distribution des richesses conformément à la satisfaction sociale des besoins. A cette fin, le gouvernement de l'une complète le gouvernement de l'autre. 


\section{Conclusion}

\section{Pour une nouvelle science : la technologie politique}

Retour à la Table des Matières

\section{Le chaînon manquant.}

L'exploration active des autres planètes du système solaire nous met en face d'états géologiques révolus de notre planète ; à l'aide de ces témoignages de temps très reculés, nous faisons notre présent et nous préparons notre avenir. Le regard jeté ici vers le passé nous amène également à y retrouver, non pas les signes d'une enfance dont nous vivons l'âge mûr, mais les éléments essentiels pour concevoir notre devenir. Le lieu d'une science se dessine là où ces éléments doivent être assimilés, élevés à l'universalité, modifiés par la pratique, et là où la réalité change de dimensions, acquiert un excès de signification. Les analyses théoriques et les notions dégagées au cours de cet essai tendent à déterminer ce lieu, en aménageant la voie à une systématisation des connaissances et des intuitions éparses, à une discipline qui en effectue la sommation.

Dans un article pénétrant, ayant valeur de programme, André Haudricourt constate que :

«La technologie, science des forces productives, est encore loin d'être reconnue comme science autonome et d'avoir la place qu'elle mérite $»{ }^{1031}$.

1031 A. HAUdRICOURT : La technologie, science humaine, La Pensée, 1964, n 115, p. 28. 
Certes, les forces productives requièrent une étude rigoureuse dans le cadre d'une spécialité indépendante. Associées à ce qu'on appelle couramment « le progrès scientifique », elles sont censées expliquer et déterminer l'évolution de la société. Comment peut-on croire qu'une collectivité est capable de dominer son histoire, de prévoir les phases successives de son développement si, justement, l'enchaînement causal de celui-ci échappe à toute connaissance théoriquement attestée ? Quel sens exact attribuer à la prétendue maîtrise de la nature, si non seulement on postule le caractère contingent de nos rapports avec elle, mais si, de plus, on ignore leur teneur ? Cette maîtrise signifie-t-elle uniquement l'accumulation des forces matérielles et des informations au sujet de l'univers? Celle-ci a toujours existé et ne s'arrêtera qu'avec la disparition de l'espèce. A refuser d'y rechercher une régularité particulière aux pouvoirs qui naissent de nos échanges avec le monde matériel — ce qui invite à établir leur savoir propre - on se condamne à laisser planer l'incertitude sur le devenir des sociétés, de l'humanité. Pour réagir contre ce refus persistant, pour combattre un intérêt exclusivement tourné vers les relations économiques et sociales, et combler un manque, l'étude des forces productives s'impose. Celles-ci comprennent, bien sûr, une vaste gamme de techniques matérielles. Néanmoins, associée à chaque instrument, à chaque objet, nous retrouvons une suite de gestes, de réflexes qui leur correspond étroitement. Pour souligner l'importance de ces montages physiologiques et psychiques, Marcel Mauss a forgé le terme de « techniques du corps $\gg{ }^{1032}$. Celles-ci constituent la véritable texture d'un matériau, d'un outil, d'une chose. La chaîne est continue qui mène de l'organisation des mouvements, de la combinaison des postures, à l'agencement des parties d'une charrue ou d'une machine simple :

«L'analogie entre l'évolution des êtres vivants et l'évolution des techniques peut être poussée assez loin sans paradoxe, à condition de comprendre que l'objet n'est comparable qu'au squelette du vertébré ou à la coquille du mollusque. De la même façon que le naturaliste essaie de rétablir les parties molles: muscles et viscères de l'animal, il faut mettre autour de l'objet l'ensemble des gestes humains qui le produisent et le font fonctionner $»{ }^{1033}$.

1032 M. MAUSS : Sociologie et anthropologie, Paris, 1950, pp. 365-386.

1033 A. HAUDRICOURT : art. cit. p. 31. 
Au delà du geste, de l'habitude musculaire, se retrouvent aussi le calcul ou le coup d'œil, la recette ou la loi, le schéma intellectuel ou perceptif, la discipline naturelle ou productive qui les organise de concert. Le classement des techniques implique le classement de leurs disciplines respectives, la recherche de leur filiation historique tout autant que l'analyse de leur hybridation, c'est-à-dire de leur reproduction et de leur invention ou diffusion. Ce n'est pas, on le conçoit, le produit de la technique, mais la production de la technique, et plus généralement celle des savoirs — arts ou sciences — qui est le but de la « science des forces productives ». En un mot son objet est moins la cristallisation du travail sous formes d'artifices que la création du travail. Celui-ci, et A. Haudricourt le relève avec raison, n'a été envisagé, examiné, que sous l'angle des structures économiques et sociales :

«Ce qui a longtemps empêché, écrit-il ${ }^{1034}$, l'introduction de ces points de vue en technologie est évidemment le statut inférieur de ces études dans l'optique universitaire du XIX ${ }^{\mathrm{e}}$ siècle. Les différentes « histoires du travail » ou les « histoires des classes laborieuses» étaient beaucoup plus centrées sur l'histoire des modes de production que sur l'histoire des forces productives ».

Si une autre optique paraît aujourd'hui s'imposer, pourquoi attribuer le point de vue qui l'a précédée aux conceptions « universitaires » du XIX ${ }^{\mathrm{e}}$ siècle, et non pas aux réalités de cette époque-là ? De même que l'histoire de la société et l'économie, l'histoire humaine de la nature et la technologie viennent au premier plan, chacune en son temps, pour répondre aux interrogations qui ont mûri. Entre le $\mathrm{XIX}^{\mathrm{e}}$ et le $\mathrm{XX}^{\mathrm{e}}$ siècles, ce n'est pas la « résistance de l'université » qui a interposé un écran : ce sont les problèmes qui se sont transformés de fond en comble, et appellent une connaissance différente, hors des contextes traditionnels.

L'essor des sciences, le pouvoir qu'elles recèlent et l'avenir qu'elles définissent, comme la responsabilité que nous prenons à leur sujet, sont au cœur de l'action et de la conscience universelles. C'est là que se trouve aujourd'hui la matière concrète des forces producti-

${ }^{1034}$ Ibidem. 
ves. Pour l'appréhender, les démarches habituelles s'avèrent insuffisantes. Analyser la science dans ces contextes divers, du côté des idées dans l'histoire de la philosophie ou dans l'histoire des sciences, du côté des effets (rentabilité économique, système d'institutions ou de valeurs, etc.) dans la sociologie ou l'économie politique, laisse échapper son originalité. Bien plus, écartelée entre la sphère de la pensée et la sphère de l'action, rattachée tour à tour à l'esprit tendu vers la vérité et à la société avide de richesses, elle ne saurait permettre ni l'élaboration d'une pratique la concernant, ni la naissance d'une théorie conforme aux intérêts que les hommes y poursuivent. La réalité a raison de ces divisions, et la place que la science occupe dans la vie intellectuelle et politique des nations oblige les divers ordres d'études à converger ${ }^{1035}$ et à la saisir d'une manière positive.

La description exacte de la production des connaissances scientifiques est déjà commencée ${ }^{1036}$. On analyse la diffusion, l'influence et l'accroissement du nombre d'articles suivant les branches du savoir. L'évolution du nombre des savants, des conditions dans lesquelles ils travaillent, font également l'objet de recherches très variées. L'examen statistique des inventions, des publications théoriques et expérimentales, a, de plus, prouvé que des lois de nature mathématique pouvaient déterminer le sens du développement d'une science. Ainsi la distribution des travaux scientifiques par domaine ou par pays paraît suivre la courbe de Zipf. Cette courbe, qui suppose la constance du produit de la fréquence et du rang d'un acte, d'un signal, etc. a été appliquée à la description de la distribution hiérarchique de la taille des villes, des mots d'une langue, etc. Plus précisément, on a montré que l'augmentation du nombre de publications en physique ou en chimie manifestait une loi de croissance exponentielle. Donc, l'invention engendre plus d'invention, la science engendre plus de science. De ces études on peut encore tirer d'autres conclusions. A

1035 «Les disciplines qui analysent la science ont été créées par fragments, mais de nombreux signes montrent qu'elles commencent à s'assembler en un tout plus grand que la somme de ses parties ». D.J. de SOlla PRICE : The Science of Science, in M. GOldSMiTH, A. MACKAY : op. cit. p. 251.

1036 E. Hulme : Statistical Bibliography in relation to the growth of modern civilisation, Londres, 1923 ; S. DEDIJER : Measuring the growth of science, Science, 1960, 130, pp. 781-794 ; P. WEISS : Knowledge : a growth process, Science, 1960, 131, pp. 1756-1719; J.H. WestBROOK : Identifying significant research, Science, 1960, 131, pp. 1229-1234. 
savoir, que le nombre de savants compétents s'accroît comme le carré du nombre des savants exceptionnellement doués qui fournissent presque la moitié des articles de la discipline considérée. Si l'on ajoute aux scientifiques les ingénieurs, les collaborateurs de tout rang, on constate que l'investissement dans la science croît comme le carré du nombre des scientifiques présents à un moment donné. La plupart de ces distributions représentent une simplification utile des phénomènes réels ; le fait important est qu'elles s'accordent avec les informations quantitatives dont nous disposons. Partant, on est en droit d'inférer que la création des connaissances scientifiques pourrait être soumise à une étude rigoureuse :

« Je crois, écrit D.J. de Solla Price ${ }^{1037}$, que nous avons à présent posé les fondements théoriques de cette étude de la science ».

Stimulé par les résultats obtenus, il propose la constitution d'une « science de la science », encore innommée ou mal définie ${ }^{1038}$, mais dont la nécessité ne fait pas de doute. Le poids politique des décisions en matière d'efforts et de recherche scientifiques, le rôle joué par les scientifiques, leur formation et leurs découvertes, dans la création d'organismes gouvernementaux, le réclament. La naissance d'un champ d'investigation à la fois précis et fécond attire les énergies intellectuelles qui y voient un mode d'attaque nouveau des problèmes familiers à l'histoire des sciences et des techniques. Le rapprochement avec l'étude des processus économiques est assez frappant :

« La différence qui sépare l'analyse de la science et l'analyse des affaires économiques se trouve dans les paramètres ${ }^{1039}$.

Le parallélisme signalé est capable de guider les premiers pas de la discipline qu'il s'agit d'établir et d'étoffer. La similitude des résultats, envisagés du point de vue mathématique, offre de plus une assurance

1037 D.J. de Solla Price : Little science, big science, ed. cit. p. 55.

1038 «Je crois que la nouvelle force la plus stimulante de l'histoire des sciences est la proximité d'un nouveau domaine à moitié défini et fâcheusement nommé (science de la science, n.n.) qui se propose de déterminer d'une façon scientifique ce qui donne du crédit à la science ». D.J. de Solla PrICE : Science as a science, Times Literary Suppl. 28 juillet 1966, p. 661.

1039 D.J. de SOLLA PRICE : Little science, big science, ed. cit. p. 55. 
et une ouverture méthodologique. Les isomorphismes ainsi attestés sont d'un grand secours pour l'avancement des connaissances, comme ce fut le cas pour l'analogie remarquée entre la loi de la gravitation de Newton et la loi de l'attraction magnétique de Coulomb. Néanmoins, si ces ressemblances facilitent la formulation des hypothèses indispensables, elles ne se substituent pas à l'analyse empirique et théorique autonome, car elles ne contribuent pas à la compréhension des phénomènes spécifiques. La reconnaissance de l'analogie de la loi de Newton et de celle de Coulomb a pu préparer le terrain, mais n'a pas eu pour conséquence l'intelligence véritable des phénomènes magnétiques ou électriques. Se maintenir au niveau des équivalences formelles comporte un inconvénient : celui de négliger la fonction heuristique d'une science, et d'ignorer ses répercussions spécifiques sur l'existence concrète des hommes. Aucune connaissance ne subsiste à répondre à d'autres questions que les siennes, à rechercher le confort par la réaffirmation de ses similitudes avec d'autres sciences, au lieu d'insister sur ce qu'elle a d'individuel et d'indépendant. Les « fondements théoriques » de cette discipline ne sont donc pas posés tant que les concepts, les principes historiques, le domaine du réel dans lequel s'insère l'examen systématique de l'évolution des sciences — ou des techniques - ne sont pas énoncés et tant que les fins sont indiquées uniquement par comparaison :

« Notre discipline, écrit D.J. de Solla Price ${ }^{1040}$ a essayé de faire pour le monde scientifique ce que fait précisément l'économie pour le monde des affaires et du commerce ».

On observe justement que l'économie ne s'occupe pas exclusivement "des affaires et du commerce». Elle s'intéresse surtout à la production, aux agents économiques, à la dynamique de la structure sociale. De même, la science et la technique auxquelles se réfère la nouvelle discipline ne sont pas seulement une somme d'expériences ou de théories, ni un nombre déterminé d'articles ou de revues. Les expériences et les théories ne s'engendrent pas les unes les autres, pas plus que les articles ne donnent naissance à d'autres articles. En dernière analyse, on retrouve des groupes humains qui détiennent certains

1040 D.J. de SOLla PRICE : Science since Babylon, ed. cit. p. 128. 
codes, qui utilisent une masse de talents et d'informations et établissent, à cette occasion, des rapports entre eux. Partant des intentions et des règles qui dirigent l'activité de ces groupes, on rejoint et on comprend la floraison des théories et des articles, le sens de leur expansion. Celle-ci traduit à chaque instant la mouvance du monde matériel, des hommes qui y participent, et non pas la dilatation d'un univers de papier ou de pensées. N'est-il pas clair qu'à travers la science, l'industrie de la découverte, les collectivités ne font pas qu'accroître leurs profits, satisfaire leurs besoins ou fournir une réponse à leur curiosité ? L'état naturel est immédiatement visé, et c'est lui que les disciplines scientifiques et techniques affectent et instituent.

Pour compléter l'analogie avec l'économie politique, la «science de la science » devrait s'appliquer à cet état dans son ensemble, et non pas seulement à ses manifestations. Détachée de ce contexte, elle conduirait à accepter la perspective des groupes qui réduisent les habiletés, les savoirs, à la fonction de purs instruments ${ }^{1041}$ de la richesse et du pouvoir, et à traiter d'une hypostase, d'une totalité réifiée, au lieu de révéler sa vie authentique. En épousant une attitude strictement pragmatique, on ne peut s'attendre que la nouvelle science change quoi que ce soit aux routines déjà instaurées ; sa mission se bornerait à les corriger, à les adapter, à extrapoler. A plus forte raison, pour prix de sa reconnaissance, elle abandonnerait le rôle de critique pour se plier aux normes de respectabilité qui ont été imposées à la plupart des disciplines, lorsqu'elle-même n'existait pas. Qu'ajouterait-elle alors à ce qui existe déjà ? Comment saisirait-elle l'ampleur véritable de son sujet qui débouche sur des options fondamentales, ayant une résonance éthique et assurément politique ? C'est là sa justification profonde. La lumière qu'elle peut jeter sur un côté de l'histoire qu'il convient désormais non plus de subir mais de faire, dépasse de loin la portée des services qu'elle est susceptible de rendre à une catégorie étroite de fonctionnaires ou d'administrateurs des affaires publiques et privées. Il ne s'agit donc pas de se limiter à une science du calcul, des instruments théoriques destinés à faciliter la gestion des disciplines

1041 «L'espoir (d'une science de la science) étant naturellement que la connaissance sérieuse puisse être mise à profit dans la grande quantité de décisions pratiques qu'il faut prendre concernant une politique de la science qui a maintenant pour résultats si souvent de graves dommages et une mauvaise administration »... D.J. de SolLA PRICE : art. cit. p. 661. 
naturelles ou productives, séparées de leur cadre originel et comptées pour de purs moyens. Ce danger est d'autant plus grand pour la « science de la science » qu'elle aurait, avec le temps, le besoin impérieux de défaire ses liens unilatéraux avec l'économie pour se rapprocher de l'épistémologie - théorie de la connaissance scientifique et technique - et de la biologie, pour autant que celle-ci nous enseigne les lois des populations, les conditions de l'unité de l'organisme et du milieu, ou les mécanismes génétiques. L'étude, qui est de son ressort, des forces productives anciennes - arts, techniques, philosophies ou modernes - sciences fondamentales ou appliquées - l'engagent sur cette voie. Dans le tableau de Mendéléeff des sciences de l'homme, sa place est toute désignée.

L'étape suivant sa détection doit être celle de la définition précise de son contenu, des propriétés de celui-ci et de la réalité dont elles relèvent. La technologie politique, ainsi que je propose de la nommer, serait la science de notre ordre naturel, des processus par lesquels il est institué. Elle aurait trait à l'évolution simultanée des forces matérielles et de l'espèce humaine envisagée dans ses relations avec ces forces. Elle embrasse ainsi les aspects intérieurs, qualitatifs, tels qu'ils se manifestent dans la vie quotidienne et les groupements de disciplines organisées, à côté des aspects extérieurs, quantitatifs, du commerce continu de l'homme avec l'univers. L'aboutissement de cette science peut résider, certes dans la connaissance des caractéristiques apparentes, telles que le nombre de savants, l'accroissement quantitatif des brevets d'invention ou la filiation d'une théorie neuve. Toutefois, le domaine spécifique de la technologie politique ne sera pleinement appréhendé que par l'analyse conjuguée de ces paramètres généraux et de l'enchaînement intellectuel et pratique des découvertes dans les sciences, les techniques, les arts et les philosophies : ce sont les processus d'autocréation propres à une catégorie naturelle qui indiquent son objet. Le vocable même de technologie, dégagé du mépris et de la crainte qui l'entourent dans notre société, prendra alors tout son sens :

«En effet, depuis le Paléolithique supérieur, mais surtout depuis l'agriculture, le monde des symboles (religieux, esthétiques ou sociaux) a toujours prévalu sur le monde des techniques, et la pyramide sociale s'est édifiée 
de manière ambiguë en donnant la prééminence aux fonctions symboliques sur la technologie, pourtant moteur de tout progrès $\gg{ }^{1042}$.

Pour s'adapter aux faits, une révolution dans les idées est donc devenue nécessaire. Vouloir que ce soit justement l'ordre naturel qui fasse l'objet d'une science appelée technologie, voilà qui semble mal s'accorder avec les conceptions généralement admises. En réalité, là non plus, il n'y a pas, il n'y a plus de scandale ${ }^{1043}$. On commence à entrevoir le rôle constitutif de l'action humaine, présente aussi bien dans l'effet de masse de l'espèce que dans les modifications qu'elle provoque dans la biosphère. La vie végétale et animale se déroule dans des conditions neuves qui engendrent des changements profonds :

«La surface de la planète est en train d'être bouleversée, observe W.I. Vernandsky ${ }^{1044}$. Un processus d'épanouissement turbulent est en cours dans l'enveloppe biosphèrique de la terre, et l'on peut s'attendre que la suite de ce processus prenne des proportions gigantesques ».

Outre les preuves fournies au cours de cet essai, la reconnaissance empirique du "faire » humain comme variante du faire universel a pour résultante la disparition des frontières rigides : la technique artificielle et la nature se révèlent alors comme des modalités de celui-ci.

Cependant, tout comme l'économie, science de la société et de son histoire, la technologie, science de notre ordre naturel et de son histoire, est politique. Par ce qualificatif, on récuse, en effet, l'idée que cette discipline est vouée, dans ce qu'elle a de plus général, à la description et au classement analytique des procédés industriels, de leurs produits et de leurs agents. La technologie est assurément une science politique dans la mesure où son contenu, ses fins, sont inscrits parmi les préoccupations essentielles des sociétés modernes. Si, jusqu'au

\footnotetext{
1042 A. Leroi-Gourhan : Le geste et la parole, Paris, 1964, p. 258.

1043 «Ne nous payons pas de mots creux. L'homme d'une part, la Machine de l'autre? Eh ! non, pas plus que l'Homme et la Nature, ou que la Technique et la Nature. Avec des majuscules. La Nature "nature ", où donc la trouver?» L. FEBVRE: Les techniques, la science et l'évolution humaine, Europe, 1938, n 185, 47, p. 498.

1044 W.I. VERNANDSKY : Problems of Biogeochemistry, II, Newhaven (Conn.), 5944 p. 488.
} 
$\mathrm{XX}^{\mathrm{e}}$ siècle, l'éducation, l'amélioration des habiletés, les inventions et la diversification des forces matérielles ont été considérées comme aussi spontanées que le changement des saisons et les éclipses de Lune ${ }^{1045}$, il n'en sera plus de même à l'avenir. Tous les phénomènes relatifs à la communication avec le monde matériel - promotion des sciences, reproduction des savoirs, découvertes de procédés et de matières premières ou finales - deviennent systématiques, se détachent en tant que résultats. Leur étude rigoureuse est une exigence pratique ${ }^{1046}$ et logique. Depuis quelques décennies, nous savons mesurer le volume des agents naturels (substances, énergies, populations, facultés, etc.) existant à une époque donnée. Nous sommes préparés à évaluer à l'avance les besoins d'une nation en «bras » et en «cerveaux ». Notre sensibilité s'est considérablement affinée sur ce point, et nous avons de plus en plus conscience du caractère à la fois limité et remplaçable des possibilités matérielles du globe. Cependant, si le corps social ajustement pour obligation de commander l'évolution de ces phénomènes, sa tâche est de suivre les principes qui leur sont spécifiques, de s'accommoder à leur structure. Le gouvernement de l'ensemble des processus naturels en dépend, comme en dépend celui de la société. Qu'est-ce à dire, sinon que la production des talents est située au premier plan. Or, ces talents ne sauraient être créés, quels que soient les investissements, à volonté. Leur combinaison est difficile, longue, et son issue maintes fois imprévisible. Il s'agit toujours d'augmenter au maximum les chances pour qu'un événement rare ait lieu. Imposer à cet égard un programme conduirait à restreindre l'attention prêtée aux découvertes les moins probables, qui sont les plus souhaitables, et à imposer des normes dans un champ de réalité qui change constamment. Le système des plans, recommandé pour éliminer les contradictions du marché ou de la société, provoquerait des effets opposés aux effets désirés. Les institutions sociales, les spé-

1045 « Mais ils (les économistes du XIX ${ }^{\mathrm{e}}$ siècle) Vivaient une époque où les hommes se tournaient vers une direction nouvelle et où le progrès économique n'était pas seulement consciemment recherché mais semblait, d'une certaine façon, engendré par la nature des choses. Les améliorations, à cette époque, n'avaient pas à être expliquées. C'étaient des phénomènes naturels, comme la précession des équinoxes ». A. YouNG : Increasing returns and economic progress, Econ. Journal, 1928, 38, p. 529.

1046 " Il eût été difficile au savant du XIX ${ }^{\mathrm{e}}$ siècle de s'occuper du volume de la recherche et du développement d'une industrie. C'est un phénomène contemporain, lié à la croissance de l'entreprise moderne. De son temps, l'invention était une question secondaire, sauf si on pouvait la faire breveter ». J.K. GALBRAITH : op. cit. p. 127. 
cialistes qu'elles délèguent, doivent se comporter comme les généticiens agronomes. Ceux-ci savent que les combinaisons génétiques arbitraires ou conformes à un modèle préétabli sont interdites. Leur travail consiste dans l'élaboration patiente de règles et de stratégies qui leur permettent de reconnaître et de traiter une variété végétale ou animale qui surgit dans une région ou à un moment donné.

Pour la création des dextérités et des facultés, des stratégies semblables sont nécessaires. Tout d'abord, elles doivent permettre de repérer, à travers leur diversité, les "variétés d'informations », si l'on peut dire, que l'on recherche. Ensuite, après que l'on a appris à juger de la valeur des connaissances ou des procédés obtenus, un savoirfaire particulier et des mesures appropriées parviendraient à les conserver, à favoriser ou accélérer leur éclosion. De pareilles stratégies, par le passé, auraient permis aux hommes de distinguer ce qu'ils ont longtemps confondu - le métal et la pierre, par exemple — ou de s'occuper directement et sans délai d'une classe de phénomènes. L'électricité ayant été jugée comme un effet artificiel jusqu'à ce que Benjamin Franklin démontre le contraire n'a pas été incluse dans le cadre des études théoriques et expérimentales.

Bien entendu, les disciplines contiennent implicitement des paradigmes ${ }^{1047}$, des principes qui contribuent à sélectionner un savoir ou une propriété matérielle. Néanmoins, ces principes, les méthodes qui les suivent, n'ont pas encore inspiré une démarche cohérente; ce qui a été fait pour accumuler et composer les qualités des autres espèces n'a pas été fait pour la nôtre. La technologie politique pourrait pallier ce manque, dès l'instant où elle est science des ressources, comme l'économie politique est la science des richesses. La réflexion sur ces ressources est restée des plus pauvres, dépourvue qu'elle était de stimulation intellectuelle et de justification immédiate. Coupée de l'examen des disciplines naturelles, purement comptable et totalement anhistorique, non expérimentale, elle s'est uniquement intéressée à la conservation ou à l'inventaire des matériaux ou des énergies. Sa qualité politique, le fait qu'elle a trait au véritable gouvernement de la nature, ont été méconnus. Qu'il soit naturel ou social, le rapport de

1047 T.S. KUHN : op. cit. 
l'homme à la matière et à un autre homme, à ce sujet, doit acquérir une rationalité qui lui fait actuellement défaut. Ce qui explique les tentatives pour constituer une nouvelle science, et éclaire la signification que j'attache à la technologie politique.

$\underline{\text { Retour à la Table des Matières }}$

\section{Le programme de la technologie politique.}

Le repérage du champ d'exploration scientifique exige que l'on y ajoute une carte où figurent les phénomènes, les facteurs et les problèmes dont la mise en évidence prélude à des progrès ultérieurs. Ces données préliminaires indiquent la direction dans laquelle l'étude doit s'engager. Je voudrais d'abord montrer son importance du point de vue de la société. Ensuite il me faudra rappeler succinctement le répertoire des sujets auxquels elle s'applique.

Lorsque s'est constituée une science de la société, de ses processus économiques, la question s'est posée de savoir si les techniques, les connaissances et, plus généralement, le «capital intellectuel» devaient ou non y être inclus. L'impossibilité de proposer une mesure de ces facteurs, l'hétérogénéité des buts des agents économico-sociaux et de ceux des agents techniques ou scientifiques, la disproportion entre le caractère systématique des efforts poursuivis dans l'ordre de la production et la dispersion de ceux consacrés à l'invention, ont eu pour conséquence légitime d'exclure ces « richesses immatérielles » ${ }^{1048} \mathrm{de}$ l'économie sociale ou politique.

Avec une constance remarquable, tout ce qui a trait à la genèse de nos habiletés, les modalités propres à l'amélioration des connaissances et le travail qui s'y investit ont été éliminés du cercle des richesses distribuées entre les classes sociales et des motifs qui les incitent à

1048 «Le travail qui s'exerce sur la matière engendre une richesse et aboutit à notre cercle d'études; le travail qui agit sur l'homme engendre une qualité et aboutit à un autre ordre de connaissances; voilà les différences essentielles ». C. TURGEON : Des prétendues richesses immatérielles, Rev. d'Econ. Pol. 1889, 3, p. 269. 
établir des relations réciproques ${ }^{\mathbf{1 0 4 9}}$. Les facteurs intellectuels, matériels, techniques sont classés comme des résidus, leur réalité et son analyse transcendant les limites de la science des structures économiques et sociales ${ }^{1050}$. On les range ainsi couramment parmi les « économies externes ». Ces « économies » sont d'une part gratuites ${ }^{1051}$, et d'autre part peuvent difficilement faire l'objet d'une appropriation permanente. La gratuité est évidente lorsqu'un producteur rend service à un autre

« sans qu'il lui en coûte rien à lui-même et sans même qu'il en ait le propos délibéré » ${ }^{1052}$.

La plantation de fleurs constitue une telle économie externe pour un apiculteur, si celui qui les a plantées ne songeait nullement à modifier la flore de manière à rendre possible la survivance des abeilles. Le reboisement d'une région ayant pour effet d'augmenter la pluviosité encourage la production de blé. Nous voyons que cette variété d'économies se réfère au changement de la biosphère, de notre existence naturelle, de sorte qu'on les nomme parfois «créations d'atmosphère », mais on pourrait également les nommer "créations de nature ». Elles sont gratuites comme l'air, l'eau et les autres agents matériels, même si l'homme contribue à leur génération. Les procédés techniques, au cours de leur diffusion, sont rangés parmi ces éléments dont chacun dispose. Ils ont des conséquences si supérieures à leur coût et suivent un cheminement si malaisé que le calcul exact de leur rentabilité reste inexact et, à la limite, inutile.

1049 G. PIROU : Introduction à l'Économie politique, Paris, 1946, p. 105 ; O. LANGE : Économie politique, t. I, Paris, 1962, p. 1 ; E. BOHM-BAWERK : Une nouvelle théorie du capital, Rev. d'Econ. Pol. 1889, 3, p, 99 ; V.I. LenINE : Pour caractériser le romantisme économique, ed. Moscou, 1954, p. 85.

1050 «En effet, étant donné un accroissement du Produit National pendant une période donnée, on explique une partie de cet accroissement par les augmentations observées dans les inputs de travail et de capital. Il reste alors une partie inexpliquée, un résidu que l'on met au compte des facteurs intellectuels précédemment énumérés ». A. PAGE : La mesure des effets économiques de l'éducation, Revue économique, 1964, 2, p. 252.

1051 «On convient qu'elles (les économies externes) signifient des services (et des dommages) rendus gratuitement (sans compensation) par un producteur à un autre ; mais on n'est pas d'accord sur la nature et la forme de ces services ou la raison de leur gratuité ". T. SCITOVSKY : Two concepts of external economies, J. of Pol. Econ. 1954, 62, p. 143.

1052 M. Flamant : Concepts et usages des « économies externes », Rev. d'Econ. Pol. 1964, 74, p. 96. 
Ajoutons que l'échelle des ressources, leur étendue, leur volume ont un impact démontré sur la productivité d'une économie, pour mesurer jusqu'à quel point ces économies dites externes, non-payées, non-appropriables, ont une importance décisive pour le développement de l'ensemble social. Toutefois, dans l'optique de celui-ci, de ses lois, on ne peut ni les décrire complètement, ni les analyser scientifiquement. Pour y parvenir, il est indispensable de découvrir le contenu positif, spécifique de celles du moins qui résultent du commerce entre l'homme et la matière, de la répartition des talents entre les hommes. Dans un autre chapitre ${ }^{1053}$, on a pu voir que le contenu de ces « économies externes » était proche de celui de notre nature. La nouvelle science, on le remarque, ne se distingue pas seulement par la reprise des concepts rejetés dans la zone obscure de l'économie politique, elle s'attache à ce qui la dépasse et la complète.

Bien mieux, le développement de la technologie politique est indispensable à l'étude de deux séries de mécanismes essentiels de la vie sociale : les mécanismes de crise et les mécanismes de croissance. Les premiers ont trait au déséquilibre entre la production et la consommation, entre les cycles d'emploi et de chômage ; les seconds sont relatifs à l'accroissement des moyens de production, à l'élargissement du marché, à l'essor des besoins et aux investissements connexes. Leur caractère économique et social ne fait point de doute, et leur explication se situe surtout à ce point de vue. Toute tentative pour les attribuer en entier ou en majeure partie à des causes accidentelles ou naturelles, et non pas aux rapports qui prédominent dans une société, ne peut que conduire à la confusion. Cependant, on ne saurait ignorer et on n'a pas ignoré que des facteurs étiquetés facteurs « exogènes » impriment fortement leur marque sur le cours de ces phénomènes dynamiques. Les inventions, les changements scientifiques ou technologiques, la découverte de nouvelles ressources et de nouveaux savoir-faire déterminent également crise et croissance ${ }^{\mathbf{1 0 5 4}}$,

1053 Chapitre II de la I ${ }^{\text {re }}$ Partie.

1054 «Le but d'une théorie de la croissance économique est de montrer la nature des variables nonéconomiques [souligné par moi] qui contribuent à faire croître le niveau général de production d'une économie, et par conséquent d'aider à faire comprendre pourquoi certaines sociétés croissent beaucoup plus vite que d'autres. On s'accorde à reconnaître que les facteurs critiques 
suivant la conjoncture et les structures sociales dans lesquelles ils se produisent. La machine à vapeur a pu entraîner la ruine de la manufacture et son remplacement par la machinofacture, la découverte des matières plastiques a donné un coup de fouet à l'industrie des produits chimiques. Les «facteurs exogènes » ou les "données naturelles» n'ont pas, dans l'optique sociale, un effet univoque, pas plus qu'on ne saurait les différencier à cet égard. Deux inventions, deux familles de ressources, qualitativement distinctes, peuvent avoir des effets rigoureusement identiques si on les envisage sous l'angle économique. Pour cette raison, et aussi parce qu'on méconnaît leurs lois et leur signification, dans les recherches sur le développement économique et l'accumulation du capital - ils sont considérés comme des constantes ${ }^{1055}$ ou comme des paramètres arbitraires ${ }^{1056}$.

« Lorsqu'il (l'économiste) analyse des problèmes de croissance et de développement, il trouvera souvent commode de supposer, soit un état donné des arts, soit un taux donné de progrès, quelle qu'en soit la signification » ${ }^{1057}$.

Que ces paramètres représentent les forces productives, l'état des arts industriels, les ressources matérielles ou le progrès technique, les considérer uniquement sous l'angle de la quantité se justifie pour les besoins de la théorie, mais on ne peut rejeter indéfiniment dans l'ombre la question de leur signification. Bien au contraire, seule une appréhension de celle-ci, la connaissance des lois des « facteurs exogènes », des processus qui leur sont propres, sont susceptibles d'aider à dépasser ce stade d'emploi d'indices dont on sait pertinemment que, tout en étant en partie non-économiques, ils possèdent des propriétés

qui déterminent le taux de tendance à l'accroissement doivent être recherchés dans le penchant à l'épargne de la communauté (qui détermine le taux d'accumulation), le flux d'invention et d'innovation (qui détermine le taux de croissance de la productivité) et la croissance de la population ». N. KALDOR : A model of economic growth, The Econ. Jour. 1957, 67, p. 591.

1055 «Le traitement normal de l'accumulation dans la doctrine néo-classique, comme l'a calculé en particulier Wicksell, est soumis à l'hypothèse d'une " connaissance technique donnée ". J. ROBINSON : Essays in the theory of economic growth, Londres, 1962, p. 102.

1056 « Mais avec une exception mineure - à savoir, la théorie de la protection des brevets - le fonds de connaissances et en particulier l'état des connaissances ont été généralement traités comme des variables exogènes ou comme des fonctions de tendance dans les modèles économiques ». F. MACHLUP : The production and distribution of knowledge in the United States, ad. cit. p. 5. Voir aussi : E. DOMAR : On the measurement of technological change, Econ. Jour. 1961, p. 702.

${ }^{1057}$ F. MACHLUP : op. cit. p. 4. 
suffisamment claires pour mériter l'analyse. C'est seulement une fois ces propriétés connues que les phénomènes de crise et de croissance pourront être rationnellement saisis, les rapports de la nature à la société élucidés. Jusqu'ici, on les a abordés uniquement dans la perspective des intérêts sociaux limités, mais non en eux-mêmes. L'économie a pu se dispenser longtemps des "données naturelles », de même que la mécanique a pu se passer des forces électriques ou chimiques. Néanmoins, une fois celles-ci apparues, et les forces mécaniques ou gravitationnelles replacées à côté d'elles parmi les forces physiques quelconques, de nouvelles généralisations sont devenues indispensables, une nouvelle science de l'énergie, de l'espace et du temps, reposant sur des principes nouveaux, s'est imposée. Le relief qu'ont pris les mécanismes - qui nous sont naturels - d'invention et de reproduction exigera vraisemblablement une refonte analogue.

Sur le plan du savoir, la technologie politique paraît destinée à devenir une généralisation de l'économie politique, à se substituer à elle lorsque les lois de celle-ci seront devenues transparentes ou formelles et que leur action dépendra directement de l'action des lois régissant la création du travail. Le déplacement du centre de gravité est un problème pratique et non théorique. L'effort des savants y contribue, la transformation de la société, des rapports avec la nature, restant seule déterminante.

Si nous nous plaçons maintenant du point de vue de l'état naturel, de sa formation historique, le répertoire des phénomènes auxquels la technologie politique doit accorder toute son attention se laisse décrire aisément. En premier lieu viennent les processus qui représentent le système nerveux et l'appareil circulatoire de cet état : l'invention et la reproduction. La plupart des études et des théories se concentrent sur leur aspect psychologique - par exemple sur les caractéristiques des inventeurs ou de l'enseignement, etc. - au lieu de mettre l'accent sur ce qui est vraiment essentiel dans ces phénomènes : à savoir qu'ils constituent des actes chaque jour répétés des millions de fois depuis les débuts de l'espèce, qu'ils mettent en jeu des groupements humains particuliers, que leurs lois sont les lois mêmes de l'édification des capacités des hommes au cours de leurs échanges avec le monde extérieur. Les aspects économiques et sociaux ont certes leur importance, 
mais ne présentent pas sur ces points de formes spécifiques. La théorie des brevets d'invention ou celle de l'innovation ${ }^{1058}$ excluent de facto le mouvement inventif lui-même. L'étude de la reproduction des talents a pris récemment un certain essor : elle néglige toutefois des dimensions du phénomène telles que les déplacements des hommes détenteurs de certaines habiletés, ou la diffusion de l'information scientifique, auxquels il conviendrait pourtant de prêter une grande attention. Il faudrait, de même, analyser dans le détail la répartition des savoirfaire et les qualifications des divers groupes humains. Surtout, toutes ces dimensions de la création du travail devraient être examinées avec la conscience aiguë qu'il ne s'agit pas d'un univers abstrait, se développant en dehors des individus et des collectivités humaines, mais au contraire que les hommes, divisés en catégories naturelles, par leurs activités mêmes d'invention et de reproduction déterminent les formes que prennent ces phénomènes. Les relations existant entre l'invention et la reproduction constituent des indices précieux pour comprendre les caractères d'un ordre naturel et la manière dont les forces sociales s'adaptent à cet ordre.

En deuxième lieu, les agents qu'il faut considérer sont les ressources et la population, expression la plus générale de ce qui est habituellement dénommé la terre et le travail. Ces facteurs de production, estimés naturels, ont été repérés, mais n'ont pas été examinés systématiquement. D'emblée, il faut voir qu'ils sont associés à un état de nature particulier. Assurément, une ressource correspond à un savoir détenu par une classe d'hommes. La population n'est pas exprimée par le nombre des individus, mais par une organisation, une structure de catégories et de subcatégories, d'individus auxquels des habiletés ont été imparties. La création d'habiletés — ce n'est pas le seul facteur mais il est essentiel — rend possible l'accroissement de la population générale ${ }^{1059}$. Les hommes deviennent nécessaires, productifs, lorsque des

1058 Schumpeter n'a pas seulement rejeté l'idée que l'innovation dépend de l'invention d'une manière directe ; il a aussi affirmé que le processus social qui produit des innovations est nettement différent, du point de vue économique et social, du processus social qui produit les inventions ». V.W. RUTTAN : Usher and Schumpeter on invention, innovation and technical change, Quart. J. of Econ. 1959, 73, p. 597.

1059 «Retournant à une position plus classique, nous reconnaissons dans la permanence de l'histoire humaine le résultat de plusieurs développements. Parmi eux, une expansion de la capacité productive, conduisant à la croissance de la population. Les activités productives dé- 
talents sont mis à leur disposition; réciproquement, la présence d'un volume important d'individus suscite l'utilisation de capacités qui, sans cela, péricliteraient. Donc, dans cette direction encore, la corrélation des savoirs, des disciplines, et de la population, de ses variations ${ }^{1060}$, appelle un approfondissement scientifique. L'influence de la population sur les processus de création du travail est tellement évidente qu'il faudrait en rechercher les lois, au lieu de se contenter d'une démographie purement génétique et statistique. Sans conteste, les liens entre les caractères génétiques de l'espèce et la reproduction de ses facultés, le nombre d'individus que celle-ci intéresse, sont importants lorsqu'il s'agit de dégager la place et l'avenir de l'humanité dans l'univers. Toutes ces perspectives non-économiques sont essentielles ${ }^{1061}$.

Les rapports entre les ressources et la population appellent aussi un examen du point de vue historique. Ainsi, dans la nature mécanique, les ressources matérielles n'apparaissent pas uniquement comme des moyens, des formes techniques du savoir, mais aussi comme des éléments de reproduction du savoir d'une partie des hommes, donc de ces hommes eux-mêmes. Inversement, les hommes - plus précisément les travailleurs qui ne disposent que de leur force physique s'insèrent de façon relativement nette parmi les forces matérielles. Ceci prouve que ressources et population doivent être comparées, confrontées, dans leur interdépendance et sous l'angle des qualités et pas seulement des quantités, si l'on veut appréhender les principes et les mécanismes de leur évolution. Cette confrontation peut être étayée par une analyse approfondie des formes techniques, des métiers, des

pendent aussi, dans une mesure croissante, de la coopération et de l'emploi de ressources et de connaissances accumulées ». J.H. STEWARD, O.S. SHIMKIN : Some mechanisms of sociocultural revolution, Daedalus, 1961, p. 479.

1060 « La conséquence la plus directe du niveau technique sur le groupe social intéresse la densité même de ce groupe ; à partir du moment où l'évolution intellectuelle crée des valeurs propres à l'homo sapiens, le rapport «niveau technique-densité sociale» devient le facteur principal de progrès ». A. LEROI-GOURHAN : op. cit. p. 206.

1061 «Bien entendu, outre ces aspects purement économiques du peuplement d'un territoire donné, il y a lieu de tenir compte des effets non-économiques mais qui peuvent avoir une incidence sur l'activité économique. Par exemple, plus la densité d'un territoire est grande, plus, toutes choses égales d'ailleurs, on peut penser que sont créées des conditions favorables au développement de la culture, de l'échange des idées, des innovations ». C. BettelHeim : op. cit. p. 153. 
matériaux, des disciplines, des opérations productives et de leurs résultats. Une anatomie, ou plutôt une dissection classificatrice, analogue à celles que l'on pratique en biologie, préparerait la voie à une physiologie qui étalerait sous nos yeux un tableau beaucoup plus complet et encore insoupçonné des facteurs, des éléments qui composent les ressources et la population, et ferait voir les fils qui courent d'un terme à l'autre. Pour l'instant, on en est encore à dénombrer les réserves d'énergie et à supputer l'explosion démographique, sans remarquer qu'une prédiction véritablement digne de ce nom doit tenir compte des transformations structurelles, et que la comptabilité de ces réserves et de cette explosion est pauvre, si le facteur habileté, connaissance, n'est pas rétabli dans l'unité ressources-population, en même temps que l'on reconnait les traits historiquement et qualitativement distincts de l'une et de l'autre. La méthode d'extrapolation doit faire place aux lois théoriquement établies et rapportées aux processus vrais.

Appréhendée dans sa totalité, la technologie politique aborde ces processus et ces agents, ainsi que la structure qui leur est commune, de manière systématique et historique. L'aspect systématique réside dans l'analyse des mécanismes généraux d'invention et de reproduction des ressources en matériaux et facultés, dans les lois qui expriment ces mécanismes et les démarches pratiques qui en découlent. De cet aspect relèvent par exemple le problème des rapports entre le travail productif et le travail inventif, celui de l'organisation efficace de ce dernier. De même, la prévision du développement des groupements de disciplines - la science notamment — est de son ressort. Ainsi sera déchiré le voile qui masque les mystères prétendus ineffables de la création humaine et celle-ci retrouvera clarté et grandeur. On ne parviendra certes pas à annuler son caractère contingent et spontané, mais rien ne s'oppose à ce que l'on repère les obstacles, les distorsions et les conditions nécessaires.

L'aspect historique de la technologie politique est aussi son aspect dynamique. Les lois systématiques sont généralement celles d'un état de nature particulier. Leur projection au delà de ce champ de validité les rend abstraites et même vides, puisqu'il faudrait les rattacher à un sujet universel qui n'a pas d'existence concrète. Par contre, la recher- 
che des lois propres à chaque état naturel et de leurs transformations rétablit dans leur perspective réelle les traits généraux des rapports entre l'homme et la matière, la société et la nature.

Par la même occasion, la technologie politique fournit un cadre et une importance nouvelle à l'histoire des sciences, des arts, des philosophies et des techniques, et, sans conteste, à l'histoire générale de l'éducation, comme à celle des sociétés savantes ${ }^{1062}$, donc à l'histoire de la formation de l'espèce humaine par ses propres efforts et ses visées spécifiques. Ces différentes histoires ont eu, jusqu'à ce jour, une fonction purement marginale. D'une part elles fournissent tout juste un complément, parfois négligé et souvent périphérique, à l'analyse et à l'histoire de la société et de l'économie. D'autre part, on les traite uniquement comme un terrain d'exercice pour la philosophie ou l'esthétique, ou un réservoir de matériaux destinés à servir aux constructions particulières à ces dernières. Au sens fort du terme, on estime que ce sont des histoires auxiliaires, ancillaires à des fins qui leur sont, par définition, extérieures. La place qu'elles occupent dans l'enseignement et dans la recherche est, à cet égard, un indice qui ne trompe pas. Certes, chaque histoire de nos disciplines naturelles doit continuer à jeter une lumière sur la société et sur la formation de notre intelligence en général. Toutefois ces services, ces contributions ne peuvent ni constituer la raison suffisante du développement des disciplines, ni se substituer à un travail indépendant de connaissance de la réalité qu'elles expriment et dont elles procèdent, à savoir, l'histoire humaine de la nature.

Les analyses auxquelles doit participer l'histoire des sciences, des arts, des techniques et des philosophies, ont une importance décisive pour l'avenir effectif de l'homme. Dépassant le stade du colligement et de la monographie, des controverses sur la priorité ou l'influence de tel auteur sur tel autre, il faut qu'elles se forgent des concepts, des instruments méthodologiques destinés à appréhender des mouvements d'ensemble où les hommes, en tant que groupes et catégories naturelles, trouvent leur place au même titre que les idées. Les membres épars et les termes séparés de ces mouvements convergent dès qu'un

1062 R.E. SCHOFIELD : Histories of scientific societies, History of Science, 1963, 2, pp. 70-83. 
objectif commun et autonome leur est assigné. Pourquoi ne chercherait-on pas des rapports entre l'évolution démographique et celle des sciences, entre le mode de reproduire et de répartir les talents, et la structure d'un groupement de disciplines ? Pourquoi ne rapprocheraiton pas un système de reproduction des habiletés, qui sert de lien entre les catégories naturelles, du système des sciences, des techniques, des arts existant à un moment donné ? Pourquoi négligerait-on l'influence qu'exercent les rapports de la société avec la nature sur le contexte dans lequel se déroule chaque groupement de disciplines ${ }^{1063}$ ? Ce qu'a fait l'histoire sociale, à partir $\mathrm{du} \mathrm{XIX}^{\mathrm{e}}$ siècle, dès sa création, l'histoire humaine de la nature peut l'accomplir maintenant : créer des concepts, des méthodes, et synthétiser les parties jusqu'ici dispersées. L'aspect dynamique de la technologie politique l'exige ; l'observation et la théorie historiques déboucheraient directement sur l'intelligence de notre ordre naturel et sur son gouvernement. Dans l'histoire, ce n'est pas la sagesse que nous voulons, que nous devons apprendre, mais la vie. Et dans le présent, ce n'est pas le dernier moment du passé qu'elle doit nous montrer, mais le premier moment de l'avenir. Le point de vue historique ne saurait être le point de vue de ce qui est mort. Cela est vrai pour les sciences, les arts, les philosophies, les techniques, comme pour toutes les choses qui touchent au plus profond de nous-mêmes.

A côté des sciences de notre société, une science de notre nature a sa fonction et sa place. Suscitée par l'esprit du temps, elle donne à ce temps un esprit. De la sorte, elle prépare la voie à une anthropologie authentique, savoir de ce qui est essentiel à l'homme, anastomose du sujet naturel et du sujet social.

\section{$\underline{\text { Retour à la Table des Matières }}$}

${ }^{1063}$ L'absence de notions claires et d'analyse suivie des conditions de l'évolution historique des sciences est généralement reconnue. On ne réussira pas à la pallier en décrivant des ensembles " socio-techniques-économiques » qui ne constituent qu'une manière de baptiser la réalité que l'on évite d'aborder de front : celle de notre état naturel. Voir, au sujet des réticences et des difficultés qui entravent cette tâche, l'article de A.R. HALL, qui écrit notamment : "Il peut aussi se développer une historiographie socio-technique-économique, dont l'objet sera la transformation progressive de la société par la science et non (comme ce fut trop souvent le cas) la transformation rapide de la science par la société ». (Merton revisited, History of science, 1963, 2, p. 15.) 


\section{Deux cultures ou une seule}

$\underline{\text { Retour à la Table des Matières }}$

Parmi les thèmes qui confèrent à la technologie un caractère politique, celui des rapports de l'humanisme au naturalisme ou réalisme, donc des rapports de la société à la nature, figure en bonne place. C'est un des mobiles qui incitent à la constituer :

«Le développement de la technologie dans l'enseignement, note A. Haudricourt ${ }^{1064}$, aurait des avantages multiples. D'abord il donnerait à l'enseignement technique un prolongement dans l'enseignement supérieur, il permettrait d'insérer chaque technique particulière dans l'histoire générale du progrès humain, surmonterait l'antinomie apparente du machinisme et de l'humanisme ».

D.J. de Solla Price, de son côté, exprime un intérêt analogue ${ }^{1065}$ :

« On convient en général que toute séparation des sciences et des humanités est mauvaise. Il faut jeter des ponts entre elles, ou faire disparaître le fossé qui les sépare en interprétant la science comme faisant partie des humanités, ou les humanités comme des sciences ».

Le souci d'une réconciliation des savoirs est général. Dans un petit ouvrage dont le titre est déjà un programme - Les deux cultures et la révolution scientifique - C.P. Snow a brossé à grands traits la fresque de la division, actuellement profonde, du savoir social et du savoir naturel :

«L'intellectuel littéraire à un pôle, le scientifique à l'autre. Entre les deux, un abîme d'incompréhension mutuelle - parfois (en particulier chez les jeunes) de l'hostilité et de l'aversion, mais surtout un manque de compréhension ${ }^{1066}$.

\footnotetext{
1064 A. HAUDRICOURT : art. cit. p. 33.

1065 D.J. de SOlLA PRICE : Science since Babylon, ed. cit. p. 125.

1066 C.P. SNOw : The two cultures and the scientific revolution, Cambridge, 1961, p. 4.
} 
Comment n'y aurait-il pas méfiance et hostilité, quand chacun des « pôles » voit dans l'autre le symbole de sa propre annihilation, le signe de sa négation? La position de l'intellectuel formé aux arts et aux lettres, héritier de la rhétorique et de l'histoire, nourri des idéaux d'une culture totale qui, apparemment, ne se donne pas d'autre fin qu'elle-même, cette position est la plus difficile, malgré le privilège dont il a longtemps joui ${ }^{1067}$. La seule éducation digne de ce nom, utile à la société, élevée sur le plan de l'esprit, n'était-ce pas la sienne ? Vénérable, libérale, policée, elle dispensait l'unique culture, et voyait dans l'humaniste son incarnation exclusive. Ce qui se rapportait à la nature, à la technique, au monde des dextérités ou des spécialités, restait étranger au domaine de l'intelligence. La société et la politique n'y trouvaient que les instruments indispensables à la poursuite de leurs buts et à la résolution de leurs difficultés.

Le surgissement des sciences et des scientifiques a provoqué une perturbation ${ }^{1068}$ de la hiérarchie établie, constituant une grave menace pour l'idéal auquel on avait fermement cru ${ }^{1069}$. Leur autonomie, leur aptitude à définir et à entretenir une vie intellectuelle propre, leur impact sur le plan de l'organisation économique et des relations collectives, mettent en question à la fois la suprématie et l'adéquation des disciplines humanistes. L'institution pédagogique elle-même, conçue et édifiée avec tant de soin, s'avère mal préparée ${ }^{1070}$ à élaborer les facultés nécessaires à la plupart des hommes. A travers le boulever-

1067 On oublie trop volontiers que cette culture avait pour condition l'ignorance. Et il ne serait pas sans profit d'écrire une histoire de l'ignorance, montrant que celle-ci a été systématiquement maintenue comme repoussoir de l'éducation élevée, tout comme une histoire de la misère est le cœur et l'ossature de l'histoire de la richesse.

1068 «Dans cet éclairage, une question sensée et caractéristique serait : comment peut-on définir la culture de telle façon que les sciences ne soient pas automatiquement jugées comme une composante perturbatrice de notre culture ? » G. HOLTON : Introduction to the issue « Science and culture », Daedalus, 1965, 94, p. VI

1069 «La tradition humaine - arts, lettres, philosophie et les sciences sociales — court le risque d'être négligée en tant que non-réaliste, dans ce qui est devenu une lutte technique pour survivre », in R. Thruelsen, J. KoBler : Adventures of the mind, New York, 1959, p. 17

1070 «Il n'est cependant plus concevable que les hommes qui ont en charge l'avenir de nos sociétés connaissent à peine le présent, n'empruntent, comme c'est encore souvent le cas, leurs conceptions et leurs comportements qu'à un savoir dit "humaniste », qui se réfère à une société pré-technique et non à la nôtre ». La recherche scientifique, l'État et la société, Prospective, $1965, \mathrm{n}^{\circ} 12$, p. 80. 
sement d'un ordre si longtemps préservé, à côté de la culture, jugée unique $^{1071}$, s'est façonnée une seconde culture à laquelle on ne peut dénier en droit ni la valeur intellectuelle ni le poids dans la réalité. Cette culture, qui s'appuie sur la science, ayant instauré une démarche originale, propose aux humanistes un miroir où il leur est difficile de se reconnaître. Ils n'y aperçoivent qu'une de leurs particularités, héritée de tout temps, mais cette fois dénoncée avec vigueur comme infériorité et péché mortel, à savoir, leur ignorance de l'état naturel.

Par contraste, aux yeux des humanistes, le scientifique fait figure d'intrus, de membre d'un groupe nouveau venu dans les cercles restreints du pouvoir et de l'éminence. Ayant pris la place de l'artisan et de l'ingénieur, dirigeant la création du travail et la production, il hérite du mépris qui a entouré ses prédécesseurs ${ }^{1072}$. Quelle que soit la valeur de leurs découvertes, sciences et scientifiques demeurent cantonnés dans la sphère du monde extérieur; on leur refuse le droit de se proclamer porteurs d'une connaissance conforme à notre être authentique :

« Si désireux que soient les scientifiques d'élargir les connaissances et d'améliorer le sort de l'homme, ils poursuivent des buts et des idées qui sont éloignés de l'humain ${ }^{1073}$.

Détachés de ce qu'est la pensée consciente des objectifs ultimes de l'homme, les scientifiques jouent le rôle de purs instruments aveugles au service de leurs maîtres. Cette ablation des facultés sociales, cette

1071 « Il leur plait toujours de prétendre que la culture traditionnelle est la totalité de la culture, comme si l'ordre naturel n'existait pas. Comme si l'exploration de l'ordre naturel ne présentait pas d'intérêt, dans sa valeur intrinsèque ou dans ses conséquences. Comme si l'édifice scientifique du monde physique n'était pas, dans sa profondeur intellectuelle, sa complexité et son articulation, la plus belle et merveilleuse ouvre collective de l'esprit humain ». C.P. SNOW : op. cit. p. 14.

1072 «L'ancienne humanitas impliquait en premier lieu un contraste entre l'homme et l'animal, et par extension entre une classe sociale supérieure et une classe sociale servile proche de la bête brute. Aujourd'hui le concept d'humaniste suggère plus ouvertement (souligné par moi) une opposition entre l'homme et un monde d'objets inanimés (où le travail n'est pas forcément physiquement brut.) Notre tendance à opposer l'humaniste et le super-spécialiste renforce cette suggestion, car, dans une société où les détails sont de plus en plus l'affaire des calculatrices, la spécialisation suggère fortement une sorte de mécanisation des fonctions intellectuelles ». W.J. ONG : art. cit. p. 419.

1073 B. BLANSHEND : Education in the age of science, New York, 1960, p. 175. 
indifférence supposée à l'égard des raisons et des effets que peuvent avoir les découvertes scientifiques par rapport à l'existence collective, frappent. De là viennent leur incompréhension, leur manque d'intérêt et leur dédain pour les disciplines libérales et les sciences sociales, qui ne semblent guère refléter leur expérience. Et ce, quel que soit le système social auquel ils appartiennent :

«Il suffit, pour montrer le danger de ce point de vue, de rapprocher l'attitude des savants qui, en U.R.S.S., ravalent les sciences sociales au second plan de celle, identique, adoptée par leurs collègues du secteur capitaliste. Procédant de la même erreur, ils ne se soucient pas de savoir quels buts et quels intérêts servent leurs réacteurs, les machines électroniques qu'ils construisent $\gg{ }^{1074}$.

Bref, des barrières diverses s'élèvent pour empêcher une intégration des sciences et des scientifiques dans le courant général, barrières qu'il faut à tout prix supprimer.

Le spectacle de ces membres disjoints, qui se compléteraient parfaitement pour former un organisme que l'on peut supposer harmonieux, fascine. Un peu de sagesse, présume-t-on, réduirait les antagonismes. Il y va de l'intérêt de chacun. Ainsi l'humaniste serait associé aux créations qui ont pour champ la nature et pour objet le travail. Inversement, le savant et l'ingénieur scientifique, ayant accès aux humanités, dépasseraient l'horizon étriqué de leur spécialité. Mieux entraînés à s'intéresser aux jeux — à leurs yeux souvent futiles, et pourtant si décisifs - de la politique et de la direction de la société, ils apprendraient à reconnaître le sens et la valeur de leurs savoirs. L'humanisme serait légitimé par le réel, le naturalisme par l'idéal; tous deux serviraient le genre humain, puisque le modèle de l'individu complet et de l'intelligence réconciliée substituerait la paix à la discorde, la plénitude au manque. Telles sont les opinions qui inspirent les mesures dont on attend la restauration de l'équilibre. La plupart d'entre ces dernières se rapportent au système pédagogique, à la réorganisation des disciplines. On espère notamment qu'elles ouvriront les voies de communication entre les connaissances sociales et les

${ }^{1074}$ La nouvelle Critique, Mai 1964, p. 150. 
connaissances naturelles, entre les arts et les techniques. A cet égard, il incomberait à la « science de la science », à l'histoire ${ }^{1075}$ — histoire de la société, histoire des sciences et des techniques — de remplir le rôle de médiatrice, de rendre possible le dialogue ${ }^{1076}$ après avoir situé à nouveau les interlocuteurs dans le domaine de la culture. Par ailleurs, l'introduction des études littéraires, humanistes, dans le programme de l'éducation scientifique, et, réciproquement, l'assimilation des informations scientifiques par ceux qui se préparent aux disciplines sociales et humaines, assureraient le succès de cette science charnière entre les deux ordres de connaissances.

Telles sont les visées, et tels sont les remèdes proposés par la plupart de ceux qui dénoncent vivement l'existence du dualisme que j'ai décrit. Celui-ci serait donc extirpé par l'enseignement homogène qui réaliserait ce projet, groupant les diverses branches d'un savoir, rendu unique, afin de produire des hommes complets.

Faut-il dénombrer les illusions qui pavent cette quête d'une voie moyenne ? J'y aperçois surtout le signe d'un tâtonnement imposé par les circonstances, alors que le principal est ailleurs. Notamment dans la saisie de l'essence vraie de ces produits de la faculté imaginative, qui occupent l'espace mental réservé par chaque groupe à l'utopie. Reprenons le problème de l'antagonisme des savoirs. Cet antagonisme, nous le savons ${ }^{1077}$, ne fait que prolonger les conflits et propager la hiérarchie d'une société qui a pour moteur la différence des richesses et l'inégalité des pouvoirs. Partant, une cloison étanche isole les individus qui se consacrent à forger les appareils étatiques, les idéologies ou les représentations associées, de ceux qui remplissent une fonction de production et de création des habiletés nécessaire à la subsistance collective. La prééminence de l'humanisme, dans ce contexte, exprime la prééminence d'une couche sociale, et surtout

1075 «L'histoire si on l'écrit avec une juste appréciation du rôle de la science et de la technique devrait avoir pour effet utile de clore la brèche qui, dans la vie universitaire sépare trop souvent ceux qui étudient la nature de ceux qui étudient la nature et la société humaines ». A. SCHLESINGER : An American historian looks at science and technology, Isis, 1946, 36, p. 165.

1076 «Ainsi tant que le divorce des cultures subsistera, et tant qu'une méthodologie du travail scientifique n'aura pas été clairement élaborée et surtout assimilée, le dialogue ne saurait se dérouler en pleine franchise ». Prospective, art. cit. p. 48.

1077 Chapitre II de la $3^{\mathrm{e}}$ partie. 
d'un mode de gouvernement qui correspond à la situation. Ce dernier ne requiert guère de ses maîtres ou de ses serviteurs, directs ou indirects, une compétence qui ait trait à l'échange avec l'univers matériel, ni un contact régulier avec les hommes engagés dans cet échange. Le fossé constaté au niveau de l'éducation ne fait que traduire la grande découverte de la civilisation : la scission des rapports naturels et des rapports sociaux, la scission des hommes selon les lignes de clivage de ces rapports. Personne n'a le sentiment de faire partie de ce qui est commun, alors que le sort commun est pour chacun d'être seulement partie, d'être constamment à côté et en dehors de l'unité, si bien que l'unité est coupée de ses parties, située au-delà ou au-dessus d'elles, et que le mouvement de la totalité, ainsi caché, est comme annulé.

Envisagée à la lumière de l'expérience historique, la réconciliation des disciplines naturelles et des disciplines sociales n'est point une question académique, mais - ce qu'elle n'a jamais cessé d'être une question politique ${ }^{1078}$. Plus exactement, une double question ayant trait à la composition du corps politique et à ses compétences, d'une part, aux conditions et aux fins d'une politique conforme aux relations de l'ordre social et de l'ordre naturel, d'autre part. Si une solution est réclamée aujourd'hui avec tant d'urgence, c'est que les termes de ces relations, et les relations elles-mêmes, subissent des modifications évidentes.

Comme il fallait s'y attendre, la position des disciplines et des catégories naturelles, celle des sciences et des scientifiques surtout, est en jeu. L'état et la promotion de ces derniers ne sont plus déterminés, comme c'était le cas pour les artisans ou les ingénieurs, les philosophes naturalistes ou mécaniques, par le processus de division. Pour la première fois, une catégorie naturelle peut effectivement se dispenser de considérer d'autres hommes comme sa matière ou son instrument. Elle peut également renoncer au dédoublement qui s'ensuivait et obligeait chacune des parties à s'affirmer par le canal d'une projection subjective — dieu horloger ou démiurge, à la place de l'homme hor-

1078 «Par conséquent, le problème du rapport des sciences aux humanités est devenu significatif, non seulement à cause de son intérêt pour le savoir, mais à cause de son impact sur le monde de la politique ». D.K. PrICE : The established dissenters, Daedalus, 1965, 94, p. 84. 
loger ou démiurge. Dans cette perspective, qui abolit la projection de soi corrélative à la négation de l'autre, le scientifique acquiert la possibilité de manifester, sans les travestir outre mesure, ses propres buts, ses modalités d'agir. Telle est bien son invention majeure : l'homme n'est pas l'exécutant des prescriptions d'un ordre naturel extérieur à lui, il est l'auteur des décrets et le sujet reconnu de l'ordre naturel. Cet état de choses ne trouve pas d'écho dans notre organisation sociale, où le travailleur scientifique est ravalé au rang d'objet, soumis à des institutions qui le placent parmi les instruments de la richesse et du pouvoir ${ }^{1079}$. La contradiction de sa position, d'être recherché partout et de n'avoir une voix décisive nulle part, sauf à recourir aux armes de la flatterie ou à se plier à l'étiquette de la servitude, de faire une histoire qui n'est pas appréhendée en tant qu'histoire humaine mais comme son image renversée, l'inhumanité de l'histoire, éclate au grand jour.

Ce contraste ne jouerait pas un rôle essentiel, on n'y décèlerait pas des exigences générales, en passe de menacer la structure des institutions ${ }^{1080}$, s'il ne s'agissait d'un groupe concentré, nombreux, et qui, par son travail quotidien et sa préparation intellectuelle, accède à la pleine conscience de sa fonction. On prétend que $90 \%$ de tous les savants qui ont jamais existé vivent aujourd'hui. On estime à plus de $20 \%$ de la population active le pourcentage de ceux qui devront se consacrer à la recherche fondamentale ou appliquée. L'opinion émise à propos des scientifiques au début de ce siècle par Lord Balfour ne restera pas indéfiniment valable :

«Ce sont les hommes qui sont en train de changer le monde et ils ne le savent pas. Les politiciens ne sont que le volant - les hommes de science sont la puissance motrice ».

${ }^{1079}$ Comme le dit J.K. Galbraith qui connaît intimement le capital et son économie : « Les scientifiques ne manquent pas de prestige de nos jours, mais nous considérons que, pour être vraiment utiles, ils doivent se trouver sous la direction d'un industriel ». J.K. GALBRAITH : op. cit. p. 252.

${ }^{1080}$ «Du fait de leur nombre, de leur prestige et de leur influence, de tels hommes contribuent sans doute de plus en plus à ces remises en question des institutions sociales et politiques ». Prospective, art. cit. p. 36. 
$\mathrm{Au}$ contraire, cette puissance se sachant et se voulant motrice, il ne lui est plus loisible de se réfugier dans la neutralité et l'abstention; elle se pénètre de la responsabilité qui lui incombe, touchant à l'avenir qu'elle engendre ${ }^{\mathbf{1 0 8 1}}$, et de l'importance des tâches qu'elle accomplit. Elle ne peut que mettre en péril une tradition et une sphère politique dont le but avoué est de la diminuer ou de l'exclure, et tendre à fonder une tradition nouvelle dont elle serait la source ${ }^{{ }^{1082}}$.

Par le truchement de la science, une interférence presque directe avec l'ensemble des processus matériels est visible partout. La prévision relative aux résultats de cette interférence, la capacité d'orienter leur recherche, aussi bien que celle des ressources, d'élaborer une stratégie à leur propos, sont des traits généralement reconnus. Le danger réel n'est pas constitué par le contact avec les forces matérielles, mais par la perte de ce contact. Ce qui soulève des difficultés n'est point que ces forces nous soient étrangères, ou que nous leur soyons étrangers, mais que l'interdépendance concrète soit appréhendée et vécue comme une aliénation. Rien n'est plus contraire à la pratique que l'autonomie présumée de la sphère sociale, l'aptitude qu'on lui suppose de maîtriser rationnellement son destin sans devoir s'enraciner solidement dans la nature. Des normes et des institutions qui prétendaient préserver intacte cette conviction se défont les unes après les autres :

« Nous devons en venir, écrit un observateur qualifié ${ }^{1083}$, à considérer l'individu comme un élément coopérateur de la société, et la société ellemême comme une partie d'un système naturel en marche. Ceci peut, je crois, être équitablement considéré comme un pas en avant dans l'accroissement de la sagesse $»$.

« Il (le milieu scientifique) se reconnaît dépositaire d'intérêts supérieurs, d'autant plus respectables qu'ils sont désintéressés. Il travaille pour comprendre, et pour le bien de l'humanité. Ses valeurs sont de vérité et d'universalité. Il se sait créateur de pouvoir et de progrès. Il se sent à l'origine de la société à venir ». Prospective, art. cit. p. 38.

1082 «La question se pose maintenant de savoir si la science est l'alliée ou la rivale de cette tradition (humaniste); si elle doit trouver un rôle en collaboration avec les branches du savoir qui servent de fondement intellectuel aux affaires politiques, ou si elle doit devenir elle-même la base d'une nouvelle idéologie ou dialectique, une nouvelle théorie politique ». D.K. PRICE : art. cit. p. 38 .

1083 C.H. WAdDington, in N. CALDER : op. cit. t. 2, p. 15. 
Cette sagesse ne peut se concilier avec une méthode de gouvernement qui s'est lentement édifiée pour infléchir les comportements des hommes dans le sens de leurs intérêts sociaux exclusivement. Elle ne saurait guère se réduire à la démarche par laquelle les fonctionnaires, forts de leur culture classique, membres d'une société dans la société, décrètent ce qui est indispensable à la science et à ses découvertes. Et ce n'est pas non plus faire un pas en avant vers son accroissement, sa complétude, que de laisser ces mêmes fonctionnaires fixer la signification d'œuvres et de connaissances particulières au monde matériel, dont le principe comme le cheminement leur échappe ${ }^{1084}$. Cela concerne en premier lieu les scientifiques, lorsqu'il s'agit d'orienter efforts et investissements.

On le voit, les conditions et les dimensions du rapprochement souhaité entre sciences et humanités, disciplines naturelles et disciplines sociales, ne sauraient plus être ramenées à une simple refonte des programmes pédagogiques. Ce n'est pas non plus par la dénonciation morale ou philosophique de la dualité des cultures, ou par la condamnation de ses conséquences néfastes, et moins encore par la tentative d'en limiter l'importance au domaine universitaire, que ceux qu'elle touche peuvent espérer retrouver la voie de l'unité. Au contraire, ils ne font que détacher un peu plus le problème de la réalité. Lorsqu'on incite les « humanistes » à acquérir les rudiments de la science et les « scientifiques » à accorder quelque attention aux humanités, on masque par des discours, en apparence innocents ${ }^{1085}$, l'objet de la critique, la société, et les termes de son renouvellement effectif. Celui-ci implique, certes, que ceux qui exercent des fonctions concernant l'ordre naturel soient dégagés des contradictions dont on a mesuré l'ampleur. Une tâche tout aussi importante est de redéfinir le corps politique et les qualités indispensables aux individus pour leur permettre d'assurer la gestion des institutions auxquelles ils participent. Leur

1084 «A propos de l'urgence qu'il y a à organiser la science en accord avec les problèmes à résoudre, je voudrais attirer l'attention sur un point. Le Professeur Bernal a dit que les administrateurs commençaient à jouer un grand rôle dans la science, et que de bons administrateurs étaient nécessaires pour l'organisation des problèmes scientifiques. Je ne suis pas d'accord avec le Professeur Bernal — non pas sur la question du besoin d'organisateurs dans la science, mais sur ce point que ceux-ci ne doivent pas être des administrateurs, mais les scientifiques eux-mêmes ». P. KAPITSA : in M. GoldSMith, A. MACKAY, op. cit. p. 126.

1085 D.E. APTER : Ideology and discontent, New York, 1964. 
vocation commune, en particulier, est de s'intégrer à l'histoire de leur nature, non que nous vivions sa fin ou que nous soyons libérés de sa nécessité, comme l'affirme un philosophe («Dans la mesure où elle secoue le joug de la nature, notre époque se trouve en état d'en faire l'histoire ${ }^{1086}$ ), mais parce qu'elle parcourt une étape dans laquelle sa structure est devenue plus claire, comme aussi nos obligations envers elle. Dans cet enchaînement, la technologie politique n'est pas une discipline médiatrice entre des champs éloignés du savoir, elle constitue le savoir qui permet aux hommes à la fois de diriger leur destin collectif, et, en concevant à l'avance leur évolution, d'en provoquer les phases successives. Bien qu'elle ne soit pas encore parvenue à maturité, cette perspective fournit déjà des motifs suffisants d'acquérir et de produire les capacités indispensables pour organiser la vie sociale sans la dissocier des lois qui la relient au monde matériel, donc pour les gouverner ensemble. Assurément, ces capacités ne proviendront pas, comme on l'a prétendu maintes fois, de la juxtaposition de celles qui existent, de l'assemblage des disciplines qui les incarnent. Il ne s'agit pas de pallier, au moyen de l'humanisme ou du réalisme scientifique, une déficience. Force est de chercher une solution originale propre à cette situation où l'ordre social s'inscrit comme forme de l'ordre naturel, et non comme entité opposée à lui ${ }^{1087}$. L'histoire ne les connaît pas isolément, et l'ambition de les maîtriser séparément n'est pas fondée. Un mouvement commun les entraîne ; ce qui anime l'un des deux, la progression naturelle, agit aussi sur leur lien. La progression naturelle n'a aucune impulsion propre, et on ne saurait la prendre pour un automatisme au déroulement préétabli, doué d'une visée relativement indépendante. D'autre part, elle n'est pas l'affaire d'ingénieurs sociaux, phantasme hypostasié d'un jeu sans protagonistes. Au contraire, nous savons qu'elle est le terrain et la résultante de rapports humains. Lorsque ce fait se sera mieux traduit dans la pratique, on lui reconnaîtra ce qu'on a du mal à accepter pour l'instant, sa qualité de principe historique. Ce qui s'oppose à cette vue nous est maintenant familier ce sont d'un côté la division des catégories naturelles, de l'autre l'existence des classes sociales, et leurs contradictions.

1086 J. LACROIX : La nature, Le Monde, 19 septembre 1964, p. 13.
${ }^{1087}$ Voir Chapitre III de la $3^{\text {e }}$ partie. 
Les premières nous renseignent sur ce qui limite son rôle dans l'histoire humaine de la nature, les secondes sur les freins qui s'opposent à sa manifestation claire dans l'histoire humaine de la société. Nous observons toutefois que la suppression des obstacles à la progression naturelle, c'est-à-dire à l'établissement d'une relation manifeste entre ces deux évolutions historiques, est devenue un impératif de la vie concrète. Ne serait-ce que parce qu'elle passe par le bouleversement du mode de répartition des facultés, et la refonte du mode d'appropriation des richesses, réclamés et préparés avec tant de vigueur.

Des groupes importants en font un thème de lutte politique, et les possibilités d'y aboutir transforment une échéance jugée lointaine en un objectif réalisable. Mais, pour y parvenir véritablement, ces groupes ne peuvent pas se contenter de vouloir une autre société, une société socialiste à la place d'une société capitaliste, une société plus développée à la place d'une société qui l'était moins. Ils doivent aussi vouloir un autre type de société, à la fois capable de se fixer un programme et de se prendre pour matière d'expérience, donc de se donner les formes qui expriment son articulation avec l'état naturel, avec le dynamisme qui lui est propre. En d'autres termes, ils doivent viser un ensemble social susceptible de maintenir la correspondance des processus et des rapports sociaux avec les processus et les rapports naturels entre les hommes, et d'assurer leur conversion réciproque.

La transformation du régime de la propriété et l'atténuation de la troisième inégalité, celle des facultés, impliquent nécessairement la révision de la fonction de l'État. Étranger à la société civile, il courbe et subordonne toute œuvre, toute action, à ses normes et à ses pouvoirs, ne reconnaissant comme initiatives valables que celles qui lui reviennent. Il étend au-dessus des autres groupes le voile de sa raison, le réseau de ses fonctionnaires, de ses hommes d'armes et de ses hommes de plume. Dans son sein se perpétue une contrainte dont la disparition serait possible, à condition que prenne corps la conviction qu'Albert Einstein avait partagée avec des millions d'hommes : 
« Je suis persuadé, écrivait-il ${ }^{\mathbf{1 0 8 8}}$, qu'il n'y a qu'une seule façon d'éliminer ces maux graves, à savoir, l'établissement d'une économie socialiste, accompagnée d'un système éducatif qui serait orienté vers des buts sociaux ».

Et Lénine formulait la même idée de façon encore plus tranchante :

« Tant que l'État existe, il n'y a pas de liberté. Quand il y aura la liberté, il n'y aura plus d'État. » ${ }^{1089}$

On sait que, sur le plan conceptuel, le dépérissement de l'État est lié à l'instauration du gouvernement de la nature. Toutefois, partant des théories que j'ai exposées ici, on voit que la socialisation de la propriété, condition que l'on posait à ce dépérissement, a pour effet, non pas, comme on le croyait, de mettre les hommes en prise directe sur l'univers, mais de rendre plus transparents les rapports sociaux et les rapports naturels entre les hommes, et réciproquement. Dans cette perspective, la destinée de l'État n'est peut-être pas de disparaître, mais de se transformer radicalement, d'être supprimé comme instrument et gardien de la société civile pour devenir le véhicule par lequel est assurée la communication entre le côté naturel et le côté social de nos rapports. C'est là une conséquence du fait que le gouvernement de la nature et le gouvernement de la société sont tous deux, à l'encontre de ce que l'on a cru, gouvernement des hommes. Ceux qui essaient de faire en sorte que le second signifie justice et liberté sont immanquablement amenés à se consacrer au premier, en ce qu'il assure notre intégrité et notre universalité. L'humanité se trouve doublement associée à cet égard : dans la nature et dans la société.

Ainsi chaque force collective, pour résoudre aujourd'hui la question sociale dont les solutions et les programmes ont été stipulés au siècle dernier, est obligée d'inclure parmi ses préoccupations la question naturelle. Une critique de la société qui n'est pas simultanément critique de sa relation à la nature, de l'action des hommes pour constituer l'une et l'autre, demeure incomplète. Les contradictions qui tiraillent le scientifique, la division du travail en manuel et intellectuel et

1088 A. EINSTEIN : Why socialism ? New York, 1963, p. II.

1089 V.I. LENINE : L'État et la Révolution, Paris, 1937, p. 98. 
les oppositions dont elle est le siège nous le démontrent par leurs effets.

La puissance et le caractère contraignant de cette prise en considération proviennent de ce que, finalement, rien de ce qui nous concerne ne saurait plus être attribué exclusivement à quelque agent extérieur, supra- ou infra-humain, ni pour ce qui touche à la vie collective, ni pour ce qui touche aux échanges avec le monde matériel. Si tout part de nous et retourne à nous, si ce qui semblait échelonné dans le temps se présente à l'échéance simultanément, il faut que la fonction de sujet qui est la nôtre à tant de titres soit remplie avec promptitude et intensité.

Rien de tout cela ne transparaît à travers les recherches qui se proposent de modeler la culture. Elles font appel, pour le principal, à des facteurs nourris davantage à l'école du contrôle et de la servitude qu'à celle de la création et de la liberté. L'essentiel ne réside pourtant pas dans ces formules énoncées dans des compartiments séparés, dont on remarque mal l'interdépendance, et qui ont nom : loisir accolé au travail, culture générale ajoutée à l'éducation spécialisée, réunion du travail manuel au travail intellectuel, compensation des sciences par l'art, ou encore réconciliation du savoir naturel et du savoir social ou humaniste.

Comment l'unité postulée serait-elle possible, tant que les hommes ne pourront se fixer à la fois les fins et les moyens, tant que chacun se laissera dire, par un porte-voix, ce qui est le vrai, le beau et le juste ? Comment cette unité ne nous semblerait-elle pas abstraite, éloignée de la substance de la vie, quand les prémisses et les conséquences de sa réalité sont appréhendées hors de ce qui assure sa réalisation?

Il faut donc que chaque membre de l'ordre social ait l'occasion de parler en son nom propre, afin que ce qui est obtenu par lui soit obtenu pour lui ; cela se produit lorsque le travail, la littérature, la science et l'art ne figurent pas des instruments dont la destinée est fixée de l'extérieur, mais lorsque, au contraire, ceux qui se les donnent pour fins les parachèvent aussi comme moyens. Bref, lorsque l'état social 
et l'état naturel laissent leurs sujets s'exprimer et communiquer en tant que tels. Même si, dans la réalité, cette étape n'a pas encore été atteinte, elle s'affirme de toutes parts comme l'aboutissement nécessaire d'une évolution où la position de l'individu dans la société est coordonnée avec sa position en tant qu'il produit et invente : sés $» 1090$

« Il convient donc... que le talent et la possession ne soient point divi-

Telle est la condition préalable de la culture, situation d'une humanité qui ne se dédouble ni ne se partage foncièrement, pour agir dans l'univers matériel et dans l'univers social. Vouloir dessiner ses contours et exposer son contenu serait se livrer à un jeu gratuit, à l'instar de ceux qui prétendent pouvoir composer son image en partant de morceaux disjoints. Alors que rien n'indique, de nos jours, qu' elle soit le terme d'une aventure surhumaine, tout nous incline à refuser d'y voir l'incarnation d'un monde plat, calme, harmonieux, d'un audelà du Jugement dernier, où toutes les questions auraient reçu leur réponse. Bien plutôt, et j'y ai déjà fait allusion, elle est l'esquisse d'un autre mode de résoudre ces questions et de leur concevoir une réponse.

Toutes ces inférences se déduisent de l'examen de l'histoire humaine de la nature et de ses rapports avec la société. J'ai tenté d'exprimer, en termes aussi mesurés que possible, ce qu'elles me paraissent enseigner sur la marche de l'humanité, et la signification qu'elles confèrent à une gamme de pratiques ou de tendances courantes qui vont de l'éducation à la politique, du régime de la propriété à la structure de la connaissance. Une science particulière leur donnera plus de force.

Les perspectives concrètes auxquelles je me réfère peuvent sembler lointaines ; cet éloignement est relatif, il dépend de l'effort collectif et

1090 C.H. de SAINT-Simon : Réorganisation de la société européenne, Paris, 1854, t. I, p. 200. 
non du jugement individuel. Leur théorie, comme toute théorie, est plus assurée quant au passé qui la rend nécessaire, et plus conjecturale quant à l'avenir qui doit lui conférer la réalité. A ce titre, elle est à la fois instrument critique et préparation à l'action. Cependant, ni dans un cas, ni dans l'autre, elle n'a la prétention de prédire un résultat qui se manifestera inéluctablement. Son domaine n'est pas la croyance mais le savoir. On oublie souvent, lorsqu'on émet une opinion sur une théorie, que les phénomènes auxquels elle se rapporte se révèlent rarement d'eux-mêmes, comme en astronomie où Le Verrier a pu calculer l'apparition observable d'une planète grâce aux équations de Newton. Dans la plupart des cas, il faut en convenir, seuls l'expérience et le perfectionnement des instruments expérimentaux facilitent la venue au jour de corps ou de processus, entrevus de façon conceptuelle, et qui, sans cela, n'acquerraient pas une individualité, et, pour ainsi dire, n'existeraient pas. La vérification d'une proposition chimique ou physique n'attend pas l'éclosion spontanée des faits: elle est le fruit de leur recherche et de leur matérialisation. Pourquoi en irait-il autrement de la connaissance des phénomènes humains? S'ils sont vie et non point purement idée, s'ils touchent à la pratique des collectivités et non pas aux rêves d'un esprit abstrait, si leur cours n'est pas dévoilement d'un être caché mais poursuite du faire, génération de l'événement, alors celui qui en élabore la théorie conçoit leur mouvement et son langage en sachant que seul le genre humain, en tant qu'il s'affirme expérimentateur suprême, ajoute à l'annonce du vrai la puissance du réel.

Princeton - Paris 1962-1967. 